Key Words:

RPP-WTP

Envelope C

Precipitation

Ion-Exchange

Retention:

Permanent

Key WTP R\&T References:

Test Specification 24590-WTP-TSP-RT-01-006, Rev. 0 Task Plan WSRC-TR-2001-00425, Rev. 1

Test Exceptions 24590-WTP-TEF-RT-02-063

R\&T Focus Area Pretreatment-Precipitation

Test Scoping Statement(s) S-126

\title{
PARAMETERS INFLUENCING THE FORMATION OF POST-FILTRATION SOLIDS IN THE 241-AN-107 AND 241-AN-102 HANFORD HIGH-LEVEL WASTE SIMULANT
}

\section{J. T. Coates, J. M. Brown, J. D. Navratil, D. Denard, and K. Cole, Clemson University}

September 24, 2003

Westinghouse Savannah River Company

Savannah River Site

Aiken, SC 29808

Pre pare d for the U.S. De partment of Energy Un der Con tract Number DE-AC09-96SR18500

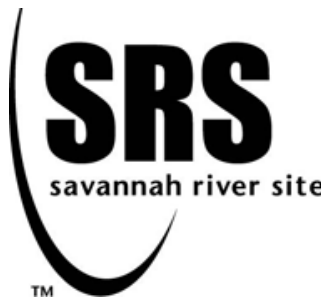




\section{FINAL REPORT}

\section{PARAMETERS INFLUENCING THE FORMATION OF POST-FILTRATION SOLIDS IN THE 241-AN-107 AND 241- AN-102 HANFORD HIGH-LEVEL WASTE SIMULANTS}

J. T. Coates, J. M. Brown, J. D. Navratil, D. Denard, and K. Cole

Issue Date: September 24, 2003

Environmental Engineering and Science Clemson University Anderson, SC 29625 
This document was prepared in conjunction with work accomplished under Contract No. DE-AC09-96SR18500 with the U. S. Department of Energy.

\section{DISCLAIMER}

This report was prepared as an account of work sponsored by an agency of the United States Government. Neither the United States Government nor any agency thereof, nor any of their employees, makes any warranty, express or implied, or assumes any legal liability or responsibility for the accuracy, completeness, or usefulness of any information, apparatus, product or process disclosed, or represents that its use would not infringe privately owned rights. Reference herein to any specific commercial product, process or service by trade name, trademark, manufacturer, or otherwise does not necessarily constitute or imply its endorsement, recommendation, or favoring by the United States Government or any agency thereof. The views and opinions of authors expressed herein do not necessarily state or reflect those of the United States Government or any agency thereof.

This report has been reproduced directly from the best available copy.

Available for sale to the public, in paper, from: U.S. Department of Commerce, National Technical Information Service, 5285 Port Royal Road, Springfield, VA 22161, phone: (800) 553-6847, fax: (703) 605-6900

email: orders@ntis.fedworld.gov

online ordering: http://www.ntis.gov/help/index.asp

Available electronically at http://www.osti.gov/bridge

Available for a processing fee to U.S. Department of Energy and its contractors, in paper, from: U.S. Department of Energy, Office of Scientific and Technical Information, P.O. Box 62, Oak Ridge, TN 37831-0062,

phone: (865)576-8401,

fax: (865)576-5728

email: $\underline{\text { reports@ adonis.osti.gov }}$ 
WSRC-TR-2003-00232, Rev. 0

SRT-RPP-2003-00105, Rev. 0

\section{TABLE OF CONTENTS}

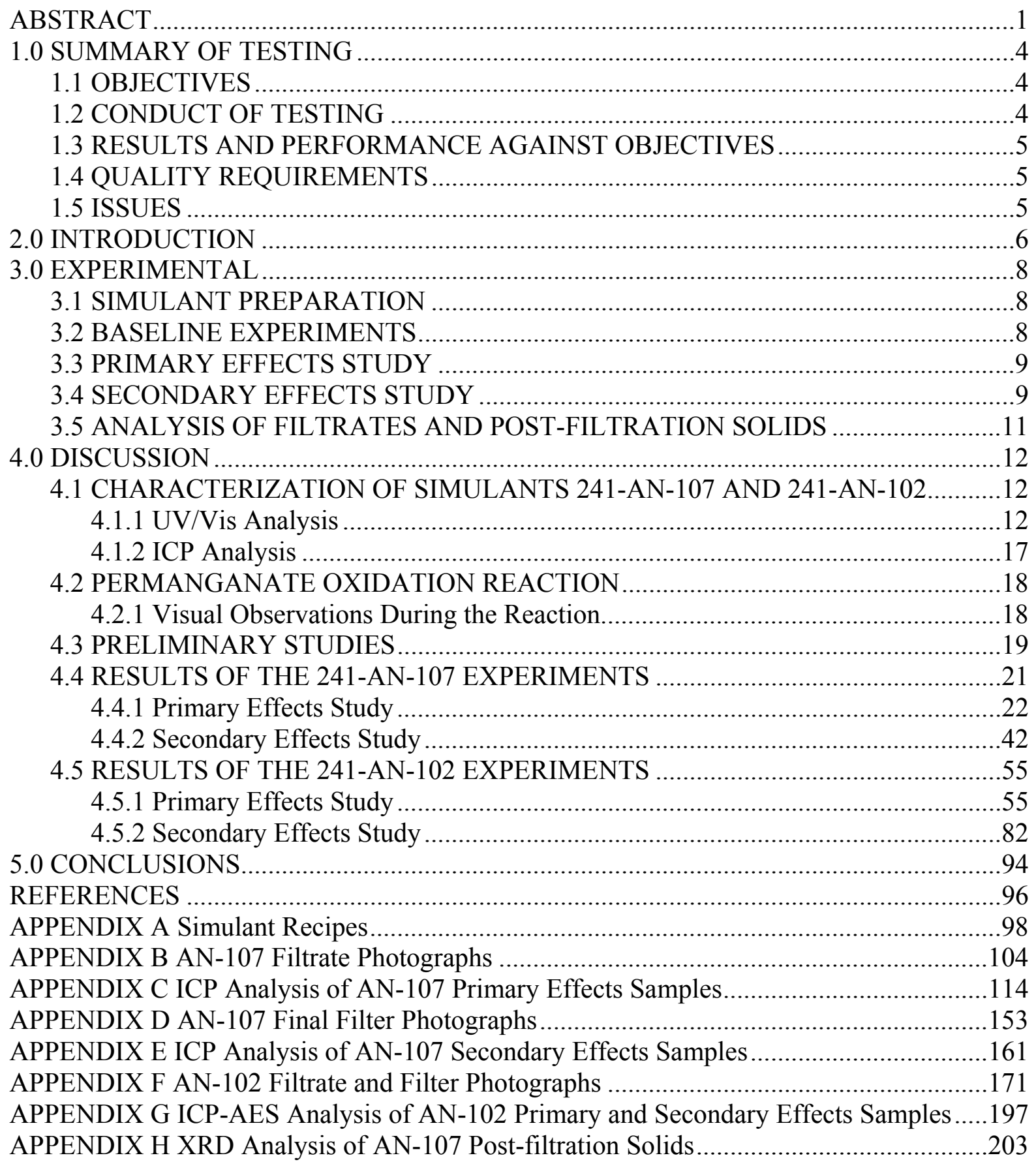


WSRC-TR-2003-00232, Rev. 0

SRT-RPP-2003-00105, Rev. 0

\section{LIST OF FIGURES}

Figure 3.4.1 Storage Conditions for the 241-AN-107 Factorial Design Experiments.............11

Figure 3.4.2 Secondary Effects Experiments Conducted for the 241-AN-102 Simulant........12

Figure 4.1.1.1 UV/VIS Spectra of Simulant 7 Used in the 241-AN-107 Experiments ...........13

Figure 4.1.1.2 UV/VIS Spectra of Simulant 8 Used in the 241-AN-107 Experiments ...........14

Figure 4.1.1.3 UV Spectra of Simulant 7 Used in the 241-AN-107 Experiments..................14

Figure 4.1.1.4 UV Spectra of Simulant 8 Used in the 241-AN-107 Experiments..................15

Figure 4.1.1.5 UV/VIS Spectra of Simulant A Used in the 241-AN-102 Experiments ..........15

Figure 4.1.1.6 UV/VIS Spectra of Simulant B Used in the 241-AN-102 Experiments ..........16

Figure 4.1.1.7 UV Spectra of Simulant A Used in the 241-AN-102 Experiments.................16

Figure 4.1.1.8 UV Spectra of Simulant B Used in the 241-AN-102 Experiments .................17

Figure 4.4.1.1 Particulates Collected After 48 Hours Exposure to Oxygen for the Base Case

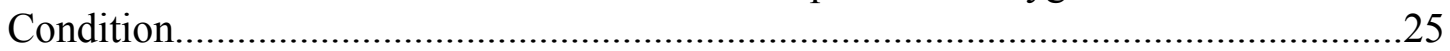

Figure 4.4.1.2 Particulates Collected After 48 Hours Exposure to Oxygen for the Light

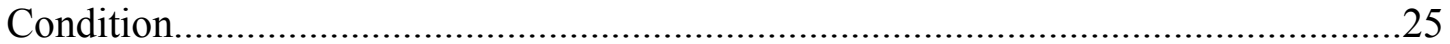

Figure 4.4.1.3 Manganese, Iron and Strontium Concentration in the $0-48 \mathrm{hr}$. Base Case

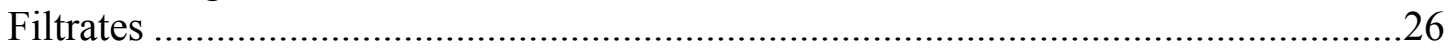

Figure 4.4.1.4 Manganese, Iron and Strontium Concentration in the $0-48 \mathrm{hr}$. Filtrate

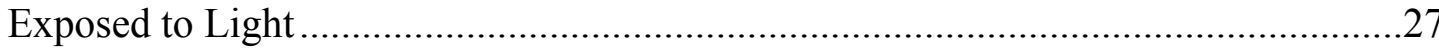

Figure 4.4.1.5 Manganese, Iron and Strontium Concentration in the $0-48 \mathrm{hr}$., $8 \mathrm{hr}$. Hold at

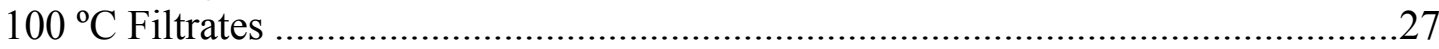

Figure 4.4.1.6 Manganese, and Iron Concentration in the $0-48 \mathrm{hr}$. Filtrates With no Added

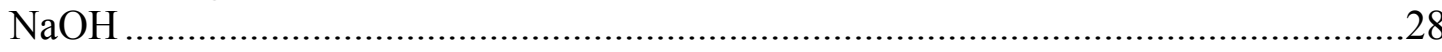

Figure 4.4.1.7 Strontium Concentration in the $0-48 \mathrm{hr}$. Filtrates With no Added $\mathrm{NaOH}$.....28

Figure 4.4.1.8a Mean Cation Concentration for the $0-48 \mathrm{hr}$. Reaction Temperature Filtrate

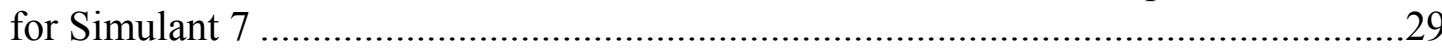

Figure 4.4.1.8b Figure 4.4.1.8a Scaled to see Minor Cations..............................................30

Figure 4.4.1.9a Mean Cation Concentration for the $0-48 \mathrm{hr}$. Reaction Temperature Filtrate

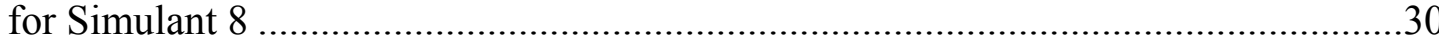

Figure 4.4.1.9b Figure 4.4.1.9a Scaled to see Minor Cations............................................31

Figure 4.4.1.10a Mean Cation Concentration for the $0-48$ hr. Filtrates with Added $\mathrm{NaOH}$

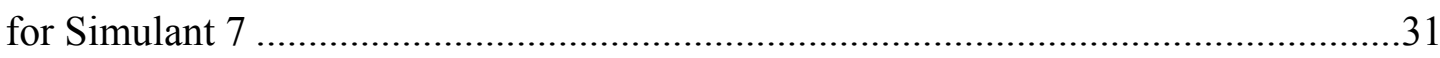

Figure 4.4.1.10b Figure 4.4.1.10a Scaled to see Minor Cations ...........................................32

Figure 4.4.1.11a Mean Cation Concentration for the $0-48$ hr. Filtrates with Added $\mathrm{NaOH}$

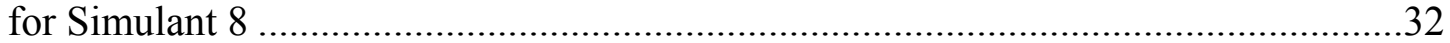

Figure 4.4.1.11b Figure 4.4.1.11a Scaled to see Minor Cations ............................................33

Figure 4.4.1.12 $\mathrm{E}_{\mathrm{H}}$ Measurements for the AN-107 Base Case, Oxygen Purge, and Nitrogen

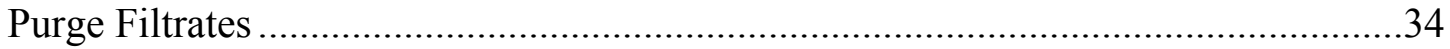

Figure 4.4.1.13 a \& b Mean $0-48 \mathrm{hr}$. Concentration of Selected Cations Plotted as a

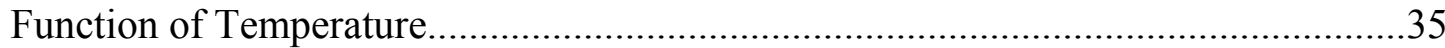

Figure 4.4.1.14 a \& b Mean $0-48$ hr. Concentration of Selected Cations Plotted as a

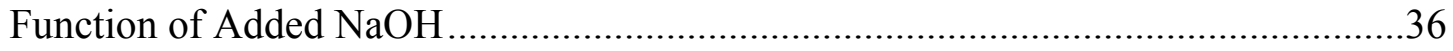

Figure 4.4.1.15 a \& b Mean 0 - $48 \mathrm{hr}$. Concentration of Selected Cations Plotted as a Function of Permanganate Concentration 
Figure 4.4.1.16 a \& b Mean 0 - 48 hr. Concentration of Selected Cations Plotted as a

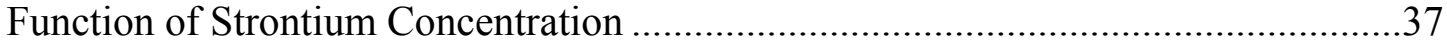

Figure 4.4.2.1 Particulate Solids Summary ...........................................................................44

Figure 4.4.2.2 Manganese concentration in 0 - 16 Day Filtrates for Manganese, Light, and

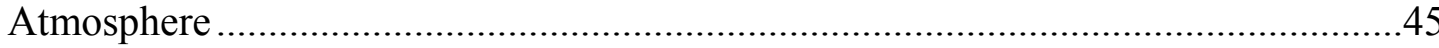

Figure 4.4.2.3 Manganese concentration in 0 - 16 Day Filtrates for Manganese, Dark, and

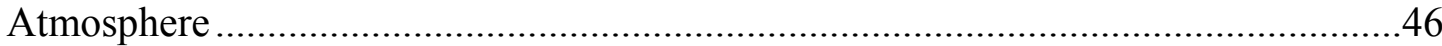

Figure 4.4.2.4 Manganese concentration in 0 - 16 Day Filtrates for Manganese, Light, and

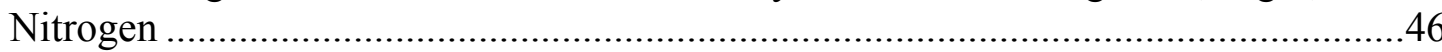

Figure 4.4.2.5 Manganese concentration in 0 - 16 Day Filtrates for Manganese, Dark, and

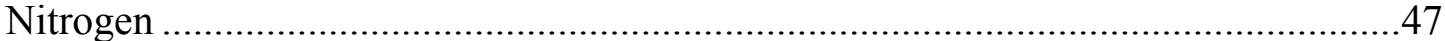

Figure 4.4.2.6 Iron concentration in 0 - 16 Day Filtrates for Manganese, Light, and Atmosphere

Figure 4.4.2.7 Iron concentration in 0 - 16 Day Filtrates for Manganese, Dark, and Atmosphere

Figure 4.4.2.8 Iron concentration in 0 - 16 Day Filtrates for Manganese, Light, and Nitrogen48 Figure 4.4.2.9 Iron concentration in 0 - 16 Day Filtrates for Manganese, Dark, and Nitrogen..

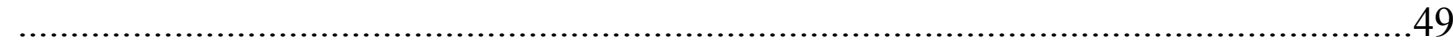

Figure 4.4.2.10 Strontium concentration in 0 - 16 Day Filtrates for Manganese, Light, and Atmosphere

Figure 4.4.2.11 Strontium concentration in 0 - 16 Day Filtrates for Manganese, Dark, and Atmosphere

Figure 4.4.2.12 Strontium concentration in 0 - 16 Day Filtrates for Manganese, Light, and Nitrogen ....

Figure 4.4.2.13 Strontium concentration in 0 - 16 Day Filtrates for Manganese, Dark, and

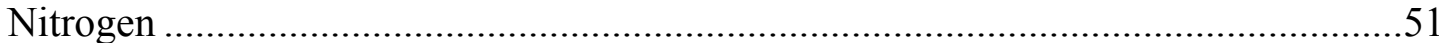

Figure 4.4.2.14 Manganese (III) Oxy-hydroxide and Manganese (IV) Dioxide on Filters.....53

Figure 4.5.1.1 $\mathrm{E}_{\mathrm{H}}$ Measurements for the AN-102 Base Case and Oxygen Purge Filtrates .....57

Figure 4.5.1.2 $\mathrm{E}_{\mathrm{H}}$ Measurements for the AN-102 NOC Base Case and Oxygen Purge Filtrates

Figure 4.5.1.3a Manganese Concentration in Replicate A Filtrates for the AN-102 Baseline Primary Effects Study ...............................................................................58

Figure 4.5.1.3b Manganese Concentration in Replicate A Filtrates for the AN-102 Baseline

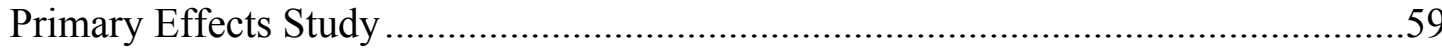

Figure 4.5.1.4a Manganese Concentration in Replicate B Filtrates for the AN-102 Baseline

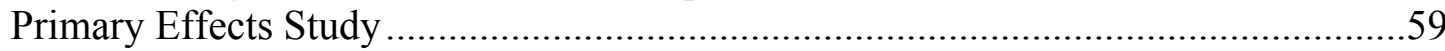

Figure 4.5.1.4a Manganese Concentration in Replicate B Filtrates for the AN-102 Baseline Primary Effects Study....

Figure 4.5.1.5 Iron Concentration in Replicate A Filtrates for the AN-102 Baseline Primary

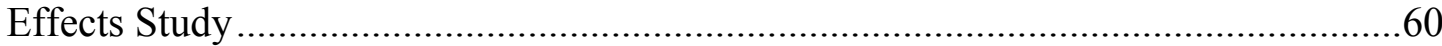

Figure 4.5.1.6 Iron Concentration in Replicate B Filtrates for the AN-102 Baseline Primary Effects Study.....

Figure 4.5.1.7a Strontium Concentration in Replicate A Filtrates for the AN-102 Baseline Primary Effects Study

Figure 4.5.1.7b Strontium Concentration in Replicate A Filtrates for the AN-102 Baseline Primary Effects Study 
WSRC-TR-2003-00232, Rev. 0

SRT-RPP-2003-00105, Rev. 0

Figure 4.5.1.8a Strontium Concentration in Replicate B Filtrates for the AN-102 Baseline Primary Effects Study

Figure 4.5.1.8b Strontium Concentration in Replicate B Filtrates for the AN-102 Baseline

Primary Effects Study....

Figure 4.5.1.9 Manganese Concentration in Replicate A Filtrates for the AN-102 NOC

Primary Effects Study

Figure 4.5.1.10 Manganese Concentration in Replicate B Filtrates for the AN-102 NOC

Primary Effects Study

Figure 4.5.1.11 Iron Concentration in Replicate A Filtrates for the AN-102 NOC Primary

Effects Study

Figure 4.5.1.12 Iron Concentration in Replicate B Filtrates for the AN-102 NOC Primary Effects Study

Figure 4.5.1.13 Strontium Concentration in Replicate A Filtrates for the AN-102 NOC

Primary Effects Study

Figure 4.5.1.14 Strontium Concentration in Replicate B Filtrates for the AN-102 NOC

Primary Effects Study

Figure 4.5.1.15 Manganese Concentration in Time Zero Filtrates for the Variables Included in the AN-102 Baseline Primary Effects Study

Figure 4.5.1.16 Iron Concentration in Time Zero Filtrates for the Variables Included in the AN-102 Baseline Primary Effects Study

Figure 4.5.1.17 Strontium Concentration in Time Zero Filtrates for the Variables Included in the AN-102 Baseline Primary Effects Study 70

Figure 4.5.1.18 Lanthanum Concentration in Time Zero Filtrates for the Variables Included in the AN-102 Baseline Primary Effects Study

Figure 4.5.1.19 Neodymium Concentration in Time Zero Filtrates for the Variables Included in the AN-102 Baseline Primary Effects Study .........................................................72

Figure 4.5.1.20 Zirconium Concentration in Time Zero Filtrates for the Variables Included in the AN-102 Baseline Primary Effects Study ........................................................73

Figure 4.5.1.21 Manganese Concentration in Time Zero Filtrates for the Variables Included in the AN-102 NOC Study

Figure 4.5.1.22 Iron Concentration in Time Zero Filtrates for the Variables Included in the AN-102 NOC Study.

Figure 4.5.1.23 Strontium Concentration in Time Zero Filtrates for the Variables Included in the AN-102 NOC Study. 75

Figure 4.5.1.24 Lanthanum Concentration in Time Zero Filtrates for the Variables Included in the AN-102 NOC Study

Figure 4.5.1.25 Neodymium Concentration in Time Zero Filtrates for the Variables Included in the AN-102 NOC Study. .76

Figure 4.5.1.26 Zirconium Concentration in Time Zero Filtrates for the Variables Included in the AN-102 NOC Study....

Figure 4.5.1.27 Time Zero Filtrate Concentration of $\mathrm{Mn}, \mathrm{Fe}$, and $\mathrm{Sr}$ as a Function of $\mathrm{Mn}$ Reaction Concentration............................................................................... 78

Figure 4.5.1.28 Time Zero Filtrate Concentration of Ce, La, Nd, and $\mathrm{Zr}$ as a Function of Mn Reaction Concentration .78

Figure 4.5.1.29 Solids Concentration $(\mathrm{mg} / \mathrm{L})$ in Filtrates after 16 Days for the AN-102 Baseline and NOC Experiments 
WSRC-TR-2003-00232, Rev. 0

SRT-RPP-2003-00105, Rev. 0

Figure 4.5.2.1 Concentration of Manganese in the 0 - 16 Day Simulant A filtrates for the Baseline Secondary Effects Study ........................................................................ 85

Figure 4.5.2.2 Concentration of Manganese in the 0-16 Day Simulant B filtrates for the

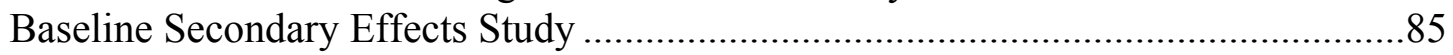

Figure 4.5.2.3 Concentration of Iron in the 0-16 Day Simulant A filtrates for the Baseline Secondary Effects Study …………….............................................................86

Figure 4.5.2.4 Concentration of Iron in the 0 - 16 Day Simulant B filtrates for the Baseline Secondary Effects Study ............................................................................... 86

Figure 4.5.2.5 Concentration of Strontium in the $0-16$ Day Simulant A filtrates for the Baseline Secondary Effects Study .....................................................................87

Figure 4.5.2.6 Concentration of Strontium in the 0 - 16 Day Simulant A filtrates for the Baseline Secondary Effects Study ........................................................................87

Figure 4.5.2.7 Manganese Concentration in Time Zero Filtrate for the Variables Included in the AN-102 Secondary Effects Study …………………........................................8

Figure 4.5.2.8 Iron Concentration in Time Zero Filtrate for the Variables Included in the AN102 Secondary Effects Study

Figure 4.5.2.9 Strontium Concentration in Time Zero Filtrate for the Variables Included in the AN-102 Secondary Effects Study

Figure 4.5.2.10 Lanthanum Concentration in Time Zero Filtrate for the Variables Included in the AN-102 Secondary Effects Study

Figure 4.5.2.11 Neodymium Concentration in Time Zero Filtrate for the Variables Included in the AN-102 Secondary Effects Study

Figure 4.5.2.12 Zirconium Concentration in Time Zero Filtrate for the Variables Included in the AN-102 Secondary Effects Study

Figure 4.5.1.13 Concentration of Solids as a Function of Treatment Condition in the Baseline Secondary Effects Samples 
WSRC-TR-2003-00232, Rev. 0

SRT-RPP-2003-00105, Rev. 0

\section{LIST OF TABLES}

Table 3.3.1 Variables Included in the Primary Effects Study for 241-AN-107 and 241-AN102

Table 4.1.2.1 Concentration of Selected Cations in the AN-107 and AN-102 Simulants.......18

Table 4.3.1 Presence of Solids in AN-107 Filtrates for the 0.0 M Sodium Hydroxide Preliminary Experiments

Table 4.3.2 Presence of Solids in AN-107 Filtrates for the 1.3 M Sodium Hydroxide Preliminary Experiments .21

Table 4.4.1.1 Presence of Solids in AN-107 Filtrates for the Primary Effects Study ............23

Table 4.4.1.2 The Effect of Oxygen on the Concentration of Manganese, Iron, and Strontium in Filtrates

Table 4.4.1.3 Ratio of Concentration for $\mathrm{Fe}, \mathrm{Mn}, \mathrm{Sr}$ (0-48 Hr avg/final filtrate concentration)

Table 4.4.2.1 Factorial Design for the Newly Optimized Condition...................................42

Table 4.4.2.2 Appearance of Solids in Filtrates During the 16-day Period (AN-107) ...........43

Table 4.4.2.3 Error Estimate of ICP-AES Analysis for Manganese Measured in the Secondary Effects Filtrate

Table 4.4.2.4 Range of ICP-AES Analysis for Manganese Measured in the Secondary Effects Filtrate

Table 4.4.2.5 Calculated First Order Rate Constants for Loss of Strontium from Secondary Effects Filtrates .....

Table 4.4.2.6 Percent of the Initial Cation Concentration present in the Precipitates Collected

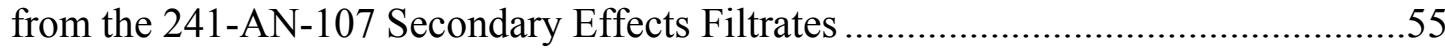

Table 4.5.1.1 Visual Observations for 241-AN-102 Post Filtration Precipitation Study ........56

Table 4.5.1.2 Concentration of Selected Cations for the $0-16$ Day Observation Period for the 241-AN-102 Primary Effects Study....

Table 4.5.1.3 Percent of Cation Mass Present in the Solids Relative to Time Zero Cation Mass in the AN-102 Baseline Primary Effects Study....

Table 4.5.1.4 Percent of Cation Mass Present in Solids Relative to Time Zero Cation Mass in AN-102 NOC Primary Effects Study

Table 4.5.1.5 Estimated First Order Rate Constants and Half-lives for Loss of Manganese From the Primary Effects Filtrates During the 16-Day Observational Period.

Table 4.5.2.1 Visual Observations for 241-AN-102 Post Filtration Precipitation Study Secondary Effects Experiments

Table 4.5.2.2 Concentration of Selected Cations for the $0-16$ Day Observation Period for the Baseline Secondary Effects Study

Table 4.5.2.3 Percent of Cation Mass Present in the Solids Relative to Time Zero Cation Mass in Filtrates for the AN-102 Secondary Effects Study.

Table 4.5.2.4 Estimated First Order Rate Constants and Half-lives for Loss of Manganese ..93 
WSRC-TR-2003-00232, Rev. 0

SRT-RPP-2003-00105, Rev. 0

\section{LIST OF ACRONYMS AND ABBREVIATIONS}

BNFL - British Nuclear Fuel Limited

Dk - Dark

DOE - Department of Energy

EDTA - Ethylenediaminetetraacetic acid

HLW - High Level Waste

ICP-AES - Inductively Coupled Plasma-Atomic Emission Spectroscopy

LAW - Low Activity Waste

Lt - Light

Mp - Mass precipitate

$\mathrm{Mt}$ - Mass total

NOC - Newly Optimized Condition

ORP - Oxidation Reduction Potential

RPP - River Protection Project

Rxn -- Reaction

SCUREF - South Carolina Research Education Foundation

Sim 7 - Simulant 7

Sim 8 - Simulant 8

Sim A - Simulant A

Sim B - Simulant B

$\mathrm{t}_{1 / 2}$ - Half life

TRU - Transuranic

$\mathrm{U} / \mathrm{F}$ - Ultra filtration

UV/VIS - Ultra-violet/Visible

WSRC - Westinghouse Savannah River Company

WTP - Waste Treatment Plant 
WSRC-TR-2003-00232, Rev. 0

SRT-RPP-2003-00105, Rev. 0

\begin{abstract}
Envelope ' $\mathrm{C}$ ' high-level waste simulants were prepared to represent the chemical composition of the supernates of two tanks, 241-AN-107 and -102 located at the Hanford Site in Washington State. Experiments were conducted with these simulants to determine the impact of several chemical and physical parameters on the phenomena of post-filtration precipitation. Baseline experiments were conducted for flow sheet conditions, which involved a reaction of each simulant with $0.075 \mathrm{M}$ strontium nitrate, $0.05 \mathrm{M}$ sodium permanganate, and 1.0 M added sodium hydroxide at $50{ }^{\circ} \mathrm{C}$ for four hours. Simulants were filtered at $0.1 \mu \mathrm{m}$ and stored in the dark under a nitrogen blanket. Chemical and physical parameters investigated were categorized as either reaction or filtrate variables. Reaction variables examined the effect of reaction temperature, free sodium hydroxide concentration, reagent concentrations, and shear level during the precipitation reaction on post-filtration solids formation. Filtrate variables examined the effects of light intensity, temperature of the filtrate, filtration at $50{ }^{\circ} \mathrm{C}$ (omitted for $\mathrm{AN}-102$ ), filter pore size (omitted for AN-102), and oxidation-reduction potential (ORP) on post-filtration solids formation. Experiments were designed to study both primary effects and secondary effects of the parameters.
\end{abstract}

Data presented for the 241-AN-107 primary effects study indicated that post-filtration solids formed with all treatments examined given sufficient time. However, in the short term (within 48 hours), reacting the simulant at flow sheet conditions but eliminating the addition of sodium hydroxide from the reaction mixture and minimizing exposure to oxygen in the filtrates minimized the formation of precipitates. In addition, the formation of post-filtration solids could also be minimized by reducing the concentration of sodium permanganate to approximately $0.01 \mathrm{M}$.

With exception of two experimental conditions, the 8-hr hold of the filtrate at $100{ }^{\circ} \mathrm{C}$ and the oxygen sparge, solids that formed during the 48 -hr period were very light in color. The filtrates sparged with oxygen contained brown solids within six hours, and significant black solids formed in the filtrates held at $100{ }^{\circ} \mathrm{C}$ for eight hours. The formation of brown solids in the filtrates sparged with oxygen is commensurate with permanganate reduction in alkaline media to manganese hydroxide, which is a white precipitate, and subsequent oxidation in the presence of air to the brown manganese (III) oxy-hydroxide and oxide and ultimately to the black manganese dioxide. Formation of black solids in the 8-hr hold filtrates supports the hypothesis that the precipitation reaction kinetics are too slow for the reaction to be complete after a four hour reaction time.

Very near the end of the analytical effort for the AN-241-107 primary effects study, discussions were initiated concerning reconsideration of the reaction conditions. A "newly optimized condition' (NOC) was proposed in which the concentration of reactants was reduced to $0.03 \mathrm{M}$ strontium nitrate and sodium permanganate. In addition, the sodium hydroxide concentration was set at $0.3 \mathrm{M}(0.0 \mathrm{M}$ added to the AN-102 simulant), and a reaction temperature at $25^{\circ} \mathrm{C}$. A $2^{3}$ factorial experiment using the NOC reaction and varying the sodium permanganate concentration, the light level and the influence of oxygen was designed. 
WSRC-TR-2003-00232, Rev. 0

SRT-RPP-2003-00105, Rev. 0

During the 16-day observation period, dark solids appeared in all treatment pairs in contact with the atmosphere. Dark solids also formed for the light/nitrogen pairs reacted at 0.01 and $0.03 \mathrm{M}$ sodium permanganate. Dark solids did not form for reaction at the NOC and at the NOC with $0.01 \mathrm{M}$ sodium permanganate. Therefore, it would appear that reacting at the NOC or at lower permanganate concentration could mitigate the formation of dark solids within 16 days of an oxidation reaction with a 241-AN-107 waste.

Cation concentration for manganese and iron measured in the 16-day filtrates did not show a measurable decrease with time, even though solids collected at the end of the 16 days did indicate the presence of manganese and iron. Therefore, rate constants describing the formation of those solids could not be determined. Rate constants describing the formation of strontium solids during the 16-day period were calculated. Half-lives calculated for filtrates maintained in the light ranged from 15.3 to 21.2 days $^{-1}$ while those maintained in the dark ranged from 22.4 to 60.3 days $^{-1}$ suggesting that light may play an important role in the precipitation of strontium.

The primary effects study for the 241-AN-102 simulant resulted in the formation of brown to black solids in all treatments except the zero molar added sodium hydroxide and the $25{ }^{\circ} \mathrm{C}$ reaction under otherwise baseline conditions, the NOC, and the $0.01 \mathrm{M}$ sodium permanganate reaction under otherwise NOC. Estimated rate constants and half-lives describing the loss of manganese from filtrates during the 16-day observation period were calculated. Half-lives ranged between 7 and 495 days. Treatment conditions exhibiting small half-lives could potentially result in an accumulation of post-filtration solids that may be problematic in the ion exchange process. Conditions involving light and oxygen exposure had the shortest half-lives.

Secondary effects studied for the $241-\mathrm{AN}-102$ simulant involved examining the effect of 0.0 $\mathrm{M}$ added sodium hydroxide and a $25^{\circ} \mathrm{C}$ reaction condition with $0.03 \mathrm{M}$ strontium, $0.03 \mathrm{M}$ permanganate, light, and the presence of oxygen. Results indicated that a $25{ }^{\circ} \mathrm{C}$ reaction temperature is not effective in inhibiting the formation post-filtration solids when crossed with primary effects variables that did promote solids formation. Lowering the reaction temperature from 50 to $25^{\circ} \mathrm{C}$ should have resulted in less of a reaction precipitate leaving more iron in solution as noted above. However, the behavior of iron in response to the lowered reaction temperature follows that of manganese suggesting that co-precipitation or adsorption may be an important removal mechanism for iron.

The $0.0 \mathrm{M}$ added $\mathrm{NaOH}$ reaction condition does not promote solid formation and may inhibit the formation of solids when crossed with other primary effects variables that promote solid formation. Exposure to light is also seen to be very effective in promoting the formation of dark brown to black post-filtration solids.

For all treatment conditions, white or clear solids on the bottom of the flasks were the first to appear. In some filtrates, these solids were then covered by a thin layer of light brown solids. Light solids that appeared on the surface generally became darker with time, presumably as they were oxidized. 
In summary, the data suggests that for the base case conditions, lowered reaction temperature and the absence of added $\mathrm{NaOH}$ do not result in the formation of dark solids within 16-days. Similarly, the variable evaluated for the newly optimized conditions that did not result in the formation of dark solids was the $0.01 \mathrm{M}$ permanganate treatment. The newly optimized conditions also did not result in the formation of dark solids.

Post-filtration solids that formed in both the AN-107 and -102 filtrates were completely soluble in 0.5 molar nitric acid. Additionally, the mass of predominantly manganese containing solids that formed in the filtrates was small, generally in the $\mathrm{mg} / \mathrm{L}$ range. 
WSRC-TR-2003-00232, Rev. 0

SRT-RPP-2003-00105, Rev. 0

\subsection{SUMMARY OF TESTING}

\subsection{OBJECTIVES}

$>$ The purpose of this task was to determine the first order effects for selected physical and chemical parameters that lead to post-filtration precipitation of manganese- and ironcontaining solids in Sr/TRU 241-AN-107 and -102 simulant filtrates. Additionally, second order effects were explored after some of the first order effects were eliminated.

$>$ First order effects were studied using a completely random experimental design where replicated experiments for each of the physical and chemical parameters noted in WSRCTR-2001-00425/SRT-RPP-2001-00147, Revision 1 and the R\&T Test Exception 24590WTP-TEF-RT-02-063 were compared to baseline experiments.

$>$ Second order effects were studied using a factorial experimental design for first order parameters that resulted in a negative main effect response.

\subsection{CONDUCT OF TESTING}

Testing was performed on a 100 to $150 \mathrm{~mL}$ scale using 241-AN-107 and -102 nonradioactive simulants in $250 \mathrm{~mL}$ Erlenmeyer flasks. The simulants were diluted to a sodium concentration of $6 \mathrm{M}$ and heated to $50{ }^{\circ} \mathrm{C}$ in a circulating water bath. Simulants were then adjusted to $1 \mathrm{M}$ free hydroxide by the addition of $17 \mathrm{M}$ sodium hydroxide $(\mathrm{NaOH})$. One molar strontium nitrate $\left(\mathrm{SrNO}_{3}\right)$ was added to the reaction mixture to achieve a final concentration of $0.075 \mathrm{M}$ strontium $(\mathrm{Sr})$. After reacting for a period of 15 minutes, $1 \mathrm{M}$ sodium permanganate $\left(\mathrm{NaMnO}_{4}\right)$ was added to achieve a final concentration of $0.05 \mathrm{M}$ permanganate $\left(\mathrm{MnO}_{4}^{-}\right)$, and the suspension was allowed to react for a period of 4 hours. Following the reaction period, the mixture was cooled to room temperature $\left(23-25^{\circ} \mathrm{C}\right)$ in a re-circulating water bath, centrifuged to remove bulk solids and filtered with 0.1 micron nylon filters. Filtrates were collected and stored in the dark under a nitrogen blanket during the observation period. Details of the above procedure are provided in Bannochie, 2002.

Treatment variables examined the effects of reaction temperature, free sodium hydroxide concentration, reagent concentrations, filtration at $50{ }^{\circ} \mathrm{C}$ (omitted for $\mathrm{AN}-102$ ), shear level of the precipitate, and filter pore size (omitted for $\mathrm{AN}-102$ ) on post-filtration solids formation. Filtrate variables examined the effects of light intensity, temperature of the filtrate, and oxidation-reduction potential (ORP) on post-filtration solids formation. Light intensity was adjusted by storing the filtrate directly under a fluorescent light as opposed to the base case conditions of being stored in the dark. The light intensity at the surface of the filtrate was measured to be 1600 Lux. To examine the effect of temperature, the filtrate was heated to $100{ }^{\circ} \mathrm{C}$ for eight hours. Filtrates were also sparged with oxygen and nitrogen gases (omitted in $\mathrm{AN}-102)$ in an attempt to raise or lower the bulk redox potential of the filtrate.

In addition to studying the above reaction and treatment variables, experiments were conducted to study the formation of post-filtration solids for a set of experimental conditions termed the newly optimized conditions (NOC). The concentration of reactants for the NOC 
WSRC-TR-2003-00232, Rev. 0

SRT-RPP-2003-00105, Rev. 0

was $0.03 \mathrm{M} \mathrm{SrNO}_{3}$ and $\mathrm{NaMnO}_{4}$ and $0.3 \mathrm{M}$ added $\mathrm{NaOH}$. The reaction temperature was maintained at $25^{\circ} \mathrm{C}$ for 4 hours. The NOC were examined during the secondary effects study for 241-AN-107 and the primary effects study for 241-AN-102.

Testing was performed in accordance with technical task plan ( Bannochie and Nash, 2001) and the test exception (Abodishish, 2002).

\subsection{RESULTS AND PERFORMACE AGAINST OBJECTIVES}

The first objective of this testing was to evaluate the influence of several chemical and physical parameters individually (primary effect) on post-filtration solids formation for two Hanford waste tank simulants, 241-AN-107 and -102. In this work with the 241-AN-107 simulant, the research suggests that eliminating the addition of sodium hydroxide from the reaction mixture and minimizing exposure to oxygen in the filtrates may minimize the formation of solids. Studies with the 241-AN-102 simulant resulted in the formation of brown to black solids in all treatments except four: the zero molar added sodium hydroxide, the $25{ }^{\circ} \mathrm{C}$ reaction temperature at the baseline condition, the $\mathrm{NOC}$, and the $0.01 \mathrm{M}$ sodium permanganate reaction for the NOC.

The second objective was to determine synergistic effects of the negative primary effects variables crossed with (among and between) select positive primary effects variables. During the 16-day observational period for the 241-AN-107 simulants, dark solids appeared in all treatment pairs in contact with the atmosphere. Dark solids also formed for the light/nitrogen pairs reacted at 0.01 and $0.03 \mathrm{M}$ sodium permanganate. Dark solids did not form during the 16-day period for reaction at the NOC and at the NOC with $0.01 \mathrm{M}$ sodium permanganate. Studies with the 241-AN-102 simulant indicated that the $0.0 \mathrm{M}$ added NaOH reaction condition did not promote solids formation within the 16-day period and may inhibit the formation of solids when crossed with other primary effects variables that promote solids formation. Exposure to light was also seen to be very effective in promoting the formation of dark brown to black post-filtration solids.

\subsection{QUALITY REQUIREMENTS}

This task was performed in accordance with Quality Assurance Project Plan EES-01-001, Rev. 2. September 24, 2002 and the technical task plan WSRC-TR-2001-00425/SRT-RPP2001-00147, "Evaluation of Post-Filtration Precipitation Mechanisms". The technical work associated with this task was performed by a sub-tier supplier (Clemson University) under a South Carolina Research Education Foundation (SCUREF) contract. Appendix A in the above technical task plan contains a graded application of the NQA-1-1989 and NQA-2a1990 QA Programmatic elements applicable to this task. Since the tests do not affect the quality of a high level waste (HLW) form, the requirements of DOE/RW-0333P Revision 10 do not apply to this task.

\subsection{ISSUES}

No issues were identified. 
WSRC-TR-2003-00232, Rev. 0

SRT-RPP-2003-00105, Rev. 0

\subsection{INTRODUCTION}

The Department of Energy (DOE) has established the River Protection Project (RPP) to oversee nuclear waste treatment at the Hanford Site in Washington State. High-level waste (HLW) stored in tanks has been segregated into envelopes based on general tank chemistry and processing requirements. At Hanford, at least two tanks are classified as Envelope C waste. An Envelope $\mathrm{C}$ waste is defined as an alkaline supernate containing organic complexants [e.g., ethylenediaminetetraacetic acid (EDTA), gluconate, citrate, etc.], high strontium (Sr)-90 activity, and transuranic (TRU) elements (e.g., plutonium $(\mathrm{Pu})$ and americium (Am)). The goal of the RPP Waste Treatment Plant (WTP) is to process the different waste envelopes into high level waste (HLW) and low activity waste (LAW) streams and to vitrify each stream separately.

The treatment process for Envelope $\mathrm{C}$ waste is a batch process consisting of evaporation, precipitation, cross-flow ultrafiltration $(\mathrm{U} / \mathrm{F})$, ion exchange, and ultimately vitrification (McCabe and Nash, 2000). Envelope $\mathrm{C}$ waste treatment required removal of strontium to below $1.1 \times 10^{-3} \mathrm{Ci} /$ mole waste sodium and the TRU elements to below $1.5 \times 10^{-5} \mathrm{Ci} / \mathrm{mole}$ sodium (Townson, 1999). New requirements are $20 \mathrm{Ci} \mathrm{Sr} / \mathrm{m}^{3}$-glass and $100 \mathrm{nCi} \mathrm{Tru} / \mathrm{m}^{3}$ glass. Strontium nitrate is added for isotopic dilution, and sodium permanganate is used as an organic oxidant and to promote the formation of adsorptive species in the waste. Precipitate formation effectively reduces the concentration of TRU elements to acceptable levels.

The treatment process is being designed using both simulant and actual Envelope $\mathrm{C}$ waste. Nonradioactive simulant recipes for tanks 241-AN-107 and 241-AN-102 wastes were developed by Westinghouse Savannah River Company (WSRC) to mimic, both physically and chemically, actual tank waste.

In the course of developing the treatment scheme for the Envelope $\mathrm{C}$ waste, it was discovered that solids formed in the filtrate of treated waste. After the treated waste was filtered at 0.1 micrometers $(\mu \mathrm{m})$, solids appeared in the filtrate within days. These solids have been observed in both treated Envelope $\mathrm{C}$ tank waste and in the simulant waste (Nash and Rosencrance, 2000). Different hypotheses were proposed to explain the appearance of postfiltration solids. If reaction kinetics are slow, a four-hour reaction time may be insufficient for the reaction to be completed. Complexation and hydrolysis may also kinetically limit the precipitation reaction. The chelating agents present in the waste could affect precipitation by keeping the metal cations complexed during the reaction. The rate of hydrolysis of the free metal cations may also affect post-filtration solids formation. Sub-micron (less than $0.1 \mu \mathrm{m}$ ) particles not captured by the filter could agglomerate over time and form visible solids. It was also hypothesized that visible light may photochemically promote solids growth in the filtrate. Similarly, photochemical reactions due to the decay of nuclides in the waste could play a role in post-filtration solids formation.

Post-filtration solids entering the ion exchange column could potentially reduce the removal of target nuclides by blocking exchange sites. In addition, solids could build up in the resin 
WSRC-TR-2003-00232, Rev. 0

SRT-RPP-2003-00105, Rev. 0

and increase the pressure drop across the resin bed and thus alter process efficiency. The formation of post-filtration solids must therefore be addressed before final design is completed. (Bannochie and Nash, 2001).

Variables that affected the permanganate oxidation reaction and the filtrate were studied. Variables included in this investigation are listed in the experimental detail section and literature findings in support of their use are discussed below.

Under alkaline conditions, sodium permanganate is reduced to manganese hydroxide $\left(\mathrm{Mn}(\mathrm{OH})_{2}\right)$, which is easily oxidized by ambient air to manganese (III) oxyhydroxide $(\mathrm{MnO}(\mathrm{OH}))$ and oxide $\left(\mathrm{Mn}_{2} \mathrm{O}_{3}\right)$ and can ultimately be oxidized to manganese dioxide $\left(\mathrm{MnO}_{2}\right)($ Cotton and Wilkinson, 1988). These reactions depend on the redox state of the solution. $\mathrm{E}_{\mathrm{H}}$ values of less than $-0.2 \mathrm{~V}$ at high $\mathrm{pH}$ favor the formation of $\mathrm{Mn}$ (II) hydroxides. $\mathrm{E}_{\mathrm{H}}$ values of greater than -0.1 favor the reduction to Mn (IV) oxides.

As temperature affects reaction kinetics, it may therefore affect the formation of postfiltration solids. In a British Nuclear Fuel Limited (BNFL) study published by Hildred, et al. (2000), effects of temperature on particle formation were briefly examined. The study indicated that as temperature increased, particles became more crystalline in structure. Cho et al. (2000) investigated the formation of lepidocrocite fine particles by oxidation of ferrous hydroxide between the temperatures of $20^{\circ} \mathrm{C}$ and $30^{\circ} \mathrm{C}$ and reported that an increase in temperature resulted in increased reaction rates and smaller lepidocrocite particle sizes.

Filter pore size was examined to investigate the hypothesis that submicron particles agglomerated into visible solids. A larger filter pore size $(0.45 \mu \mathrm{m}$ vs. $0.1 \mu \mathrm{m})$ should allow a larger number of smaller particles to pass into the filtrate. Therefore, a larger mass of small particles may be present in filtrate that is treated with larger filter pore sizes. Agglomeration of the smaller particles could result in the formation of visible solids. Likewise, fewer postfiltration solids are expected in filtrates that are filtered at $0.1 \mu \mathrm{m}$.

Several researchers have reported the effects of light and ionizing radiation on the formation of submicron sized particles. Mallick, et al. (2001) reported that ultraviolet (UV) irradiation of seeded gold particles produced nanoparticles with size and shape control. Kuga, et al. (1996) showed that $U_{5}$ nano-particles were photoproduced by InfraRed MultiPhoton Dissociation, and that the formation of particles was enhanced by ionizing radiation from an alpha $(\alpha)$-emitting Am-241 source. These observations indicate that particle growth can be affected by light energy and radiation energy.

Both reducing and oxidizing environments could also impact the formation of post-filtration solids. Kamei and Ohmoto (2000), reported that the rate of oxidation in an aqueous solution was approximately equal to the rate of dissolved oxygen consumption. In a study on the formation of particles by oxidation of an aqueous suspension of ferrous hydroxide, Cho, et al. (2000) observed that increasing the oxygen concentration in a system decreased the formation of particles from $0.60 \mu \mathrm{m}$ to $0.35 \mu \mathrm{m}$. 
WSRC-TR-2003-00232, Rev. 0

SRT-RPP-2003-00105, Rev. 0

\subsection{EXPERIMENTAL DETAIL}

The experimental methods used to accomplish the research objectives consisted of preparing a simulant, treating the simulant to oxidize and precipitate metal cations, filtering it at $0.1 \mu \mathrm{m}$ to collect filtrates, exposing filtrates to several physical and chemical conditions for either 48 hours or 16 days depending on the experimental requirements, and analyzing the filtrates to determine the quantity and composition of post-filtration solids. Each of these aspects will be discussed in detail in the following sections.

Initially, post-filtration solids formation was monitored visually for a 48-hr period. During this period, particle size measurements were taken in an attempt to obtain kinetic data. These efforts were abandoned due to the formation of visible solids in the filtrates before the measurement of sub-micron and micron sized particles. The initial 48-hr period was selected because the process flow sheet called for processing through the ion exchange resin within 48 hours. Subsequent discussions at Hanford during a review indicated that filtrates might require one week to process through the ion exchange media. Therefore the author made a decision to visually monitor the filtrates for approximately 16 days.

\subsection{SIMULANT PREPARATION}

Experiments were performed with simulant wastes representing the contents of Hanford tanks 241-AN-107 and 241-AN-102. Simulant recipes shown in Appendix A (Eibling and Nash, 2001; Eibling, 2003) were prepared using ACS-grade chemicals. Replicate simulants were prepared using the WSRC-recipes shown in Table A.1 and A.2. Simulants were prepared in sufficient quantities to replicate all proposed experiments. The 241-AN-107 simulant pair was aged under atmospheric conditions, in a closed Nalgene ${ }^{\circledR}$ container for a period of one month prior to conducting experiments. Replicate 241-AN-102 simulants were aged under a nitrogen blanket for a period of one week prior to experimentation and stored under nitrogen for the duration of the investigation. After preparation and aging, simulants were diluted to $6 \mathrm{M}$ sodium immediately prior to conducting each experiment.

During the investigation, visual observations regarding changes in color of the simulants and spectrophotometer measurements were used to indicate chemical or physical changes in the simulants with time. Slight color changes were apparent during the first week of aging. Generally simulants became slightly darker in color. Changes in the ultraviolet and visible wavelength spectra (190-1100 nm) were monitored using a Beckman DU Series 600 Spectrophotometer.

\subsection{BASELINE EXPERIMENTS}

Baseline experiments were conducted for each of the waste simulants (241-AN-107 and 241AN-102). Replicate aliquots of the simulants were diluted to a sodium concentration of $6 \mathrm{M}$ and heated to $50{ }^{\circ} \mathrm{C}$ in a circulating water bath. Simulants were then adjusted to $1 \mathrm{M}$ free hydroxide by the addition of $17 \mathrm{M}$ sodium hydroxide $(\mathrm{NaOH})$. One molar strontium nitrate 
WSRC-TR-2003-00232, Rev. 0

SRT-RPP-2003-00105, Rev. 0

$\left(\mathrm{SrNO}_{3}\right)$ was added to the reaction mixture to achieve a final concentration of $0.075 \mathrm{M}$ strontium ( $\mathrm{Sr})$. After reacting for a period of 15 minutes, $1 \mathrm{M}$ sodium permanganate $\left(\mathrm{NaMnO}_{4}\right)$ was added to achieve a final concentration of $0.05 \mathrm{M}$ permanganate $\left(\mathrm{MnO}_{4}{ }^{-}\right)$, and the suspension was allowed to react for a period of 4 hours. Following the reaction period, the mixture was cooled to room temperature $\left(23-25^{\circ} \mathrm{C}\right)$ in a re-circulating water bath, centrifuged to remove bulk solids and filtered at 0.1 micrometers. Filtrates were collected and stored in the dark under a nitrogen blanket during the observation period. Details of the above procedure are provided in Bannochie, 2002.

\subsection{PRIMARY EFFECTS STUDY}

Variations from the base case treatment and filtrate conditions are summarized in Table 3.3.1 for the AN-107 and AN-102 studies. Treatment variables (hereafter referred to as reaction variables) examined the effects of reaction temperature, free sodium hydroxide concentration, reagent concentrations, and shear level of the precipitate on post-filtration solids formation. Filtrate variables examined the effects of light intensity, temperature of the filtrate, filtration at $50{ }^{\circ} \mathrm{C}$ (omitted for $\mathrm{AN}-102$ ), filter pore size (omitted for $\mathrm{AN}-102$ ), and oxidation-reduction potential (ORP) on post-filtration solids formation. Light intensity was adjusted by storing the filtrate directly under a fluorescent light as opposed to the base case conditions of being stored in the dark. The light intensity at the surface of the filtrate was measured to be 1600 Lux. To examine the effect of filtrate temperature, the filtrate was heated to $100{ }^{\circ} \mathrm{C}$ for eight hours. Filtrates were also sparged with oxygen and nitrogen (omitted in AN-102) gases in an attempt to lower or raise the bulk redox potential of the filtrate. 
WSRC-TR-2003-00232, Rev. 0

SRT-RPP-2003-00105, Rev. 0

Table 3.3.1 Variations From the Base Case Included in the Primary Effects Study for 241AN-107 and 241-AN-102

\begin{tabular}{|c|c|}
\hline AN-241-107 & AN-241-102 \\
\hline $\begin{array}{l}\quad \text { Reaction Variables } \\
15^{\circ} \mathrm{C} \text { Rxn } \\
25^{\circ} \mathrm{C} \text { Rxn } \\
0.01 \mathrm{M} \text { Sodium Permanganate } \\
0.25 \mathrm{M} \text { Sodium Permanganate } \\
0.01 \mathrm{M} \text { Strontium Nitrate } \\
0.02 \mathrm{M} \text { Strontium Nitrate } \\
0.0 \mathrm{M} \text { added } \mathrm{NaOH} \\
0.2 \mathrm{M} \text { added } \mathrm{NaOH} \\
\text { Shear@ } 10,000 \mathrm{RPM} \\
\qquad \text { Filtrate Variables } \\
\text { Light } \\
\text { Filter Pore Size } \\
8 \text { Hr Hold @ } 100{ }^{\circ} \mathrm{C} \\
\text { Oxygen Sparge } \\
\text { Nitrogen Sparge } \\
\text { Filter@ } 50{ }^{\circ} \mathrm{C}\end{array}$ & $\begin{array}{l}\quad \text { Reaction Variables } \\
\text { 25 C Rxn } \\
0.01 \text { M Sodium Permanganate } \\
0.03 \text { M Sodium Permanganate } \\
\text { 0.03 M Strontium Nitrate } \\
0.0 \mathrm{M} \text { added NaOH } \\
\text { Shear @ 10,000 RPM } \\
\qquad \text { Filtrate Variables } \\
\text { Light } \\
\text { 8 Hr Hold @ } 100{ }^{\circ} \mathrm{C} \\
\text { Oxygen Sparge } \\
\text { NOC Variables } \\
\text { NOC Base Case } \\
\text { NOC 0.01 M Sodium Permanganate } \\
\text { NOC Light } \\
\text { NOC Oxygen }\end{array}$ \\
\hline
\end{tabular}

\subsection{SECONDARY EFFECTS STUDY}

Synergistic or cross effects for selected primary effects variables were investigated for both 241-AN-107 and -102 simulants. Variables investigated for the AN-107 simulant were variations from the Newly Optimized Conditions (NOC) and included the variables that provided a negative main effect response during the primary effects study. Experimental conditions for the NOC included dilution to $6 \mathrm{M} \mathrm{Na}$, reaction at $25{ }^{\circ} \mathrm{C}$ for 4 hours, addition of $0.3 \mathrm{M}$ sodium hydroxide, and $0.03 \mathrm{M}$ strontium nitrate and sodium permanganate, filtration at $0.1 \mu \mathrm{m}$, and storage in the dark under nitrogen. Variables investigated included the cross of a reaction with $0.01 \mathrm{M}$, or the base case value of $0.03 \mathrm{M}$, sodium permanganate with the storage conditions noted in Figure 3.4.1. In addition to investigating the second order effects, a factorial design was used to obtain both primary effects and tertiary effects for a $2^{3}$ design. This design was used to obtain primary effects data for the NOC because the primary effects study for AN-107 did not include the NOC. Each experiment was replicated. 


\section{Storage Conditions}

1. Dark and Nitrogen

- stored in $\mathrm{N}_{2}$ purged glove bag

2. Light and Nitrogen

- placed under fluorescent light

3. Dark and Atmosphere

- placed in dark cabinet

4. Light and Atmosphere

- placed under fluorescent light

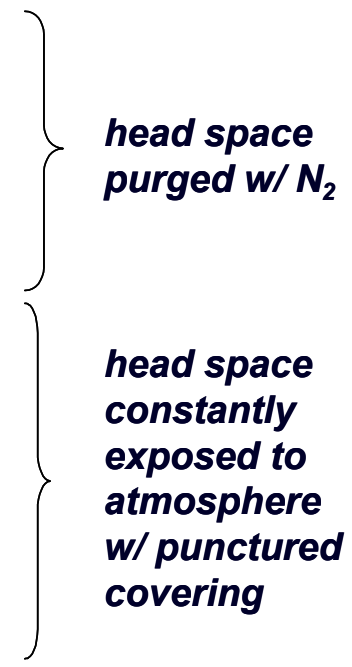

Figure 3.4.1 Storage Conditions for the 241-AN-107 Factorial Design Experiments

Experimental conditions for the 241-AN-102 secondary effects study are summarized in Figure 3.4.2 and focus on the zero effect variables from the primary effects study crossed with selected reaction and filtrate variables. This study examined the secondary effects for the baseline experiments only. The secondary effects of $0.0 \mathrm{M}$ added sodium hydroxide and $25^{\circ} \mathrm{C}$ reaction temperature crossed separately with $0.03 \mathrm{M}$ strontium nitrate, $0.03 \mathrm{M}$ sodium permanganate, light and oxygen sparge were investigated. These experiments were also replicated.

\subsection{ANALYSIS OF FILTRATES AND POST-FILTRATION SOLIDS}

During the observation period, $10-\mathrm{mL}$ aliquots of the filtrates were collected periodically and filtered at $0.1 \mu \mathrm{m}$. The aliquots were then acidified to $\mathrm{pH} 1$ or below and analyzed by ICPAES to determine the concentration of the important cations in the filtrates. These data were used to evidence the formation of post-precipitation solids over time. The filtrates were also monitored visually throughout the observation period. Additionally, the $\mathrm{E}_{\mathrm{H}}$ was measured periodically throughout the observation period for baseline filtrates as well as those sparged with oxygen and nitrogen in order to determine the ability of these variables to affect the bulk redox potential of the filtrate.

At the end of the observation period, the filtrates were re-filtered at $0.1 \mu \mathrm{m}$. Filter solids were then analyzed gravimetrically to determine the quantity of solids produced. Visual observations were made to give a general indication of the solids composition. In addition, 
filter solids were dissolved in $0.5 \mathrm{M}$ nitric acid and analyzed by ICP-AES to determine the major cations present in the particulate mass.

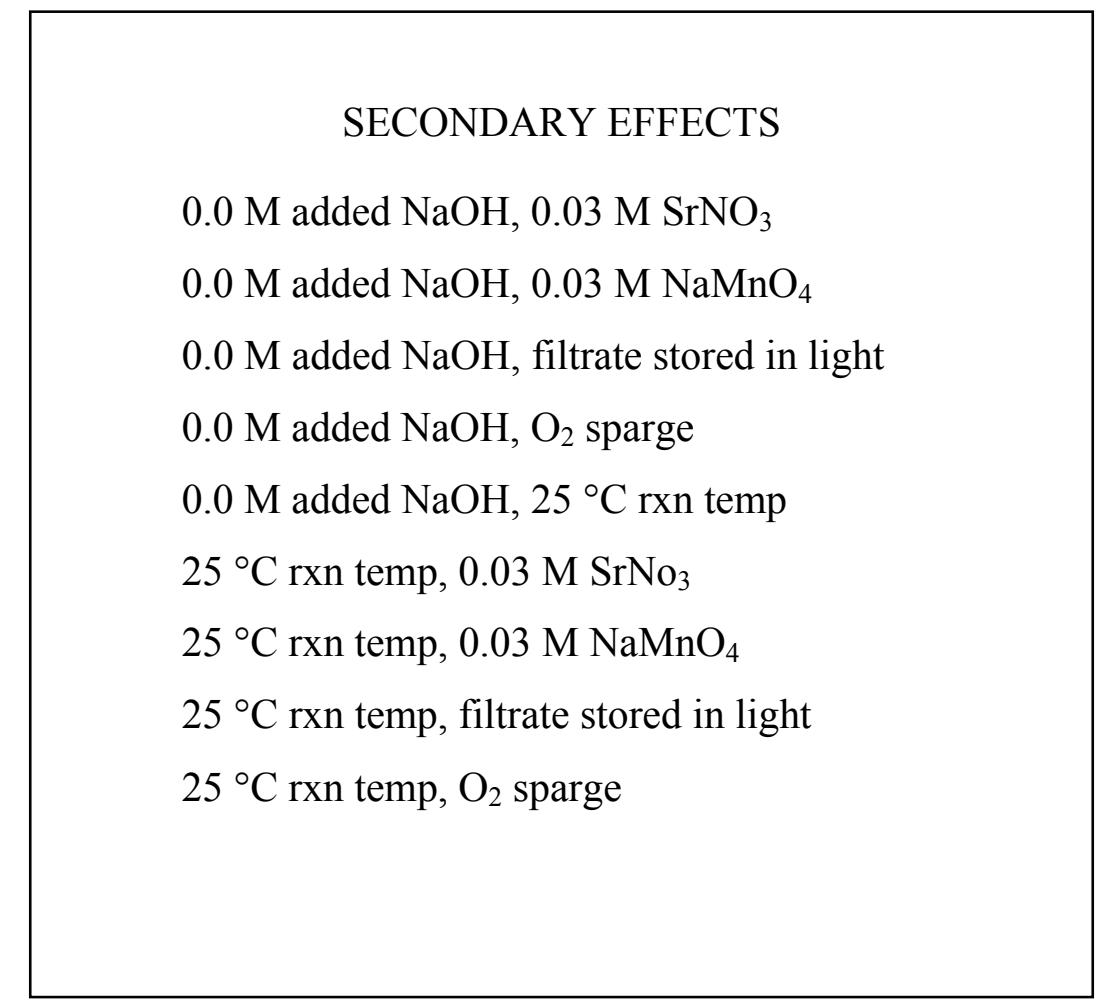

Figure 3.4.2 Secondary Effects Experiments Conducted for the 241-AN-102 Simulant

\subsection{DISCUSSION}

\subsection{CHARACTERIZATION OF SIMULANTS 241-AN-107 AND 241-AN-102}

Simulants 241-AN-107 and 241-AN-102 were prepared in replicate bulk quantities sufficient to conduct all of the first and second order experiments. Replicate 241-AN-107 simulants were designated as simulant 7 and 8 , and replicate 241-AN-102 simulants were designated as simulant A and B. The simulants were aged at least one week before conducting the experiments. During the first week after preparation, ultraviolet/visible (UV/VIS) analysis was obtained to compare to similar scans collected during the experimental phase of this work. In addition, an aliquot of each simulant was analyzed by ICP-AES to determine the actual cation concentration in the simulant.

\subsubsection{UV/Vis Analysis}

UV/VIS scans are shown in Figures 4.1.1.1 through 4.1.1.8 for the 241-AN-107 and 241AN-102 simulants. Scans were obtained using a $1 \mathrm{~cm}$ fused silica cell over a wavelength range of 200 to $1100 \mathrm{~nm}$ and a $0.1 \mathrm{~cm}$ fused silica cell over the ultraviolet range of 200 to 
WSRC-TR-2003-00232, Rev. 0

SRT-RPP-2003-00105, Rev. 0

$400 \mathrm{~nm}$. An examination of the scans using the $1 \mathrm{~cm}$ cell did not reveal significant absorption in the visible range for any of the simulants. Ultraviolet scans using the $0.1 \mathrm{~cm}$ cell revealed significant absorption, but little difference over the 51 to 58 days monitored for the simulants. These data indicate that changes in the composition of the simulants with time as measured by UV/VIS did not appear to be significant.

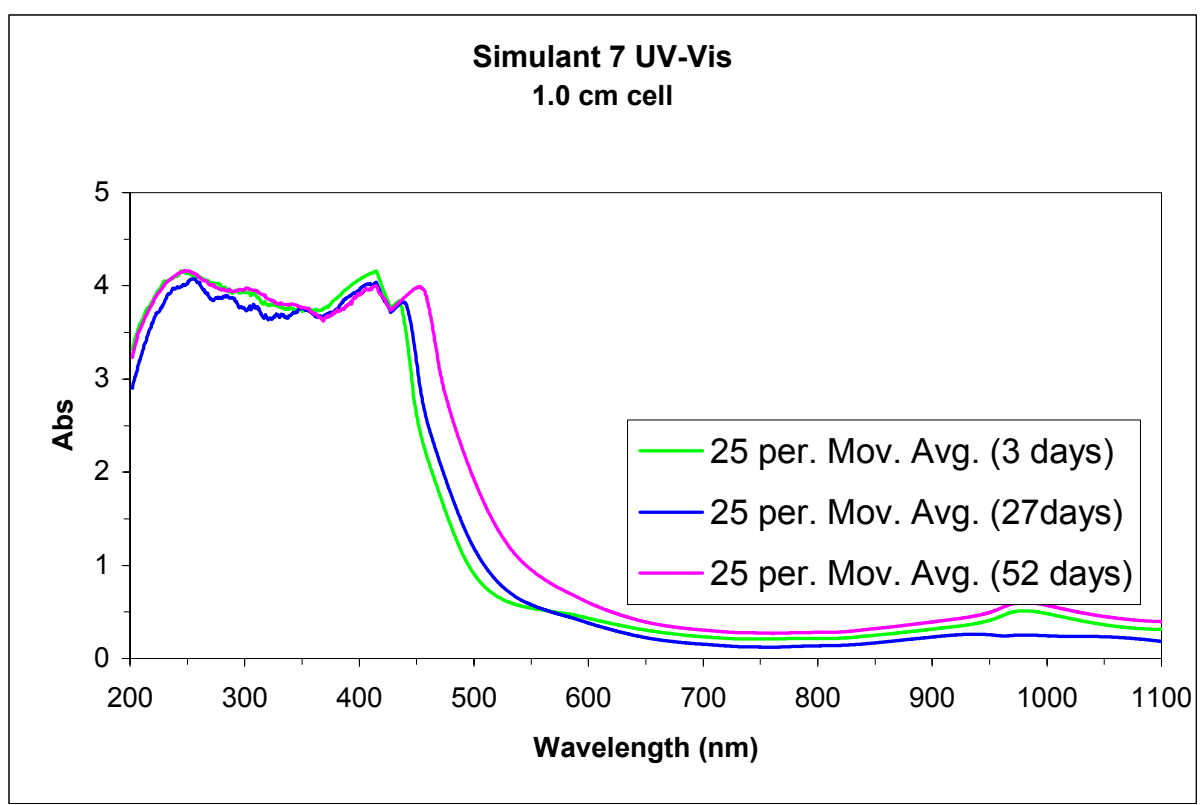

Figure 4.1.1.1 UV/VIS Spectra of Simulant 7 Used in the 241-AN-107 Experiments 
WSRC-TR-2003-00232, Rev. 0

SRT-RPP-2003-00105, Rev. 0

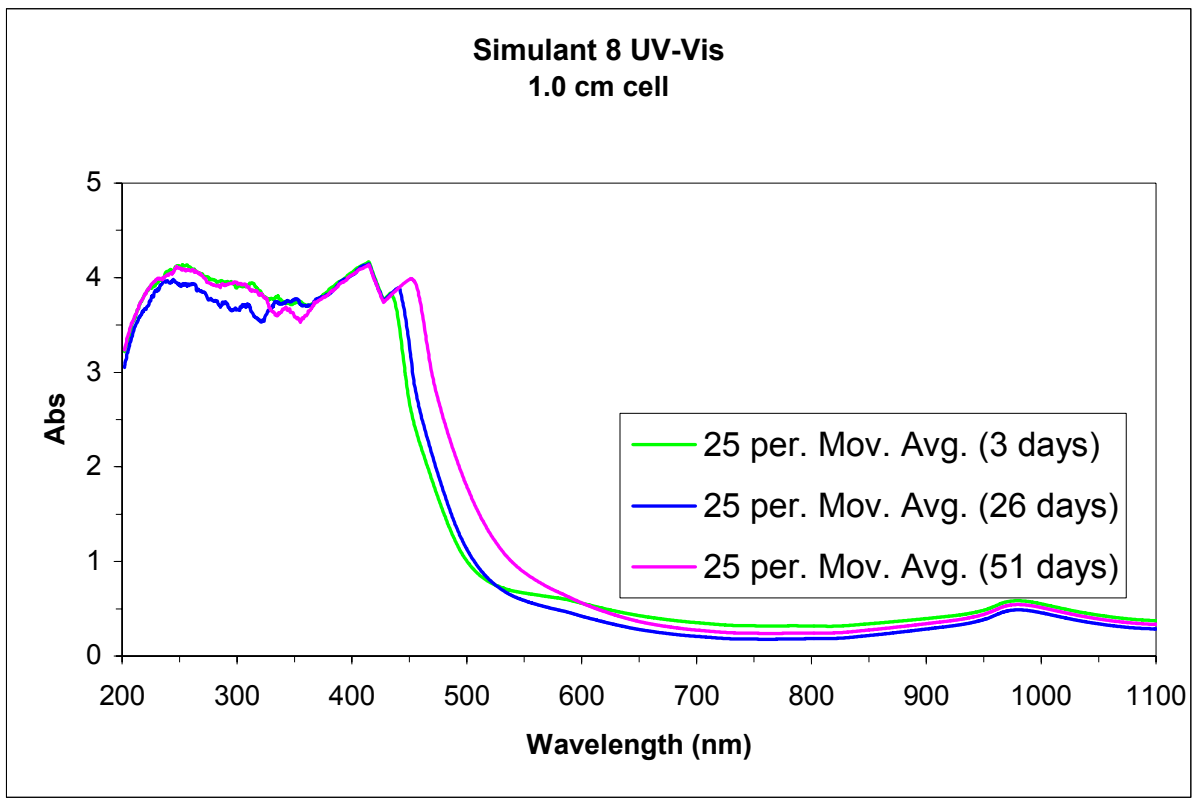

Figure 4.1.1.2 UV/VIS Spectra of Simulant 8 Used in the 241-AN-107 Experiments

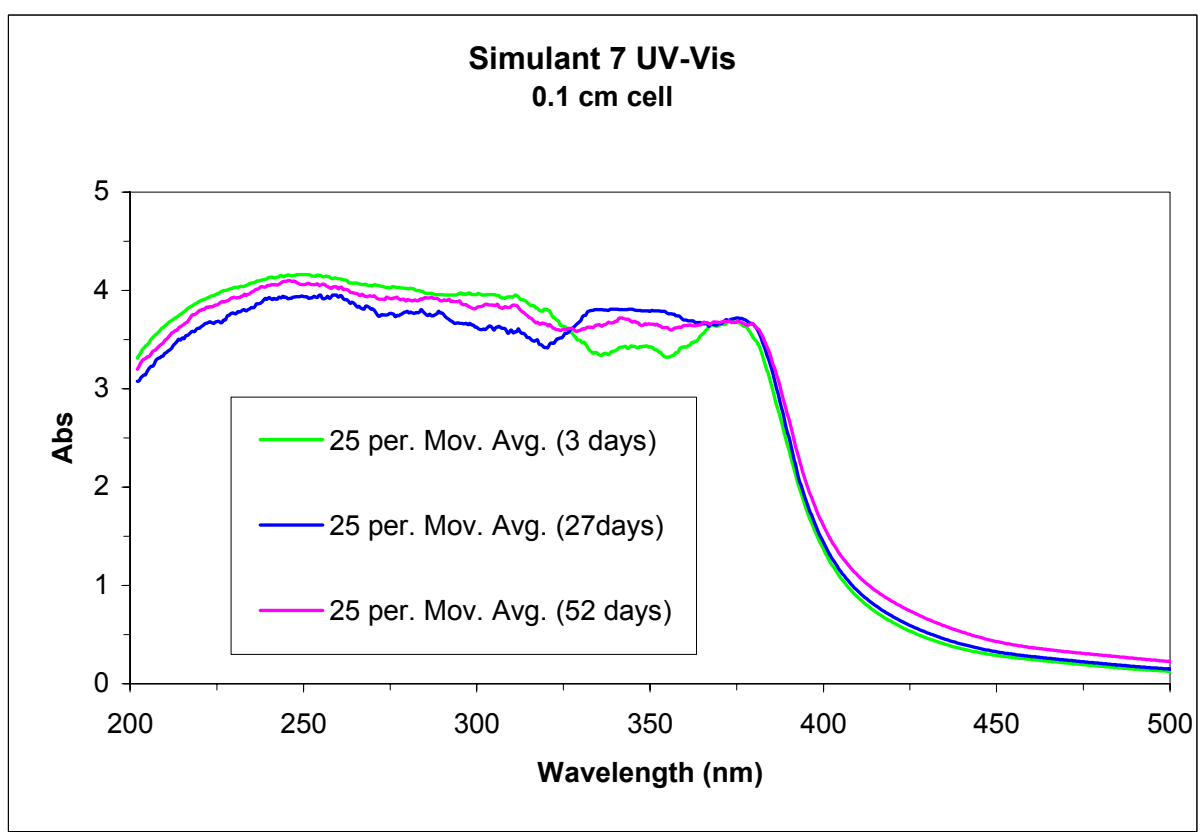

Figure 4.1.1.3 UV Spectra of Simulant 7 Used in the 241-AN-107 Experiments 
WSRC-TR-2003-00232, Rev. 0

SRT-RPP-2003-00105, Rev. 0

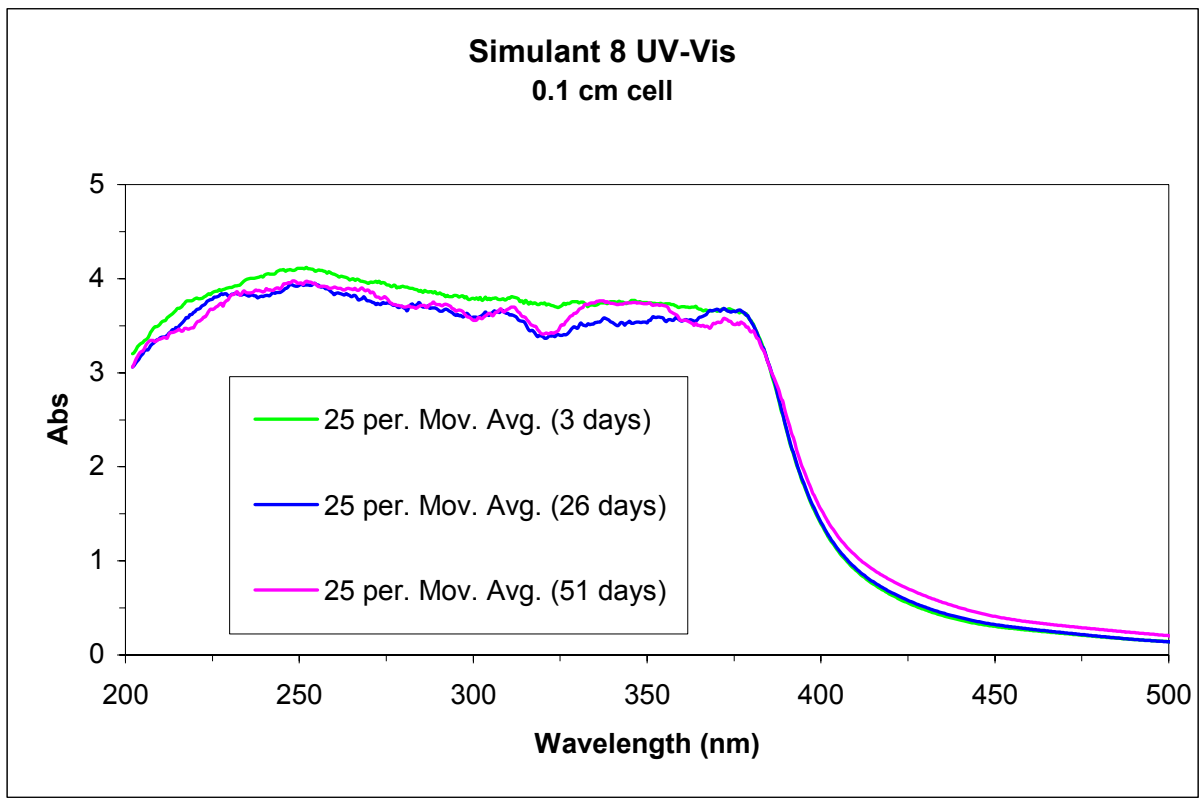

Figure 4.1.1.4 UV Spectra of Simulant 8 Used in the 241-AN-107 Experiments

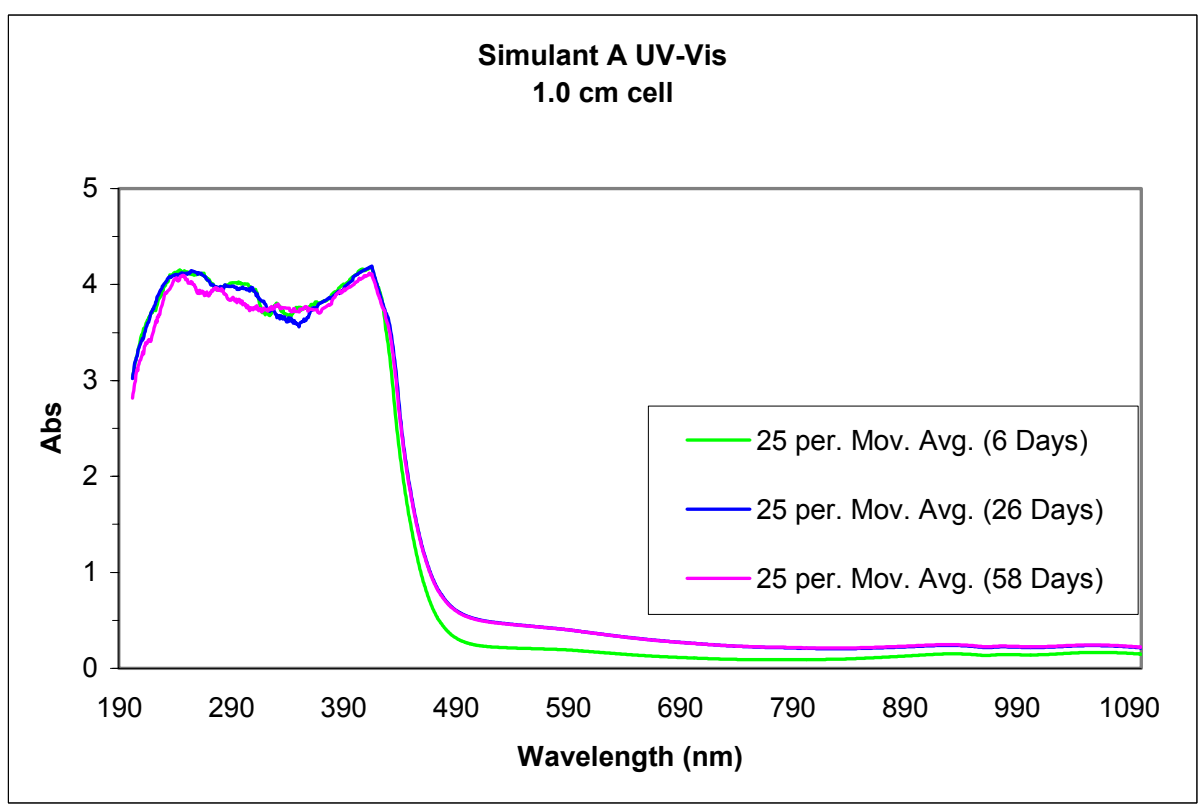

Figure 4.1.1.5 UV/VIS Spectra of Simulant A Used in the 241-AN-102 Experiments 
WSRC-TR-2003-00232, Rev. 0

SRT-RPP-2003-00105, Rev. 0

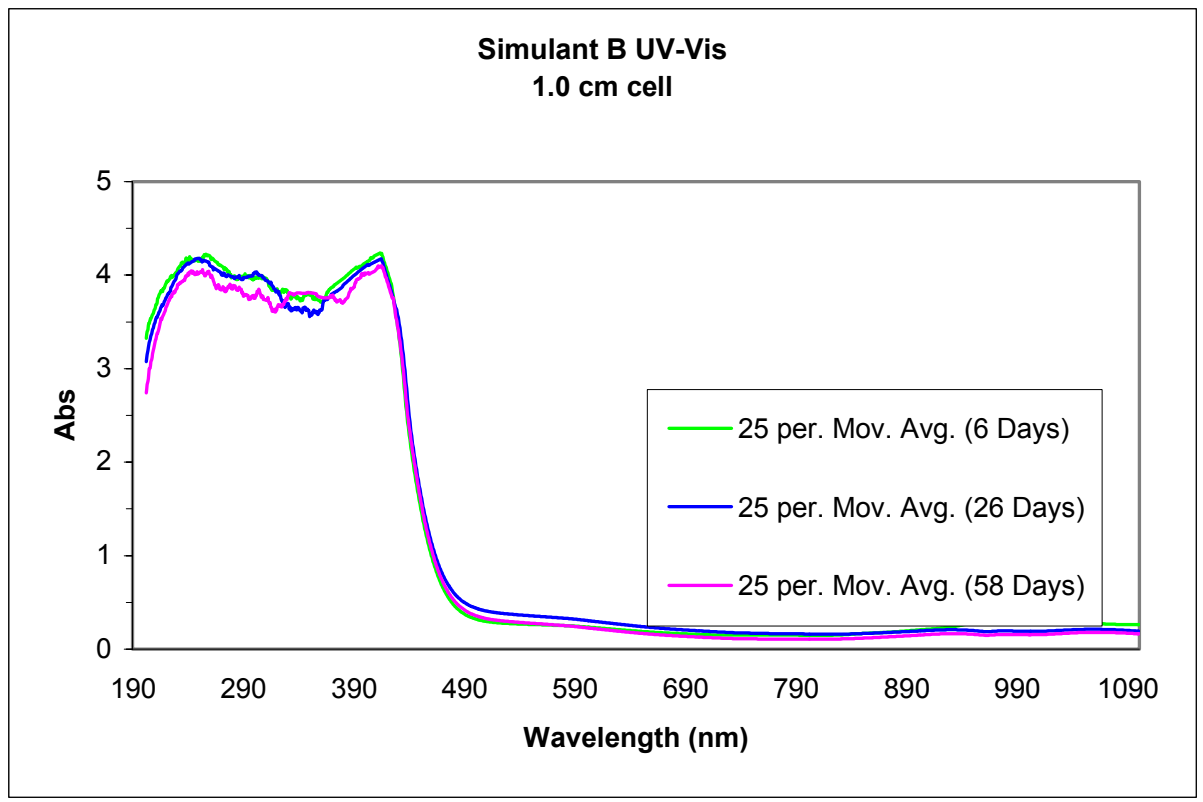

Figure 4.1.1.6 UV/VIS Spectra of Simulant B Used in the 241-AN-102 Experiments

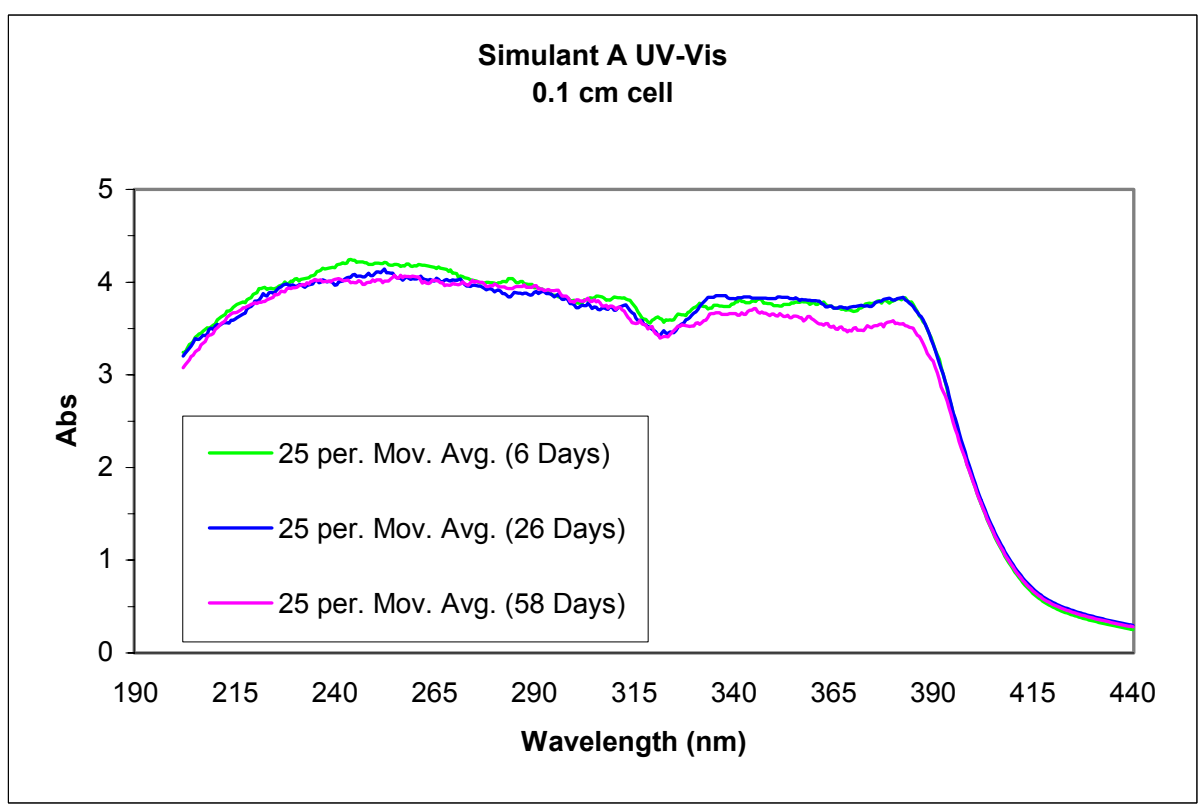

Figure 4.1.1.7 UV Spectra of Simulant A Used in the 241-AN-102 Experiments 
WSRC-TR-2003-00232, Rev. 0

SRT-RPP-2003-00105, Rev. 0

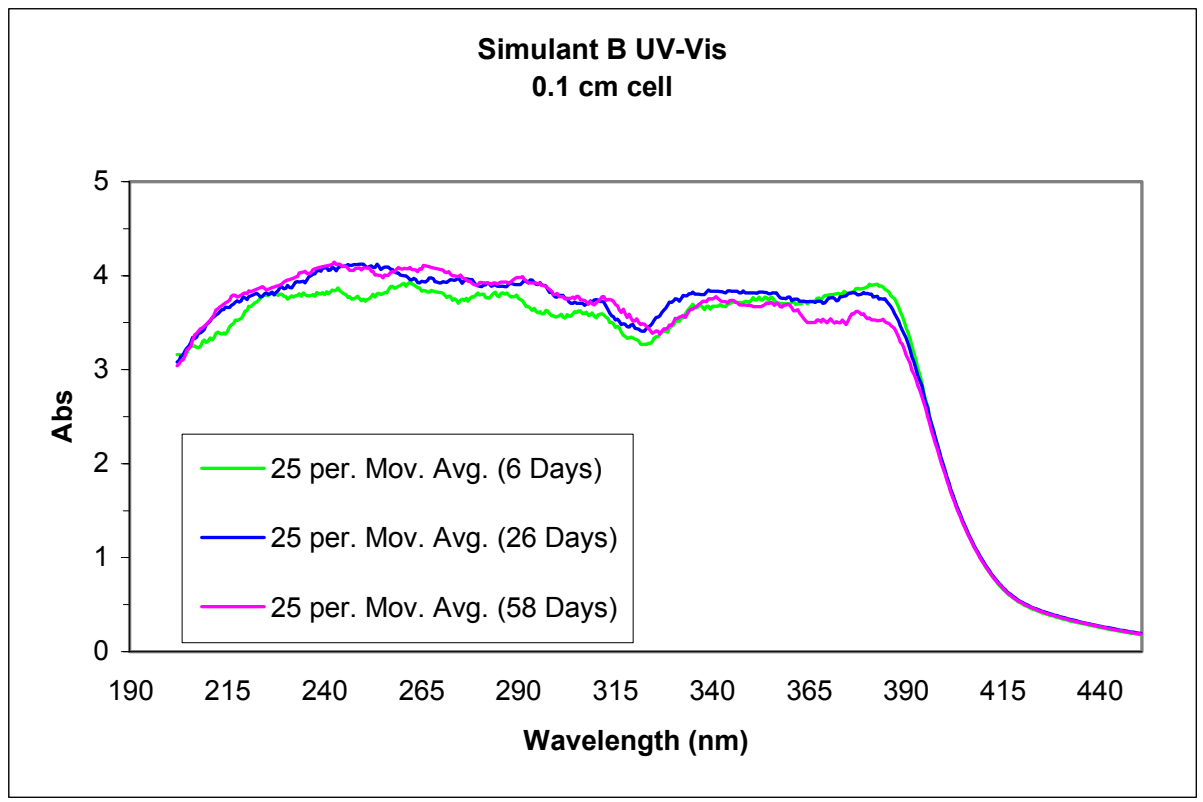

Figure 4.1.1.8 UV Spectra of Simulant B Used in the 241-AN-102 Experiments

\subsubsection{ICP Analysis}

Cation concentrations in simulants used during the AN-107 and AN-102 post filtration studies are shown in Table 4.1.2.1. Target values are shown to provide comparison with measured concentration. For most of the cations, measured values agree reasonably well with target values with the exception of phosphorus and potassium. Sodium levels were not measured by ICP-AES. 
WSRC-TR-2003-00232, Rev. 0

SRT-RPP-2003-00105, Rev. 0

Table 4.1.2.1 Concentration of Selected Cations in the AN-107 and AN-102 Simulants at $6 \mathrm{M} \mathrm{Na}$.

\begin{tabular}{|l|c|c|c|c|c|c|c|c|}
\hline & AN-107 Sim 7 & AN-107 Sim 8 & AN-107 Avg & AN-107 Target & AN-102 Sim A & AN-102 Sim B & AN-102 Avg & AN-102 Target \\
\hline Elem & $\mathrm{mg} / \mathrm{L}$ & $\mathrm{mg} / \mathrm{L}$ & $\mathrm{mg} / \mathrm{L}$ & $\mathrm{mg} / \mathrm{L}$ & $\mathrm{mg} / \mathrm{L}$ & $\mathrm{mg} / \mathrm{L}$ & $\mathrm{mg} / \mathrm{L}$ & $\mathrm{mg} / \mathrm{L}$ \\
\hline Al3082 & 514 & 430 & 472 & 386 & 9899 & 9846 & 9872 & 9231 \\
\hline B_2497 & 33 & 33 & 33 & 35 & 25 & 25 & 25 & 27 \\
\hline Ca3179 & 871 & 625 & 748 & 591 & 364 & 372 & 368 & 369 \\
\hline Ce4186 & 55 & 53 & 54 & 52 & $\mathrm{ND}$ & $\mathrm{ND}$ & $\mathrm{ND}$ & 32 \\
\hline Cr3578 & 140 & 134 & 137 & 177 & 201 & 199 & 200 & 190 \\
\hline Cu3247 & 33 & 33 & 33 & 30 & 19 & 19 & 19 & 19 \\
\hline Fe2599 & 1656 & 1662 & 1659 & 1691 & 30 & 30 & 30 & 31 \\
\hline K_7664 & 2207 & 2145 & 2176 & 1808 & 1668 & 1688 & 1678 & 1467 \\
\hline La3949 & 53 & 49 & 51 & 45 & 13 & 14 & 14 & 12 \\
\hline Mg2790 & 13 & 10 & 12 & 25 & $\mathrm{ND}$ & $\mathrm{ND}$ & $\mathrm{ND}$ & 0 \\
\hline Mn2576 & 551 & 557 & 554 & 564 & 21 & 21 & 21 & 23 \\
\hline Mo2020 & 39 & 38 & 39 & 36 & 36 & 36 & 36 & 23 \\
\hline Nd4061 & 109 & 103 & 106 & 95 & 26 & 26 & 26 & 25 \\
\hline Ni2316 & 537 & 540 & 538 & 531 & 310 & 314 & 312 & 313 \\
\hline P_1774 & 484 & 481 & 482 & 362 & 1931 & 1280 & 1606 & 1355 \\
\hline Pb2203 & 397 & 397 & 397 & 388 & 134 & 136 & 135 & 138 \\
\hline Si2516 & 6 & 7 & 7 & 0 & 20 & 18 & 19 & 0 \\
\hline Sr3464 & 9 & 6 & 7 & 7 & 2 & 2 & 2 & 2 \\
\hline Zn2062 & 47 & 48 & 48 & 46 & 4 & 4 & 4 & 4 \\
\hline Zr3391 & 65 & 62 & 64 & 70 & 9 & 10 & 10 & 9 \\
\hline
\end{tabular}

\subsection{PERMANGANATE OXIDATION REACTION}

\subsubsection{Visual Observations During The Reaction}

Replicate 241-AN-107 simulants (simulant 7 and 8) were observed to be shades of dark coffee before initiation of the permanganate reaction. Simulant 8 was slightly darker than simulant 7 . The addition of strontium nitrate to the reaction mixture resulted in the immediate formation of a white crystalline solid. Immediately following the addition of sodium permanganate, a large mass of brown precipitate formed, thereby masking the actual color of the reaction mixture.

Filtrate colors ranged from a light olive color to a dark coffee color with simulant 7 filtrates being lighter than simulant 8 filtrates. Base case reactions were replicated throughout the study, and noticeably lighter filtrates were observed as the simulant aged even though visible absorbance did not change noticeably during the study period. Filtrates for the base case condition were generally medium coffee color. Those exposed to light were light olive. Simulants treated with 1.0, 0.2 and $0.0 \mathrm{M}$ added $\mathrm{NaOH}$ were successively lighter in color beginning with a dark coffee color. Simulants treated with 0.025 and $0.01 \mathrm{M}$ sodium permanganate had an increasingly darker coffee color than the base case condition of $0.05 \mathrm{M}$. Digital photographs of the filtrates were taken and are included in Appendix B.

241-AN-102 simulants were observed to be greenish brown before reaction. During the reaction, the dark mass of precipitate formed masked the simulant color. However, after filtering, distinct colors were apparent in the filtrates. Most of the reaction conditions produced filtrates that exhibited a greenish yellow color. Filtrates that differed in color were those exposed to light, which appeared to take on a distinctly lime green color; those exposed 
WSRC-TR-2003-00232, Rev. 0

SRT-RPP-2003-00105, Rev. 0

to oxygen, which became darker and took on an orange tint; those reacted with $0.03 \mathrm{M}$ strontium nitrate, which were green in appearance; and those reacted with lower concentrations of sodium permanganate, which took on an orangish brown color that was correspondingly darker with lower concentrations of sodium permanganate. The latter filtrates lost much of their brown tint and became more yellow upon aging. Digital photographs are included in Appendix F.

\subsection{PRELIMINARY STUDIES}

During the early stages of this investigation, two preliminary studies were conducted before final reaction conditions were established for both the 241-AN-107 and -102 simulants. These experiments were conducted using the 241-AN-107 simulant to gain familiarity with the reaction and to evaluate the formation of post-filtration solids for $0.0 \mathrm{M}$ added and $1.3 \mathrm{M}$ added sodium hydroxide (conditions were to have been at $1.0 \mathrm{M}$ added sodium hydroxide). Also included in these preliminary studies were many of the variables ultimately promulgated for the design of the primary and secondary effects studies.

Listed in Table 4.3.1 is a summary of the results for the $0.0 \mathrm{M}$ sodium hydroxide experiments. Included are replicates of the base case scenario and several experiments conducted at reaction temperatures of $50{ }^{\circ} \mathrm{C}$ and $25^{\circ} \mathrm{C}$. Also included in the table are days noting the presence or absence of solids in each of the filtrates. The importance of these results is not found in the details, but in the overall summary of the observations. First, for the base case experiments, post-filtration solids were not observed during the observation period (28 to 37 days). Secondly, for experiments conducted at $50{ }^{\circ} \mathrm{C}$ post-filtration solids were observed before the 28-day period only when air was sparged into the filtrates. Thirdly, with exception of one replicate, post-filtration solids were observed during the 28-day period for all experiments conducted at $25{ }^{\circ} \mathrm{C}$. In summary, this initial study strongly suggests that reaction temperature and the presence of entrained air in the filtrates may play a role in the formation of post-filtration solids.

A summary of results for the second preliminary study, in which $1.3 \mathrm{M}$ sodium hydroxide was added to the base case reaction, is provided in Table 4.3.2. The formation of postfiltration solids was examined for reaction variables (temperature and concentration of reactants), and several filtrate variables (light, filter pore size, oxygen sparge, nitrogen sparge, carbon dioxide sparge, and an elevated temperature of the filtrate). Unlike Table 4.3.1, the time that solids appeared in the filtrates is presented in hours. The overall observation is that solids formed within hours for all experiments. By comparison to results presented in Table 4.3.1, it appears that concentrations of 1.3 to 2.0 molar added sodium hydroxide significantly impact the formation of post-filtration solids within hours of the permanganate reaction and subsequent filtration at $0.1 \mu \mathrm{m}$. 
WSRC-TR-2003-00232, Rev. 0

SRT-RPP-2003-00105, Rev. 0

Table 4.3.1 Presence of Solids in AN-107 Filtrates for the 0.0 M Sodium Hydroxide Preliminary Experiments

\begin{tabular}{|c|c|}
\hline Condition & $\begin{array}{c}\text { Time Solid Appeared } \\
\text { (days) }\end{array}$ \\
\hline Base Case & ND@37 \\
\hline Base Case Replicate & ND@28 \\
\hline \multicolumn{2}{|l|}{$50{ }^{\circ} \mathrm{C}$ Reaction } \\
\hline - $\quad$ Light, $0.1 \mu \mathrm{m}$, Air Sparge & 28 \\
\hline - $\quad$ Light, $0.45 \mu \mathrm{m}$, Air Sparge & 28 \\
\hline - Dark, $0.1 \mu \mathrm{m}$, Air Sparge & 28 \\
\hline - $\quad$ Dark, $0.45 \mu \mathrm{m}$, Air Sparge & 28 \\
\hline - Light, $0.1 \mu \mathrm{m}, \mathrm{N}_{2}$ Sparge & ND@28 \\
\hline - $\quad$ Light, $0.1 \mu \mathrm{m}, \mathrm{N}_{2}$ Sparge & ND@28 \\
\hline - $\quad$ Light, $0.45 \mu \mathrm{m}, \mathrm{N}_{2}$ Sparge & ND@28 \\
\hline - $\quad$ Light, $0.45 \mu \mathrm{m}, \mathrm{N}_{2}$ Sparge & ND@28 \\
\hline - $\quad$ Dark, $0.1 \mu \mathrm{m}, \mathrm{N}_{2}$ Sparge & ND@28 \\
\hline - $\quad$ Dark, $0.45 \mu \mathrm{m}, \mathrm{N}_{2}$ Sparge & ND@28 \\
\hline - $\quad$ Dark, $0.45 \mu \mathrm{m}, \mathrm{N}_{2}$ Sparge & ND@28 \\
\hline \multicolumn{2}{|l|}{$25^{\circ} \mathrm{C}$ Reaction } \\
\hline - $\quad$ Light, $0.1 \mu \mathrm{m}, \mathrm{N}_{2}$ Sparge & 11 \\
\hline - $\quad$ Light, $0.1 \mu \mathrm{m}$, Air Sparge & 3 \\
\hline - $\quad$ Light, $0.1 \mu \mathrm{m}, \mathrm{N}_{2}$ No Sparge & 25 \\
\hline - $\quad$ Light, $0.45 \mu \mathrm{m}, \mathrm{N}_{2}$ Sparge & 8 \\
\hline - $\quad$ Light, $0.45 \mu \mathrm{m}$, Air Sparge & 8 \\
\hline - $\quad$ Light, $0.45 \mu \mathrm{m}, \mathrm{N}_{2}$ No Sparge & ND@25 \\
\hline - $\quad$ Dark, $0.1 \mu \mathrm{m}, \mathrm{N}_{2}$ Sparge & 11 \\
\hline - $\quad$ Dark, $0.1 \mu \mathrm{m}$, Air Sparge & 1 \\
\hline - $\quad$ Dark, $0.1 \mu \mathrm{m}, \mathrm{N}_{2}$ No Sparge & 19 \\
\hline - $\quad$ Dark, $0.45 \mu \mathrm{m}, \mathrm{N}_{2}$ Sparge & 20 \\
\hline - Dark, $0.45 \mu \mathrm{m}$, Air Sparge & 11 \\
\hline - $\quad$ Dark, $0.45 \mu \mathrm{m}, \mathrm{N}_{2}$ No Sparge & 20 \\
\hline
\end{tabular}


WSRC-TR-2003-00232, Rev. 0

SRT-RPP-2003-00105, Rev. 0

Table 4.3.2 Presence of Solids in AN-107 Filtrates for the 1.3 M Sodium Hydroxide Preliminary Experiments

\begin{tabular}{|l|c|}
\hline \multicolumn{1}{|c|}{ Condition } & $\begin{array}{c}\text { Time Solid Appeared } \\
\text { (hours) }\end{array}$ \\
\hline Base Case & 15 \\
\hline Base Case Replicate & 3 \\
\hline Light & 10 \\
\hline Light Replicate & 3 \\
\hline Filter Size $0.45 \mu \mathrm{m}$ & 15 \\
\hline Filter Size $0.45 \mu \mathrm{m}$ Replicate & 3 \\
\hline $25^{\circ} \mathrm{C}$ reaction & 10 \\
\hline $25^{\circ} \mathrm{C}$ reaction Replicate & 10 \\
\hline $60{ }^{\circ} \mathrm{C}$ reaction & 4 \\
\hline $60{ }^{\circ} \mathrm{C}$ reaction Replicate & 4 \\
\hline $0.07 \mathrm{M}$ Sodium Permanganate & 15 \\
\hline $0.07 \mathrm{M}$ Sodium Permanganate Replicate & 7 \\
\hline $0.01 \mathrm{M}$ Sodium Permanganate & 6 \\
\hline $0.01 \mathrm{M}$ Sodium Permanganate Replicate & 18 \\
\hline $0.01 \mathrm{M}$ Calcium Nitrate & $<16$ \\
\hline $0.01 \mathrm{M}$ Calcium Nitrate Replicate & $<16$ \\
\hline $0.03 \mathrm{M}$ Calcium Nitrate & $<16$ \\
\hline $0.03 \mathrm{M}$ Calcium Nitrate Replicate & $<16$ \\
\hline $2 \mathrm{M}$ added NaOH & 9 \\
\hline $2 \mathrm{M}$ added NaOH Replicate & 9 \\
\hline Filtrate Held for 8 Hours $@ 100^{\circ} \mathrm{C}$ & 1 \\
\hline Filtrate Held for 8 Hours $@ 100^{\circ} \mathrm{C}$ Replicate & 2 \\
\hline Oxygen Bubbled in Filtrate & 2 (turbid) \\
\hline Oxygen Bubbled in Filtrate Replicate & 3 (turbid) \\
\hline Nitrogen Bubbled in Filtrate & 50 \\
\hline Nitrogen Bubbled in Filtrate Replicate & 8.5 \\
\hline Carbon Dioxide Bubbled in Filtrate & 2 \\
\hline Carbon Dioxide Bubbled in Filtrate Replicate & 4 \\
\hline & \\
\hline & \\
\hline
\end{tabular}

\subsection{RESULTS OF THE 241-AN-107 EXPERIMENTS}

The formal conduct of the 241-AN-107 experiments included an investigation to determine the effect of single variables on the formation of post-filtration solids (primary effects). Similarly, a second set of experiments was completed to determine second order synergistic effects on the formation of post-filtration solids (secondary effects). Data obtained for these experiments included visual observations to indicate the color of filtrates and to document the appearance of visible solids, ICP-AES analysis of the filtrates to document changes in cation concentrations with time, gravimetric analysis to document solids formation at the end 
WSRC-TR-2003-00232, Rev. 0

SRT-RPP-2003-00105, Rev. 0

of the visual observation period, solubility of the precipitate in $0.5 \mathrm{M}$ nitric acid, ICP-AES analysis to determine the cationic composition of the precipitate, and photographic record of both the filtrates and post-filtration solids formation. ICP-AES analyses were conducted using filtrates in which the waste sodium molarity was less than 6 molar due to the addition of reactants. These data have been normalized to 6 molar waste sodium for comparative purposes and should not be considered as measured quantities at 6 molar waste sodium.

\subsubsection{Primary Effects Study}

\section{$\underline{\text { Visual Observations }}$}

Variables investigated for the 241-AN-107 primary effects study are listed in Table 4.4.1.1. The appearance of post-filtration solids during the 48-hr observation period is also included in the table. With exception of two experimental conditions, the 8-hr hold of the filtrate at $100{ }^{\circ} \mathrm{C}$ and the oxygen sparge, solids that formed during the 48-hr period were very light in color. The filtrates sparged with oxygen contained brown solids within six hours, and significant black solids formed in the filtrates held at $100{ }^{\circ} \mathrm{C}$ for 8 hours. The formation of brown solids in the filtrates sparged with oxygen is commensurate with permanganate reduction in alkaline media to manganese hydroxide, which is a white precipitate, and subsequent oxidation in the presence of air to the brown manganese (III) oxy-hydroxide and oxide and ultimately to the black manganese dioxide. Formation of black solids in the 8-hr hold filtrates supports the hypothesis that the precipitation reaction kinetics are too slow for the reaction to be complete after a 4 hour reaction time.

It is also important to note that a reduction of added sodium hydroxide from the base case condition of 1.0 M to 0.2 and $0.0 \mathrm{M}$ resulted in no solids being formed during the 48-hr period. Recall also, for preliminary experiments conducted at $0.0 \mathrm{M}$ added sodium hydroxide, at $50{ }^{\circ} \mathrm{C}$, and in the absence of sparged air (Table 4.3.1), solids did not form in the filtrates during the 28-day observation period.

Both preliminary and primary effects studies strongly suggest that a low reaction temperature $\left(25^{\circ} \mathrm{C}\right)$, the presence of dissolved oxygen, and concentrations of added sodium hydroxide at 1.0 $\mathrm{M}$ favor the formation of post-filtration solids in the filtrate within the first 48 hours after ultra filtration. In addition, light may also promote the formation of solids. This observation was supported by experiments in which filtrates were exposed to laser light. During the preliminary experiments, base case filtrates were continuously exposed to a laser source. Visible solids formed within 48 hours of exposure. 
WSRC-TR-2003-00232, Rev. 0

SRT-RPP-2003-00105, Rev. 0

Table 4.4.1.1 Presence of Solids in AN-107 Filtrates for the Primary Effects Study

\begin{tabular}{|c|c|c|}
\hline PRIMARY EFFECTS STUDY & $\begin{array}{c}\text { Time Visible } \\
\text { (hours) }\end{array}$ & COLOR OF SOLIDS \\
\hline Base Case & 7 & White, Some Brown @ 12-24 Hr \\
\hline Base Case Replicate & 7 & White, Some Brown @, 12-24 Hr \\
\hline Light & 7 & White, Some Brown @ 12-24 Hr \\
\hline Light Replicate & 7 & White, Some Brown @ 12-24 Hr \\
\hline Filter Size $0.45 \mathrm{M}$ & 7 & White, Some Brown@12-24 Hr \\
\hline Filter Size 0.45 M Replicate & 7 & White, Some Brown@12-24 Hr \\
\hline $25^{\circ} \mathrm{C}$ reaction & 6 & White \\
\hline $25^{\circ} \mathrm{C}$ reaction Replicate & 6 & White \\
\hline 0.01 M Sodium Permanganate & $24-48$ & Turbid, Yellow \\
\hline 0.01 M Sodium Permanganate Replicate & $24-48$ & Turbid, Yellow \\
\hline Filtrate Held for 8 Hours at $100^{\circ} \mathrm{C}$ & 0 & Significant Black Solids During Heating \\
\hline Filtrate Held for 8 Hours at $100^{\circ} \mathrm{C}$ Replicate & 0 & Significant Black Solids During Heating \\
\hline Oxygen Bubbled in Filtrate & 6 & Brown colloids \\
\hline Oxygen Bubbled in Filtrate Replicate & 6 & Brown colloids \\
\hline Nitrogen Bubbled in Filtrate & 48 & White \\
\hline Nitrogen Bubbled in Filtrate Replicate & 48 & White \\
\hline 0.025 M Sodium Permanganate & 0 & Possibly Some White Solids at $48 \mathrm{Hr}$ \\
\hline 0.025 M Sodium Permanganate Replicate & 0 & Possibly Some White Solids at $48 \mathrm{Hr}$ \\
\hline Filter at $50^{\circ} \mathrm{C}$ & 3 & White, Some Brown@12-24 Hr \\
\hline Filter at $50^{\circ} \mathrm{C}$ Replicate & 48 & White \\
\hline $0 \mathrm{M} \mathrm{NaOH}$ Added & 0 & None at $48 \mathrm{Hr}$ \\
\hline $0 \mathrm{M} \mathrm{NaOH}$ Added Replicate & 0 & None at $48 \mathrm{Hr}$ \\
\hline $0.2 \mathrm{M} \mathrm{NaOH}$ Added & 0 & None at $48 \mathrm{Hr}$ \\
\hline $0.2 \mathrm{M} \mathrm{NaOH}$ Added Replicate & 0 & None at $48 \mathrm{Hr}$ \\
\hline $0.01 \mathrm{M}$ Strontium Added & 24 & White \\
\hline 0.01 M Strontium Added Replicate & 24 & White \\
\hline 0.02 M Strontium Added & 24 & White \\
\hline 0.02 M Strontium Added Replicate & 24 & White \\
\hline $15^{\circ} \mathrm{C}$ reaction & 48 & White \\
\hline $15^{\circ} \mathrm{C}$ reaction Replicate & 48 & White \\
\hline 10 Minute Shear & 18 & White \\
\hline 10 Minute Shear Replicate & 18 & White \\
\hline
\end{tabular}

Additional evidence supporting the theory that dissolved oxygen and possibly light promoted the formation of post-filtration solids was investigated by creating replicate filtrates for the base case condition where filtrates were stored under a nitrogen blanket in the dark and creating replicate filtrates stored under nitrogen in the light (1600 lux). Filtrates were stored under these conditions for 48 hours then purged with oxygen for 15 minutes and stored under an oxygen blanket for 48 hours. During the 48-hour periods, samples of the filtrates were filtered at $0.1 \mu \mathrm{m}$ and the final filtrates analyzed by ICP-AES for manganese, iron and strontium. These data are summarized in Table 4.4.1.2 and include the average concentration in the filtrate and the standard deviation in parenthesis. By comparing the base case- $\mathrm{N}_{2}$ data with the Light- $\mathrm{N}_{2}$ data for each of the cations, there is no evidence to suggest the formation of $\mathrm{Mn}, \mathrm{Fe}$, or Sr solids in the filtrates. However, after a 15-min sparge of each of the test filtrates with oxygen, visible solids were observed at the end of the 48-hr period. ICP-AES analyses of these filtrates support the visual observation. The concentrations of both Mn and 
WSRC-TR-2003-00232, Rev. 0

SRT-RPP-2003-00105, Rev. 0

$\mathrm{Fe}$ in the filtrates sparged with oxygen are significantly lower than concentrations measured in filtrates processed under a nitrogen blanket, suggesting the loss of $\mathrm{Mn}$ and possibly $\mathrm{Fe}$ solids from solution. Digital photographs of the particulate masses were taken to document the presence of solids in the filtrates purged with oxygen and are included in Figures 4.4.1.1 and 4.4.12.

Table 4.4.1.2 The Effect of Oxygen on the Concentration of Manganese, Iron, and Strontium in Filtrates

\begin{tabular}{|c|c|c|c|c|}
\hline \multirow{2}{*}{ Sample } & \multirow{2}{*}{ Condition } & \multicolumn{3}{|c|}{ AverageConcentration in Filtrate } \\
\cline { 3 - 5 } & & $\begin{array}{c}\mathbf{F e} \\
\mathbf{m g} / \mathbf{L}(\mathbf{s d})\end{array}$ & $\begin{array}{c}\mathbf{M n} \\
\mathbf{m g} / \mathbf{L}(\mathbf{s d})\end{array}$ & $\begin{array}{c}\mathbf{S r} \\
\mathbf{m g} / \mathbf{L}(\mathbf{s d})\end{array}$ \\
\hline 0528-211A & Base Case, $\mathrm{N}_{2}$ & $44.3(2.1)$ & $33.1(1.5)$ & $76.6(3.2)$ \\
\hline 0528-211B & Base Case, $\mathrm{N}_{2}$ & $45.2(1.4)$ & $34.0(1.0)$ & $80.1(2.2)$ \\
\hline & & & & \\
\hline 0528-211A & Base Case, $\mathrm{O}_{2}$ & $42.1(1.6)$ & $22.5(1.8)$ & $77.1(3.2)$ \\
\hline 0528-211B & Base Case, $\mathrm{O}_{2}$ & $40.8(1.1)$ & $21.7(0.9)$ & $78.1(1.9)$ \\
\hline & & & & \\
\hline 0528-111A & Light, $\mathrm{N}_{2}$ & $45.1(0.5)$ & $34.0(0.2)$ & $81.6(0.5)$ \\
\hline 0528-111B & Light, $\mathrm{N}_{2}$ & $43.1(1.5)$ & $35.3(1.1)$ & $74.8(2.3)$ \\
\hline & & & & \\
\hline 0528-111A & Light, $\mathrm{O}_{2}$ & $40.7(2.0)$ & $25.0(5.2)$ & $79.5(1.2)$ \\
\hline 0528-111B & Light, $\mathrm{O}_{2}$ & $37.9(2.9)$ & $22.7(4.7)$ & $73.5(2.5)$ \\
\hline
\end{tabular}


WSRC-TR-2003-00232, Rev. 0

SRT-RPP-2003-00105, Rev. 0

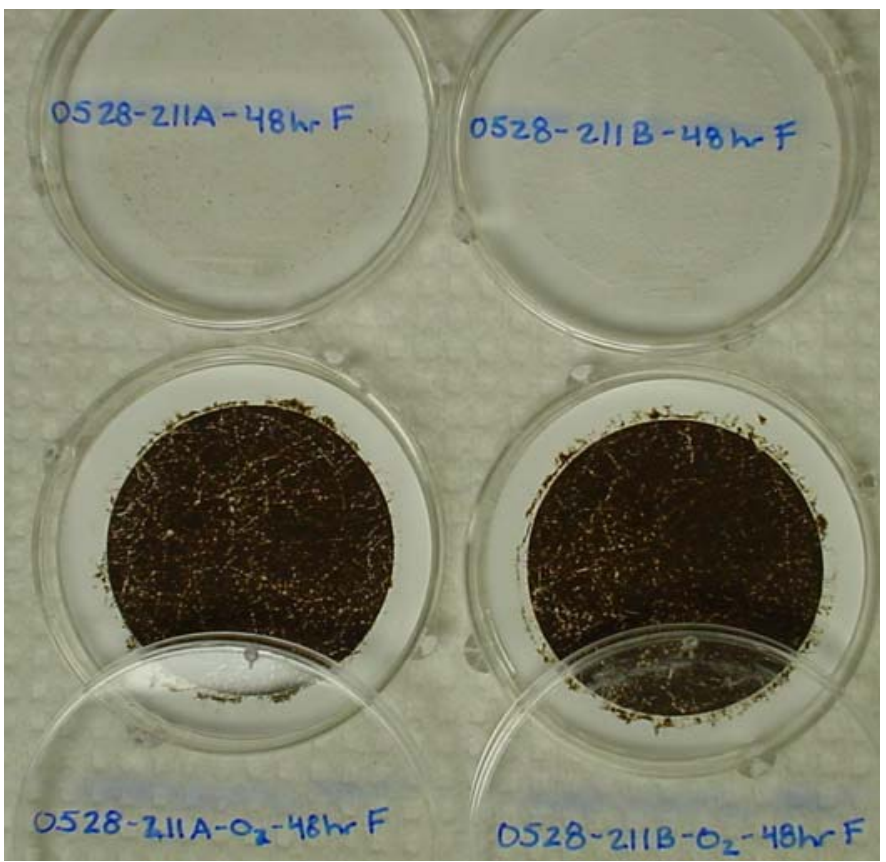

Figure 4.4.1.1 Particulates Collected After 48 hours Exposure to Oxygen for the Base Case Condition.

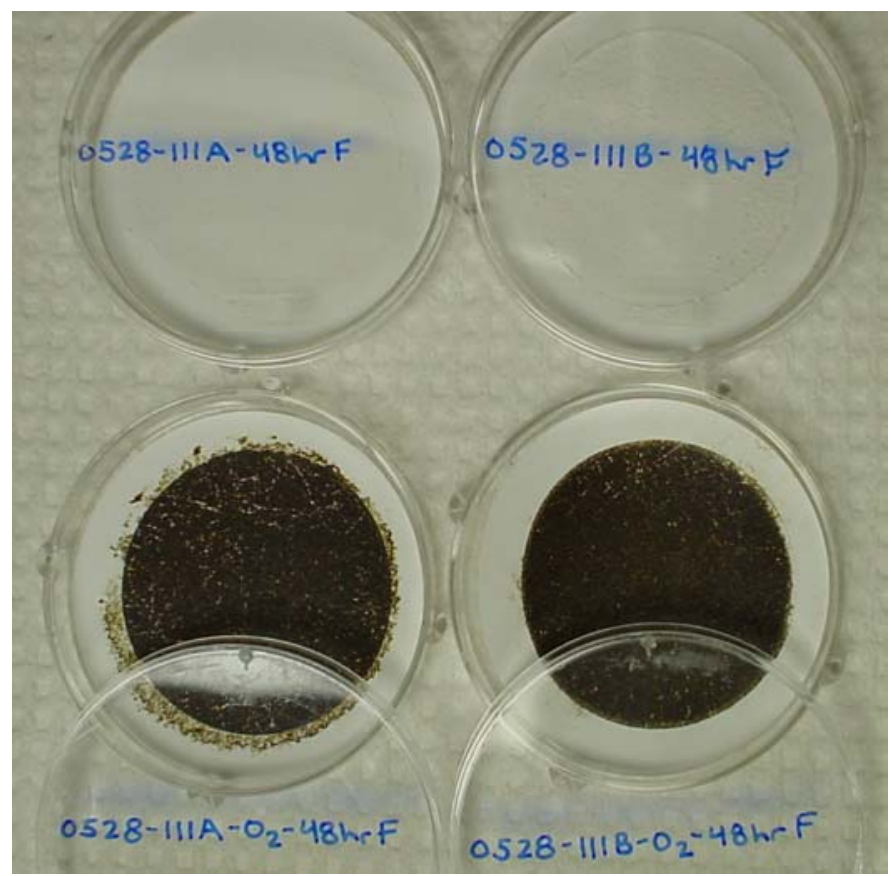

Figure 4.4.1.2 Particulates Collected After 48 hours Exposure to Oxygen for the Light Condition. 
WSRC-TR-2003-00232, Rev. 0

SRT-RPP-2003-00105, Rev. 0

Change in Metals Concentration During the 48-Hour Observation Period for AN-107

During the 48-hr observation period, filtrate samples were collected and filtered at $0.1 \mu \mathrm{m}$ at time zero and at $6,12,24$, and 48 hours. Each of the filtrates was analyzed by ICP-AES to determine the concentration of the important cations in the simulant. A decrease in concentration of a cation would suggest the formation of post-filtration solids containing that cation in the filtrates. Included in Figures 4.4.1.3 through 4.4.1.7 are $\mathrm{Mn}, \mathrm{Fe}$, and $\mathrm{Sr}$ data for a base case condition, exposure to light, an 8 -hr hold at $100^{\circ} \mathrm{C}$, and $0.0 \mathrm{M}$ added sodium hydroxide, respectively. Similar plots of the ICP-AES data for the remainder of the variables investigated during the primary effects study are included in Appendix C. Tabulated data for all cations measured in the filtrates is also included in Appendix C.

Figure 4.4.1.3 Manganese, Iron and Strontium Concentration in the $0-48 \mathrm{hr}$. Base Case

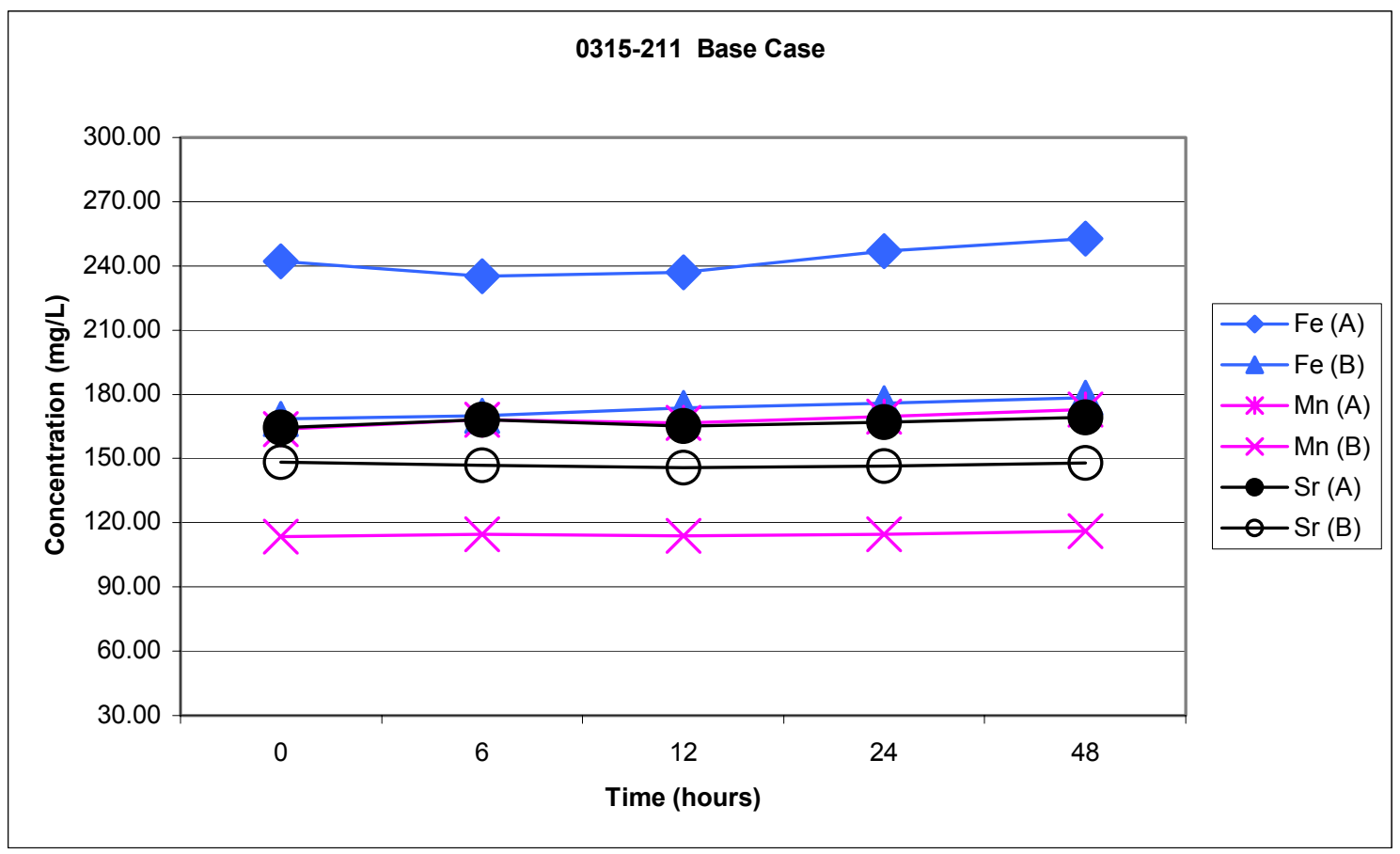

Filtrates 
WSRC-TR-2003-00232, Rev. 0

SRT-RPP-2003-00105, Rev. 0

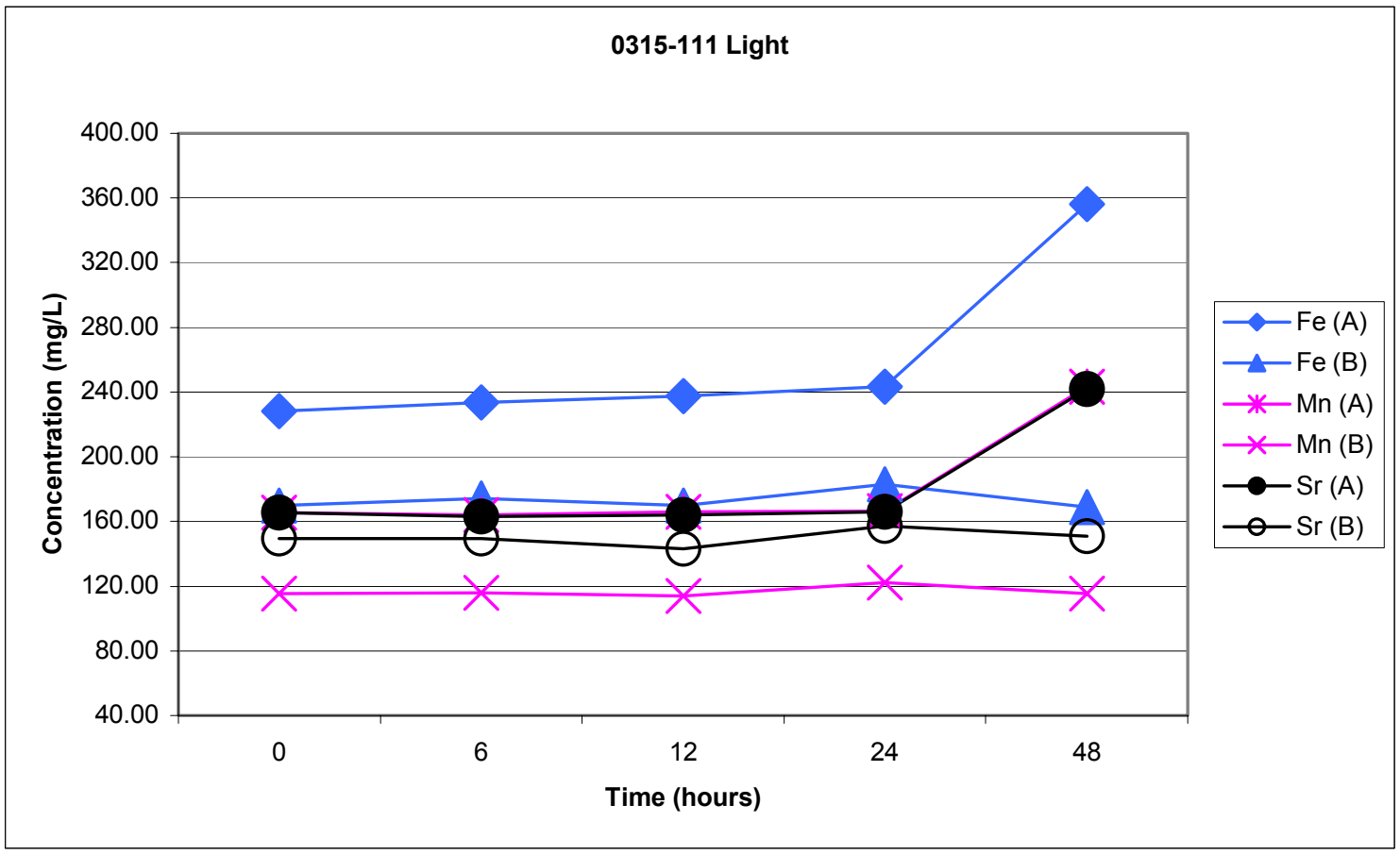

Figure 4.4.1.4 Manganese, Iron and Strontium Concentration in the $0-48 \mathrm{hr}$. Filtrate Exposed to Light

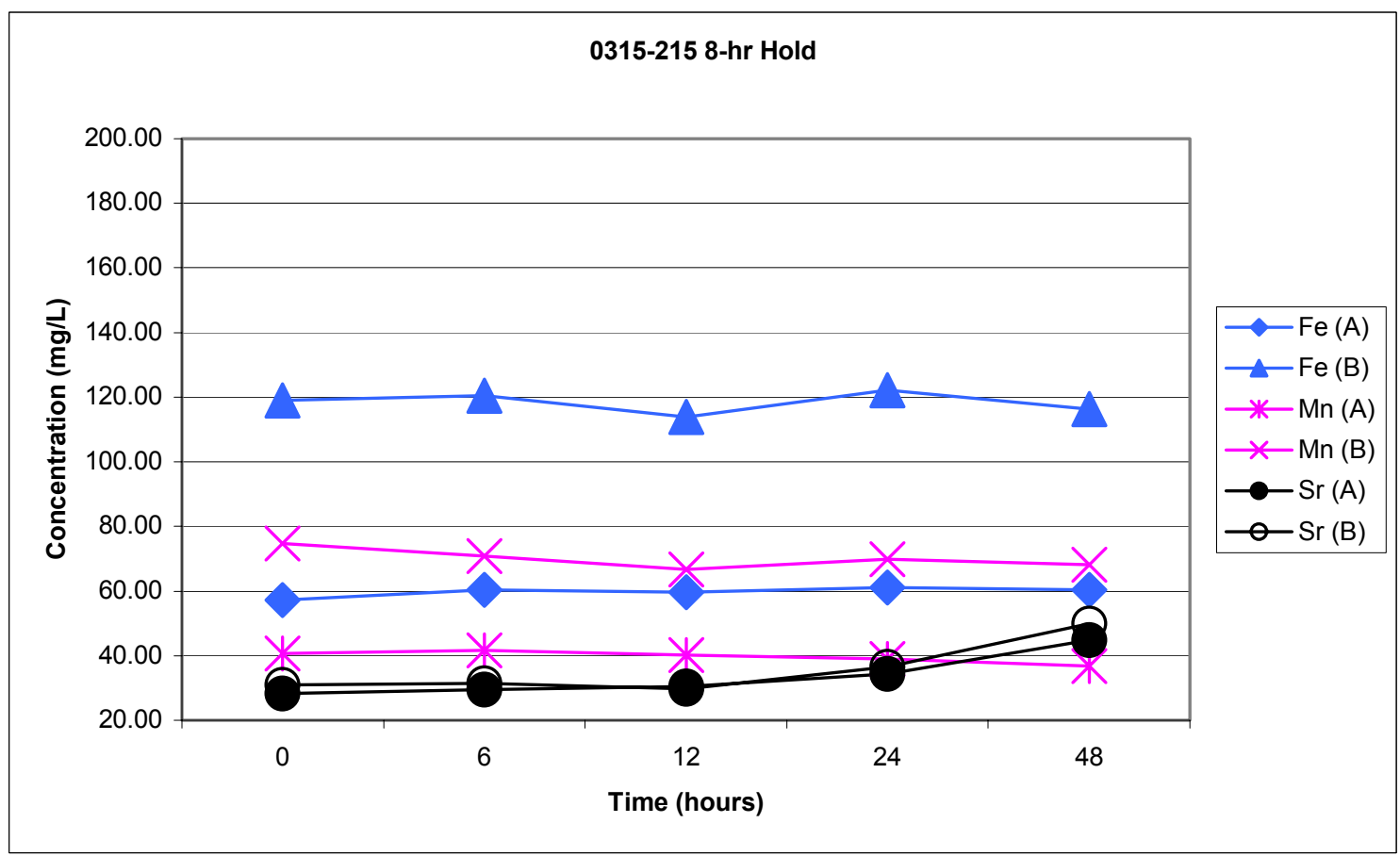

Figure 4.4.1.5 Manganese, Iron and Strontium Concentration in the $0-48 \mathrm{hr}$. Filtrate, 8 -hr Hold at $100{ }^{\circ} \mathrm{C}$ Filtrates 
WSRC-TR-2003-00232, Rev. 0

SRT-RPP-2003-00105, Rev. 0

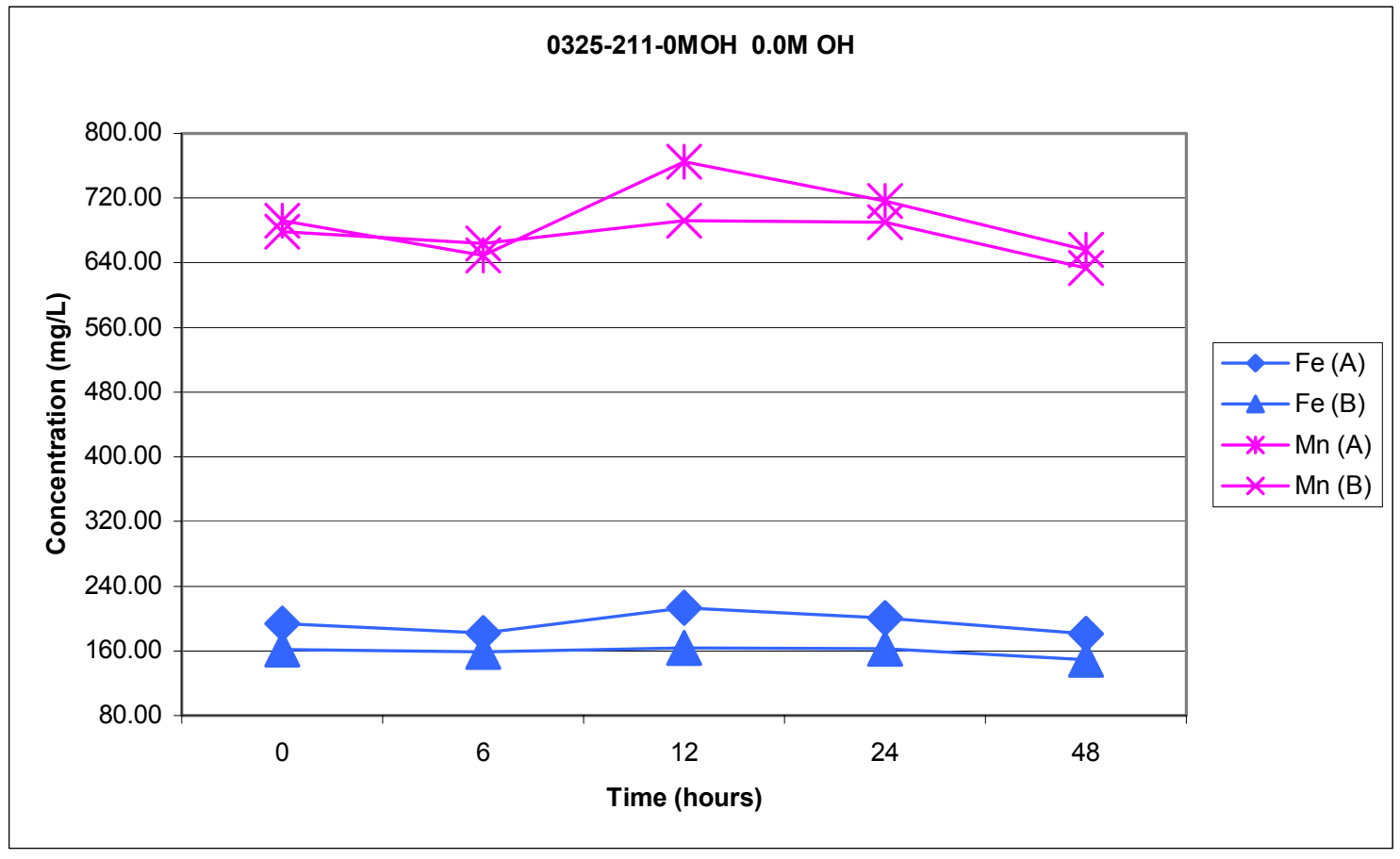

Figure 4.4.1.6 Manganese and Iron Concentration in the $0-48 \mathrm{hr}$. Filtrates With No Added $\mathrm{NaOH}$

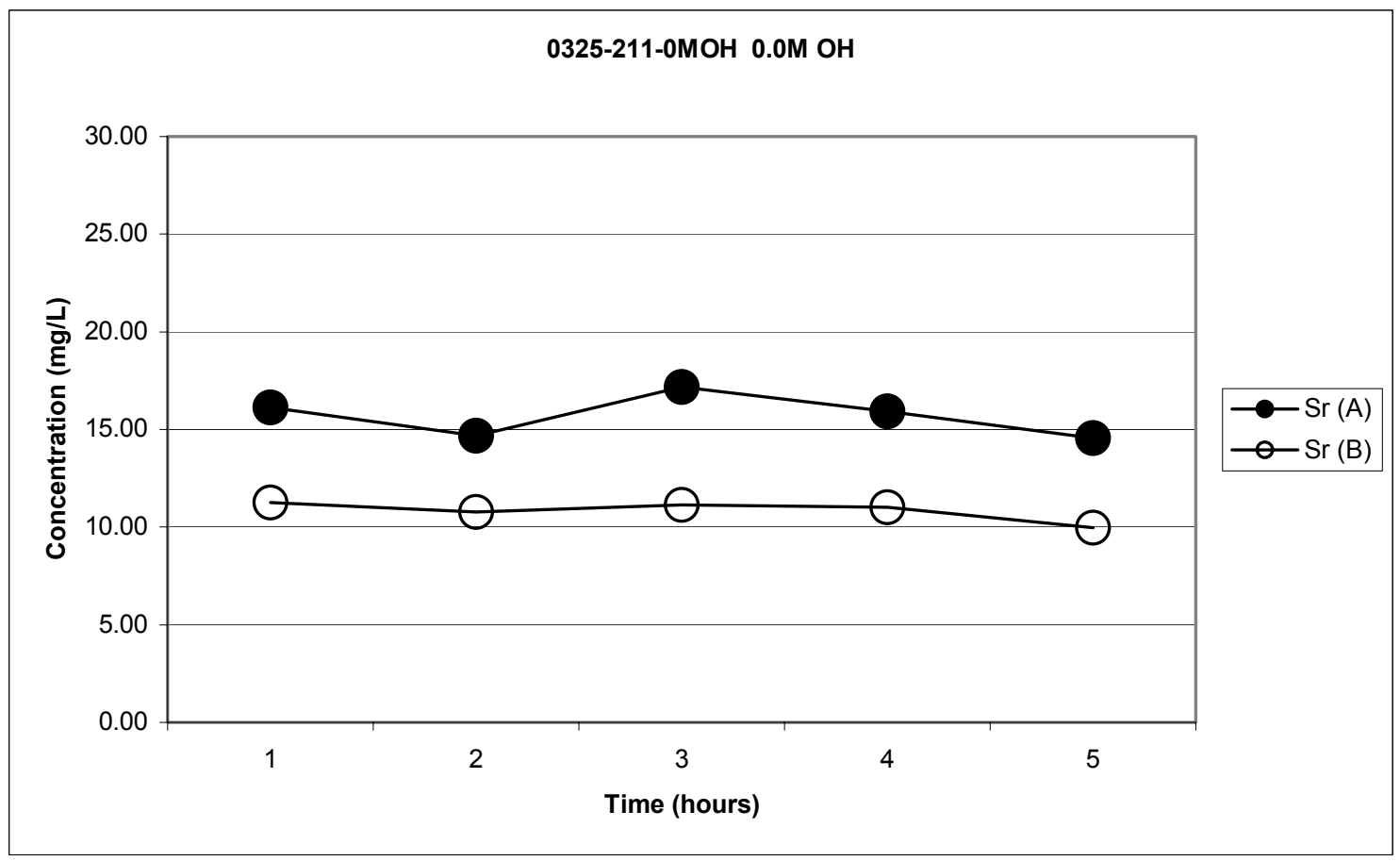

Figure 4.4.1.7 Strontium Concentration in the $0-48$ hr. Filtrates With No Added $\mathrm{NaOH}$ 
WSRC-TR-2003-00232, Rev. 0

SRT-RPP-2003-00105, Rev. 0

Two important observations can be made from examining the data presented in Appendix C. First, with exception of filtrates exposed to oxygen and filtrates held at $100{ }^{\circ} \mathrm{C}$ for 8 hours after the precipitation reaction, the concentration of the cations included in the data sets is relatively constant over the 48 -hr period, providing no evidence that post-filtration solids formed during the period. To support the observed precipitation, digital photographs were taken of the particulate mass collected at the end of the 48-hr period and these are shown in Appendix D. The 0-48 hr plot for the filtrates exposed to oxygen (Figure C.13b) does not appear to be as invariant as the others, suggesting the loss of Mn solids and possibly Fe and $\mathrm{Sr}$ from solution. Second, there is a difference in the magnitude of the concentration for each of the cations as a function of treatment condition.

From the tabulated data in Appendix C, bar graphs representing the mean concentration for each cation measured for the base case condition, and two treatment variables (reaction temperature and added sodium hydroxide) are shown in Figures 4.4.1.8 through 4.4.1.11. Similar bar graphs for the remainder of the variables are included in Appendix C. Plotted in the bar graphs are mean data for all replicated base case conditions for each AN-107 simulant (simulant 7 or simulant 8) averaged over the 48-hr period and mean data for each treatment averaged over the 48-hr period for the appropriate simulant. Also included on the bar graphs are the appropriate error estimates. A careful review of the data presented here and in Appendix $\mathrm{C}$ indicates that the only cations that differed significantly between treatments and the base case condition were manganese, iron, strontium, neodymium, lanthanum, cerium and zirconium.

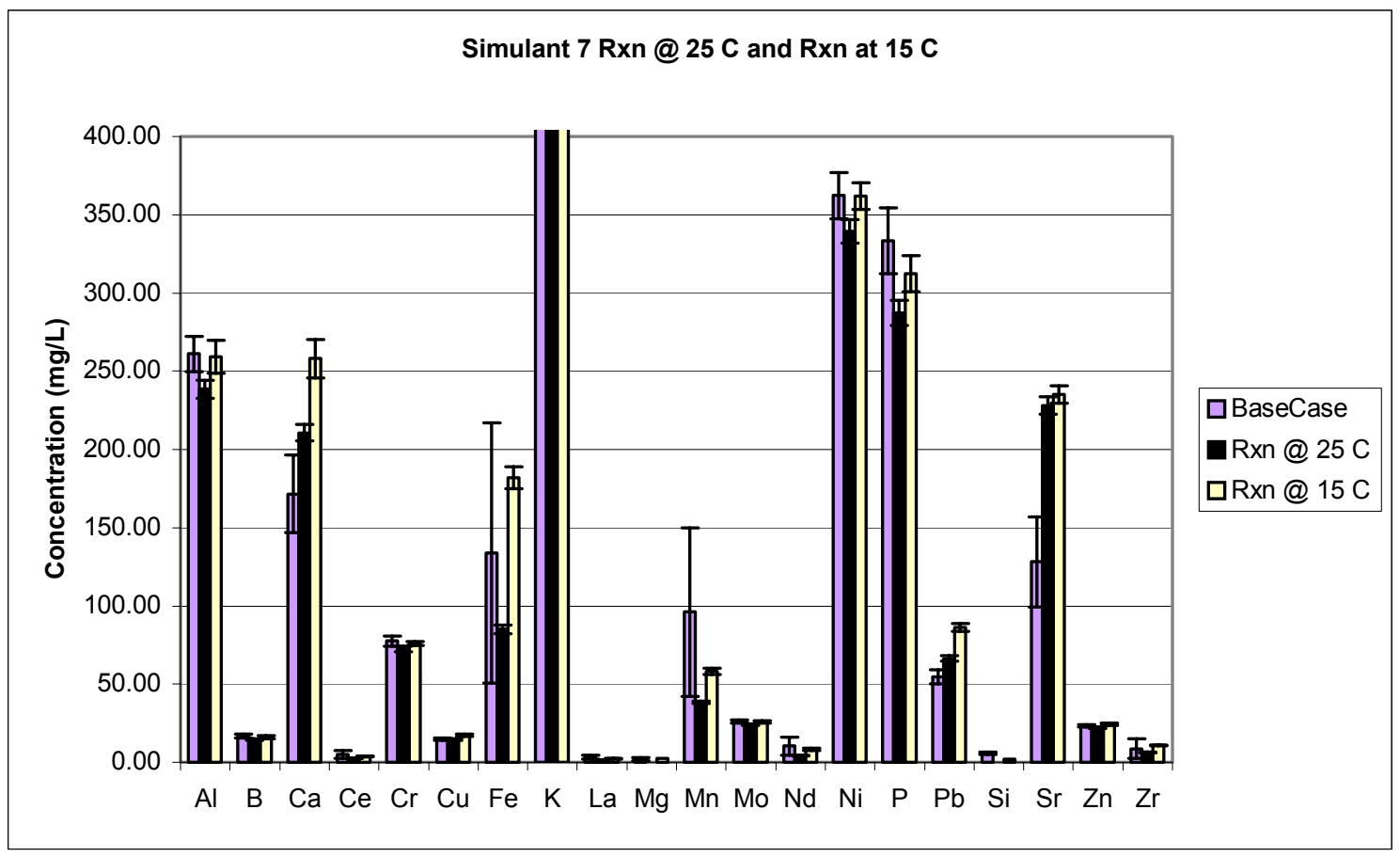

Figure 4.4.1.8a Mean Cation Concentration for the $0-48 \mathrm{hr}$. Reaction Temperature Filtrate for Simulant 7 (AN-107) 
WSRC-TR-2003-00232, Rev. 0

SRT-RPP-2003-00105, Rev. 0

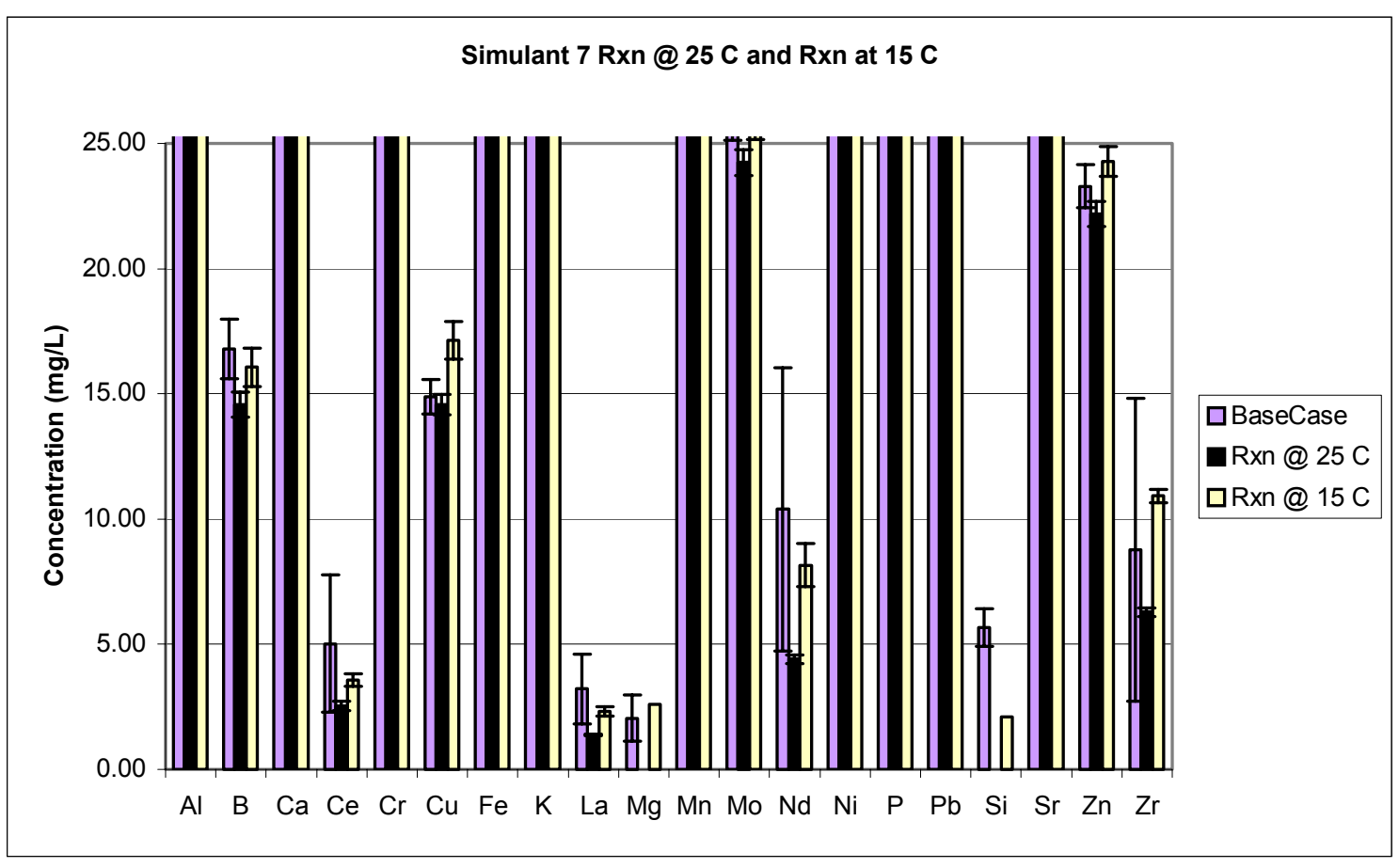

Figure 4.4.1.8b Figure 4.4.1.8a Scaled to see Minor Cations

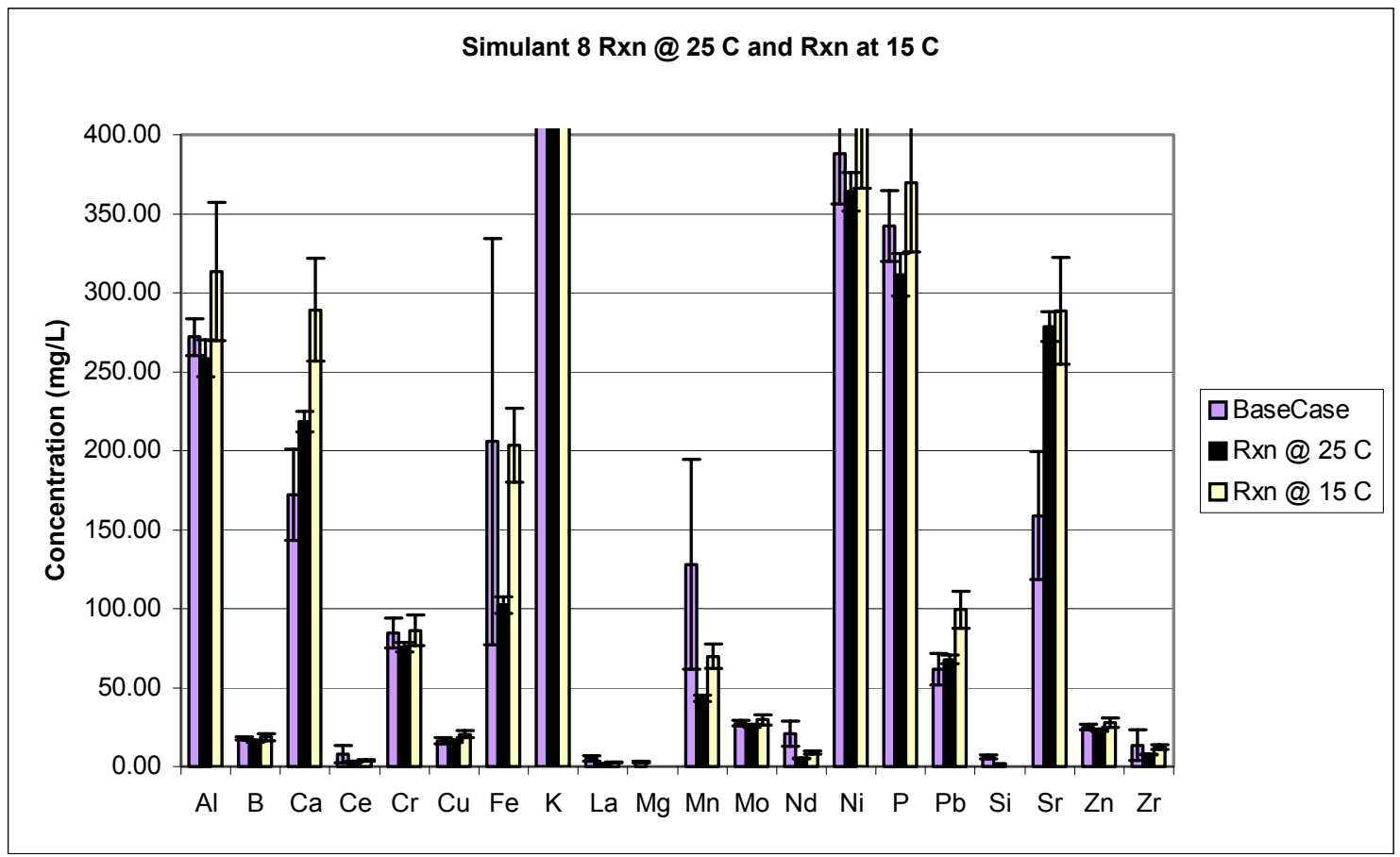

Figure 4.4.1.9a Mean Cation Concentration for the $0-48 \mathrm{hr}$. Reaction Temperature Filtrate for Simulant 8 (AN-107) 


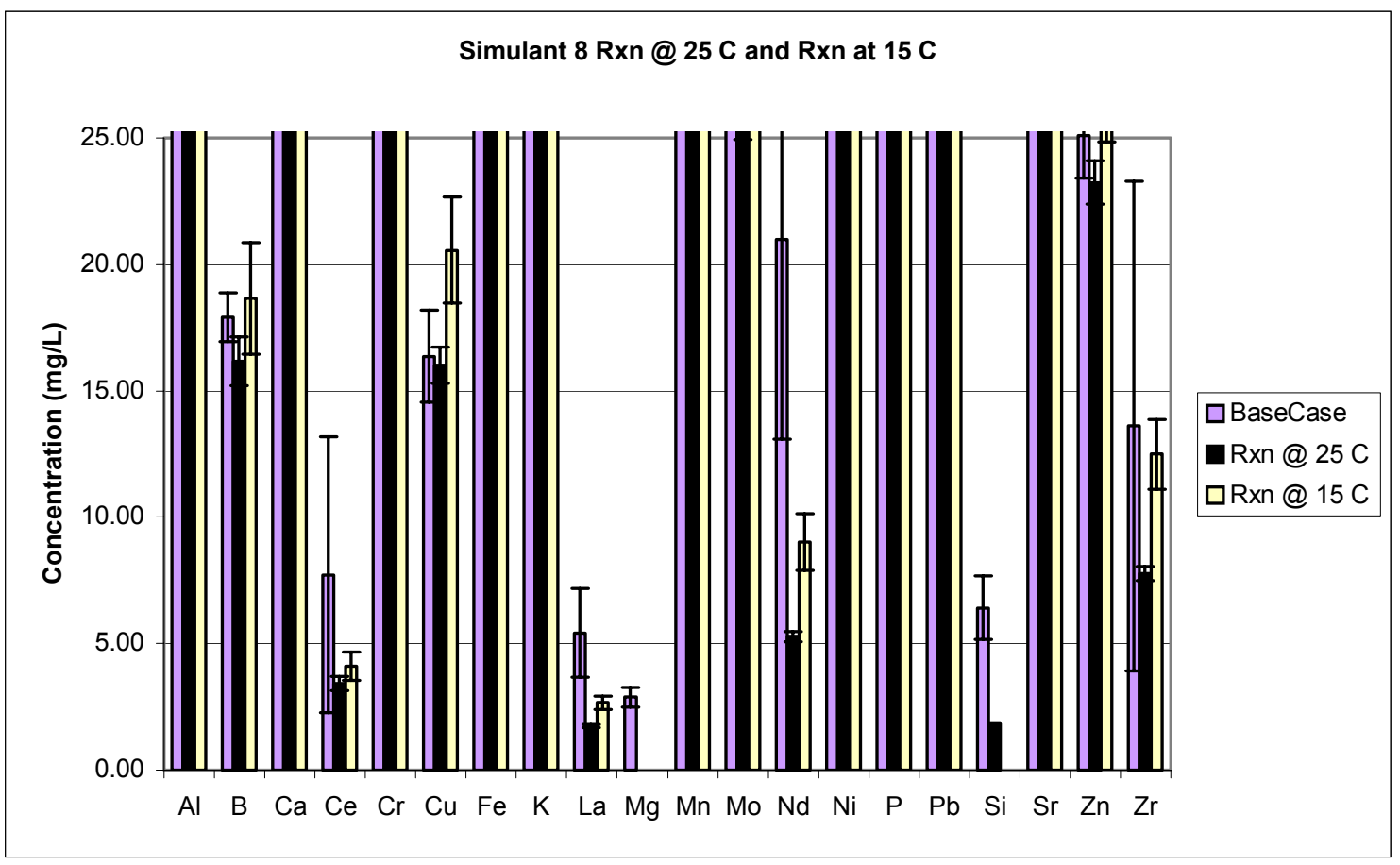

Figure 4.4.1.9b Figure 4.4.1.9a Scaled to see Minor Cations

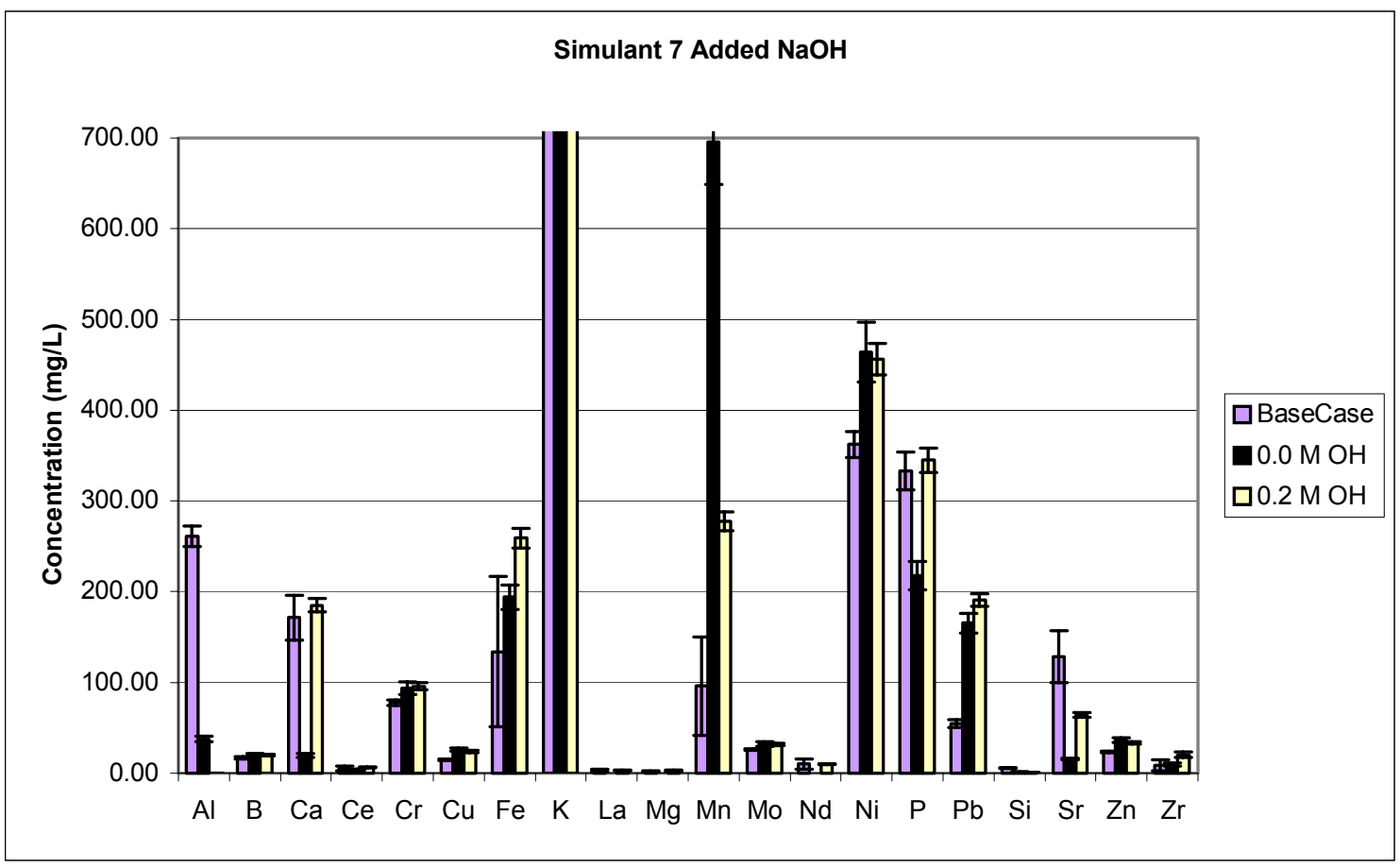

Figure 4.4.1.10a Mean Cation Concentration for the $0-48 \mathrm{hr}$. Filtrates with Added $\mathrm{NaOH}$ for Simulant 7 (AN-107) 
WSRC-TR-2003-00232, Rev. 0

SRT-RPP-2003-00105, Rev. 0

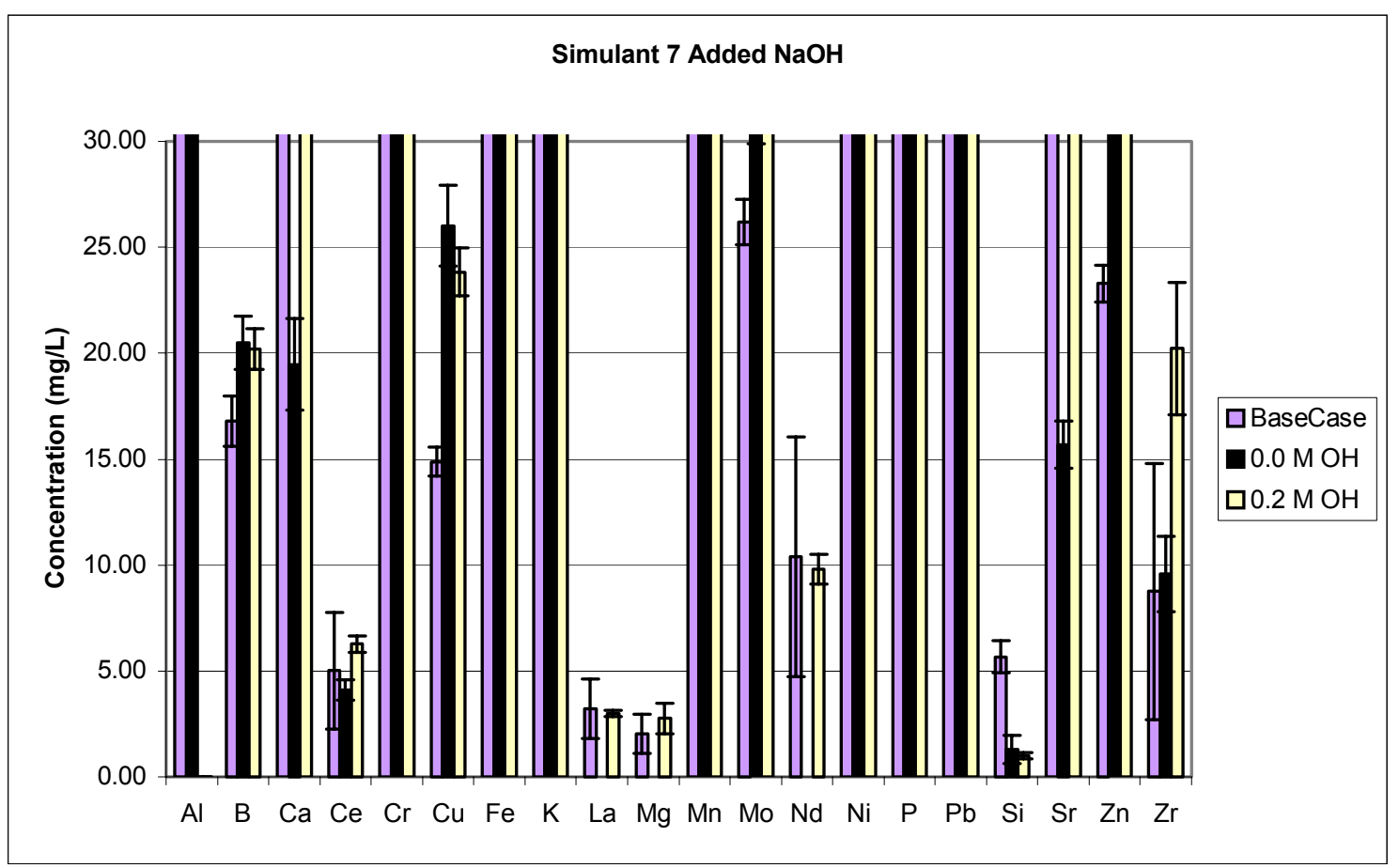

Figure 4.4.1.10b Figure 4.4.1.10a Scaled to see Minor Cations

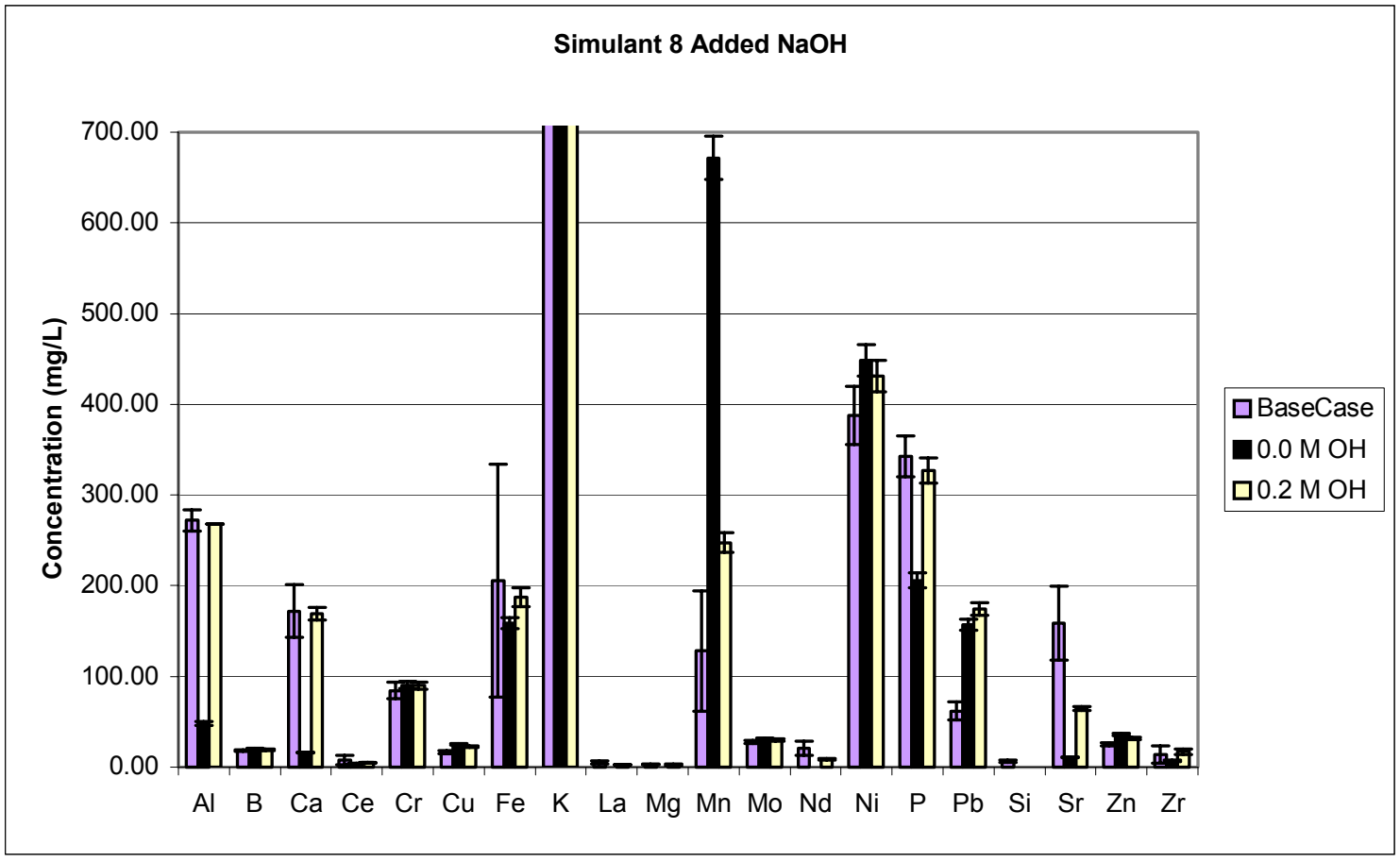

Figure 4.4.1.11a Mean Cation Concentration for the $0-48 \mathrm{hr}$. Filtrates with Added $\mathrm{NaOH}$ for Simulant 8 (AN-107) 


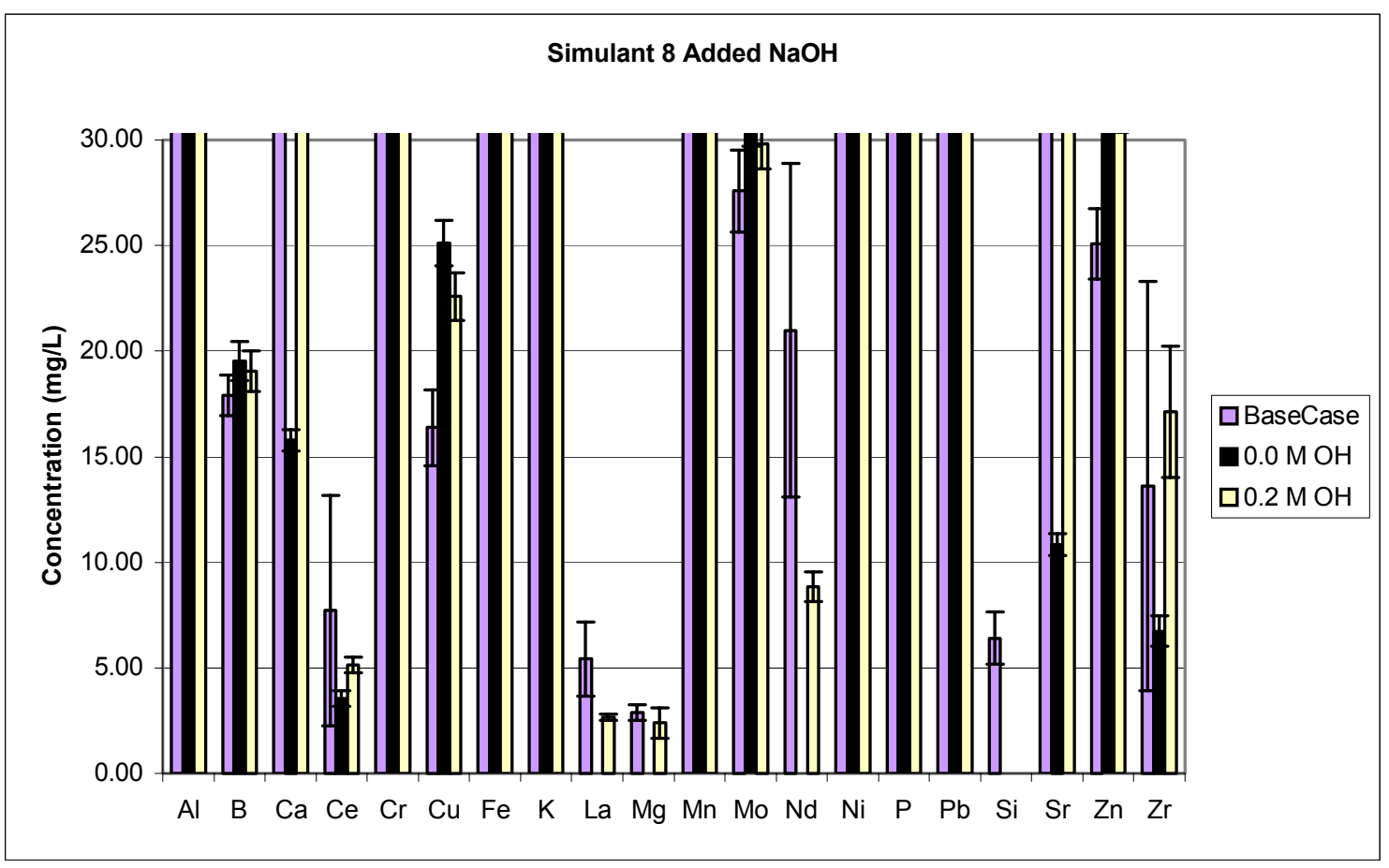

Figure 4.4.1.11b Figure 4.4.1.11a Scaled to see Minor Cations

Comparisons to the base case condition can also be made for all filtrate variables and reaction variables from these plots. Considering the filtrate variables, namely, sparged oxygen and nitrogen, light and filtration at $0.45 \mu \mathrm{m}$, and shear (Appended Figures C.14 through C.18), several observations can be made. Sparging the filtrates with nitrogen did not significantly affect the 0 to 48 -hr average filtrate concentration of $\mathrm{Mn}, \mathrm{Fe}, \mathrm{Sr}, \mathrm{Ce}, \mathrm{La}, \mathrm{Nd}$, and $\mathrm{Zr}$. This observation is plausible since purging the filtrates with nitrogen had little effect on the $\mathrm{E}_{\mathrm{H}}$ of the bulk filtrate, (Figure 4.4.1.12). Exposing the filtrate to visible light also did not appear to be significant compared to the base case condition. However, filtering at 0.45 $\mu \mathrm{m}$ did seem to lower the concentration of the above cations with exception of strontium in the filtrates relative to the base case. This observation was unexpected since filtering at 0.45 $\mu \mathrm{m}$ would allow smaller colloids to pass the filter and thus represent a surface for particle agglomeration. It is plausible that filtering at $0.45 \mu \mathrm{m}$ and acidifying the filtrate before ICPAES analysis would result in a higher concentration of the cations compared to the base case, which was filtered at $0.1 \mu \mathrm{m}$. This observation remains unexplained.

Similar comparisons can also be made for the reaction variables, namely, reaction temperature, added sodium hydroxide, sodium permanganate addition and strontium nitrate addition. Each of these reaction variables were investigated for three levels; reaction temperature at 15,25 and $50{ }^{\circ} \mathrm{C}$, added sodium hydroxide at $0.0,0.2$, and $1.0 \mathrm{M}$, sodium permanganate addition at $0.01,0.025$, and $0.05 \mathrm{M}$, and strontium nitrate addition at 0.01 , 0.02 , and $0.075 \mathrm{M}$. These data are summarized on three-dimensional plots in Figures 4.4.1.13 through 4.4.1.16 respectively. 
WSRC-TR-2003-00232, Rev. 0

SRT-RPP-2003-00105, Rev. 0

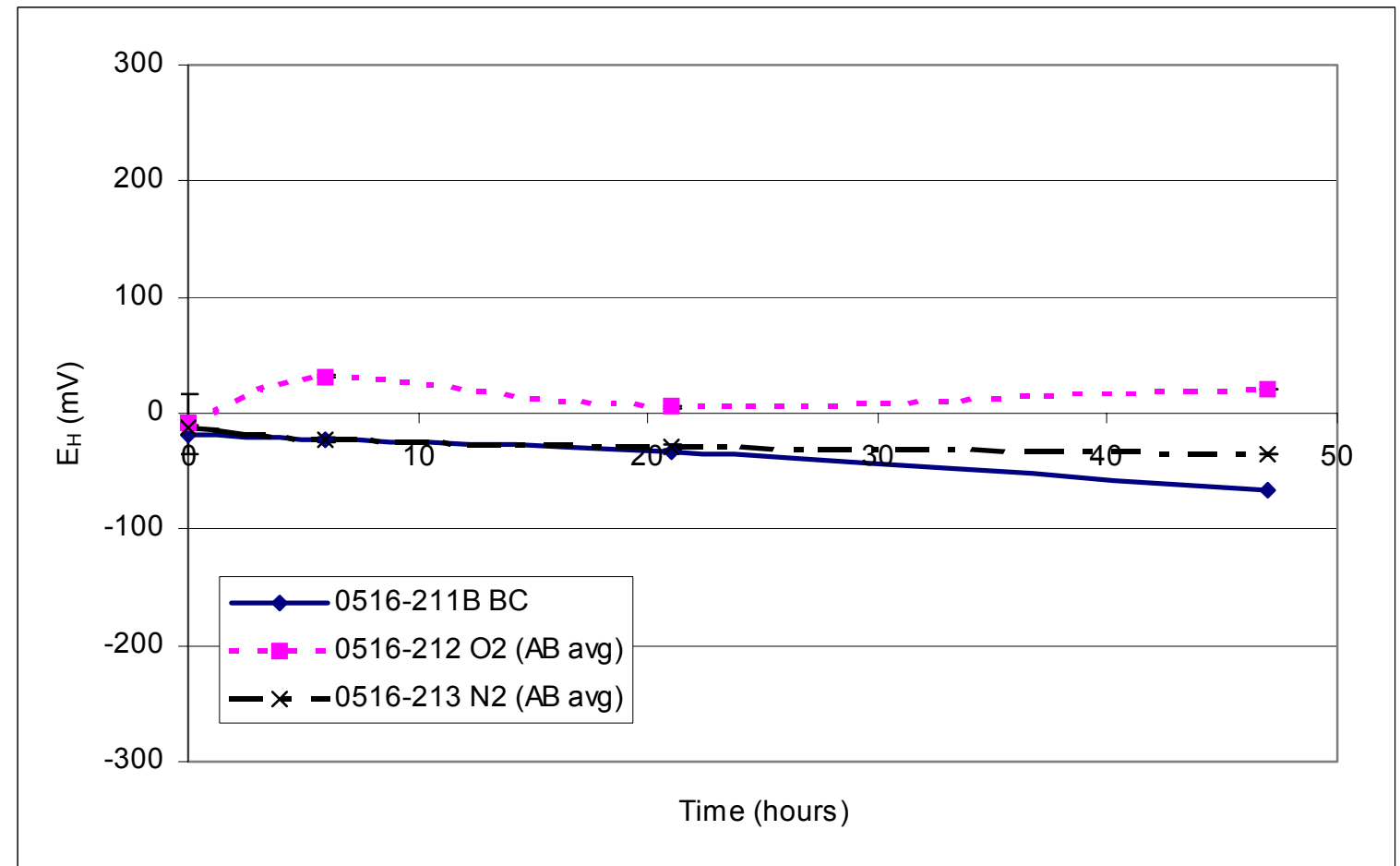

Figure 4.4.1.12 $\mathrm{E}_{\mathrm{H}}$ Measurements for the AN-107 Base Case, Oxygen Purge, and Nitrogen Purge Filtrates 
WSRC-TR-2003-00232, Rev. 0

SRT-RPP-2003-00105, Rev. 0
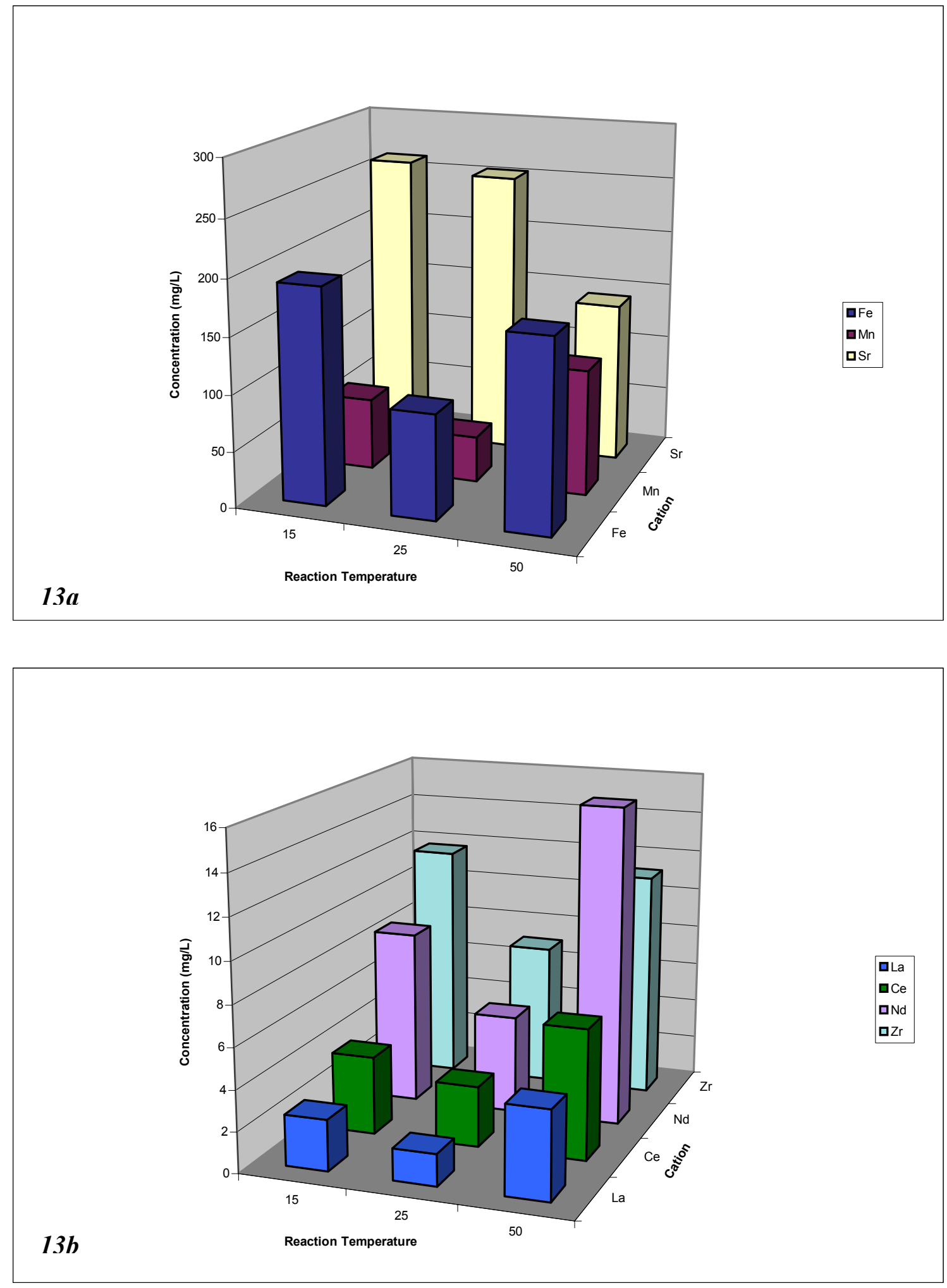

Figure 4.4.1.13 a \& b Mean 0 - 48 hr. Concentration of Selected Cations Plotted as a Function of Temperature 
WSRC-TR-2003-00232, Rev. 0

SRT-RPP-2003-00105, Rev. 0
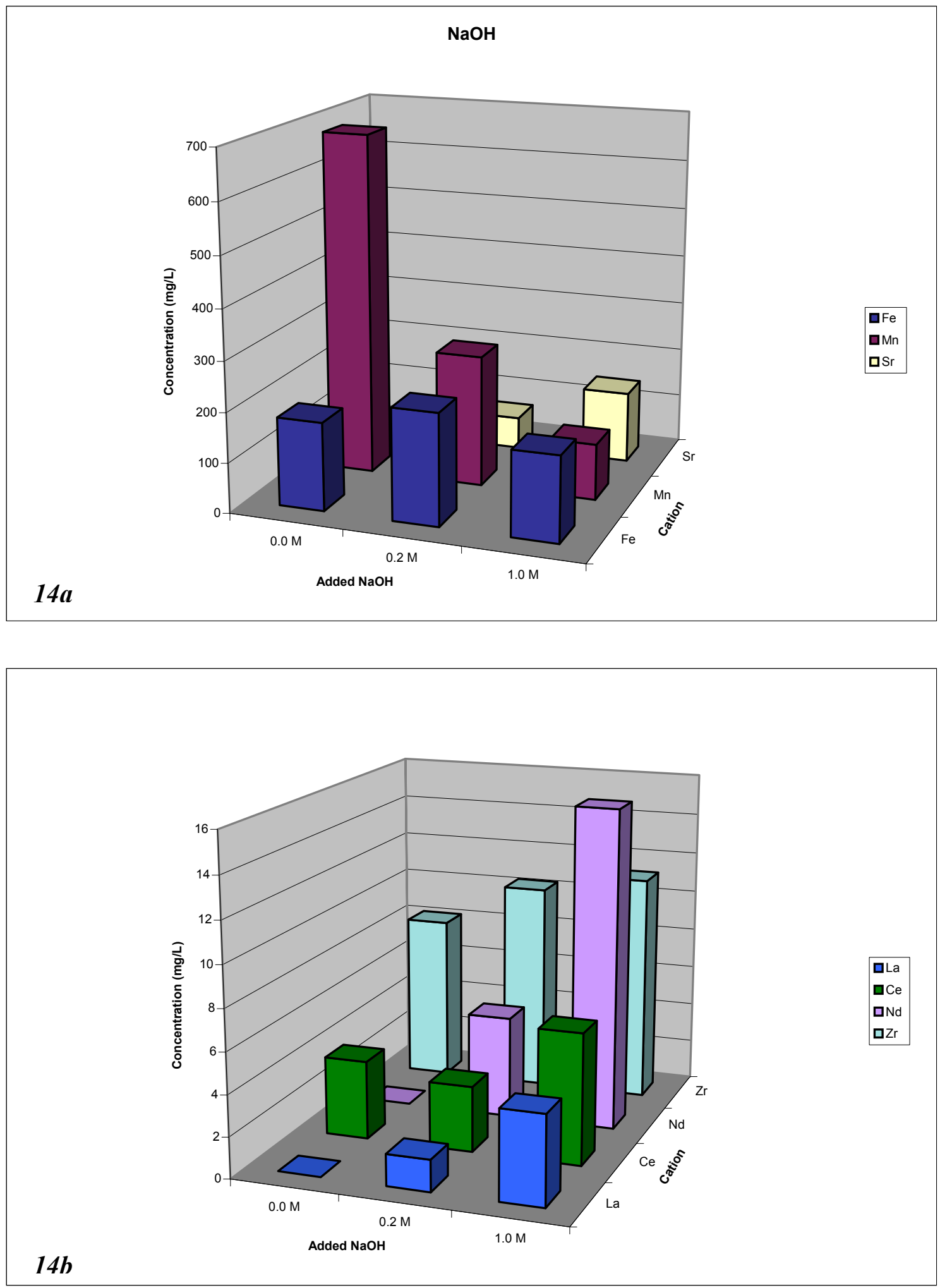

Figure 4.4.1.14 a \& b Mean $0-48$ hr. Concentration of Selected Cations Plotted as a Function of Added $\mathrm{NaOH}$ 
WSRC-TR-2003-00232, Rev. 0

SRT-RPP-2003-00105, Rev. 0
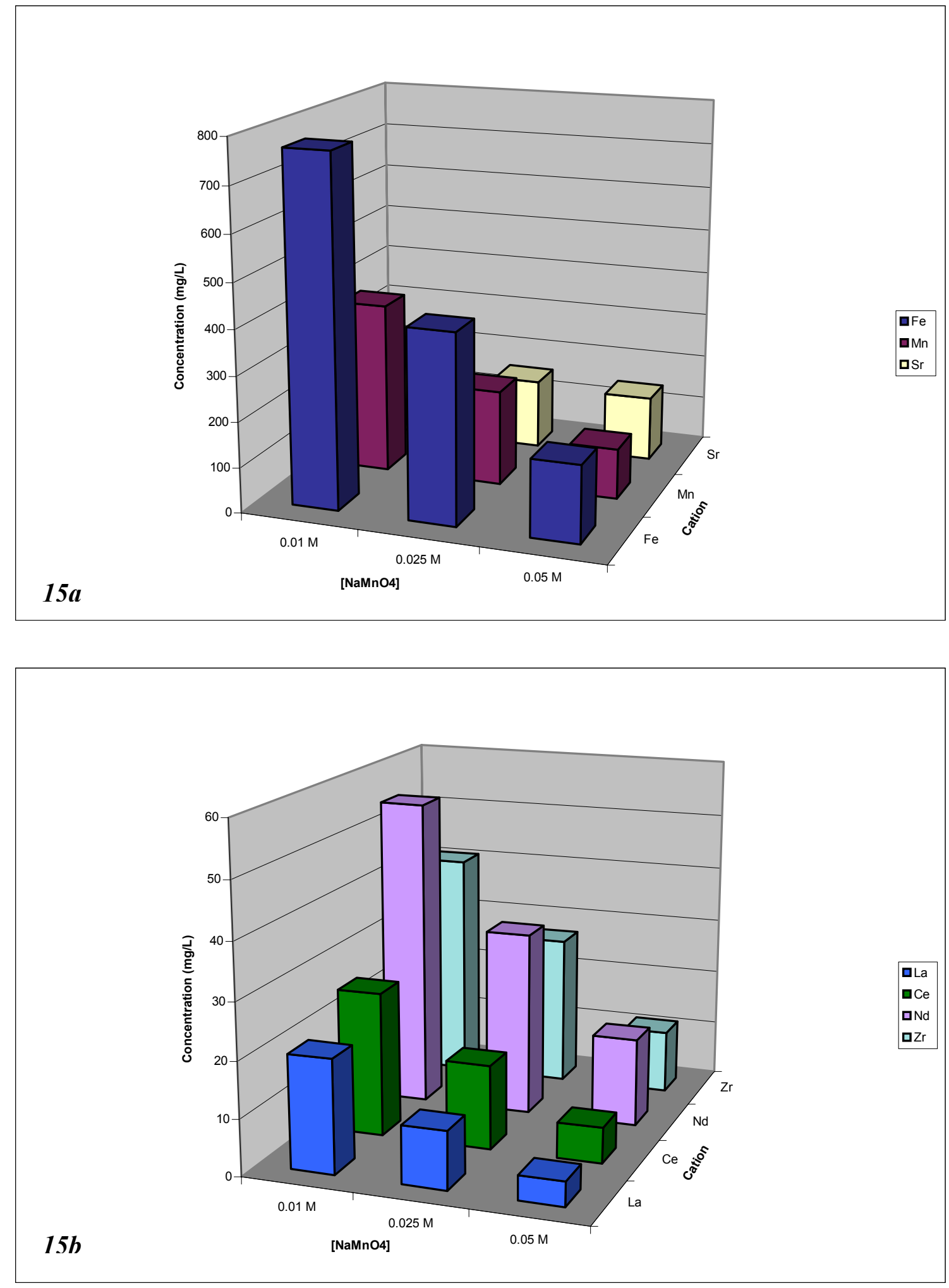

Figure 4.4.1.15 a \& b Mean 0-48 hr. Concentration of Selected Cations Plotted as a Function of Permanganate Concentration 
WSRC-TR-2003-00232, Rev. 0

SRT-RPP-2003-00105, Rev. 0
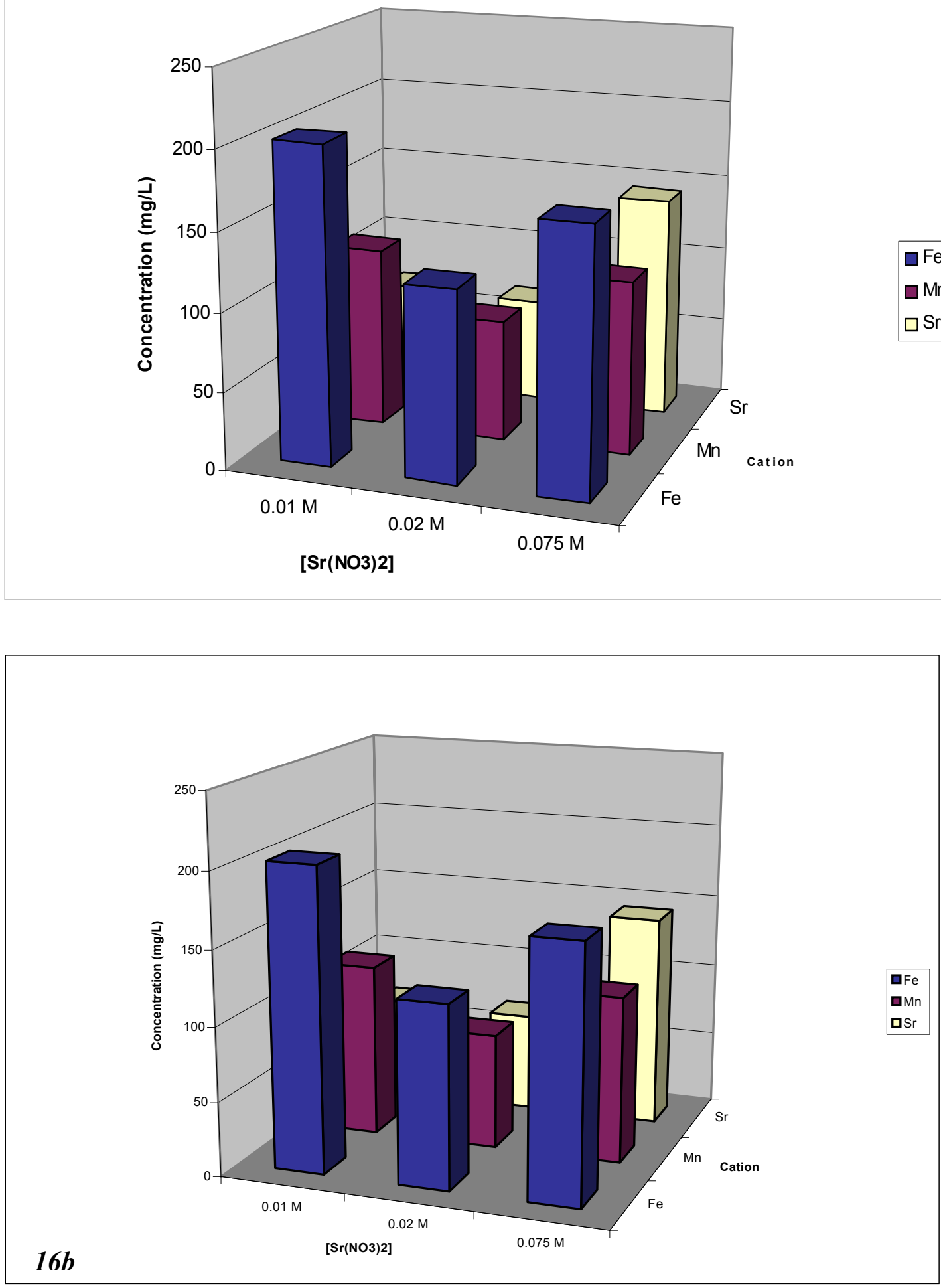

Figures 4.4.1.16 a \& b Mean 0 - 48 hr. Concentration of Selected Cations Plotted as a Function of Strontium Concentration 
WSRC-TR-2003-00232, Rev. 0

SRT-RPP-2003-00105, Rev. 0

Metal ion concentration data at time zero ( 0 to $48 \mathrm{hr}$ data since concentration as a function of time, did not vary) after reaction and filtration is plotted as a function of reaction temperature in Figure 4.4.1.13a and $\mathrm{b}$. Concentration data for strontium was inversely proportional to reaction temperature, reflecting a decrease in solubility of strontium carbonate with increasing temperature. Concentration data for the other metals generally increased with increasing temperature with the notable exception for reaction at $25{ }^{\circ} \mathrm{C}$. These results are unexpected since increasing reaction temperature should increase reaction rates thus increasing the mass of initial precipitate formed during the reaction and decrease the concentration of metal ion remaining in solution.

Cation data plotted as a function of added $\mathrm{NaOH}$, Figures $4.4 .1 .14 \mathrm{a} \& \mathrm{~b}$, suggests that as free hydroxide increases, manganese precipitation increases (during the initial reaction) thus decreasing the concentration of manganese in the filtrate. Iron and strontium concentration in the filtrates either remain relatively constant or increase slightly, suggesting that increasing free hydroxide does not affect the formation of initial iron or strontium precipitates as drastic as manganese. The concentration of $\mathrm{La}, \mathrm{Ce}, \mathrm{Nd}$, and $\mathrm{Zr}$ in the filtrate increases with increasing free hydroxide, suggesting that adsorption onto the manganese solid may not play a significant role in the removal of these cations.

Cation data plotted as a function of concentration of manganese in the reaction mixture, Figures 4.4.1.15a \& b, shows that as the reactant concentration (manganese) increases, the concentration of manganese and other metals decrease, suggesting that adsorption may be an important removal mechanism, when the free hydroxide ion concentration is constant at 1.0 molar.

Strontium data presented in Figures 4.4.1.16a \& b, does not appear to trend with increasing reactant concentration. However, the concentration of metal cations plotted may be slightly higher at the higher reactant concentration. The obvious dip in the data presented at a $\mathrm{Sr}$ reactant concentration of $0.02 \mathrm{M}$ remains unexplained.

\section{Change in Metals Concentration in Filtrates Between 48 Hours and Final Filtration}

Results from the preliminary study indicated the filtrates from reactions carried out at 1.3 and 2.0 added sodium hydroxide resulted in the formation of dark post-filtration solids within hours of the reaction. During the initial 48-hr period after the permanganate oxidation reaction for the primary effects study, dark solids only appeared in filtrates exposed to a 15minute oxygen sparge and in filtrates that were maintained at $100{ }^{\circ} \mathrm{C}$ for 8 hours following the reaction. To observe the formation of additional solids beyond the 48 -hr observation period, the primary effects study filtrates were stored for an additional 17 to 74 days. After the additional period, filtrates were again filtered at $0.1 \mu \mathrm{m}$ and analyzed by ICP-AES. A summary of these data is presented in Table 4.4.1.3. Since the data presented are ratios of the cationic concentration of the 0 to $48 \mathrm{hr}$ and the final filtrate concentration, actual measured data are tabulated. Data for manganese, iron, and strontium are listed for the base case replicates and replicates for reaction and filtrate variables. Presented is data representing the ratio of the mean 0 to 48 -hr filtrate concentration to the concentration of $\mathrm{Mn}$, 
WSRC-TR-2003-00232, Rev. 0

SRT-RPP-2003-00105, Rev. 0

$\mathrm{Fe}$, and $\mathrm{Sr}$ in the filtrates after final filtration. A ratio of 1.0 would therefore indicate no loss of the cation from solution during the extended storage period.

The average ratio presented for Mn suggests that in almost all treatments, additional manganese solids formed during the extended storage period. Two of the treatments, namely, the $0.0 \mathrm{M}$ added sodium hydroxide and the $0.01 \mathrm{M}$ sodium permanganate addition had average ratios of 1.19 and 1.11 respectively suggesting very little formation of manganese solids. The remainder of treatment conditions are represented with ratios of 1.42 to 13.60. Digital photographs shown in Appendix D of particulates collected during final filtration confirm the presence of dark brown to black solids. A photo of the filter for the 0.0 $M$ added sodium hydroxide was not taken because visible solids were not present in the filtrate. Although no visible solids were evident for this sample, it is possible that an inspection of a filtered sample may have revealed a small amount of solids present. This supposition is based on the appearance of the particulate mass for the $0.01 \mathrm{M}$ sodium permanganate. Recall that the average $\mathrm{Mn}$ ratios for the $0.0 \mathrm{M} \mathrm{NaOH}$ and the $0.01 \mathrm{M} \mathrm{Mn}$ were 1.19 and 1.11, respectively, and there was a small accumulation of brown solids on the filter for the $0.01 \mathrm{M} \mathrm{Mn}$ treatment. (see photo D.5)

During the preliminary study and the primary effects study usig the 241-AN-107 simulant, several samples were submitted for X-Ray Diffraction analysis (XRD). These spectra are included in Appendix G. With the exception of one sample, namely a filtrate filtered at 0.45 $\mu \mathrm{m}$ and maintained in the dark under a nitrogen blanket, crystalline manganese solids were not detected. Manganese solids that formed during observation periods were likely amorphous and transparent to XRD. Crystalline solids detected included sodium nitrate and nitrite, sodium oxalate, Trona $\left(\mathrm{Na}_{3} \mathrm{H}\left(\mathrm{CO}_{3}\right)_{2}-2 \mathrm{H}_{2} \mathrm{O}\right)$, sodium carbonate, sodalite, and strontium carbonate. Crystalline strontium carbonate was present only in the sample reacted at $25{ }^{\circ} \mathrm{C}$. 
WSRC-TR-2003-00232, Rev. 0

Table 4.4.1.3 Ratio of Concentration for $\mathrm{Fe}, \mathrm{Mn}, \mathrm{Sr}$ (0-48 $\mathrm{Hr}$ avg/final filtrate concentration)

\begin{tabular}{|c|c|c|c|c|c|c|c|c|c|c|c|c|c|}
\hline \multirow{2}{*}{ Filtrate Sample } & \multirow{2}{*}{$\begin{array}{l}\text { Days from rxn to } \\
\text { final filtration }\end{array}$} & \multicolumn{4}{|c|}{$\mathrm{Fe}(\mathrm{mg} / \mathrm{L})$} & \multicolumn{4}{|c|}{$\mathrm{Mn}(\mathrm{mg} / \mathrm{L})$} & \multicolumn{4}{|c|}{$\mathrm{Sr}(\mathrm{mg} / \mathrm{L})$} \\
\hline & & $48 \mathrm{hr}$ & Final & Ratio & Avg Ratio & $48 \mathrm{hr}$ & Final & Ratio & Avg Ratio & $48 \mathrm{hr}$ & Final & Ratio & Avg Ratio \\
\hline \multirow[t]{2}{*}{ Light } & 76 & 176.7 & ND & & & 123.2 & ND & & & 122.5 & ND & & \\
\hline & 76 & 117.9 & $\mathrm{ND}$ & & & 79.4 & ND & & & 102.1 & ND & & \\
\hline \multirow[t]{2}{*}{$0.45 \mu \mathrm{m}$} & 76 & 48.7 & 33.5 & 1.45 & \multirow{2}{*}{1.39} & 39.9 & 5.8 & 6.88 & \multirow{2}{*}{13.60} & 92.0 & 87.9 & 1.05 & \multirow{2}{*}{1.06} \\
\hline & 76 & 89.5 & 65.8 & 1.36 & & 67.0 & 2.1 & 32.52 & & 93.7 & 88.0 & 1.06 & \\
\hline \multirow{2}{*}{ Filter $@ 50{ }^{\circ} \mathrm{C}$} & 76 & 159.3 & 136.3 & 1.17 & \multirow{2}{*}{1.28} & 119.0 & 46.5 & 2.56 & \multirow{2}{*}{2.14} & \begin{tabular}{|l|}
79.8 \\
\end{tabular} & 73.6 & 1.08 & \multirow{2}{*}{1.15} \\
\hline & 66 & 257.4 & 188.8 & 1.36 & & 154.6 & 81.5 & 1.920 & & 94.4 & 77.8 & 1.21 & \\
\hline \multirow[t]{2}{*}{8 hour hold } & 76 & 40.1 & 23.8 & 1.68 & \multirow{2}{*}{1.48} & 26.6 & 2.5 & 10.64 & \multirow{2}{*}{5.24} & 22.5 & 28.6 & 0.79 & \multirow{2}{*}{0.78} \\
\hline & 76 & 80.0 & 57.6 & 1.39 & & 47.3 & 11.6 & 4.08 & & \begin{tabular}{|l|}
24.1 \\
\end{tabular} & 31.3 & 0.77 & \\
\hline \multirow[t]{2}{*}{$0 \mathrm{M} \mathrm{OH}$} & 66 & 141.6 & 115.7 & 1.22 & \multirow{2}{*}{1.23} & 507.9 & 427.8 & 1.19 & \multirow{2}{*}{1.19} & 11.5 & 4.1 & 2.80 & \multirow{2}{*}{2.59} \\
\hline & 66 & 116.2 & 94.5 & 1.23 & & 490.3 & 413.4 & 1.19 & & 7.9 & 3.4 & 2.32 & \\
\hline \multirow[t]{2}{*}{$0.2 \mathrm{M} \mathrm{OH}$} & 66 & 186.3 & 99.7 & 1.87 & \multirow{2}{*}{1.35} & 199.6 & 115.4 & 1.73 & & 46.3 & 37.5 & 1.23 & \\
\hline & 66 & 134.7 & 138.7 & 0.97 & & 178.1 & 139.3 & 1.28 & 1.48 & 46.5 & 36.8 & 1.26 & 1.25 \\
\hline $0.01 \mathrm{M} \mathrm{Mn}$ & 48 & 534.6 & 586.4 & 0.91 & & 269.7 & 274.2 & 0.98 & & 123.6 & 128.8 & 0.96 & \\
\hline & 48 & 553.5 & 470.4 & 1.18 & 1.03 & 265.2 & 208.0 & 1.28 & 1.11 & 132.5 & 105.8 & 1.25 & 1.09 \\
\hline $0.025 \mathrm{M} \mathrm{Mn}$ & 52 & 215.6 & 198.8 & 1.08 & & 130.9 & 89.7 & 1.46 & & 96.2 & 88.7 & 1.08 & \\
\hline & 52 & 369.1 & 341.4 & 1.08 & 1.08 & 164.0 & 118.0 & 1.39 & 1.42 & 118.2 & 105.1 & 1.12 & 1.11 \\
\hline $0.01 \mathrm{M} \mathrm{Sr}$ & 52 & 165.4 & 92.1 & 1.80 & 1.58 & 62.0 & 30.4 & 2.04 & 221 & \begin{tabular}{|l|}
41.7 \\
\end{tabular} & 36.9 & 1.13 & 125 \\
\hline & 52 & 185.0 & 129.4 & 1.43 & 1.58 & 104.0 & 44.6 & 2.33 & 2.21 & 56.0 & 41.3 & 1.36 & 1.25 \\
\hline $0.02 \mathrm{M} \mathrm{Sr}$ & 52 & 86.1 & 65.7 & 1.31 & 131 & 53.9 & 21.3 & 2.53 & 240 & 44.9 & 40.2 & 1.12 & 111 \\
\hline & 52 & 88.4 & 68.0 & 1.30 & 1.31 & 55.5 & 23.1 & 2.45 & 2.49 & \begin{tabular}{|l|}
49.8 \\
\end{tabular} & 44.9 & 1.11 & 1.11 \\
\hline $\mathrm{Rxn} @ 25^{\circ} \mathrm{C}$ & 47 & 57.9 & 51.1 & 1.13 & 117 & 26.1 & 8.9 & 2.93 & 203 & 155.1 & 132.8 & 1.17 & 145 \\
\hline & 47 & 69.6 & 58.2 & 1.20 & 1.17 & 29.5 & 10.1 & 2.92 & 2.93 & 189.6 & 105.1 & 1.80 & 1.43 \\
\hline $\mathrm{Rxn} @ 15^{\circ} \mathrm{C}$ & 40 & 122.1 & 109.5 & 1.12 & & 39.0 & 20.2 & 1.93 & & 157.9 & 147.0 & 1.07 & \\
\hline & 40 & 136.5 & 103.7 & 1.32 & 1.21 & 46.9 & 19.9 & 2.36 & 2.14 & 193.7 & 155.9 & 1.24 & 1.16 \\
\hline $\mathrm{O}_{2}$ & 19 & 48.5 & 39.6 & 1.22 & 1.19 & 31.9 & 16.4 & 1.95 & & \begin{tabular}{|l|}
86.0 \\
\end{tabular} & 79.3 & 1.08 & \\
\hline & 19 & 45.2 & 39.0 & 1.16 & 1.19 & 32.4 & 17.0 & 1.91 & 1.93 & \begin{tabular}{|l|}
77.4 \\
\end{tabular} & 79.5 & 0.97 & 1.03 \\
\hline $\mathrm{N}_{2}$ & 19 & 49.9 & 44.0 & 1.13 & & 38.2 & 23.1 & 1.65 & 178 & \begin{tabular}{|l|}
84.1 \\
\end{tabular} & 83.9 & 1.00 & \\
\hline & 19 & 49.9 & 40.2 & 1.24 & 1.19 & 38.7 & 20.0 & 1.94 & 1.18 & \begin{tabular}{|l|}
87.5 \\
\end{tabular} & 74.1 & 1.18 & 1.09 \\
\hline Shear & 59 & 40.8 & 36.3 & 1.12 & 121 & 33.4 & 9.5 & 3.52 & & 83.5 & 86.6 & 0.96 & \\
\hline & 59 & 36.1 & 27.1 & 1.33 & 1.21 & 32.0 & 10.3 & 3.11 & 3.30 & \begin{tabular}{|l|}
73.1 \\
\end{tabular} & 71.4 & 1.02 & 0.99 \\
\hline Base Case & 78 & 165.1 & 128.8 & 1.282 & 126 & 114.4 & 49.9 & 2.2926 & 24 & 113.5 & 110.9 & 1.0234 & 107 \\
\hline & 50 & 72.7 & 59.3 & 1.226 & 1.20 & 49.8 & 18 & 2.7667 & 2.42 & \begin{tabular}{|l|}
74.4 \\
\end{tabular} & 65.4 & 1.1376 & 1.01 \\
\hline Base Case & 78 & 117.8 & 92.2 & 1.278 & & 77.9 & 30.4 & 2.5625 & & \begin{tabular}{|l|}
100 \\
\end{tabular} & 98.4 & 1.0163 & \\
\hline & 68 & 255.8 & 182.8 & 1.399 & 1.36 & 146.4 & 70.4 & 2.0795 & 2.23 & 145.5 & 116.1 & 1.2532 & 1.14 \\
\hline
\end{tabular}


WSRC-TR-2003-00232, Rev. 0

SRT-RPP-2003-00105, Rev. 0

In summary, data presented for the primary effects study suggests that post-filtration solids form in all treatments considered given sufficient time. However, in the short term, within 48 hours, reacting the simulant at process conditions, but eliminating the addition of sodium hydroxide from the reaction mixture and minimizing exposure to oxygen in the filtrates may minimize the formation. In addition, the formation of post-filtration solids could also be minimized by reducing the concentration of sodium permanganate to approximately $0.01 \mathrm{M}$ from the process design of $0.05 \mathrm{M}$. This change however may seriously impact the formation of reaction precipitates and reduce decontamination of the nuclides in the actual waste (discussions in the project review meeting, 2002).

\subsubsection{Secondary Effects Study}

Very near the end of the analytical effort for the AN-241-107 primary effects study, discussions were initiated concerning reconsideration of the reaction conditions. A "newly optimized conditions' (NOC) was proposed in which the concentration of reactants was reduced from $0.075 \mathrm{M}$ strontium nitrate and $0.05 \mathrm{M}$ sodium permanganate to 0.03 and 0.03 $\mathrm{M}$ respectively. In addition, the sodium hydroxide concentration would be at $0.3 \mathrm{M}$ added and the reaction temperature was proposed to be $25^{\circ} \mathrm{C}$. Since these conditions were not included in the original task plan, we proposed to investigate these conditions and include variables that resulted in minimal post-filtration solids formation from the primary effects study. A $2^{3}$ factorial experiment using the NOC reaction and varying the sodium permanganate concentration from $0.03 \mathrm{M}$ to $0.01 \mathrm{M}$ (A treatment, two levels), light and dark (B treatment, two levels) and the presence or absence of oxygen ( $\mathrm{C}$ treatment, two levels) was designed. The factorial design is presented in Table 4.4.2.1.

Table 4.4.2.1 Factorial Design for the Newly Optimized Conditions

\begin{tabular}{|c|c|c|c|}
\hline \multicolumn{5}{|c|}{$\mathbf{2}^{\mathbf{3}}$ Factorial Design } \\
\hline Effect & A & B & C \\
\hline & {$\left[\mathrm{MnO}_{4}{ }^{-}\right]$} & Lt/Dk & ATM/ $\mathrm{N}_{2}$ \\
\hline$(1)$ & $0.03 \mathrm{M}$ & Dark & $\mathrm{N}_{2}$ \\
\hline $\mathrm{a}$ & $0.01 \mathrm{M}$ & Dark & $\mathrm{N}_{2}$ \\
\hline $\mathrm{b}$ & $0.03 \mathrm{M}$ & Light & $\mathrm{N}_{2}$ \\
\hline $\mathrm{ab}$ & $0.01 \mathrm{M}$ & Light & $\mathrm{N}_{2}$ \\
\hline $\mathrm{c}$ & $0.03 \mathrm{M}$ & Dark & Atm \\
\hline $\mathrm{ac}$ & $0.01 \mathrm{M}$ & Dark & Atm \\
\hline $\mathrm{bc}$ & $0.03 \mathrm{M}$ & Light & Atm \\
\hline $\mathrm{abc}$ & $0.01 \mathrm{M}$ & Light & Atm \\
\hline
\end{tabular}


WSRC-TR-2003-00232, Rev. 0

SRT-RPP-2003-00105, Rev. 0

$\underline{\text { Visual Observations }}$

The visual observation period was extended to 16 days for two reasons. First, with exception of the treatment conditions, $8-\mathrm{hr}$ hold at $100^{\circ} \mathrm{C}$ and the oxygen sparge, all remaining treatments included in the primary effects study did not result in the formation of postfiltration solids. Secondly, some concern was expressed that ion exchange at the treatment facility may not be accomplished within 24 to 48 hours; therefore, determining the potential for the formation of post-filtration solids in filtrates for several days should be investigated. Included in Table 4.4.2.2 are visual observations noting the time solids formed in the filtrates. The cross effect of light and atmosphere at the newly optimized condition resulted in the formation of dark post-filtration solids between days 4 and 5. The cross effect of 0.01 $\mathrm{M}$ sodium permanganate and light also resulted in the formation of solids within 6 to 7 days. The cross effect of $0.01 \mathrm{M}$ sodium permanganate and atmosphere did not result in the formation of solids within the 16-day observation period.

Table 4.4.2.2 Appearance of Solids in Filtrates During the 16-Day Period (AN-107)

\begin{tabular}{|c|c|c|c|c|c|}
\hline \multicolumn{6}{|c|}{$\begin{array}{c}\text { VISUAL OBSERVATIONS FOR THE AN-107 NOC FACTORIAL } \\
\text { EXPERIMENTS }\end{array}$} \\
\hline & & & White Solids & $\begin{array}{c}\text { Ring on } \\
\text { Flask }\end{array}$ & Dark Solids \\
\hline $0.03 \mathrm{M}$ & Light & ATM & $1-2 d$ & $4 \mathrm{~d}$ & $4-5 d$ \\
\hline $0.03 \mathrm{M}$ & Dark & ATM & $3-6 d$ & $X$ & $\mathrm{X}$ \\
\hline $0.03 \mathrm{M}$ & Light & $\mathrm{N}_{2}$ & $2-3 d$ & $5 d$ & $5-6 d$ \\
\hline $0.03 \mathrm{M}$ & Dark & $\mathrm{N}_{2}$ & $5-9 d$ & $X$ & $X$ \\
\hline $0.01 \mathrm{M}$ & Light & ATM & $2 d$ & $5 d$ & $5-6 d$ \\
\hline $0.01 \mathrm{M}$ & Dark & ATM & $2 \mathrm{~d}$ & $X$ & $X$ \\
\hline $0.01 \mathrm{M}$ & Light & $\mathrm{N}_{2}$ & $3 d$ & $6 \mathrm{~d}$ & $6-7 d$ \\
\hline $0.01 \mathrm{M}$ & Dark & $\mathrm{N}_{2}$ & $3 d$ & $X$ & $X$ \\
\hline
\end{tabular}

In addition to examining secondary effects, the primary effects of a reduced level of sodium permanganate, the presence of air, and light on the NOC; and the tertiary effect of $0.01 \mathrm{M}$ sodium permanganate, atmosphere and light can be measured from the factorial design. The primary effect of light resulted in the formation of solids within 5 to 6 days. The primary effect of atmosphere or $0.01 \mathrm{M}$ sodium permanganate did not result in the formation of solids within 16 days. The tertiary effect resulted in the formation of solids within 5 to 6 days. From visual observations, it appears that with respect to the NOC, the presence of light may result in the formation of post-filtration solids.

At the end of the 16-day observation period, all filtrate samples were filtered at $0.1 \mu \mathrm{m}$ and digital photographs of the filters were taken to further document the formation of solids. These photographs are shown in Figure 4.4.2.1. As can be seen, dark solids formed in all filtrates maintained in contact with air. The presence of dark solids on the filters correlate well with the visual observation for the cross effects of light and atmosphere for the NOC, 
the primary effect of light for the NOC, and the cross effect of $0.01 \mathrm{M}$ permanganate and light for the NOC. However, visual observations for the neither the cross effect of 0.01 sodium permanganate and atmosphere for the NOC, nor the primary effect of atmosphere correlate with the presence of solids on the respective filter. White solids formed early, but dark solids were not observed at day 16 .

\section{Particulate Solids Summary}

$0.1 \mu \mathrm{m}$

Filters

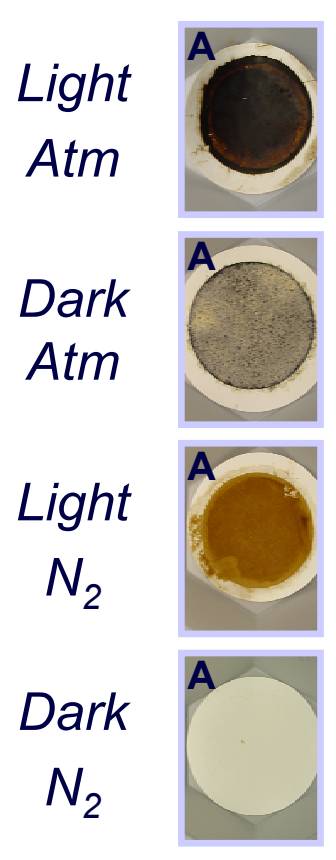

$0.01 \mathrm{MnO}_{4}^{-}$

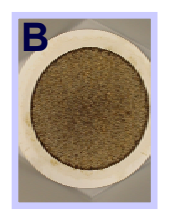

B
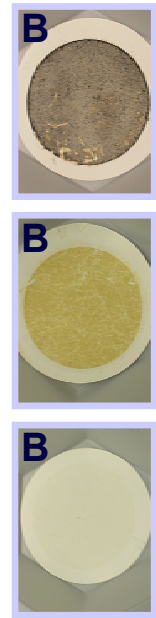

$0.03 \mathrm{MnO}_{4}$

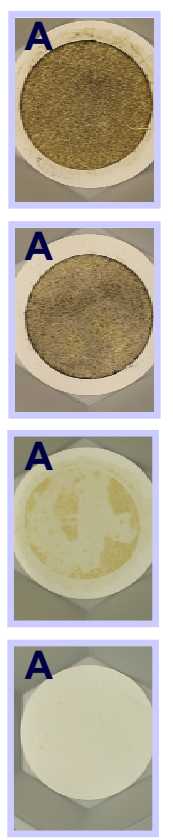

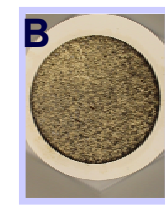
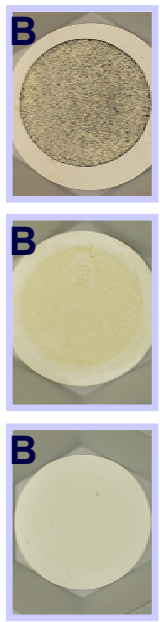

Figure 4.4.2.1 Particulate Solids Summary for the AN-107 Secondary Effects Study

The tertiary effect of $0.01 \mathrm{M}$ permanganate, light and atmosphere, resulted in the formation of solids within 5 to 6 days and is confirmed by the presence of dark solids on the respective filter. For the NOC, dark solids were not observed on the filter or in the filtrate at day 16. In addition dark solids were not expressed for the primary effect of $0.01 \mathrm{M}$ permanganate. Therefore, it would appear that reacting at the NOC or at a lower permanganate concentration could mitigate the formation of dark solids within 16 days of an oxidation reaction with a $241-\mathrm{AN}-107$ waste.

Discrepancies between the photographic record of the particulate filters and the visual observations noted in the above paragraph for two conditions ( $0.03 \mathrm{M} \mathrm{Mn}$, dark, atmosphere and the $0.01 \mathrm{M} \mathrm{Mn}$, dark, atmosphere) are not understood. However, it is plausible that the light colored solids noted in Table 4.4.2.2 were oxidized by oxygen in the atmosphere during filtration and drying to Mn (III) and Mn (IV) oxy-hydroxides and oxides respectively (Cotton and Wilkinson, 1988). 
Change in Metal Ion Concentrations During the 16-Day Observation Period for the Secondary Effects Study for 241-AN-107

During the sixteen-day period of observation, aliquots of the filtrates were collected, filtered at $0.1 \mu \mathrm{m}$, and analyzed by ICP-AES to determine metal ion concentrations. A summary of these data is presented in Appendix E in tabular form. Data for $\mathrm{Mn}, \mathrm{Fe}$ and $\mathrm{Sr}$ are plotted in Figures 4.4.2.2 through 4.4.2.13 respectively. The 0.03 M Mn data cover an observation period of 16 days and the $0.01 \mathrm{M} \mathrm{Mn}$ data span an 18-day observation period. Interestingly, data for manganese does not indicate that manganese was lost from solution during the sixteen days. This observation does not correlate with several of the photographic records of particulate filters (Figure 4.4.2.1), specifically, the secondary effect of $0.01 \mathrm{M}$ sodium permanganate with (1) atmosphere and (2) light, the secondary effect of $0.03 \mathrm{M}$ sodium permanganate with light, and the tertiary effect of $0.01 \mathrm{M} \mathrm{Mn}$, light, and atmosphere. Although dark solids are seen on the filters for these conditions, the concentration of soluble manganese measured in the filtrates at specific times during the 16-day period does not decrease with time.

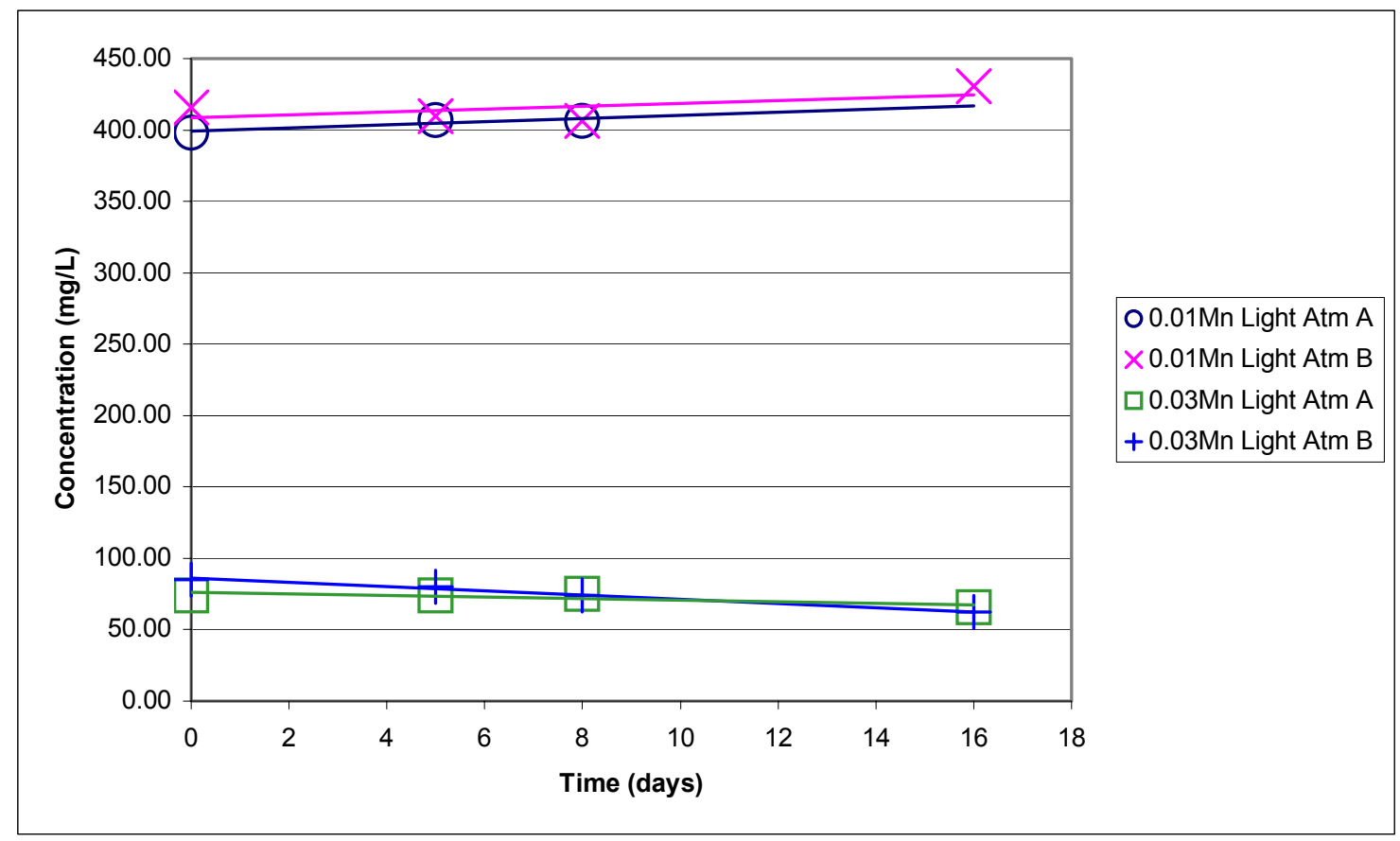

Figure 4.4.2.2 Manganese Concentration in 0-16 Day Filtrates for Manganese, Light, and Atmosphere 
WSRC-TR-2003-00232, Rev. 0

SRT-RPP-2003-00105, Rev. 0

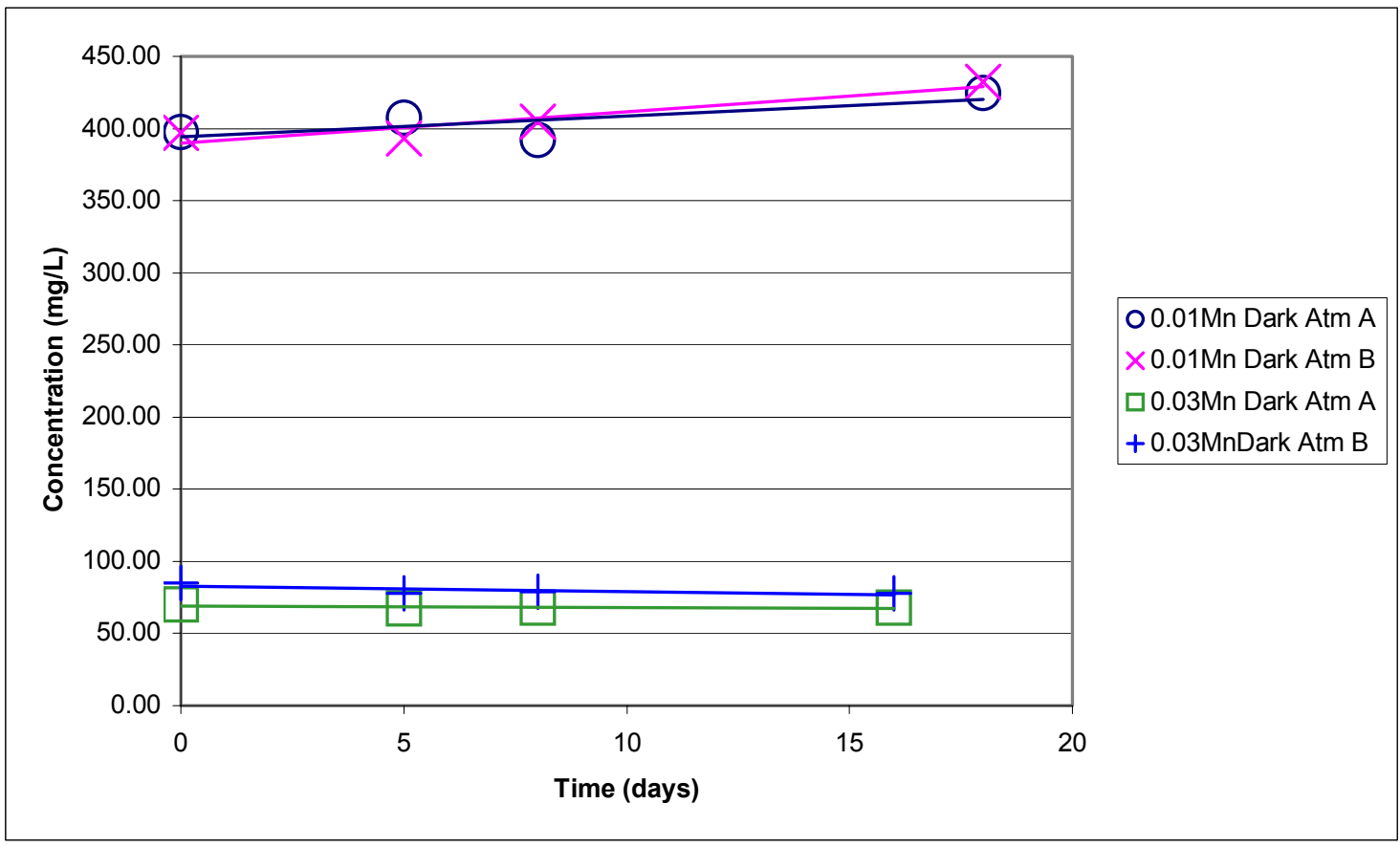

Figure 4.4.2.3 Manganese Concentration in 0-16 Day Filtrates for Manganese, Dark, and Atmosphere

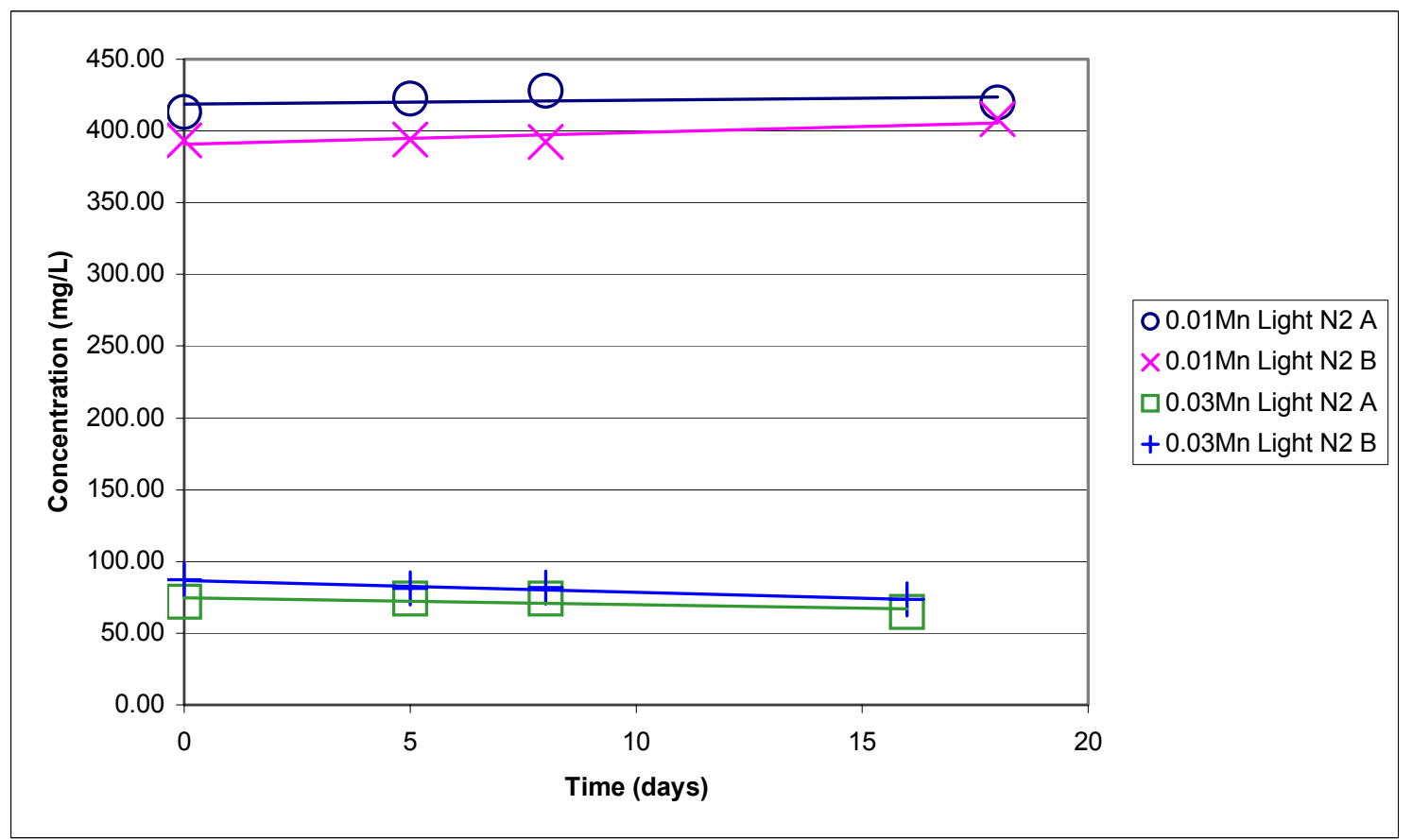

Figure 4.4.2.4 Manganese Concentration in 0-16 Day Filtrates for Manganese, Light, and Nitrogen 
WSRC-TR-2003-00232, Rev. 0

SRT-RPP-2003-00105, Rev. 0

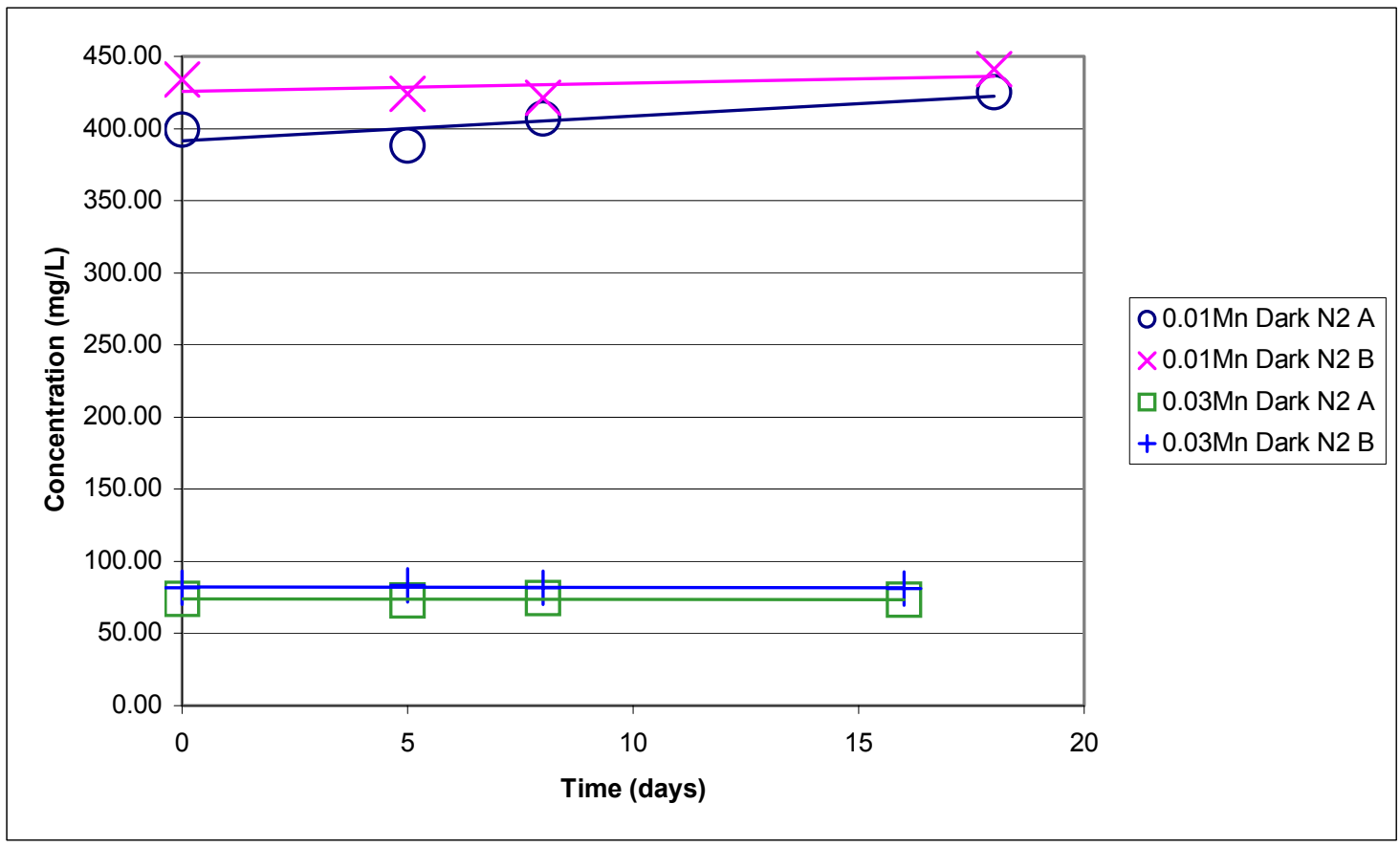

Figure 4.4.2.5 Manganese Concentration in 0-16 Day Filtrates for Manganese, Dark, and Nitrogen

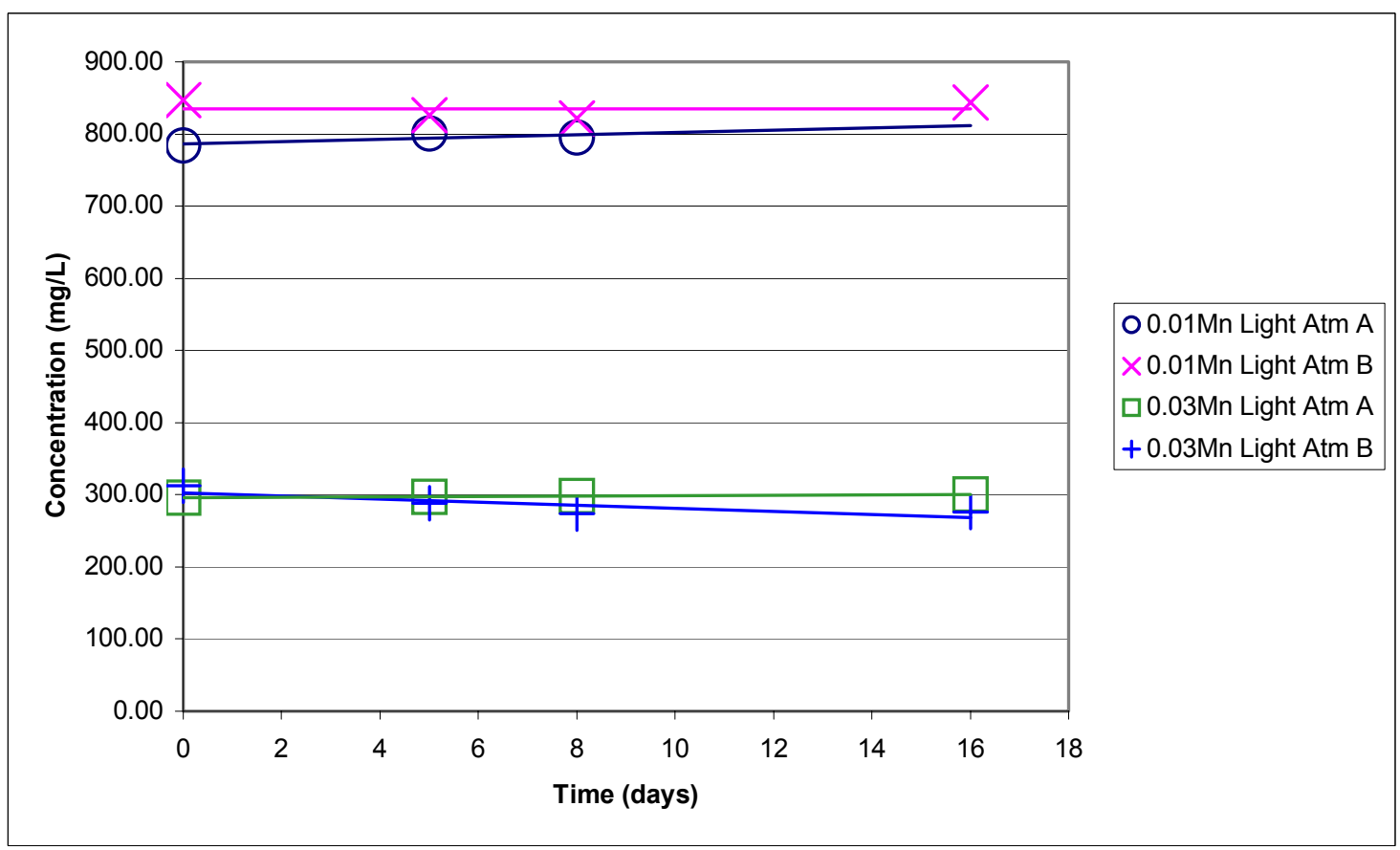

Figure 4.4.2.6 Iron Concentration in 0-16 Day Filtrates for Manganese, Light, and Atmosphere 
WSRC-TR-2003-00232, Rev. 0

SRT-RPP-2003-00105, Rev. 0

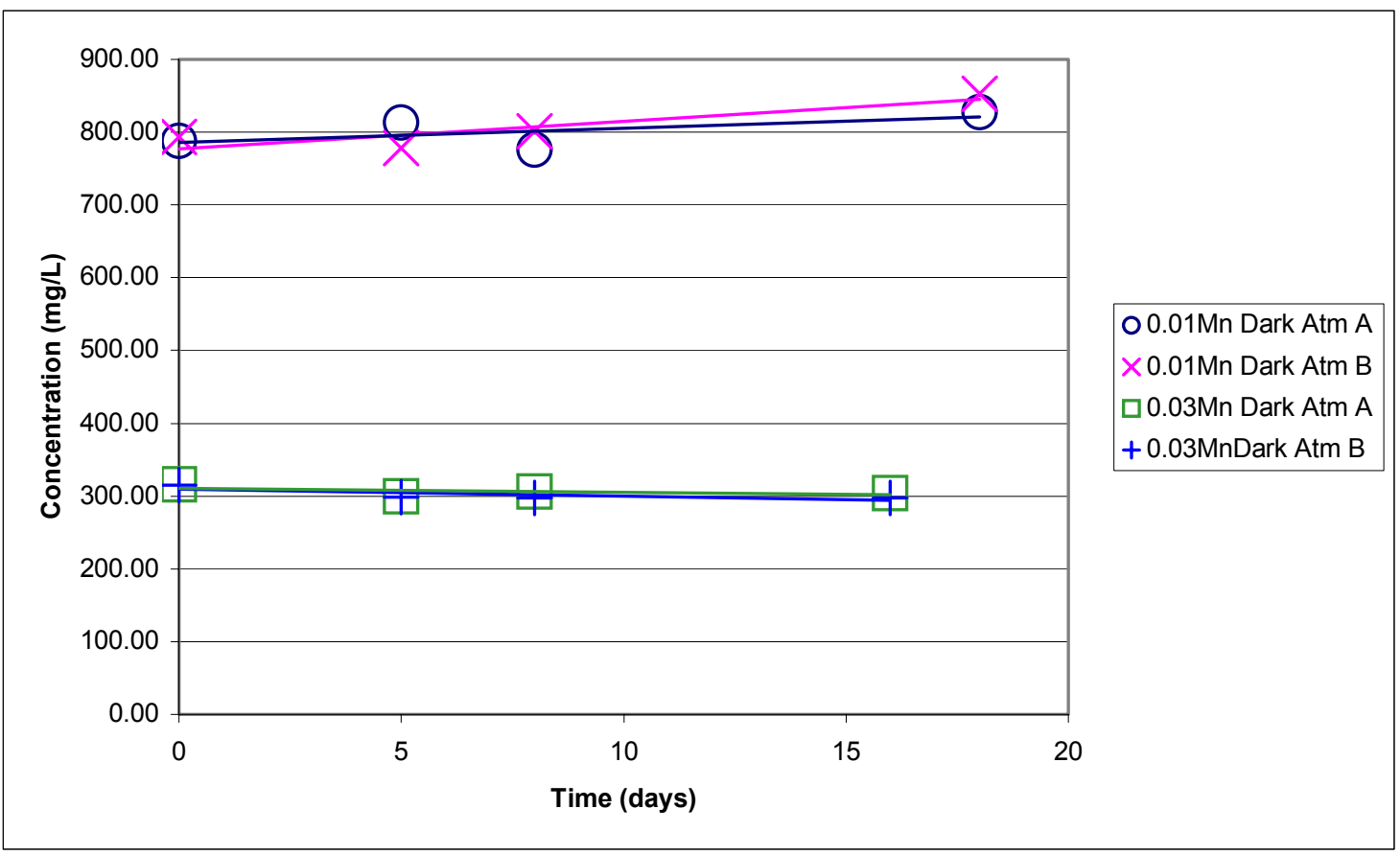

Figure 4.4.2.7 Iron Concentration in 0-16 Day Filtrates for Manganese, Dark, and Atmosphere

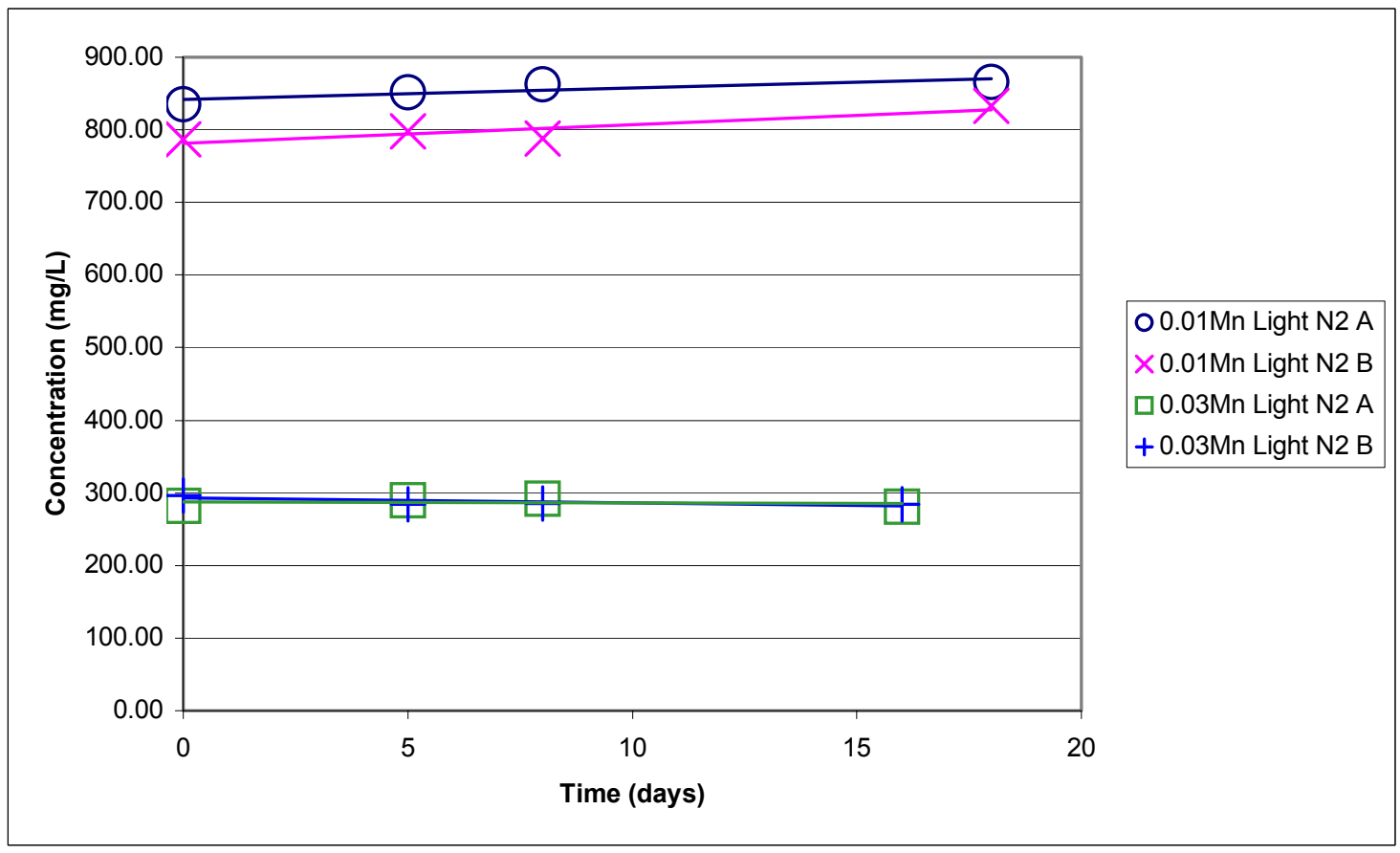

Figure 4.4.2.8 Iron Concentration in 0-16 Day Filtrates for Manganese, Light, and Nitrogen 
WSRC-TR-2003-00232, Rev. 0

SRT-RPP-2003-00105, Rev. 0

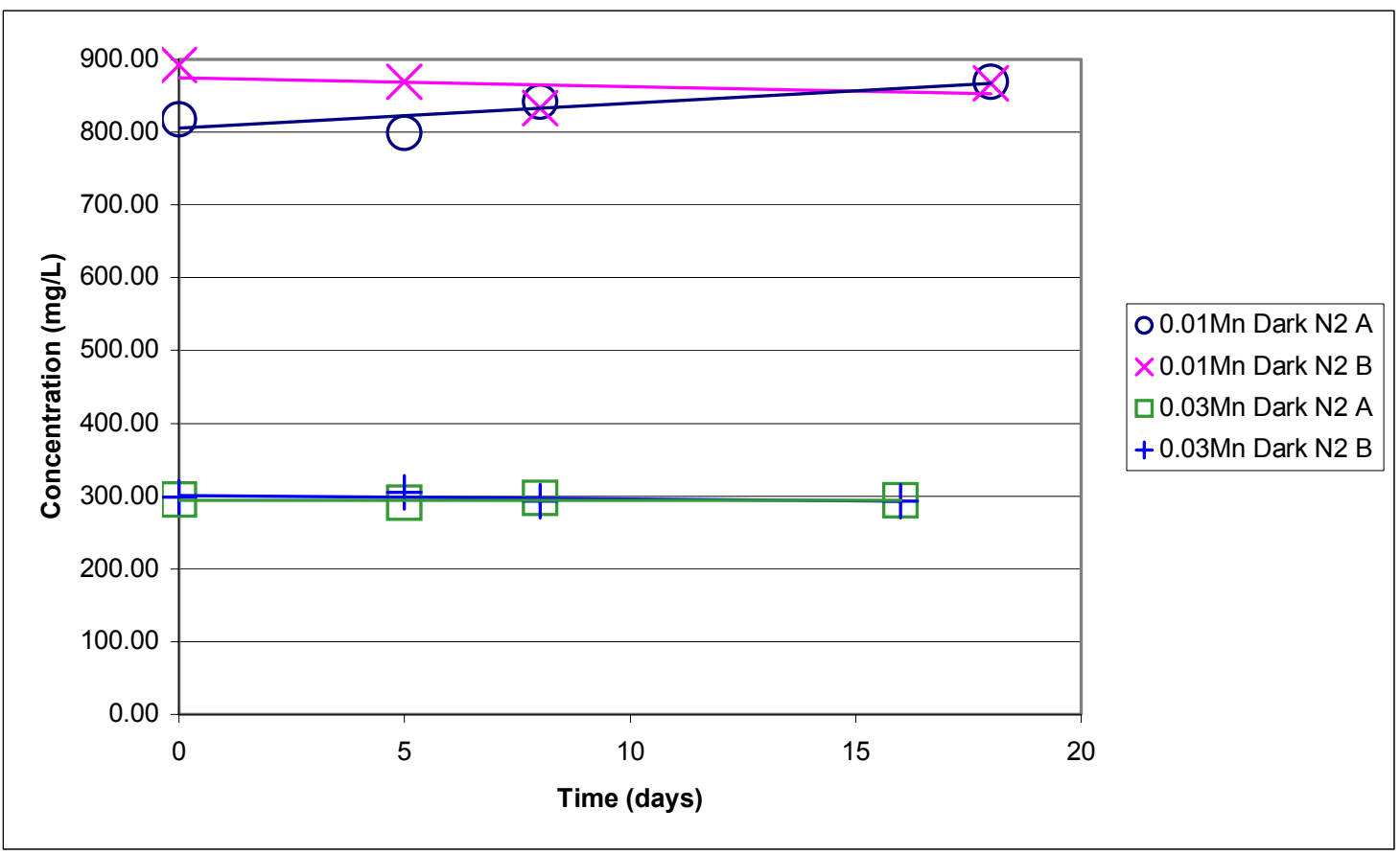

Figure 4.4.2.9 Iron Concentration in 0-16 Day Filtrates for Manganese, Dark, and Nitrogen

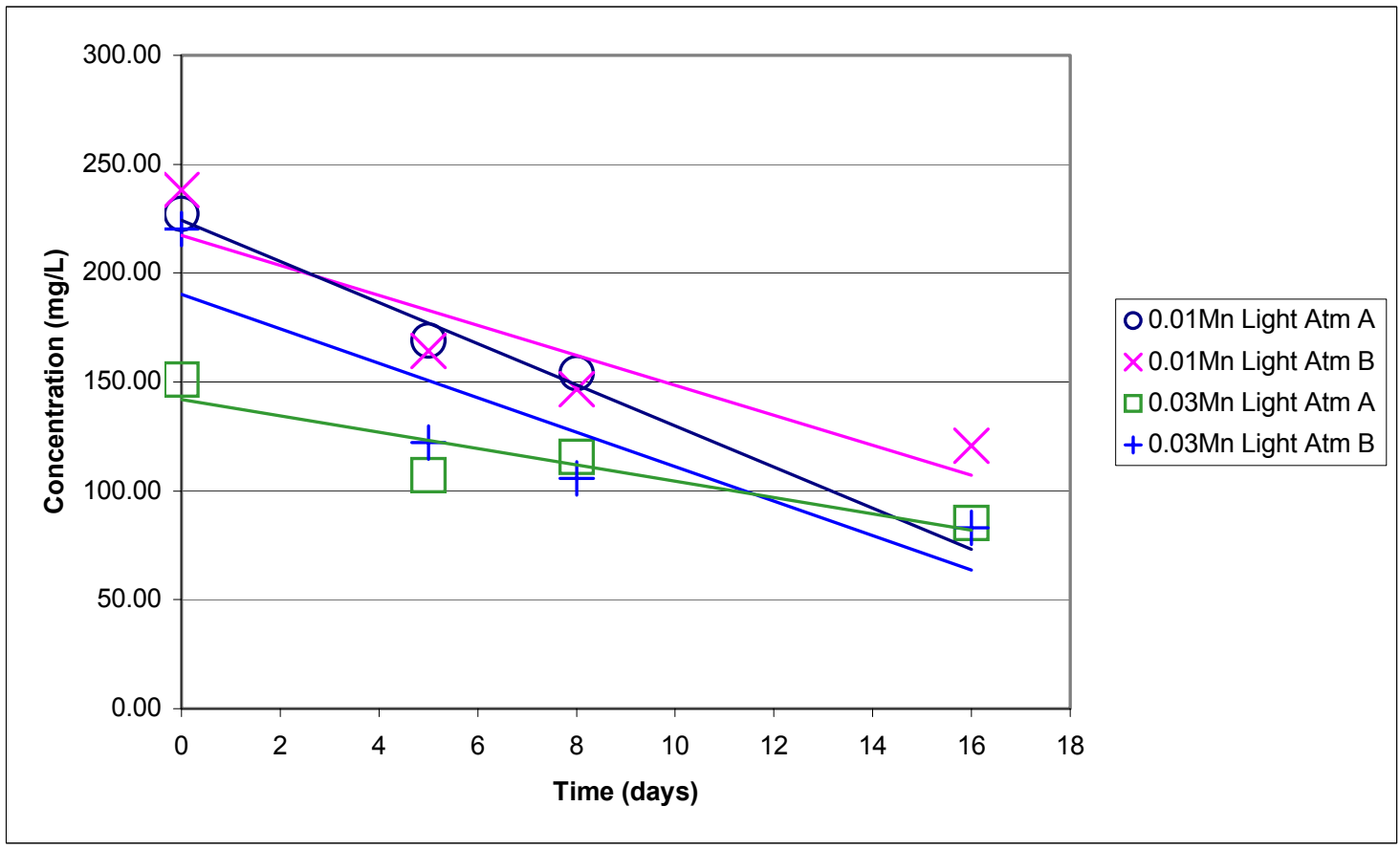

Figure 4.4.2.10 Strontium Concentration in 0-16 Day Filtrates for Manganese, Light, and Atmosphere 
WSRC-TR-2003-00232, Rev. 0

SRT-RPP-2003-00105, Rev. 0

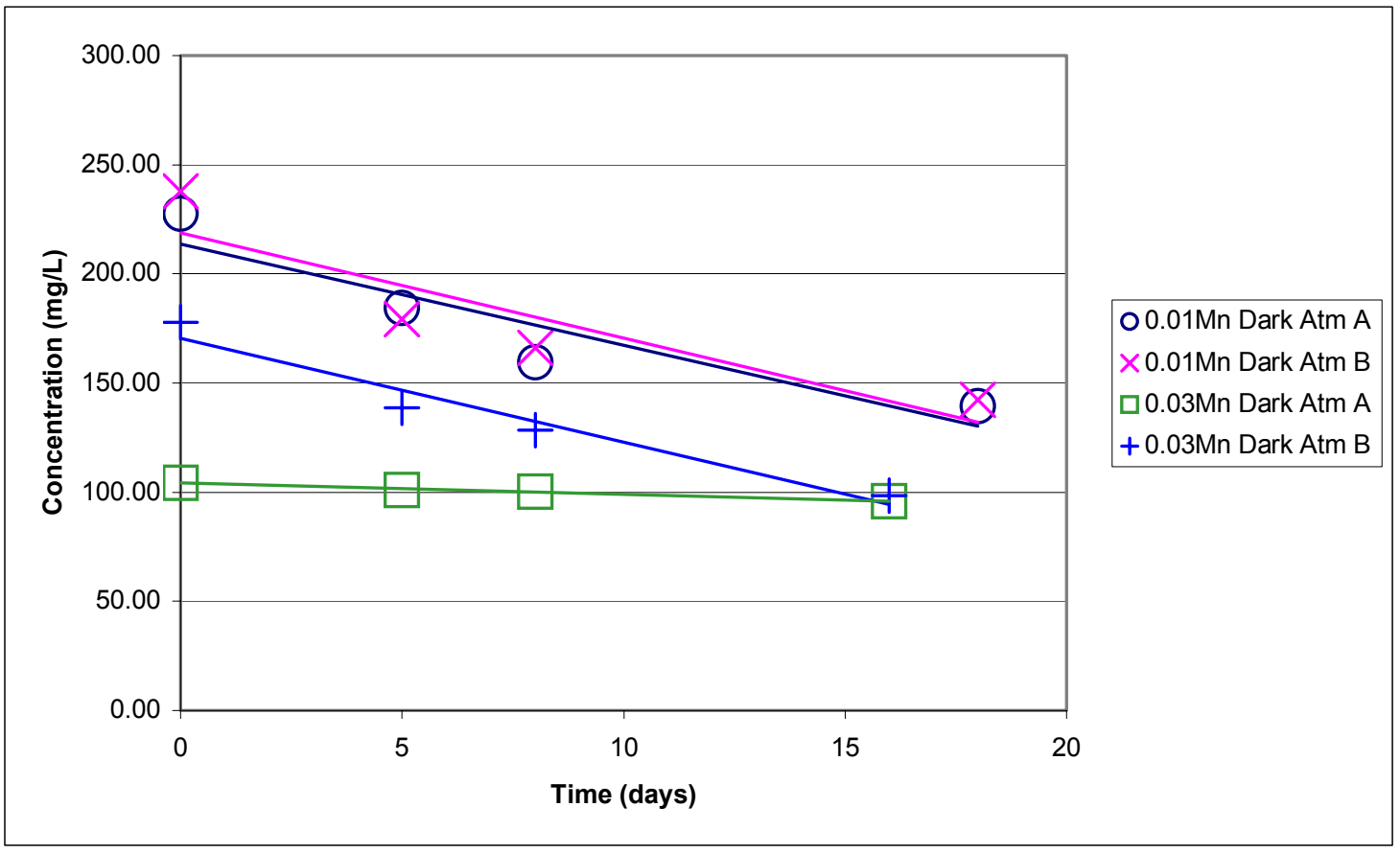

Figure 4.4.2.11 Strontium Concentration in 0-16 Day Filtrates for Manganese, Dark, and Atmosphere

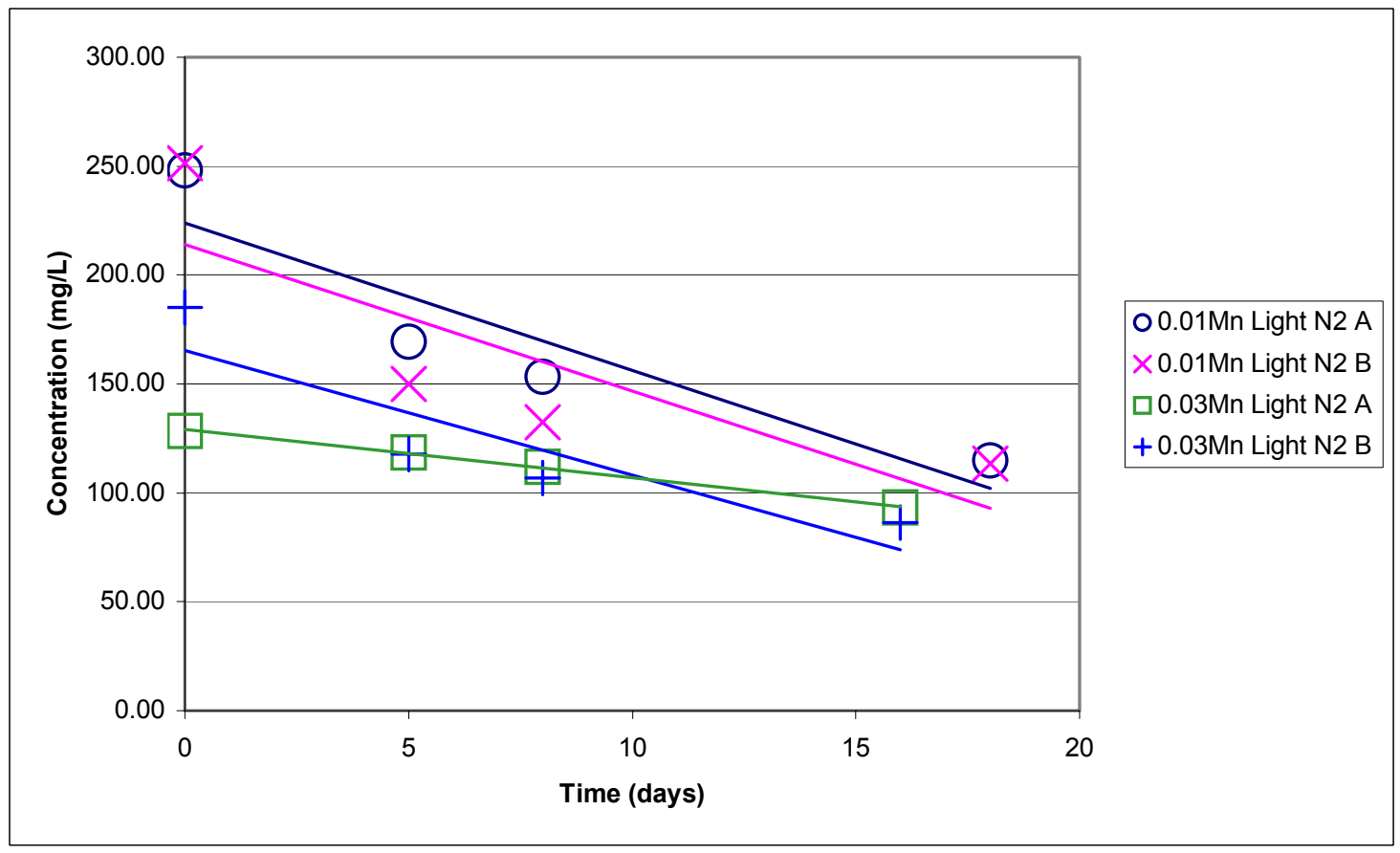

Figure 4.4.2.12 Strontium Concentration in 0-16 Day Filtrates for Manganese, Light, and Nitrogen 
WSRC-TR-2003-00232, Rev. 0

SRT-RPP-2003-00105, Rev. 0

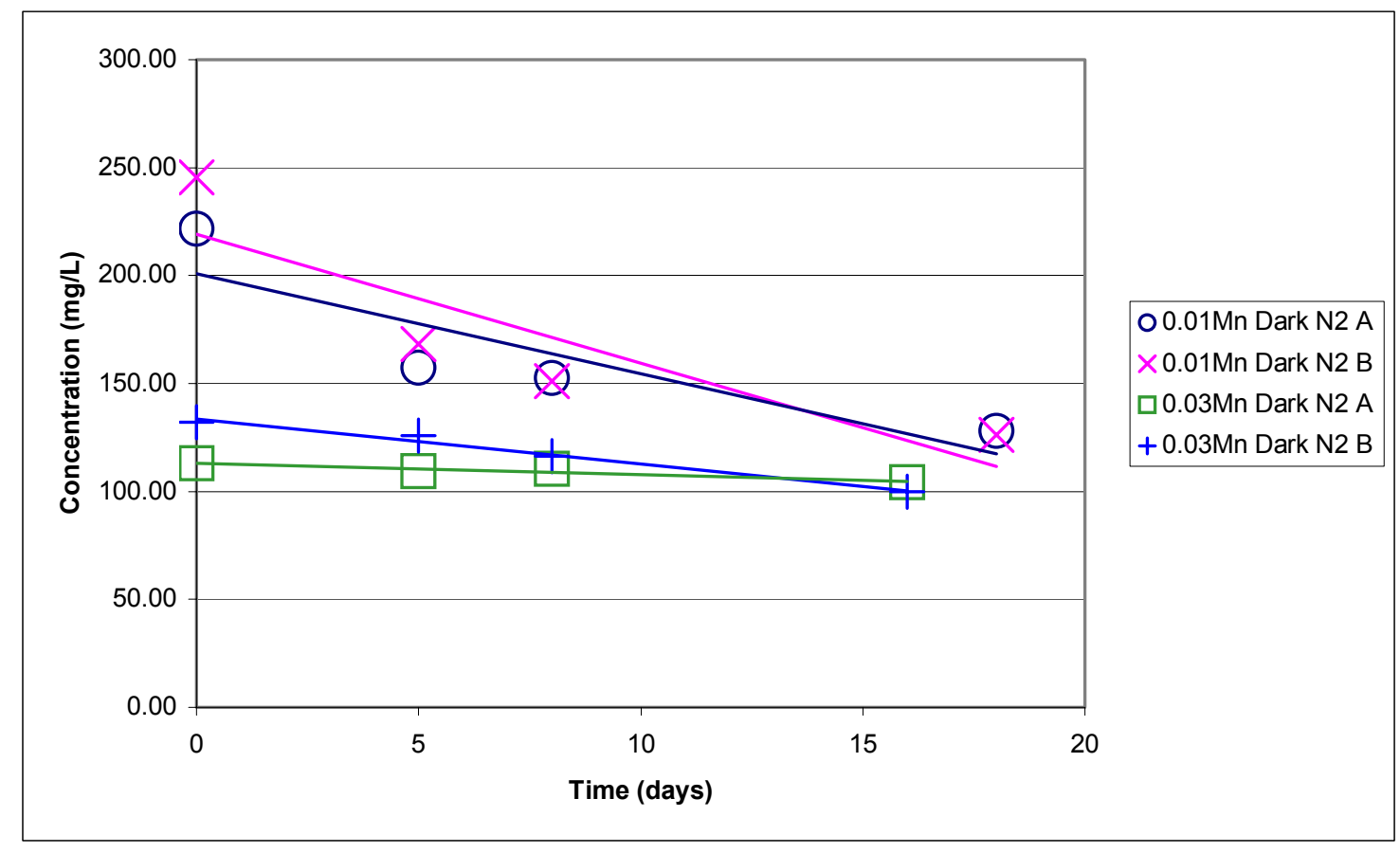

Figure 4.4.2.13 Strontium Concentration in 0-16 Day Filtrates for Manganese, Dark, and Nitrogen

This discrepancy may be explained by an examination of the error structure for the ICP-AES analysis presented in Table E.1 through E.7. Tables 4.4.2.3 and 4.4.2.4 include a summary of standard deviation and the range for filtrate analyses conducted during the 16-day period and predicted mass of manganese on filters. As can be seen, the standard deviation of the manganese ICP-AES analyses for the $0.03 \mathrm{M}$ sodium permanganate experiments ranged from 0.46 to $7.44 \mathrm{mg} / \mathrm{L}$, and for the $0.01 \mathrm{M}$ experiments the standard deviation ranged from 4.31 to $14.65 \mathrm{mg} / \mathrm{L}$. Standard errors of this magnitude translate into a range for the mass of manganese collected on filters of 0.046 to $1.47 \mathrm{mg}$. A similar analysis of the data presented in Table 4.4.2.4 representing the range or spread of the manganese concentration measured in the filtrates translates into a mass of manganese collected on filters of 0.1 to $3.6 \mathrm{mg}$. From these data it is conceivable that within the bound of error for the ICP-AES measurements, solids could be collected on filters without being indicated by the change in concentration of manganese with time in the filtrates. To determine if this mass of manganese solids collected on the $47 \mathrm{~mm}$ filters used in the study appeared visibly similar to the masses of dark solids noted in Figures 4.4.2.1, suspensions of manganese (III) oxy-hydroxide were prepared such that upon filtering, $0.4,1.0$ and $3.0 \mathrm{mg}$ of manganese would be deposited on the filters. This would result in a mass of manganese (III) oxy-hydroxide of $0.64,1.6$, and $4.8 \mathrm{mg}$ respectively. A digital photograph of these filters is shown in Figure 4.4.2.14, which also includes a precipitate mass of manganese (IV) dioxide. As can be seen, the visual appearance of solids is similar to solids collected from the filtrates for the secondary effects study and shown in Figure 4.4.2.1. 
WSRC-TR-2003-00232, Rev. 0

SRT-RPP-2003-00105, Rev. 0

Table 4.4.2.3 Error Estimate of ICP-AES Analysis for Manganese Measured in the Secondary Effects Filtrate

\begin{tabular}{|l|c|c|c|c|}
\hline & $\begin{array}{c}\mathbf{0 . 0 3} \mathbf{M} \text { Mn } \\
\text { SD (mg/L) }\end{array}$ & $\begin{array}{c}\text { Mass on } \\
\text { Filter } \\
(\mathbf{m g})\end{array}$ & $\begin{array}{c}\mathbf{0 . 0 1} \mathbf{M} \text { Mn } \\
\text { SD (mg/L) }\end{array}$ & $\begin{array}{c}\text { Mass on } \\
\text { Filter } \\
(\mathbf{m g})\end{array}$ \\
\hline DK N $_{\mathbf{2}}$ & $0.46(\mathrm{NS})$ & 0.046 & $6.31(\mathrm{NS})$ & 0.63 \\
\hline & $0.70(\mathrm{NS})$ & 0.070 & $14.65(\mathrm{NS})$ & 1.47 \\
\hline & & & & \\
\hline LT N $_{\mathbf{2}}$ & $3.28(\mathrm{NS})$ & 0.33 & $6.0(\mathrm{DS})$ & 0.60 \\
\hline & $4.36(\mathrm{NS})$ & 0.44 & $7.17(\mathrm{DS})$ & 0.72 \\
\hline & & & & \\
\hline DK ATM & $0.91(\mathrm{DS})$ & 0.09 & $9.82(\mathrm{DS})$ & 0.98 \\
\hline & $2.52(\mathrm{DS})$ & 0.25 & $13.97(\mathrm{DS})$ & 1.40 \\
\hline LT ATM & & & & \\
\hline & $3.29(\mathrm{DS})$ & 0.34 & $4.31(\mathrm{DS})$ & 0.43 \\
\hline & $7.44(\mathrm{DS})$ & 0.74 & $7.47(\mathrm{DS})$ & 0.75 \\
\hline
\end{tabular}

NS $=$ No Dark Solids Present

DS $=$ Dark Solids Present

Table 4.4.2.4 Range of ICP-AES Analysis for Manganese Measured in the Secondary Effects Filtrate

\begin{tabular}{|l|c|c|c|c|}
\hline & $\begin{array}{c}\text { 0.03 M Mn } \\
\text { Range (mg/L) }\end{array}$ & $\begin{array}{c}\text { Mass on } \\
\text { Filter } \\
(\mathbf{m g})\end{array}$ & $\begin{array}{c}\text { 0.01 M Mn } \\
\text { Range (mg/L) }\end{array}$ & $\begin{array}{c}\text { Mass on } \\
\text { Filter } \\
(\mathbf{m g})\end{array}$ \\
\hline DK N $_{\mathbf{2}}$ & $1.0(\mathrm{NS})$ & 0.10 & $36.0(\mathrm{NS})$ & 3.60 \\
\hline & $1.5(\mathrm{NS})$ & 1.15 & $15.8(\mathrm{NS})$ & 1.58 \\
\hline LT N $_{\mathbf{2}}$ & & & & \\
\hline & $6.9(\mathrm{NS})$ & 0.69 & $19.0(\mathrm{DS})$ & 1.90 \\
\hline DK ATM & $10.6(\mathrm{NS})$ & 1.06 & $12.4(\mathrm{DS})$ & 1.24 \\
\hline & & & & \\
\hline & $2.1(\mathrm{DS})$ & 0.21 & $25.2(\mathrm{DS})$ & 2.52 \\
\hline LT ATM & $5.3(\mathrm{DS})$ & 0.53 & $30.6(\mathrm{DS})$ & 3.06 \\
\hline & & & & \\
\hline & $7.0(\mathrm{DS})$ & 0.70 & $8.20(\mathrm{DS})$ & 0.82 \\
\hline & $17.2(\mathrm{DS})$ & 1.72 & $18.8(\mathrm{DS})$ & 1.88 \\
\hline
\end{tabular}

NS $=$ No Dark Solids Present

DS $=$ Dark Solids Present 


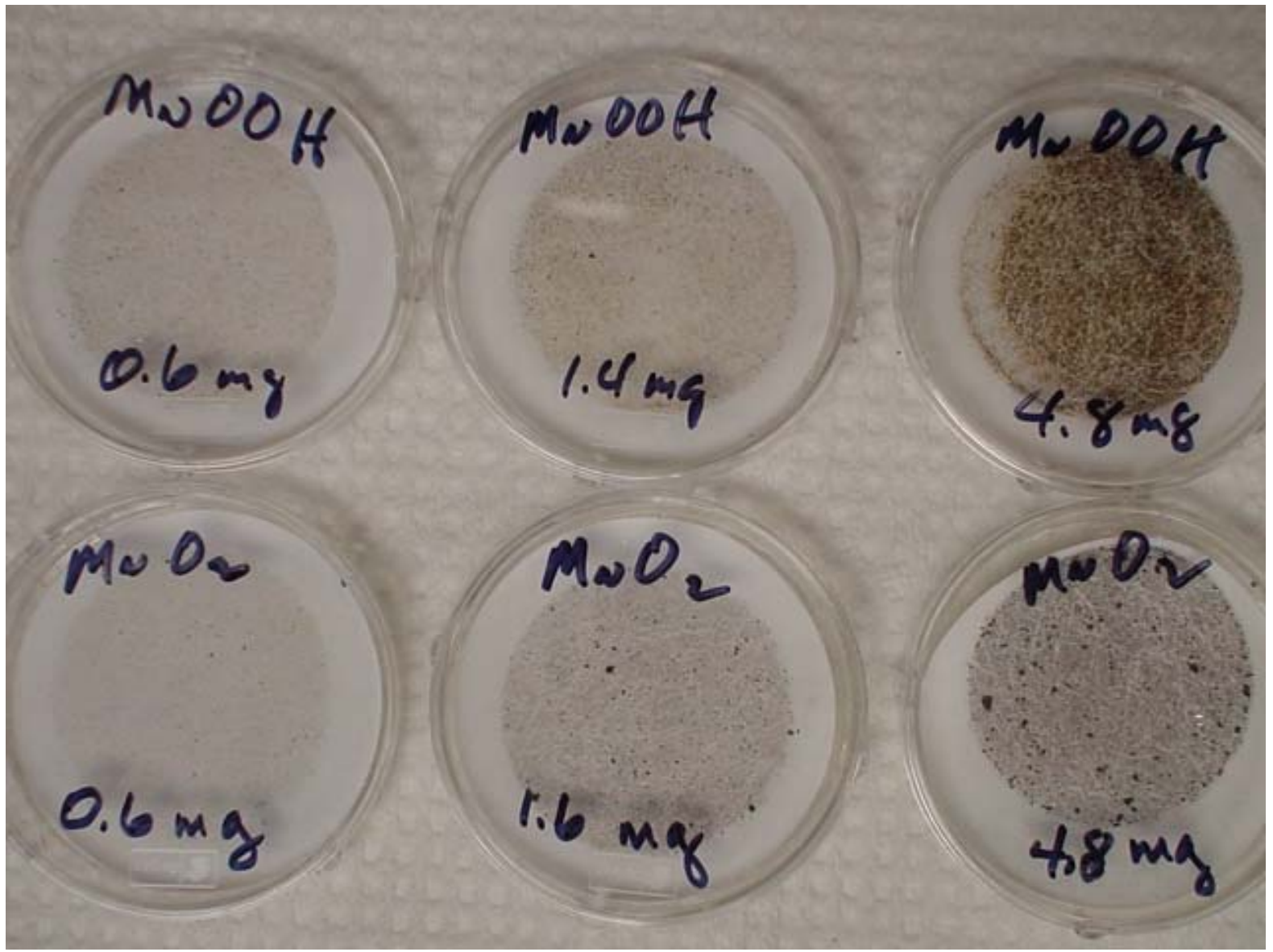

Figure 4.4.2.14 Manganese (III) Oxy-hydroxide and Manganese (IV) Dioxide on Filters

Data presented for iron plotted in Figures 4.4.2.6 through 4.4.2.9 also did not indicate the loss of iron from solution during the 16-day period. Since iron did not appear to be a major constituent in the precipitate mass collected and analyzed during the primary effects experiments (Table 4.4.1.3), the mass of iron possibly adsorbed onto the manganese solids would not be indicated from analysis of the 0-16 day filtrates.

Strontium data presented in Figures 4.4.2.10 through 4.4.2.13 indicate that strontium was lost from solution during the 16-day period for all treatment combinations. The initial strontium concentration at time zero for the $0.03 \mathrm{M}$ permanganate treatment appears to be lower than the concentration in the $0.01 \mathrm{M}$ permanganate reaction. Rate constants and half-lives describing the loss of strontium from the filtrates during the 16-day period are listed in Table 4.4.2.5. These constants were calculated from four data points and therefore should be considered as estimates. Although not significantly different, the half-lives calculated for filtrates maintained in the light ranged from 15.3 to 21.2 days $^{-1}$ while those maintained in the dark ranged from 22.4 to 60.3 days $^{-1}$. Post-filtration solids formation in the NOC $(0.03 \mathrm{M}$ $\mathrm{Mn}$, Dark, $\mathrm{N}_{2}$ ) is predicted to be much slower than the cross effect conditions reported. It should be noted that the total mass of solids formed during the 16-day period depends on the initial concentration of strontium in the filtrates. In general, the initial strontium concentrations in the filtrates were higher for the $0.01 \mathrm{M}$ permanganate reaction condition. 
WSRC-TR-2003-00232, Rev. 0

SRT-RPP-2003-00105, Rev. 0

Table 4.4.2.5 Calculated First Order Rate Constants for Loss of Strontium from AN-107 Secondary Effects Filtrates

\begin{tabular}{|l|r|r|r|r|r|r|r|}
\hline & \multicolumn{1}{|c|}{$\operatorname{Sim} \mathbf{7}$} & \multicolumn{1}{|c|}{$\mathbf{R}^{\mathbf{2}}$} & \multicolumn{1}{c|}{$\operatorname{Sim} \mathbf{8}$} & \multicolumn{1}{c|}{$\mathbf{R}^{\mathbf{2}}$} & \multicolumn{1}{c|}{ Combined } & $\mathbf{R}^{\mathbf{2}}$ & $\mathbf{t}_{\mathbf{1 / 2}}$ (Days) \\
\hline .01Mn Light Atm & 0.0498 & 0.9775 & 0.0350 & 0.8677 & 0.0369 & 0.8825 & 18.78 \\
\hline .03Mn Light Atm & 0.0330 & 0.8759 & 0.0576 & 0.8649 & 0.0453 & 0.7864 & 15.30 \\
\hline .01Mn Dark Atm & 0.0263 & 0.9003 & 0.0264 & 0.8706 & 0.0263 & 0.8827 & 26.36 \\
\hline .03Mn Dark Atm & 0.0052 & 0.9845 & 0.0359 & 0.9847 & 0.0206 & 0.3372 & 33.65 \\
\hline $.01 \mathrm{Mn}$ Light N2 & 0.0402 & 0.9230 & 0.0398 & 0.7697 & 0.0400 & 0.8290 & 17.33 \\
\hline .03Mn Light N2 & 0.0203 & 0.9917 & 0.0451 & 0.8815 & 0.0327 & 0.7716 & 21.20 \\
\hline .01Mn Dark N2 & 0.0276 & 0.8349 & 0.0341 & 0.8503 & 0.0309 & 0.8293 & 22.43 \\
\hline .03Mn Dark N2 & 0.0049 & 0.9012 & 0.0180 & 0.9803 & 0.0115 & 0.5932 & 60.27 \\
\hline
\end{tabular}

Characterization of Solids that Formed During the 16 Days

Solids collected from the filtrate samples at the end of the observation period were completely soluble in $20 \mathrm{~mL}$ of $0.5 \mathrm{M}$ nitric acid. ICP-AES analysis of the solutions is presented in Table 4.4.2.6 for $\mathrm{Mn}, \mathrm{Fe}, \mathrm{Sr}, \mathrm{Ce}, \mathrm{La}, \mathrm{Nd}$, and $\mathrm{Zr}$ and represents the percent of the initial cation concentration present in the precipitates collected from the 241-AN-107 secondary effects filtrates. A tabulation of the remaining metals is also presented in Appendix E, Table E.8.

Data presented in the table indicate that the compositions of solids precipitated from the filtrates were composed primarily of manganese and strontium with lesser amounts of iron included in the composition. Interestingly, though the samples reacted with $0.01 \mathrm{M}$ permanganate had higher time zero concentrations of manganese in the filtrate, larger percentages of manganese precipitated from the $0.03 \mathrm{M}$ permanganate reactions (light $/ \mathrm{N}_{2}$ and light/atm) compared to the $0.01 \mathrm{M}$ permanganate reaction condition. With exception of the $0.01 \mathrm{M}$ permanganate reaction maintained in the dark under an atmospheric blanket, the remaining filtrates maintained in the dark indicated that low percentages of the initial manganese were present in the post-filtration solids. The percent of iron in the initial filtrates found in the precipitated solids generally tracked the manganese results, suggesting coprecipitation of iron with the manganese precipitate.

With exception of the $0.03 \mathrm{M}$ permanganate reaction maintained in the dark, the percent of initial filtrate mass of strontium converted to a precipitate within the 16-day period ranged from 19 to 51\% (Table 4.4.2.6). The highest conversion was reported for the $0.01 \mathrm{M}$ permanganate reaction exposed to light, $44 \%$ for filtrates maintained in the atmosphere and $51 \%$ for filtrates maintained under a nitrogen blanket. It appears that light may play a more important role in the precipitation of strontium than exposure to the atmosphere. 
WSRC-TR-2003-00232, Rev. 0

SRT-RPP-2003-00105, Rev. 0

Table 4.4.2.6 Percent of the Initial Cation Concentration Present in the Precipitates Collected from the 241-AN-107 Secondary Effects Filtrates

\begin{tabular}{|c|c|c|c|c|c|c|c|c|}
\hline & $0.03 \mathrm{MMn}$ & $0.03 \mathrm{MMn}$ & $0.03 \mathrm{M} \mathrm{Mn}$ & $0.03 \mathrm{MMn}$ & $0.01 \mathrm{M} \mathrm{Mn}$ & $0.01 \mathrm{M} \mathrm{Mn}$ & $0.01 \mathrm{MMn}$ & $0.01 \mathrm{M} \mathrm{Mn}$ \\
\hline Element & SIM7-DkN2 & SIM7-LtN2 & SIM7-DkAtm & SIM7-LtAtm & SIM7-LtN2 & SIM7-DkAtm & SIM7-LtAtm & SIM7-Dk2N2 \\
\hline & & & & & & & & \\
\hline Mn & 0.04 & 7.58 & 0.01 & 10.01 & 1.61 & 1.84 & 5.57 & 0.13 \\
\hline $\mathrm{Fe}$ & 0.02 & 0.52 & 0.02 & 0.75 & 0.22 & 0.79 & 2.67 & 0.04 \\
\hline $\mathrm{Sr}$ & 2.46 & 19.28 & 0.67 & 32.51 & 50.87 & 33.71 & 43.63 & 22.89 \\
\hline La & 0.36 & 3.86 & $\mathrm{ND}$ & 7.12 & 6.34 & 5.43 & 8.49 & 2.79 \\
\hline $\mathrm{Ce}$ & 0.06 & 2.50 & $\mathrm{ND}$ & 3.78 & 2.53 & 1.81 & 4.52 & 0.65 \\
\hline Nd & 0.03 & 0.94 & $\mathrm{ND}$ & 1.71 & 1.06 & 1.61 & 2.85 & 0.50 \\
\hline Zr & 0.11 & 0.19 & 0.08 & 0.21 & 0.15 & 0.46 & 1.12 & 0.11 \\
\hline
\end{tabular}

\subsection{RESULTS OF THE 241-AN-102 EXPERIMENTS}

\subsubsection{Primary Effects Study}

\section{$\underline{\text { Visual Observations }}$}

Variables investigated for the 241-AN-102 primary effects study are listed in Table 4.5.1.1 with notation indicating the time at which visible solids appeared in the respective filtrates during the 16-day observation period. At the end of the 16-day period, filtrates were filtered under a nitrogen blanket to gravimetrically determine the mass of solids formed and the color and texture of the solids. The presence of brown to black solids on the filters is also indicated in the table.

Several observations warrant discussion. First, white or very light brown solids appeared in all filtrates during the 16-day period. These solids appeared within 1 day in all treatment conditions except the $0.0 \mathrm{M}$ added $\mathrm{NaOH}$, and light solids appeared in this filtrate at day 4 . Light colored solids appeared in the filtrates from the newly optimized conditions and the associated treatment variables at later times. Namely, they appeared in the NOC at 6 to 8 days, and in the NOC-0.01 M permanganate, NOC-light and $\mathrm{NOC}-\mathrm{O}_{2}$ at day 6, 10 and 13, respectively. Secondly, dark solids were visible in many of the filtrates, namely the base case ' $\mathrm{B}$ ' replicate, 0.01 and $0.03 \mathrm{M}$ permanganate treatments, the $0.03 \mathrm{M}$ Sr treatment, the base case treatment stored in the light, the $8-\mathrm{hr}$ hold at $100{ }^{\circ} \mathrm{C}$ and the NOC treatment stored in the light. Observations for the 8 -hour hold at $100{ }^{\circ} \mathrm{C}$ samples indicating the presence of solids were made during the 8-hr period. The presence of brown to black solids on the filters correlates with the visual observations noted for all filtrates. Digital photographs of the filtrates and particular filters are included in Appendix F.

For all treatment conditions, white or clear solids on the bottom of the flasks were the first to appear. In some filtrates, these solids were then covered by a thin layer of light brown solids. Light solids that appeared on the surface generally became darker with time, presumably as they were oxidized. The presence of brown to black solids is indicated from visual observations of the filtrates, but should be evaluated from particulate data for better clarity. 
WSRC-TR-2003-00232, Rev. 0

SRT-RPP-2003-00105, Rev. 0

Table 4.5.1.1 Visual Observations for 241-AN-102 Post Filtration Precipitation Study

\begin{tabular}{|c|c|c|c|c|c|}
\hline $\begin{array}{c}\text { Sample } \\
\text { Condition }\end{array}$ & Filtrate Color & $\begin{array}{l}\text { Light solids } \\
\text { on bottom }\end{array}$ & $\begin{array}{c}\text { Light solids } \\
\text { on surface }\end{array}$ & $\begin{array}{l}\text { Dark solids } \\
\text { on surface }\end{array}$ & $\begin{array}{c}\text { Dark solids } \\
\text { on bottom }\end{array}$ \\
\hline Base Case & Yellow/olive oil & Day 1 & Day 8 & $\mathrm{X}$ & $\mathrm{X}$ \\
\hline Light & Yellow/lime green & Day 1 & $\bar{X}$ & Day 1 & $\mathrm{X}$ \\
\hline $\mathrm{O}_{2}$ Sparge & Yellow/orange & Day 1 & Day 8 & $\mathrm{X}$ & $\mathrm{X}$ \\
\hline $\begin{array}{c}0.0 \mathrm{M}^{\text {(added })} \\
\mathrm{OH}^{-}\end{array}$ & Yellow & Day 4 & $\mathrm{X}$ & $X$ & $\mathrm{X}$ \\
\hline $0.03 \mathrm{M} \mathrm{Sr}$ & Olive/lime green & Day 1 & Day 4 & $\sim$ Day 14 & $\mathrm{X}$ \\
\hline $\begin{array}{c}\text { Shear @ } \\
10,000 \mathrm{rpm}\end{array}$ & Yellow & Day 1 & Day 4 & $\mathrm{X}$ & $\mathrm{X}$ \\
\hline $8 \mathrm{hr} @ 100^{\circ} \mathrm{C}$ & Yellow & Hour 6 & $X$ & Hour 3 & Hour 6 \\
\hline $0.01 \mathrm{M} \mathrm{Mn}$ & Tea & Day 1 & Day 1 & $\sim$ Day 8 & $\mathrm{X}$ \\
\hline $0.03 \mathrm{M} \mathrm{Mn}$ & Lighter Tea & Day 1 & Day 1 & $\sim$ Day 12 & $\mathrm{X}$ \\
\hline Base Case & Yellow/olive oil & Day 1 & Day 2 & $\sim$ Day 12 & $\mathrm{X}$ \\
\hline $25^{\circ} \mathrm{Rxn}$ & Yellow/olive & Day 1 & Day 1 & $X$ & $\mathrm{X}$ \\
\hline NOC-BC (1) & Yellow/olive & Day 8 & & $\mathrm{X}$ & $\mathrm{X}$ \\
\hline NOC-.01M Mn & Brownish yellow & Day 6 & $\mathrm{X}$ & $\mathrm{X}$ & $\mathrm{X}$ \\
\hline NOC-BC (1) & Yellow & Day 6 & $X$ & $\mathrm{X}$ & $X$ \\
\hline NOC-O ${ }_{2}$ & Orangish yellow & $\begin{array}{c}\text { Day } 3(\mathrm{~B}) \\
13(\mathrm{~A})\end{array}$ & $X$ & $X$ & $\mathrm{X}$ \\
\hline NOC-Light & Greenish yellow & Day 10 & Day 2 & Day 10 & Day 10 \\
\hline
\end{tabular}

$\mathrm{X}$ denotes no solids present at Day 16

Light solids are white to light brown

Dark solids are dark brown to black

From the particulate data collected at the end of the 16-day period, all treatments indicated the presence of brown to black solids except the $0.0 \mathrm{M}$ added $\mathrm{NaOH}$ and the $25{ }^{\circ} \mathrm{C}$ reaction conditions compared to the base case scenario; and the NOC and NOC $0.01 \mathrm{M} \mathrm{Mn}$. It should also be noted that for both the AN-107 base case and NOC experiments that were reacted at $25{ }^{\circ} \mathrm{C}$ no brown to black solids formed during the 16-day period.

In summary, the data suggests that for the base case conditions, lowered reaction temperature and the absence of added $\mathrm{NaOH}$ do not result in the formation of dark solids within 16-days. Similarly, the variable evaluated for the newly optimized conditions that did not result in the formation of dark solids was the $0.01 \mathrm{M}$ permanganate treatment. The newly optimized conditions also did not result in the formation of dark solids.

Bulk $\mathrm{E}_{\mathrm{H}}$ was monitored during the 16 day period for the baseline and newly optimized conditions in addition to the respective oxygen purge treatments. These data are presented in Figures 4.5.1.1 and 4.5.1.2. Oxygen purge samples were sparged with oxygen for 15 minutes on day 0 , and the headspace was purged with oxygen for 15 minutes on days $1,2,4,8$, and 16, afterwards, samples were taken for ICP-AES analysis. As can be seen, the bulk $\mathrm{E}_{\mathrm{H}}$ of the 
WSRC-TR-2003-00232, Rev. 0

SRT-RPP-2003-00105, Rev. 0

solutions was not significantly altered by the oxygen purge. This is supported by the lack of dark solids formed in the NOC oxygen sample and by the presence of dark solids on the bottom of the baseline oxygen sample only after appearance of dark solids on the surface.

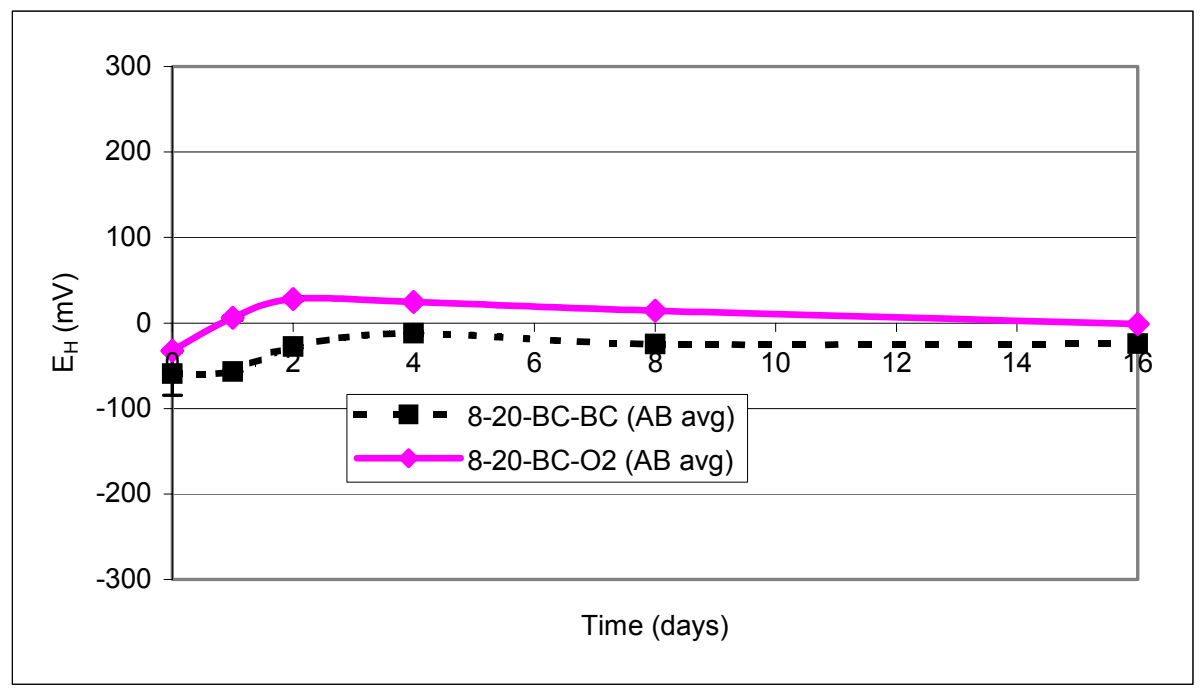

Figure 4.5.1.1 $\mathrm{E}_{\mathrm{H}}$ Measurements for the AN-102 Base Case and Oxygen Purge Filtrates

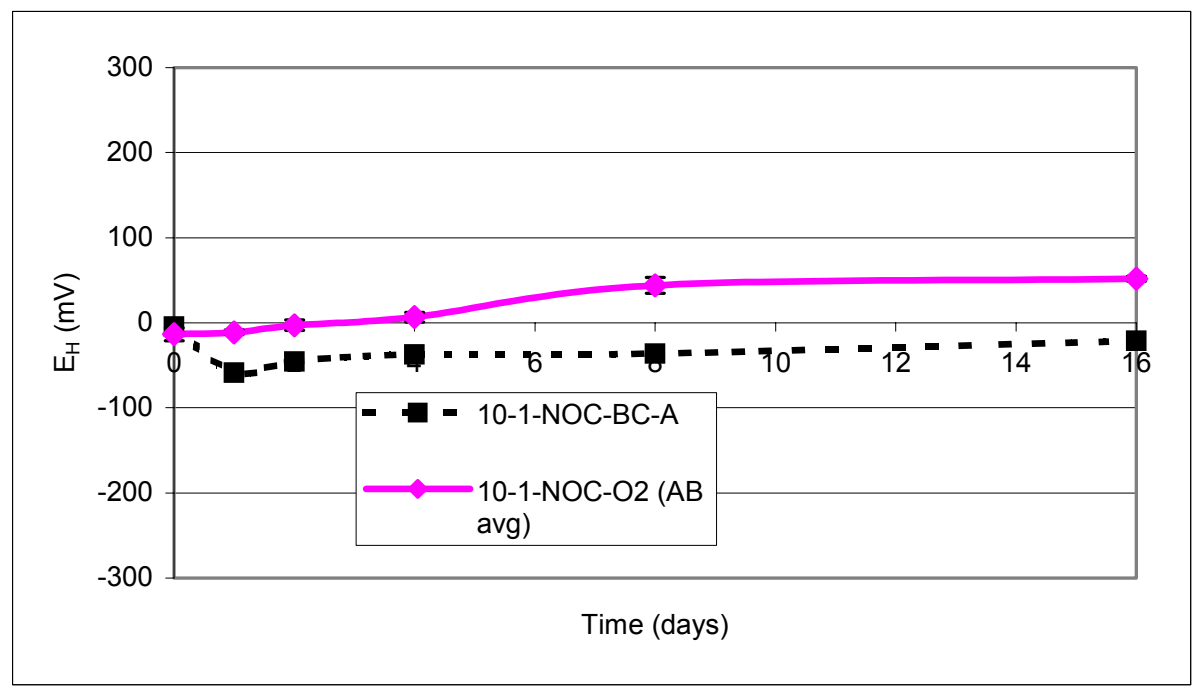

Figure 4.5.1.2 $\mathrm{E}_{\mathrm{H}}$ Measurements for the AN-102 NOC Base Case and Oxygen Purge Filtrates

Change in Metal Ion Concentration During the 16-Day Observation Period for AN-102

During the 16-day period, $10-\mathrm{mL}$ aliquots of the filtrates were collected and filtered at 0.1 $\mu \mathrm{m}$ at time zero; days $1,2,4,8$, and 16 . Aliquots collected at time zero, day 8 and day 16 were acidified to $\mathrm{pH} 1$ or below and analyzed by ICP-AES. A decrease in the concentration of cations present in the filtrates with time would suggest precipitation of solids containing 
WSRC-TR-2003-00232, Rev. 0

SRT-RPP-2003-00105, Rev. 0

the respective cation. These data are shown in Figures 4.5.1.3 through 4.5.1.8 for $\mathrm{Mn}, \mathrm{Fe}$, and $\mathrm{Sr}$ for each treatment condition included in the baseline primary effects study. Data plots for the treatments included in the primary effects study for the NOC are shown in Figures 4.5.1.9 through 4.5.1.14. The notation ' $\mathrm{A}$ ' and ' $\mathrm{B}$ ' indicates replicates of the treatment with simulant A and simulant B. The notation used for the AN-107 study was ' 7 ' and ' 8 ' indicating treatments with simulant 7 and 8. ICP-AES data for cerium, lanthanum, neodymium, and zirconium for each of the primary effects considered for the base case condition and the newly optimized condition are summarized in Table 4.5.1.2, which is discussed later.

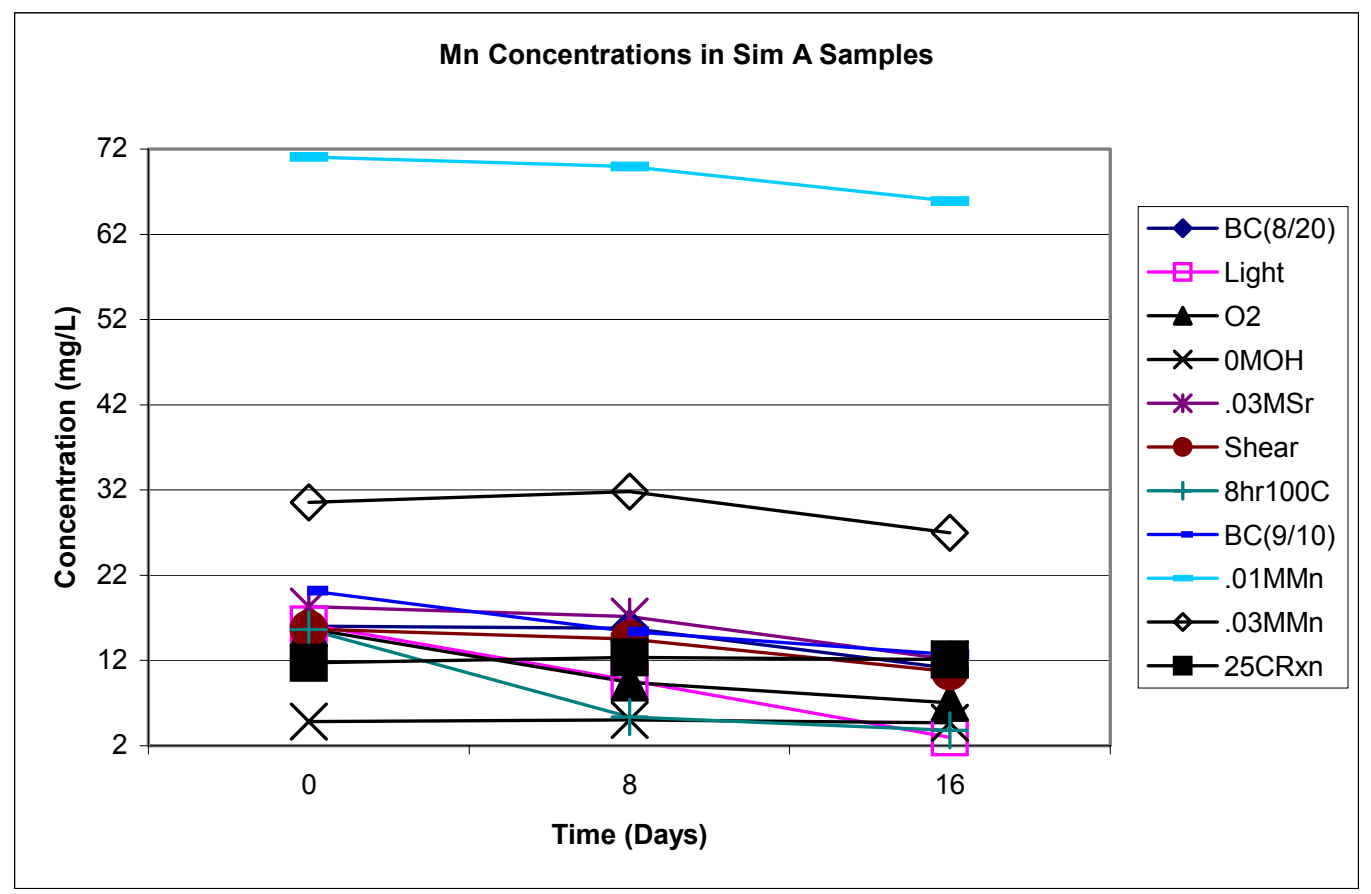

Figure 4.5.1.3a Manganese Concentration in Replicate A Filtrates for the AN-102 Baseline Primary Effects Study 
WSRC-TR-2003-00232, Rev. 0

SRT-RPP-2003-00105, Rev. 0

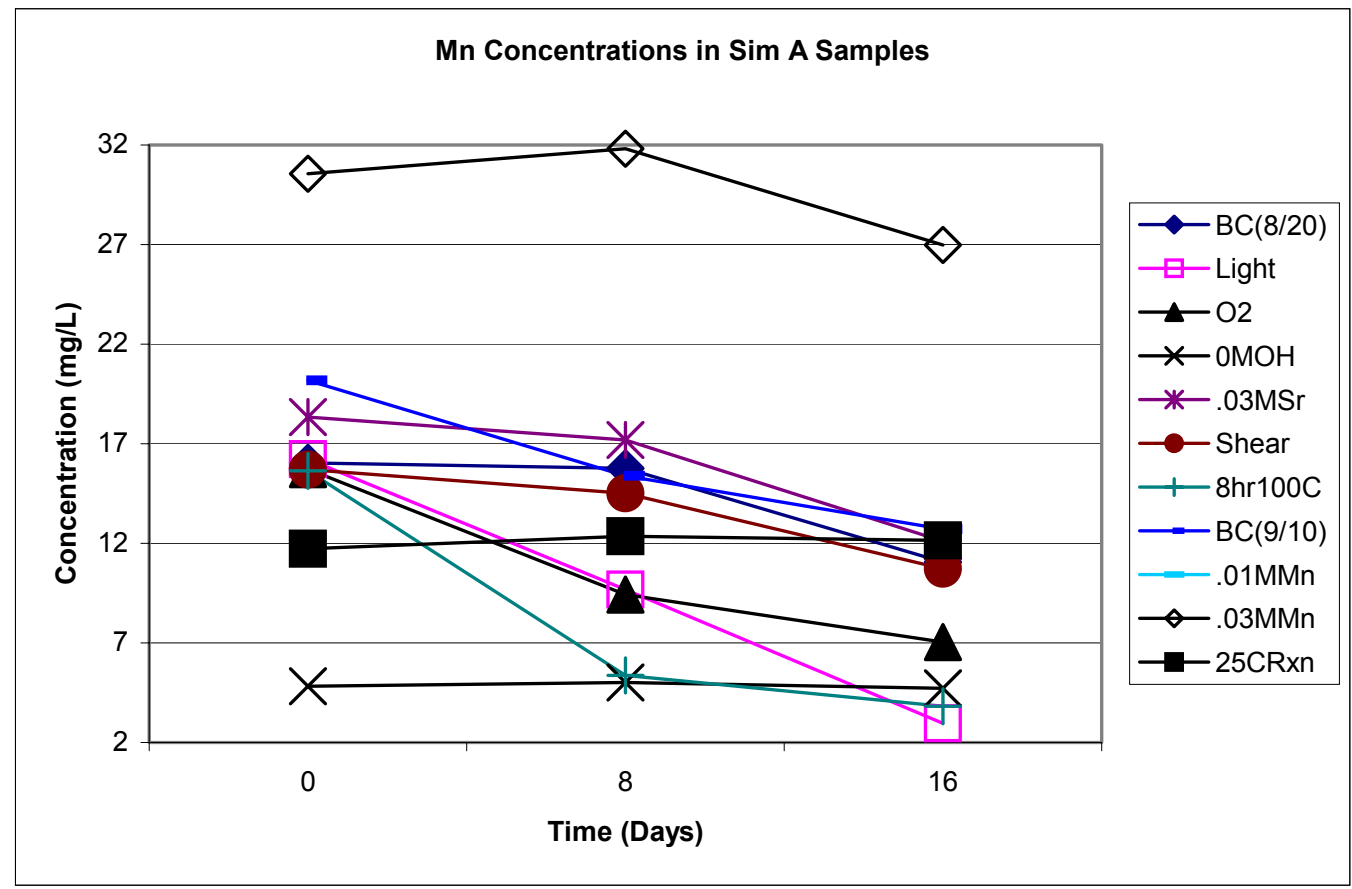

Figure 4.5.1.3b Manganese Concentration in Replicate A Filtrates for the AN-102 Baseline Primary Effects Study (Data Scaled for Clarity. 0.01 M Mn Condition not shown)

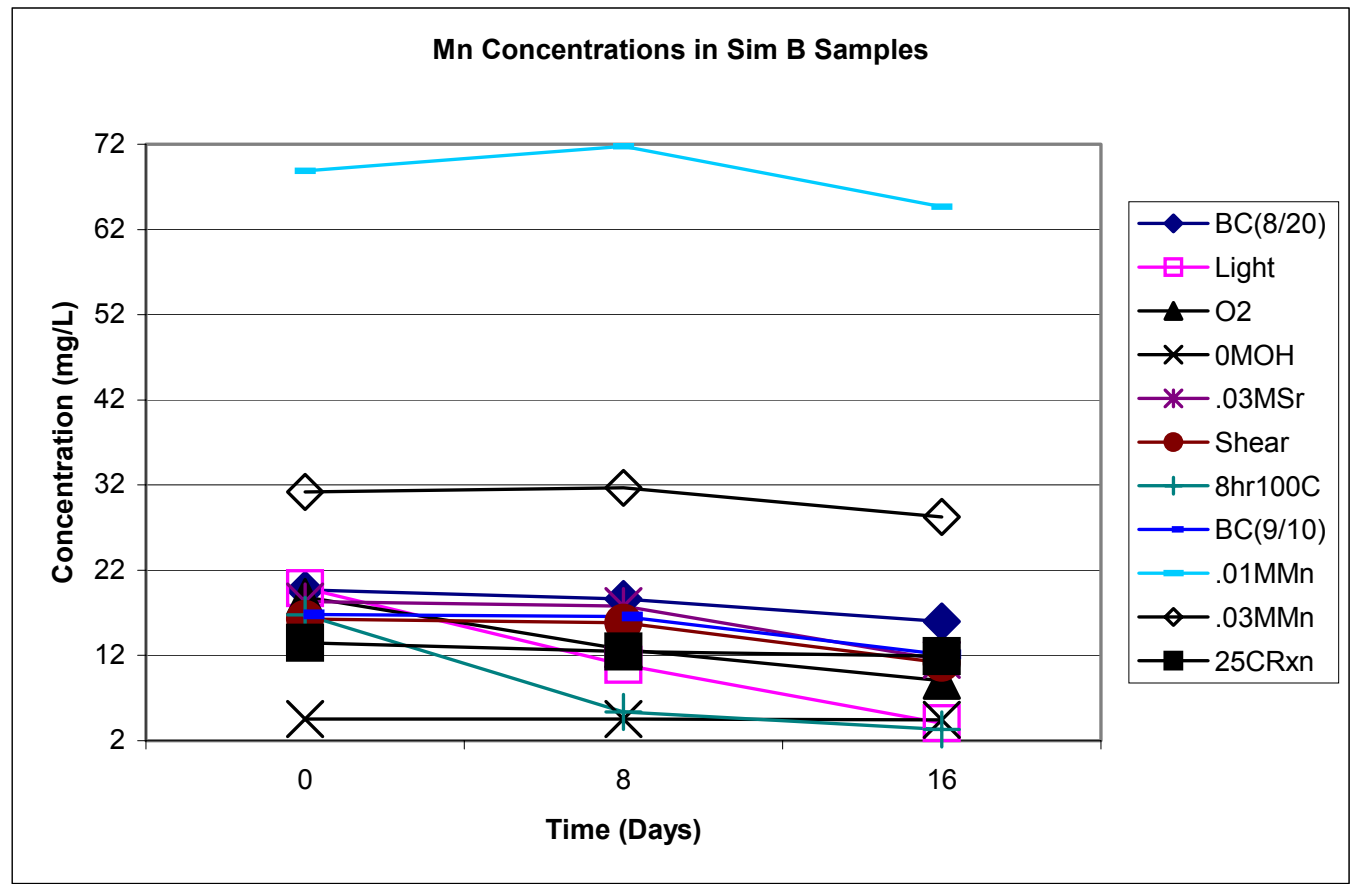

Figure 4.5.1.4a Manganese Concentration in Replicate B Filtrates for the AN-102 Baseline Primary Effects Study 
WSRC-TR-2003-00232, Rev. 0

SRT-RPP-2003-00105, Rev. 0

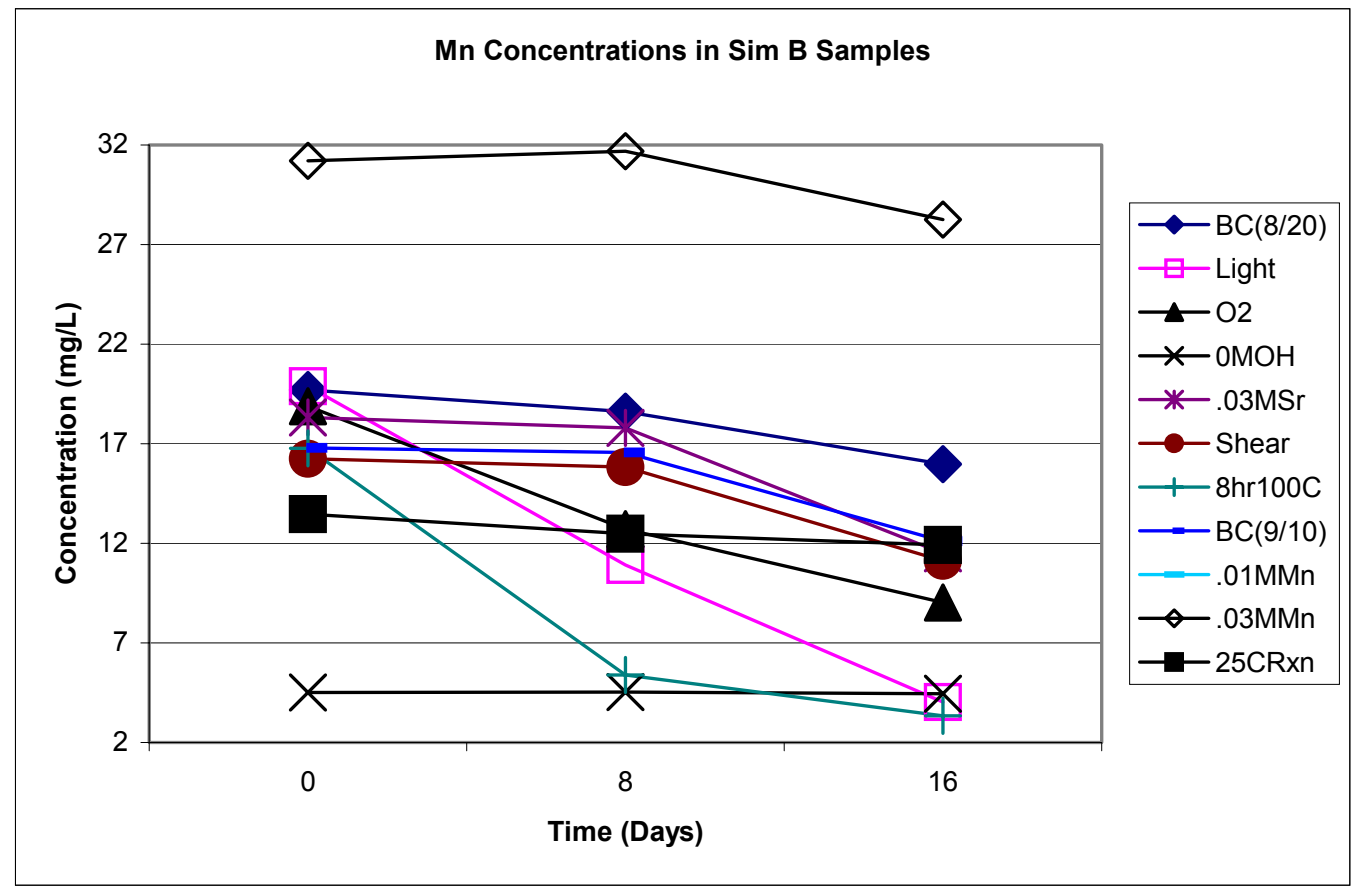

Figure 4.5.1.4b Manganese Concentration in Replicate B Filtrates for the AN-102 Baseline Primary Effects Study (Data Scaled for Clarity. 0.01 M Mn not shown)

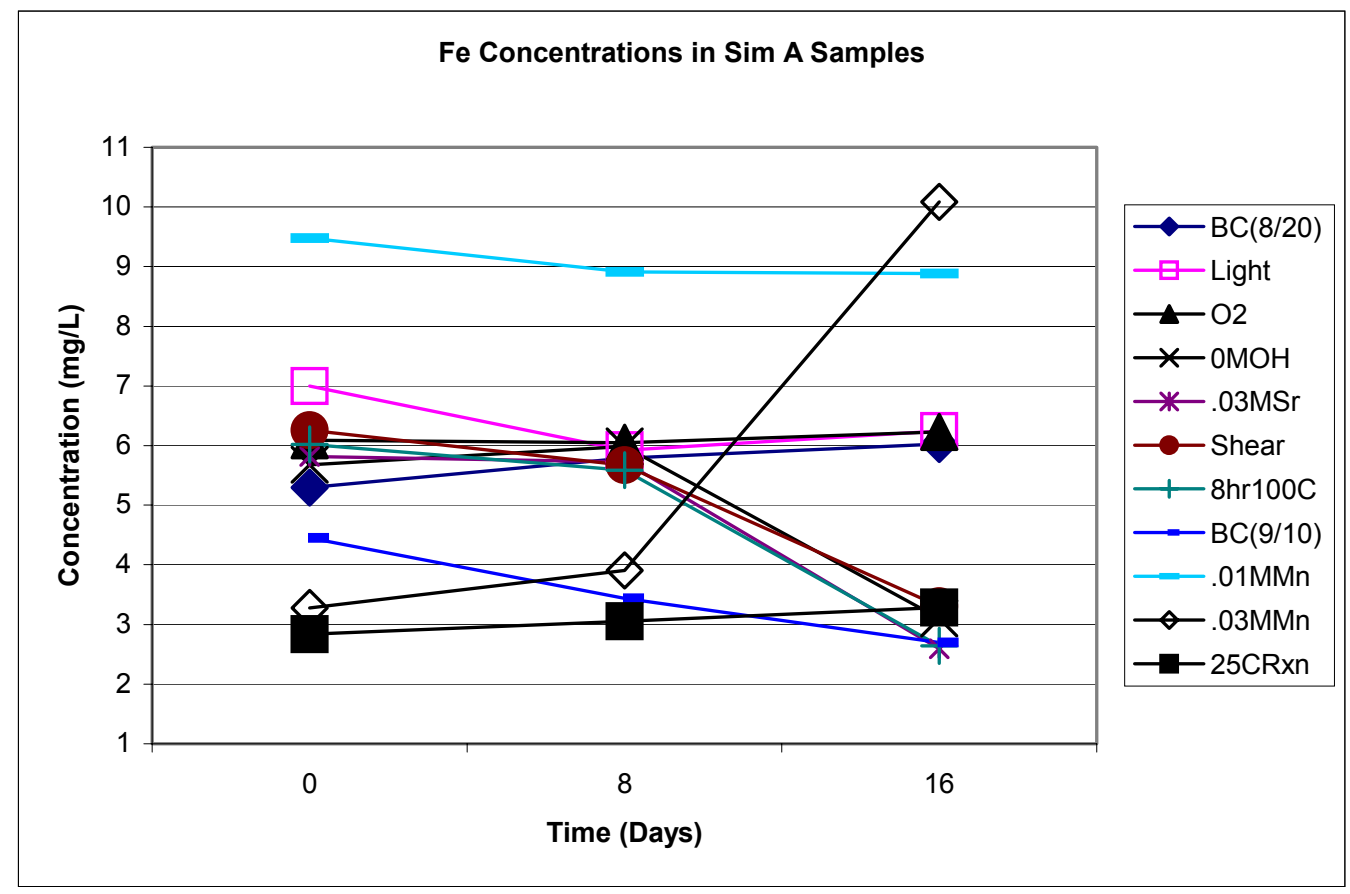

Figure 4.5.1.5 Iron Concentration in Replicate A Filtrates for the AN-102 Baseline Primary Effects Study 
WSRC-TR-2003-00232, Rev. 0

SRT-RPP-2003-00105, Rev. 0

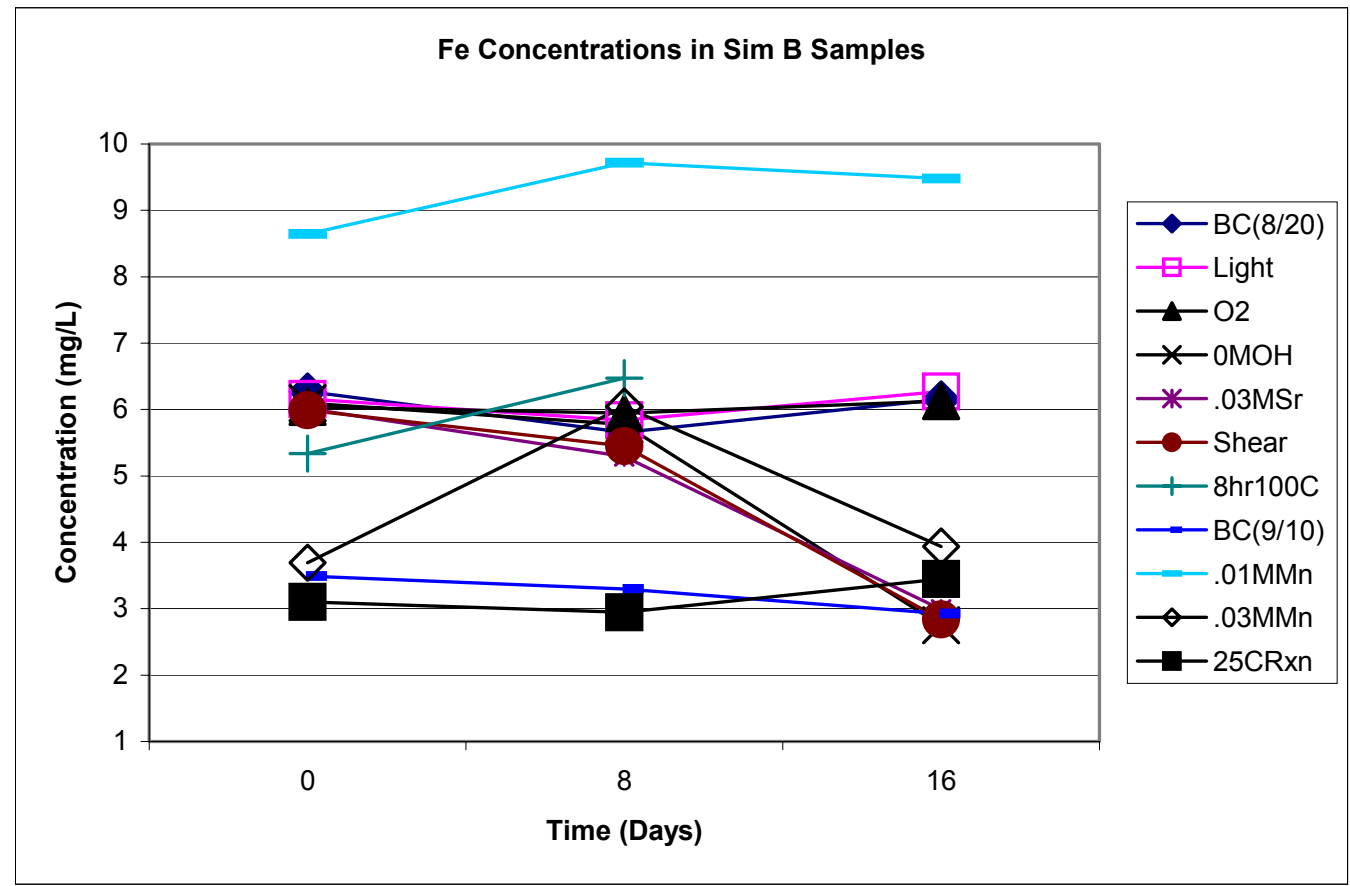

Figure 4.5.1.6 Iron Concentration in Replicate B Filtrates for the AN-102 Baseline Primary Effects Study

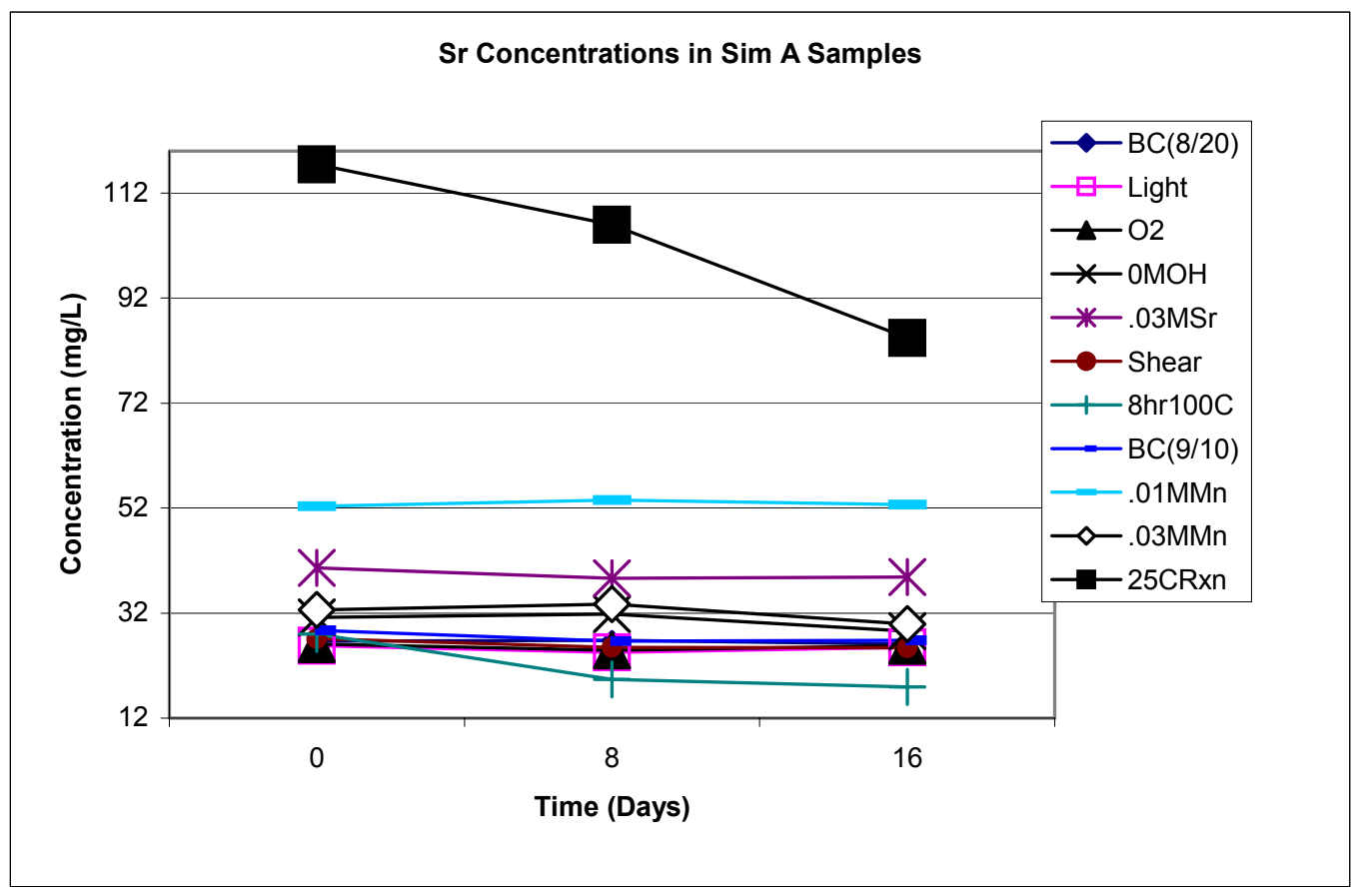

Figure 4.5.1.7a Strontium Concentration in Replicate A Filtrates for the AN-102 Baseline Primary Effects Study 
WSRC-TR-2003-00232, Rev. 0

SRT-RPP-2003-00105, Rev. 0

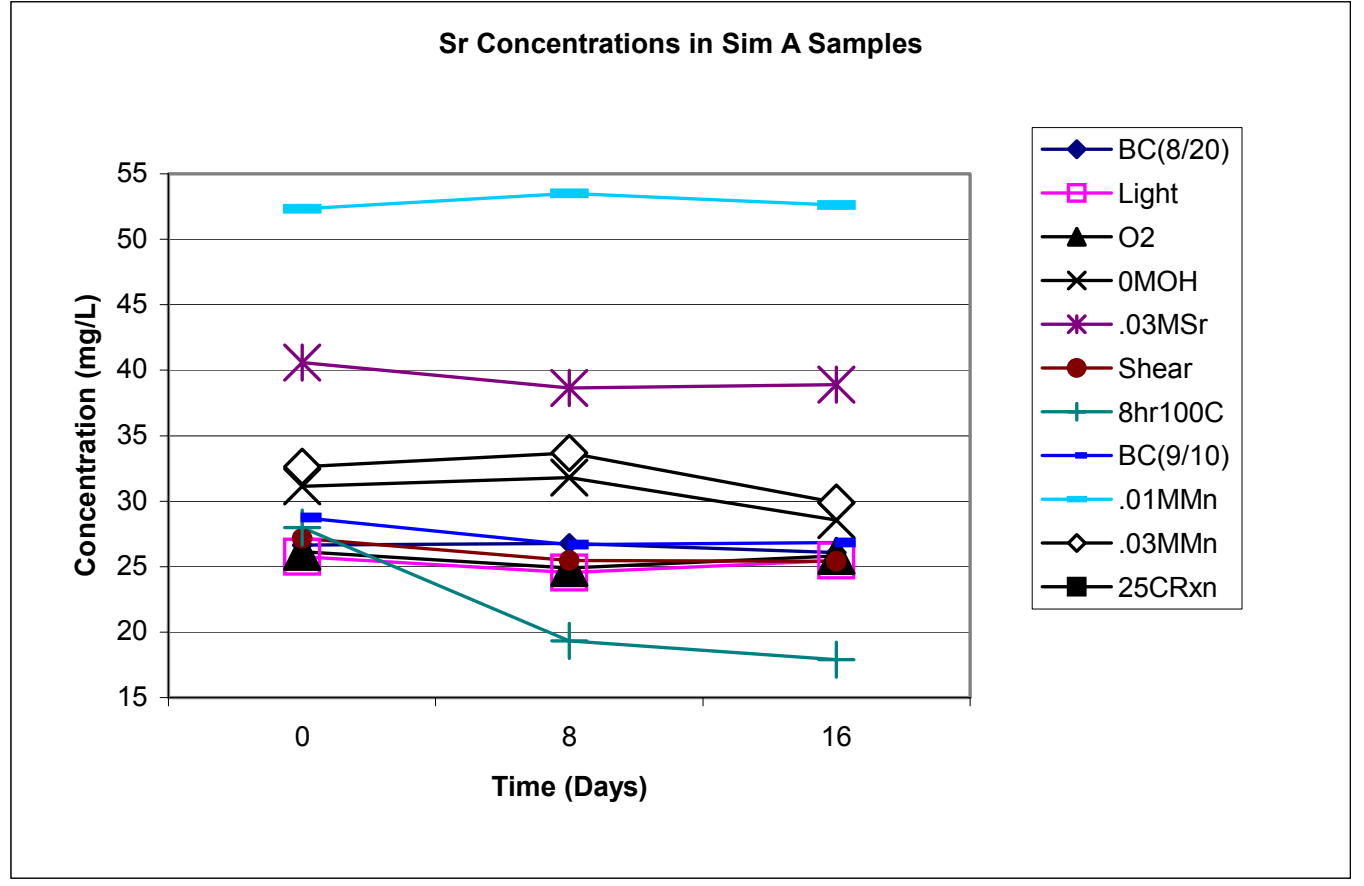

Figure 4.5.1.7b Strontium Concentration in Replicate A Filtrates for the AN-102 Baseline Primary Effects Study (Data Scaled for Clarity, $25^{\circ} \mathrm{C}$ Rxn Condition not shown)

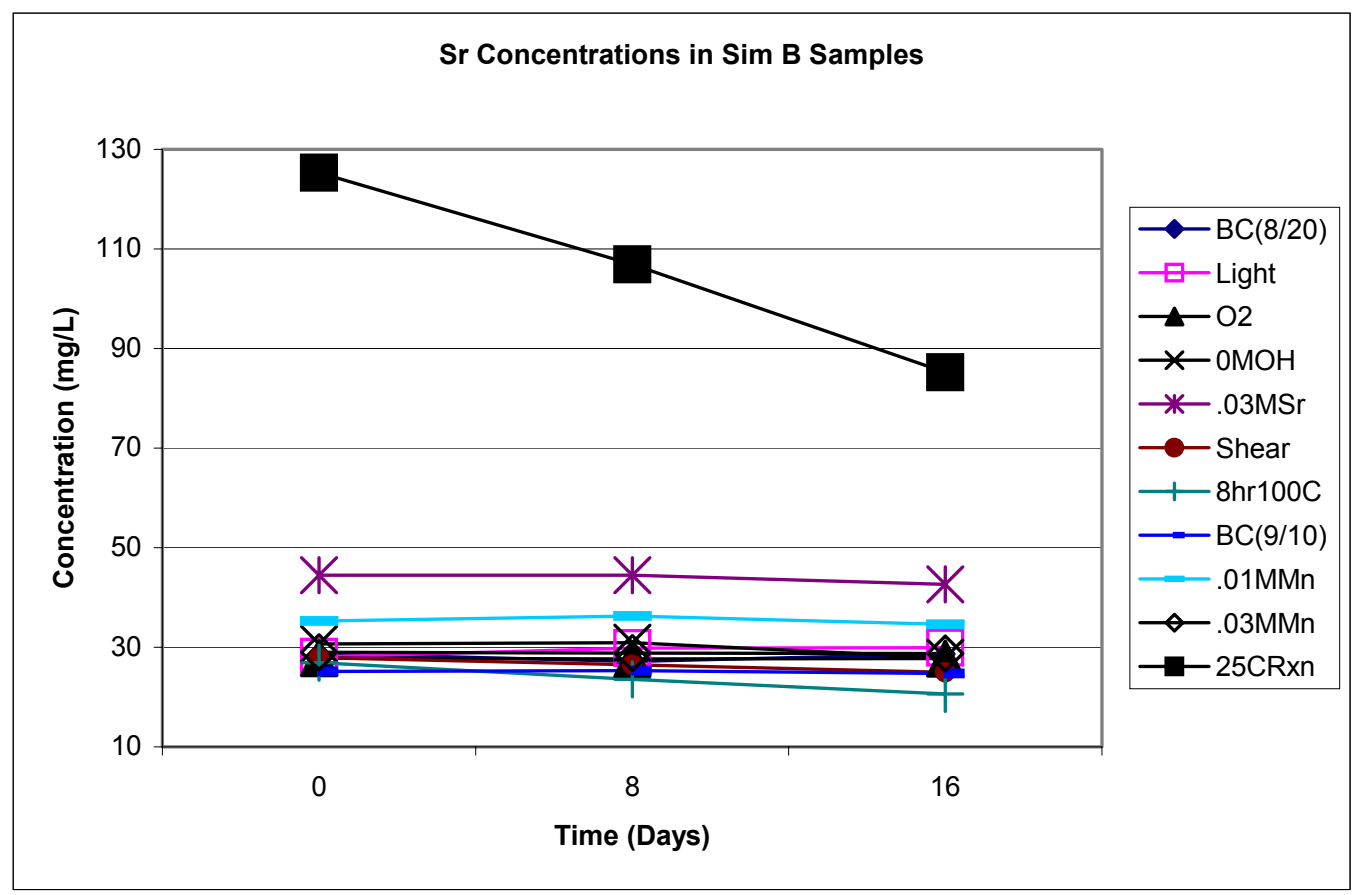

Figure 4.5.1.8a Strontium Concentration in Replicate B Filtrates for the AN-102 Baseline Primary Effects Study 
WSRC-TR-2003-00232, Rev. 0

SRT-RPP-2003-00105, Rev. 0

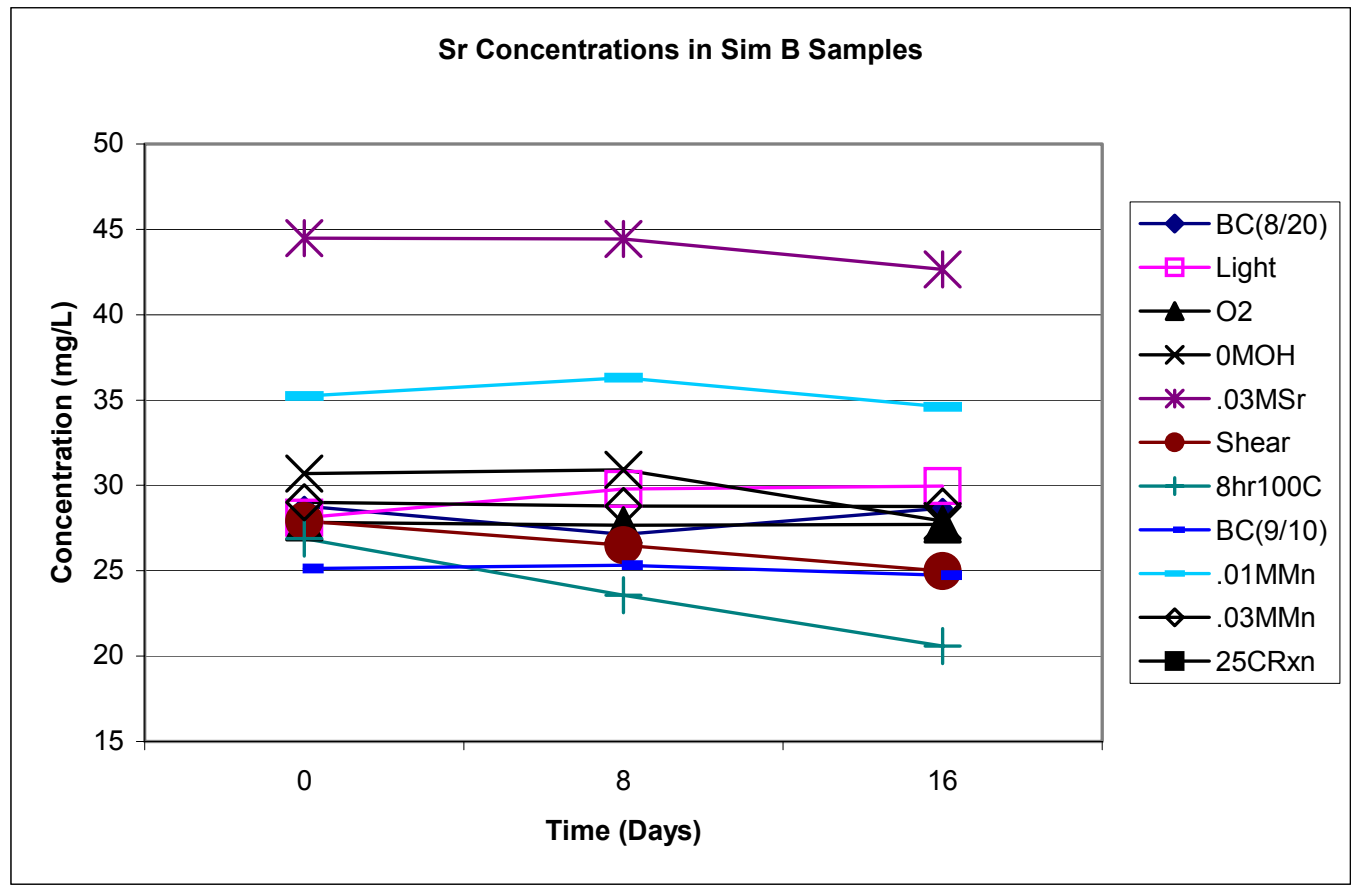

Figure 4.5.1.8b Strontium Concentration in Replicate B Filtrates for the AN-102 Baseline Primary Effects Study (Data Scaled for Clarity, $25{ }^{\circ} \mathrm{C}$ Rxn Condition not shown)

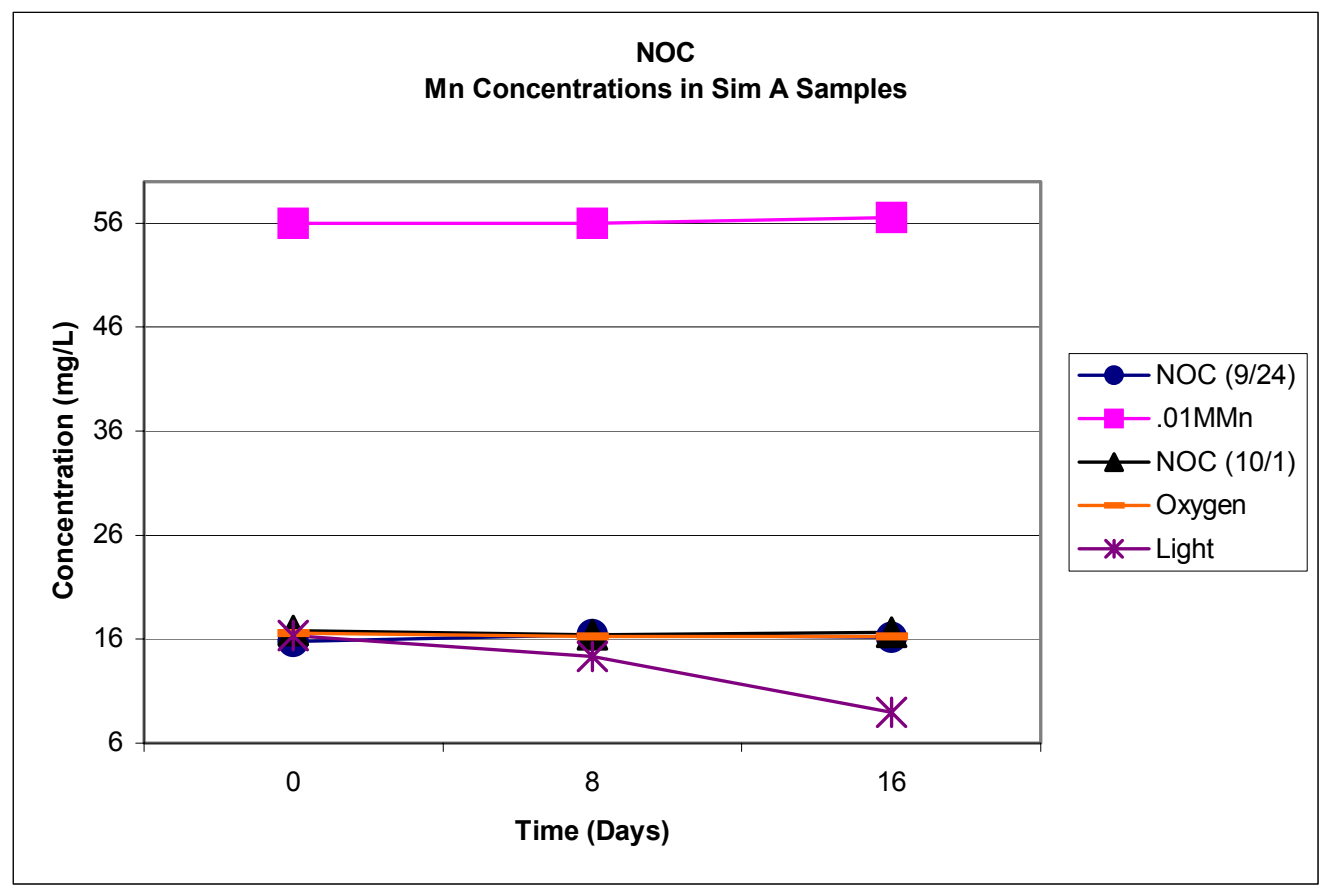

Figure 4.5.1.9 Manganese Concentration in Replicate A Filtrates for the AN-102 NOC Primary Effects Study 
WSRC-TR-2003-00232, Rev. 0

SRT-RPP-2003-00105, Rev. 0

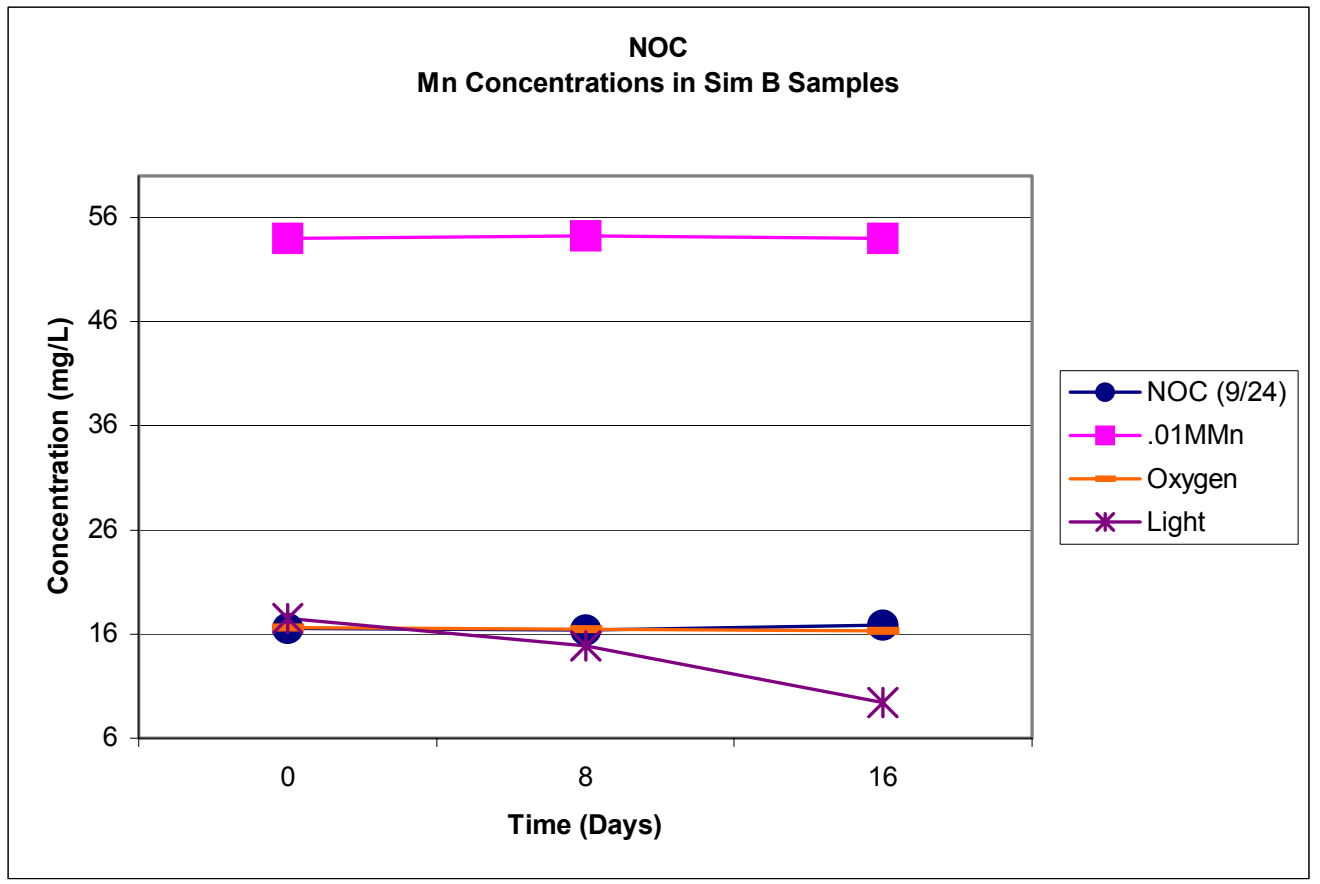

Figure 4.5.1.10 Manganese Concentration in Replicate B Filtrates for the AN-102 NOC Primary Effects Study

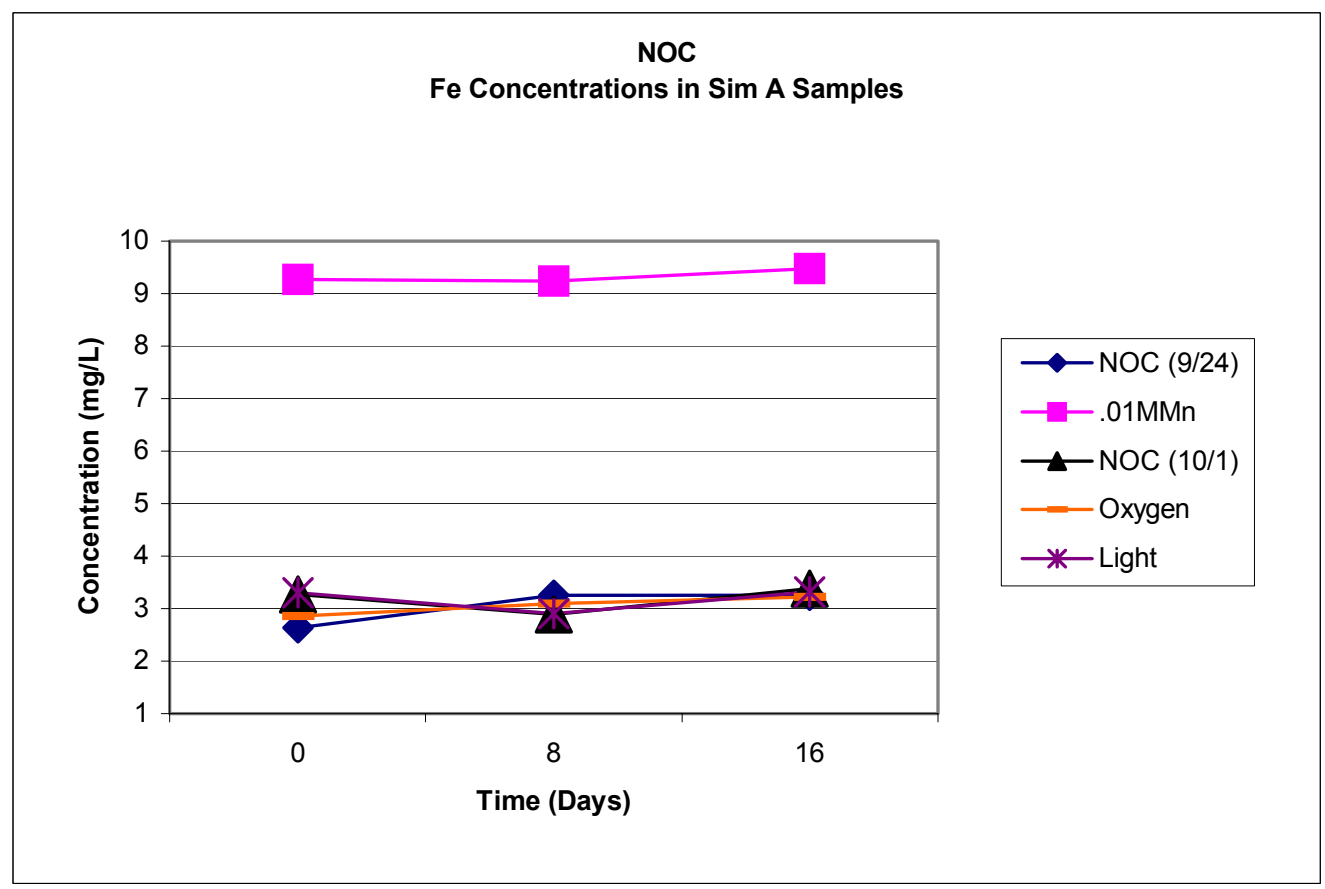

Figure 4.5.1.11 Iron Concentration in Replicate A Filtrates for the AN-102 NOC Primary Effects Study 
WSRC-TR-2003-00232, Rev. 0

SRT-RPP-2003-00105, Rev. 0

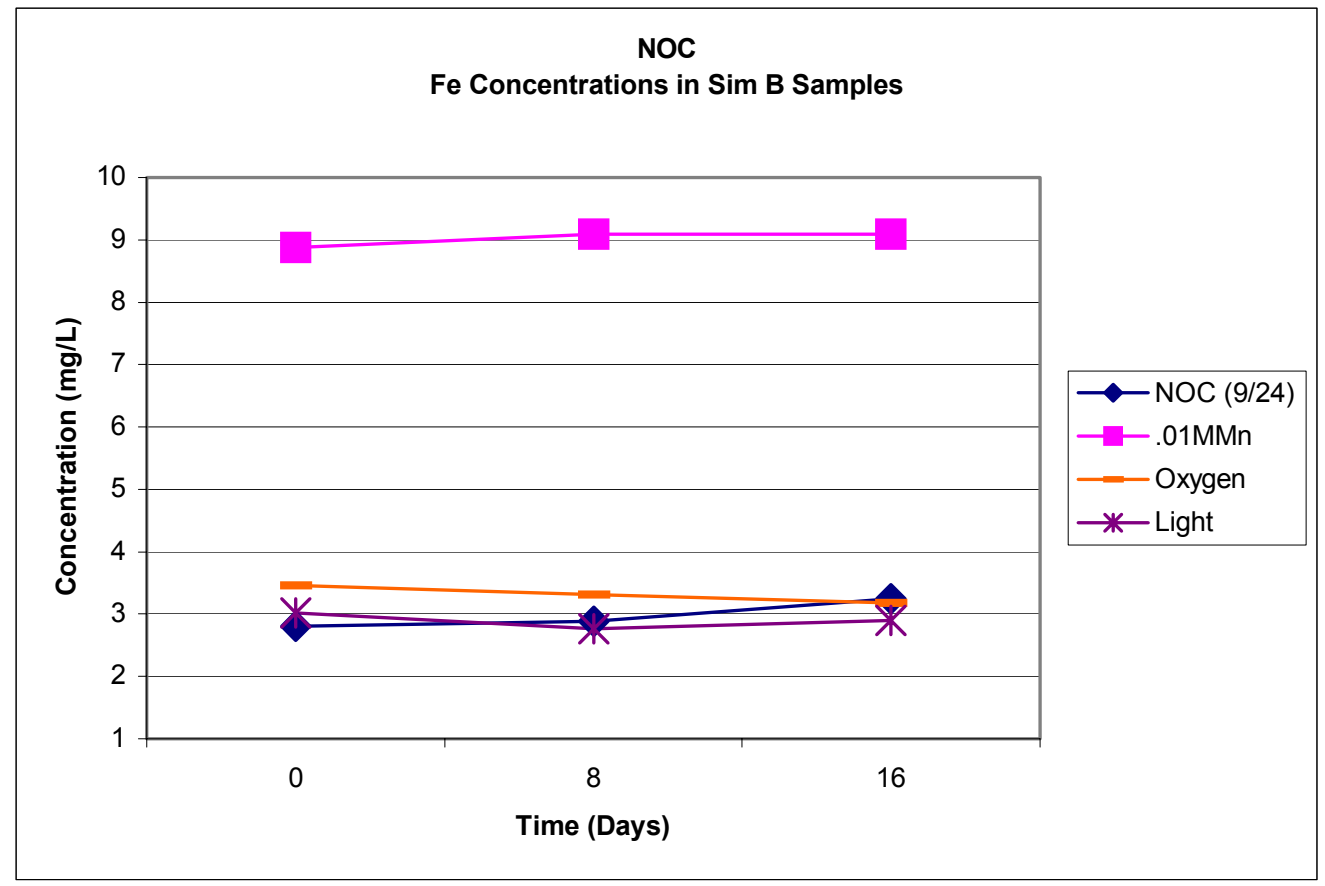

Figure 4.5.1.12 Iron Concentration in Replicate B Filtrates for the AN-102 NOC Primary Effects Study

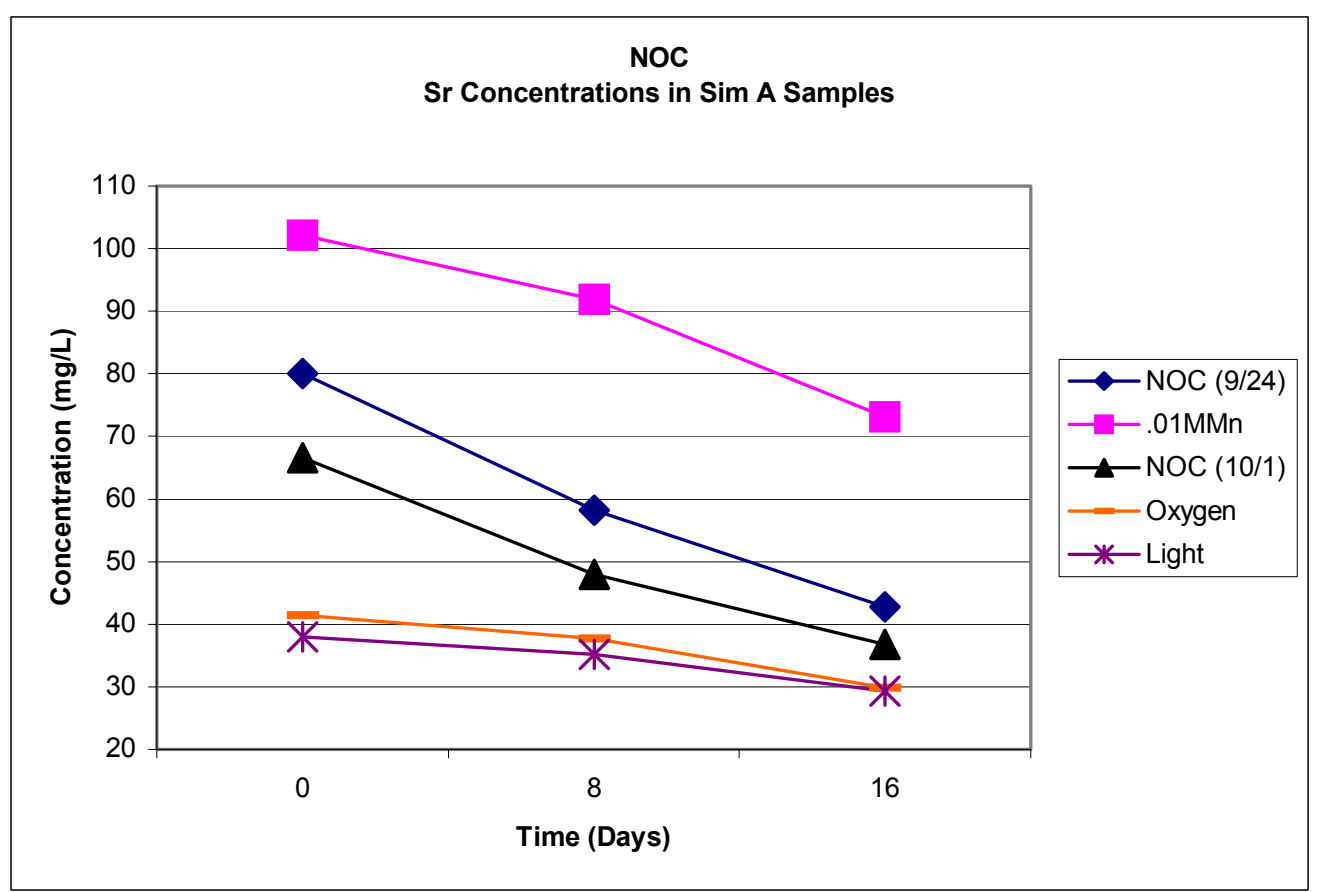

Figure 4.5.1.13 Strontium Concentration in Replicate A Filtrates for the AN-102 NOC Primary Effects Study 
WSRC-TR-2003-00232, Rev. 0

SRT-RPP-2003-00105, Rev. 0

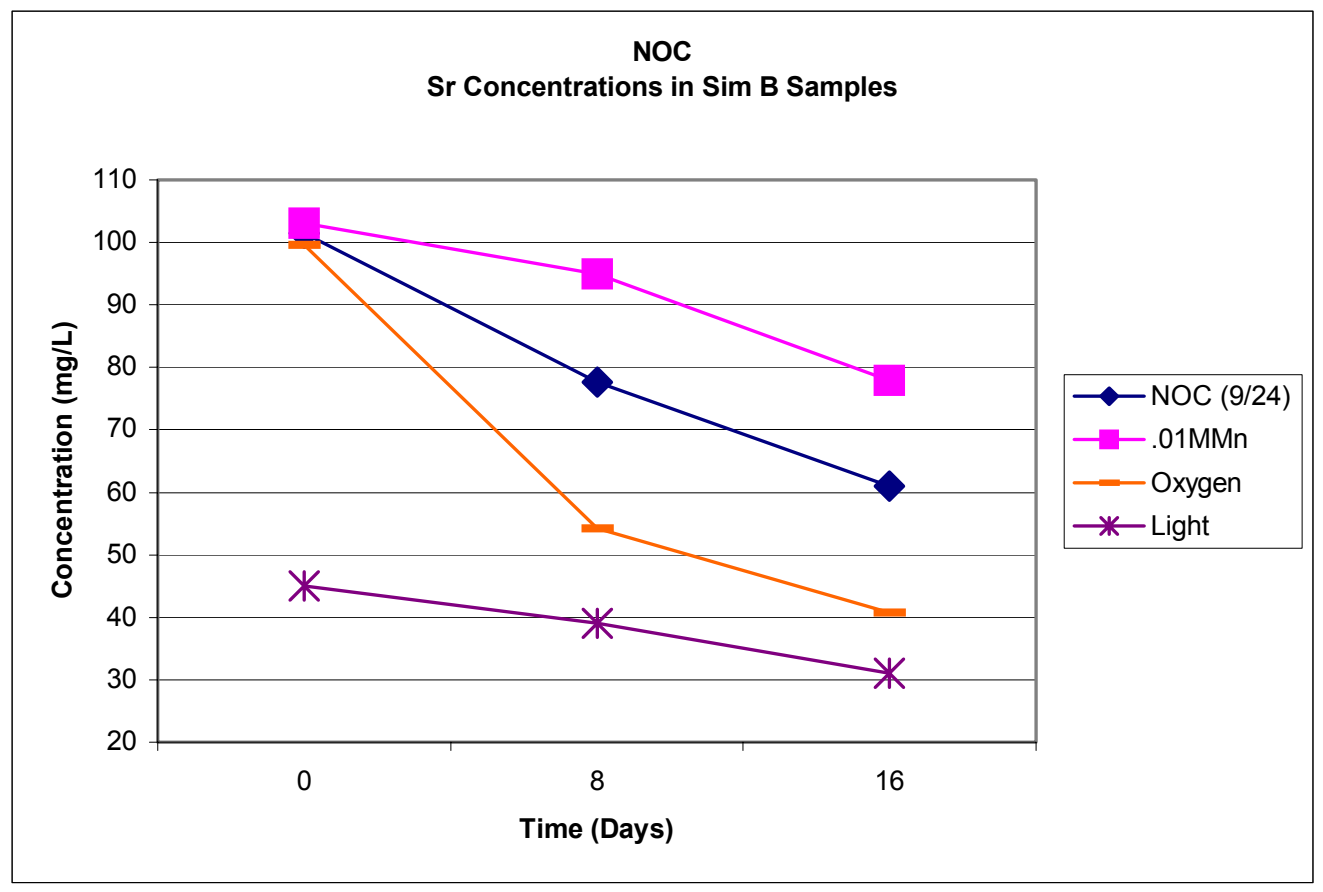

Figure 4.5.1.14 Strontium Concentration in Replicate B Filtrates for the AN-102 NOC Primary Effects Study

Data presented for Mn in Figures 4.5.1.3 and 4.5.1.4 indicate that the Mn concentration in the $0.0 \mathrm{M}$ added $\mathrm{NaOH}$ and $25{ }^{\circ} \mathrm{C}$ reaction conditions did not decrease during the 16-day period. Recall from the above discussion, the only treatment conditions that did not result in the appearance of dark solids on the filter cakes were the $0.0 \mathrm{M}$ added $\mathrm{NaOH}$ and $25{ }^{\circ} \mathrm{C}$ reaction conditions. Similarly, comparisons of the manganese data presented for the variables studied for the NOC indicate that the concentration of soluble manganese decreased only for the light condition, Figures 4.5.1.9 and 4.5.1.10. These results also agree with the photographic evidence noting the presence of dark solids on the respective filters.

Some of the data presented for strontium in Figures 4.5.1.7a $\& \mathrm{~b}$ and 4.5.1.8 $\mathrm{a} \& \mathrm{~b}$ for the base case variables and in Figures 4.5.1.13 and 4.5.1.14 for the NOC variables also show a decrease in soluble strontium during the 16-day period. Five of the variables, namely, $0.0 \mathrm{M}$ added $\mathrm{NaOH}, 0.03 \mathrm{M} \mathrm{Sr}, 8-\mathrm{hr}$ hold at $100{ }^{\circ} \mathrm{C}$, shear at $10,000 \mathrm{rpm}$, and the $25{ }^{\circ} \mathrm{C}$ reaction investigated during the base case study and all of the variables investigated during the NOC study suggest the formation of strontium post-filtration solids. Interestingly, all of the NOC variables and the $25{ }^{\circ} \mathrm{C}$ reaction experiment conducted during the base case study were reacted at $25^{\circ} \mathrm{C}$. The time zero strontium concentration in these filtrates was significantly higher than the commensurate strontium concentration for the reactions conducted at $50{ }^{\circ} \mathrm{C}$ during the base case study. These higher values likely reflect the increased solubility of strontium carbonate at lower temperatures which would lower the isotopic dilution effect. Supersaturated conditions at the lower temperature could result in the slow formation of additional strontium carbonate during the 16-day period. Alternatively, the lower 
WSRC-TR-2003-00232, Rev. 0

SRT-RPP-2003-00105, Rev. 0

permanganate levels with the NOC could result in less oxidation of EDTA and therefore more chelate available to solubilize strontium. Absorption of carbon dioxide could also account for additional precipitation of strontium. Even though filtrates were maintained under a nitrogen blanket during the 16-day period, they were exposed to the atmosphere while sampling at time zero, and at days 1, 2, 4, 8, and 16 .

The decrease in the soluble strontium concentration for the remaining four of the five variables noted in the above paragraph, namely, $0.0 \mathrm{M} \mathrm{OH}, 0.03 \mathrm{M} \mathrm{Sr}$, 8-hr hold, and shear correlate with a similar decrease in the soluble iron concentration, Figures 4.5.1.5 and 4.5.1.6. Two possible scenarios may explain the simultaneous decrease in concentration of these two cations. First both iron and strontium solids could have formed during the 16-day period, or only one was formed, and the reduction in concentration of the other cation was a result of co-precipitation or adsorption. Since strontium carbonate forms during the initial precipitation reaction, it is plausible that strontium carbonate forms during the 16-day period and that iron may adsorb onto the solids.

One could also argue that iron co-precipitated with the formation of manganese solids since there is a commensurate decrease in the iron and manganese concentrations for three of the four variables currently being discussed. However, for the remainder of the variables investigated during the base case study, there is no indication that iron co-precipitated with or was adsorbed onto the manganese solids. These observations may be more easily understood by examination of Table 4.5.1.2, which summarizes the change in concentration of several cations during the 16-day period for the primary effects study.

Table 4.5.1.2. Concentration of Selected Cations for the 0-16 Day Observation Period for the 241-AN-102 Primary Effects Study

\begin{tabular}{|c|c|c|c|c|c|c|c|}
\hline \multicolumn{8}{|c|}{ Cation Concentrations Over 16 Days (mg/L) } \\
\hline Sample & Mn & $\mathbf{F e}$ & $\mathrm{Sr}$ & $\mathrm{Ce}$ & La & Nd & $\mathbf{Z r}$ \\
\hline BC 8/20 & $21.4-16.2$ & C $5.87 \pm .361$ & C $27.3 \pm 1.12$ & $\mathrm{ND}<.2125$ & ND $<.175$ & C $2.51 \pm .456$ & C $0.811 \pm .225$ \\
\hline BC $9 / 10$ & $18.5-12.4$ & C $3.38 \pm .606$ & C $26.2 \pm 1.50$ & ND $<.221$ & C $0.349 \pm .0495$ & C $3.08 \pm .396$ & C $0.719 \pm .0680$ \\
\hline $\mathrm{OMOH}$ & C $4.68 \pm .217$ & $5.89-2.93$ & $30.9-28.2$ & ND $<.213$ & ND $<.175$ & $1.35-\mathrm{ND}<.513$ & $.575-\mathrm{ND}<.150$ \\
\hline $.03 \mathrm{M} \mathrm{Sr}$ & $18.3-11.8$ & $5.92-2.79$ & $42.5-40.8$ & $N D<.213$ & ND $<.175$ & $3.54-1.86$ & $0.846-0.163$ \\
\hline $.01 M \mathrm{Mn}$ & $70.0-65.3$ & C $9.18 \pm .427$ & C $44.1 \pm 9.57$ & C $0.362 \pm .0558$ & C $1.72 \pm .0891$ & C $9.95 \pm .285$ & C $5.20 \pm .119$ \\
\hline $.03 \mathrm{M} M \mathrm{n}$ & $30.9-27.6$ & C $5.16 \pm 2.60$ & C $30.5 \pm 2.15$ & ND $<.221$ & C $0.822 \pm .0435$ & C $5.07 \pm .708$ & C $1.92 \pm .122$ \\
\hline 25C Rxn & C $12.4 \pm .608$ & C $3.11 \pm .222$ & $121-84.8$ & ND $<.213$ & C $1.17 \pm .0674$ & C $5.03 \pm .336$ & C . $.910 \pm .0321$ \\
\hline Light & $18.1-3.64$ & C $6.24 \pm .411$ & C $27.3 \pm 2.34$ & ND $<.2125$ & ND $<.175$ & C $2.37 \pm .546$ & C $0.827 \pm .134$ \\
\hline 02 & $17.3-8.04$ & C $6.06 \pm .0955$ & C $26.7 \pm 1.20$ & ND $<.2125$ & ND <.175 & C $2.38 \pm .544$ & C $0.807 \pm .113$ \\
\hline $8 \mathrm{hr} 100 \mathrm{C}$ & $16.2-3.59$ & $5.68-2.64$ & $27.4-19.2$ & $N D<.213$ & ND $<.175$ & $3.26-1.62$ & $0.760-\mathrm{ND}<.15$ \\
\hline shear & $16.0-10.9$ & $6.12-3.07$ & $27.5-25.2$ & ND $<.213$ & ND $<.175$ & $3.82-2.22$ & $0.757-\mathrm{ND}<.15$ \\
\hline NOC 9/24 & C $16.3 \pm .347$ & C $3.01 \pm .274$ & $90.8-51.9$ & ND $<.2125$ & C $1.55 \pm .101$ & C $6.22 \pm .233$ & C $2.69 \pm .0612$ \\
\hline NOC 10/1 & C $16.6 \pm .230$ & C $3.18 \pm .251$ & $66.7-36.7$ & ND $<.2125$ & C $1.02 \pm .0471$ & C $5.98 \pm .104$ & C $2.30 \pm .0288$ \\
\hline NOC .01Mn & C $55.1 \pm 1.16$ & C $9.18 \pm .200$ & $103-75.5$ & ND $<.2125$ & C $2.03 \pm .0474$ & C $9.48 \pm .287$ & C $6.35 \pm .123$ \\
\hline NOC 02 & $16.6-16.2$ & C $3.19 \pm .207$ & $70.5-35.3$ & ND $<.2125$ & C $0.878 \pm .208$ & C $5.57 \pm .617$ & C $2.22 \pm .0694$ \\
\hline NOC Light & $17.0-9.20$ & C $3.04 \pm .230$ & $41.5-30.1$ & ND $<.2125$ & C $1.08 \pm .0651$ & C $6.18 \pm .318$ & C $2.42 \pm .0978$ \\
\hline
\end{tabular}

The data presented in this table also suggests that the soluble concentration of the cations measured immediately after reaction and filtration varied depending on the treatment 
WSRC-TR-2003-00232, Rev. 0

SRT-RPP-2003-00105, Rev. 0

condition. In the table these values are noted as constant values designated with a ' $\mathrm{C}$ ' and represent average values for the 16-day period for those element concentrations that were invariant, and as the first value noted for cations that did decrease during the 16-day period. For example, in the data range presented for $\mathrm{Mn}, 21.4$ - 16.2, (for the BC 8/20 sample) the value of 21.4 represents the initial concentration of $\mathrm{Mn}$ in the filtrate.

Time zero concentration data for each treatment condition are shown in Figures 4.5.1.15 through 4.5.1.20 for $\mathrm{Mn}, \mathrm{Fe}, \mathrm{Sr}, \mathrm{La}, \mathrm{Nd}$, and $\mathrm{Zr}$ respectively. Cerium concentrations were below detection limits in all filtrates. Clearly, the concentration of these cations in the filtrates immediately after reaction and filtration is dependent on the treatment condition. Data presented in the figures includes error estimates, either a difference in two values or a standard deviation when the averages were calculated from more than two measurements. Statistics were not applied to determine significant differences due to the large number of comparisons to be made with so few degrees of freedom. Instead, significance is implied based on a comparison of concentration values for treatment conditions and considering overlapping error estimates.

The Mn concentration at time zero (Figure 4.5.1.15) for the base case does not differ significantly from the $0.03 \mathrm{M} \mathrm{Sr}$, light, $\mathrm{O}_{2}$, and shear conditions. With exception of the 0.03 $\mathrm{M}$ Sr condition, all were reacted at base case conditions and therefore should be similar. The $25{ }^{\circ} \mathrm{C}$ reaction condition, $0.0 \mathrm{M}$ added $\mathrm{NaOH}$, and the 8 -hr hold at $100{ }^{\circ} \mathrm{C}$ result in a lower initial concentration compared to the base case condition. Conversely, the 0.01 and $0.03 \mathrm{M}$ Mn treatments resulted in higher initial concentrations compared to the base case condition of $0.05 \mathrm{M}$ permanganate. These observations are reasonable given that the conditions that are similar to the base case did not involve a change in reaction conditions, with exception of $0.03 \mathrm{M} \mathrm{Sr}$ condition and the shear condition, which only affected the quality of the precipitate. Conditions that differed did involve a change in reagent parameters.

Lowering the reaction concentration of manganese likely resulted in a lower mass of precipitate, which would decrease the removal of soluble manganese if soluble manganese is scavaged by the manganese precipitate (McKenzie, 1980). Increasing the reaction time and temperature would increase the rate and extent of the precipitation reaction, thus lowering the manganese concentration relative to the base case. Decreasing the reaction temperature should have decreased the rate and extent of the precipitation reaction, thus increasing the manganese concentration relative to the base case. However, as evidenced in Figure 4.5.1.15, the manganese concentration was lower than the base case, which cannot be explained.

Lowering the concentration of permanganate in the reaction mixture could also affect the manganese concentration in the filtrate by increasing the degree of solution metal ion complexation. A lower concentration of oxidant (sodium permanganate) may result in a higher concentration of organic ligand, thus increasing complexation and solubility of the metal. 
WSRC-TR-2003-00232, Rev. 0

SRT-RPP-2003-00105, Rev. 0

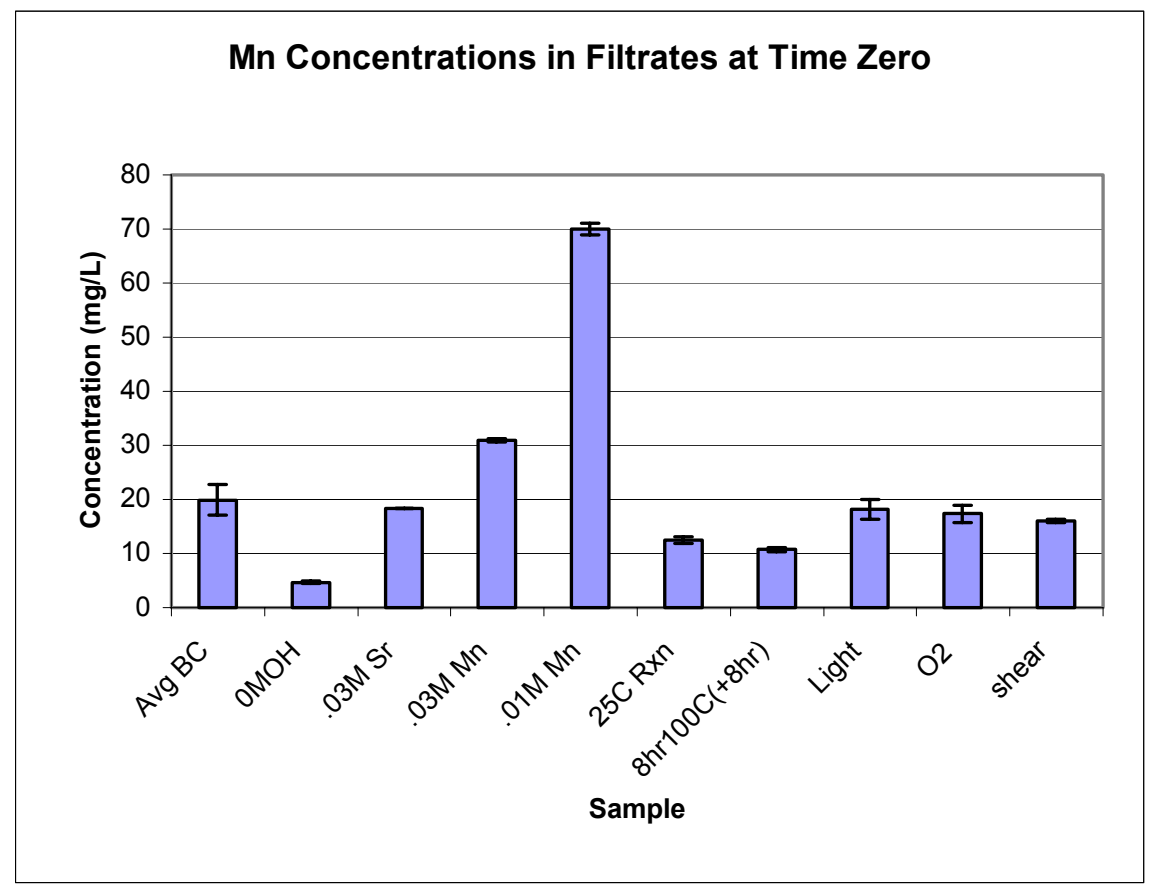

Figure 4.5.1.15 Manganese Concentration in Time Zero Filtrates for the Variables Included in the AN-102 Baseline Primary Effects Study

The time zero concentrations of iron (Figure 4.5.1.16) for the 0.01 M permanganate treatment and the $25^{\circ} \mathrm{C}$ reaction condition appear to be significantly different from the base case condition. The iron concentration in the $0.01 \mathrm{M}$ permanganate treatment is higher than the base case. This is reasonable given that a permanganate reaction concentration of $0.01 \mathrm{M}$ compared to a treatment at $0.05 \mathrm{M}$ (base case) would result in less of a reaction precipitate and consequently less iron removed by co-precipitation or adsorption. The apparent lower concentration of iron for the $25{ }^{\circ} \mathrm{C}$ reaction condition is as of yet unexplained. Lowering the reaction temperature from 50 to $25^{\circ} \mathrm{C}$ should have resulted in less of a reaction precipitate leaving more iron in solution as noted above. However, the behavior of iron in response to the lowered reaction temperature follows that of manganese.

Data presented for strontium (Figure 4.5.1.17) is more difficult to rationalize. First, error estimates for many of the treatment conditions are very small, and the means are similar in magnitude. Four reaction treatments may be significantly different than the base case condition, namely, the $0.03 \mathrm{M}$ strontium treatment, $0.01 \mathrm{M}$ permanganate treatment, $25^{\circ} \mathrm{C}$ reaction condition and the 8 -hr hold at $100{ }^{\circ} \mathrm{C}$. With exception of the 8 -hr hold condition, all appear to be have higher concentration of strontium than the base case. Adding less strontium and permanganate to the reaction mixture may result in less of a reaction precipitate and less removal of strontium by co-precipitation or adsorption. Additionally, as previously stated a lower reaction concentration of oxidant could result in less oxidation of the organic complexants thus increasing complexation and solubility. 
WSRC-TR-2003-00232, Rev. 0

SRT-RPP-2003-00105, Rev. 0

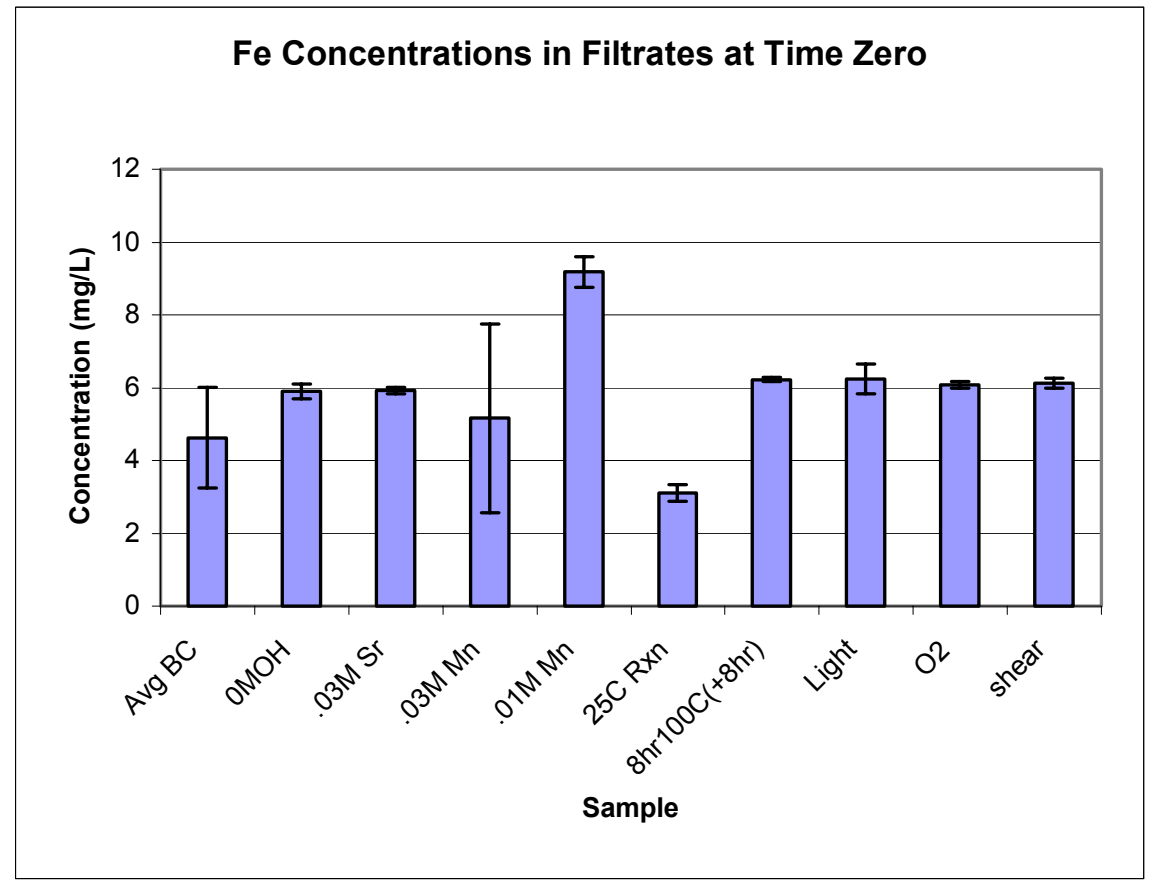

Figure 4.5.1.16 Iron Concentration in Time Zero Filtrates for the Variables Included in the AN-102 Baseline Primary Effects Study

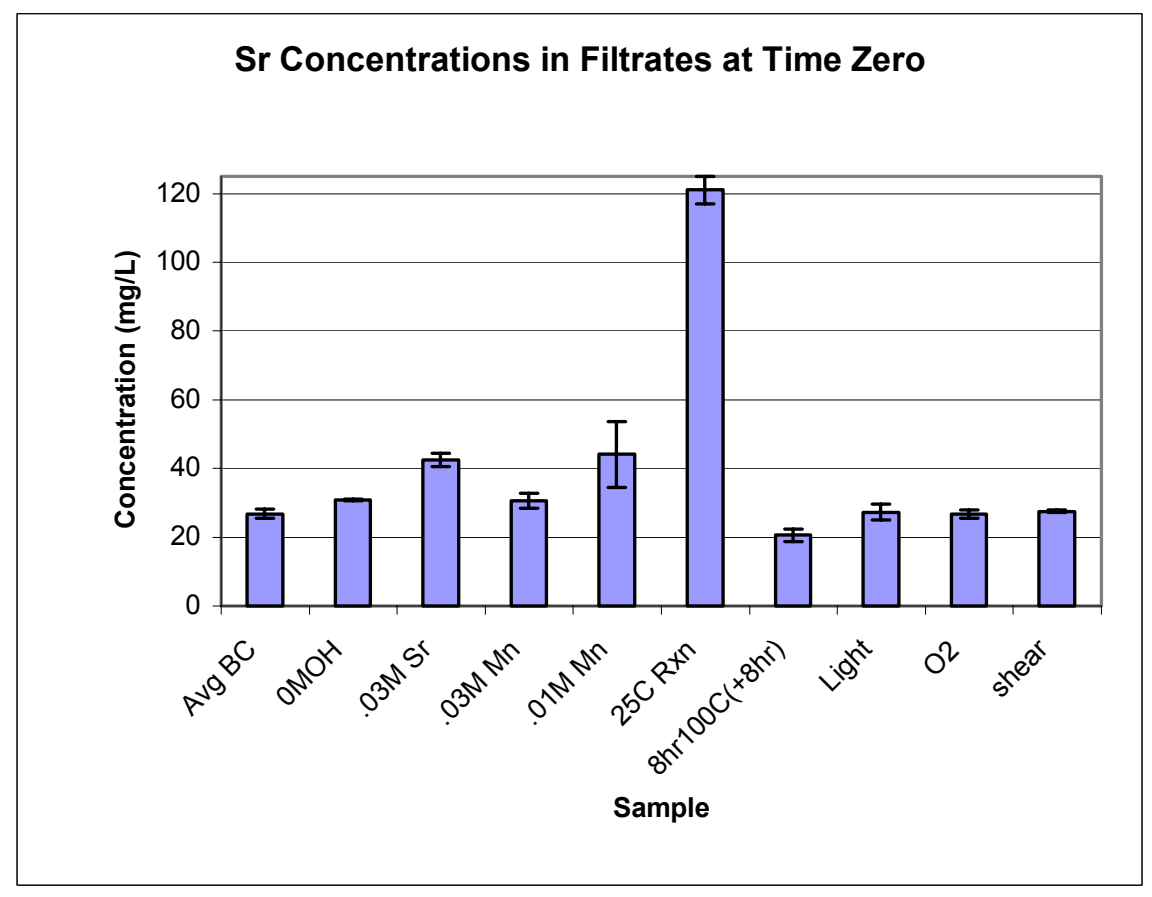

Figure 4.5.1.17 Strontium Concentration in Time Zero Filtrates for the Variables, Included in the AN-102 Baseline Primary Effects Study 
WSRC-TR-2003-00232, Rev. 0

SRT-RPP-2003-00105, Rev. 0

The most noticeable effect on time zero strontium concentrations is that of a lowered reaction temperature, which resulted in less strontium removal and thus higher strontium concentrations in the time zero filtrate. This effect is most likely a result of the increased solubility of strontium at lower temperatures. This rationale may be counterintuitive since all reaction mixtures were cooled to $25{ }^{\circ} \mathrm{C}$ before filtering, which would contradict the above explanation. However, kinetic limitations regarding attainment of equilibrium solubility may result in the observed solubility of strontium.

Data presented for lanthanum, neodymium, and zirconium in Figures 4.5.1.18, 19, and 20 appear also to differ for many of the reaction variables. Lanthanum concentration at time zero for the reaction at $0.0 \mathrm{M}$ added $\mathrm{NaOH}$ was below detection. In addition, the lanthanum concentration for two of the treatment variables, namely, exposure to light and oxygen was also below detection. Presumably the removal mechanism for these surrogates is by adsorption, and as a result, the time zero concentration of each should be higher than the base case condition when the change in reaction variable resulted in less of a precipitate mass of manganese oxy-hydroxide or oxide during the initial permanganate oxidation reaction.

Likewise, the time zero concentrations of the surrogates with exception of lanthanum, should be elevated or reduced in correspondence with time zero manganese concentrations. However, the $25{ }^{\circ} \mathrm{C}$ reaction condition and the filtrate held at $100{ }^{\circ} \mathrm{C}$ for 8 hours does not follow this pattern. No data exist to explain the difference; however, it is possible that the nature of particles formed in the initial reaction precipitate may differ between 25 and $50{ }^{\circ} \mathrm{C}$, resulting in less adsorption and a higher concentration in the filtrate. For the $8 \mathrm{hr}$ hold sample, sorption may be more complete, that is less kinetically hindered, thus resulting in a lower concentration in the filtrate.

This relationship can be seen through a comparison of Figures 4.5.1.15 and 4.5.1.18 through 4.5.1.20. 
WSRC-TR-2003-00232, Rev. 0

SRT-RPP-2003-00105, Rev. 0

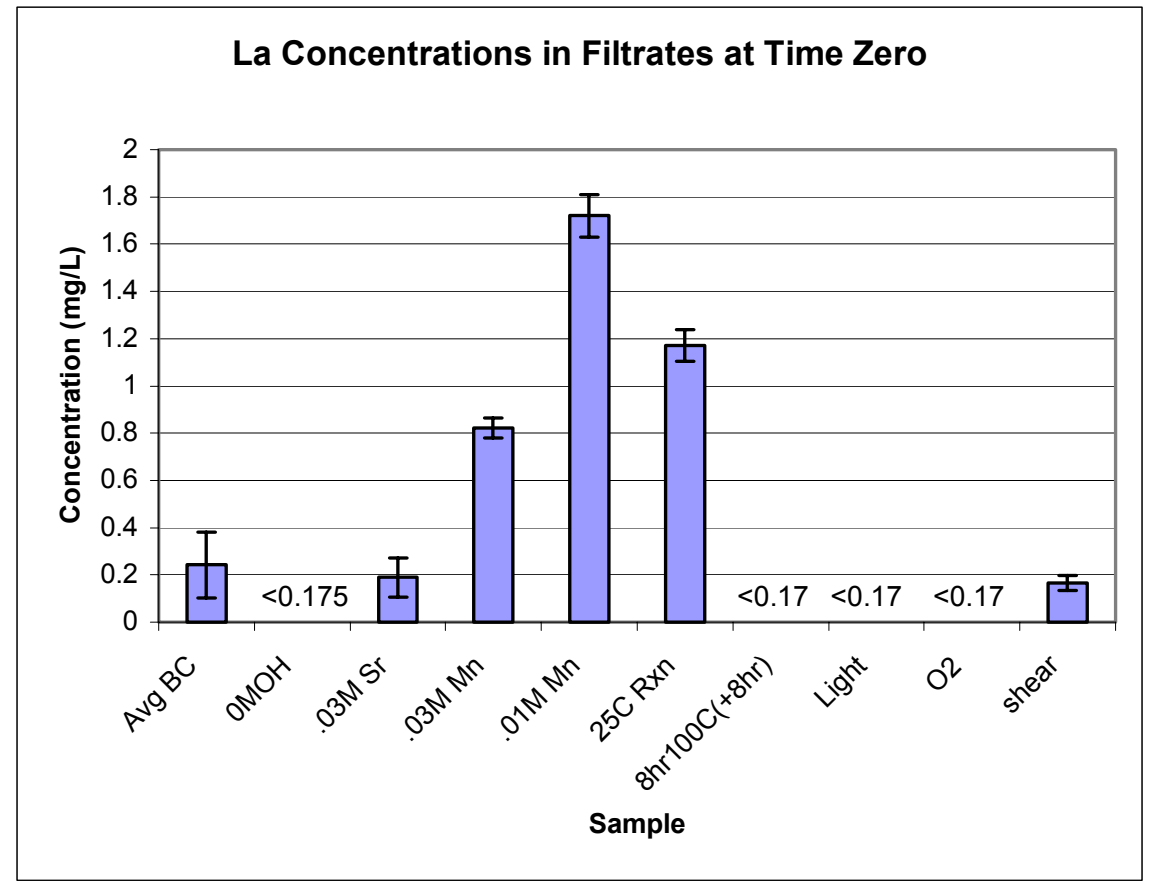

Figure 4.5.1.18 Lanthanum Concentration in Time Zero Filtrates for the Variables Included in the AN-102 Baseline Primary Effects Study

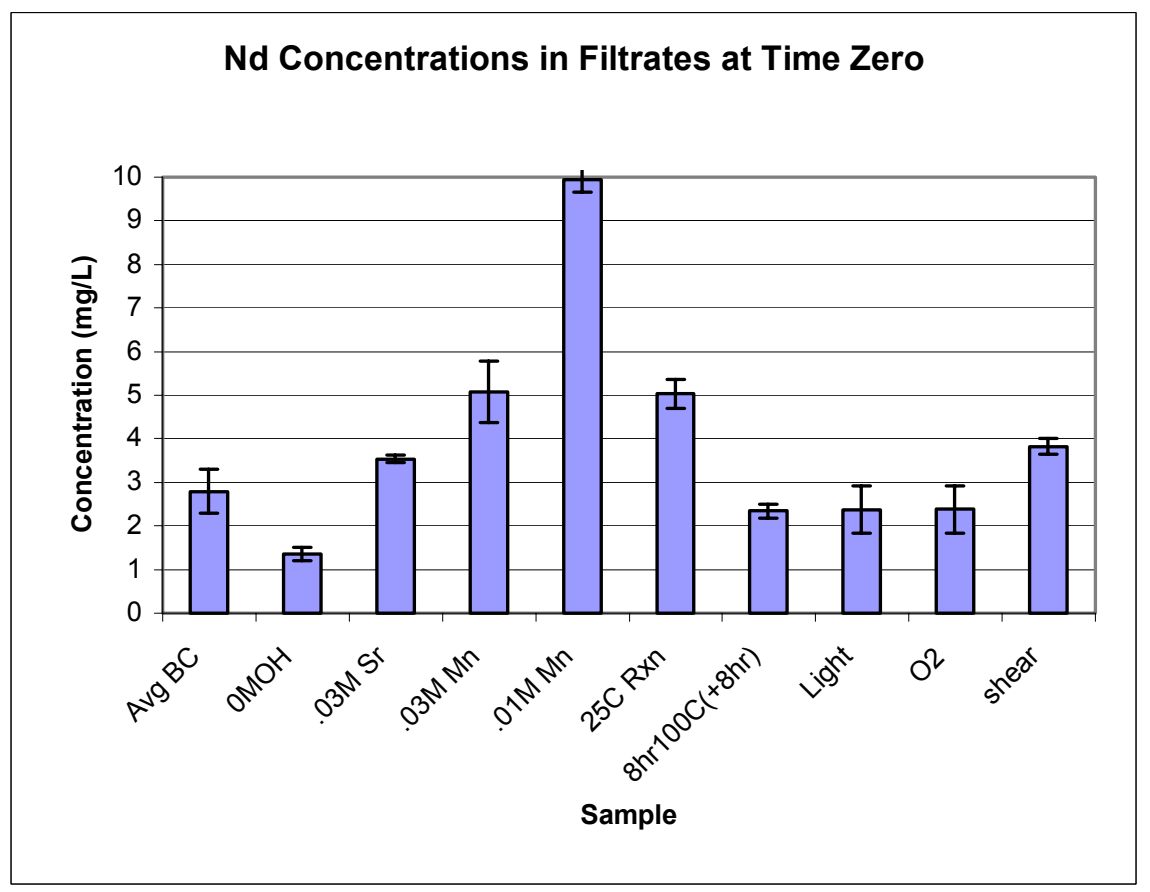

Figure 4.5.1.19 Neodymium Concentration in Time Zero Filtrates for the Variables Included in the AN-102 Baseline Primary Effects Study 
WSRC-TR-2003-00232, Rev. 0

SRT-RPP-2003-00105, Rev. 0

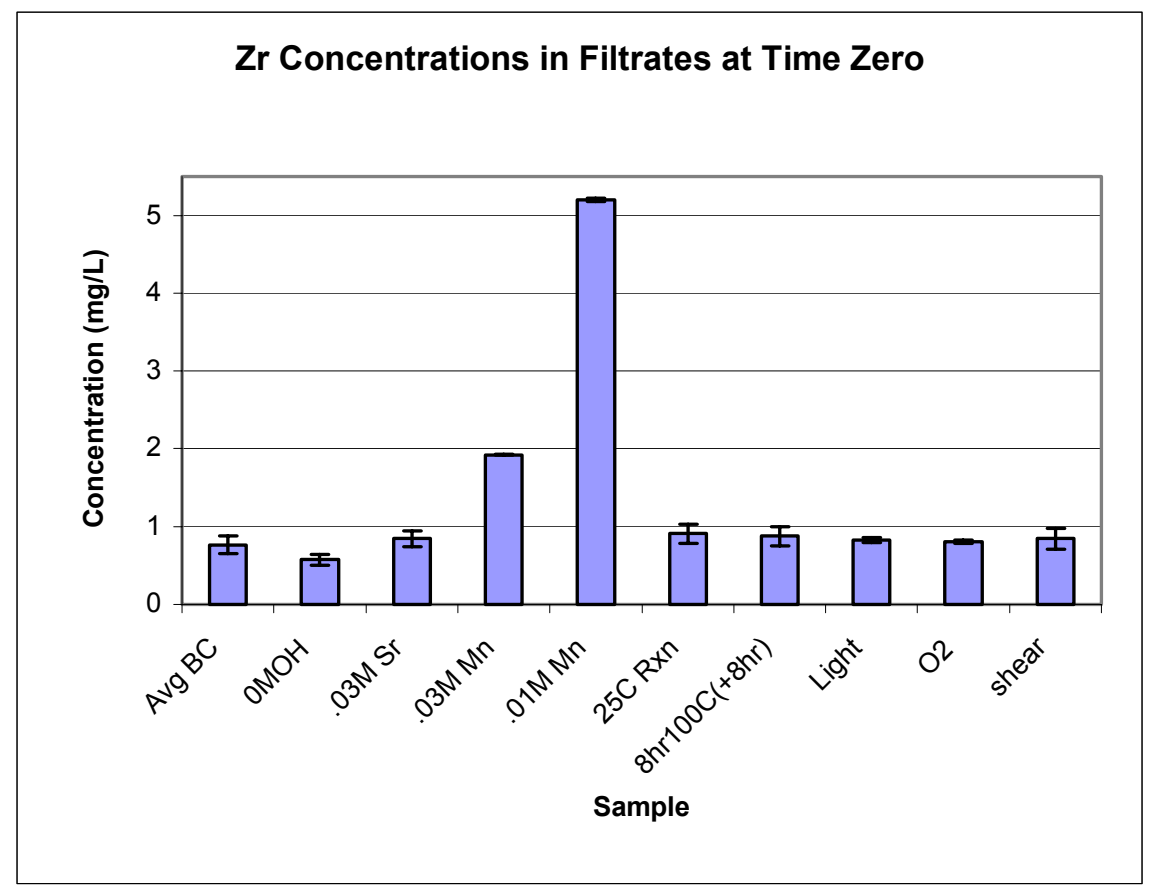

Figure 4.5.1.20 Zirconium Concentration in Time Zero Filtrates for the Variables Included in the AN-102 Baseline Primary Effects Study

Similar data plots are also presented for experiments conducted for the newly optimized condition. Shown in Figures 4.5.1.21 through 4.5.1.26 are data for $\mathrm{Mn}, \mathrm{Fe}, \mathrm{Sr}, \mathrm{La}, \mathrm{Nd}$, and $\mathrm{Zr}$. The Mn and Fe data suggest that the only variable tested that differed from the baseline condition was the NOC where the Mn concentration in the reaction mixture was lowered to $0.01 \mathrm{M}$. Recall that in the baseline primary effects study, Figure 4.5.1.15 and 4.5.1.16, the time zero concentration for both $\mathrm{Mn}$ and Fe were higher than the baseline values for the 0.01 $\mathrm{M} \mathrm{Mn}$ reaction condition, but not for the $0.03 \mathrm{M} \mathrm{Mn}$ reaction condition.

The time zero strontium concentration for all of the variables tested differed from the baseline condition. All were higher than the base case condition, $(0.075 \mathrm{Mn}, 0.05 \mathrm{Sr}$, and 50 ${ }^{\circ} \mathrm{C}$ reaction temperature). This is most likely due to the fact that all of the NOC experiments were conducted at room temperature. Recall the base case reaction temperature was at $50{ }^{\circ} \mathrm{C}$ while the NOC reaction temperature was $25^{\circ} \mathrm{C}$. A lowering of the reaction temperature would decrease the rate of reaction, and for a four reaction time, the extent reaction. Less of an initial precipitate could result in less adsorption of co-metals. An increase in the concentration of organic ligands due to the addition of less oxidant (permanganate) could also account for the increase in filtrate concentration of strontium.

Time zero concentration data for the surrogate cations shown in Figures 4.5.1.24 through 4.5.1.26 are higher than the baseline condition for all variables tested. Three reaction conditions of the NOC, namely the $25{ }^{\circ} \mathrm{C}$ reaction temperature and the lower concentrations of $\mathrm{Sr}$ and $\mathrm{Mn}$ in the reaction mixture, (compared to the baseline conditions), likely affect the formation of the manganese precipitate during the reaction. A smaller mass of precipitate 
WSRC-TR-2003-00232, Rev. 0

SRT-RPP-2003-00105, Rev. 0

would translate into a higher concentration of cations in the time zero filtrates if the primary removal mechanism for the cations were adsorption onto the manganese precipitate.

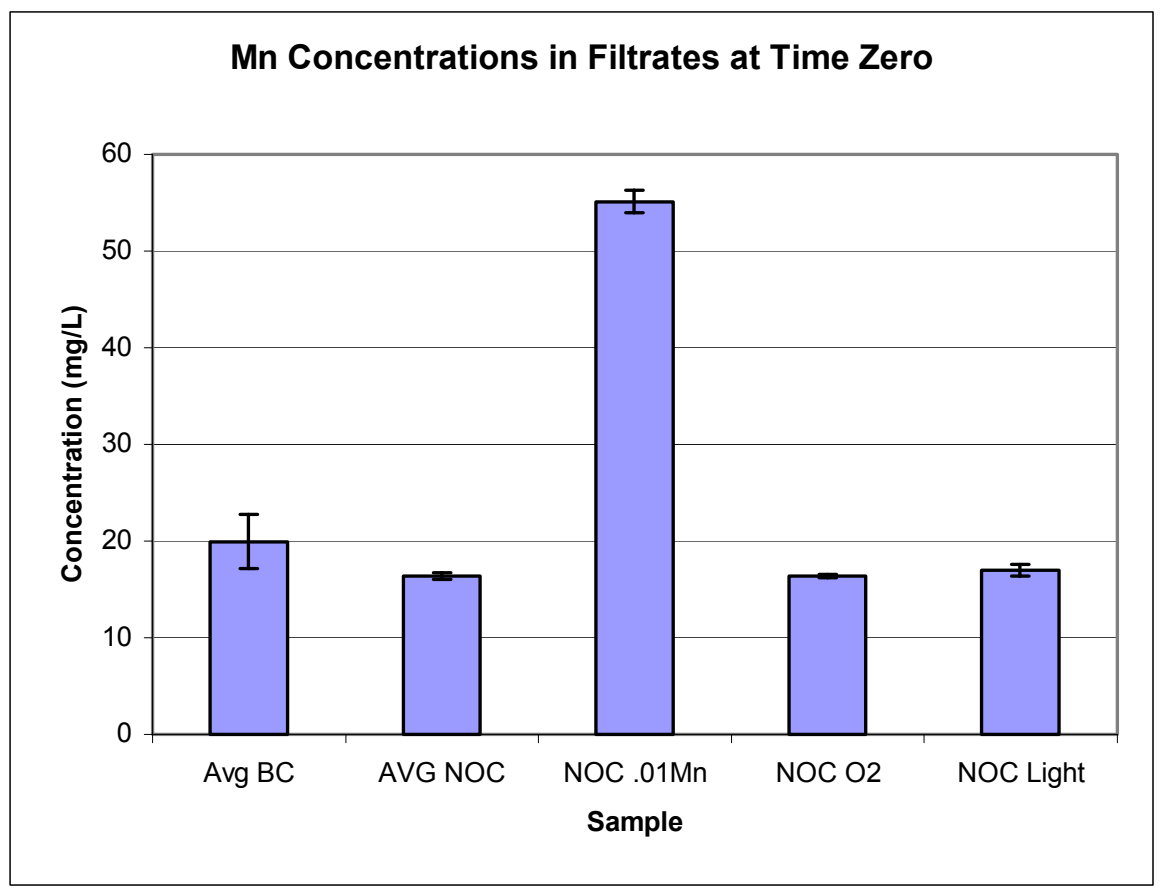

Figure 4.5.1.21 Manganese Concentration in Time Zero Filtrates for the Variables Included in the AN-102 NOC Study 
WSRC-TR-2003-00232, Rev. 0

SRT-RPP-2003-00105, Rev. 0

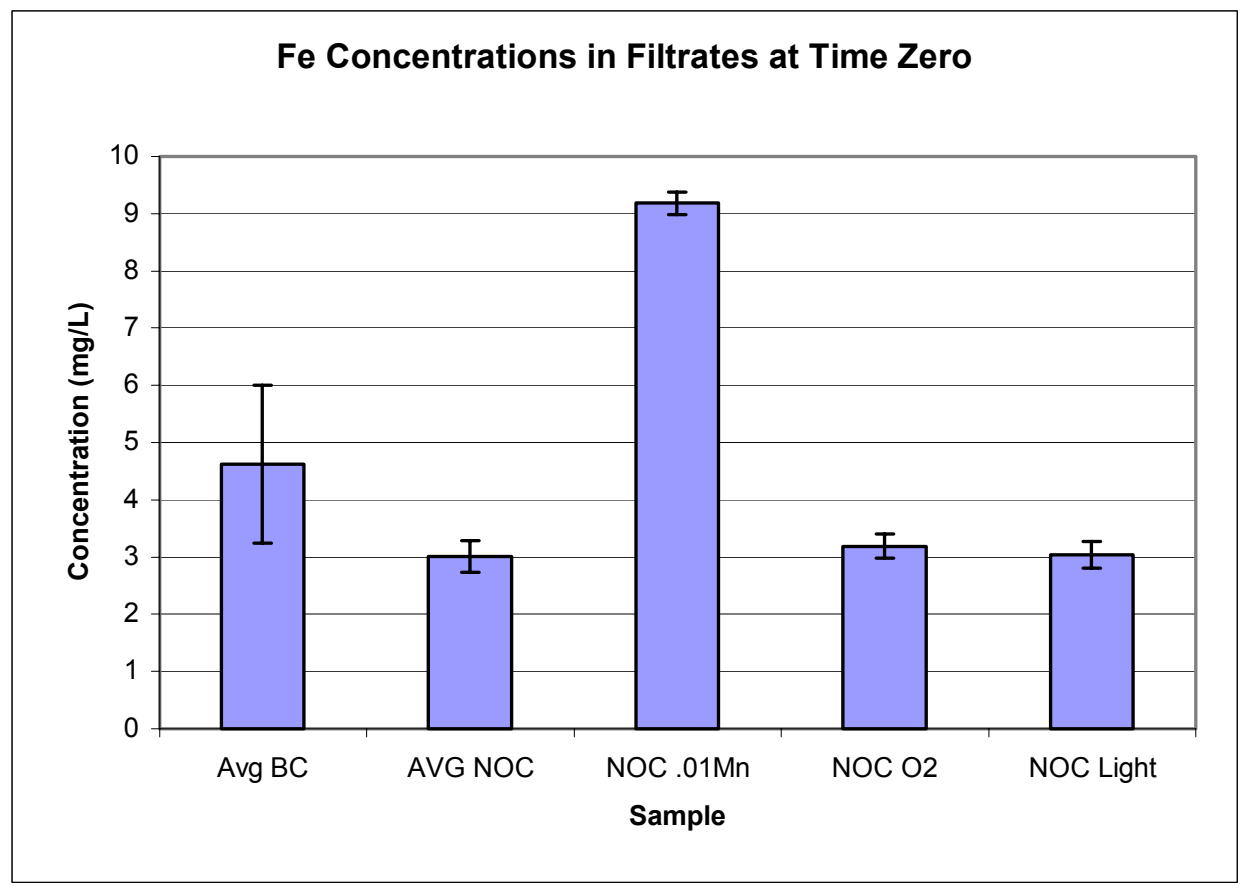

Figure 4.5.1.22 Iron Concentration in Time Zero Filtrates for the Variables Included in the AN-102 NOC Study

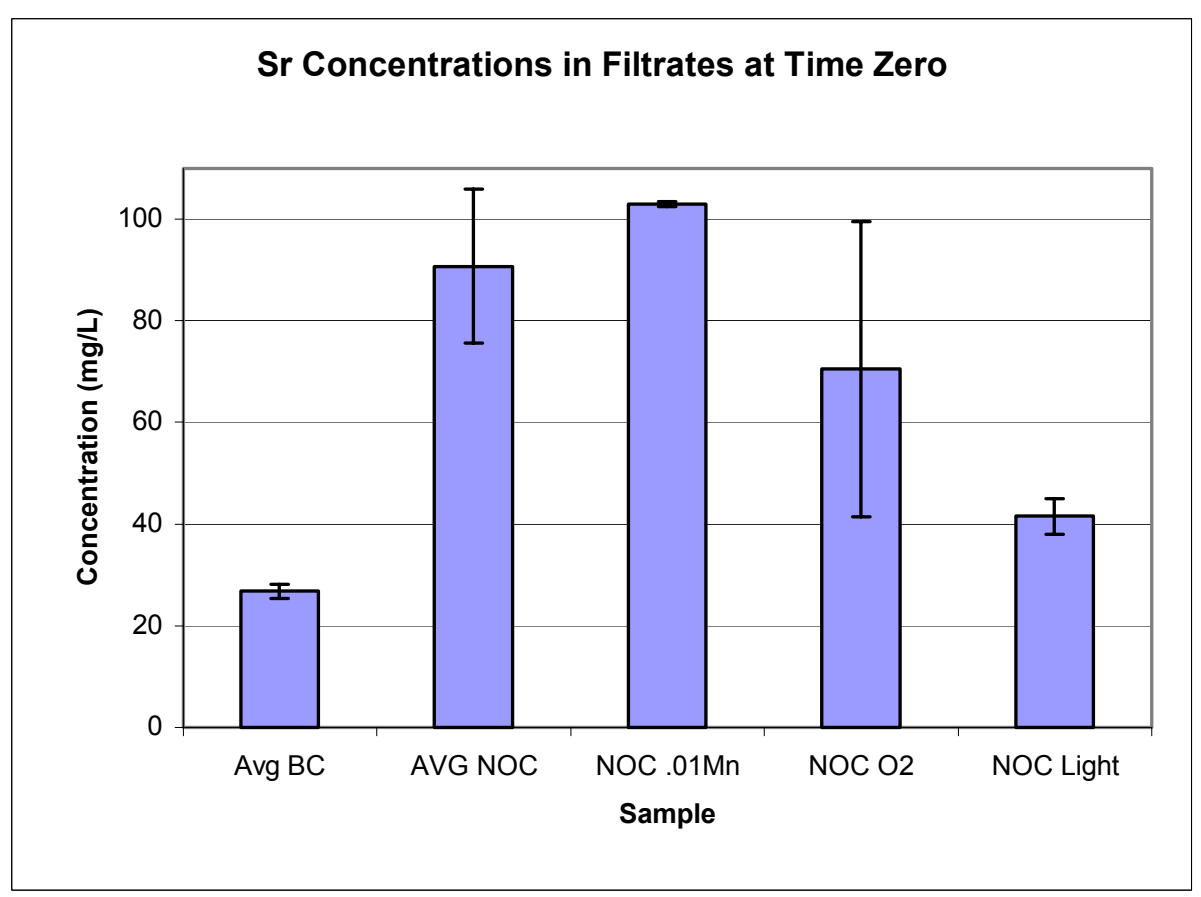

Figure 4.5.1.23 Strontium Concentration in Time Zero Filtrates for the Variables Included in the AN-102 NOC Study 
WSRC-TR-2003-00232, Rev. 0

SRT-RPP-2003-00105, Rev. 0

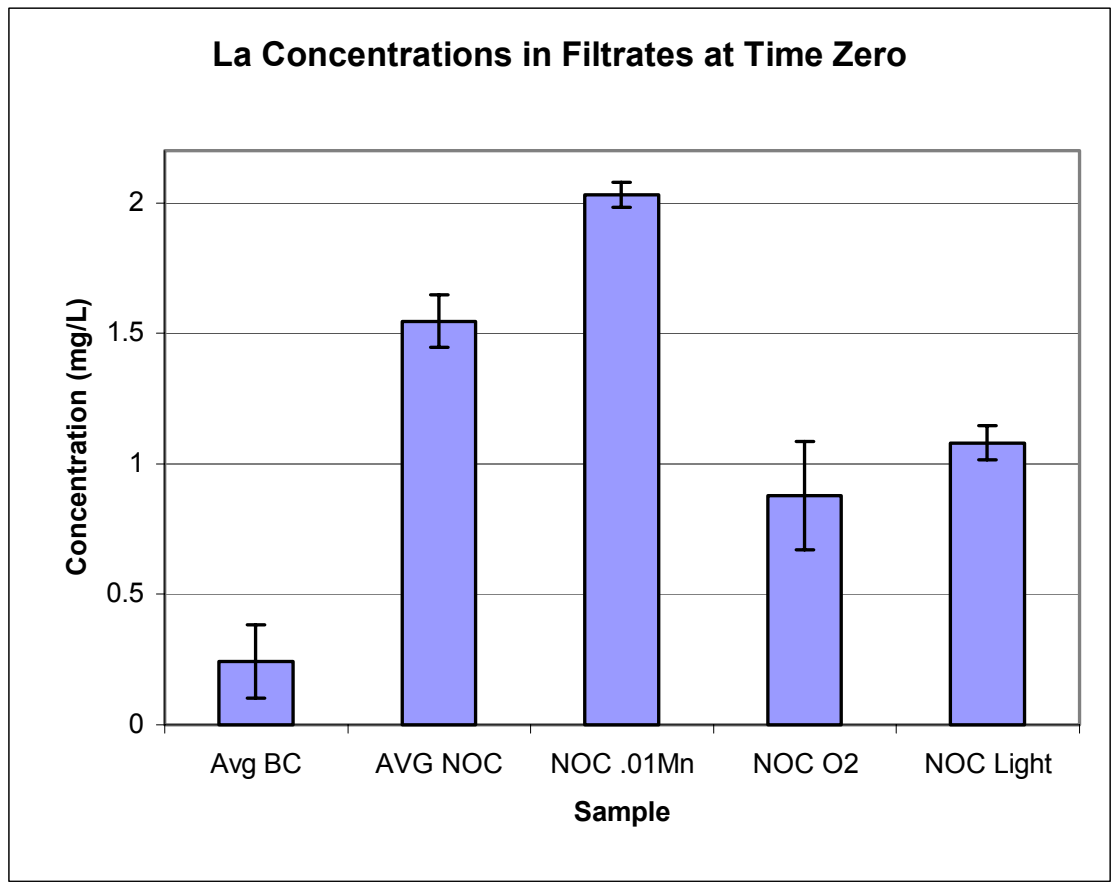

Figure 4.5.1.24 Lanthanium Concentration in Time Zero Filtrates for the Variables Included in the AN-102 NOC Study

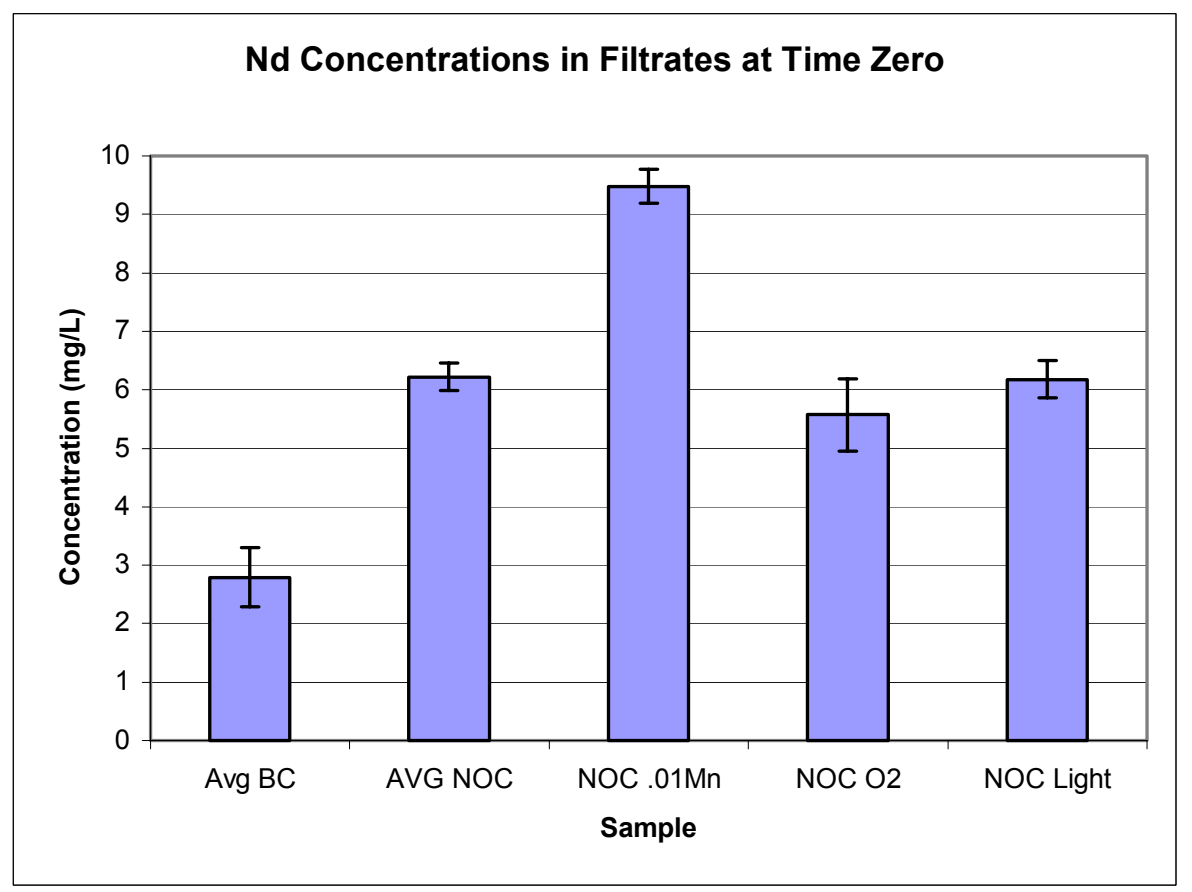

Figure 4.5.1.25 Neodymium Concentration in Time Zero Filtrates for the Variables Included in the AN-102 NOC Study 
WSRC-TR-2003-00232, Rev. 0

SRT-RPP-2003-00105, Rev. 0

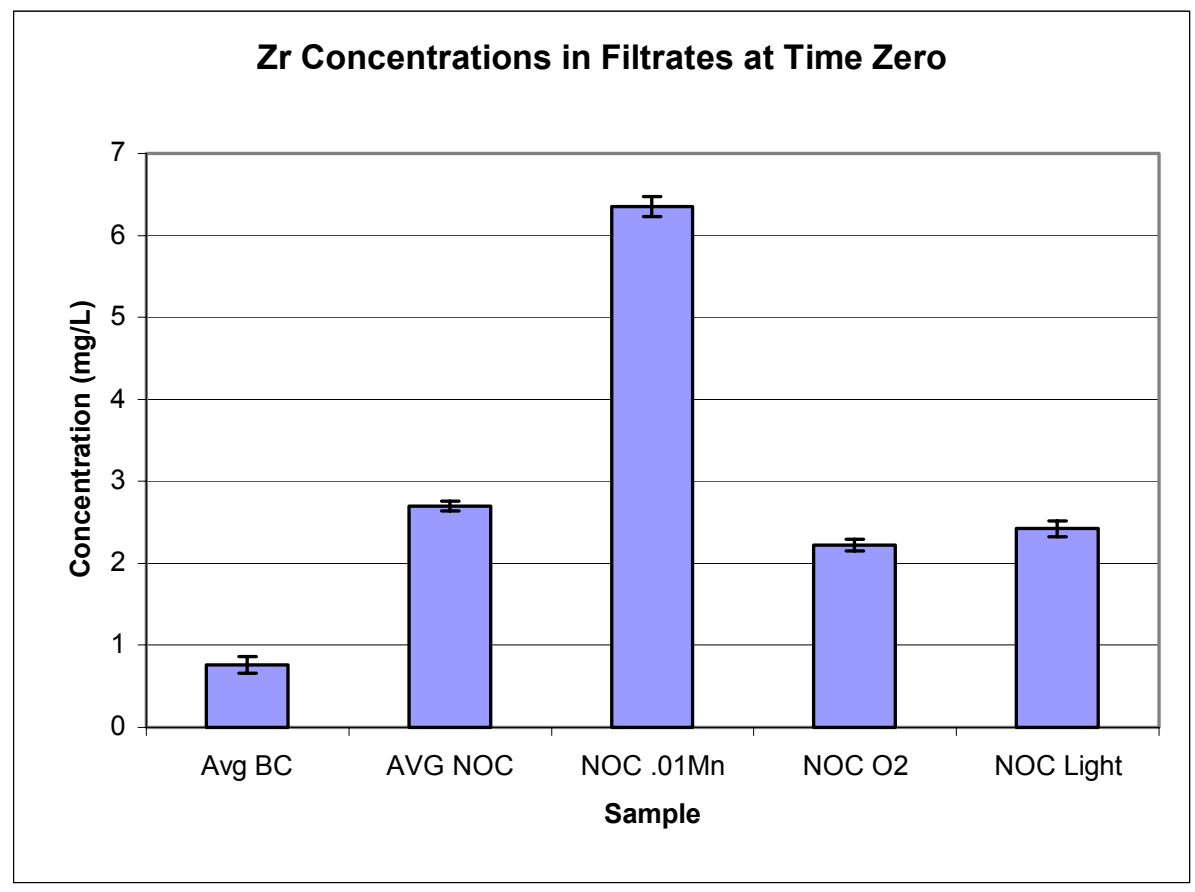

Figure 4.5.1.26 Zirconium Concentration in Time Zero Filtrates for the Variables Included in the AN-102 NOC Study

During the conduct of the 241-AN-102 primary effects study, the manganese concentration in the reaction mixture was $0.01,0.03$, and $0.05 \mathrm{M}$. A plot of the time zero filtrate data for $\mathrm{Mn}, \mathrm{Fe}$, and $\mathrm{Sr}$ is shown in Figure 4.5.1.27 as a function of the manganese reaction concentration. For each of the cations, the time zero concentration is inversely proportional to the $\mathrm{Mn}$ reaction concentration. A similar effect was seen for $\mathrm{Ce}, \mathrm{La}, \mathrm{Nd}$, and $\mathrm{Zr}$ (Figure 4.5.1.28). A lower concentration of $\mathrm{Mn}$ in the reaction mixture would result in a lower mass of precipitate, which would decrease the removal of soluble manganese and all other coprecipitating or co-adsorbing cations (McKenzie, 1980). Again, it is also possible that a lower reaction concentration of permanganate resulted in less destruction of organic ligands, thus increasing complexation and solubility of the metals. 
WSRC-TR-2003-00232, Rev. 0

SRT-RPP-2003-00105, Rev. 0

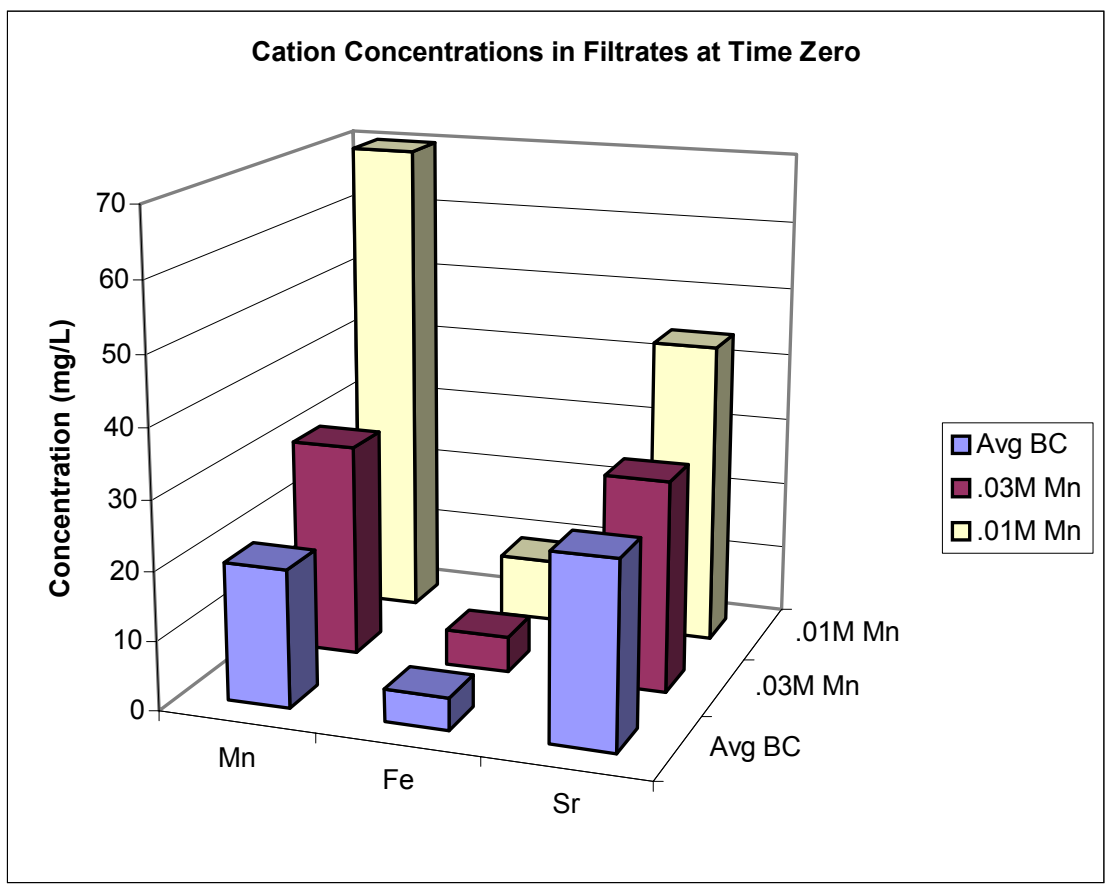

Figure 4.5.1.27 Time Zero Filtrate Concentration of $\mathrm{Mn}, \mathrm{Fe}$, and $\mathrm{Sr}$ as a Function of $\mathrm{Mn}$ Reaction Concentration

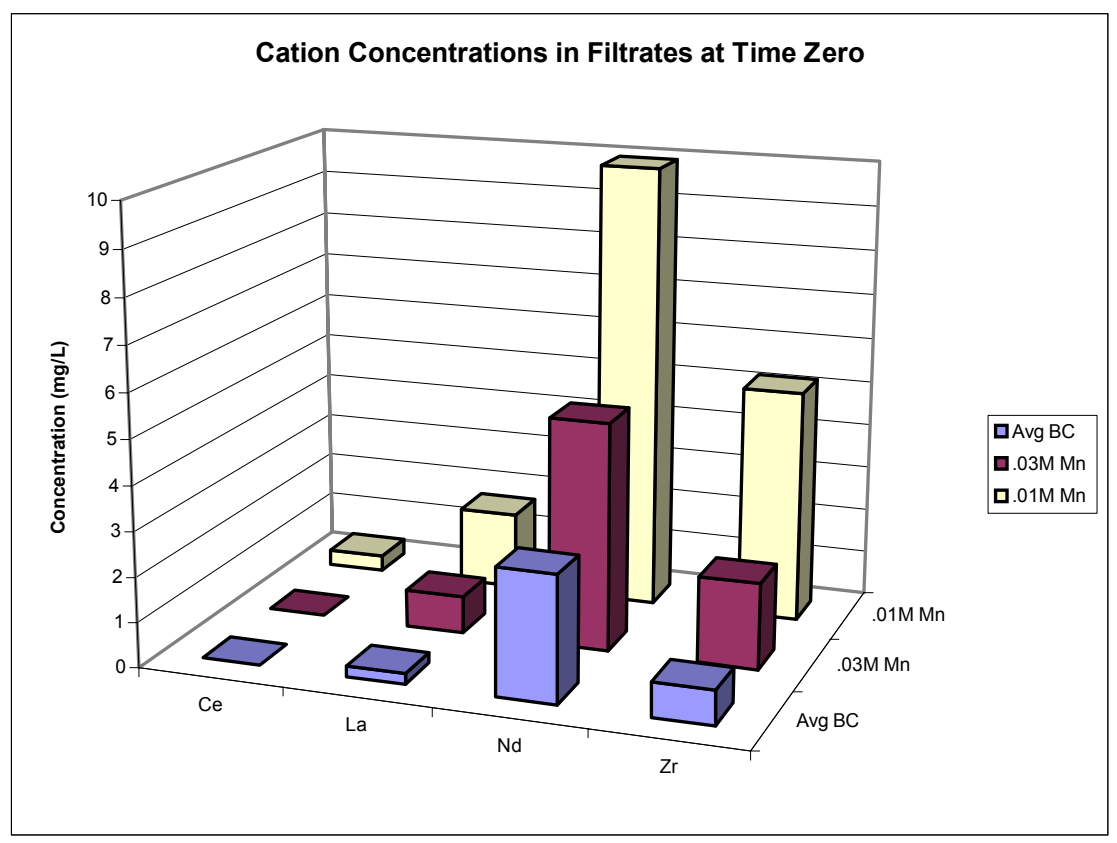

Figure 4.5.1.28 Time Zero Filtrate Concentration of Ce, $\mathrm{La}, \mathrm{Nd}$, and $\mathrm{Zr}$ as a Function of Mn Reaction Concentration 
WSRC-TR-2003-00232, Rev. 0

SRT-RPP-2003-00105, Rev. 0

\section{Characterization of Solids Formed During the 16 Days}

At the end of the 16-day observation period, samples were filtered to determine the mass of post-filtration solids that formed in the filtrates. Samples were filtered under nitrogen to reduce the formation of sodium bicarbonate on the filters by reaction of the base media with carbon dioxide in the atmosphere. Mass data was normalized to the final filtrate volume of $100 \mathrm{mls}$ and corrected for soluble solids retained on the filters. The initial volume of filtrate stored was $150 \mathrm{mls}$, and five $10-\mathrm{mL}$ aliquots were removed during the 16-day period for ICPAES analysis. Post-filtration solids concentration data for all of the primary effects variables is shown in Figure 4.5.1.29 and is presented to show the magnitude of solids formed for the baseline primary effects study compared to the NOC primary effects study. The amount of post-filtration solids formed for the NOC samples was significantly lower, by an order of magnitude, than for many of the variables tested during the baseline study with exception of the $0.0 \mathrm{M}$ added $\mathrm{NaOH}$.

Post-filtration solids that formed during the 16-day period not only included manganese solids, but a significant accumulation of white solids. Precipitates were dissolved in $0.5 \mathrm{M}$ nitric acid and analyzed by ICP-AES to determine the major cations present in the particulate mass. These data are presented in Tables 4.5.1.3 and 4.5.1.4 for the baseline and NOC experiments respectively. Represented in the tables are the percents of each cation present in the precipitate mass relative to the time zero mass of the cation in the filtrate. The predominant cations found in the precipitate mass are manganese and phosphorus, with sporadic notations of silica and strontium. Sodium concentrations in the samples were not measured.

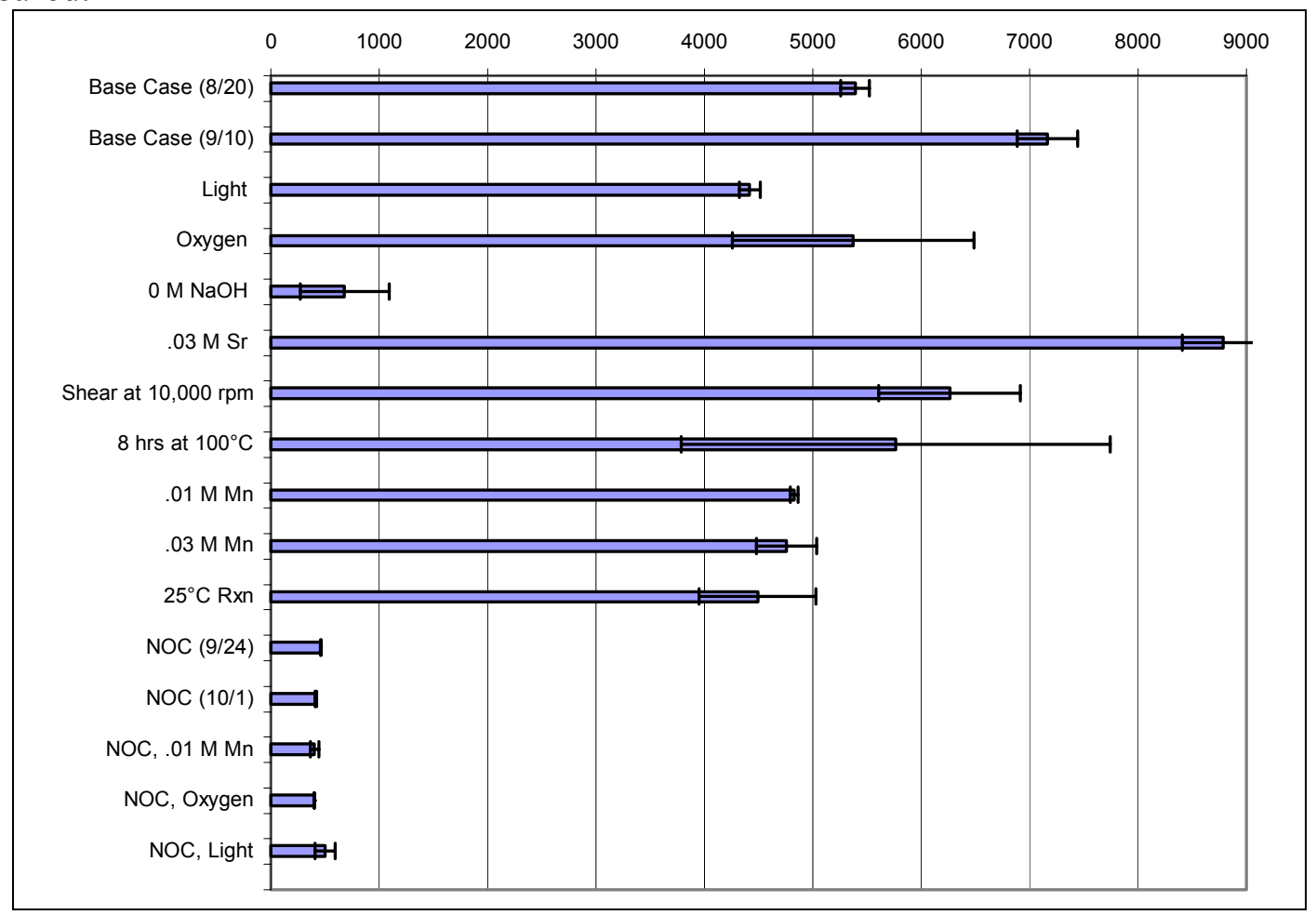

Figure 4.5.1.29 Solids Concentration $(\mathrm{mg} / \mathrm{L})$ in Filtrates after 16 Days for the AN-102 Baseline and NOC Experiments 
WSRC-TR-2003-00232, Rev. 0

SRT-RPP-2003-00105, Rev. 0

Table 4.5.1.3 Percent of Cation Mass Present in the Solids Relative to Time Zero Cation Mass in the AN-102 Baseline Primary Effects Study

\begin{tabular}{|c|c|c|c|c|c|c|c|c|c|c|}
\hline \multicolumn{11}{|c|}{ Percent of Cation Present at Time 0 Found in Dissolved Solids } \\
\hline \multicolumn{11}{|c|}{$(=m$ ass in solid $/ m$ ass in time 0 filtrate $* 100)$} \\
\hline Elem & Average $\mathrm{BC}$ & Oxygen & Light & Shear & $8 \mathrm{hr} 100 \mathrm{C}$ & $25 \mathrm{C} \mathrm{Rxn}$ & $.03 \mathrm{MMn}$ & $.01 \mathrm{MMn}$ & $.03 \mathrm{M} \mathrm{Sr}$ & $\mathrm{OMOH}$ \\
\hline Al & 0.37 & 0.33 & 0.40 & 0.43 & 0.24 & 0.35 & 0.10 & 0.09 & 0.34 & 0.06 \\
\hline$B$ & ND & ND & ND & ND & ND & ND & ND & ND & ND & ND \\
\hline $\mathrm{Ca}$ & $N D$ & ND & ND & 0.39 & ND & 1.07 & ND & ND & 0.25 & ND \\
\hline $\mathrm{Ce}$ & $N D$ & ND & ND & $N D$ & ND & $\mathrm{ND}$ & ND & ND & ND & ND \\
\hline $\mathrm{Cr}$ & 0.36 & 0.30 & 0.47 & 0.43 & 0.20 & 0.31 & 0.11 & 0.12 & 0.39 & 0.05 \\
\hline $\mathrm{Cu}$ & ND & ND & ND & $N D$ & ND & $\mathrm{ND}$ & ND & ND & ND & ND \\
\hline $\mathrm{Fe}$ & ND & ND & ND & ND & ND & ND & ND & ND & ND & ND \\
\hline $\mathrm{K}$ & 0.37 & 0.33 & 0.40 & 0.42 & 0.17 & 0.34 & 0.10 & 0.09 & 0.35 & 0.07 \\
\hline La & $N D$ & ND & ND & ND & ND & 5.04 & ND & ND & ND & ND \\
\hline $\mathrm{Mg}$ & ND & ND & ND & ND & ND & ND & ND & ND & ND & ND \\
\hline $\mathrm{Mn}$ & 11.61 & 35.53 & 49.73 & 16.92 & 33.68 & 2.13 & 5.75 & 3.79 & 18.83 & ND \\
\hline Mo & ND & ND & ND & ND & ND & ND & ND & ND & ND & ND \\
\hline $\mathrm{Nd}$ & ND & ND & ND & ND & ND & 1.48 & ND & ND & ND & ND \\
\hline $\mathrm{Ni}$ & 0.39 & 0.34 & 0.41 & 0.46 & 0.18 & 0.35 & 0.10 & 0.10 & 0.38 & 0.07 \\
\hline$P$ & 16.37 & 7.68 & 1.23 & 11.30 & 23.52 & 0.29 & 32.57 & 34.58 & 31.15 & 2.32 \\
\hline $\mathrm{Pb}$ & 0.37 & 0.54 & 0.83 & 0.46 & 0.34 & 0.23 & 0.16 & 0.24 & 0.38 & ND \\
\hline Si & ND & ND & ND & 8.84 & 114.23 & ND & 12.56 & 4.51 & 30.92 & ND \\
\hline $\mathrm{Sr}$ & 0.38 & 0.40 & 0.68 & 0.51 & 0.46 & 19.36 & ND & 0.16 & 0.46 & ND \\
\hline $\mathrm{Zn}$ & ND & ND & ND & ND & ND & ND & ND & ND & ND & ND \\
\hline $\mathrm{Zr}$ & $N D$ & ND & ND & $N D$ & ND & $\mathrm{ND}$ & ND & ND & ND & ND \\
\hline
\end{tabular}

The manganese level in the $0.0 \mathrm{M}$ added $\mathrm{NaOH}$ baseline experiments were below detection. The percent noted for the $25{ }^{\circ} \mathrm{C}$ reaction temperatures, 0.01 and $0.03 \mathrm{M} \mathrm{Mn}$ conditions were significantly lower than those due to filtrate variables, suggesting again that a reduced mass of manganese solids was present in the filtrate after 16 days. The mass percent found in these filtrates was 2.13 to 5.75 percent of the time zero mass to 10 to 50 percent noted for the base case reaction condition. The highest percent of manganese was found in the light condition, oxygen condition, and the $8 \mathrm{hr}$ hold experiments.

Strontium and manganese were the predominant cations present in post-filtration solids collected for the NOC primary effects study. The mass percent of strontium in the precipitates relative to the time zero masses ranged from 10.4 to 25.3 for reaction and treatment conditions included in the study. These relatively high values reflect the increased solubility of strontium at the $25{ }^{\circ} \mathrm{C}$ reaction condition and subsequent precipitation, likely as carbonates. Again this explanation is only plausible if solubility was impacted due to kinetic limitations. Reaction mixtures conducted at $50{ }^{\circ} \mathrm{C}$ were quickly cooled to 25 degrees, centrifuged, and filtered immediately.

Recall that dark solids were not present on the 16-day particulate filters (Appendix F) for the NOC base case experiments. Similar filters for the $0.01 \mathrm{M}$ manganese and oxygen treatments were devoid of a significant particulate mass and were light brown and gray in color. Percent manganese measured on these filters was non-detect to 0.04 percent. However, solids collected on the particulate filters for the light treatment were dark 
WSRC-TR-2003-00232, Rev. 0

SRT-RPP-2003-00105, Rev. 0

crystalline solids (observed by light microscope) and were composed primarily of manganese (Table 4.5.1.4).

Table 4.5.1.4 Percent of Cation Mass Present in Solids Relative to Time Zero Cation Mass in AN-102 NOC Primary Effects Study

\begin{tabular}{|c|c|c|c|c|}
\hline \multicolumn{5}{|c|}{$\begin{array}{l}\text { Percent of Cation Present at Time 0 Found in Dissolved Solids (=mass } \\
\left.\text { in solid/mass in time } 0 \text { filtrate }{ }^{*} 100\right)\end{array}$} \\
\hline Elem & Avg NOC & NOC-.01Mn & NOC-Light & NOC-O2 \\
\hline $\mathrm{Al}$ & 0.07 & 0.07 & 0.08 & 0.06 \\
\hline$B$ & ND & ND & ND & ND \\
\hline $\mathrm{Ca}$ & ND & 0.48 & ND & ND \\
\hline $\mathrm{Ce}$ & ND & ND & ND & ND \\
\hline $\mathrm{Cr}$ & 0.05 & 0.04 & 0.07 & 0.06 \\
\hline $\mathrm{Cu}$ & ND & ND & ND & ND \\
\hline $\mathrm{Fe}$ & ND & ND & ND & ND \\
\hline $\mathrm{K}$ & 0.07 & 0.06 & 0.08 & 0.07 \\
\hline La & ND & ND & ND & ND \\
\hline $\mathrm{Mg}$ & ND & ND & ND & ND \\
\hline Mn & ND & 0.04 & 27.53 & ND \\
\hline Mo & ND & ND & ND & ND \\
\hline $\mathrm{Nd}$ & ND & ND & ND & ND \\
\hline $\mathrm{Ni}$ & 0.07 & 0.07 & 0.08 & 0.08 \\
\hline $\mathrm{P}$ & 0.54 & 0.06 & 0.17 & 0.23 \\
\hline $\mathrm{Pb}$ & ND & 0.05 & 0.51 & ND \\
\hline $\mathrm{Si}$ & ND & ND & 1.47 & ND \\
\hline $\mathrm{Sr}$ & 25.28 & 10.43 & 12.24 & 15.11 \\
\hline $\mathrm{Zn}$ & ND & ND & ND & ND \\
\hline $\mathrm{Zr}$ & ND & ND & ND & ND \\
\hline
\end{tabular}

Estimated rate constants and half-lives describing the loss of manganese from filtrates during the 16-day observation period are listed in Table 4.5.1.5 for the 241-AN-102 primary effects study. Also listed in the table is the percent of manganese lost from solution compared with the initial filtrates. These data indicate a good correlation to the estimated half-lives for the treatment conditions. For example, the half-lives calculated for the $0.01 \mathrm{M}$ and $0.03 \mathrm{M}$ permanganate reaction condition are 161 and 99 days respectively, and the mass of manganese lost from the filtrates was 3.8 and 5.8\% respectively. Similarly, the estimated half-lives calculated for the light and oxygen treatment were 6.9 and 14.4 days, and the mass of manganese lost from the filtrates was 49.7 and $33.7 \%$ respectively. Treatment conditions exhibiting small half-lives could potentially result in an accumulation of post-filtration solids that may be problematic in the ion exchange process. 
WSRC-TR-2003-00232, Rev. 0

SRT-RPP-2003-00105, Rev. 0

Table 4.5.1.5 Estimated First Order Rate Constants and Half-lives for Loss of Manganese From the Primary Effects Filtrates During the 16-Day Observational Period

\begin{tabular}{|c|c|c|c|c|c|c|c|c|}
\hline & \multicolumn{2}{|c|}{ Simulant A } & \multicolumn{2}{|c|}{ Simulant B } & \multicolumn{4}{|c|}{ Combined } \\
\hline & $k\left(d^{-1}\right)$ & $\mathbf{R}^{2}$ & $k\left(d^{-1}\right)$ & $\mathbf{R}^{2}$ & $k\left(d^{-1}\right)$ & $\mathbf{R}^{2}$ & $t_{1 / 2}$ (Days) & $(\mathrm{Mp} / \mathrm{Mt})^{*} 100$ \\
\hline BC 8/20 & 0.0231 & 0.7828 & 0.0131 & 0.9359 & 0.0181 & 0.4166 & 38 & 116 \\
\hline BC 9/10 & 0.0289 & 0.9897 & 0.0205 & 0.7827 & 0.0247 & 0.8627 & 28 & \\
\hline $0.03 \mathrm{M} \mathrm{Sr}$ & 0.0259 & 0.8641 & 0.0291 & 0.7963 & 0.0275 & 0.8219 & 25 & 18.8 \\
\hline $0.01 M \mathrm{Mn}$ & 0.0047 & 0.8997 & 0.0039 & 0.3598 & 0.0043 & 0.5468 & 161 & 3.8 \\
\hline $0.03 \mathrm{M} M n$ & 0.0078 & 0.5268 & 0.0062 & 0.6355 & 0.0070 & 0.5413 & 99 & 5.8 \\
\hline Light & 0.2007 & 0.9589 & 0.0997 & 0.9799 & 0.1002 & 0.9516 & 7 & 49.7 \\
\hline $\mathrm{O}_{2}$ & 0.0502 & 0.9750 & 0.0461 & 0.9981 & 0.0481 & 0.8577 & 14 & 35.5 \\
\hline 8hr@100C & 0.0879 & 0.9180 & 0.1009 & 0.9479 & 0.0944 & 0.9301 & 7 & 33.7 \\
\hline Shear & 0.0239 & 0.8972 & 0.0237 & 0.8033 & 0.0238 & 0.8280 & 29 & 16.9 \\
\hline $\mathrm{NOCO}_{2}$ & 0.0014 & 0.8249 & 0.0013 & 0.9939 & 0.0014 & 0.8371 & 495 & ND \\
\hline NOC Light & 0.0378 & 0.9042 & 0.0386 & 0.9333 & 0.0382 & 0.9088 & 18 & 27.5 \\
\hline
\end{tabular}

\subsubsection{Secondary Effects Study}

\section{$\underline{\text { Visual Observations }}$}

Variables investigated for the AN-102 secondary effects study are listed in Table 4.5.2.1 with notation indicating the time at which visible light and dark solids appeared in the respective filtrates during the 16-day observation period. At the end of the 16-day period, filtrates were filtered under a nitrogen blanket to gravimetrically determine the mass of solids formed and the color and texture of the solids.

All filtrates were yellow or greenish-yellow in color, with the $25{ }^{\circ} \mathrm{C}$ Rxn, light sample having more of a green tint. Light-colored or clear solids appeared on the bottom of all sample flasks by day 1 , with the exception of the $0 \mathrm{M} \mathrm{OH} / 25{ }^{\circ} \mathrm{C} \mathrm{Rxn}$, and the $25{ }^{\circ} \mathrm{C} \mathrm{Rxn} / 0.03 \mathrm{M} \mathrm{Mn}$ samples in which they appeared on days 8 and 10 , respectively. Light-colored solids also appeared on the surface of all filtrates between days 1 and 4 . It was observed that the lightcolored surface solids in most samples became darker with time, presumably due to oxidation. Samples were maintained under a nitrogen blanket except for the short intervals when ICP-AES samples were collected. Such solids were noted recorded as dark solids when they became medium brown in color. All samples reacted at the $25{ }^{\circ} \mathrm{C}$ reaction condition had dark solids present on the surface of the filtrate and/or the bottom of the flask by day 16 with the exception of the sample reacted with $0.0 \mathrm{M}$ added $\mathrm{NaOH}$.

Correspondingly, none of the samples reacted with $0.0 \mathrm{M}$ added $\mathrm{NaOH}$ had visible dark solids in the filtrates by day 16 except for the sample that was exposed to the light. Digital photographs of all filtrates can be found in Appendix F. 
WSRC-TR-2003-00232, Rev. 0

SRT-RPP-2003-00105, Rev. 0

Table 4.5.2.1 Visual Observations for 241-AN-102 Post-Filtration Precipitation Study (Secondary Effects Experiments)

\begin{tabular}{|c|c|c|c|c|c|}
\hline Sample Condition & Filtrate Color & $\begin{array}{c}\text { Light solids on } \\
\text { bottom }\end{array}$ & $\begin{array}{l}\text { Light solids } \\
\text { on surface }\end{array}$ & $\begin{array}{c}\text { Dark solids } \\
\text { on surface }\end{array}$ & $\begin{array}{c}\text { Dark solids } \\
\text { on bottom }\end{array}$ \\
\hline $0 \mathrm{M} \mathrm{OH}, 0.03 \mathrm{M} \mathrm{Sr}$ & Yellow/lime green & $\begin{array}{c}\text { Day } 1 \\
\text { Clear crystal }\end{array}$ & Day 4 & $\mathrm{X}$ & $\mathrm{X}$ \\
\hline $\begin{array}{c}\text { 0M OH, } 0.03 \mathrm{M} \\
\mathrm{Mn}\end{array}$ & Yellow/lime green & $\begin{array}{c}\text { Day } 1 \\
\text { Clear crystals }\end{array}$ & Day 4 & $\mathrm{X}$ & $\mathrm{X}$ \\
\hline 0M OH, Light & Yellow/lime green & $\begin{array}{c}\text { Day } 1 \\
\text { Clear crystals } \\
\end{array}$ & Day 2 & Day 7 & Day 16 \\
\hline $0 \mathrm{M} \mathrm{OH}, \mathrm{O}_{2}$ & Yellow/lime green & $\begin{array}{c}\text { Day } 1 \\
\text { Clear crystals }\end{array}$ & Day 4 & $\mathrm{X}$ & $\mathrm{X}$ \\
\hline $0 \mathrm{M} \mathrm{OH}, 25^{\circ} \mathrm{C} \mathrm{Rxn}$ & Yellow/lime green & Day 8 & Day 4 & $\mathrm{X}$ & $X$ \\
\hline $25^{\circ} \mathrm{C} \mathrm{Rxn}, 0.03 \mathrm{Sr}$ & Yellow/green & Day 1 & Day 1 & Day 16 & $\mathrm{X}$ \\
\hline $25^{\circ} \mathrm{C} \mathrm{Rxn}$, light & Green/yellow & Day 1 & Day 1 & Day 4 & Day 10 \\
\hline $25^{\circ} \mathrm{C} \mathrm{Rxn}, \mathrm{O}_{2}$ & Yellow & Day 1 & Day 1 & $\mathrm{X}$ & Day 10 \\
\hline $\begin{array}{c}25^{\circ} \mathrm{C} \mathrm{Rxn}, 0.03 \mathrm{M} \\
\mathrm{Mn}\end{array}$ & Yellow & Day 10 & Day 4 & Day 16 & Day 10 \\
\hline
\end{tabular}

$\mathrm{X}$ denotes no solids present at Day 16

Light solids are white to light brown

Dark solids are dark brown to black

All filtrate observations regarding the presence of dark solids correlate with observations of the respective particulate filters, with the exception of the $0 \mathrm{M} \mathrm{OH}, \mathrm{O}_{2}$ and $25{ }^{\circ} \mathrm{C}$ sample, in which light brown solids noted on the filter could not be seen in the filtrate. This discrepancy could be due to a masking of the solids by the color of the filtrate or to the solids simply being too small to be seen in the filtrate. Light brown to black solids were present on all particulate filters except for those produced by the $0 \mathrm{M} \mathrm{OH}$ reaction condition crossed with $0.03 \mathrm{M}$ added $\mathrm{Sr}, 0.03 \mathrm{M}$ added $\mathrm{Mn}$, or the $25^{\circ} \mathrm{C}$ reaction condition.

In summary, these observations indicate that a $25{ }^{\circ} \mathrm{C}$ reaction temperature is not effective in inhibiting the formation of post-filtration solids when crossed with other variables that may promote solid formation. The $0.0 \mathrm{M}$ added $\mathrm{NaOH}$ reaction condition does not promote solid formation and may inhibit the formation of solids when crossed with other variables that promote solid formation. Exposure to light is also seen to be very effective in promoting the formation of dark brown to black post-filtration solids. 
WSRC-TR-2003-00232, Rev. 0

SRT-RPP-2003-00105, Rev. 0

Change in Metals Concentration During the 16 Day Observation Period for AN-102

ICP-AES data are shown for Mn, Fe, and $\mathrm{Sr}$ in Figures 4.5.2.1 through 4.5.2.6 for all samples included in the secondary effect study. Data for these cations as well as for cerium, lanthanum, neodymium, and zirconium are summarized in Table 4.5.2.2. Recall that a decrease in the concentration of cations present in the filtrates over the 16-day observation period indicates the formation of solids composed of the respective cations.

Data presented in Figures 4.5.2.1 and 4.5.2.2 indicate that manganese concentrations did not decrease significantly in any of the samples reacted with $0.0 \mathrm{M}$ added $\mathrm{NaOH}$, with the exception of those exposed to light. Conversely, manganese concentrations did decrease significantly in all samples reacted at $25{ }^{\circ} \mathrm{C}$ except for those reacted with $0.0 \mathrm{M}$ added $\mathrm{NaOH}$. Decreases in soluble manganese concentrations corresponded to the formation of dark post-filtration solids in filtrates, as is evidenced by photographs of the respective filters from final filtration of the samples (Appendix F). These findings indicate the importance of $0.0 \mathrm{M}$ added $\mathrm{NaOH}$ in inhibiting the formation of post-filtration solids, the importance of light exposure in promoting solids formation, and the failure of a low reaction temperature to prevent the formation of solids when crossed with other variables that promote their formation. Interestingly, as can be seen in Figure 4.5.2.7, secondary samples reacted with $0.0 \mathrm{M} \mathrm{NaOH}$ with exception of the $0.03 \mathrm{M} \mathrm{Mn}$, which is essentially constant, all had lower manganese concentrations in filtrates at time zero, which is in line with a similar observation made for the $0.0 \mathrm{M}$ added $\mathrm{NaOH}$ sample in the primary effects study. Manganese concentrations in samples reacted at $25{ }^{\circ} \mathrm{C}$, with exception of the $0.03 \mathrm{M} \mathrm{Mn}$, were also slightly lower than those observed for the respective primary effects samples. Although the mechanisms producing these effects are unclear, it is important to note that reaction conditions that result in decreased manganese concentrations in the filtrate thereby reduce the amount of manganese solids that can potentially form.

The data for iron, presented in Figures 4.5.2.3 and 4.5.2.4, indicate that iron concentrations did not decrease significantly in any of the secondary effects samples. However, as can be seen in Figure 4.5.2.8, samples reacted with $0.0 \mathrm{M}$ added $\mathrm{NaOH}$ did have slightly lower time zero iron concentrations in their filtrates, which cannot be supported by data from the primary effects sample with $0.0 \mathrm{M}$ added $\mathrm{NaOH}$, (Figure 4.5.1.16). Time zero iron concentrations in samples reacted at $25^{\circ} \mathrm{C}$ did not differ significantly from the base case.

Concentrations of all other cations $(\mathrm{Ce}, \mathrm{La}, \mathrm{Nd}, \mathrm{Zr})$ remained relatively constant over the 16day period (Table 4.5.2.2). Time zero concentrations of $\mathrm{La}$ and $\mathrm{Nd}$, however, are elevated in samples reacted at $25^{\circ} \mathrm{C}$ and lowered in samples reacted with $0.0 \mathrm{M}$ added $\mathrm{NaOH}$ (Figures 4.5.2.10 and 4.5.2.11). Additionally, a lower level of added sodium permanganate seems to have had the effect of increasing the time zero concentrations of not only $\mathrm{Mn}$, but also La, $\mathrm{Nd}$, and $\mathrm{Zr}$, offsetting the effects of $0.0 \mathrm{M}$ added $\mathrm{NaOH}$ (Figures 4.5.2.7 through 4.5.2.12). 
WSRC-TR-2003-00232, Rev. 0

SRT-RPP-2003-00105, Rev. 0

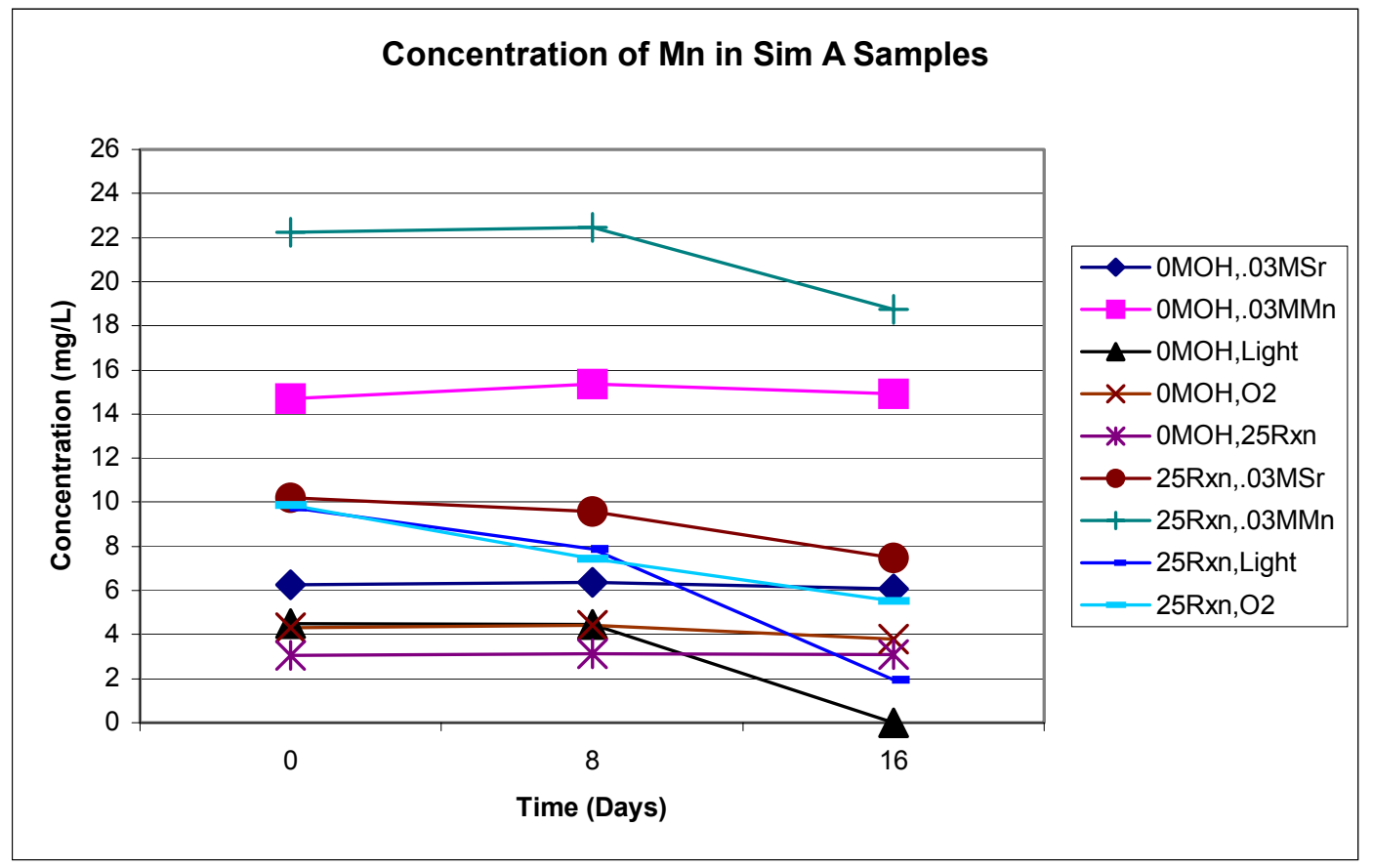

Figure 4.5.2.1 Concentration of Manganese in the 0-16 Day Simulant A Filtrates for the Baseline Secondary Effects Study (AN-102)

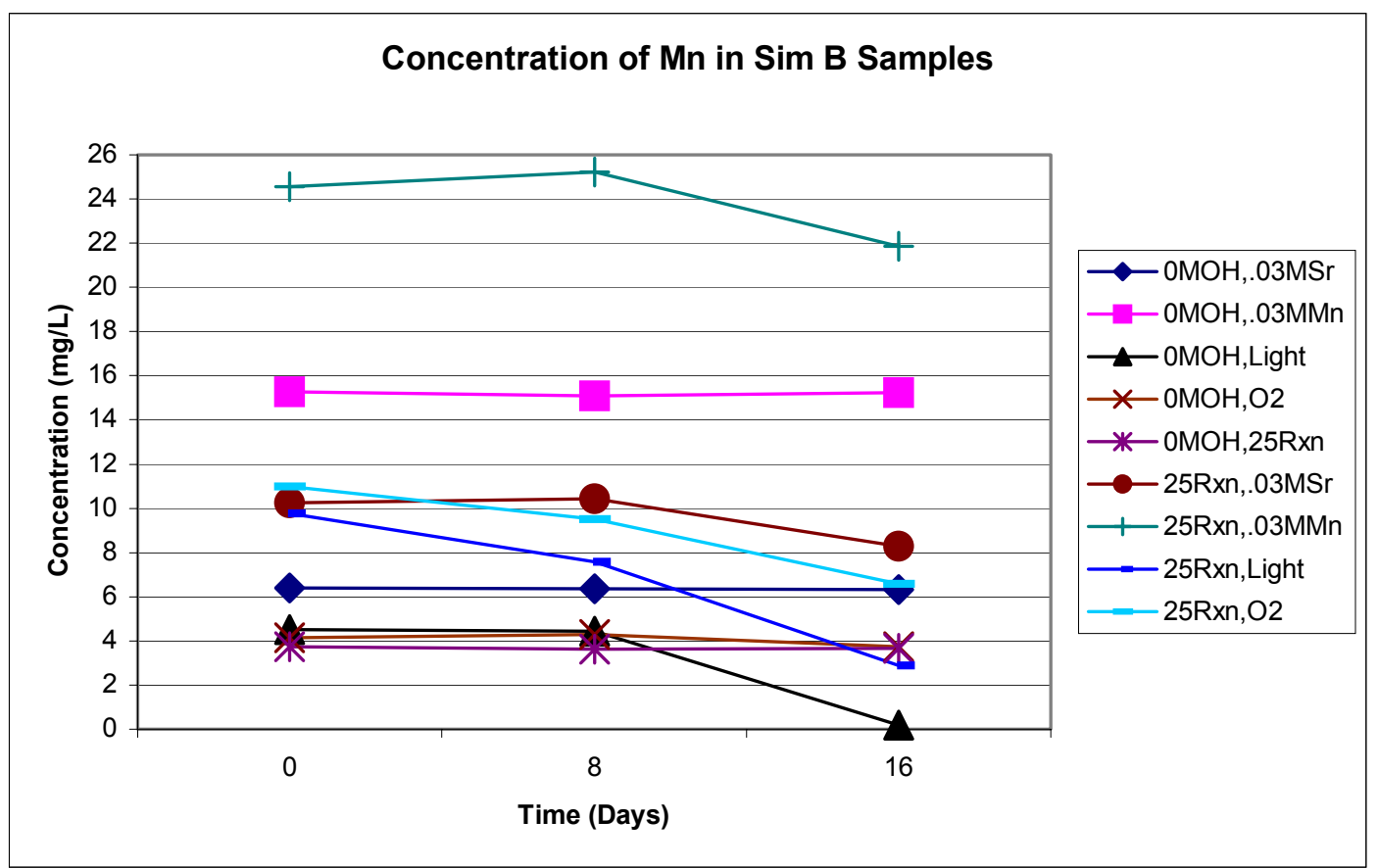

Figure 4.5.2.2 Concentration of Manganese in the 0-16 Day Simulant B Filtrates for the Baseline Secondary Effects Study (AN-102) 
WSRC-TR-2003-00232, Rev. 0

SRT-RPP-2003-00105, Rev. 0

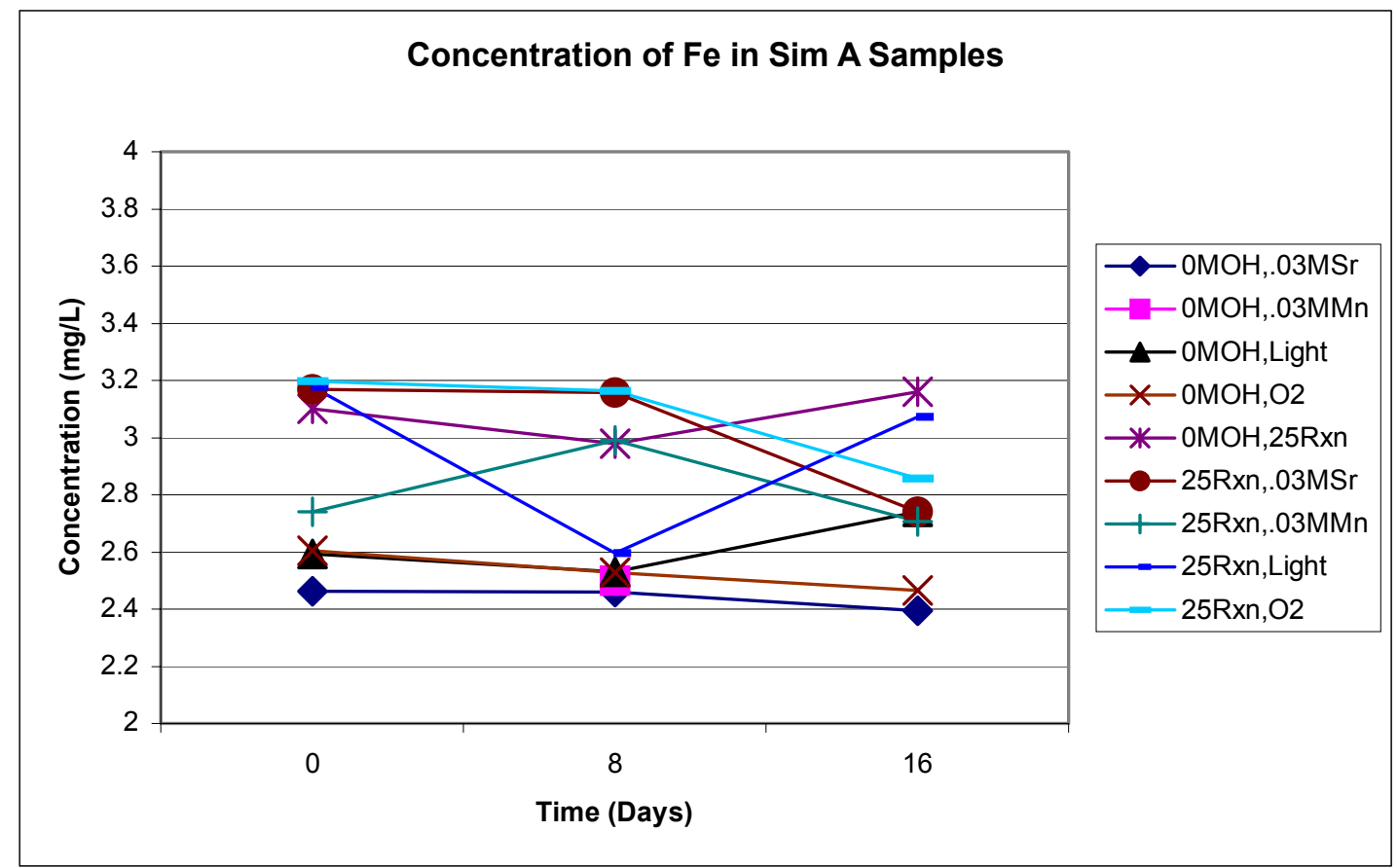

Figure 4.5.2.3 Concentration of Iron with 0-16 Day Simulant A Filtrates for the Baseline Secondary Effects Study (AN-102)

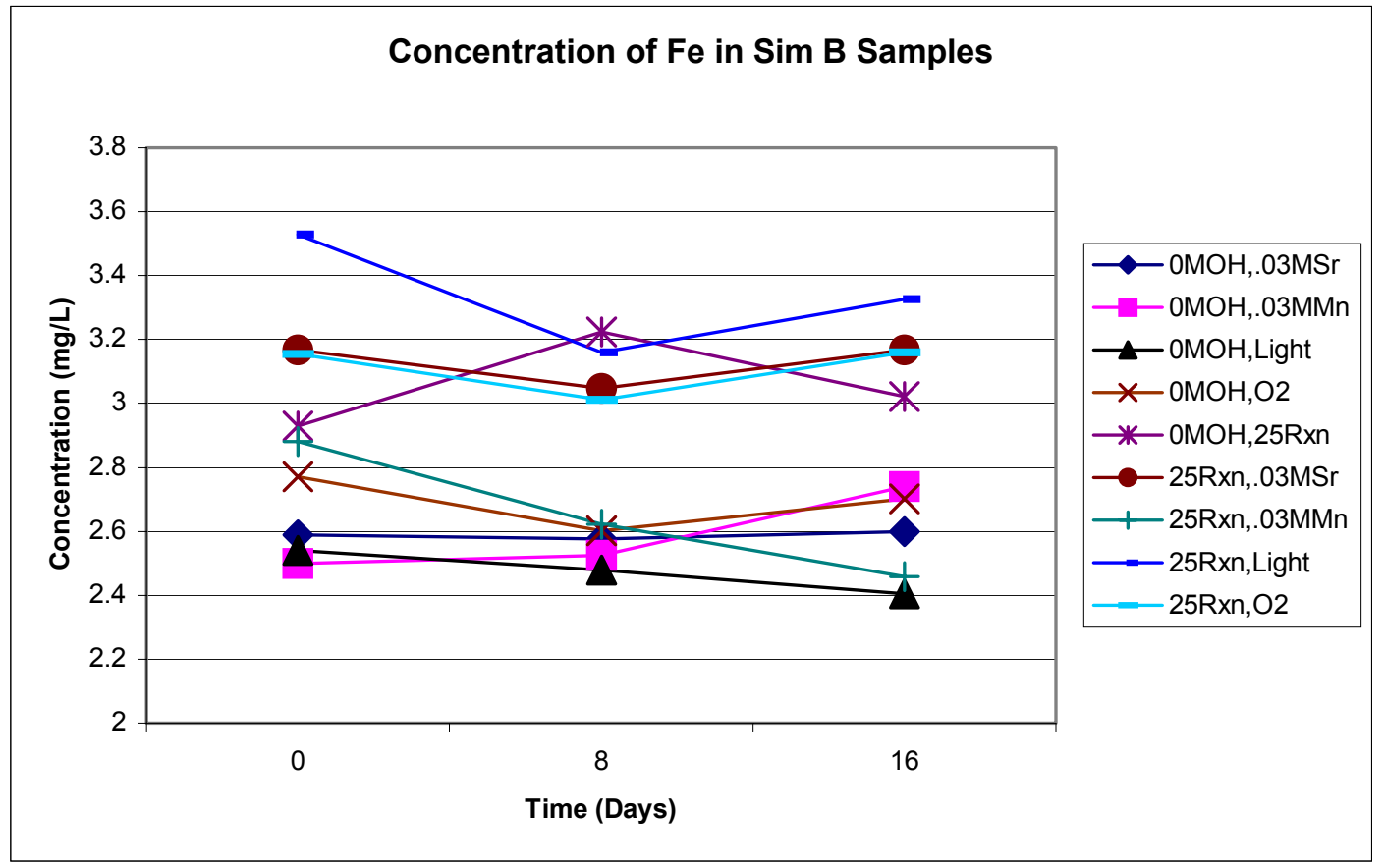

Figure 4.5.2.4 Concentration of Iron in the 0-16 Day Simulant B Filtrates for the Baseline Secondary Effects Study (AN-102) 
WSRC-TR-2003-00232, Rev. 0

SRT-RPP-2003-00105, Rev. 0

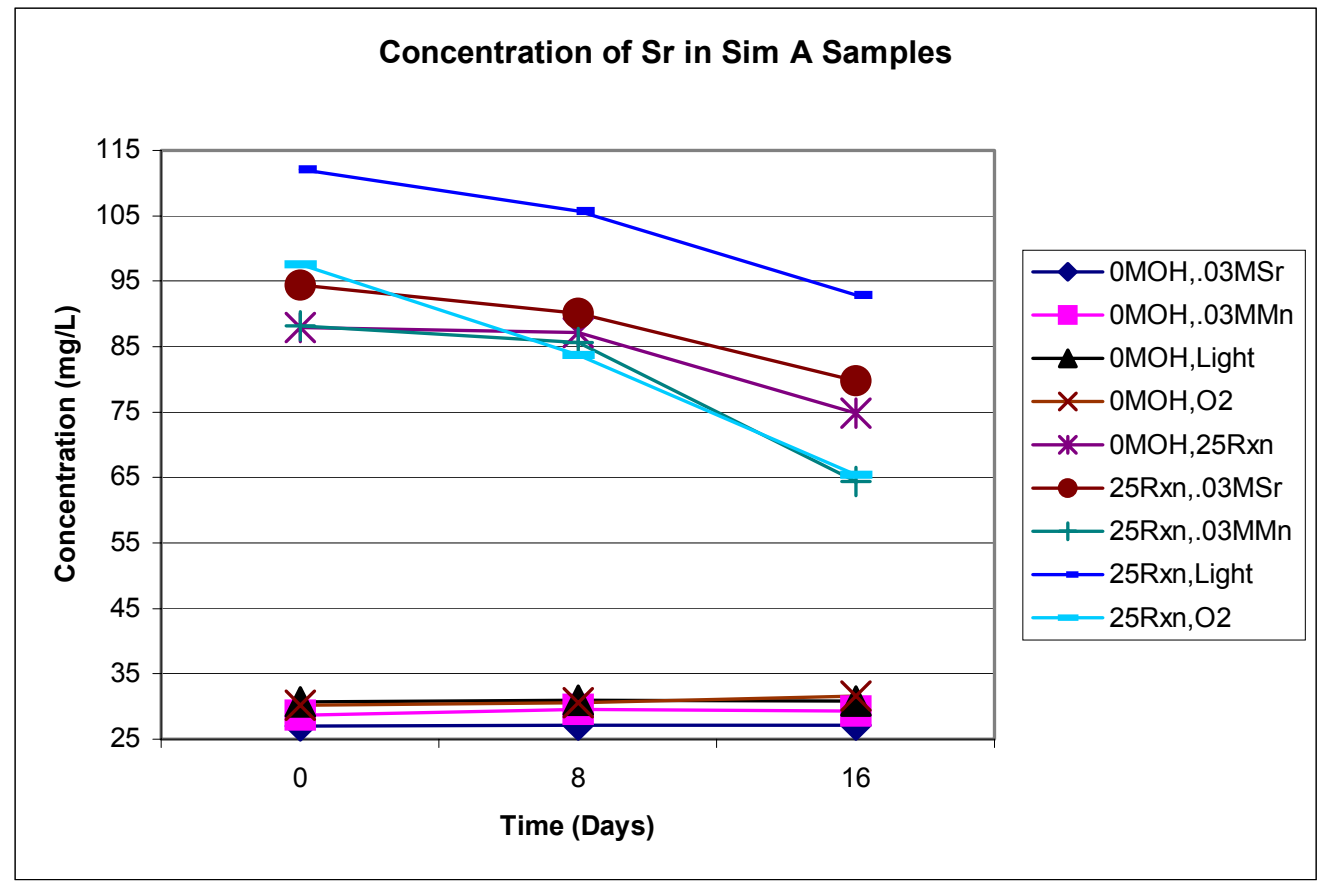

Figure 4.5.2.5 Concentration of Strontium in the 0-16 Day Simulant A Filtrates for the Baseline Secondary Effect Study (AN-102)

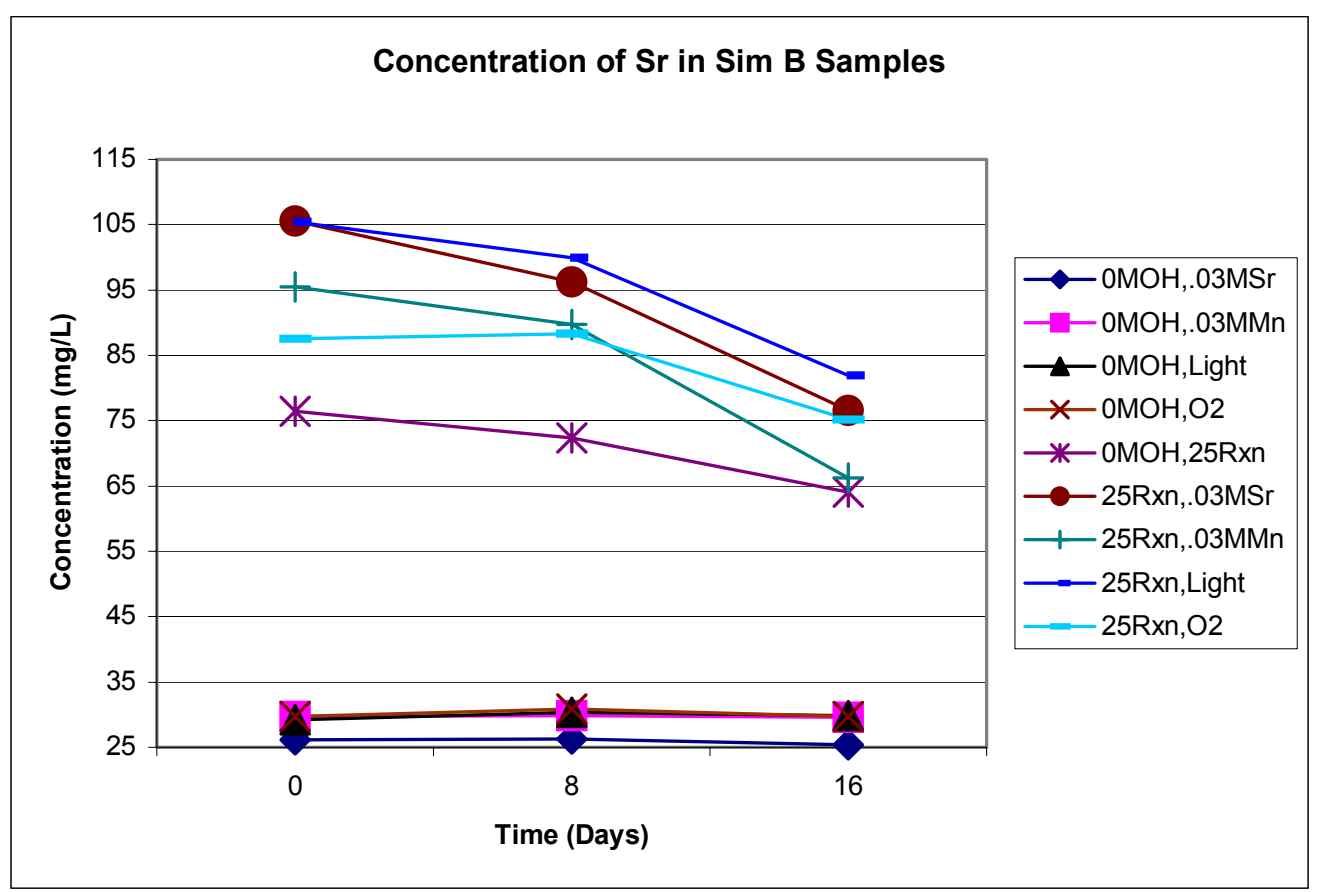

Figure 4.5.2.6 Concentration of Strontium in the 0-16 Day Simulant B Filtrates for the Baseline Secondary Effects Study (AN-102) 
WSRC-TR-2003-00232, Rev. 0

SRT-RPP-2003-00105, Rev. 0

Table 4.5.2.2 Concentration of Selected Cations for the 0-16 Day Observation Period for the Baseline Secondary Effects Study (AN-102)

\begin{tabular}{|c|c|c|c|c|c|c|c|}
\hline \multicolumn{8}{|c|}{ Cation Concentrations Over 16 Days (mg/L) } \\
\hline & Mn & $\mathrm{Fe}$ & $\mathrm{Sr}$ & $\mathrm{Ce}$ & La & Nd & $\mathrm{Zr}$ \\
\hline $\mathrm{OMOH}, .03 \mathrm{MSr}$ & C $6.30 \pm .127$ & C $2.51 \pm .0856$ & C $26.5 \pm .708$ & $N D<0.213$ & $N D<0.175$ & C $1.33 \pm .121$ & C $0.594 \pm .0174$ \\
\hline OMOH,.03MMn & C $15.1 \pm .250$ & C $\sim 2.40$ & C $29.4 \pm .400$ & $N D<0.213$ & C $0.482 \pm .0545$ & C $3.069 \pm .185$ & C $1.54 \pm .0679$ \\
\hline OMOH,Light & $4.49-0.093$ & C $2.55 \pm .115$ & C $30.3 \pm .68$ & $\mathrm{ND}<0.213$ & $\mathrm{ND}<0.175$ & C $0.956 \pm .0732$ & C $0.537 \pm .0322$ \\
\hline OMOH,02 & C $4.12 \pm .282$ & C $2.61 \pm .111$ & C $30.4 \pm .726$ & $N D<0.213$ & $N D<0.175$ & C $0.959 \pm .168$ & C $0.565 \pm .0286$ \\
\hline OMOH,25Rxn & C $3.39 \pm .321$ & C $3.07 \pm .113$ & $82.2-69.4$ & $\mathrm{ND}<0.213$ & C $0.262 \pm .0183$ & C $1.97 \pm .163$ & C $0.462 \pm .0150$ \\
\hline $25 \mathrm{Rxn}, .03 \mathrm{MSr}$ & $10.2-7.89$ & C $3.08 \pm .170$ & $100-88.0$ & $0.415-\mathrm{ND}<.2125$ & C $1.13 \pm .122$ & C $5.54 \pm .431$ & C $0.812 \pm .0645$ \\
\hline 25Rxn,.03MMn & $23.4-20.3$ & C $3.70 \pm .206$ & $109-94.9$ & C $0.320 \pm .0482$ & C $1.46 \pm .0333$ & C $5.61 \pm .135$ & C $1.84 \pm .196$ \\
\hline 25Rxn,Light & $9.77-3.40$ & C $3.14 \pm .312$ & $109-87.4$ & $C \sim 0.32$ & C $1.09 \pm .152$ & C $4.77 \pm .296$ & C $.780 \pm .0834$ \\
\hline $25 \mathrm{Rxn}, \mathrm{O2}$ & $10.4-6.06$ & C $3.09 \pm .131$ & $92.5-70.3$ & ND $<.213$ & C $1.23 \pm .155$ & C $4.97 \pm .441$ & C $0.836 \pm .103$ \\
\hline
\end{tabular}

Table 4.5.2.2 summarizes the ICP-AES data for all secondary effect samples. Concentration ranges appearing in bold differed significantly over the 16-day observation period. Those values preceded by the letter " $\mathrm{C}$ " remained relatively constant throughout the 16-day period.

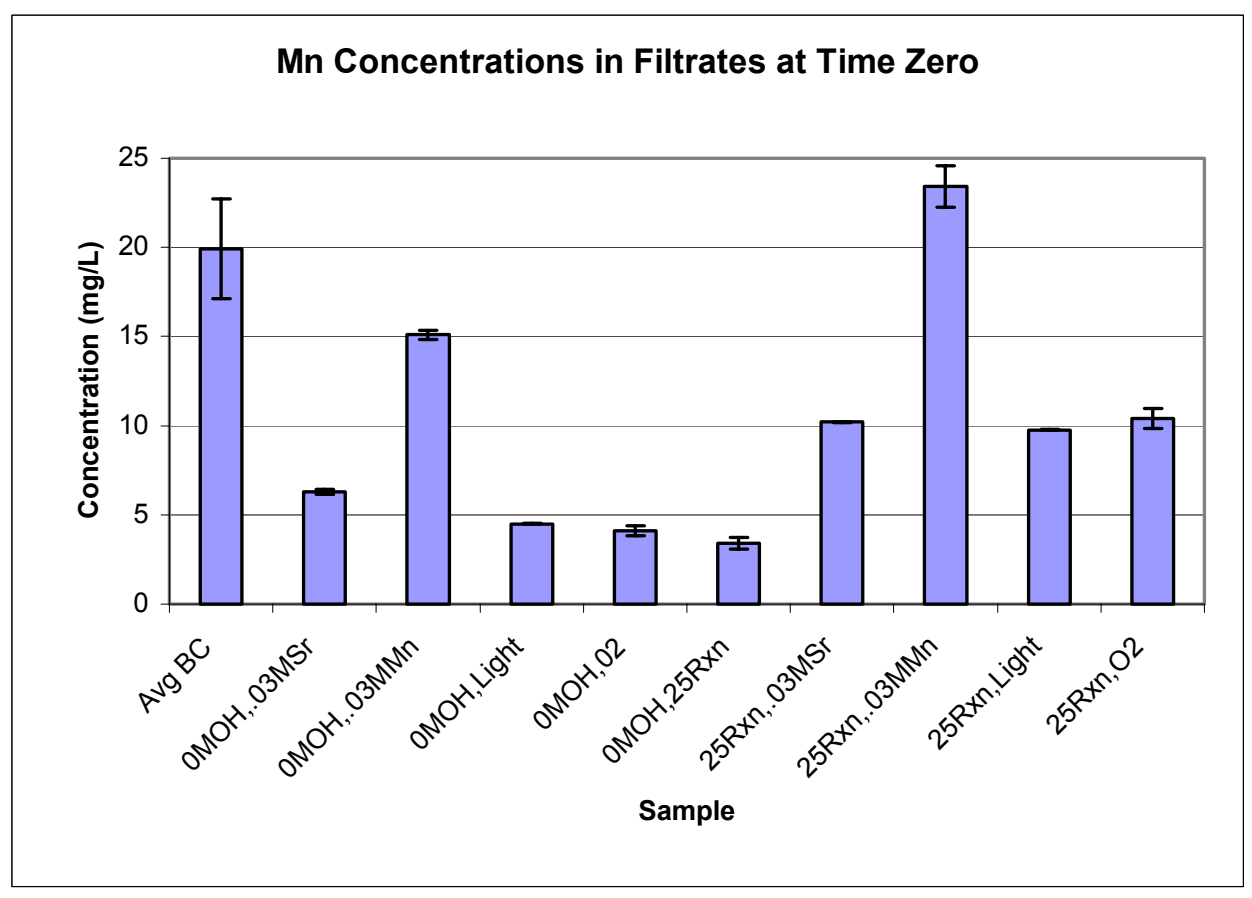

Figure 4.5.2.7 Manganese Concentration in Time Zero Filtrate for the Variables Included in the AN-102 Secondary Effects Study 
WSRC-TR-2003-00232, Rev. 0

SRT-RPP-2003-00105, Rev. 0

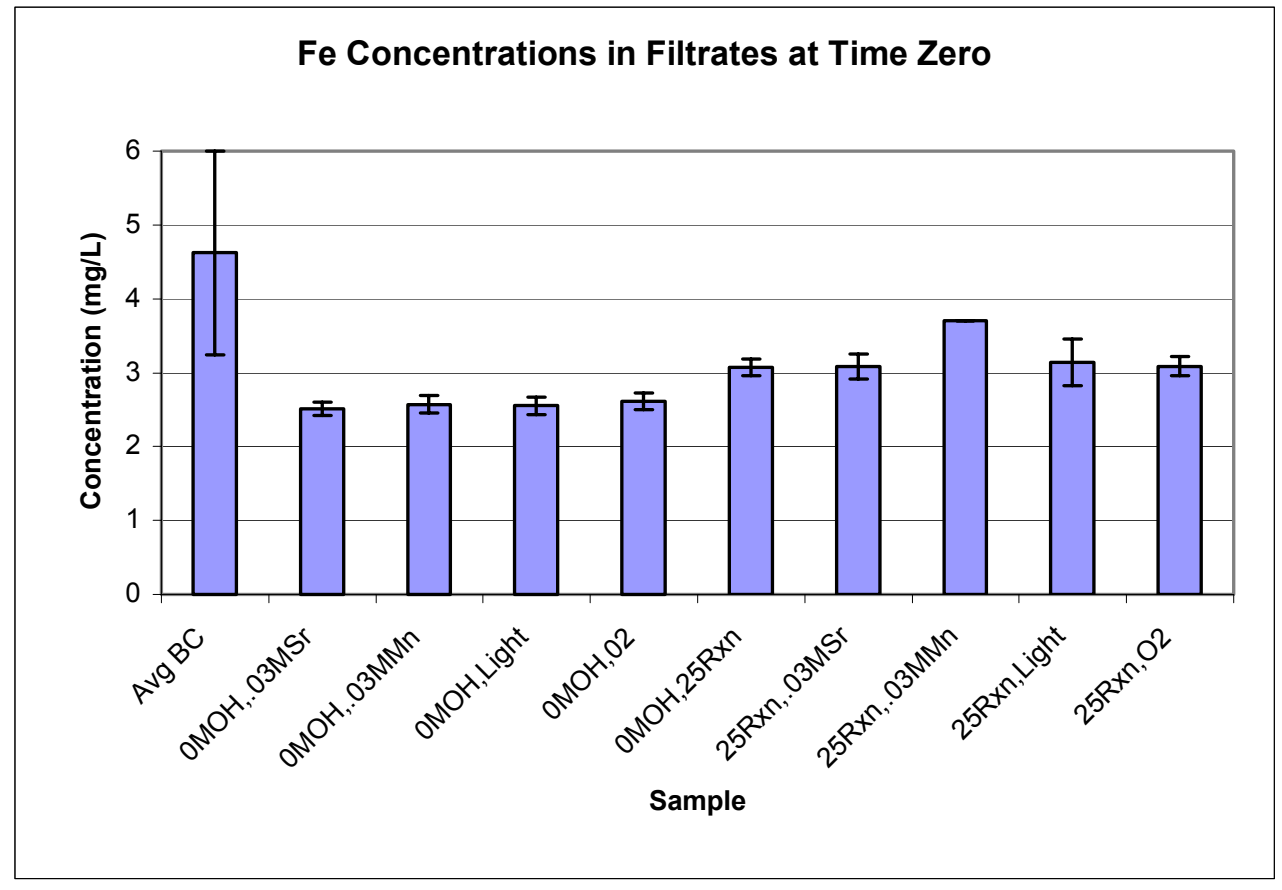

Figure 4.5.2.8 Iron Concentration in Time Zero Filtrate for the Variables Included in the AN-102 Secondary Effects Study

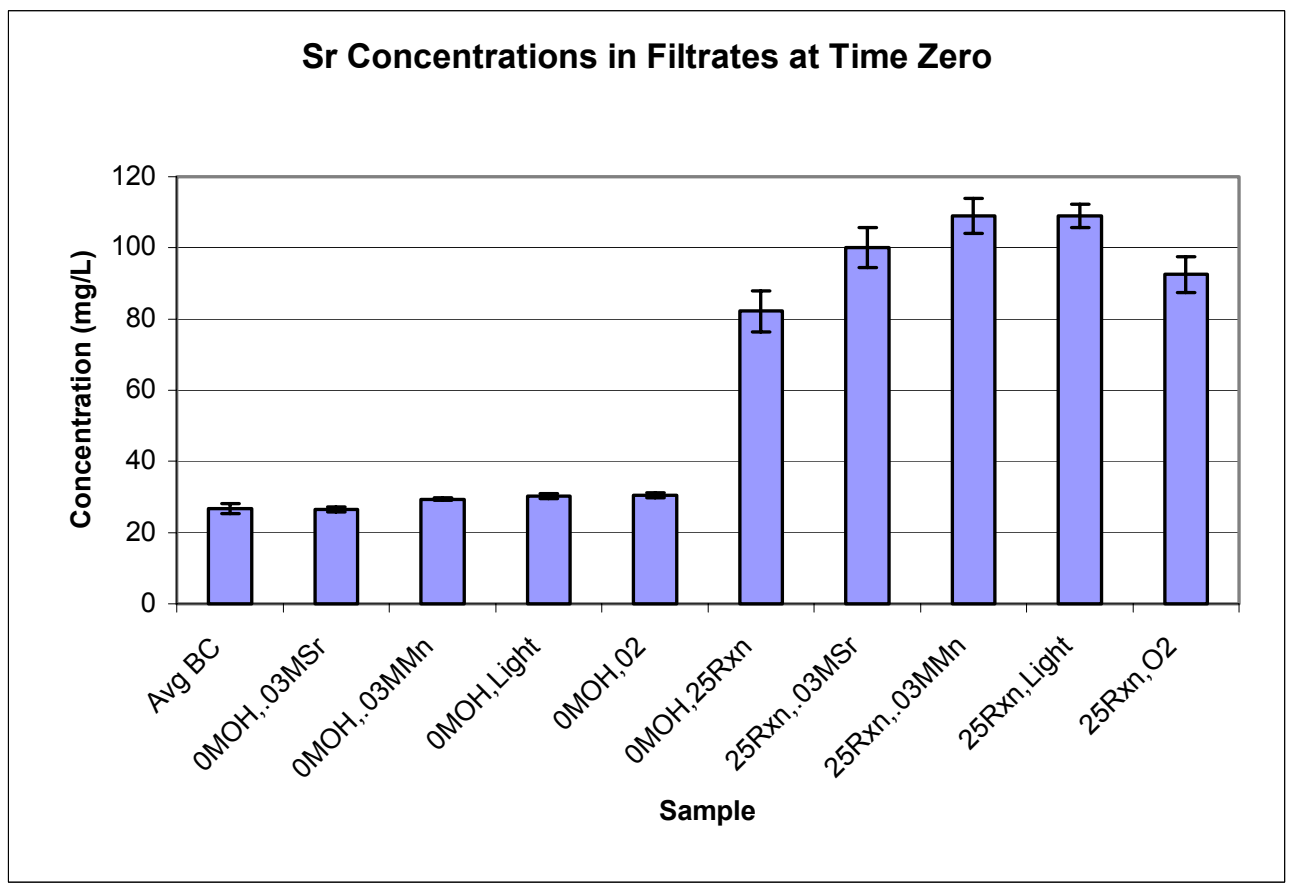

Figure 4.5.2.9 Strontium Concentration in Time Zero Filtrate for the Variables Included in theAN-102 Secondary Effects Study 
WSRC-TR-2003-00232, Rev. 0

SRT-RPP-2003-00105, Rev. 0

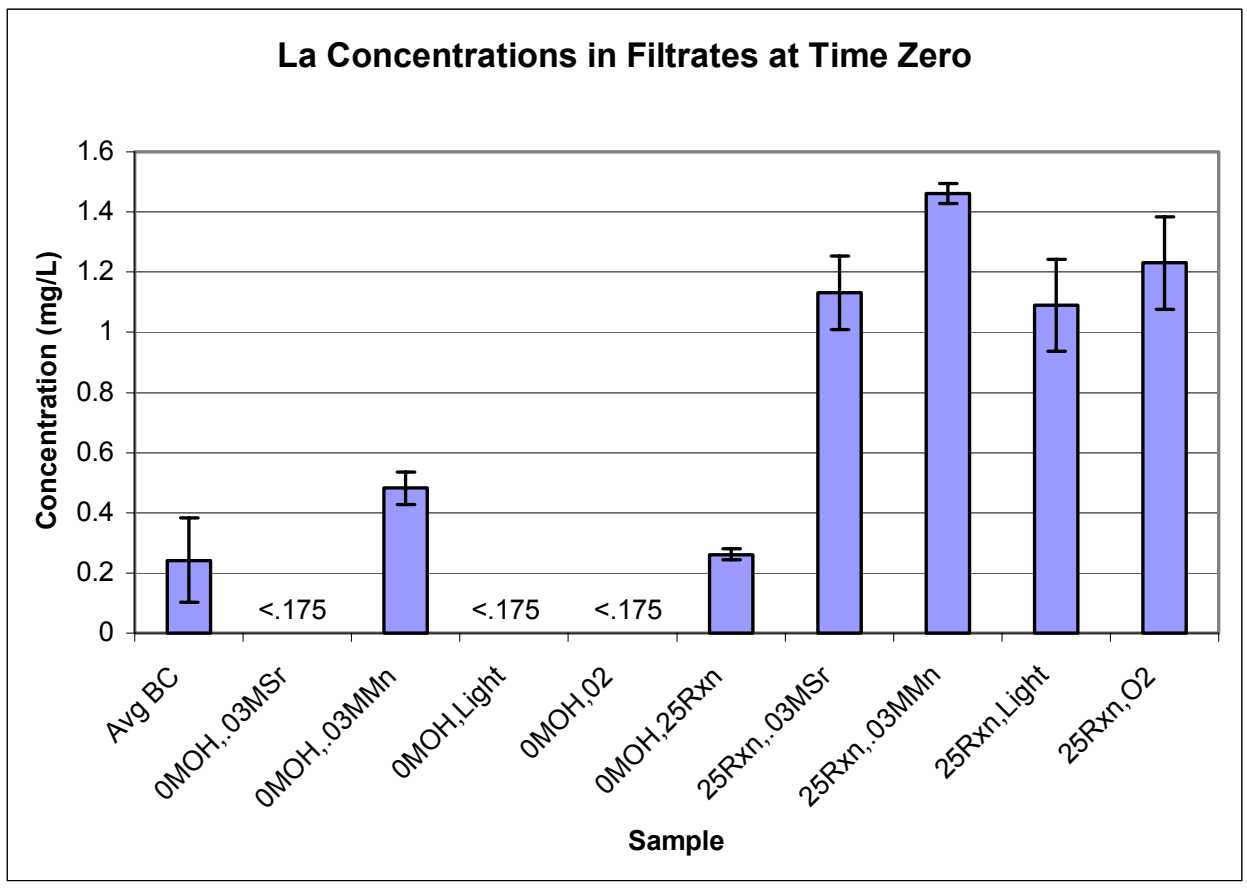

Figure 4.5.2.10 Lanthanum Concentration in Time Zero Filtrate for the Variables Included in the AN-102 Secondary Effects Study

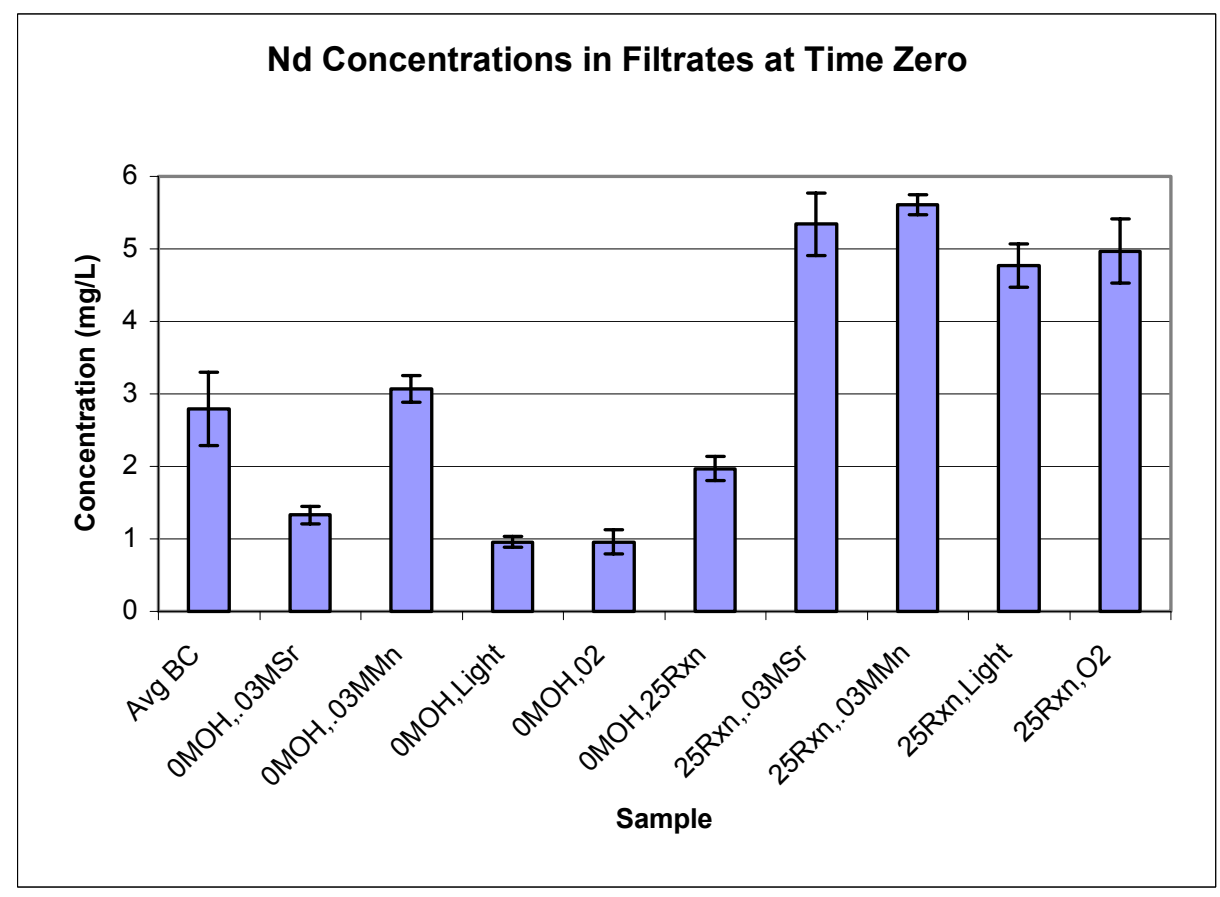

Figure 4.5.2.11 Neodymium Concentration in Time Zero Filtrate for the Variables Included in the AN-102 Secondary Effects Study 
WSRC-TR-2003-00232, Rev. 0

SRT-RPP-2003-00105, Rev. 0

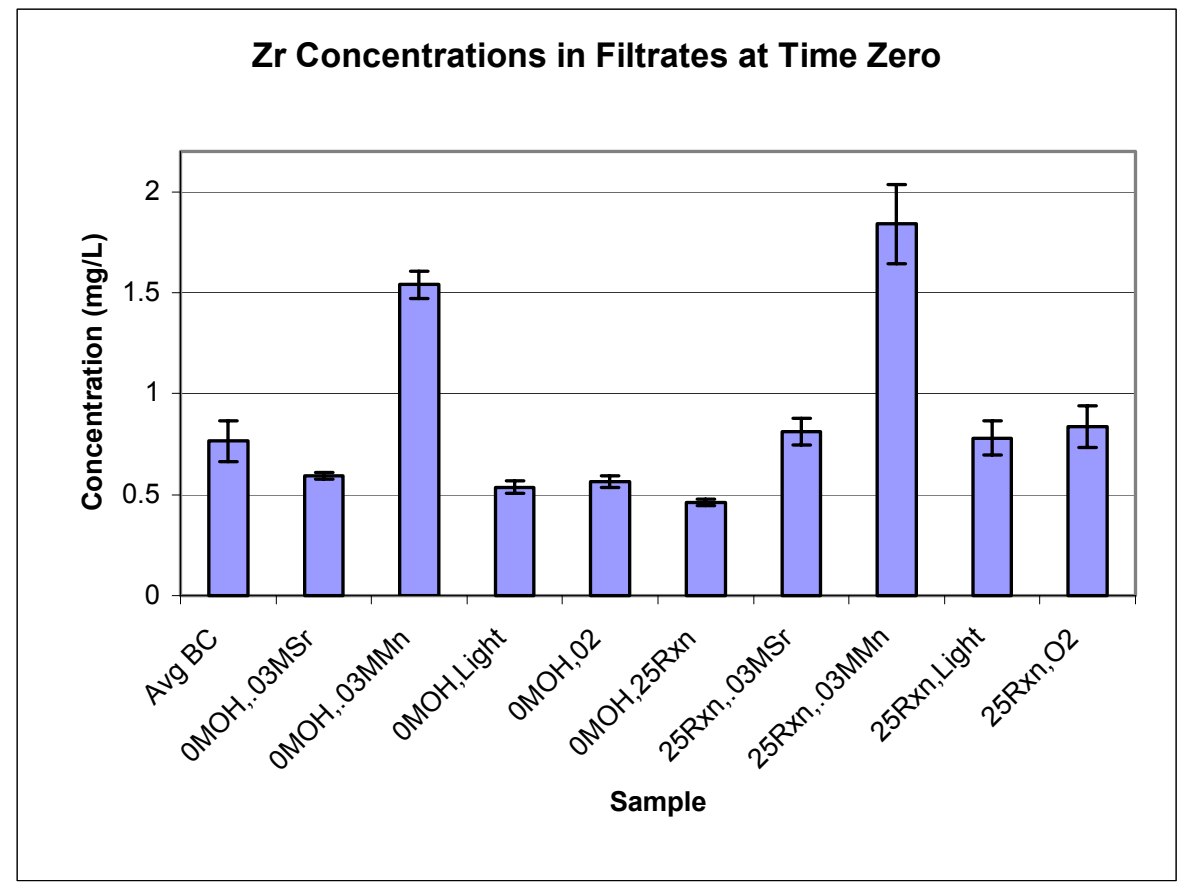

Figure 4.5.2.12 Zirconium Concentration in Time Zero Filtrate for the Variables Included in the AN-102 Secondary Effects Study

Characterization Of Solids Formed During The 16 Days

At the end of the 16-day observational period, samples were filtered to determine the mass of post-filtration solids that formed in the filtrates. Samples were filtered under nitrogen to reduce the formation of sodium bicarbonate on the filters by reaction of the base media with carbon dioxide in the atmosphere. Mass data was normalized to a filtrate volume of $100 \mathrm{mls}$. The initial volume of filtrate stored was $150 \mathrm{mls}$. Five $10-\mathrm{mL}$ aliquots were removed during the 16-day period for ICP-AES analysis. Solids concentration data for all of the primary effects variables is shown in Figure 4.5.2.13 and is presented to show the magnitude of solids formed for the baseline secondary effects study. The amount of post-filtration solids formed for all samples reacted with $0.0 \mathrm{M}$ added $\mathrm{NaOH}$ was significantly larger than that for the primary effect of $0.0 \mathrm{M} \mathrm{NaOH}$, with the exception of the sample reacted at $25{ }^{\circ} \mathrm{C}$. Of the four samples that produced more solids than during the primary effects study, all produced masses of solids that were not significantly different from those produced by the primary effect baseline experiments, with the exception of the sample exposed to the light, which produced less solids (Figure 4.5.1.28). None of the samples reacted at $25{ }^{\circ} \mathrm{C}$ produced masses of solids that were significantly different from the $25{ }^{\circ} \mathrm{C}$ primary effect samples except for the replicate $0.03 \mathrm{M}$ Mn samples and replicate $0.0 \mathrm{M} \mathrm{OH}$ samples, which both produced significantly less solids. All $25{ }^{\circ} \mathrm{C}$ experiments produced less solids than the primary effects baseline samples except for those sparged with oxygen.

Solids that formed during the 16-day period not only included dark manganese solids, but a significant accumulation of white solids. Precipitates were dissolved in $0.5 \mathrm{M}$ nitric acid and 
WSRC-TR-2003-00232, Rev. 0

SRT-RPP-2003-00105, Rev. 0

analyzed by ICP-AES to determine the major cations present in the particulate mass. These data are presented in Table 4.5.2.3. Represented in the table is the percent of cation present in the precipitate mass relative to the time zero mass of cation in the filtrate. The predominant cations found in precipitate masses were manganese and phosphorus in samples reacted with $0.0 \mathrm{M} \mathrm{NaOH}$ and manganese and strontium in samples reacted at $25^{\circ} \mathrm{C}$. There was also a predominance of cerium in the $25^{\circ} \mathrm{C}$ samples that were exposed to oxygen and in those that were reacted with $0.03 \mathrm{M} \mathrm{Mn}$. Sodium concentrations in the samples were not measured.

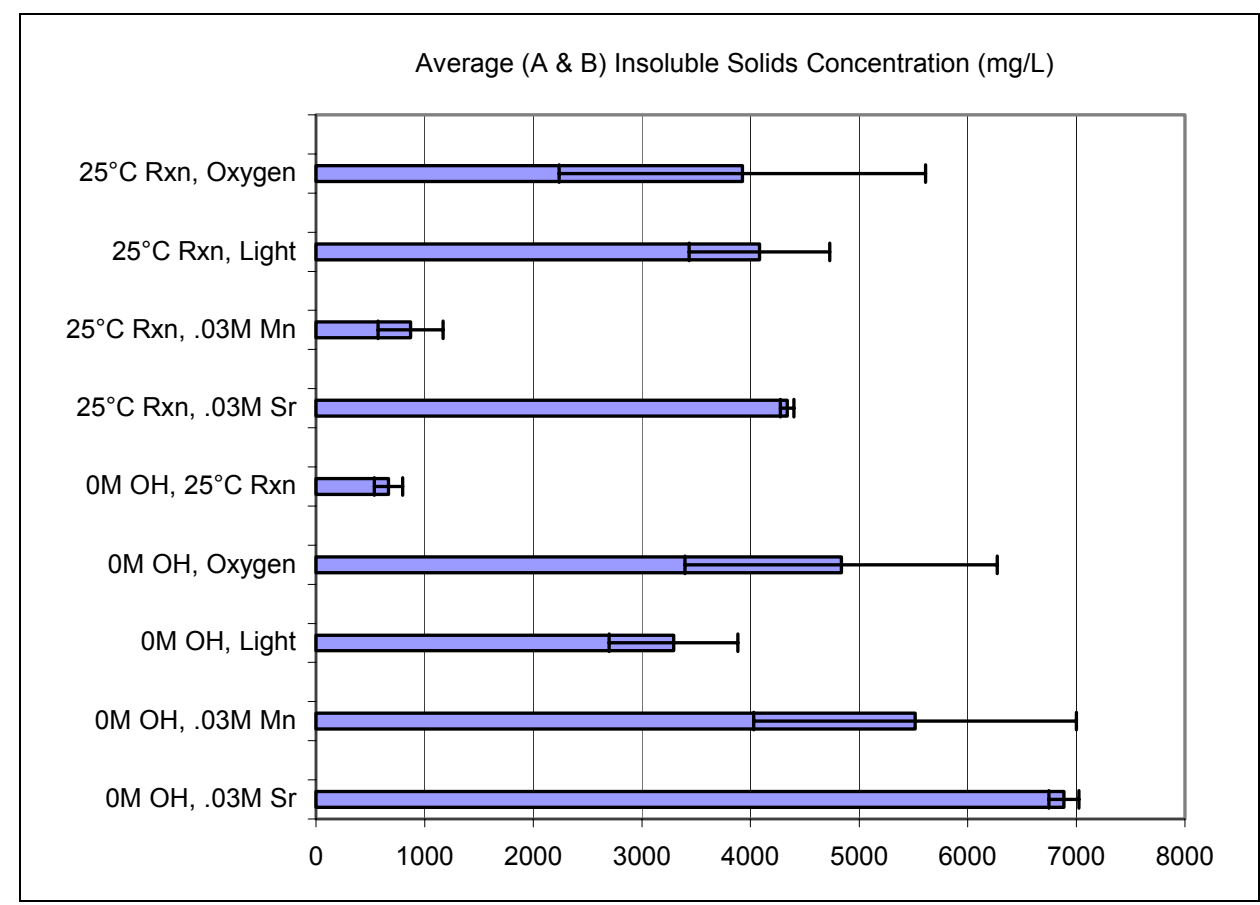

Figure 4.5.2.13 Concentration of Solids as a Function of Treatment Condition in the Baseline Secondary Effects Samples (AN-102)

Recall from Table 4.5.1.3 that manganese was below detection in the precipitates of the 0.0 $\mathrm{M}$ added $\mathrm{NaOH}$ primary effect samples. In the secondary effects samples, however, 55.6 percent of the time-zero-mass of manganese precipitated from filtrates exposed to light during the 16 day period, and 7.21 percent from filtrates sparged with oxygen (Table 4.5.2.3). The percentages of manganese that precipitated from secondary $25{ }^{\circ} \mathrm{C}$ reaction samples were all higher than that of the primary effect $25^{\circ} \mathrm{C}$ reaction sample, with the exception of the sample reacted with $0.0 \mathrm{M} \mathrm{NaOH}$. Similar to the primary effect $25{ }^{\circ} \mathrm{C}$ reaction sample, relatively large percentages of the time-zero-mass of strontium were found in all secondary effect samples reacted at $25{ }^{\circ} \mathrm{C}$. 
WSRC-TR-2003-00232, Rev. 0

SRT-RPP-2003-00105, Rev. 0

Table 4.5.2.3 Percent of Cation Mass Present in the Solids Relative to Time Zero Cation Mass in Filtrates for the AN-102 Secondary Effects Study

\begin{tabular}{|c|c|c|c|c|c|c|c|c|c|}
\hline & \multicolumn{9}{|c|}{ Percent of Cation Present at Time 0 Found in Dissolved Solids (=mass in solid/mass in time 0 filtrate ${ }^{*} 100$ ) } \\
\hline Elem & $\mathrm{OMOH}, \mathrm{O} 2$ & OMOH,Light & $\mathrm{OMOH}, .03 \mathrm{Sr}$ & $\mathrm{OMOH}, .03 \mathrm{Mn}$ & $25 \mathrm{C} \mathrm{Rxn,0MOH}$ & $25 \mathrm{C} \mathrm{Rxn}, .03 \mathrm{Mn}$ & $25 \mathrm{C}$ Rxn,O2 & $25 \mathrm{C} \mathrm{Rxn}, .03 \mathrm{Sr}$ & 25C Rxn,Light \\
\hline Al & 0.0998 & 0.0716 & 0.0983 & 0.0851 & 0.0731 & 0.0972 & 0.530 & 0.332 & 0.354 \\
\hline B & ND & ND & ND & $\mathrm{ND}$ & $\mathrm{ND}$ & $\mathrm{ND}$ & $\mathrm{ND}$ & ND & ND \\
\hline $\mathrm{Ca}$ & $\mathrm{ND}$ & ND & $\mathrm{ND}$ & $\mathrm{ND}$ & $\mathrm{ND}$ & 0.457 & 0.817 & 0.649 & 0.820 \\
\hline $\mathrm{Ce}$ & $\mathrm{ND}$ & ND & $\mathrm{ND}$ & $\mathrm{ND}$ & $\mathrm{ND}$ & 10.1 & 25.2 & ND & $\mathrm{ND}$ \\
\hline $\mathrm{Cr}$ & 0.0813 & 0.0768 & 0.130 & 0.0996 & 0.0688 & 0.0884 & 0.463 & 0.352 & 0.363 \\
\hline $\mathrm{Cu}$ & $\mathrm{ND}$ & ND & $\mathrm{ND}$ & $\mathrm{ND}$ & $\mathrm{ND}$ & $\mathrm{ND}$ & $\mathrm{ND}$ & $\mathrm{ND}$ & $\mathrm{ND}$ \\
\hline $\mathrm{Fe}$ & $\mathrm{ND}$ & ND & $\mathrm{ND}$ & $\mathrm{ND}$ & $\mathrm{ND}$ & $\mathrm{ND}$ & ND & ND & $\mathrm{ND}$ \\
\hline K & 0.0901 & 0.0772 & 0.0982 & 0.0893 & 0.0812 & 0.103 & 0.539 & 0.359 & 0.357 \\
\hline La & $\mathrm{ND}$ & ND & $\mathrm{ND}$ & $\mathrm{ND}$ & ND & $\mathrm{ND}$ & ND & ND & ND \\
\hline $\mathrm{Mg}$ & $\mathrm{ND}$ & ND & $\mathrm{ND}$ & $\mathrm{ND}$ & $\mathrm{ND}$ & $\mathrm{ND}$ & ND & ND & $\mathrm{ND}$ \\
\hline$M n$ & 7.21 & 55.6 & 0.783 & $\mathrm{ND}$ & $\mathrm{ND}$ & 9.94 & 31.2 & 14.0 & 43.9 \\
\hline Mo & ND & ND & $\mathrm{ND}$ & $\mathrm{ND}$ & ND & $\mathrm{ND}$ & 0.385 & 0.374 & 0.346 \\
\hline $\mathrm{Nd}$ & ND & ND & $\mathrm{ND}$ & $\mathrm{ND}$ & $\mathrm{ND}$ & $\mathrm{ND}$ & ND & ND & 1.80 \\
\hline $\mathrm{Ni}$ & 0.0984 & 0.0818 & 0.114 & 0.0947 & 0.0842 & 0.120 & 0.568 & 0.399 & 0.410 \\
\hline $\mathbf{P}$ & 19.8 & 12.9 & 23.0 & 21.9 & 0.142 & 0.295 & 1.31 & 0.479 & 0.333 \\
\hline $\mathrm{Pb}$ & 0.184 & 0.207 & 0.114 & 0.0982 & $\mathrm{ND}$ & 0.220 & 1.02 & 0.376 & 0.936 \\
\hline Si & $\mathrm{ND}$ & $\mathrm{ND}$ & $\mathrm{ND}$ & 1.63 & $\mathrm{ND}$ & $\mathrm{ND}$ & $\mathrm{ND}$ & $\mathrm{ND}$ & $\mathrm{ND}$ \\
\hline Sr & 0.161 & 0.253 & $\mathrm{ND}$ & $\mathrm{ND}$ & 5.21 & 5.40 & 24.6 & 11.6 & 12.0 \\
\hline $\mathrm{Zn}$ & ND & ND & $\mathrm{ND}$ & $\mathrm{ND}$ & ND & $\mathrm{ND}$ & ND & ND & $\mathrm{ND}$ \\
\hline $\mathrm{Zr}$ & ND & ND & $\mathrm{ND}$ & $\mathrm{ND}$ & $\mathrm{ND}$ & $\mathrm{ND}$ & ND & ND & ND \\
\hline
\end{tabular}

Estimated rate constants and half-lives describing the loss of manganese from filtrates during the 16-day observation period are listed in Table 4.5.2.4 for the 241-AN-102 secondary effects study. Also listed in the table are the percentages of manganese lost from solution in the initial filtrates. These data indicate a good correlation to the estimated half-lives for the treatment conditions. For example, the half-lives calculated for the $0.0 \mathrm{M} \mathrm{NaOH} /$ light pair and the $25{ }^{\circ} \mathrm{C}$ reaction/light pair are small (3.5 and 7.9 days), and the mass of manganese lost from the filtrates was 56 and $44 \%$ respectively. Similarly, the estimated half-lives calculated for the $25{ }^{\circ} \mathrm{C}$ reaction $/ 0.03 \mathrm{M} \mathrm{Sr}$ pair and the $25{ }^{\circ} \mathrm{C}$ reaction/0.03 M Mn pair were 43 and 77 days, and the mass of manganese lost from the filtrates was 10 and $14 \%$ respectively. Treatment conditions exhibiting small half-lives could potentially result in an accumulation of post-filtration solids that may be problematic in the ion exchange process.

Table 4.5.2.4 Estimated First Order Rate Constants and Half-lives for Loss of Manganese From the Secondary Effects Filtrates During the 16-Day Observational Period

\begin{tabular}{|l|c|c|c|c|c|c|c|c|}
\hline & \multicolumn{2}{|c|}{ Simulant A } & \multicolumn{2}{c|}{ Simulant $\mathbf{~}$} & \multicolumn{3}{c|}{ Combined } \\
\cline { 2 - 10 } & $\left.\mathbf{k} \mathbf{( d}^{-1}\right)$ & $\mathbf{R}^{\mathbf{2}}$ & $\left.\mathbf{k} \mathbf{( d}^{-1}\right)$ & $\mathbf{R}^{\mathbf{2}}$ & $\left.\mathbf{k} \mathbf{( d}^{-1}\right)$ & $\mathbf{R}^{\mathbf{2}}$ & $\mathbf{t}_{1 / 2}$ (Days) & $\left.\mathbf{( M}_{\mathbf{p}} / \mathbf{M}_{\mathbf{t}}\right)^{*} \mathbf{1 0 0}$ \\
\hline 0MOH, Light & 0.2037 & 0.7514 & 0.1988 & 0.7541 & 0.2012 & 0.7525 & 3 & 55.6 \\
25Rxn,.03MSr & 0.0193 & 0.8904 & 0.0131 & 0.6813 & 0.0162 & 0.7309 & 43 & 9.9 \\
25Rxn,.03MMn & 0.0106 & 0.7027 & 0.0073 & 0.5907 & 0.0090 & 0.3757 & 77 & 0.14 \\
25Rxn,Light & 0.1003 & 0.8484 & 0.0762 & 0.8984 & 0.0882 & 0.8427 & 8 & 43.9 \\
25Rxn,O2 & 0.0364 & 0.9999 & 0.0318 & 0.9411 & 0.0341 & 0.8395 & 20 & 31.2 \\
\hline
\end{tabular}


WSRC-TR-2003-00232, Rev. 0

SRT-RPP-2003-00105, Rev. 0

\subsection{CONCLUSIONS}

Data presented for the 241-AN-107 primary effects study indicated that post-filtration solids formed with all treatments examined given sufficient time. However, in the short term (within 48 hours), reacting the simulant at flow sheet conditions but eliminating the addition of sodium hydroxide from the reaction mixture and minimizing exposure to oxygen in the filtrates minimized the formation of precipitates. In addition, reducing the concentration of sodium permanganate to approximately $0.01 \mathrm{M}$ could also minimize the formation of postfiltration solids.

With exception of two experimental conditions, the 8-hr hold of the filtrate at $100{ }^{\circ} \mathrm{C}$ and the oxygen sparge, solids that formed during the 48-hr period were very light in color. The filtrates sparged with oxygen contained brown solids within six hours, and significant black solids formed in the filtrates held at $100{ }^{\circ} \mathrm{C}$ for 8 hours. The formation of brown solids in the filtrates sparged with oxygen is commensurate with the oxidation (in the presence of air) to brown manganese (III) oxy-hydroxide and oxide and ultimately to the black manganese dioxide. Formation of black solids in the 8-hr hold filtrates supports the hypothesis that the precipitation reaction kinetics are too slow for the reaction to be complete after a 4 hour reaction time.

Very near the end of the analytical effort for the AN-241-107 primary effects study, discussions were initiated concerning reconsideration of the reaction conditions. A "newly optimized condition' (NOC) was proposed in which the concentration of reactants was reduced to $0.03 \mathrm{M}$ strontium nitrate and sodium permanganate. In addition, the sodium hydroxide concentration was set at $0.3 \mathrm{M}(0.0 \mathrm{M}$ added to the AN-102 simulant), and a reaction temperature at $25^{\circ} \mathrm{C}$. Dark solids appeared in all treatment pairs in contact with the atmosphere. Dark solids also formed for the light/nitrogen pairs reacted at 0.01 and $0.03 \mathrm{M}$ sodium permanganate. Dark solids did not form for reaction at the NOC and at the NOC with $0.01 \mathrm{M}$ sodium permanganate. Therefore, it would appear that reacting at the NOC or at lower permanganate concentration could mitigate the formation of dark solids within 16 days of an oxidation reaction with a $241-\mathrm{AN}-107$ waste.

Rate constants describing the formation of manganese or iron containing solids could not be calculated for the 16-day observation period. However, rate constants describing the formation of strontium solids during the 16-day period were calculated. Half-lives calculated for filtrates maintained in the light ranged from 15.3 to 21.2 days $^{-1}$ while those maintained in the dark ranged from 22.4 to 60.3 days $^{-1}$ suggesting that light may play an important role in the precipitation of strontium.

The primary effects study for the 241-AN-102 simulant resulted in the formation of brown to black solids in all treatments except the zero molar added sodium hydroxide and the $25{ }^{\circ} \mathrm{C}$ reaction under otherwise baseline conditions, the NOC, and the $0.01 \mathrm{M}$ sodium permanganate reaction under otherwise NOC.

Secondary effects studied for the 241-AN-102 simulant involved examining the effect of 0.0 $\mathrm{M}$ added sodium hydroxide and a $25^{\circ} \mathrm{C}$ reaction condition with $0.03 \mathrm{M}$ strontium, $0.03 \mathrm{M}$ permanganate, light, and the presence of oxygen. Results indicated that a $25{ }^{\circ} \mathrm{C}$ reaction 
WSRC-TR-2003-00232, Rev. 0

SRT-RPP-2003-00105, Rev. 0

temperature is not effective in inhibiting the formation post-filtration solids when crossed with primary effects variables that did promote solids formation. Lowering the reaction temperature from 50 to $25{ }^{\circ} \mathrm{C}$ should have resulted in less of a reaction precipitate leaving more iron in solution as noted above. However, the behavior of iron in response to the lowered reaction temperature follows that of manganese suggesting that co-precipitation or adsorption may be an important removal mechanism for iron.

The $0.0 \mathrm{M}$ added $\mathrm{NaOH}$ reaction condition does not promote solid formation and may inhibit the formation of solids when crossed with other primary effects variables that promote solid formation. Exposure to light is also seen to be very effective in promoting the formation of dark brown to black post-filtration solids.

In summary, the AN-102 and -107 data suggest that for the base case condition, a lower reaction temperature and the absence of added $\mathrm{NaOH}$ inhibit the formation of dark solids within 16-days. Similarly, the variable evaluated for the newly optimized conditions that did not result in the formation of dark solids was the $0.01 \mathrm{M}$ permanganate treatment. The newly optimized conditions also did not result in the formation of dark solids.

Post-filtration solids that formed in both the AN-107 and -102 filtrates were completely soluble in 0.5 molar nitric acid. Additionally, the mass of predominantly manganese containing solids that formed in the filtrates is small, generally in the $\mathrm{mg} / \mathrm{L}$ range and may not pose a significant problem in contact with the ion-exchange resin. In any event solids collected in the resin bed would likely be solubilized during regeneration of the resin. 
WSRC-TR-2003-00232, Rev. 0

SRT-RPP-2003-00105, Rev. 0

\section{REFERENCES}

Abodishish, H.A. R\&T Test Exception, 24590-WTP-TEF-RT-02-063. September, 2002.

Bannochie, C.J. and Nash, C.A. Task Technical and Quality Assurance Plan: Evaluation of Post-Filtration Precipitation Mechanisms. WSRC-TR-2001_00425, Revision 1, November, 2001.

Bannochie, C.J. Standardized Baseline Precipitation Procedure for Hanford RPP Studies. WSRC-TR-2002-00138, Rev.0, March, 2002.

Cho, H., Kawasaki, H., and Kumazawa, H. Formation of Needle-like Lepidocrocite Fine Particles by Oxidation of an Aqueous Suspension of Ferrous Hydroxide in a Bubble Column. The Canadian Journal of Chemical Engineering. 78:842-846. 2000.

Cotton, F.A. and Wilkinson, G. Advanced Inorganic Chemistry. $5^{\text {th }}$ edition. Wiley, John, and Sons Incorporated. Pp. 699, 706, 1988.

Ebling, R.E. Development of a Supernate Simulant for Hanford Tank 241-AN-102 Waste (U). WSRC-TR-2002-00040, Rev. 0. SRT-RPP-2002-00012, Rev. 0. February, 2003.

Eibling, R.E. and Nash, C.A. Hanford Waste Simulants Created to Support the Research and Development on the River Protection Project - Waste Treatment Plant. Savannah River Technology Center. WSRC-TR-2000-00338. SRT-RPP-2000-00017. February, 2001.

Hildred, K.L, Townson, P.S., Hutson, G.V., and Williams, R.A. Characterization of Particulates in the BNFL Enhanced Actinide Removal Plant. Powder Technology. 108:164-172. 2000.

Kamei, G. and Ohmoto, H. The Kinetics of Reactions Between Pyrite and $\mathrm{O}_{2}$-bearing Water Revealed from In-situ Monitoring of DO, $\mathrm{E}_{\mathrm{H}}$ and $\mathrm{pH}$ in a Closed System. Geochimica et Cosmochimica Acta. 64(15):2585-2601. 2000.

Kuga, Y.; Isomura, S.; Takeuchi, K.; and Okuyama, K. Growth Enhancement of UF 5 Nanoparticles Assisted by $\alpha$-ray Ionization. Applied Physics A. Materials Science and Processing. 62:373-379. 1996.

Mallick, K.; Wang, Z.L.; and Pal, T. Seed-mediated Successive Growth of Gold Particles Accomplished by UV Irradiation: A Photochemical Approach for Size-controlled Synthesis. Journal of Photochemistry and Photobiology A: Chemistry. 140:75-80. 2001.

McCabe; D. J.; and Nash, C. A. BNFL River Protection Project Flowsheet Technical Support at SRTC Update. Savannah River Technology Center. April , 2000. 
WSRC-TR-2003-00232, Rev. 0

SRT-RPP-2003-00105, Rev. 0

McKenzie, R.M. The Adsorption of Lead and Other Heavy Metals on Oxides of Manganese and Iron. Aust. J. Soil Res. 18:61-73. 1980.

Nash, C.A. and Rosencrance, S.W. Initial Project Scoping Meeting. Rich Laboratory. Clemson University. October 19, 2000.

Townson, P. S. Pilot Scale Inactive LAW Entrained Solids Removal and Sr/TRU Precipitant Filtration Test Specification. TSP-W375-99-00007, Revision 0. River Protection Project, Waste Treatment Plant. August, 1999. 
WSRC-TR-2003-00232, Rev. 0

SRT-RPP-2003-00105, Rev. 0

\section{APPENDIX A}

\section{Simulant Recipes}


WSRC-TR-2003-00232, Rev. 0

SRT-RPP-2003-00105, Rev. 0

Table A.1 Recipe for AN-107 Simulant

Experiment C-7 Recent

Volume of Feed

\begin{tabular}{|l|l|}
\hline 1000 & $\mathrm{~mL}$ \\
\hline
\end{tabular}

In a tared

$1000 \quad \mathrm{~mL}$ Volumetric Flask add

Water

\begin{tabular}{|c|c|}
\hline grams & Actual Wt, grams \\
\hline 200 & \\
\hline
\end{tabular}

Transition Metals and Complexing agents

\begin{tabular}{|l|l|c|l|}
\hline \multicolumn{1}{|c|}{ Compounds } & \multicolumn{1}{c|}{ Formula } & Mass Needed & Actual Wt, grams \\
\hline Calcium Nitrate & $\mathrm{Ca}(\mathrm{NO} 3) 2.4 \mathrm{H} 2 \mathrm{O}$ & 3.48 & \\
\hline Cerium Nitrate & $\mathrm{Ce}(\mathrm{NO} 3) 3.6 \mathrm{H} 2 \mathrm{O}$ & 0.164 & \\
\hline Cesium Nitrate & $\mathrm{CsNO} 3$ & 0.027 & \\
\hline Copper Nitrate & $\mathrm{Cu}(\mathrm{NO} 3) 2.2 .5 \mathrm{H} 2 \mathrm{O}$ & 0.110 & \\
\hline Ferric Nitrate & $\mathrm{Fe}(\mathrm{NO} 3) 3.9 \mathrm{H} 2 \mathrm{O}$ & 12.23 & \\
\hline Lanthanum Nitrate & $\mathrm{La}(\mathrm{NO} 3) 3.6 \mathrm{H} 2 \mathrm{O}$ & 0.142 & \\
\hline Lead nitrate & $\mathrm{Pb}(\mathrm{NO} 3) 2$ & 0.620 & \\
\hline Magnesium Nitrate & $\mathrm{Mg}(\mathrm{NO} 3) 2.6 \mathrm{H} 2 \mathrm{O}$ & 0.264 & \\
\hline Manganous Chloride & $\mathrm{MnCl} 2.4 \mathrm{H} 2 \mathrm{O}$ & 2.03 & \\
\hline Neodymium Nitrate & $\mathrm{Nd}(\mathrm{NO} 3) 3.6 \mathrm{H} 2 \mathrm{O}$ & 0.291 & \\
\hline Nickel Nitrate & $\mathrm{Ni}(\mathrm{NO} 3) 2.6 \mathrm{H} 2 \mathrm{O}$ & 2.63 & \\
\hline Potassium Nitrate & $\mathrm{KNO} 3$ & 4.60 & \\
\hline Strontium Nitrate & $\mathrm{Sr}(\mathrm{NO} 3) 2$ & 0.016 & \\
\hline Zinc Nitrate & $\mathrm{Zn}(\mathrm{NO} 3) 2.6 \mathrm{H} 2 \mathrm{O}$ & 0.206 & \\
\hline Zirconyl Nitrate & $\mathrm{ZrO}(\mathrm{NO} 3) 2$ & 0.191 & \\
\hline EDTA & $\mathrm{Na} 2 \mathrm{EDTA}$ & 7.26 & \\
\hline HEDTA & $\mathrm{HEDTA}$ & 2.16 & \\
\hline Sodium Gluconate & & 3.93 & \\
\hline Glycolic Acid & & 26.93 & \\
\hline Citric Acid & & 9.44 & \\
\hline Nitrilotriacetic Acid & & 0.570 & \\
\hline Iminodiacetic Acid & & 6.04 & \\
\hline Boric acid & $\mathrm{H} 3 \mathrm{BO} 3$ & 0.200 & \\
\hline Sodium Chloride & $\mathrm{NaCl}$ & 1.82 & \\
\hline Sodium Fluoride & $\mathrm{NaF}$ & 0.29 & \\
\hline Sodium Chromate & $\mathrm{Na} 2 \mathrm{CrO} 4$ & 0.55 & \\
\hline Sodium Sulfate & $\mathrm{Na} 2 \mathrm{SO} 4$ & 98.47 & \\
\hline Potassium Molybdate & $\mathrm{K} 2 \mathrm{MoO} 4$ & & \\
\hline & & & \\
\hline & & & \\
\hline
\end{tabular}

In separate container mix the following

\begin{tabular}{|l|l|c|c|}
\hline Add & \multicolumn{1}{|c|}{ Formula } & Mass Needed & Actual Wt, grams \\
\hline Sodium Hydroxide & $\mathrm{NaOH}$ & 25.26 & \\
\hline Aluminum Nitrate & $\mathrm{Al}(\mathrm{NO} 3) 3.9 \mathrm{H} 2 \mathrm{O}$ & 5.37 & \\
\hline Sodium Phosphate & $\mathrm{Na3PO} 4.12 \mathrm{H} 2 \mathrm{O}$ & 4.44 & \\
\hline
\end{tabular}


WSRC-TR-2003-00232, Rev. 0

SRT-RPP-2003-00105, Rev. 0

\begin{tabular}{|c|c|c|}
\hline Sodium formate & $\mathrm{NaHCOO}$ & 15.71 \\
\hline Sodium Acetate & $\mathrm{NaCH} 3 \mathrm{COO} .3 \mathrm{H} 2 \mathrm{O}$ & 2.37 \\
\hline Sodium Oxalate & $\mathrm{Na} 2 \mathrm{C} 2 \mathrm{O} 4$ & 1.26 \\
\hline Add & grams & Actual Wt, grams \\
\hline Water & 200 & \\
\hline
\end{tabular}

Mix thoroughly. Then add this solution to the volumetric flask.

\begin{tabular}{|l|c|c|c|}
\hline Add & Formula & Mass Needed & Actual Wt, grams \\
\hline Sodium Carbonate & $\mathrm{Na} 2 \mathrm{CO} 3$ & 148.25 & \\
\hline
\end{tabular}

Mix thoroughly.

\begin{tabular}{|l|c|c|c|}
\hline Mix & Formula & Mass Needed & Actual Wt, grams \\
\hline Sodium Nitrate & NaNO3 & 297.29 & \\
\hline Sodium Nitrite & NaNO2 & 91.49 & \\
\hline Water & & 100 & \\
\hline
\end{tabular}

Add and Mix thoroughly.

Mix thoroughly and dilute to the mark.

Record Final Weight grams

The final addition of water would be $240.24 \quad$ grams based upon a density of $1.429 \mathrm{~g} / \mathrm{mL}$. 
WSRC-TR-2003-00232, Rev. 0

SRT-RPP-2003-00105, Rev. 0

Table A.2 Recipe for AN-102 Simulant

SRS AN102-Final at 9.543 Molar

Sodium recipe

Volume of Feed

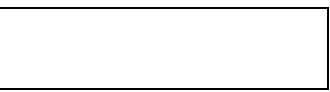

Tare a

1000

$1000 \mathrm{~mL}$

$\begin{array}{ccc}\text { Tare a } & 1000 \quad \mathrm{~mL} \text { Volumetric Flask } \\ \text { Volumetric Flask Tare Weight } & \text { grams }\end{array}$

To the Volumetric Flask add

\begin{tabular}{|l|l|l|}
\cline { 2 - 3 } \multicolumn{1}{c|}{} & grams & Actual Wt, grams \\
\hline Water & 200 & \\
\hline
\end{tabular}

Transition Metals and Complexing agents

\begin{tabular}{|c|c|c|c|}
\hline Compounds & Formula & Mass Needed & Actual Wt, grams \\
\hline Aluminum Nitrate & $\mathrm{Al}\left(\mathrm{NO}_{3}\right)_{3} \cdot 9 \mathrm{H}_{2} \mathrm{O}$ & 204.12 & \\
\hline Cadmium Nitrate & $\mathrm{Cd}\left(\mathrm{NO}_{3}\right)_{2} \cdot 4 \mathrm{H}_{2} \mathrm{O}$ & 0.20 & \\
\hline Calcium Nitrate & $\mathrm{Ca}\left(\mathrm{NO}_{3}\right)_{2} \cdot 4 \mathrm{H}_{2} \mathrm{O}$ & 3.46 & \\
\hline Cerium Nitrate & $\mathrm{Ce}\left(\mathrm{NO}_{3}\right)_{3} 6 \mathrm{H}_{2} \mathrm{O}$ & 0.00 & \\
\hline Cesium Nitrate & $\mathrm{CsNO}_{3}$ & 0.028 & \\
\hline Cobalt Nitrate & $\mathrm{Co}\left(\mathrm{NO}_{3}\right)_{2} \cdot 6 \mathrm{H}_{2} \mathrm{O}$ & 0.02 & \\
\hline Copper Nitrate & $\mathrm{Cu}\left(\mathrm{NO}_{3}\right)_{2} \cdot 2.5 \mathrm{H}_{2} \mathrm{O}$ & 0.11 & \\
\hline Ferric Nitrate & $\mathrm{Fe}\left(\mathrm{NO}_{3}\right)_{3} \cdot 9 \mathrm{H}_{2} \mathrm{O}$ & 0.36 & \\
\hline Lanthanum Nitrate & $\mathrm{La}\left(\mathrm{NO}_{3}\right)_{3} \cdot 6 \mathrm{H}_{2} \mathrm{O}$ & 0.06 & \\
\hline Lead nitrate & $\mathrm{Pb}\left(\mathrm{NO}_{3}\right)_{2}$ & 0.35 & \\
\hline Magnesium Nitrate & $\mathrm{Mg}\left(\mathrm{NO}_{3}\right)_{2} \cdot 6 \mathrm{H}_{2} \mathrm{O}$ & 0.00 & \\
\hline Manganous Chloride & $\mathrm{MnCl}_{2} \cdot 4 \mathrm{H}_{2} \mathrm{O}$ & 0.13 & \\
\hline Neodymium Nitrate & $\mathrm{Nd}\left(\mathrm{NO}_{3}\right)_{3} \cdot 6 \mathrm{H}_{2} \mathrm{O}$ & 0.12 & \\
\hline Nickel Nitrate & $\mathrm{Ni}\left(\mathrm{NO}_{3}\right)_{2} \cdot 6 \mathrm{H}_{2} \mathrm{O}$ & 2.47 & \\
\hline Potassium Nitrate & $\mathrm{KNO}_{3}$ & 6.03 & \\
\hline Rubidium Nitrate & $\mathrm{RbNO}_{3}$ & 0.02 & \\
\hline Strontium Nitrate & $\mathrm{Sr}\left(\mathrm{NO}_{3}\right)_{2}$ & 0.007 & \\
\hline Zinc Nitrate & $\mathrm{Zn}\left(\mathrm{NO}_{3}\right)_{2} 6 \mathrm{H}_{2} \mathrm{O}$ & 0.03 & \\
\hline Zirconyl Nitrate & $\mathrm{ZrO}\left(\mathrm{NO}_{3}\right)_{2} \cdot \mathrm{H}_{2} \mathrm{O}$ & 0.04 & \\
\hline Disodium Ethylenediaminetetraacetate & $\mathrm{Na}_{2} \mathrm{C}_{10} \mathrm{H}_{14} \mathrm{~N}_{2} \mathrm{O}_{8} 2 \mathrm{H}_{2} \mathrm{O}$ & 4.29 & \\
\hline $\begin{array}{l}\text { n-(2-Hydroxyethyl)ethylenediaminetriacetic } \\
\text { acid }\end{array}$ & $\mathrm{C}_{10} \mathrm{H}_{18} \mathrm{~N}_{2} \mathrm{O}_{7}$ & 0.44 & \\
\hline Sodium Gluconate & $\mathrm{HOCH}_{2}(\mathrm{CHOH})_{4} \mathrm{COONa}$ & 1.97 & \\
\hline Citric Acid & $\mathrm{C}_{6} \mathrm{H}_{8} \mathrm{O}_{7} \cdot \mathrm{H}_{2} \mathrm{O}$ & 6.20 & \\
\hline Nitrilotriacetic Acid & $\mathrm{C}_{6} \mathrm{H}_{9} \mathrm{NO}_{6}$ & 0.31 & \\
\hline
\end{tabular}


WSRC-TR-2003-00232, Rev. 0

SRT-RPP-2003-00105, Rev. 0

\begin{tabular}{|l|l|r|r|}
\hline Iminodiacetic Acid & $\mathrm{C}_{4} \mathrm{H}_{7} \mathrm{NO}_{4}$ & 5.45 & \\
\hline Succinic Acid & $\mathrm{C}_{4} \mathrm{H}_{6} \mathrm{O}_{4}$ & 0.04 & \\
\hline Glutaric Acid & $\mathrm{C}_{5} \mathrm{H}_{8} \mathrm{O}_{4}$ & 0.08 & \\
\hline Adipic Acid & $\mathrm{C}_{6} \mathrm{H}_{10} \mathrm{O}_{4}$ & 0.30 & \\
\hline Azelaic Acid & $\mathrm{C}_{9} \mathrm{H}_{16} \mathrm{O}_{4}$ & 1.25 & \\
\hline Suberic Acid & $\mathrm{C}_{8} \mathrm{H}_{14} \mathrm{O}_{4}$ & 2.19 & \\
\hline Boric acid & $\mathrm{NH}_{4} \mathrm{CH}_{3} \mathrm{COO}$ & 0.25 & \\
\hline Ammonium Acetate & $\mathrm{H}_{3} \mathrm{BO}_{3}$ & 0.75 & \\
\hline Sodium Chloride & $\mathrm{NaCl}$ & 9.36 & \\
\hline Sodium Fluoride & $\mathrm{NaF}$ & 4.54 & \\
\hline Sodium Sulfate & $\mathrm{Na}_{2} \mathrm{SO}_{4}$ & 22.34 & \\
\hline Potassium Molybdate & $\mathrm{K}_{2} \mathrm{MoO}_{4}$ & 0.13 & \\
\hline
\end{tabular}

Mix the solution well. Note that if a stopping point for an extended period of time is desired, Pause Here. Next add the following to the flask with mixing.

\begin{tabular}{|c|c|c|c|}
\hline Add & Formula & Mass Needed & Actual Wt, grams \\
\hline Sodium Hydroxide & $\mathrm{NaOH}$ & 116.44 & \\
\hline Sodium Phosphate & $\mathrm{Na}_{3} \mathrm{PO}_{4} \cdot 12 \mathrm{H}_{2} \mathrm{O}$ & 26.44 & \\
\hline Sodium Tungstate & $\mathrm{Na}_{2} \mathrm{WO}_{4} \cdot 2 \mathrm{H}_{2} \mathrm{O}$ & 0.36 & \\
\hline Sodium Metasilicate & $\mathrm{Na}_{2} \mathrm{SiO}_{3} \cdot 9 \mathrm{H}_{2} \mathrm{O}$ & 0.12 & \\
\hline Sodium Glycolate & $\mathrm{NaHCOO}$ & 16.36 & \\
\hline Sodium formate & $\mathrm{HOCH}_{2} \mathrm{COONa}$ & 15.22 & \\
\hline Sodium Acetate & $\mathrm{NaCH}_{3} \mathrm{COO} 3 \mathrm{H}_{2} \mathrm{O}$ & 0.80 & \\
\hline Sodium Oxalate & $\mathrm{Na}_{2} \mathrm{C}_{2} \mathrm{O}_{4}$ & 0.84 & \\
\hline Add & grams & Actual Wt, grams & \\
\hline Water & & & \\
\hline
\end{tabular}

Mix thoroughly.

\begin{tabular}{|l|l|r|l|}
\hline Add & Formula & Mass Needed & Actual Wt, grams \\
\hline Sodium Chromate & $\mathrm{Na}_{2} \mathrm{CrO}_{4}$ & 0.94 & \\
\hline Sodium Carbonate & $\mathrm{Na}_{2} \mathrm{CO}_{3}$ & 115.95 & \\
\hline
\end{tabular}

Mix thoroughly.

\begin{tabular}{|l|l|r|l|}
\hline Mix & Formula & Mass Needed & Actual Wt, grams \\
\hline Sodium Nitrate & $\mathrm{NaNO}_{3}$ & 128.98 & \\
\hline Sodium Nitrite & $\mathrm{NaNO}_{2}$ & 118.50 & \\
\hline Water & $\mathrm{H}_{2} \mathrm{O}$ & 100 & \\
\hline
\end{tabular}

Add and Mix thoroughly. 
WSRC-TR-2003-00232, Rev. 0

SRT-RPP-2003-00105, Rev. 0

Mix thoroughly and dilute to the mark.

\section{Record Final Gross Weight}

Measure the Density
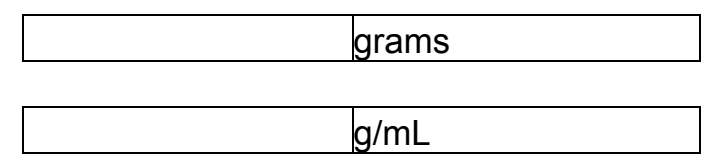

For INFO ONLY

The final addition of water would be a density of

116.53 grams based upon $1.434 \mathrm{~g} / \mathrm{mL}$.

Solution Labeling

AN-102-Final Simulant at $9.543 \mathrm{M} \mathrm{Na}$ 
WSRC-TR-2003-00232, Rev. 0

SRT-RPP-2003-00105, Rev. 0

APPENDIX B

AN-107 Filtrate Photographs 
WSRC-TR-2003-00232, Rev.
SRT-RPP-2003-00105, Rev.

A B

$$
0315-211
$$

BASE CASE

Figure B.1 Simulant AN-107 Sample 0315-211

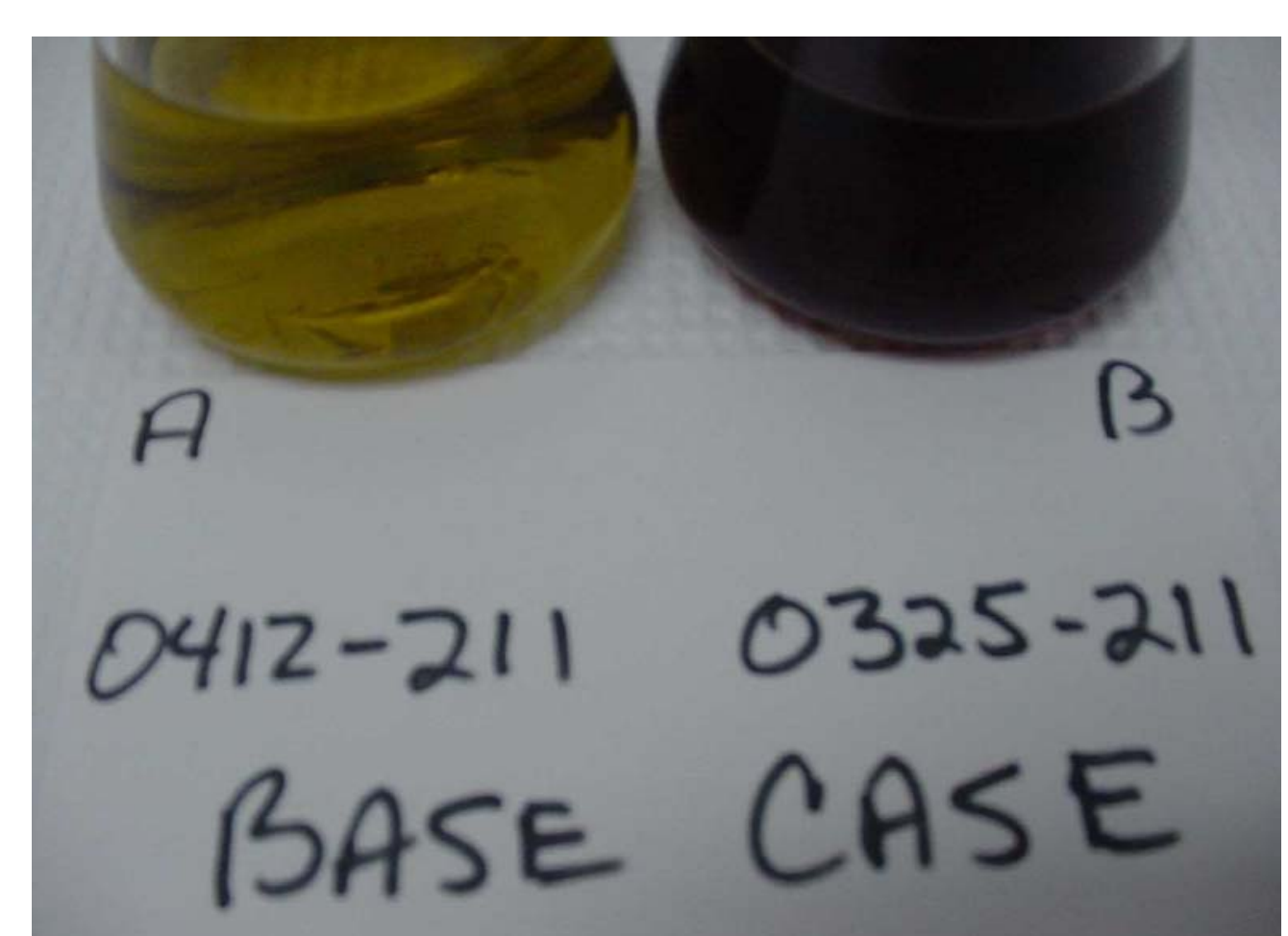

Figure B.2 Simulant AN-107 Samples 0412-211 and 0325-211

Page 105 of 22 
WSRC-TR-2003-00232, Rev. 0

SRT-RPP-2003-00105, Rev. 0

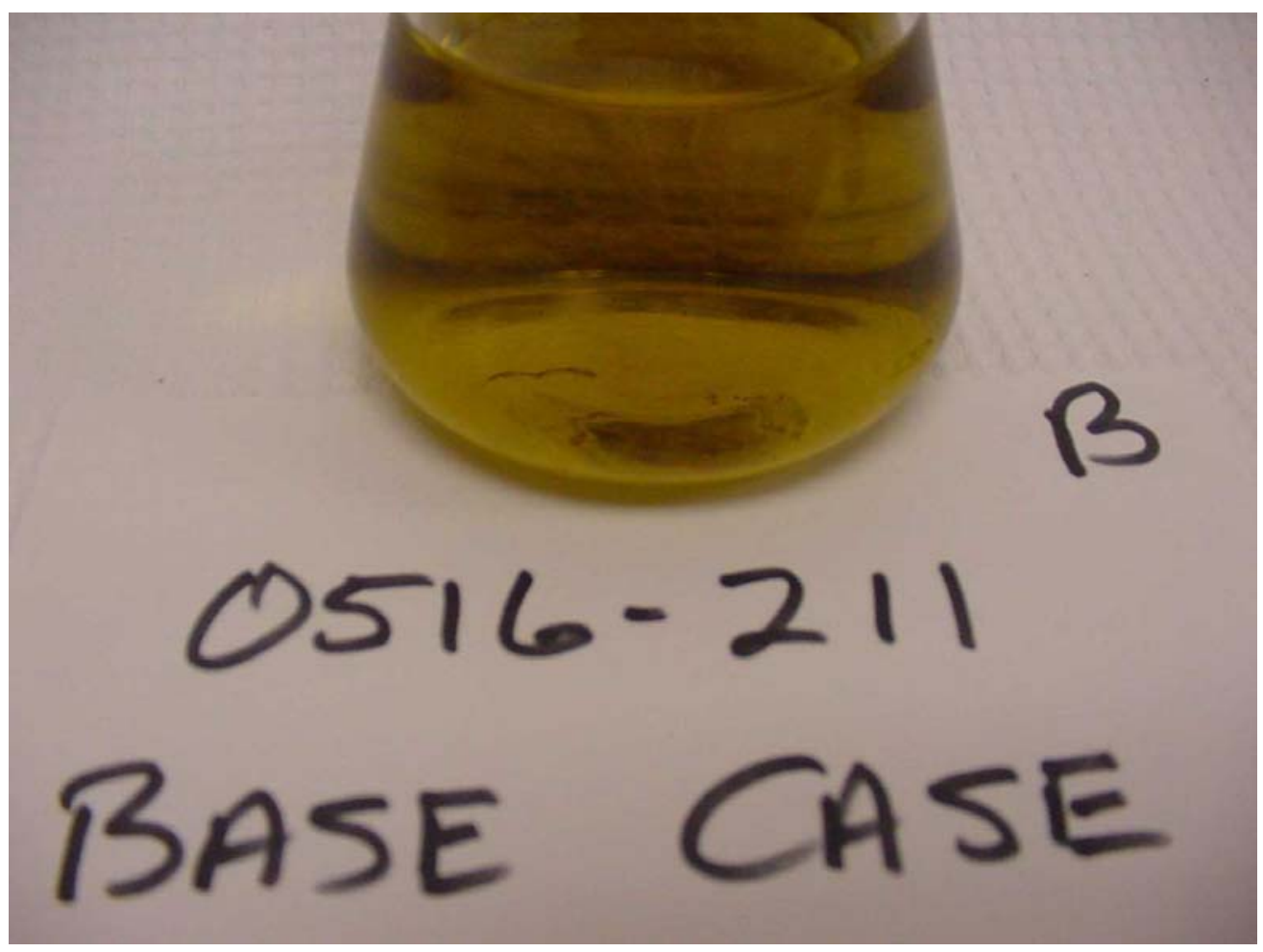

Figure B.3 Simulant AN-107 Sample 0516-211

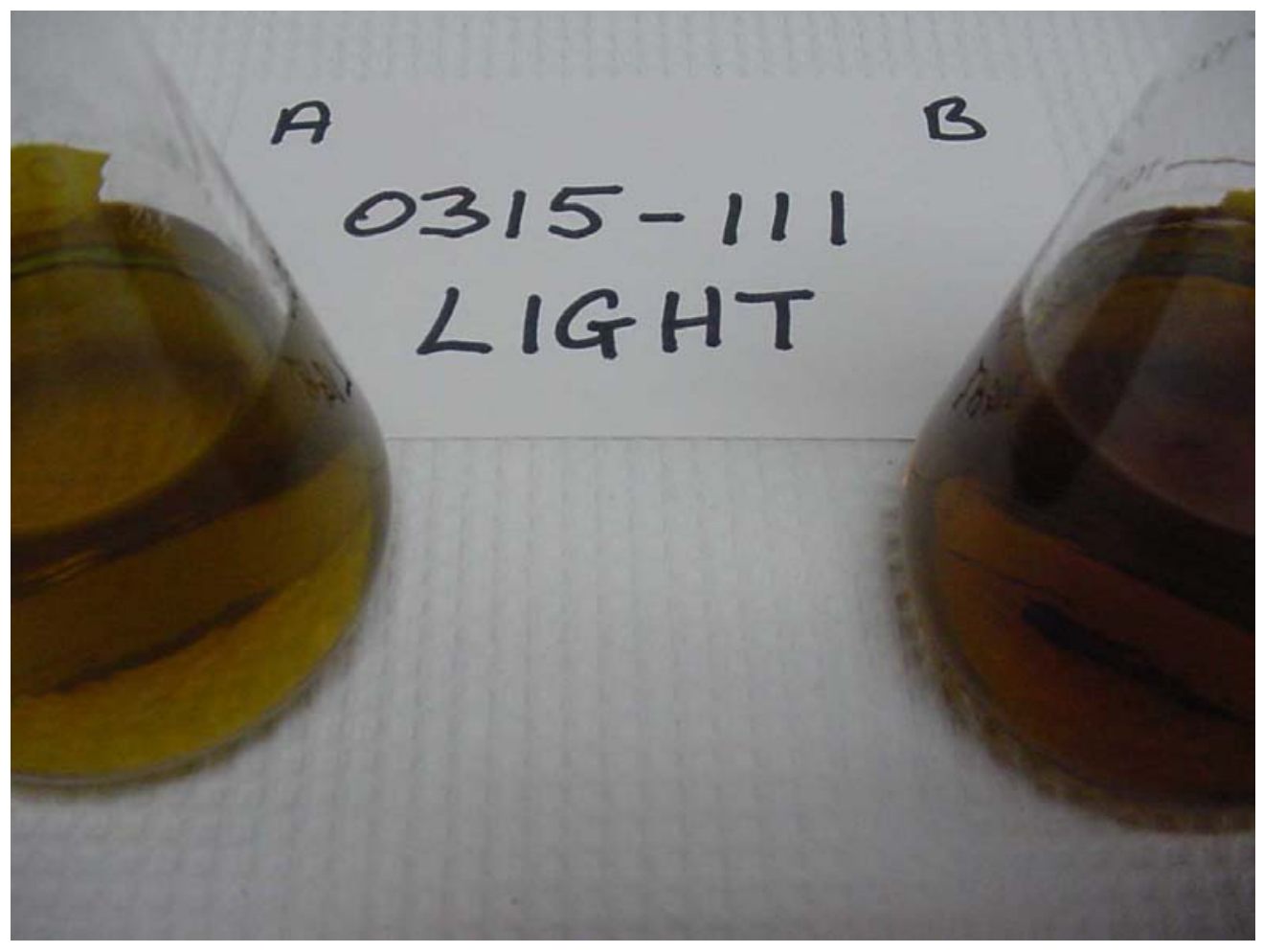

Figure B.4 Simulant AN-107 Sample 0315-111

Page 106 of 220 
A

WSRC-TR-2003-00232, Rev. 0
SRT-RPP-2003-00105, Rev. 0

$$
0315.215^{B}
$$

8hrHold@100

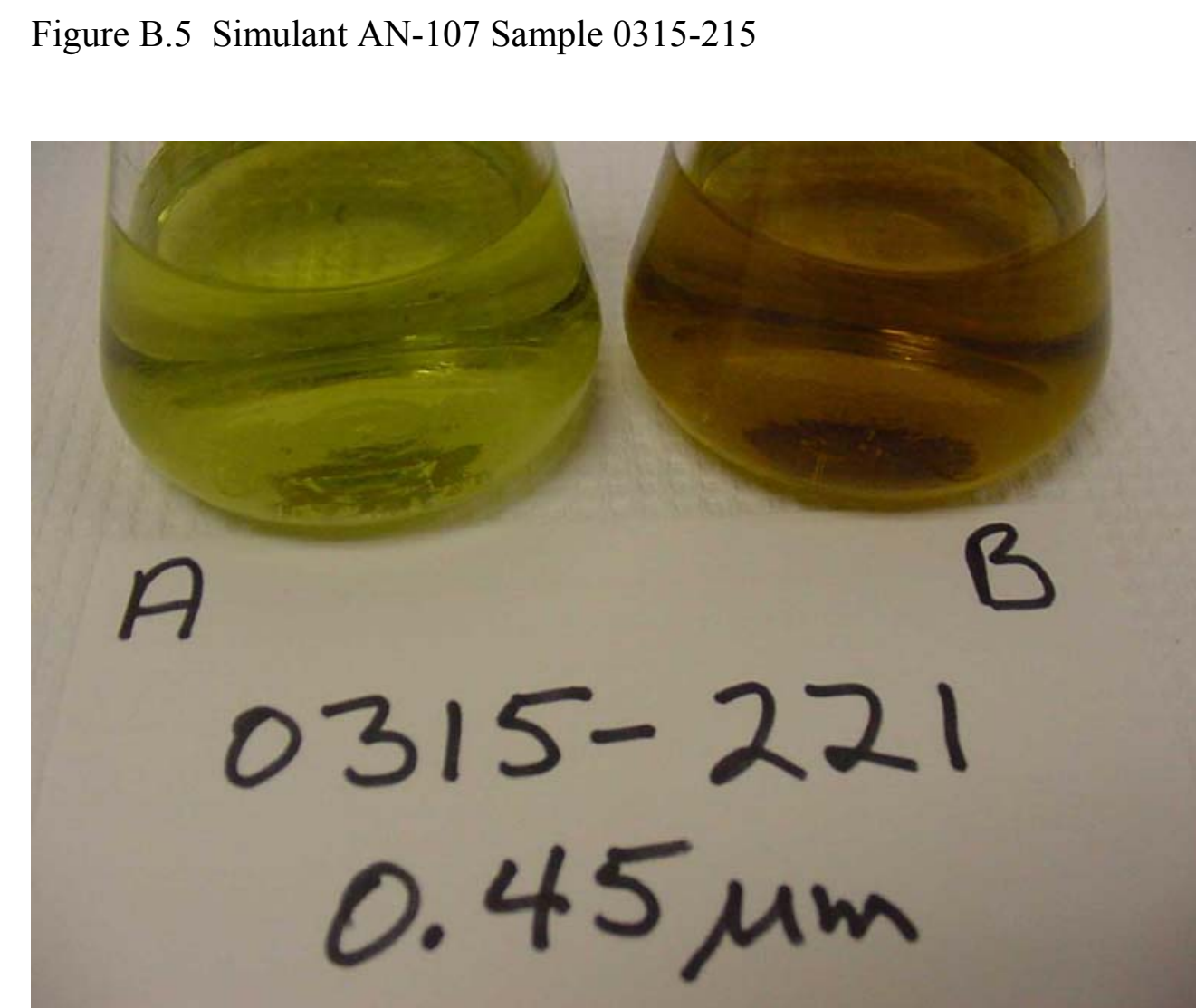




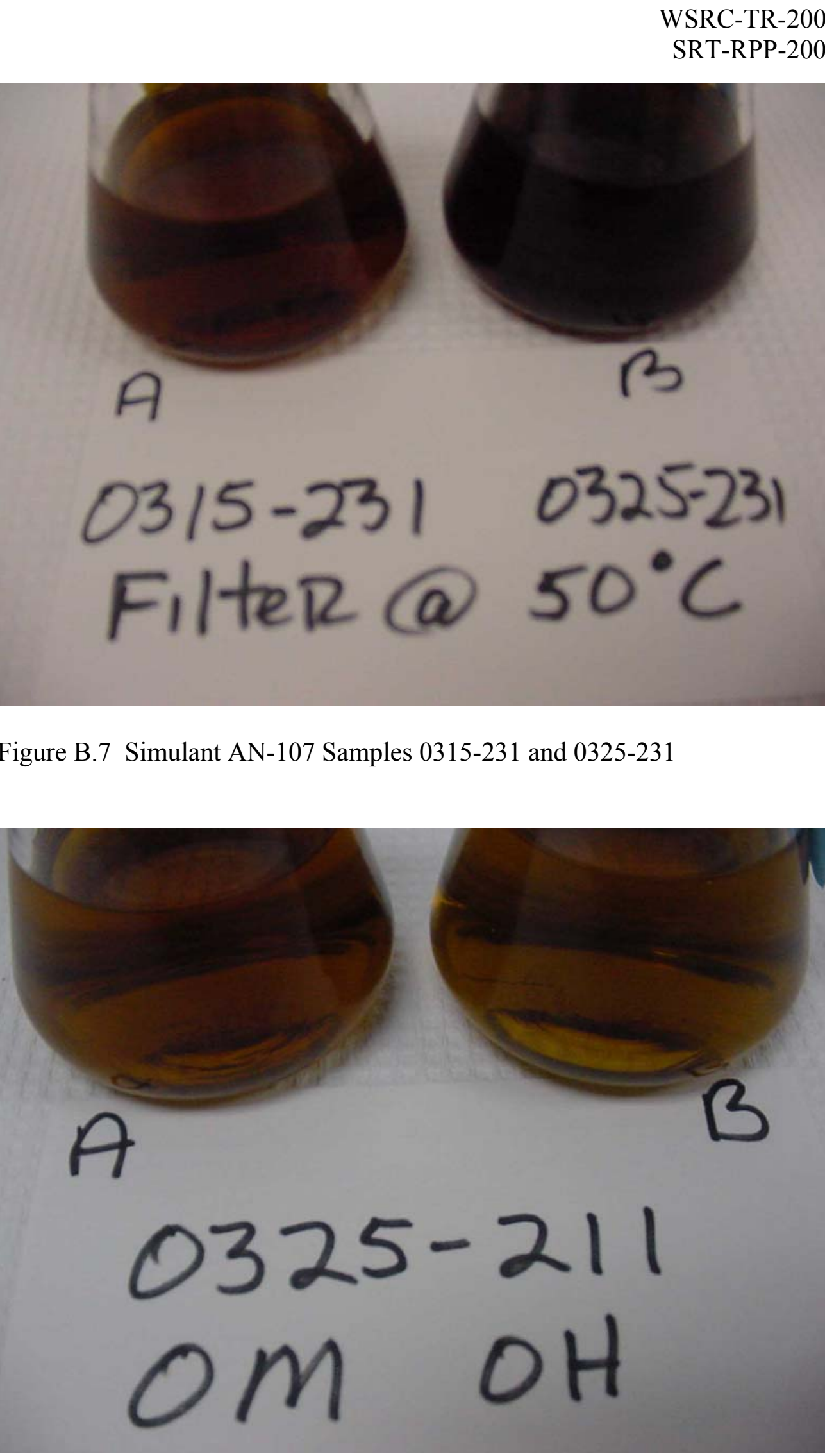


WSRC-TR-2003-00232, Rev. 0

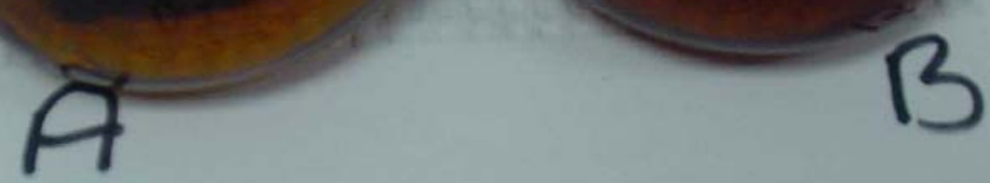

$0325-211$

$0.2 \mathrm{~m} \mathrm{OH}$

Figure B.9 Simulant AN-107 Sample 0325-211

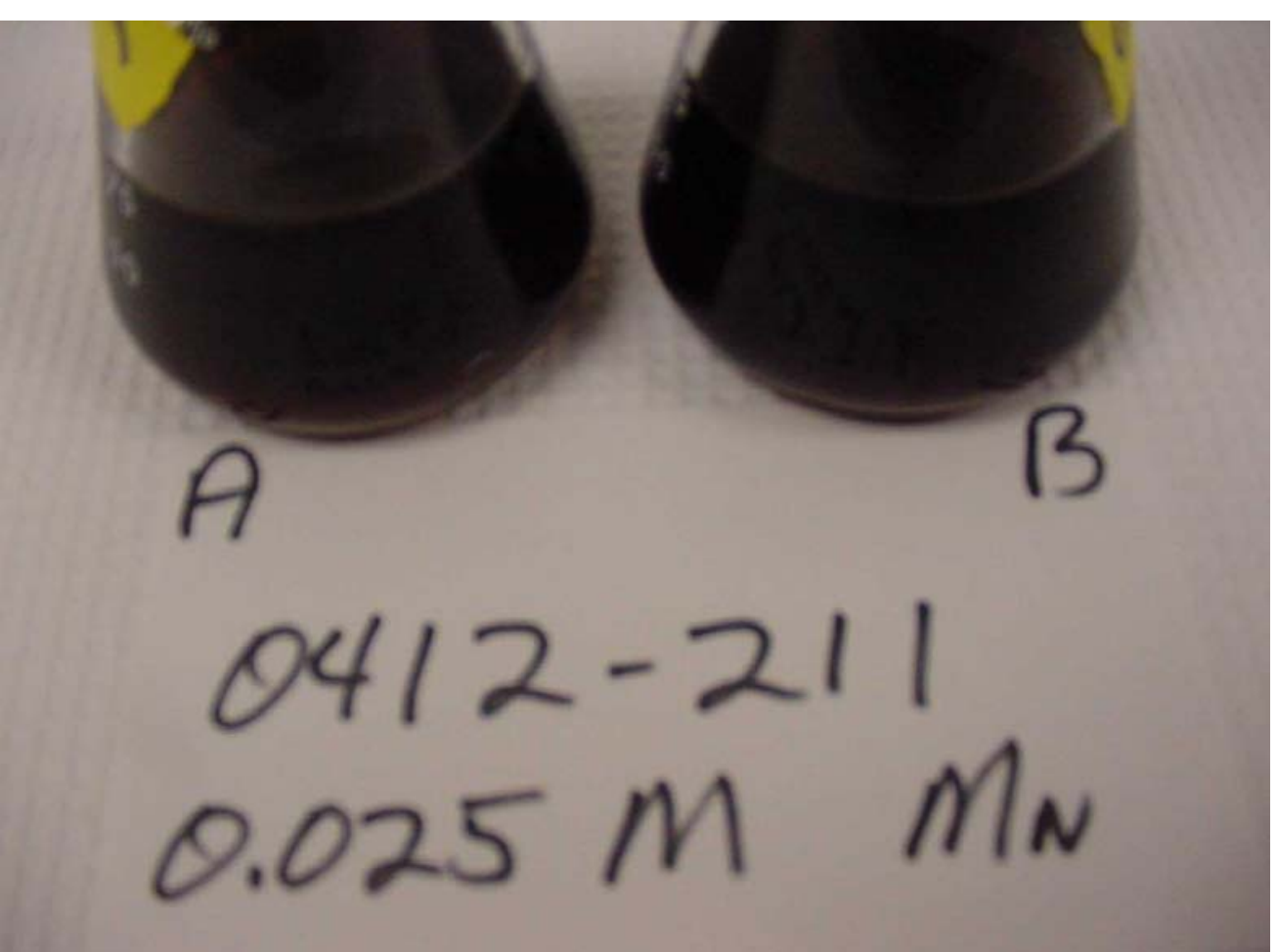

gure B.10 Singant AN-107 Sample 0412-211

Page 109 of 220 


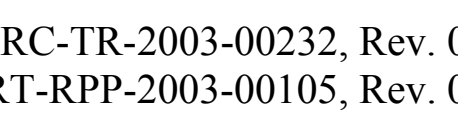

A

B

$$
\begin{aligned}
& 0412-211 \\
& 0.01 \mathrm{M} \mathrm{mN}
\end{aligned}
$$

Figure B.11 Simulant AN-107 Sample 0412-211

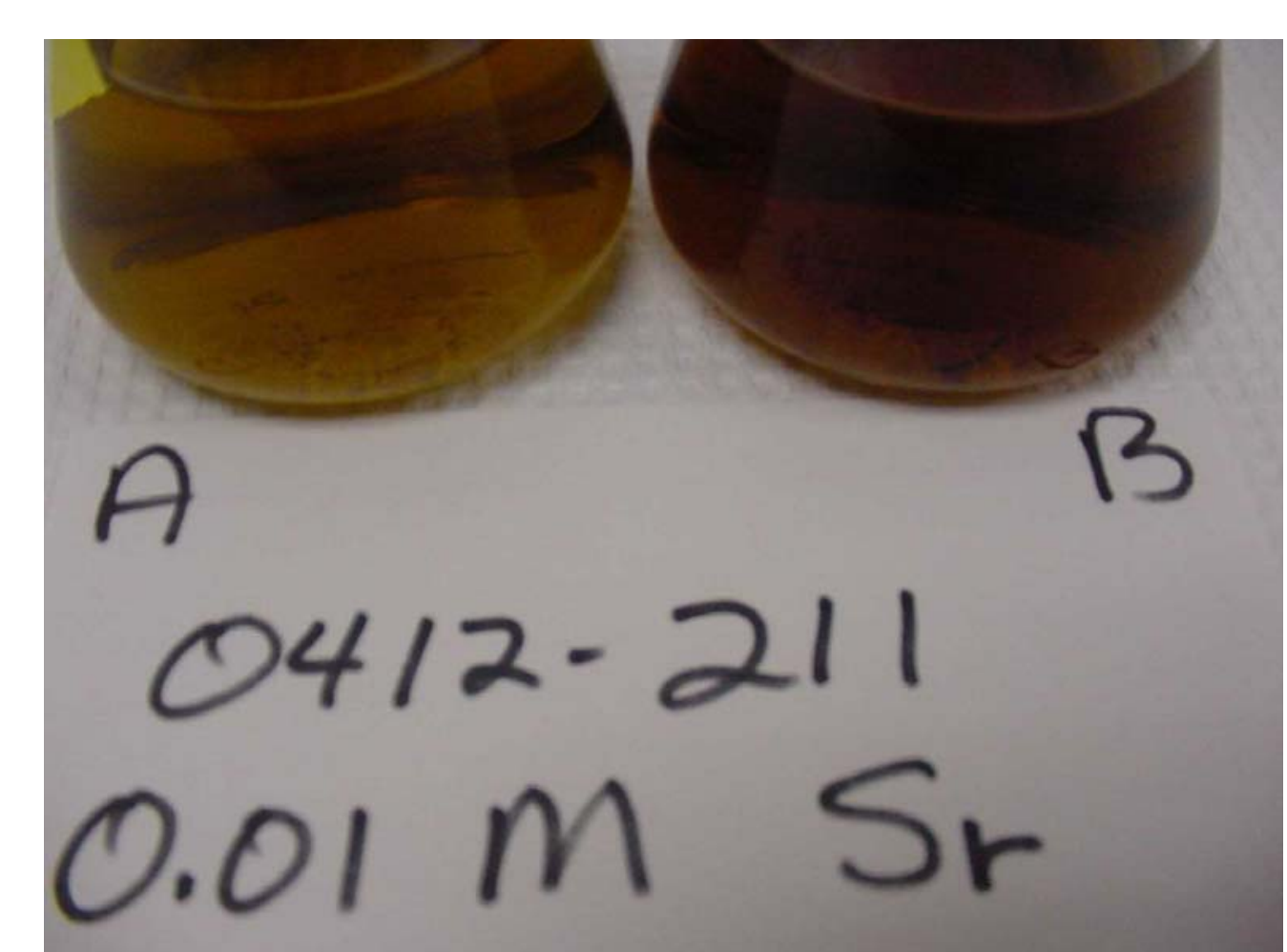

Page 110 of 220 
WSRC-TR-2003-00232, Rev. 0
SRT-RPP-2003-00105, Rev. 0

A

B

$$
\begin{aligned}
& 0412-211 \\
& 0.02 m \text { Sr }
\end{aligned}
$$

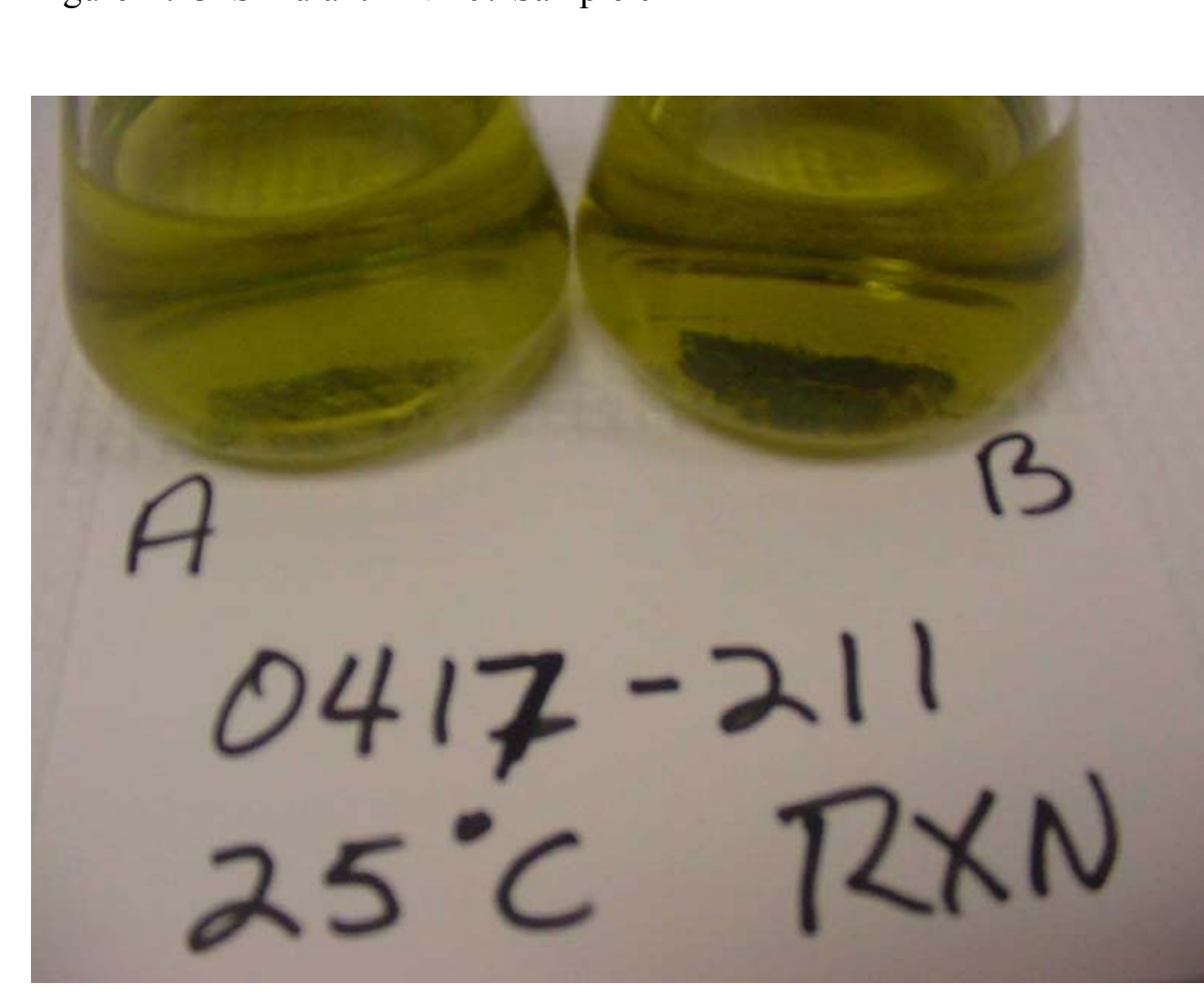


WSRC-TR-2003-00232, Rev. 0
SRT-RPP-2003-00105, Rev. 0

A

B

$0424-211$

$15^{\circ} \mathrm{C}$ RXN

Figure B.15 Simulant AN-107 Sample 0424-211

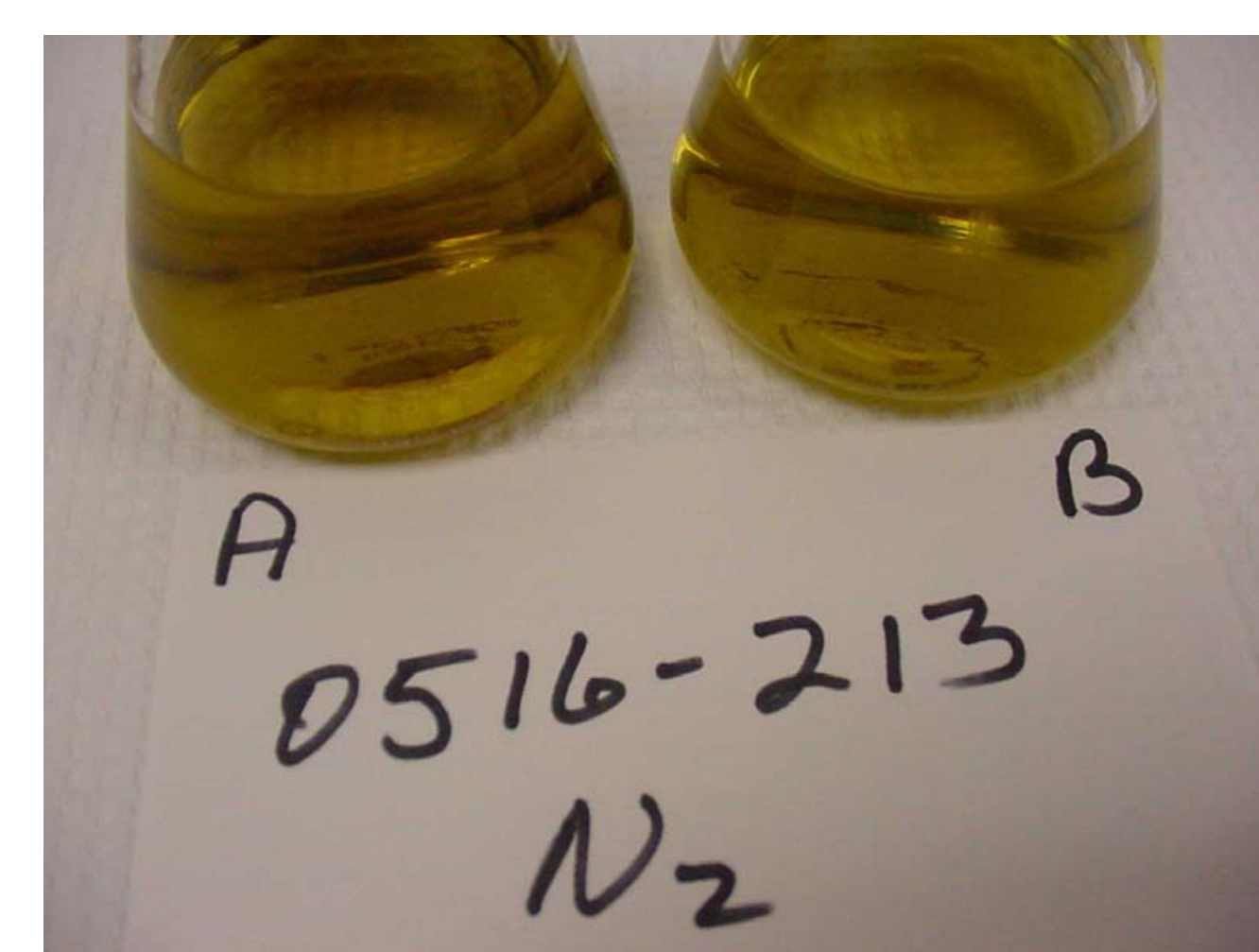

Figure B.16 Simulant AN-107 Sample 0516-213

Page 112 of 220 
WSRC-TR-2003-00232, Rev. 0

SRT-RPP-2003-00105, Rev. 0

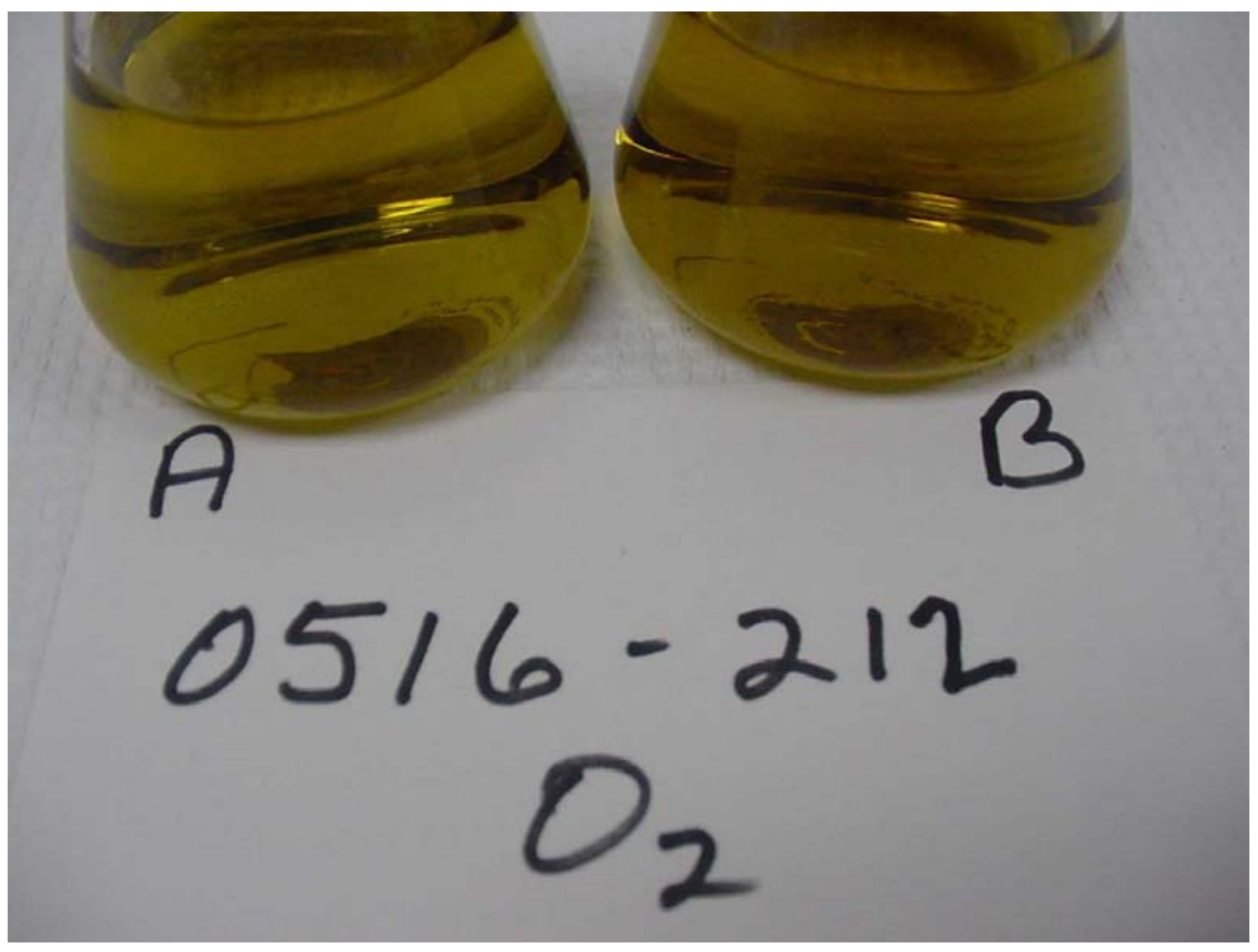

Figure B.17 Simulant AN-107 Sample 0516-212

Page 113 of 220 
WSRC-TR-2003-00232, Rev. 0

SRT-RPP-2003-00105, Rev. 0

APPENDIX C

ICP-AES Analysis of AN-107 Primary Effects Samples

Page 114 of 220 
WSRC-TR-2003-00232, Rev. 0

SRT-RPP-2003-00105, Rev. 0

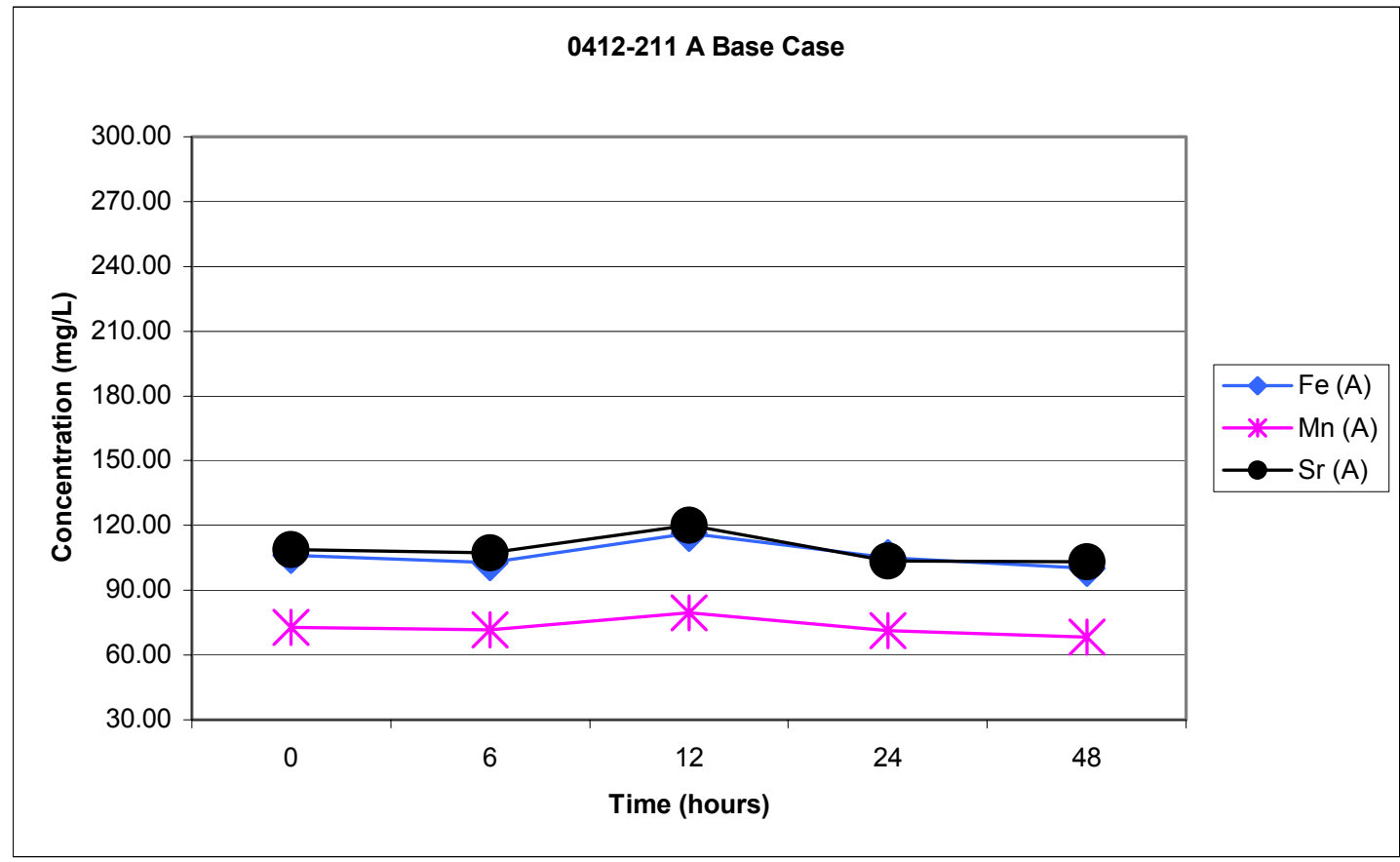

Figure C.1 Iron, Manganese, and Strontium ICP Data for Sample 0412-211A Base Case

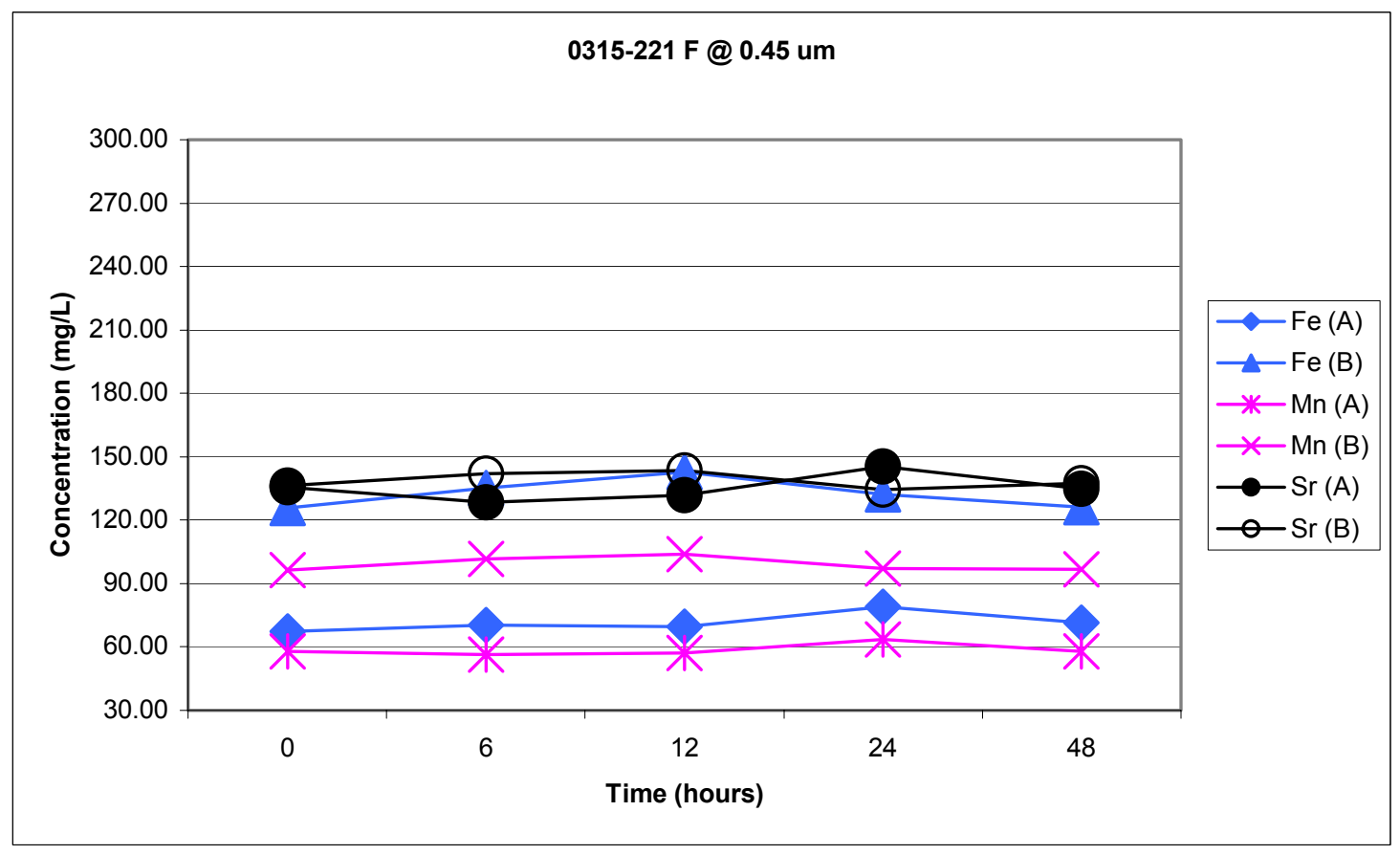

Figure C.2 Iron, Manganese, and Strontium ICP Data for Sample 0315-221 0.45 $\mu \mathrm{m}$ Filter 
WSRC-TR-2003-00232, Rev. 0

SRT-RPP-2003-00105, Rev. 0

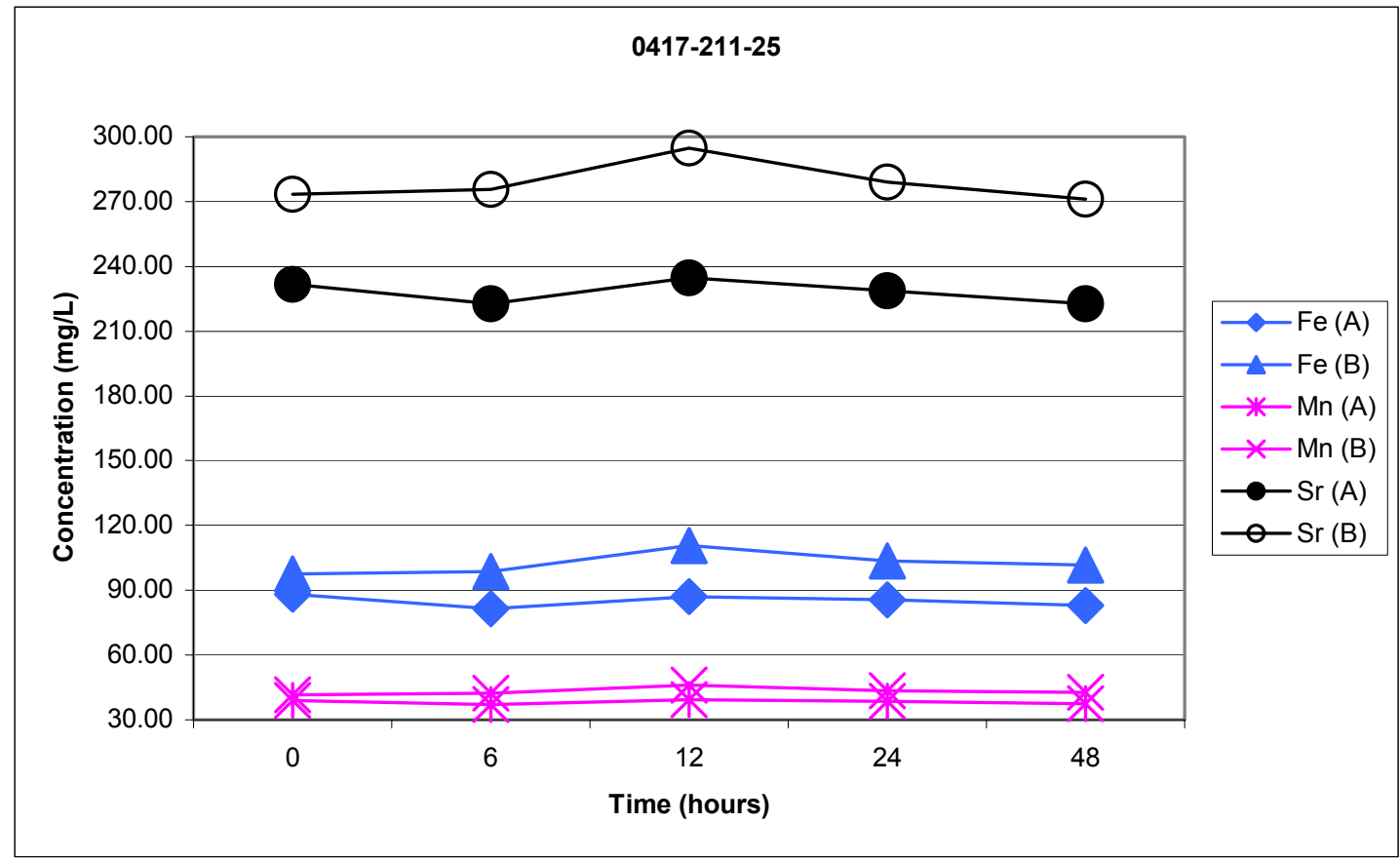

Figure C.3 Iron, Manganese, and Strontium ICP Data for Sample 0417-211-25 ${ }^{\circ} \mathrm{C}$ Rxn

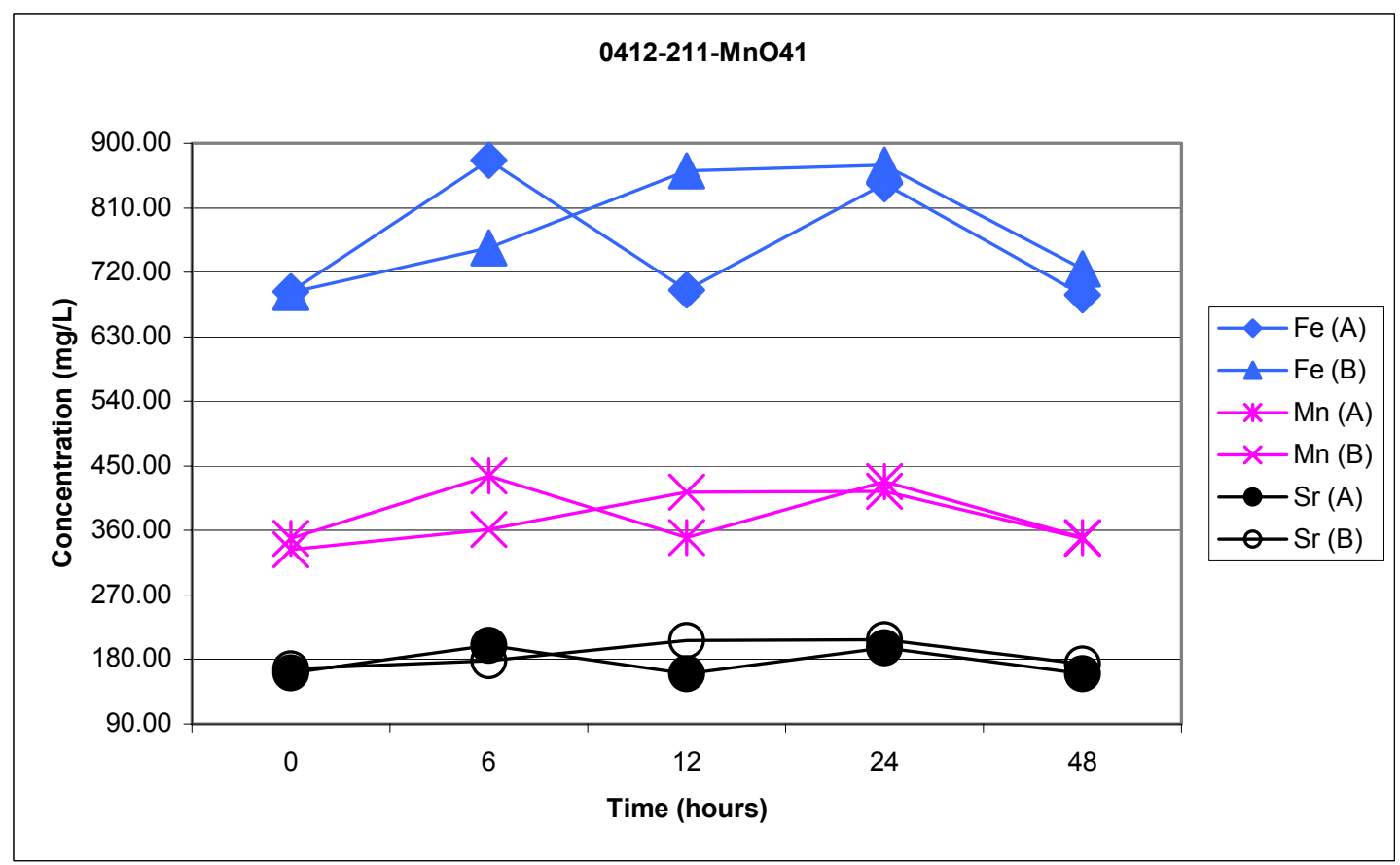

Figure C.4 Iron, Manganese, and Strontium ICP Data for Sample 0417-211-0.01M MnO 4 
WSRC-TR-2003-00232, Rev. 0

SRT-RPP-2003-00105, Rev. 0

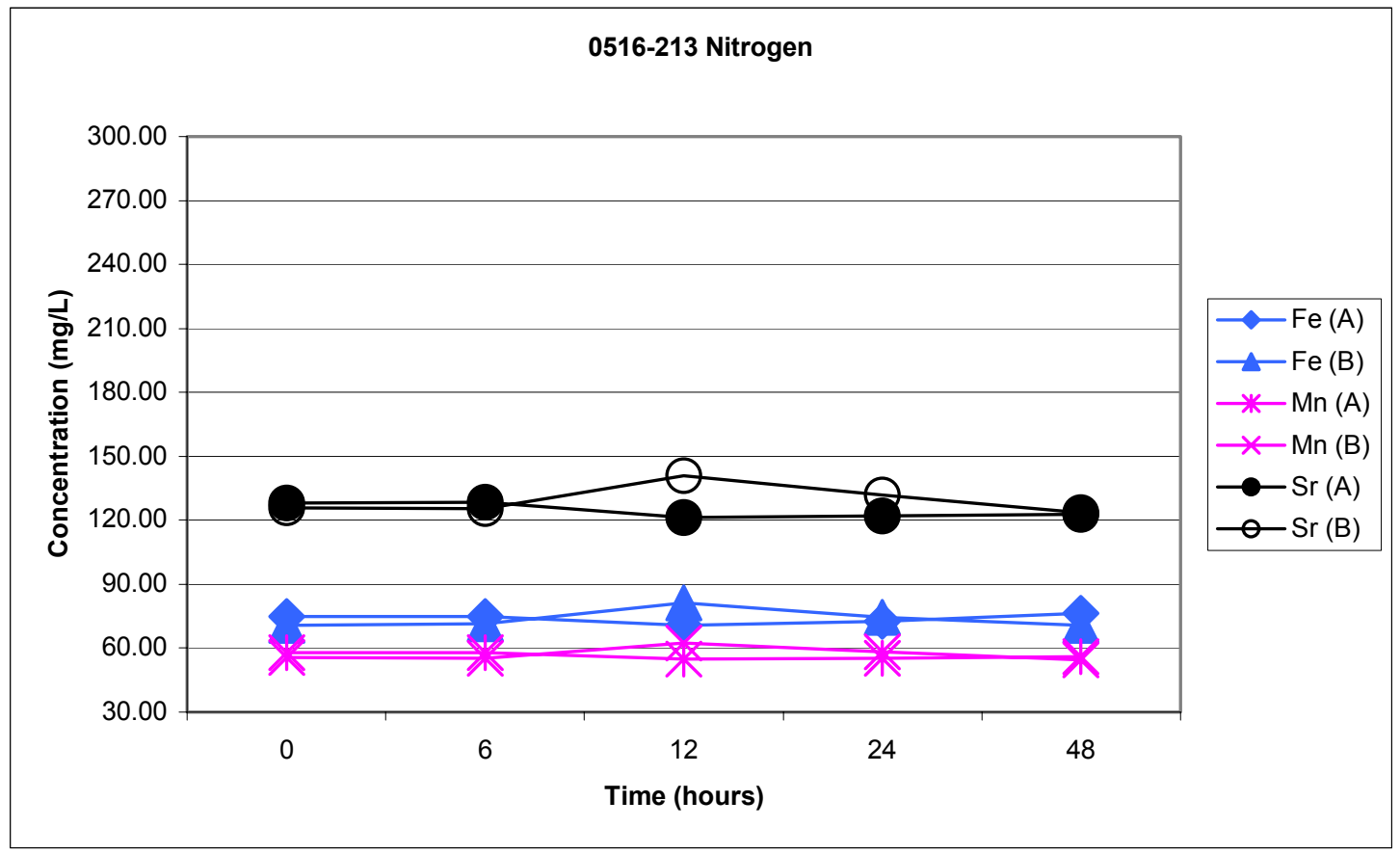

Figure C.5 Iron, Manganese, and Strontium ICP Data for Sample 0516-213 Nitrogen

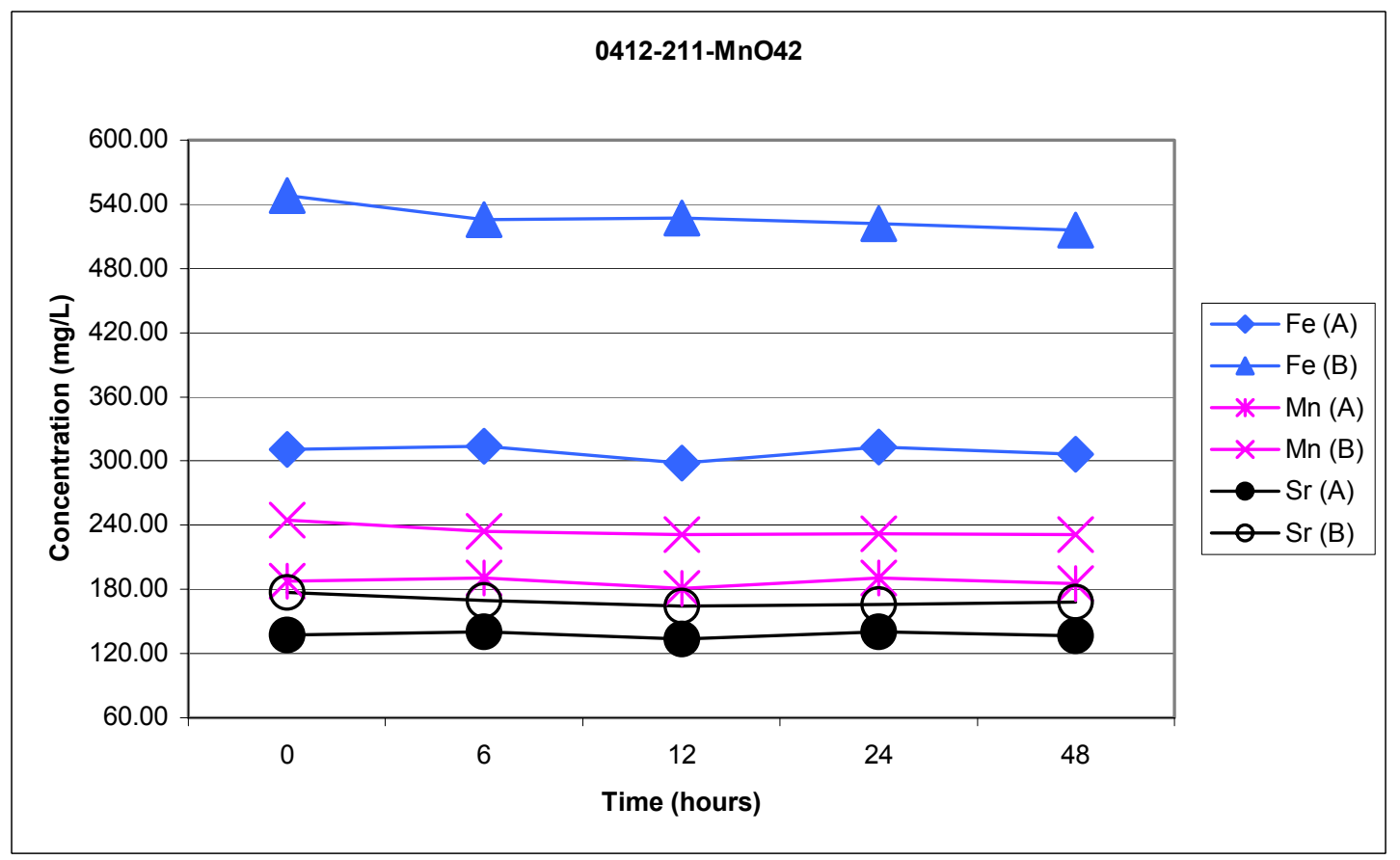

Figure C.6 Iron, Manganese, and Strontium ICP Data for Sample 0412-211-0.025M MnO 4 
WSRC-TR-2003-00232, Rev. 0

SRT-RPP-2003-00105, Rev. 0

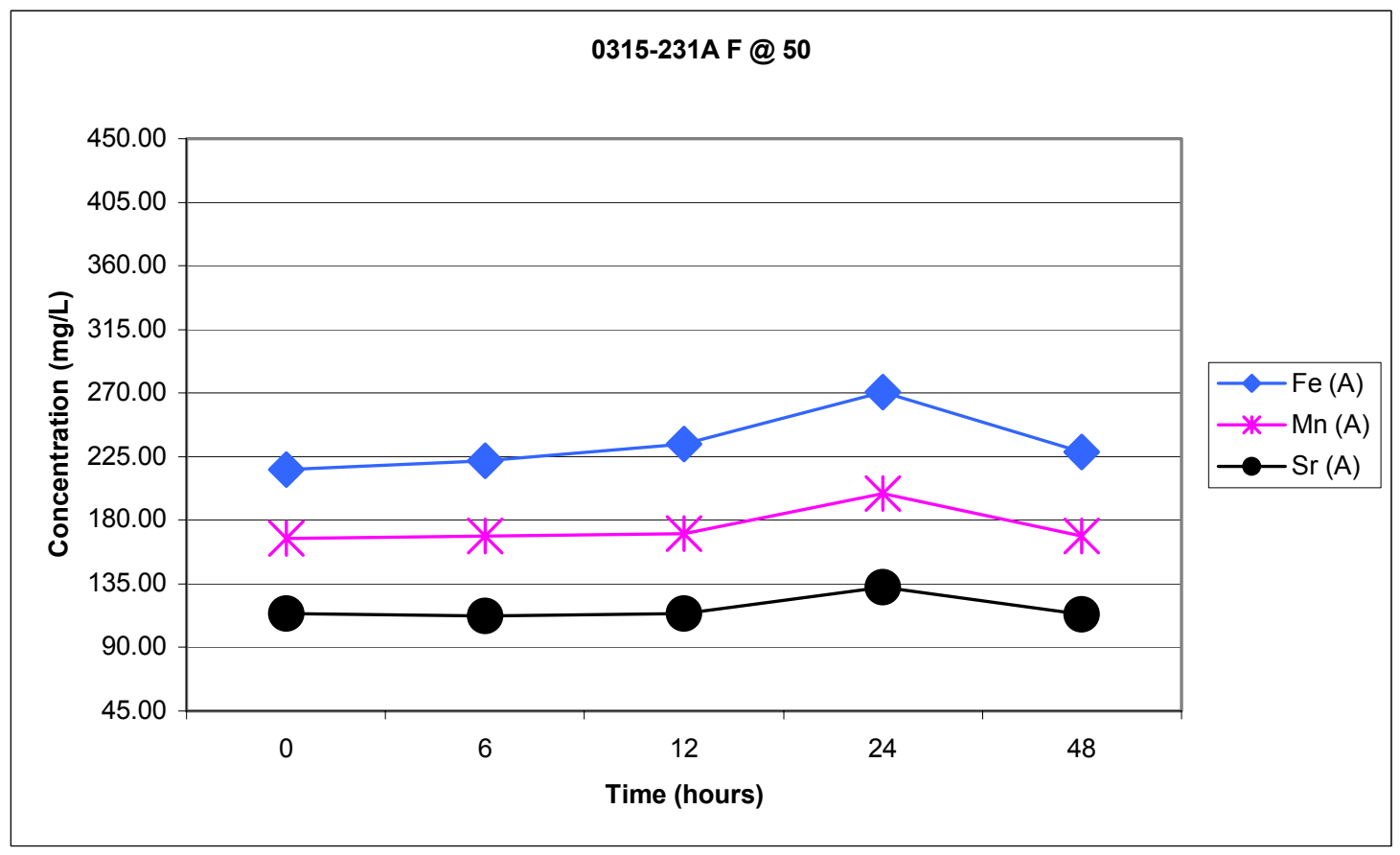

Figure C.7a Iron, Manganese, and Strontium ICP Data for Sample 0315-231A Filter @ 50 C

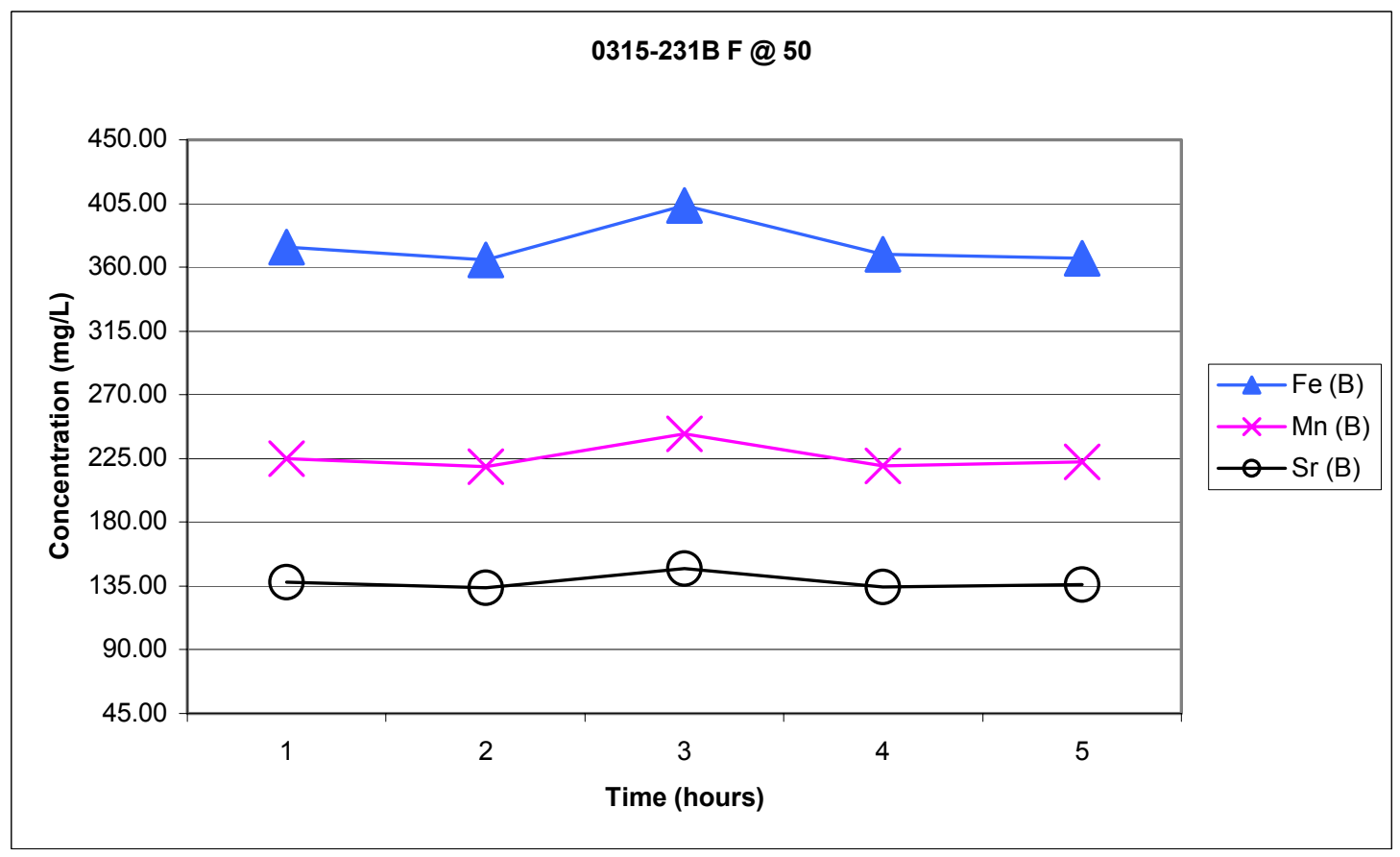

Figure C.7b Iron, Manganese, and Strontium ICP Data for Sample 0325-231B Filter @ 50 C 
WSRC-TR-2003-00232, Rev. 0

SRT-RPP-2003-00105, Rev. 0

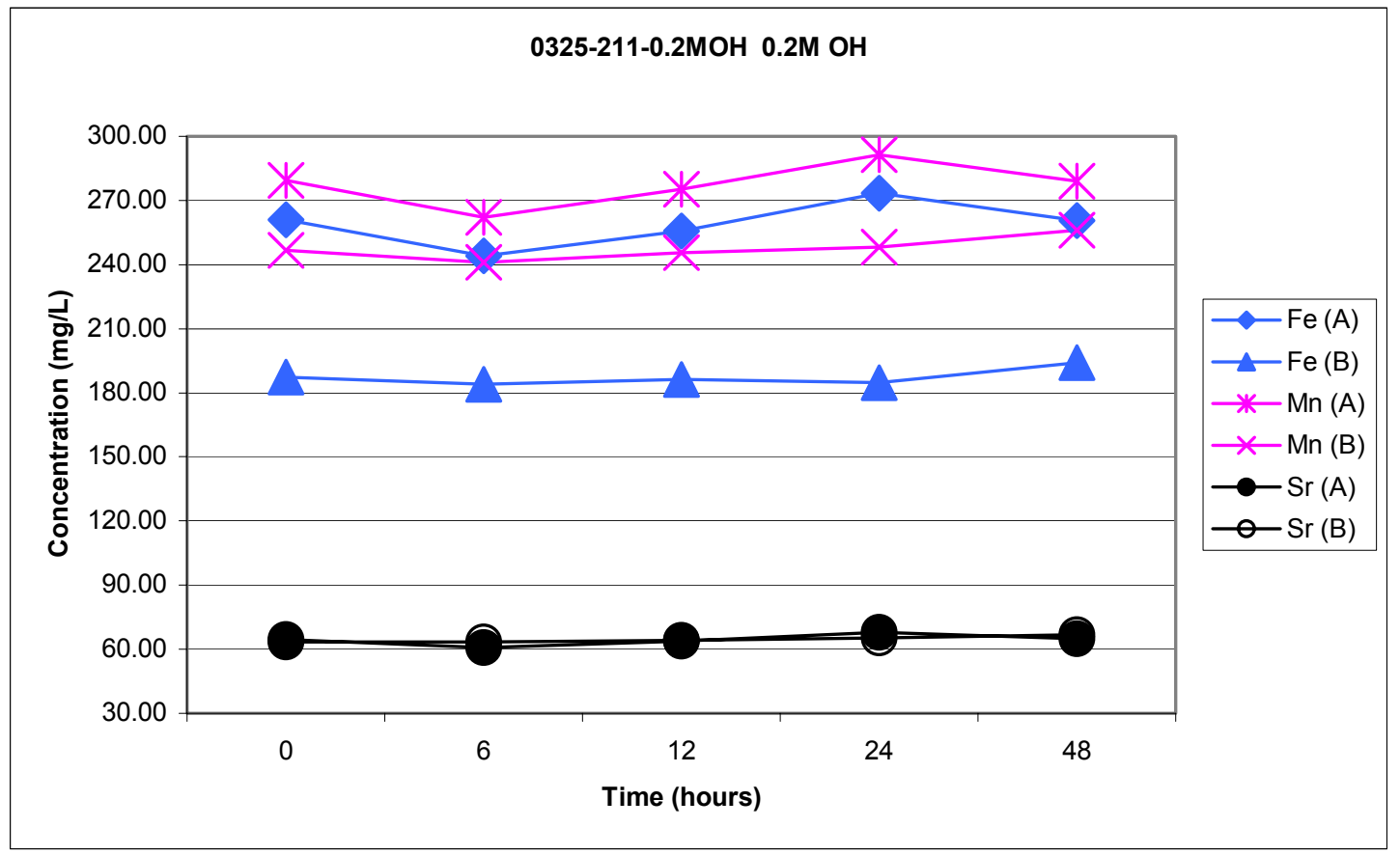

Figure C.8 Iron, Manganese, and Strontium ICP Data for Sample 0325-211-0.2 M OH

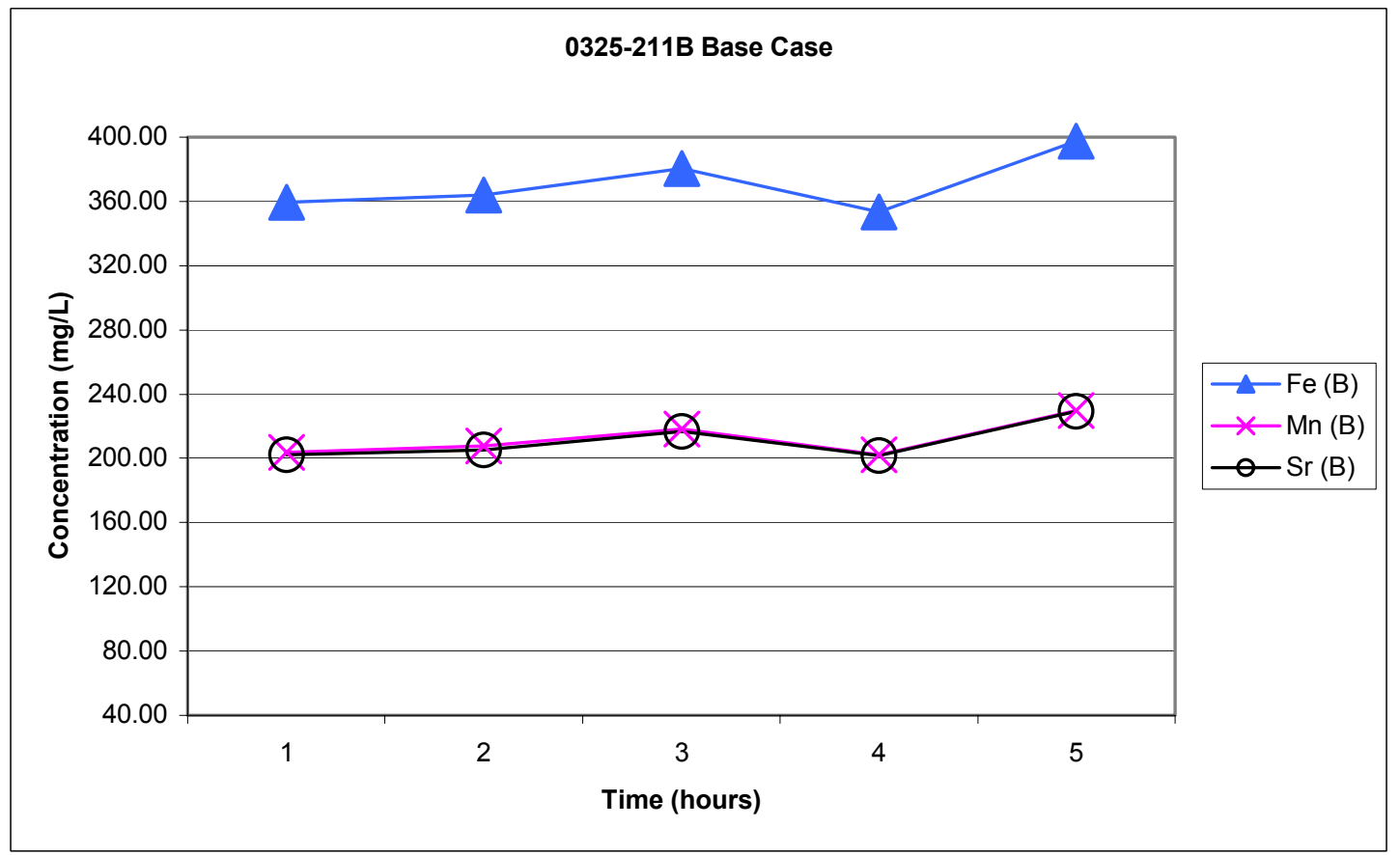

Figure C.9 Iron, Manganese, and Strontium ICP Data for Sample 0325-211B Base Case 
WSRC-TR-2003-00232, Rev. 0

SRT-RPP-2003-00105, Rev. 0

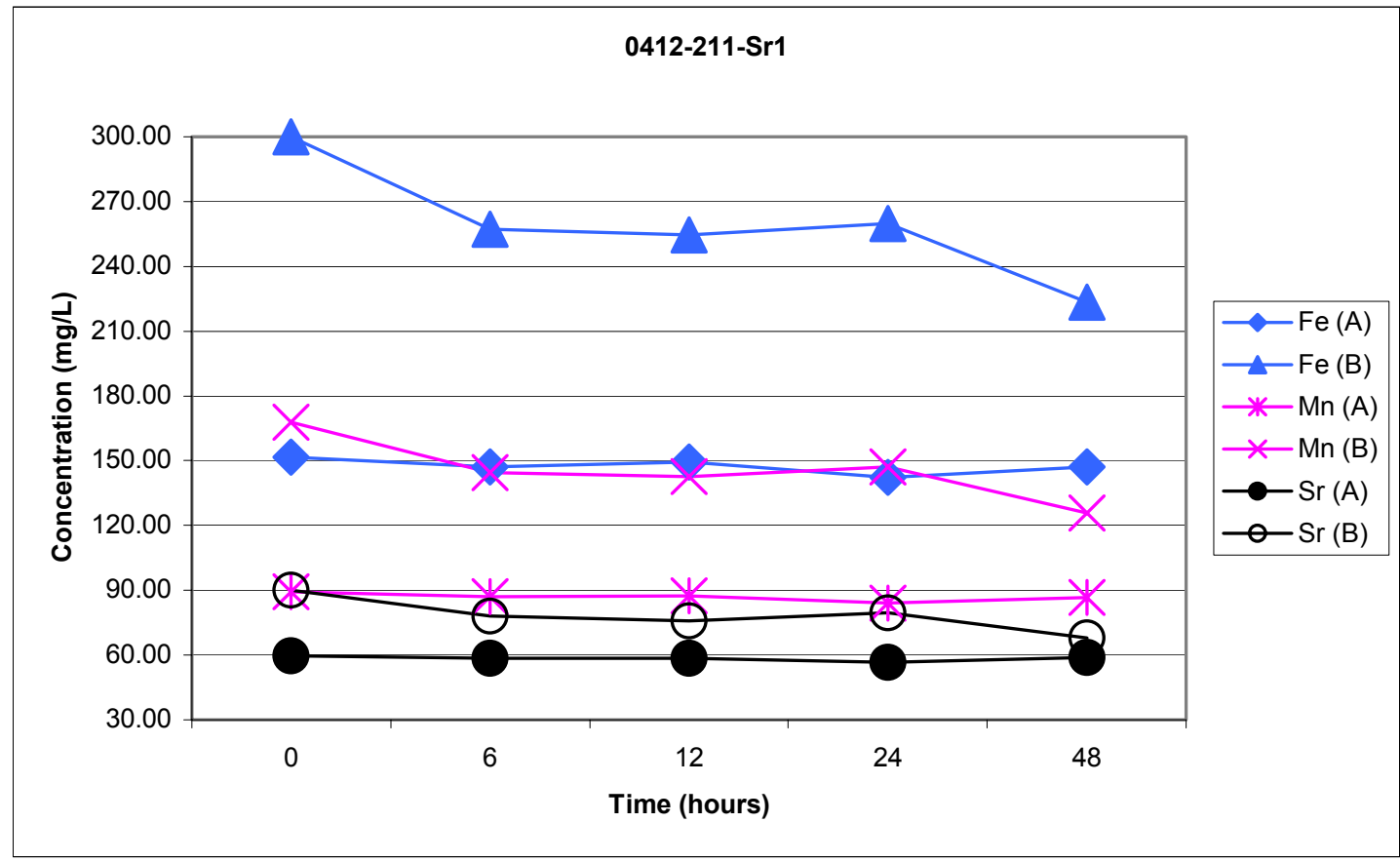

Figure C.10 Iron, Manganese, and Strontium ICP Data for Sample 0412-211-0.01 M Sr

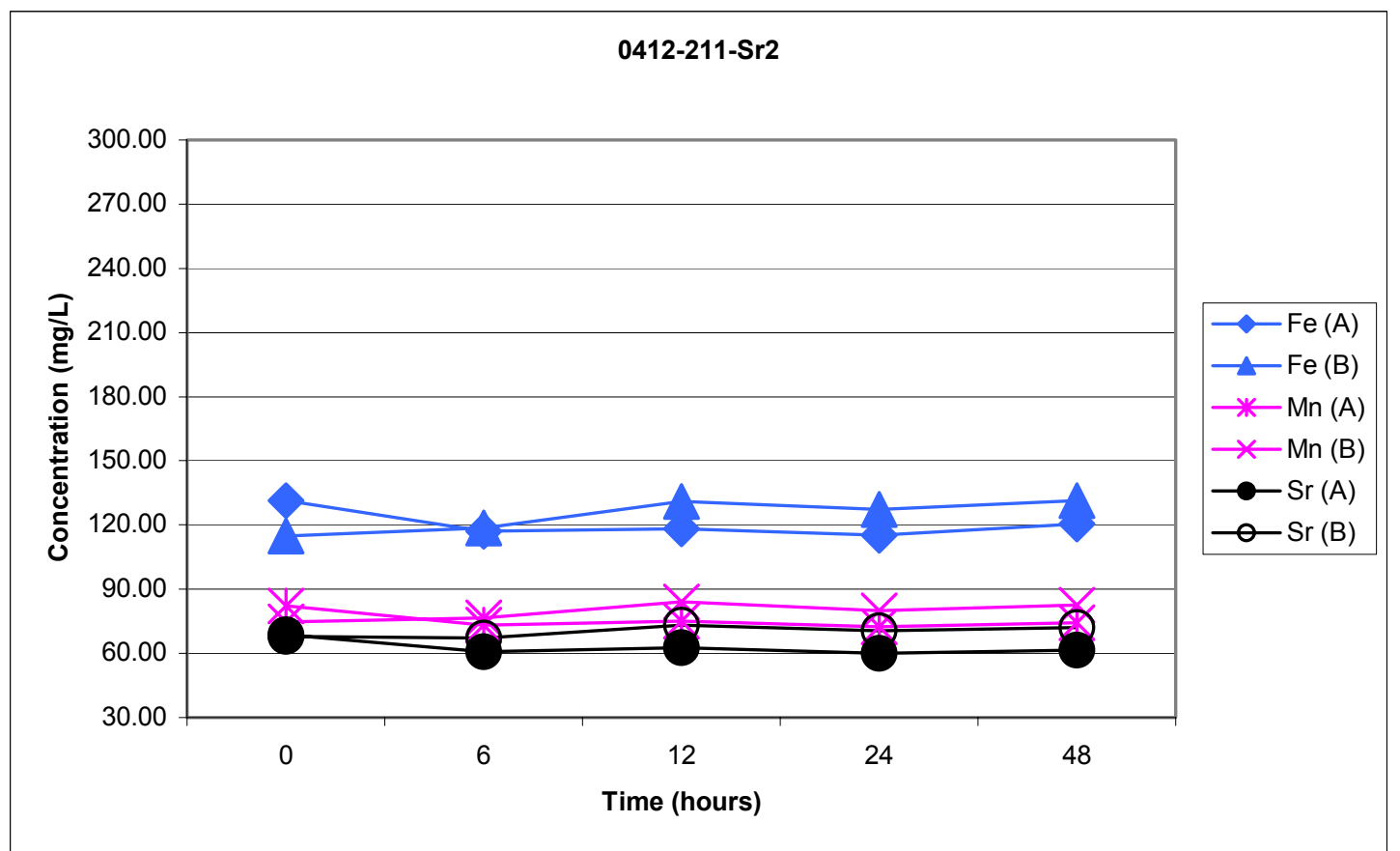

Figure C.11 Iron, Manganese, and Strontium ICP Data for Sample 0412-211-0.02 M Sr 
WSRC-TR-2003-00232, Rev. 0

SRT-RPP-2003-00105, Rev. 0

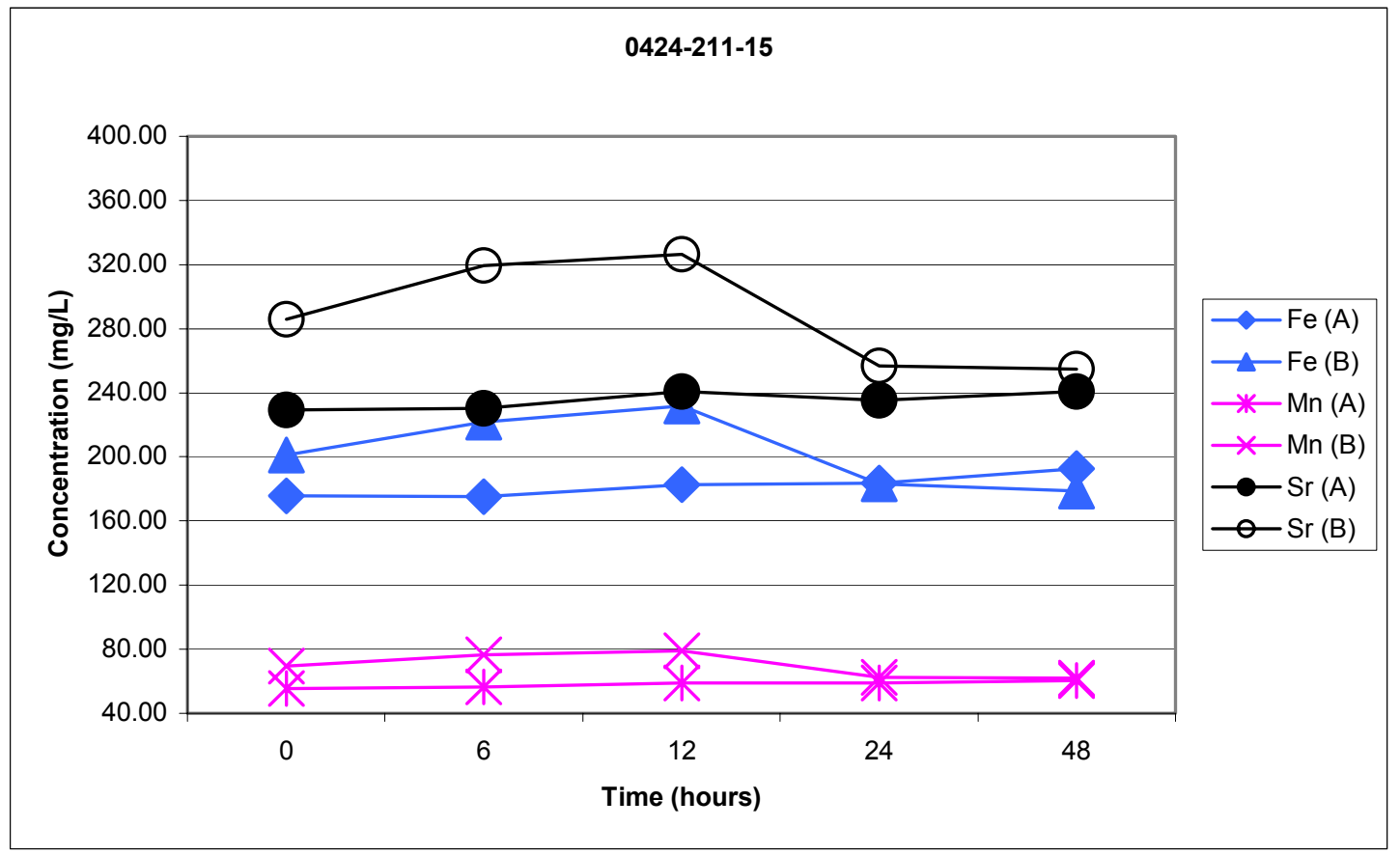

Figure C.12 Iron, Manganese, and Strontium ICP Data for Sample 0412-211-15 ${ }^{\circ} \mathrm{C}$ Rxn

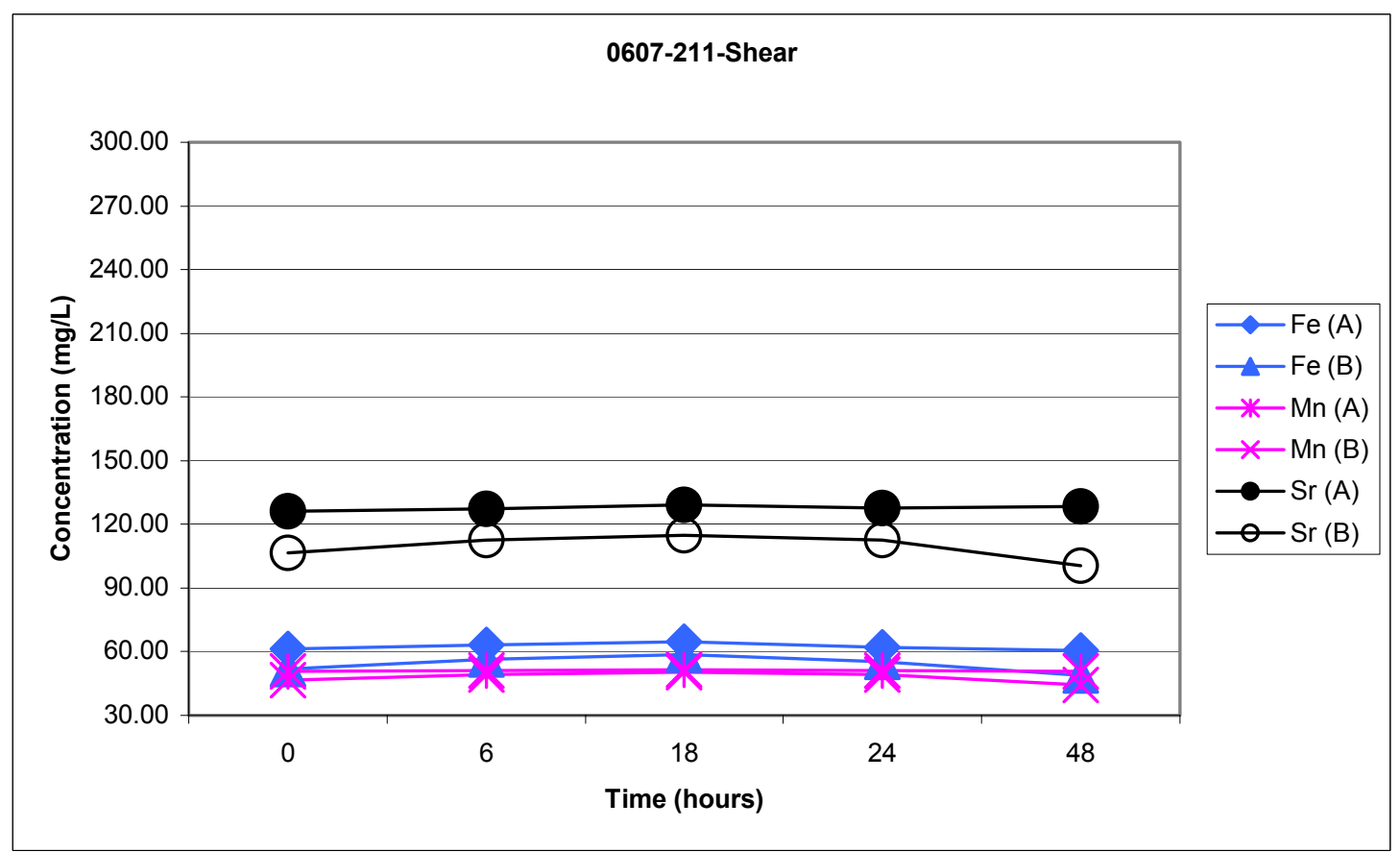

Figure C.13 Iron, Manganese, and Strontium ICP Data for Sample 0607-211 Shear 
WSRC-TR-2003-00232, Rev. 0

SRT-RPP-2003-00105, Rev. 0

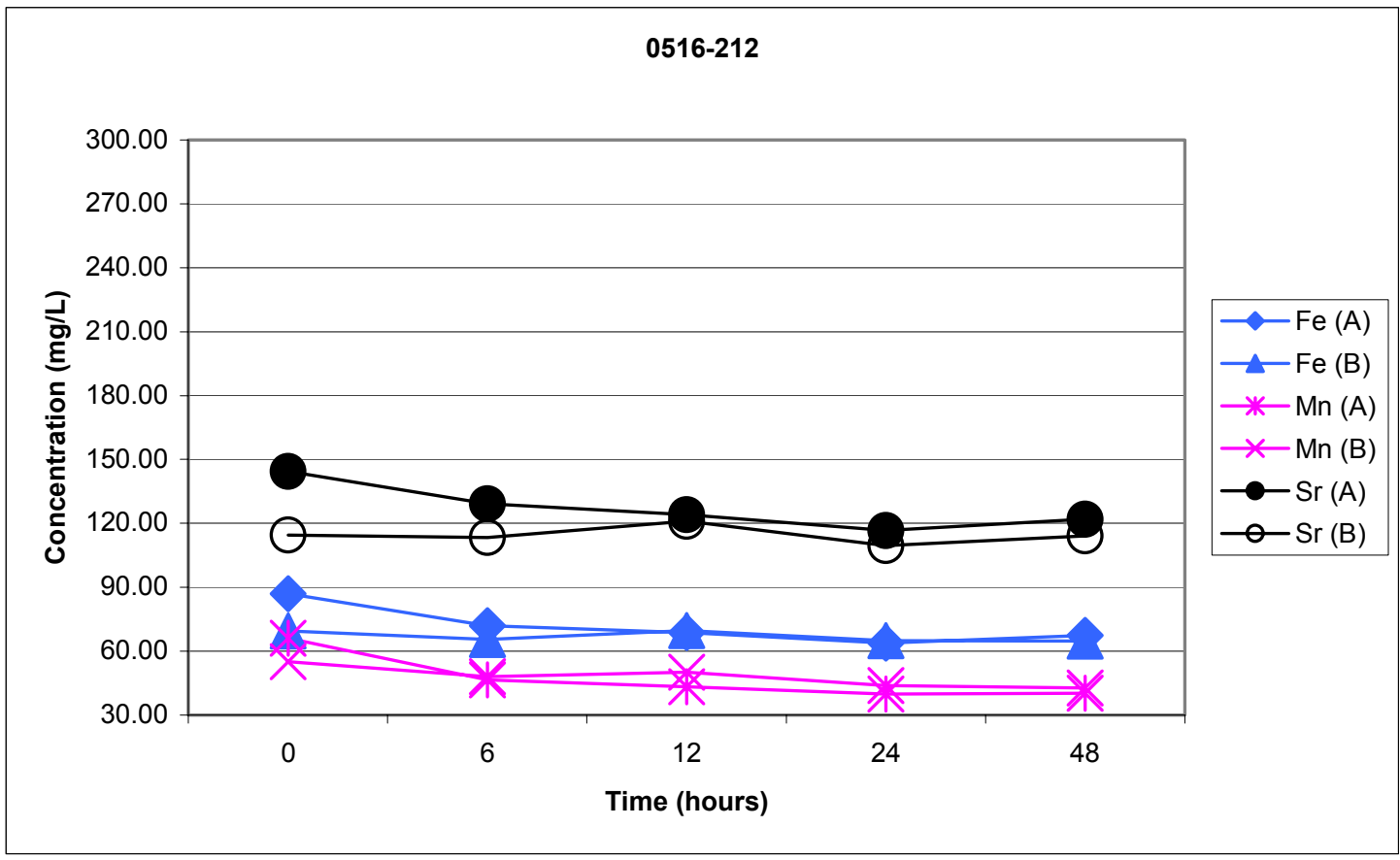

Figure C.13b Iron, Manganese, and Strontium ICP Data for Sample 0516-212 Oxygen Purge 
WSRC-TR-2003-00232, Rev. 0

SRT-RPP-2003-00105, Rev. 0

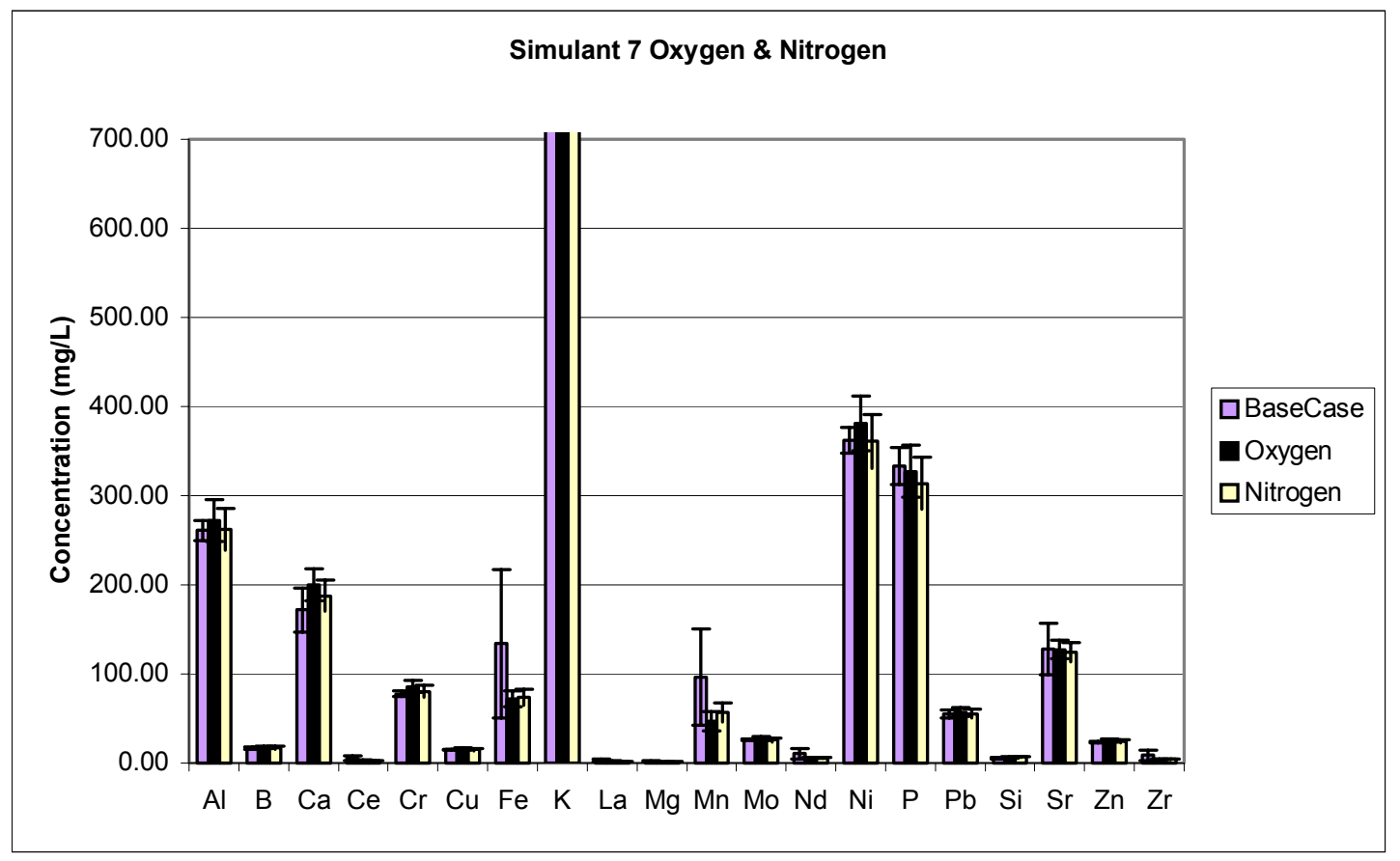

Figure C.14a Cation Concentrations in AN-107 Simulant 7 Base Case, $\mathrm{O}_{2}$, and $\mathrm{N}_{2}$ Filtrates

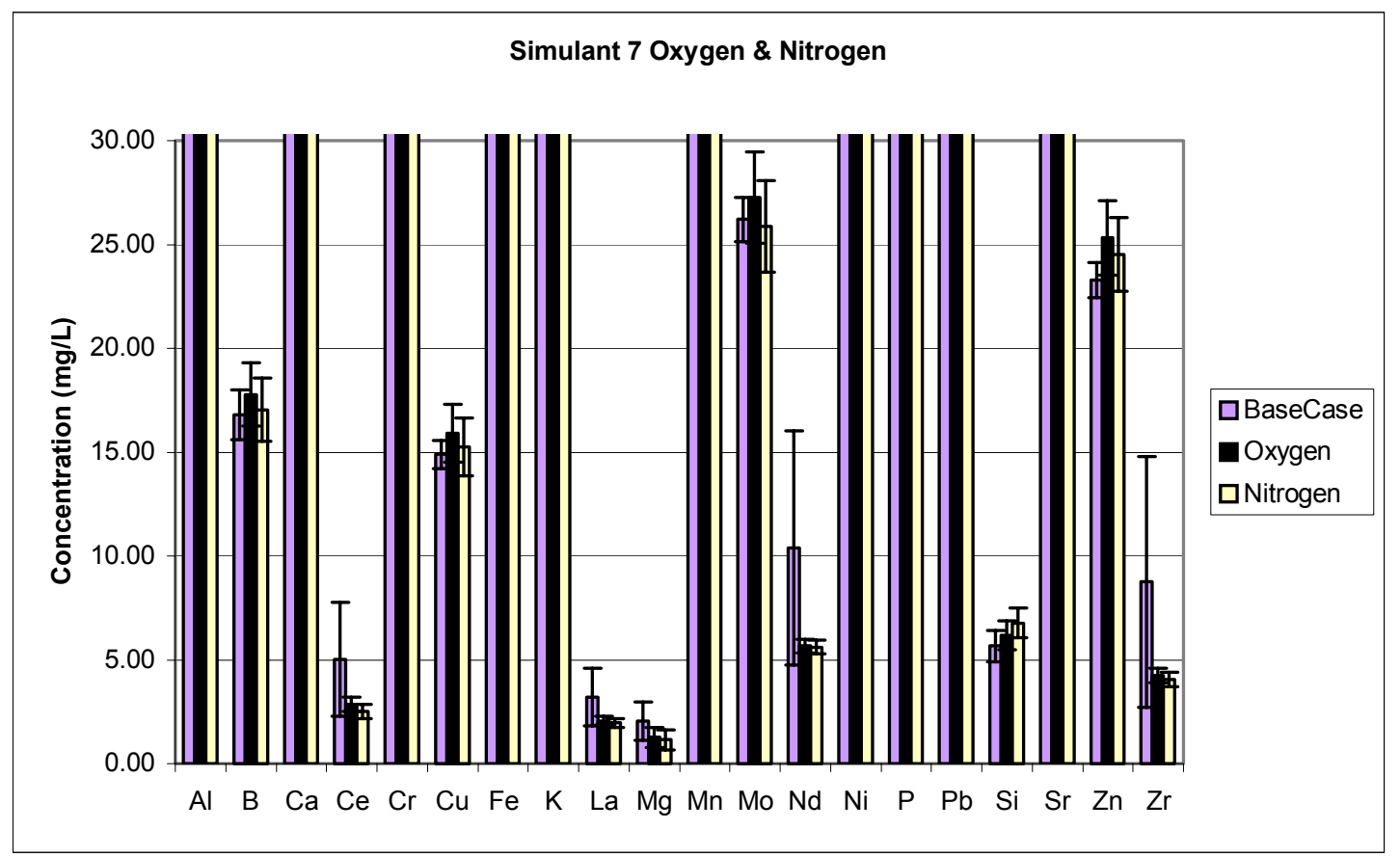

Figure C.14b Cation Concentrations in AN-107 Simulant 7 Base Case, $\mathrm{O}_{2}$, and $\mathrm{N}_{2}$ Filtrates 


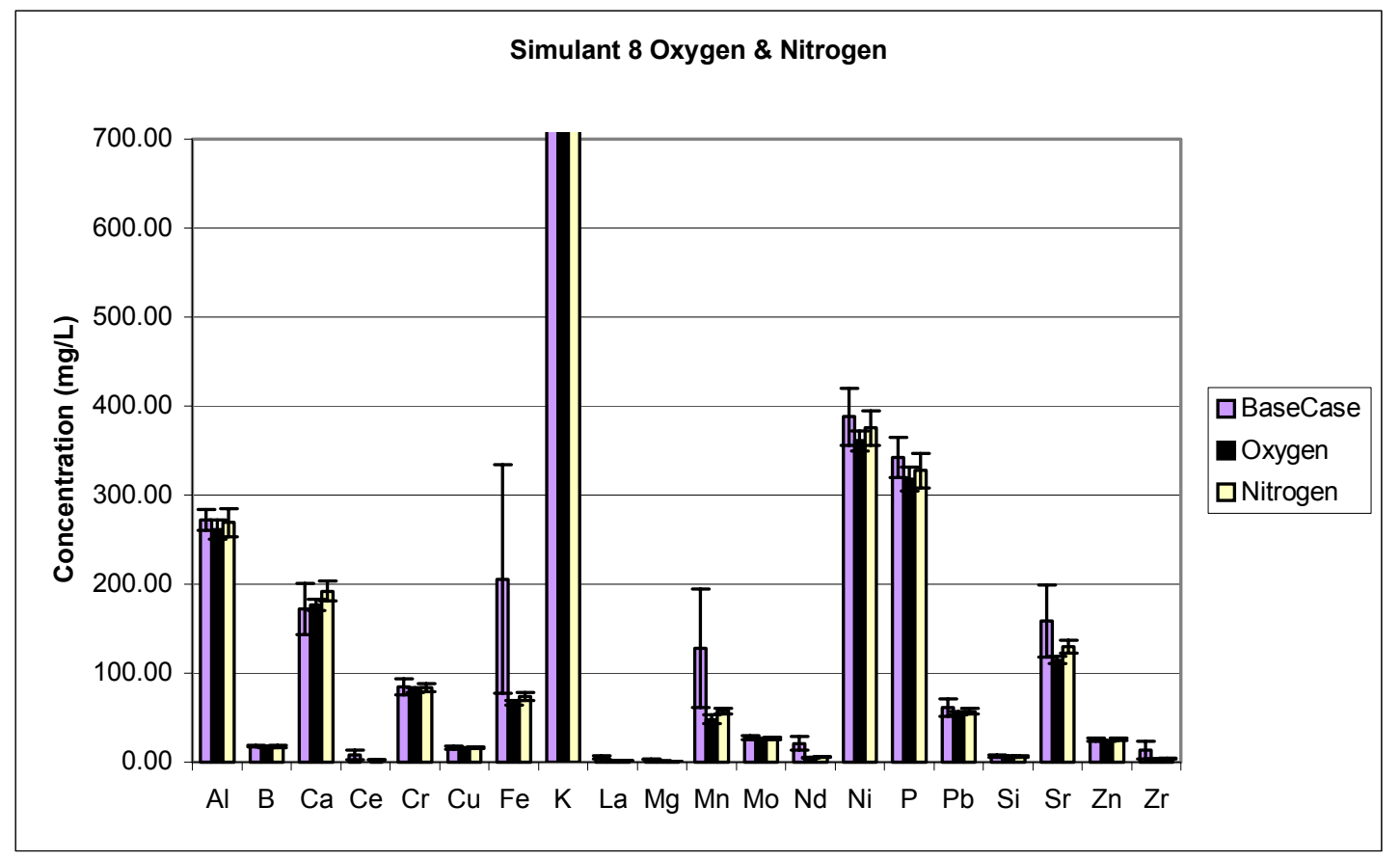

Figure C.15a Cation Concentrations in AN-107 Simulant 8 Base Case, $\mathrm{O}_{2}$, and $\mathrm{N}_{2}$ Filtrates

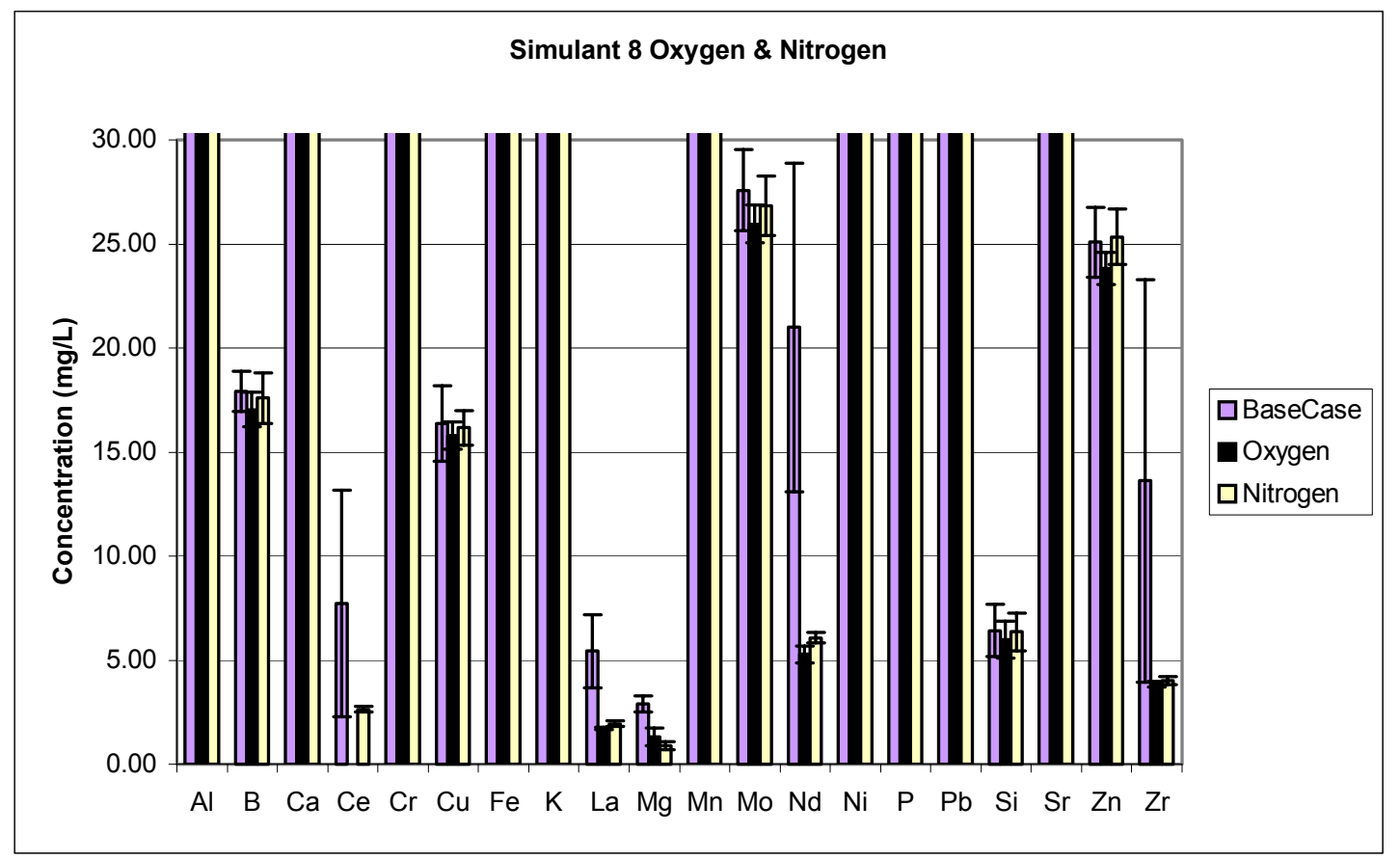

Figure C.15b Cation Concentrations in AN-107 Simulant 8 Base Case, $\mathrm{O}_{2}$, and $\mathrm{N}_{2}$ Filtrates 


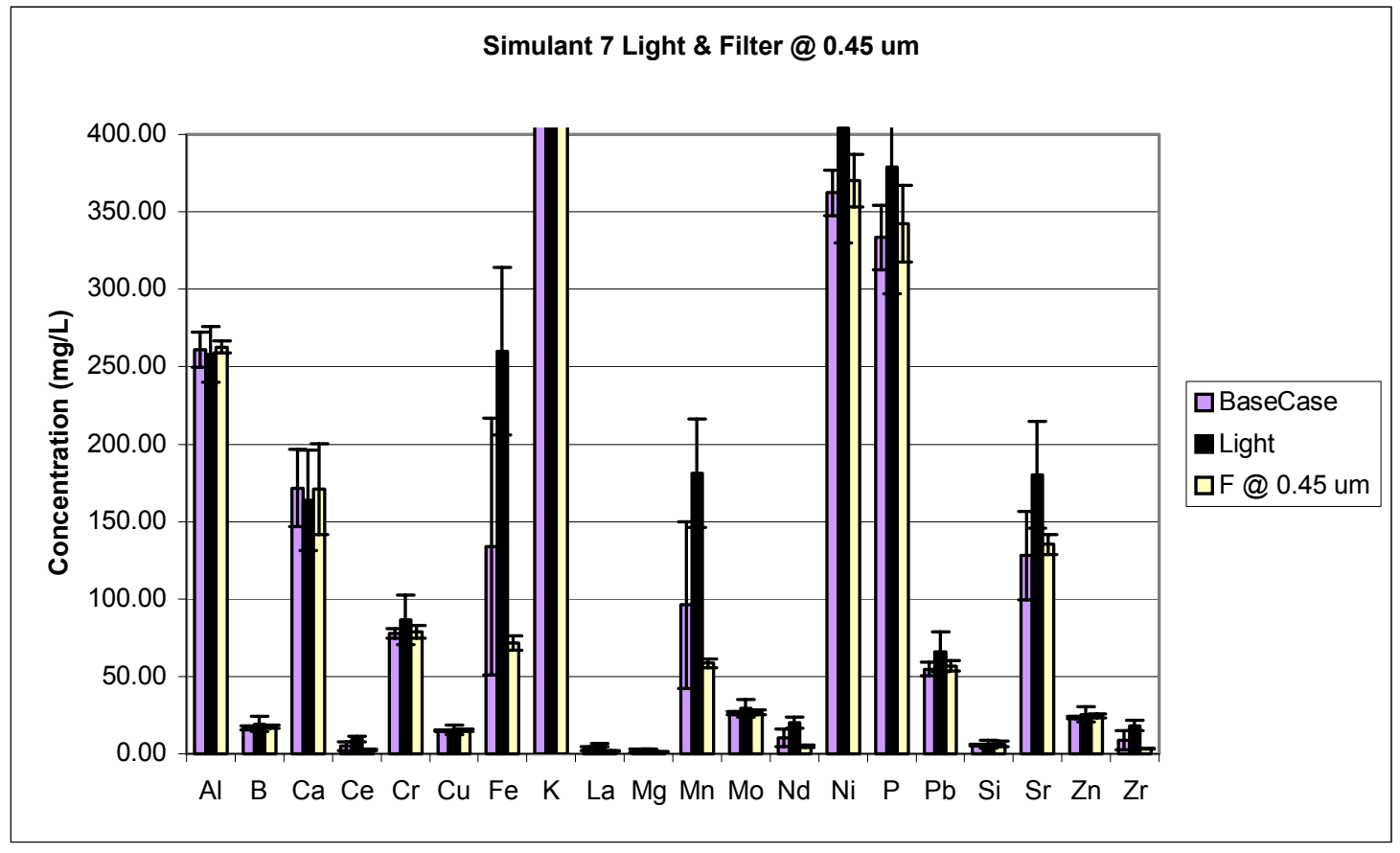

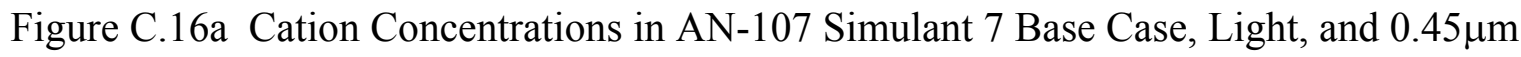
Filter Filtrates

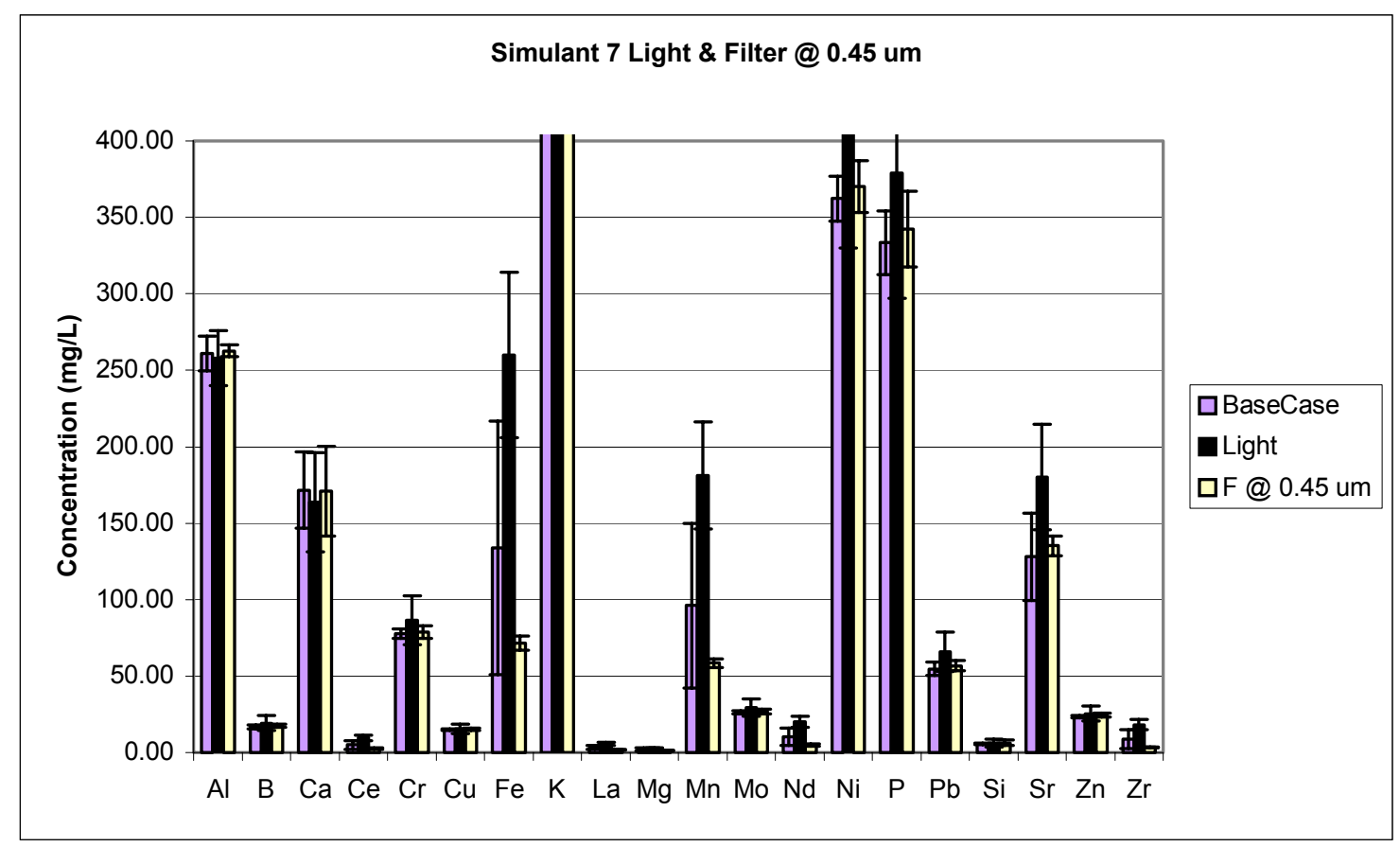

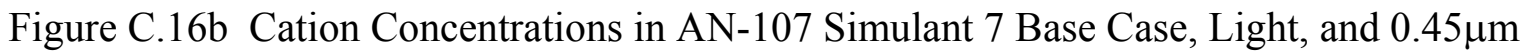
Filter Filtrates 


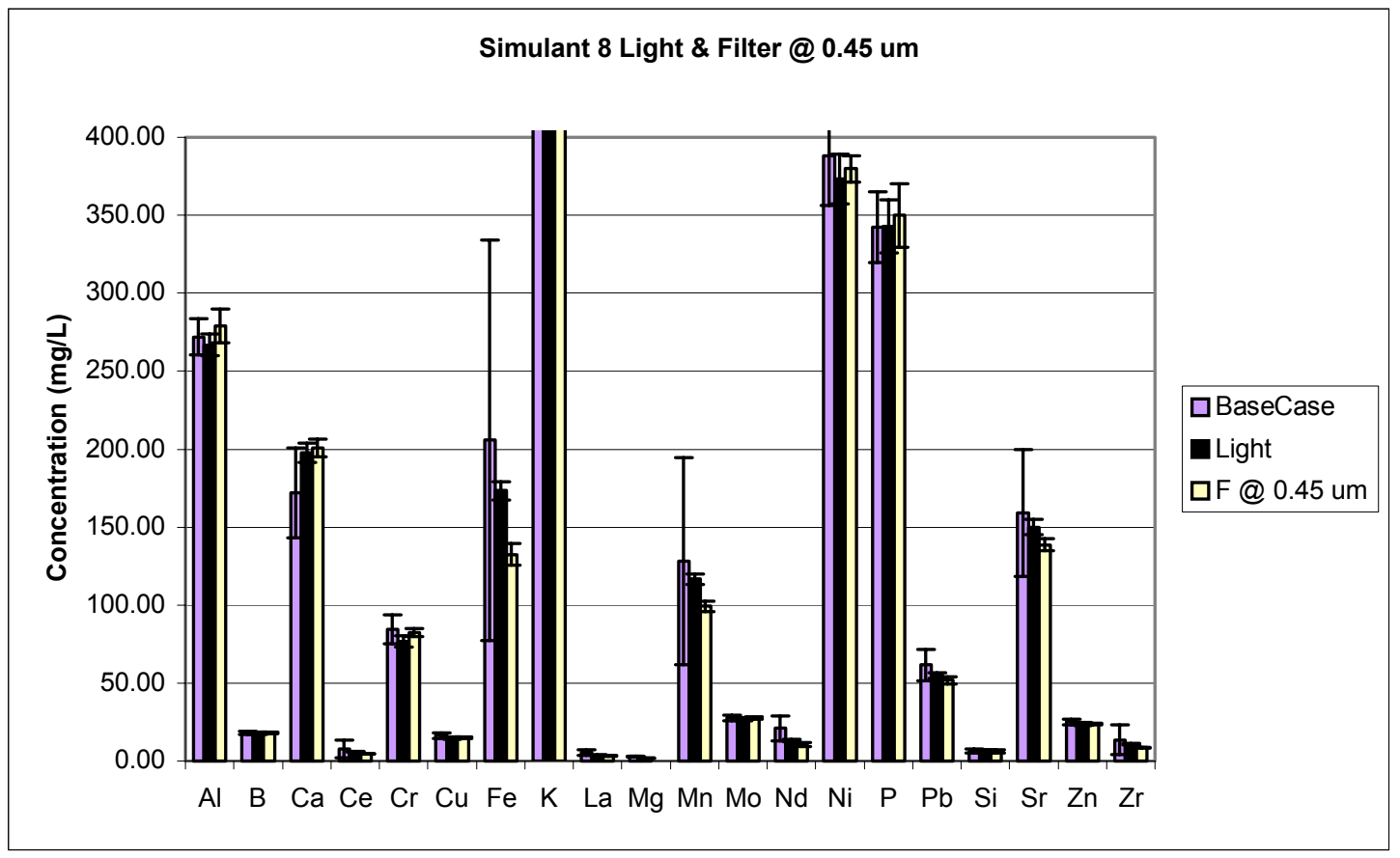

Figure C.17a Cation Concentrations in AN-107 Simulant 8 Base Case, Light, and $0.45 \mu \mathrm{m}$ Filter Filtrates

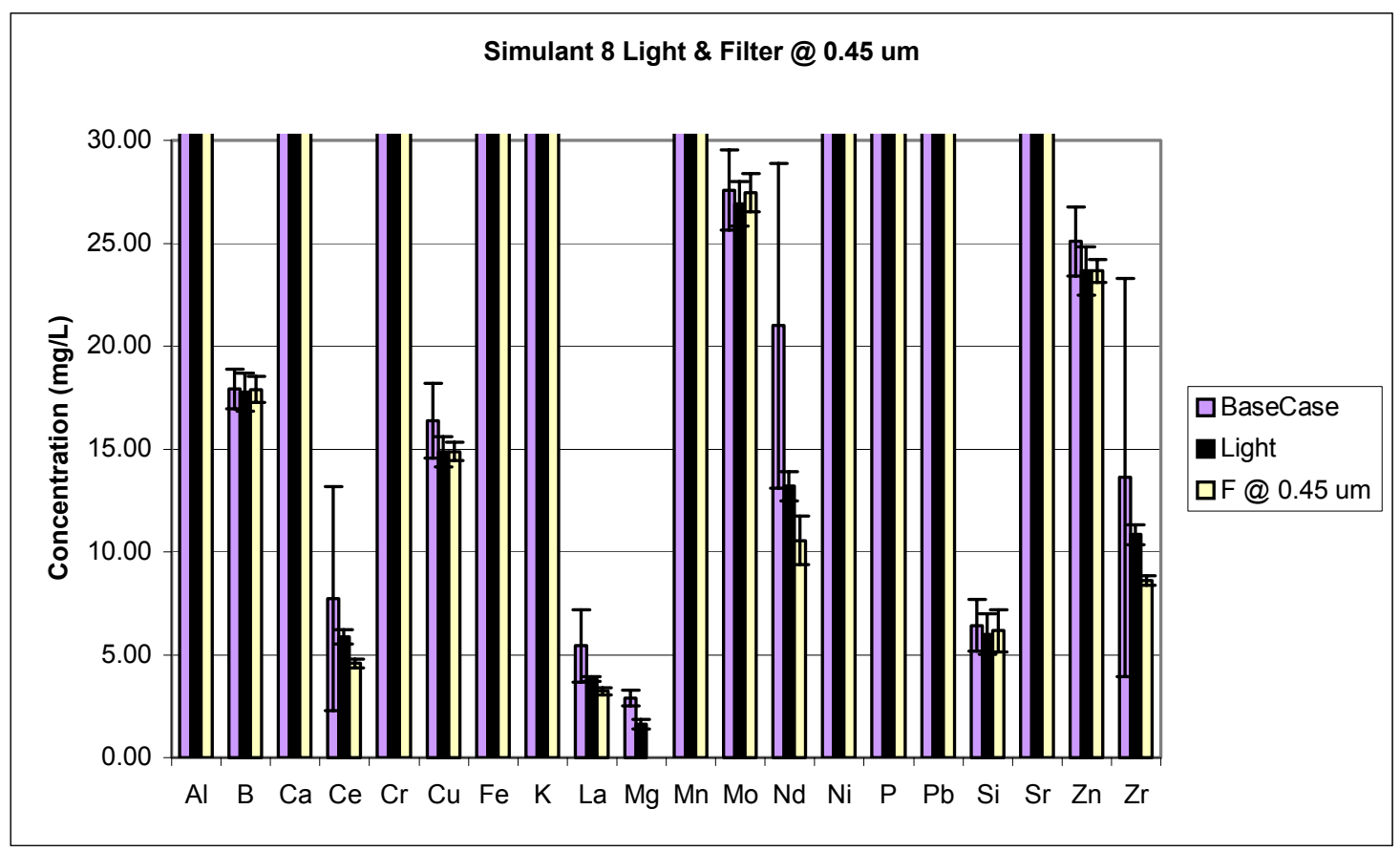

Figure C.17b Cation Concentrations in AN-107 Simulant 8 Base Case, Light, and $0.45 \mu \mathrm{m}$ Filter Filtrates 
WSRC-TR-2003-00232, Rev. 0

SRT-RPP-2003-00105, Rev. 0

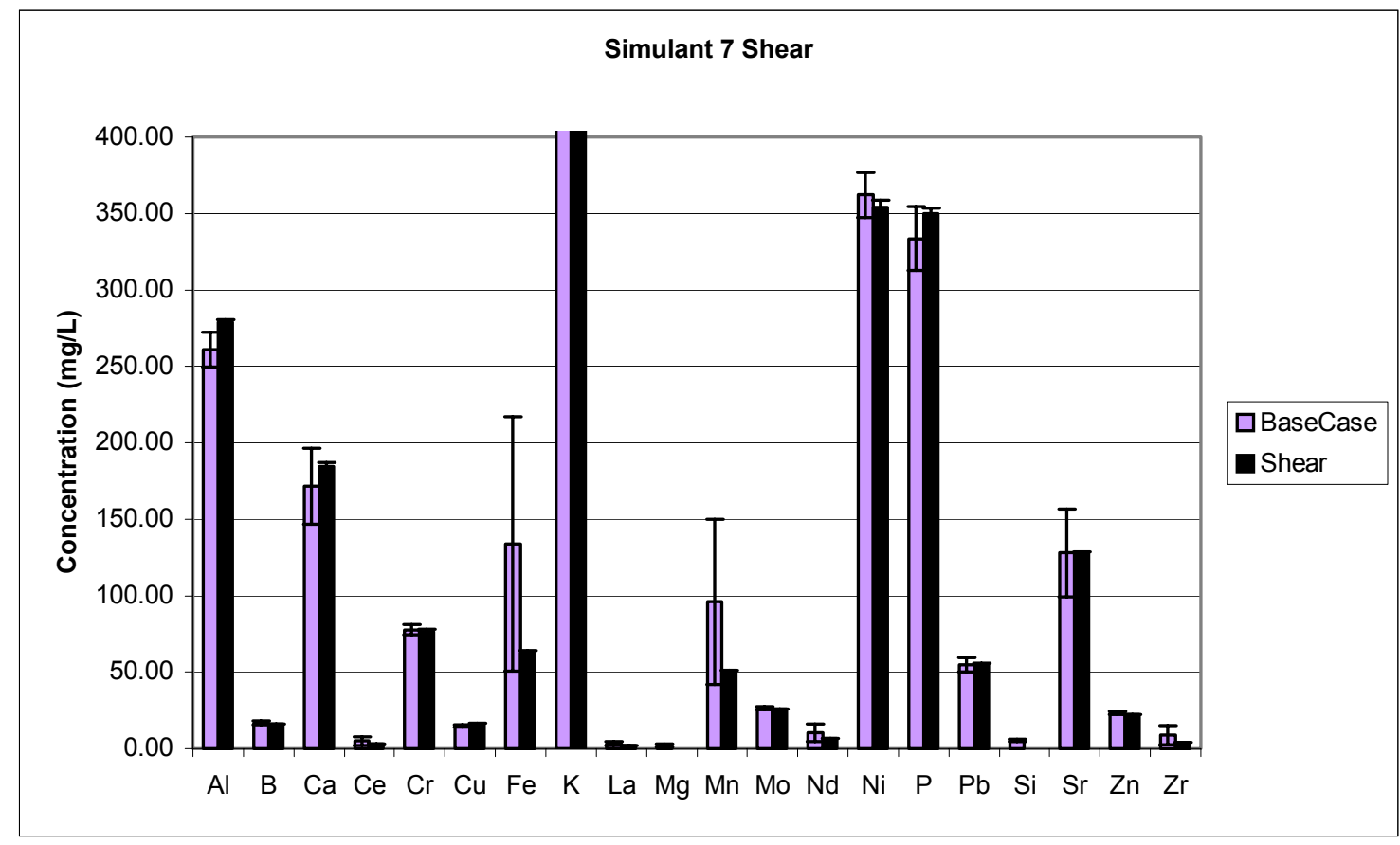

Figure C.18a Cation Concentrations in AN-107 Simulant 7 Base Case and Shear Filtrates

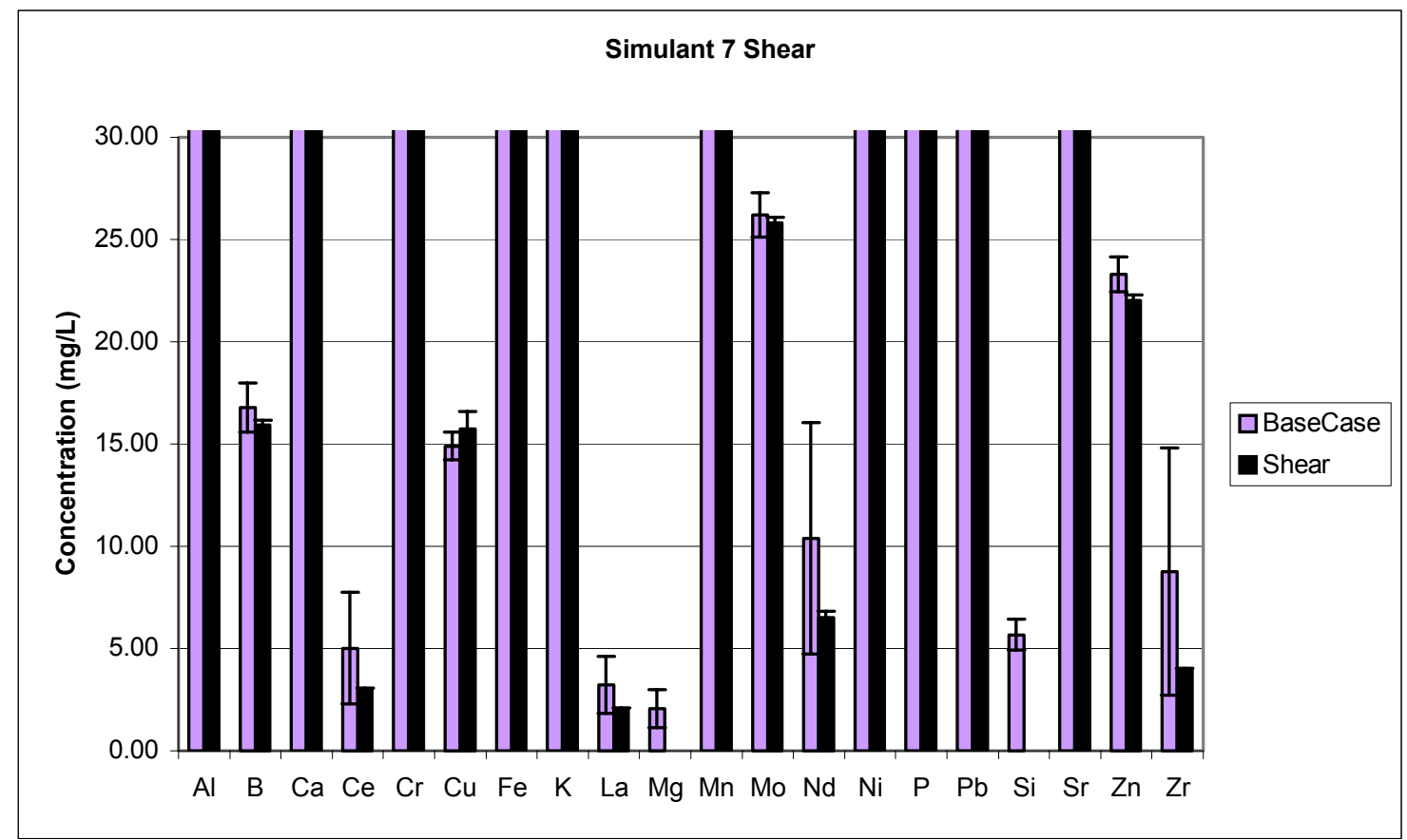

Figure C.18b Cation Concentrations in AN-107 Simulant 7 Base Case and Shear Filtrates 
WSRC-TR-2003-00232, Rev. 0

SRT-RPP-2003-00105, Rev. 0

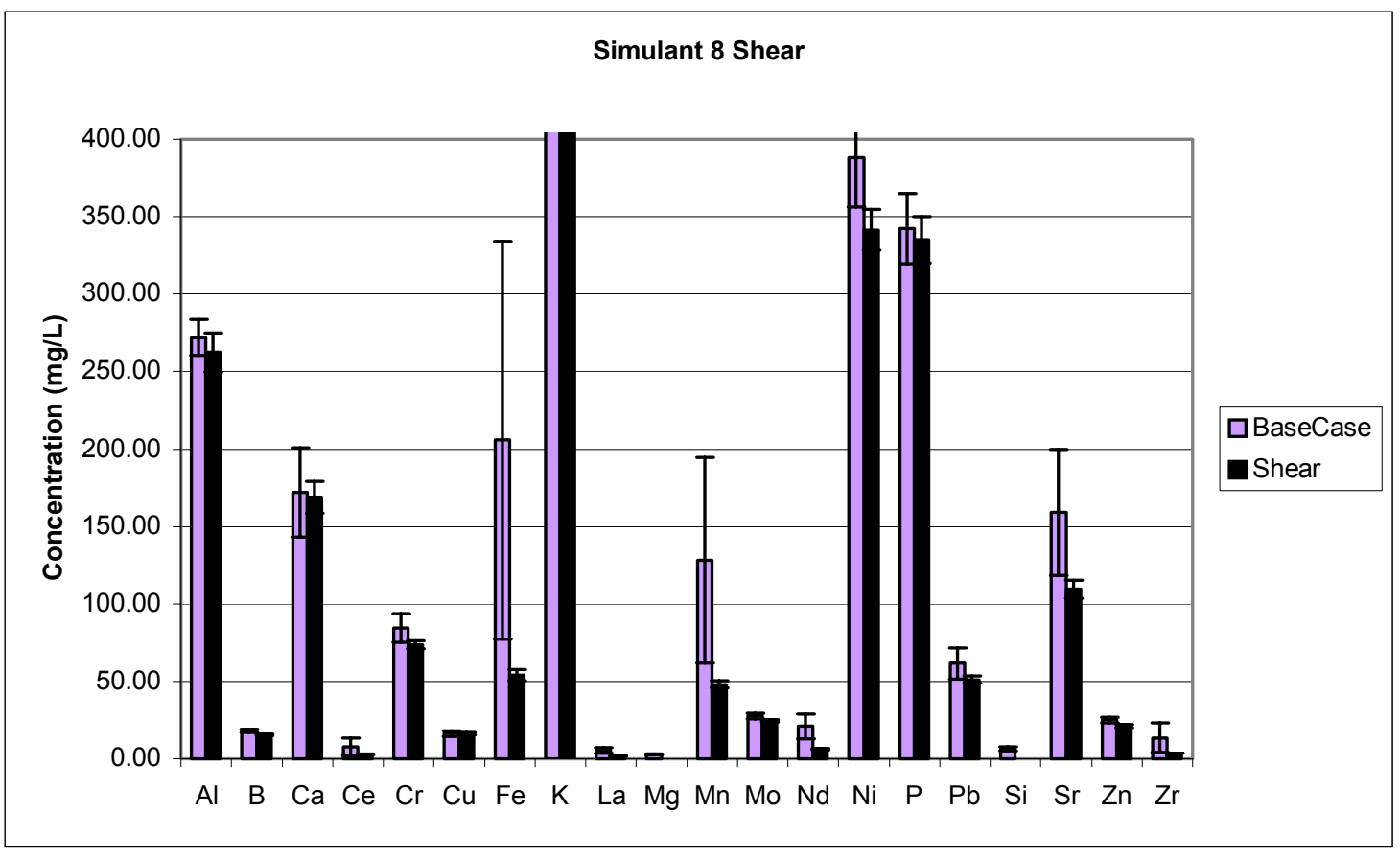

Figure C.19a Cation Concentrations in AN-107 Simulant 8 Base Case and Shear Filtrates

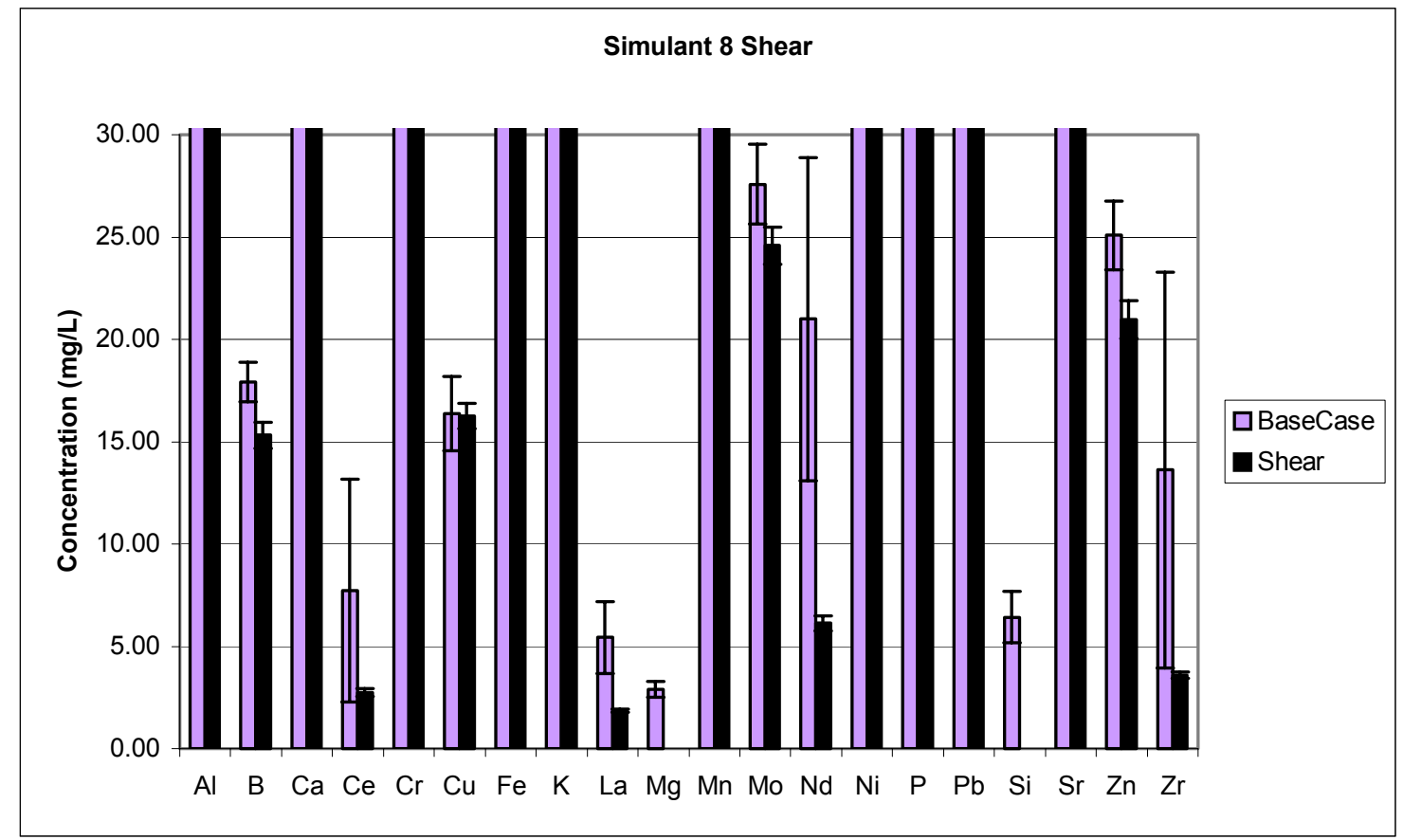

Figure C.19b Cation Concentrations in AN-107 Simulant 8 Base Case and Shear Filtrates 


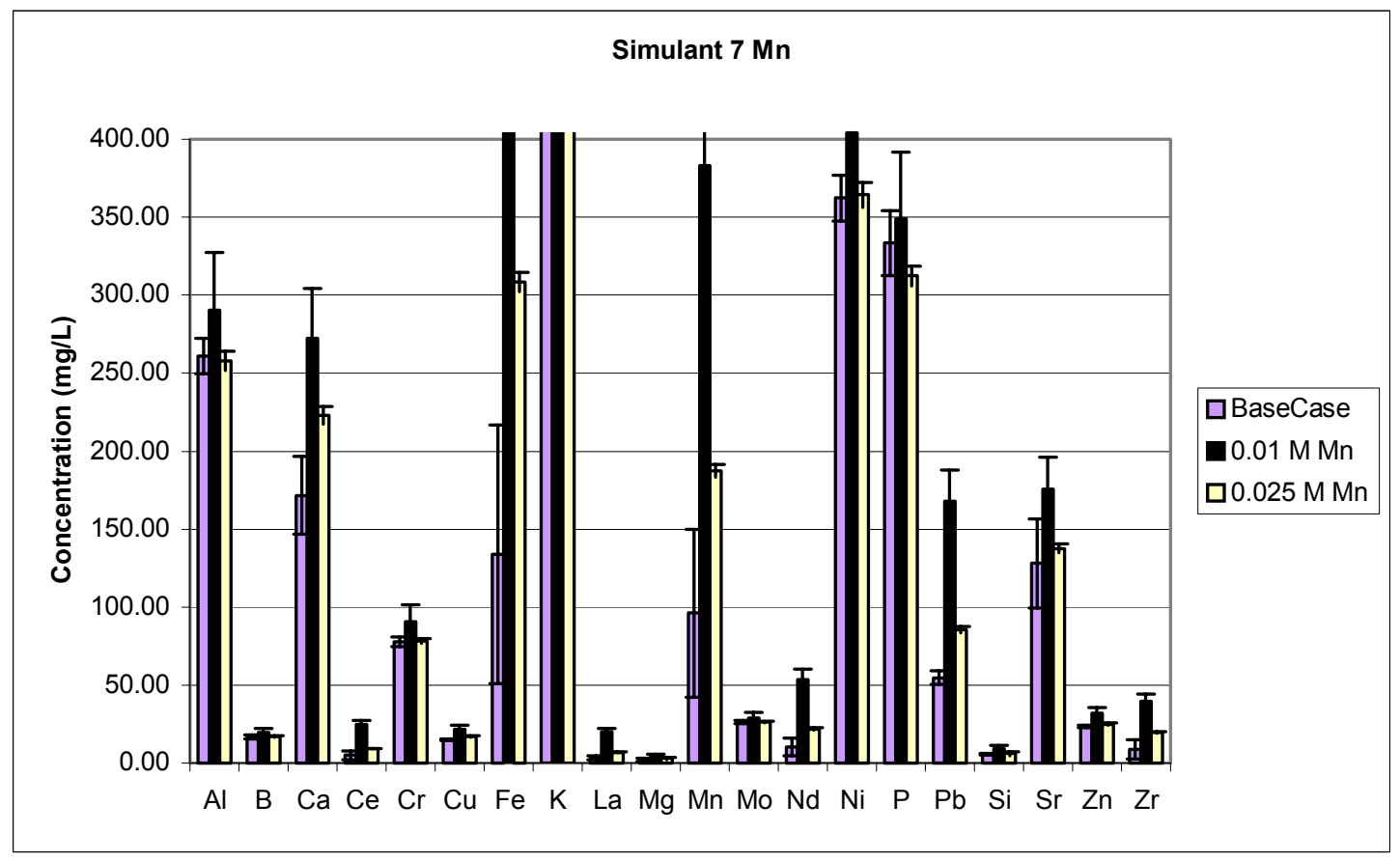

Figure C.20a Cation Concentrations in AN-107 Simulant 7 Base Case, 0.01M Mn, and $0.025 \mathrm{M}$ Mn Filtrates

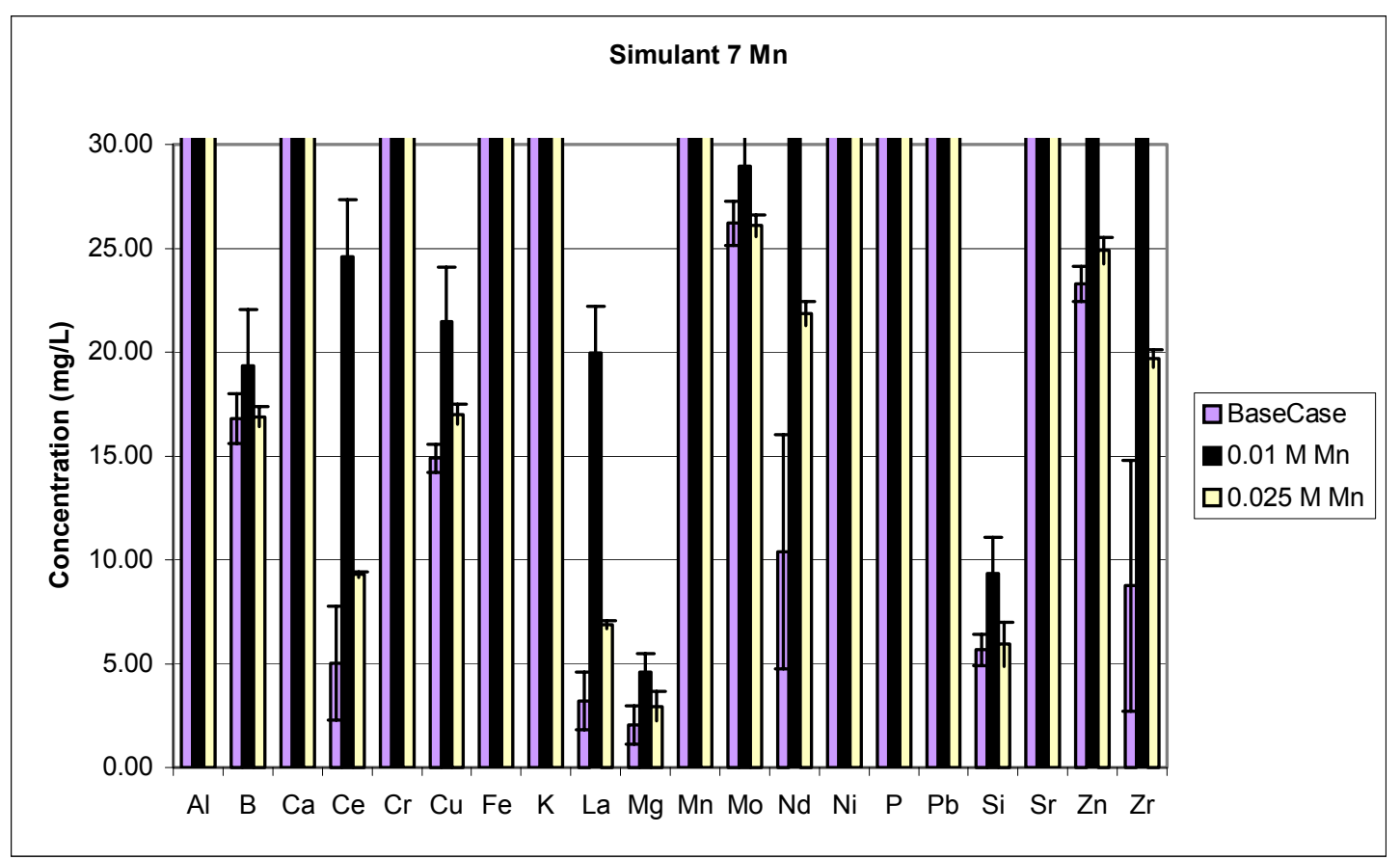

Figure C.20b Cation Concentrations in AN-107 Simulant 7 Base Case, 0.01M Mn, and $0.025 \mathrm{M}$ Mn Filtrates 
WSRC-TR-2003-00232, Rev. 0

SRT-RPP-2003-00105, Rev. 0

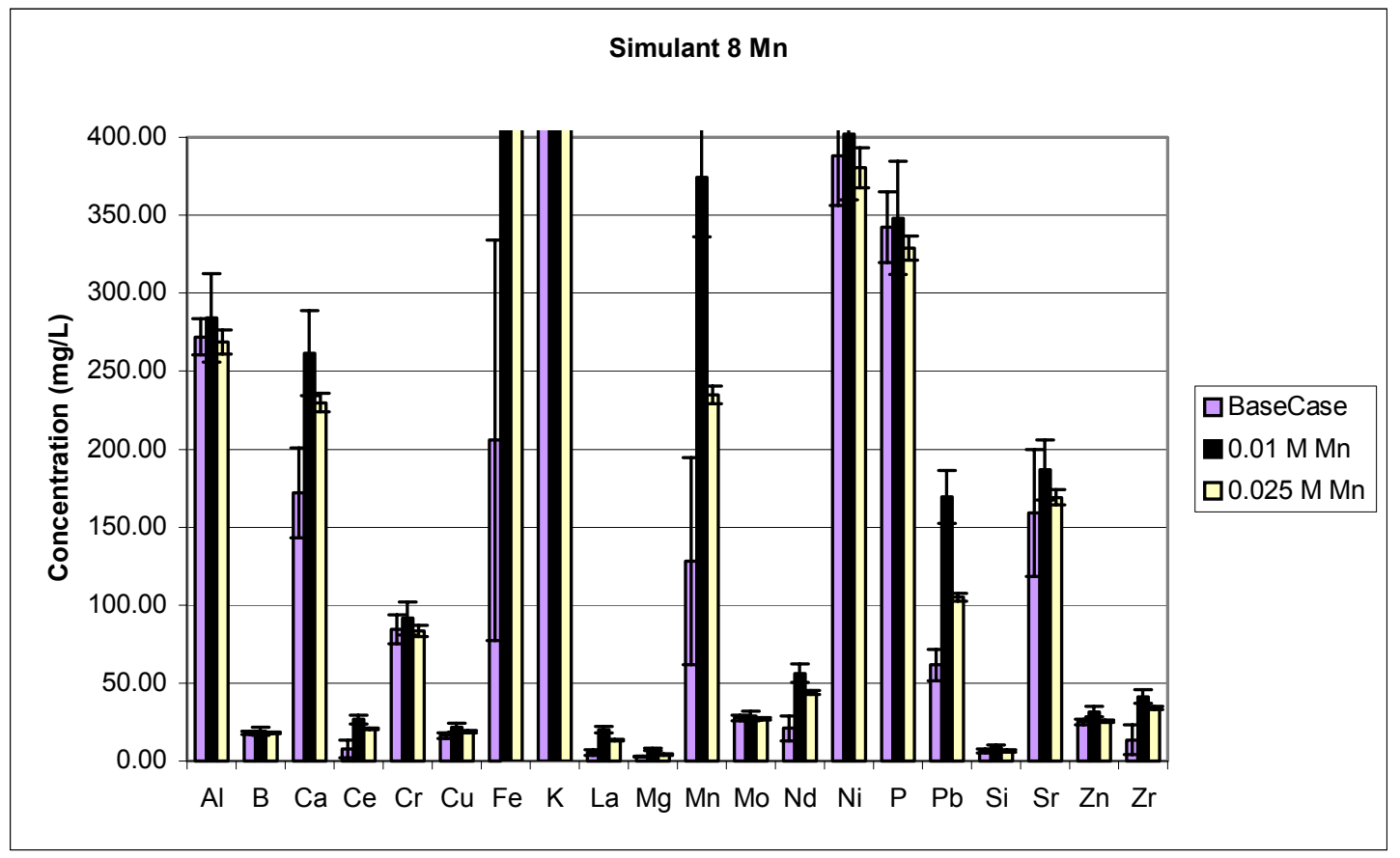

Figure C.21a Cation Concentrations in AN-107 Simulant 8 Base Case, 0.01M Mn, and $0.025 \mathrm{M}$ Mn Filtrates

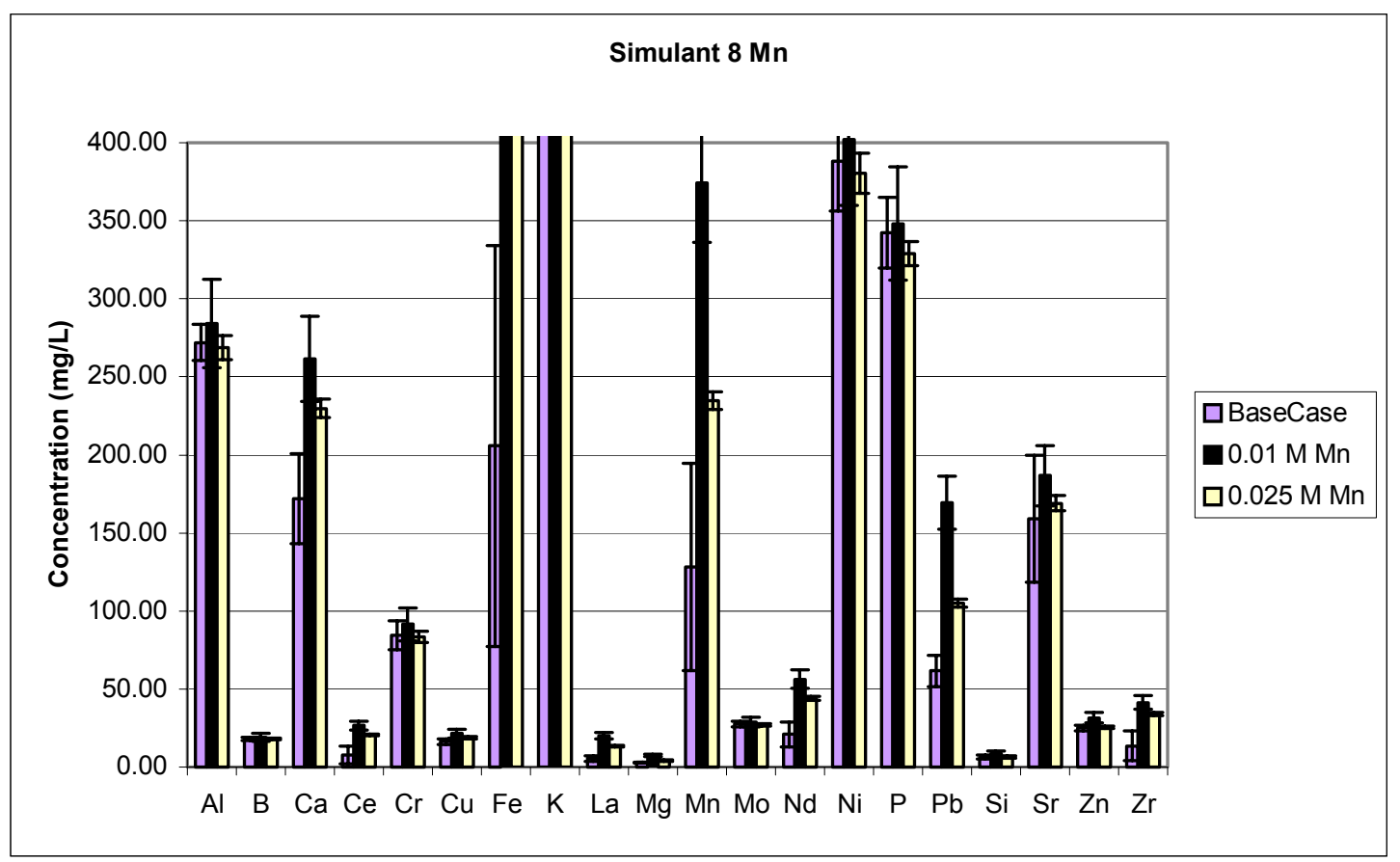

Figure C.21b Cation Concentrations in AN-107 Simulant 8 Base Case, 0.01M Mn, and $0.025 \mathrm{M}$ Mn Filtrates 
WSRC-TR-2003-00232, Rev. 0

SRT-RPP-2003-00105, Rev. 0

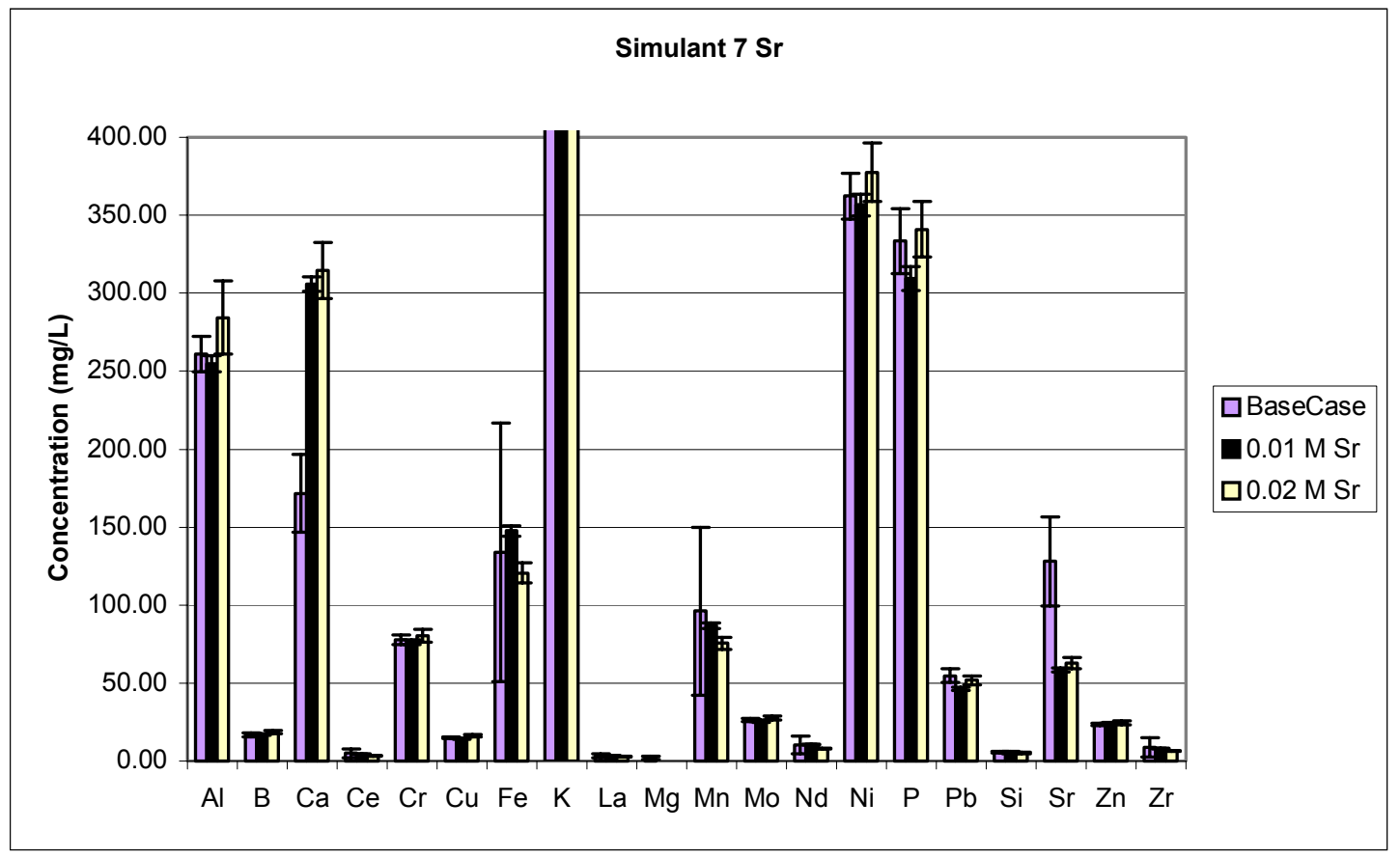

Figure C.22a Cation Concentrations in AN-107 Simulant 7 Base Case, 0.01M Sr, and $0.025 \mathrm{M}$ Sr Filtrates

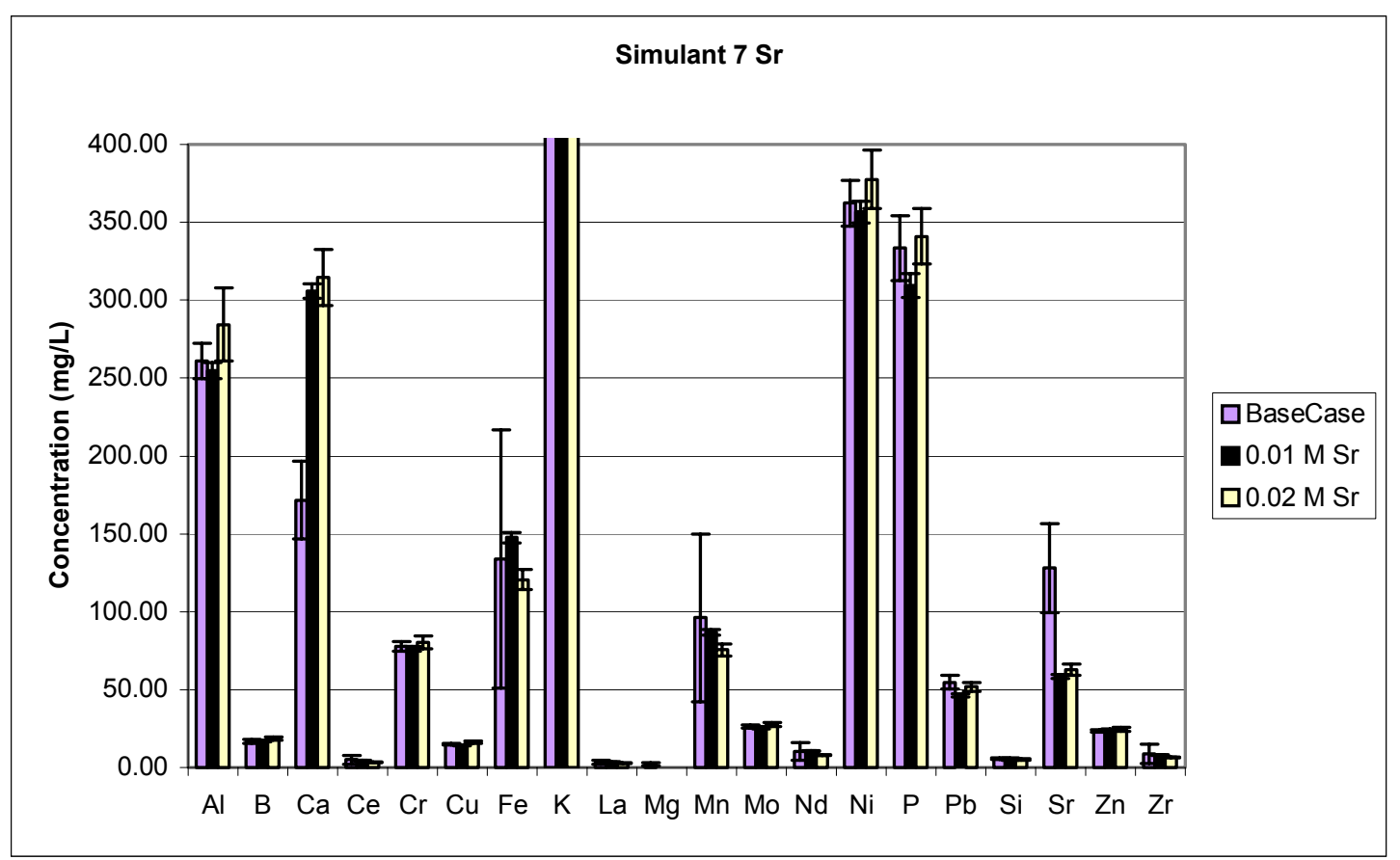

Figure C.22b Cation Concentrations in AN-107 Simulant 7 Base Case, 0.01M Sr, and $0.025 \mathrm{M}$ Sr Filtrates 
WSRC-TR-2003-00232, Rev. 0

SRT-RPP-2003-00105, Rev. 0

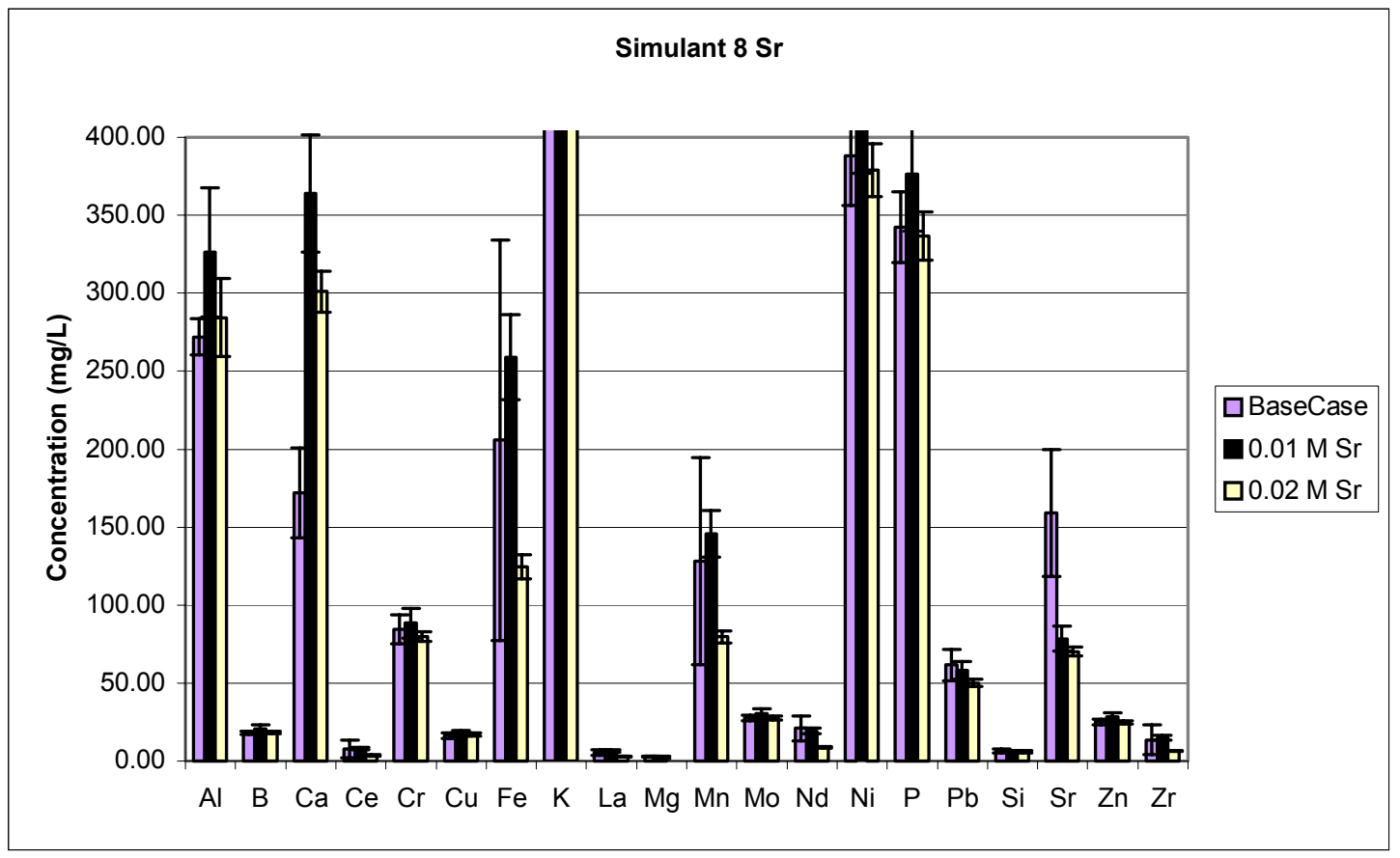

Figure C.23a Cation Concentrations in AN-107 Simulant 8 Base Case, 0.01M Sr, and $0.025 \mathrm{M}$ Sr Filtrates

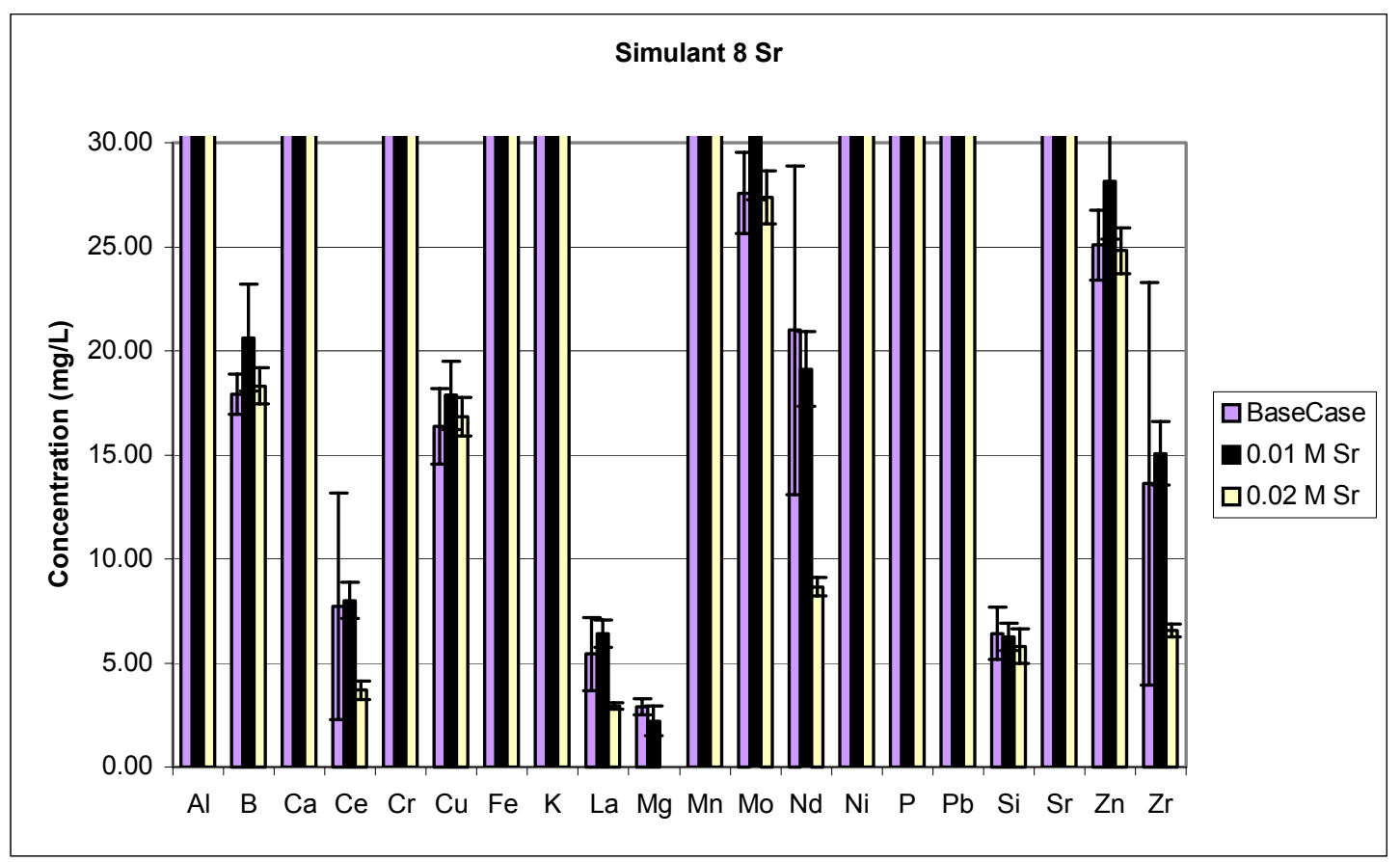

Figure C.23b Cation Concentrations in AN-107 Simulant 8 Base Case, 0.01M Sr, and 0.025M Sr Filtrates 
WSRC-TR-2003-00232, Rev. 0

SRT-RPP-2003-00105, Rev. 0

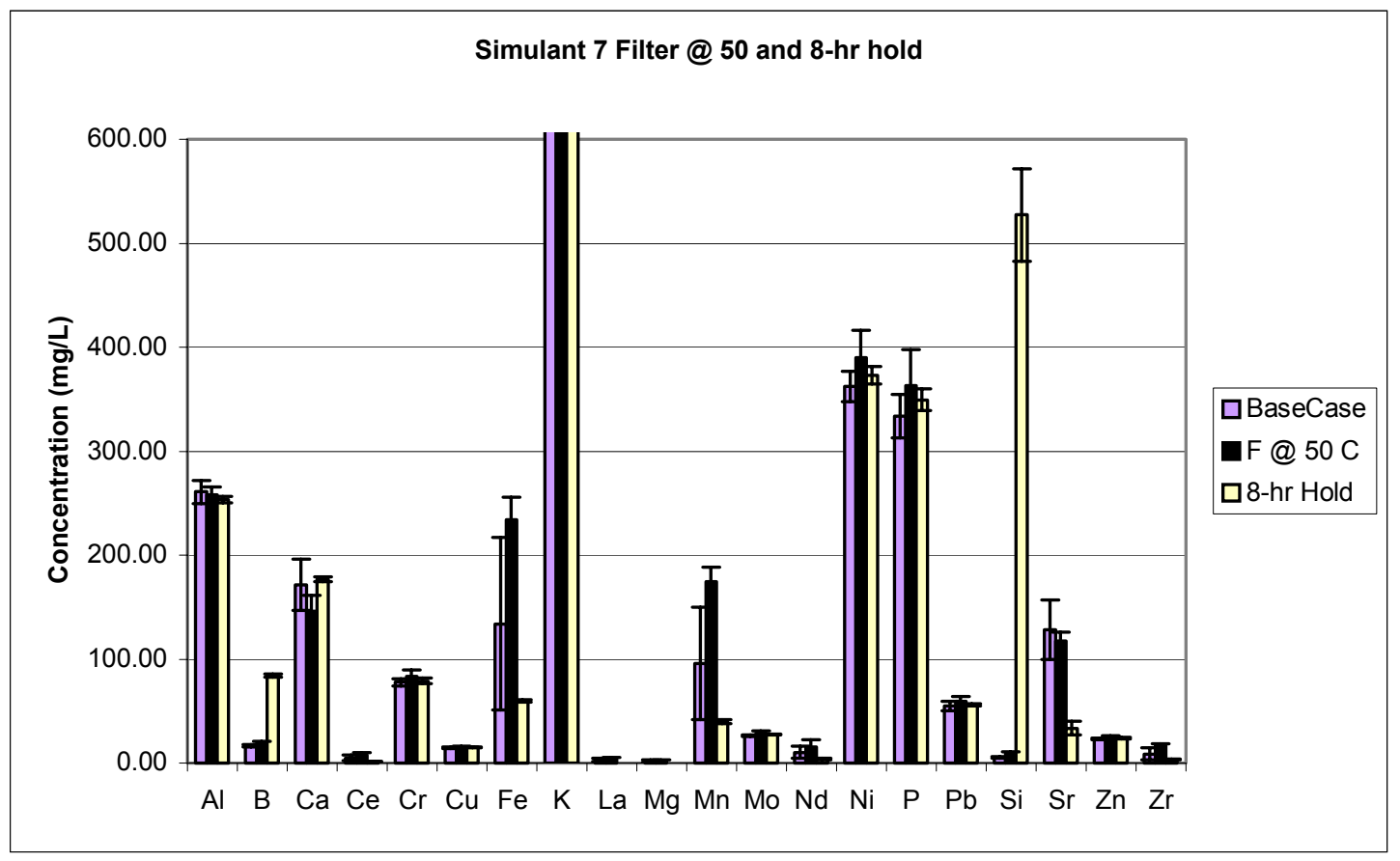

Figure C.24a Cation Concentrations in AN-107 Simulant 7 Base Case, Filter at $50{ }^{\circ} \mathrm{C}$, and 8hr Hold Filtrates

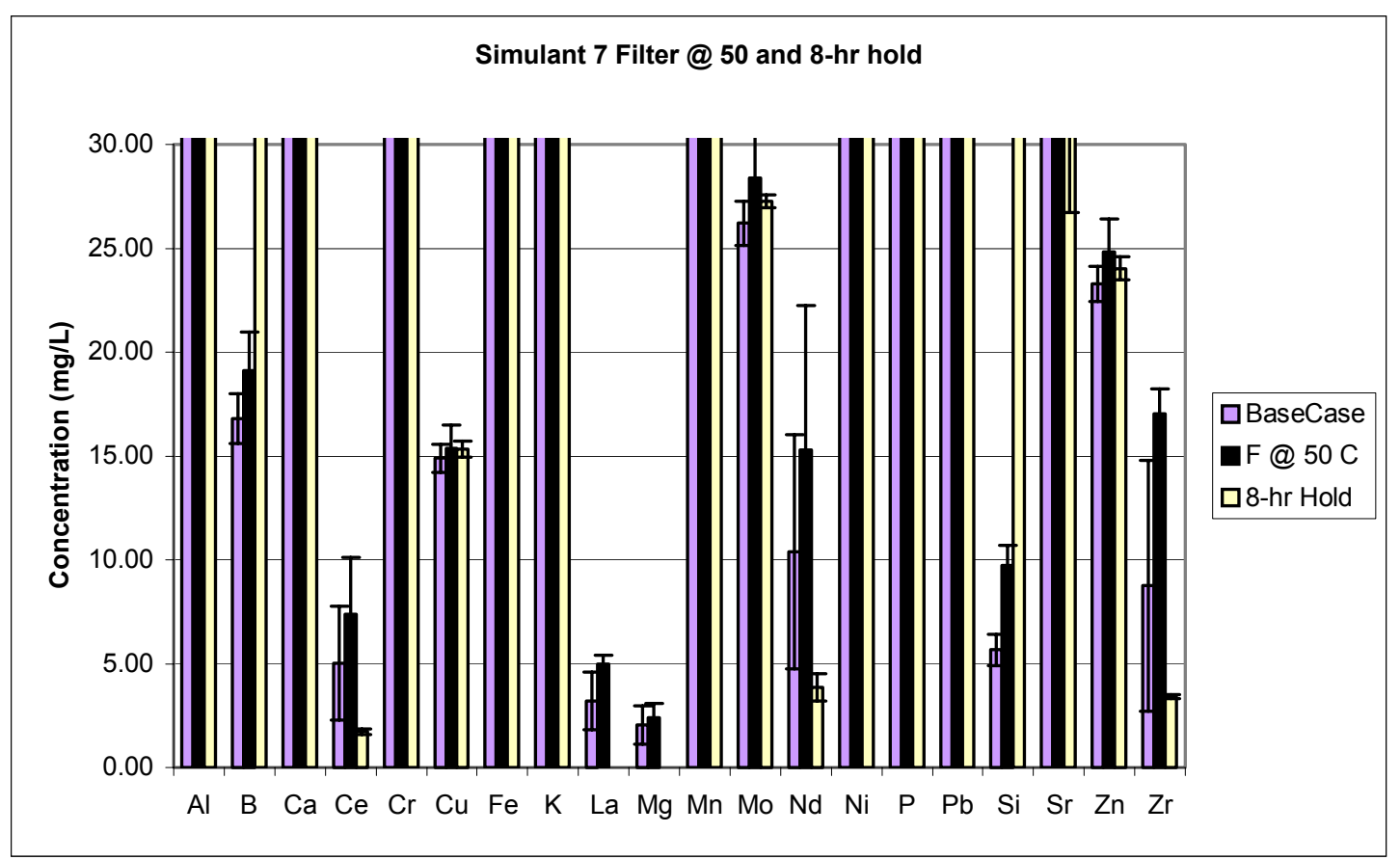

Figure C.24b Cation Concentrations in AN-107 Simulant 7 Base Case, Filter at $50{ }^{\circ} \mathrm{C}$, and 8hr Hold Filtrates 
WSRC-TR-2003-00232, Rev. 0

SRT-RPP-2003-00105, Rev. 0

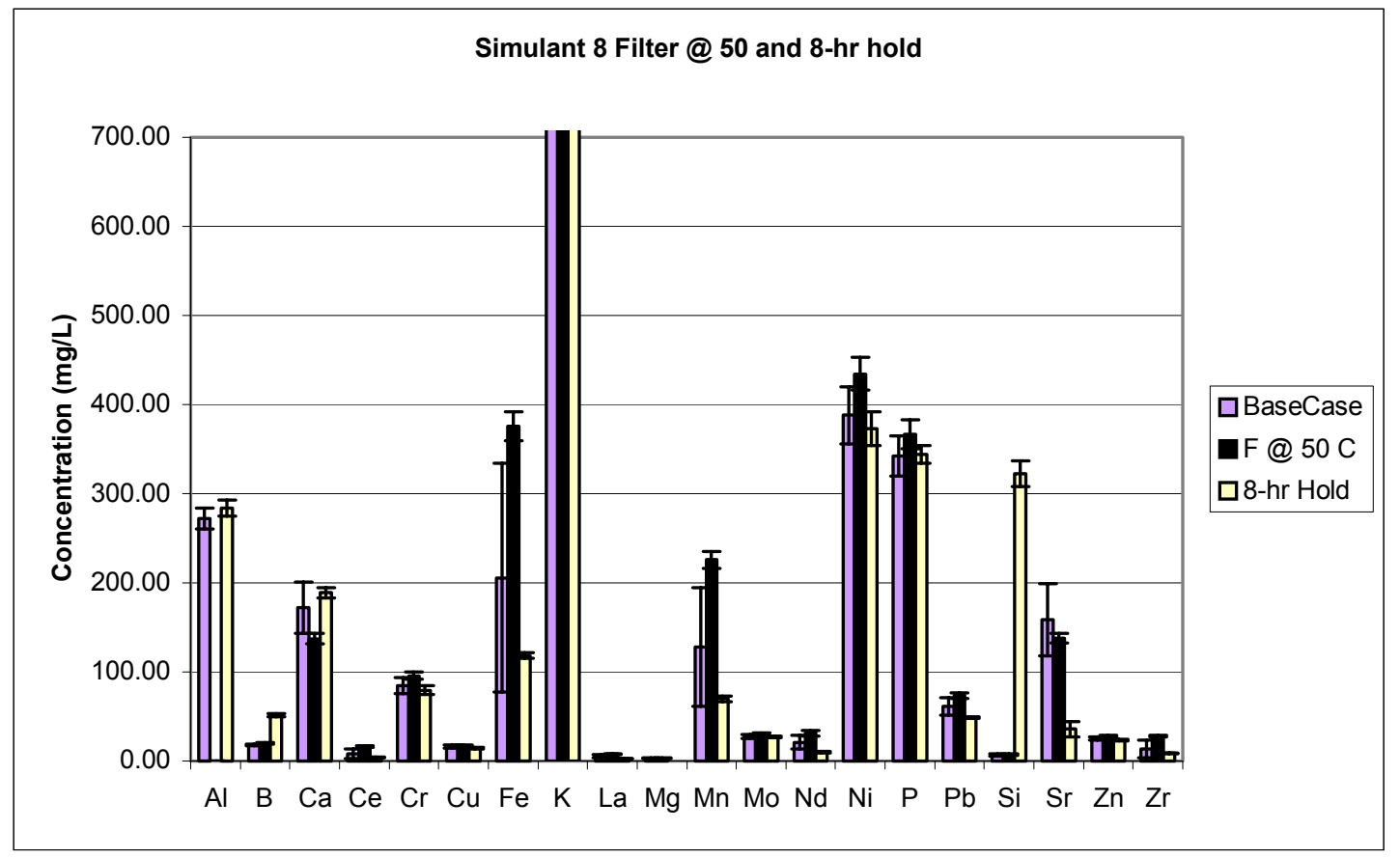

Figure C.25a Cation Concentrations in AN-107 Simulant 8 Base Case, Filter at $50{ }^{\circ} \mathrm{C}$, and 8hr Hold Filtrates

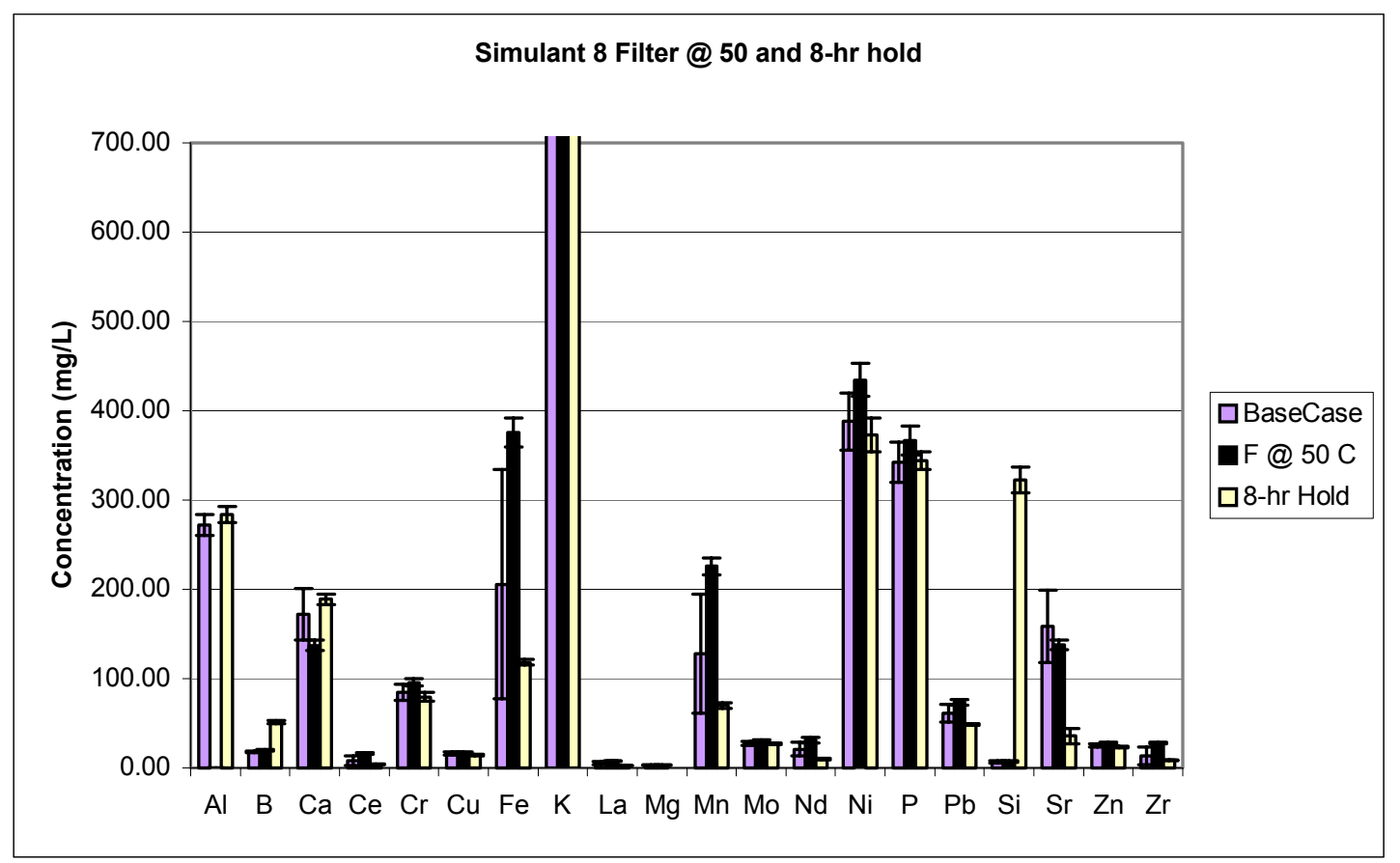

Figure C.25b Cation Concentrations in AN-107 Simulant 8 Base Case, Filter at $50{ }^{\circ} \mathrm{C}$, and 8hr Hold Filtrates 
WSRC-TR-2003-00232, Rev. 0

SRT-RPP-2003-00105, Rev. 0

Table C.1 ICP-AES Data for AN-107 Primary Effects Samples (Base Case Samples)

\begin{tabular}{|c|c|c|c|c|c|c|c|}
\hline & $0315-211 \mathrm{~A}-0$ & $0315-211 \mathrm{~A}-6$ & 0315-211A-12 & 0315-211A-24 & $0315-211 A-48$ & average & stddev \\
\hline & (ppm) & (ppm) & (ppm) & $(\mathrm{ppm})$ & (ppm) & & \\
\hline Al3082 & 242.31 & 249.55 & 250.99 & 257.72 & 265.48 & 253.21 & 8.78 \\
\hline B_2497 & 17.27 & 17.56 & 17.14 & 17.94 & 18.95 & 17.77 & 0.73 \\
\hline Ce4186 & 8.68 & 8.91 & 7.69 & 9.07 & 9.20 & 8.71 & 0.60 \\
\hline Cr3578 & 81.82 & 81.50 & 79.53 & 78.70 & 77.56 & 79.82 & 1.82 \\
\hline Cu3247 & 14.57 & 14.61 & 14.00 & 13.97 & 14.30 & 14.29 & 0.30 \\
\hline Fe2599 & 242.17 & 234.99 & 237.02 & 246.84 & 252.60 & 242.73 & 7.20 \\
\hline K_7664 & 1558.79 & 1632.58 & 1659.63 & 1662.86 & 1726.37 & 1648.05 & 60.61 \\
\hline La3949 & 5.19 & 5.16 & 4.49 & 5.17 & 5.20 & 5.04 & 0.31 \\
\hline Mg2790 & 2.60 & 3.01 & 1.89 & 2.65 & 3.64 & 2.76 & 0.64 \\
\hline Mn2576 & 163.85 & 168.05 & 166.82 & 169.40 & 172.93 & 168.21 & 3.34 \\
\hline Mo2020 & 26.34 & 27.01 & 27.11 & 27.27 & 27.66 & 27.08 & 0.48 \\
\hline Nd4061 & 18.06 & 18.51 & 14.59 & 19.02 & 19.54 & 17.94 & 1.95 \\
\hline $\mathrm{Ni2316}$ & 375.14 & 379.85 & 371.62 & 371.62 & 371.03 & 373.85 & 3.73 \\
\hline P_1774 & 324.87 & 336.92 & 345.16 & 355.74 & 366.91 & 345.92 & 16.29 \\
\hline Si2516 & 5.54 & 6.06 & 5.29 & 5.69 & 7.35 & 5.99 & 0.81 \\
\hline Sr3464 & 164.58 & 168.08 & 165.35 & 167.11 & 169.26 & 166.87 & 1.92 \\
\hline Zn2062 & 23.98 & 23.89 & 23.25 & 23.43 & 23.78 & 23.66 & 0.31 \\
\hline Zr3391 & 16.99 & 17.23 & 16.77 & 16.71 & 16.90 & 16.92 & 0.20 \\
\hline
\end{tabular}

\begin{tabular}{|c|c|c|c|c|c|c|c|}
\hline & 0315-211B-0 & 0315-211B-6 & 0315-211B-12 & $0315-211 \mathrm{~B}-24$ & $0315-211 \mathrm{~B}-48$ & average & stddev \\
\hline & $(\mathrm{ppm})$ & $(\mathrm{ppm})$ & $(p p m)$ & $(\mathrm{ppm})$ & $(\mathrm{ppm})$ & & \\
\hline Al3082 & 263.22 & 267.54 & 268.92 & 268.42 & 275.15 & 268.65 & 4.28 \\
\hline B_2497 & 16.21 & 17.00 & 17.45 & 17.67 & 17.74 & 17.22 & 0.63 \\
\hline Ca3179 & 192.83 & 193.69 & 192.60 & 193.48 & 196.51 & 193.82 & 1.57 \\
\hline Ce4186 & 5.54 & 5.72 & 6.04 & 5.64 & 5.72 & 5.73 & 0.19 \\
\hline Cr3578 & 78.59 & 75.59 & 72.82 & 72.82 & 73.74 & 74.71 & 2.44 \\
\hline Cu3247 & 15.17 & 14.70 & 14.24 & 13.94 & 14.68 & 14.55 & 0.47 \\
\hline Fe2599 & 168.49 & 169.79 & 173.61 & 175.99 & 178.25 & 173.22 & 4.10 \\
\hline K_7664 & 1580.84 & 1594.66 & 1574.96 & 1549.97 & 1604.06 & 1580.90 & 20.72 \\
\hline La3949 & 3.74 & 3.79 & 3.78 & 3.75 & 3.84 & 3.78 & 0.04 \\
\hline Mg2790 & - & - & - & - & - & & \\
\hline Mn2576 & 113.51 & 114.48 & 114.07 & 114.66 & 115.95 & 114.54 & 0.91 \\
\hline Mo2020 & 26.50 & 26.58 & 26.28 & 26.30 & 26.64 & 26.46 & 0.16 \\
\hline Nd4061 & 12.95 & 13.39 & 14.34 & 13.62 & 13.58 & 13.58 & 0.50 \\
\hline $\mathrm{Ni2316}$ & 375.14 & 365.44 & 358.09 & 358.68 & 363.38 & 364.15 & 6.89 \\
\hline P_1774 & 324.87 & 339.28 & 345.45 & 348.68 & 352.80 & 342.22 & 10.88 \\
\hline \begin{tabular}{|l|l|} 
\\
\end{tabular} & 52.74 & 53.83 & 54.33 & 54.80 & 54.77 & 54.10 & 0.85 \\
\hline Si2516 & 5.80 & 5.38 & 5.74 & 6.70 & 7.54 & 6.23 & 0.88 \\
\hline Sr3464 & 148.26 & 147.00 & 145.59 & 146.56 & 147.91 & 147.06 & 1.07 \\
\hline Zn2062 & 24.62 & 23.19 & 22.82 & 23.24 & 23.25 & 23.42 & 0.69 \\
\hline Zr3391 & 10.89 & 10.55 & 10.38 & 10.31 & 10.55 & 10.54 & 0.23 \\
\hline
\end{tabular}


WSRC-TR-2003-00232, Rev. 0

SRT-RPP-2003-00105, Rev. 0

Table C.2 ICP-AES Data for AN-107 Primary Effects Samples (Base Case Samples)

\begin{tabular}{|c|c|c|c|c|c|c|c|}
\hline & $0412-211 \mathrm{~A}-0$ & $0412-211 \mathrm{~A}-6$ & 0412-211A-12 & 0412-211A-24 & $0412-211 \mathrm{~A}-48$ & average & stddev \\
\hline Element & (ppm) & (ppm) & (ppm) & (ppm) & (ppm) & & \\
\hline Al3082 & 261.49 & 257.11 & 285.20 & 258.89 & 244.93 & 261.52 & 14.68 \\
\hline B_2497 & 17.06 & 16.76 & 18.77 & 16.85 & 15.88 & 17.06 & 1.06 \\
\hline Ca3179 & 206.82 & 204.43 & 226.74 & 177.42 & 195.82 & 202.25 & 17.91 \\
\hline Ce4186 & 3.67 & 3.44 & 4.00 & 3.23 & 3.34 & 3.54 & 0.31 \\
\hline Cr3578 & 74.69 & 73.79 & 82.11 & 72.62 & 71.92 & 75.03 & 4.10 \\
\hline Cu3247 & 14.37 & 14.70 & 15.86 & 15.01 & 14.13 & 14.81 & 0.67 \\
\hline Fe2599 & 106.08 & 102.90 & 116.30 & 105.03 & 100.13 & 106.09 & 6.15 \\
\hline K_7664 & 1523.07 & 1502.63 & 1685.13 & 1487.16 & 1464.67 & 1532.53 & 87.94 \\
\hline La3949 & 2.81 & 2.69 & 3.00 & 2.16 & 2.61 & 2.65 & 0.31 \\
\hline Mg2790 & 0.56 & 1.68 & 1.95 & 1.24 & 1.25 & 1.34 & 0.53 \\
\hline Mn2576 & 72.82 & 71.54 & 79.69 & 71.39 & 68.30 & 72.75 & 4.22 \\
\hline Mo2020 & 25.90 & 25.68 & 28.49 & 25.54 & 24.67 & 26.06 & 1.44 \\
\hline $\mathrm{Nd4061}$ & 6.88 & 6.69 & 7.45 & 6.41 & 8.01 & 7.09 & 0.64 \\
\hline $\mathrm{Ni2316}$ & 360.04 & 357.12 & 395.66 & 355.07 & 344.27 & 362.43 & 19.51 \\
\hline P_1774 & 308.64 & 306.02 & 339.01 & 305.14 & 294.34 & 310.63 & 16.78 \\
\hline $\mathrm{Pb} 2203$ & 52.18 & 51.95 & 57.41 & 51.65 & 49.76 & 52.59 & 2.86 \\
\hline Si2516 & 4.87 & 4.57 & 5.73 & 5.48 & 6.03 & 5.34 & 0.60 \\
\hline Sr3464 & 108.89 & 107.19 & 120.01 & 103.69 & 103.19 & 108.59 & 6.81 \\
\hline Zn2062 & 23.23 & 23.06 & 25.48 & 22.86 & 22.20 & 23.36 & 1.24 \\
\hline Zr3391 & 5.70 & 5.59 & 6.30 & 5.65 & 5.44 & 5.74 & 0.33 \\
\hline
\end{tabular}

\begin{tabular}{|c|c|c|c|c|c|c|c|}
\hline & $0325-211 \mathrm{~B}-0$ & 0325-211B-6 & 0325-211B-12 & 0325-211B-24 & 0325-211B-48 & average & stddev \\
\hline & (ppm) & (ppm) & (ppm) & (ppm) & (ppm) & & \\
\hline Al3082 & 283.33 & 292.90 & & 282.58 & & 286.27 & 5.76 \\
\hline B_2497 & 18.50 & 18.48 & 19.38 & 18.17 & 19.57 & 18.82 & 0.62 \\
\hline Ca3179 & 128.21 & 130.67 & 136.85 & 127.72 & 144.86 & 133.66 & 7.24 \\
\hline Ce4186 & 14.28 & 14.24 & 15.59 & 14.02 & 16.39 & 14.91 & 1.04 \\
\hline Cr3578 & 88.33 & 89.52 & 98.14 & 89.47 & 103.56 & 93.80 & 6.73 \\
\hline Cu3247 & 17.15 & 17.66 & 18.83 & 17.39 & 20.32 & 18.27 & 1.32 \\
\hline Fe2599 & 359.31 & 363.95 & 380.48 & 353.22 & 397.59 & 370.91 & 18.02 \\
\hline K_7664 & 1726.37 & 1735.36 & 1895.73 & 1712.45 & 1993.75 & 1812.73 & 125.66 \\
\hline La3949 & 6.78 & 6.80 & 7.34 & 6.70 & 7.73 & 7.07 & 0.45 \\
\hline Mg2790 & 2.64 & 2.45 & 3.16 & 2.79 & 3.39 & 2.88 & 0.38 \\
\hline Mn2576 & 203.52 & 207.67 & 218.34 & 202.36 & 229.65 & 212.31 & 11.56 \\
\hline Mo2020 & 28.41 & 28.73 & 30.65 & 28.16 & 32.36 & 29.66 & 1.80 \\
\hline Nd4061 & 27.52 & 27.16 & 29.61 & 26.97 & 30.77 & 28.41 & 1.69 \\
\hline Ni2316 & 403.97 & 409.19 & 435.87 & 406.29 & 463.71 & 423.81 & 25.75 \\
\hline P_1774 & 346.84 & 350.03 & 374.68 & 342.78 & 393.24 & 361.51 & 21.67 \\
\hline $\mathrm{Pb} 2203$ & 71.78 & 72.50 & 76.79 & 71.51 & 80.74 & 74.66 & 4.01 \\
\hline Si2516 & 5.15 & 4.84 & 4.75 & 5.45 & 6.73 & 5.38 & 0.80 \\
\hline Sr3464 & 202.25 & 205.12 & 216.80 & 201.70 & 229.30 & 211.03 & 11.90 \\
\hline Zn2062 & 24.92 & 25.07 & 26.71 & 24.95 & 28.26 & 25.98 & 1.48 \\
\hline Zr3391 & 24.91 & 25.29 & 27.22 & 25.00 & 28.74 & 26.23 & 1.69 \\
\hline
\end{tabular}


WSRC-TR-2003-00232, Rev. 0

SRT-RPP-2003-00105, Rev. 0

Table C.3 ICP-AES Data for AN-107 Primary Effects Samples (Base Case Samples)

\begin{tabular}{|c|c|c|c|c|c|c|c|}
\hline & $0412-211 \mathrm{~A}-0$ & $0412-211 \mathrm{~A}-6$ & $0412-211 \mathrm{~A}-12$ & $0412-211 \mathrm{~A}-24$ & $0412-211 A-48$ & average & stddev \\
\hline Element & (ppm) & (ppm) & (ppm) & (ppm) & (ppm) & & \\
\hline AI3082 & 261.49 & 257.11 & 285.20 & 258.89 & 244.93 & 261.52 & 14.68 \\
\hline B_2497 & 17.06 & 16.76 & 18.77 & 16.85 & 15.88 & 17.06 & 1.06 \\
\hline Ca3179 & 206.82 & 204.43 & 226.74 & 177.42 & 195.82 & 202.25 & 17.91 \\
\hline Ce4186 & 3.67 & 3.44 & 4.00 & 3.23 & 3.34 & 3.54 & 0.31 \\
\hline Cr3578 & 74.69 & 73.79 & 82.11 & 72.62 & 71.92 & 75.03 & 4.10 \\
\hline Cu3247 & 14.37 & 14.70 & 15.86 & 15.01 & 14.13 & 14.81 & 0.67 \\
\hline Fe2599 & 106.08 & 102.90 & 116.30 & 105.03 & 100.13 & 106.09 & 6.15 \\
\hline K_7664 & 1523.07 & 1502.63 & 1685.13 & 1487.16 & 1464.67 & 1532.53 & 87.94 \\
\hline La3949 & 2.81 & 2.69 & 3.00 & 2.16 & 2.61 & 2.65 & 0.31 \\
\hline Mg2790 & 0.56 & 1.68 & 1.95 & 1.24 & 1.25 & 1.34 & 0.53 \\
\hline Mn2576 & 72.82 & 71.54 & 79.69 & 71.39 & 68.30 & 72.75 & 4.22 \\
\hline Mo2020 & 25.90 & 25.68 & 28.49 & 25.54 & 24.67 & 26.06 & 1.44 \\
\hline $\mathrm{Nd} 4061$ & 6.88 & 6.69 & 7.45 & 6.41 & 8.01 & 7.09 & 0.64 \\
\hline $\mathrm{Ni2316}$ & 360.04 & 357.12 & 395.66 & 355.07 & 344.27 & 362.43 & 19.51 \\
\hline P_1774 & 308.64 & 306.02 & 339.01 & 305.14 & 294.34 & 310.63 & 16.78 \\
\hline $\mathrm{Pb} 2203$ & 52.18 & 51.95 & 57.41 & 51.65 & 49.76 & 52.59 & 2.86 \\
\hline Si2516 & 4.87 & 4.57 & 5.73 & 5.48 & 6.03 & 5.34 & 0.60 \\
\hline Sr3464 & 108.89 & 107.19 & 120.01 & 103.69 & 103.19 & 108.59 & 6.81 \\
\hline Zn2062 & 23.23 & 23.06 & 25.48 & 22.86 & 22.20 & 23.36 & 1.24 \\
\hline Zr3391 & 5.70 & 5.59 & 6.30 & 5.65 & 5.44 & 5.74 & 0.33 \\
\hline
\end{tabular}

\begin{tabular}{|c|c|c|c|c|c|c|c|}
\hline & 0516-211B-0 & 0516-211B-6 & 0516-211B-12 & $0516-211 \mathrm{~B}-24$ & $0516-211 \mathrm{~B}-48$ & AVG & SD \\
\hline & (ppm) & (ppm) & (ppm) & (ppm) & (ppm) & & \\
\hline Al3082 & 264.89 & 264.00 & 261.93 & 289.67 & 254.18 & 266.93 & 13.39 \\
\hline B_2497 & 17.83 & 17.74 & 17.39 & 18.94 & 16.52 & 17.68 & 0.87 \\
\hline Ca3179 & 185.50 & 187.28 & 184.26 & 205.45 & 181.21 & 188.74 & 9.60 \\
\hline Ce4186 & 2.54 & 2.40 & 2.46 & 3.14 & 2.13 & 2.53 & 0.37 \\
\hline Cr3578 & 84.00 & 84.18 & 83.53 & 92.68 & 81.43 & 85.17 & 4.34 \\
\hline Cu3247 & 16.14 & 16.22 & 15.79 & 17.83 & 15.47 & 16.29 & 0.91 \\
\hline Fe2599 & 71.87 & 72.46 & 71.99 & 79.51 & 69.35 & 73.04 & 3.81 \\
\hline K_7664 & 1611.13 & 1632.44 & 1613.50 & 1748.18 & 1524.99 & 1626.05 & 79.92 \\
\hline La3949 & - & - & - & - & - & & \\
\hline Mg2790 & - & - & - & - & - & & \\
\hline Mn2576 & 56.57 & 56.57 & 57.31 & 62.19 & 54.05 & 57.34 & 2.98 \\
\hline Mo2020 & 26.32 & 26.14 & 26.08 & 29.04 & 25.49 & 26.62 & 1.39 \\
\hline $\mathrm{Nd} 4061$ & - & - & - & - & - & & \\
\hline $\mathrm{Ni2316}$ & 370.59 & 371.78 & 368.52 & 410.26 & 359.94 & 376.22 & 19.59 \\
\hline P_1774 & 320.86 & 317.90 & 317.61 & 351.06 & 308.14 & 323.11 & 16.34 \\
\hline $\mathrm{Pb} 2203$ & 55.38 & 55.26 & 55.03 & 61.09 & 53.87 & 56.13 & 2.84 \\
\hline Si2516 & 6.52 & 7.20 & 7.40 & 8.85 & 8.19 & 7.64 & 0.91 \\
\hline Sr3464 & 116.92 & 117.25 & 116.98 & 129.41 & 113.10 & 118.73 & 6.21 \\
\hline Zn2062 & 25.04 & 26.61 & 25.11 & 27.94 & 24.51 & 25.84 & 1.41 \\
\hline Zr3391 & 4.01 & 4.00 & 4.00 & 4.42 & 3.90 & 4.06 & 0.20 \\
\hline
\end{tabular}


WSRC-TR-2003-00232, Rev. 0

SRT-RPP-2003-00105, Rev. 0

Table C.4 ICP-AES Data for AN-107 Primary Effects Samples (0.45 $\mu \mathrm{m}$ Filter Samples)

\begin{tabular}{|c|c|c|c|c|c|c|c|}
\hline & $0315-221 \mathrm{~A}-0$ & $0315-221 \mathrm{~A}-6$ & 0315-221A-12 & $0315-221 \mathrm{~A}-24$ & $0315-221 \mathrm{~A}-48$ & average & stddev \\
\hline & $(\mathrm{ppm})$ & $(\mathrm{ppm})$ & $(\mathrm{ppm})$ & $(\mathrm{ppm})$ & $(\mathrm{ppm})$ & & \\
\hline Al3082 & 260.01 & 258.84 & 262.69 & 263.16 & 268.83 & 262.71 & 3.87 \\
\hline B_2497 & 17.05 & 15.98 & 17.25 & 19.40 & 17.80 & 17.50 & 1.25 \\
\hline Ca3179 & 181.07 & 119.81 & 177.28 & 195.04 & 181.69 & 170.98 & 29.39 \\
\hline Ce4186 & 2.34 & - & 2.14 & 2.99 & 2.47 & 2.48 & 0.36 \\
\hline Cr3578 & 80.56 & 76.26 & 75.35 & 85.02 & 76.20 & 78.68 & 4.09 \\
\hline Cu3247 & 15.61 & 14.67 & 14.62 & 16.24 & 14.90 & 15.21 & 0.70 \\
\hline Fe2599 & 67.27 & 70.35 & 69.53 & 78.97 & 71.62 & 71.55 & 4.44 \\
\hline K_7664 & 1572.61 & 1535.86 & 1530.56 & 1756.94 & 1584.95 & 1596.18 & 92.83 \\
\hline La3949 & 1.81 & - & 1.81 & 1.98 & 1.67 & 1.81 & 0.13 \\
\hline Mg2790 & 1.15 & 1.59 & 0.64 & 1.74 & 1.06 & 1.24 & 0.44 \\
\hline Mn2576 & 57.89 & 56.48 & 57.33 & 63.62 & 57.80 & 58.62 & 2.85 \\
\hline Mo2020 & 26.52 & 25.77 & 26.10 & 29.46 & 26.83 & 26.94 & 1.47 \\
\hline $\mathrm{Nd} 4061$ & 4.28 & - & 5.37 & 5.52 & 4.42 & 4.90 & 0.64 \\
\hline $\mathrm{Ni2316}$ & 375.14 & 356.03 & 357.21 & 397.49 & 364.56 & 370.09 & 17.10 \\
\hline P_1774 & 324.28 & 323.99 & 332.81 & 382.79 & 348.10 & 342.39 & 24.61 \\
\hline $\mathrm{Pb} 2203$ & 54.83 & 54.33 & 55.24 & 62.30 & 57.12 & 56.77 & 3.27 \\
\hline Si2516 & 9.28 & 5.05 & 5.20 & 5.54 & 7.03 & 6.42 & 1.78 \\
\hline Sr3464 & 135.62 & 128.33 & 131.68 & 145.53 & 134.74 & 135.18 & 6.45 \\
\hline Zn2062 & 24.88 & 23.45 & 23.60 & 26.20 & 24.18 & 24.46 & 1.12 \\
\hline Zr3391 & 3.54 & 3.36 & 3.37 & 3.83 & 3.40 & 3.50 & 0.20 \\
\hline
\end{tabular}

\begin{tabular}{|c|c|c|c|c|c|c|c|}
\hline & $0315-221 \mathrm{~B}-0$ & 0315-221B-6 & 0315-221B-12 & $0315-221 B-24$ & $0315-221 B-48$ & average & stddev \\
\hline & (ppm) & (ppm) & (ppm) & (ppm) & (ppm) & & \\
\hline AI3082 & 269.03 & 284.37 & 295.50 & 273.21 & 273.44 & 279.11 & 10.78 \\
\hline B_2497 & 17.25 & 18.10 & 18.86 & 17.78 & 17.43 & 17.88 & 0.63 \\
\hline Ca3179 & 197.46 & 204.86 & 208.32 & 195.18 & 197.67 & 200.70 & 5.60 \\
\hline Ce4186 & 4.55 & 4.56 & 4.90 & 4.52 & 4.37 & 4.58 & 0.20 \\
\hline Cr3578 & 81.70 & 84.15 & 83.24 & 78.23 & 84.18 & 82.30 & 2.49 \\
\hline Cu3247 & 15.09 & 15.13 & 15.27 & 14.21 & 14.70 & 14.88 & 0.43 \\
\hline Fe2599 & 125.80 & 135.27 & 142.79 & 132.22 & 126.13 & 132.44 & 7.06 \\
\hline K_7664 & 1581.53 & 1672.99 & 1725.98 & 1598.10 & 1590.70 & 1633.86 & 63.04 \\
\hline La3949 & 3.24 & 3.11 & 3.52 & 3.21 & 3.09 & 3.23 & 0.17 \\
\hline $\operatorname{Mg} 2790$ & - & - & - & - & - & & \\
\hline Mn2576 & 96.50 & 101.82 & 103.75 & 96.94 & 96.76 & 99.15 & 3.39 \\
\hline Mo2020 & 26.52 & 28.03 & 28.77 & 27.03 & 26.94 & 27.46 & 0.92 \\
\hline $\mathrm{Nd} 4061$ & 10.44 & 8.68 & 11.30 & 11.75 & 10.56 & 10.55 & 1.17 \\
\hline $\mathrm{Ni} 2316$ & 375.92 & 385.69 & 387.46 & 366.74 & 383.02 & 379.77 & 8.50 \\
\hline P_1774 & 330.63 & 358.46 & 377.99 & 352.54 & 329.45 & 349.81 & 20.36 \\
\hline $\mathrm{Pb} 2203$ & 49.49 & 53.01 & 55.09 & 51.15 & 50.02 & 51.75 & 2.30 \\
\hline Si2516 & 5.42 & 5.36 & 5.96 & 6.20 & 7.89 & 6.17 & 1.03 \\
\hline Sr3464 & 136.19 & 141.81 & 143.47 & 134.32 & 137.58 & 138.68 & 3.85 \\
\hline Zn2062 & 23.39 & 24.01 & 24.39 & 23.54 & 22.93 & 23.65 & 0.56 \\
\hline Zr3391 & 8.47 & 8.84 & 8.80 & 8.30 & 8.73 & 8.63 & 0.23 \\
\hline
\end{tabular}


WSRC-TR-2003-00232, Rev. 0

SRT-RPP-2003-00105, Rev. 0

Table C.5 ICP-AES Data for AN-107 Primary Effects Samples (Light Samples)

\begin{tabular}{|c|c|c|c|c|c|c|c|}
\hline & $0315-111 \mathrm{~A}-0$ & $0315-111 \mathrm{~A}-6$ & 0315-111A-12 & $0315-111 \mathrm{~A}-24$ & $0315-111 \mathrm{~A}-48$ & average & stddev \\
\hline & $(\mathrm{ppm})$ & $(\mathrm{ppm})$ & $(\mathrm{ppm})$ & $(\mathrm{ppm})$ & $(\mathrm{ppm})$ & & \\
\hline Al3082 & 245.05 & 247.58 & 249.64 & 258.13 & 288.71 & 257.82 & 17.95 \\
\hline B_2497 & 16.58 & 16.77 & 17.14 & 18.14 & 27.61 & 19.25 & 4.71 \\
\hline Ca3179 & 149.00 & 147.32 & 148.91 & 151.38 & 222.03 & 163.73 & 32.62 \\
\hline Ce4186 & 8.79 & 8.40 & 8.51 & 9.04 & 12.98 & 9.54 & 1.94 \\
\hline Cr3578 & 82.08 & 78.50 & 77.59 & 79.73 & 115.22 & 86.62 & 16.07 \\
\hline Cu3247 & 14.65 & 14.01 & 13.74 & 14.32 & 20.99 & 15.54 & 3.06 \\
\hline Fe2599 & 228.47 & 233.55 & 237.38 & 243.40 & 356.03 & 259.77 & 54.09 \\
\hline K_7664 & 1635.23 & 1591.13 & 1588.48 & 1659.34 & 2436.97 & 1782.23 & 367.24 \\
\hline La3949 & 5.22 & 4.82 & 5.10 & 5.07 & 7.49 & 5.54 & 1.10 \\
\hline Mg2790 & 3.45 & 3.00 & 3.04 & 2.49 & 2.64 & 2.93 & 0.37 \\
\hline Mn2576 & 165.46 & 164.14 & 166.14 & 166.61 & 243.43 & 181.16 & 34.83 \\
\hline Mo2020 & 26.92 & 26.78 & 26.65 & 27.72 & 39.72 & 29.56 & 5.70 \\
\hline $\mathrm{Nd} 4061$ & 18.75 & 17.69 & 18.06 & 19.60 & 26.23 & 20.07 & 3.52 \\
\hline $\mathrm{Ni2316}$ & 378.38 & 366.32 & 365.44 & 374.56 & 536.84 & 404.31 & 74.29 \\
\hline P_1774 & 328.69 & 338.39 & 343.39 & 361.03 & 523.91 & 379.08 & 81.81 \\
\hline $\mathrm{Pb} 2203$ & 58.07 & 59.92 & 60.12 & 61.92 & 88.70 & 65.74 & 12.90 \\
\hline Si2516 & 4.50 & 4.76 & 5.03 & 5.57 & 10.48 & 6.07 & 2.50 \\
\hline Sr3464 & 165.49 & 162.96 & 164.11 & 166.02 & 241.67 & 180.05 & 34.47 \\
\hline Zn2062 & 23.40 & 22.91 & 23.04 & 23.41 & 34.31 & 25.41 & 4.98 \\
\hline Zr3391 & 17.20 & 16.63 & 16.52 & 16.66 & 24.26 & 18.25 & 3.37 \\
\hline
\end{tabular}

\begin{tabular}{|c|c|c|c|c|c|c|c|}
\hline & 0315-111B-0 & 0315-111B-6 & 0315-111B-12 & 0315-111B-24 & 0315-111B-48 & average & stddev \\
\hline & $(\mathrm{ppm})$ & (ppm) & (ppm) & $(\mathrm{ppm})$ & (ppm) & & \\
\hline Al3082 & 269.45 & 272.39 & 259.57 & 259.19 & 273.39 & 266.80 & 6.93 \\
\hline B_2497 & 17.47 & 18.24 & 16.68 & 19.11 & 17.29 & 17.76 & 0.94 \\
\hline Ca3179 & 197.33 & 197.51 & 189.57 & 207.45 & 196.74 & 197.72 & 6.37 \\
\hline Ce4186 & 6.07 & 5.66 & 5.64 & 6.40 & 5.58 & 5.87 & 0.35 \\
\hline Cr3578 & 76.88 & 75.91 & 71.41 & 80.12 & 80.29 & 76.92 & 3.64 \\
\hline Cu3247 & 15.09 & 14.78 & 13.66 & 15.44 & 15.40 & 14.87 & 0.73 \\
\hline Fe2599 & 170.08 & 174.34 & 169.87 & 183.22 & 168.99 & 173.30 & 5.92 \\
\hline K_7664 & 1596.13 & 1621.70 & 1508.81 & 1707.85 & 1624.94 & 1611.88 & 71.32 \\
\hline La3949 & 3.88 & 3.81 & 3.67 & 3.97 & 3.78 & 3.82 & 0.11 \\
\hline Mg2790 & 1.43 & 1.84 & 1.69 & 1.32 & 1.79 & 1.61 & 0.23 \\
\hline Mn2576 & 115.51 & 116.07 & 113.81 & 122.30 & 115.60 & 116.66 & 3.27 \\
\hline Mo2020 & 26.53 & 26.72 & 25.62 & 28.57 & 27.17 & 26.92 & 1.08 \\
\hline $\mathrm{Nd} 4061$ & 12.73 & 13.30 & 12.30 & 14.13 & 13.47 & 13.19 & 0.70 \\
\hline $\mathrm{Ni2316}$ & 373.09 & 366.91 & 350.45 & 391.02 & 385.43 & 373.38 & 16.00 \\
\hline P_1774 & 333.10 & 345.16 & 334.57 & 371.62 & 330.46 & 342.98 & 16.95 \\
\hline $\mathrm{Pb} 2203$ & 53.63 & 54.86 & 53.10 & 58.27 & 54.39 & 54.85 & 2.03 \\
\hline Si2516 & 5.00 & 5.41 & 5.52 & 6.66 & 7.39 & 6.00 & 0.99 \\
\hline Sr3464 & 149.47 & 149.38 & 143.06 & 157.20 & 151.12 & 150.05 & 5.05 \\
\hline Zn2062 & 23.72 & 23.40 & 22.44 & 25.59 & 23.11 & 23.65 & 1.18 \\
\hline Zr3391 & 10.80 & 10.72 & 10.11 & 11.35 & 11.20 & 10.84 & 0.48 \\
\hline
\end{tabular}


WSRC-TR-2003-00232, Rev. 0

SRT-RPP-2003-00105, Rev. 0

Table C.6 ICP-AES Data for AN-107 Primary Effects Samples (8-hr Hold Samples)

\begin{tabular}{|c|c|c|c|c|c|c|c|}
\hline & $0315-215 A-0$ & $0315-215 A-6$ & $0315-215 A-12$ & $0315-215 A-24$ & $0315-215 A-48$ & average & stddev \\
\hline & (ppm) & (ppm) & (ppm) & (ppm) & (ppm) & & \\
\hline Al3082 & 249.13 & 256.67 & 252.26 & 253.90 & 255.21 & 253.43 & 2.90 \\
\hline B_2497 & 81.83 & 85.08 & 83.65 & 84.19 & 85.79 & 84.11 & 1.52 \\
\hline Ca3179 & 175.28 & 179.75 & 174.78 & 174.99 & 179.22 & 176.80 & 2.46 \\
\hline Ce4186 & 1.77 & 1.78 & 1.59 & 1.60 & 1.87 & 1.72 & 0.12 \\
\hline Cr3578 & 83.08 & 80.70 & 75.63 & 77.45 & 78.28 & 79.03 & 2.91 \\
\hline Cu3247 & 15.86 & 15.31 & 14.81 & 15.17 & 15.44 & 15.32 & 0.38 \\
\hline Fe2599 & 57.34 & 60.40 & 59.75 & 61.09 & 60.32 & 59.78 & 1.45 \\
\hline K_7664 & 1658.37 & 1662.24 & 1596.39 & 1627.97 & 1628.27 & 1634.65 & 26.80 \\
\hline La3949 & - & - & - & - & - & & \\
\hline Mg2790 & - & - & - & - & - & & \\
\hline Mn2576 & 40.80 & 41.57 & 40.20 & 39.04 & 36.86 & 39.69 & 1.83 \\
\hline Mo2020 & 27.37 & 27.42 & 26.85 & 27.09 & 27.63 & 27.27 & 0.30 \\
\hline Nd4061 & 3.11 & 3.78 & 3.54 & 4.01 & 4.85 & 3.86 & 0.65 \\
\hline $\mathrm{Ni2316}$ & 385.61 & 377.27 & 365.35 & 365.35 & 372.50 & 373.22 & 8.58 \\
\hline P_1774 & 333.46 & 347.17 & 349.55 & 353.43 & 362.67 & 349.26 & 10.62 \\
\hline $\mathrm{Pb} 2203$ & 54.62 & 56.29 & 55.82 & 55.76 & 57.07 & 55.91 & 0.89 \\
\hline Si2516 & 560.84 & 567.99 & 548.32 & 487.83 & 470.84 & 527.16 & 44.63 \\
\hline Sr3464 & 28.37 & 29.39 & 30.43 & 34.33 & 44.91 & 33.48 & 6.77 \\
\hline Zn2062 & 24.47 & 24.70 & 23.56 & 23.40 & 23.99 & 24.02 & 0.56 \\
\hline Zr3391 & 3.55 & 3.44 & 3.32 & 3.35 & 3.43 & 3.42 & 0.09 \\
\hline
\end{tabular}

\begin{tabular}{|c|c|c|c|c|c|c|c|}
\hline & $0315-215 \mathrm{~B}-0$ & 0315-215B-6 & 0315-215B-12 & $0315-215 B-24$ & 0315-215B-48 & average & stddev \\
\hline & (ppm) & (ppm) & (ppm) & (ppm) & (ppm) & & \\
\hline Al3082 & 283.72 & 288.33 & 268.24 & 289.67 & 290.20 & 284.03 & 9.19 \\
\hline B_2497 & 49.85 & 51.56 & 48.81 & 53.40 & 51.86 & 51.10 & 1.79 \\
\hline Ca3179 & 190.51 & 188.94 & 178.61 & 191.39 & 194.62 & 188.81 & 6.07 \\
\hline Ce4186 & 4.26 & 4.19 & 3.37 & 4.04 & 3.94 & 3.96 & 0.35 \\
\hline Cr3578 & 83.06 & 78.59 & 72.64 & 77.97 & 86.08 & 79.67 & 5.15 \\
\hline Cu3247 & 15.29 & 14.54 & 13.04 & 14.35 & 14.89 & 14.42 & 0.85 \\
\hline Fe2599 & 118.90 & 120.53 & 113.93 & 122.13 & 116.24 & 118.35 & 3.29 \\
\hline K_7664 & 1638.66 & 1638.66 & 1498.94 & 1609.35 & 1652.57 & 1607.64 & 62.77 \\
\hline La3949 & 2.42 & 2.44 & 2.30 & 2.52 & 2.41 & 2.42 & 0.08 \\
\hline Mg2790 & - & - & - & - & - & & \\
\hline Mn2576 & 74.62 & 70.83 & 66.63 & 69.97 & 68.08 & 70.03 & 3.05 \\
\hline Mo2020 & 27.28 & 27.16 & 25.36 & 27.10 & 27.88 & 26.96 & 0.94 \\
\hline Nd4061 & 9.04 & 10.91 & 8.99 & 9.93 & 11.13 & 10.00 & 1.01 \\
\hline $\mathrm{Ni2316}$ & 381.84 & 370.00 & 345.73 & 368.52 & 397.53 & 372.72 & 19.05 \\
\hline P_1774 & 340.70 & 353.13 & 330.93 & 355.50 & 339.81 & 344.01 & 10.18 \\
\hline$\overline{\mathrm{Pb}} 2203$ & 48.96 & 49.28 & 47.00 & 49.91 & 49.28 & 48.89 & 1.11 \\
\hline Si2516 & 315.54 & 330.34 & 301.33 & 327.67 & 337.44 & 322.46 & 14.21 \\
\hline Sr3464 & 30.96 & 31.44 & 29.63 & 36.59 & 50.02 & 35.73 & 8.42 \\
\hline Zn2062 & 23.50 & 23.07 & 22.03 & 23.90 & 23.62 & 23.22 & 0.73 \\
\hline Zr3391 & 8.87 & 8.68 & 7.95 & 8.58 & 9.18 & 8.65 & 0.45 \\
\hline
\end{tabular}


WSRC-TR-2003-00232, Rev. 0
SRT-RPP-2003-00105, Rev. 0

Table C.7 ICP-AES Data for AN-107 Primary Effects Samples (0.0 M OH Samples)

\begin{tabular}{|c|c|c|c|c|c|c|c|}
\hline & 0325-211A-0MOH-0 & 0325-211A-0MOH-6 & $0325-211 \mathrm{~A}-0 \mathrm{MOH}-12$ & $0325-211 \mathrm{~A}-0 \mathrm{MOH}-24$ & $0325-211 \mathrm{~A}-0 \mathrm{MOH}-48$ & average & stddev \\
\hline & (ppm) & (ppm) & (ppm) & (ppm) & (ppm) & & \\
\hline Al3082 & 37.26 & 34.25 & 40.66 & 40.66 & 34.72 & 37.51 & 3.10 \\
\hline B_2497 & 20.29 & 19.42 & 22.07 & 21.45 & 19.18 & 20.48 & 1.26 \\
\hline Ca3179 & 19.17 & 17.11 & 20.39 & 22.68 & 18.03 & 19.48 & 2.17 \\
\hline Ce4186 & 3.66 & 3.88 & 4.73 & 4.49 & 3.76 & 4.10 & 0.47 \\
\hline Cr3578 & 92.89 & 87.24 & 103.49 & 97.63 & 88.20 & 93.89 & 6.78 \\
\hline Cu3247 & 25.59 & 24.28 & 28.80 & 26.99 & 24.39 & 26.01 & 1.90 \\
\hline Fe2599 & 193.86 & 181.96 & 212.98 & 200.43 & 180.70 & 193.99 & 13.45 \\
\hline K_7664 & 2093.09 & 1814.43 & 2146.52 & 2008.97 & 1806.21 & 1973.84 & 157.15 \\
\hline La3949 & - & - & - & - & - & & \\
\hline Mg2790 & - & - & - & - & - & & \\
\hline Mn2576 & 692.12 & 649.38 & 765.01 & 716.78 & 655.96 & 695.85 & 47.40 \\
\hline Mo2020 & 31.78 & 29.98 & 35.46 & 33.51 & 30.28 & 32.20 & 2.30 \\
\hline $\mathrm{Nd} 4061$ & - & - & - & - & - & & \\
\hline Ni2316 & 460.32 & 429.36 & 509.09 & 482.79 & 438.13 & 463.94 & 32.67 \\
\hline P_1774 & 212.46 & 202.98 & 239.91 & 227.23 & 205.55 & 217.63 & 15.62 \\
\hline Pb2203 & 164.62 & 154.70 & 180.54 & 170.92 & 155.88 & 165.33 & 10.79 \\
\hline Si2516 & 1.19 & 0.87 & 1.45 & 2.36 & 0.64 & 1.30 & 0.67 \\
\hline Sr3464 & 16.14 & 14.67 & 17.19 & 15.92 & 14.54 & 15.69 & 1.10 \\
\hline Zn2062 & 36.58 & 34.03 & 39.98 & 38.11 & 34.72 & 36.68 & 2.44 \\
\hline Zr3391 & 7.11 & 9.15 & 11.66 & 10.88 & 9.09 & 9.58 & 1.77 \\
\hline
\end{tabular}

\begin{tabular}{|c|c|c|c|c|c|c|c|}
\hline & 0325-211B-0MOH-0 & 0325-211B-0MOH-6 & 0325-211B-0MOH-12 & 0325-211B-0MOH-24 & 0325-211B-0MOH-48 & average & stddev \\
\hline & (ppm) & (ppm) & (ppm) & (ppm) & (ppm) & & \\
\hline Al3082 & 49.05 & 47.70 & 49.10 & 50.53 & 45.29 & 48.33 & 1.97 \\
\hline B_2497 & 19.43 & 19.76 & 20.44 & 20.04 & 18.00 & 19.54 & 0.93 \\
\hline Ca3179 & 16.13 & 15.33 & 16.28 & 15.97 & 15.18 & 15.78 & 0.49 \\
\hline Ce4186 & 3.37 & 3.41 & 3.94 & 3.96 & 3.11 & 3.56 & 0.38 \\
\hline Cr3578 & 91.27 & 85.57 & 94.48 & 94.20 & 87.65 & 90.63 & 3.95 \\
\hline Cu3247 & 25.40 & 24.05 & 26.34 & 25.82 & 23.96 & 25.11 & 1.07 \\
\hline \begin{tabular}{|l|} 
Fe2599 \\
\end{tabular} & 161.52 & 158.84 & 163.96 & 162.48 & 148.84 & 159.13 & 6.05 \\
\hline K 7664 & 1853.06 & 1779.63 & 1918.82 & 1915.53 & 1760.72 & 1845.55 & 73.93 \\
\hline La3949 & - & - & - & - & - & & \\
\hline Mg2790 & - & - & - & - & - & & \\
\hline Mn2576 & 678.15 & 664.18 & 692.40 & 689.93 & 634.04 & 671.74 & 23.86 \\
\hline Mo2020 & 31.24 & 30.00 & 32.14 & 31.92 & 29.35 & 30.93 & 1.22 \\
\hline \begin{tabular}{|l|}
$\mathrm{Nd} 4061$ \\
\end{tabular} & - & - & - & - & - & & \\
\hline $\mathrm{Ni2316}$ & 452.37 & 432.10 & 465.53 & 463.88 & 428.81 & 448.54 & 17.31 \\
\hline P_1774 & 206.79 & 203.83 & 213.64 & 212.08 & 192.62 & 205.79 & 8.36 \\
\hline $\mathrm{Pb} 2203$ & 158.21 & 155.50 & 161.99 & 161.19 & 147.41 & 156.86 & 5.87 \\
\hline Si2516 & - & - & - & - & - & & \\
\hline Sr3464 & 11.25 & 10.77 & 11.13 & 11.03 & 9.99 & 10.83 & 0.50 \\
\hline Zn2062 & 36.17 & 35.02 & 37.10 & 36.83 & 34.00 & 35.82 & 1.30 \\
\hline Zr3391 & 6.57 & 6.59 & 6.38 & 7.99 & 6.16 & 6.74 & 0.72 \\
\hline
\end{tabular}


WSRC-TR-2003-00232, Rev. 0
SRT-RPP-2003-00105, Rev. 0

Table C.8 ICP-AES Data for AN-107 Primary Effects Samples (0.2 $\mathrm{M} \mathrm{OH}^{-}$Samples)

\begin{tabular}{|c|c|c|c|c|c|c|c|}
\hline & $0325-211 \mathrm{~A}-0.2 \mathrm{MOH}-0$ & $0325-211 \mathrm{~A}-0.2 \mathrm{MOH}-6$ & $0325-211 \mathrm{~A}-0.2 \mathrm{MOH}-12$ & $0325-211 \mathrm{~A}-0.2 \mathrm{MOH}-24$ & $0325-211 \mathrm{~A}-0.2 \mathrm{MOH}-48$ & average & stddev \\
\hline & $(\mathrm{ppm})$ & (ppm) & (ppm) & (ppm) & $(\mathrm{ppm})$ & & \\
\hline $\mathrm{Al} 3082$ & - & (rpol. & - & - & - & - & $\begin{array}{lll}- & -1\end{array}$ \\
\hline B_2497 & 19.89 & 18.91 & 19.88 & 21.33 & 20.97 & 20.20 & 0.97 \\
\hline Ca3179 & 184.79 & 175.00 & 184.26 & 194.68 & 187.04 & 185.15 & 7.04 \\
\hline Ce4186 & 6.59 & 5.87 & 6.12 & 6.75 & 6.04 & 6.27 & 0.38 \\
\hline Cr3578 & 94.02 & 90.24 & 95.99 & 100.69 & 96.99 & 95.59 & 3.85 \\
\hline Cu3247 & 23.32 & 22.25 & 23.96 & 25.12 & 24.56 & 23.84 & 1.11 \\
\hline Fe2599 & 261.07 & 243.92 & 255.70 & 273.39 & 260.65 & 258.95 & 10.63 \\
\hline K_7664 & 1898.18 & 1799.22 & 1916.81 & 2016.89 & 1953.23 & 1916.87 & 79.87 \\
\hline La3949 & 2.99 & 2.77 & 3.01 & 3.20 & 2.96 & 2.99 & 0.15 \\
\hline Mg2790 & 3.29 & 1.58 & 2.85 & 3.41 & 2.65 & 2.76 & 0.73 \\
\hline Mn2576 & 279.39 & 262.10 & 275.33 & 291.34 & 279.11 & 277.46 & 10.48 \\
\hline Mo2020 & 31.94 & 29.94 & 31.80 & 33.25 & 31.89 & 31.76 & 1.18 \\
\hline $\mathrm{Nd} 4061$ & 9.11 & 9.51 & 9.76 & 9.70 & 10.98 & 9.81 & 0.70 \\
\hline $\mathrm{Ni2316}$ & 453.70 & 432.57 & 456.20 & 480.94 & 457.87 & 456.25 & 17.17 \\
\hline P_1774 & 348.89 & 323.04 & 346.67 & 361.12 & 344.72 & 344.89 & 13.79 \\
\hline$\overline{\mathrm{Pb} 2203}$ & 194.52 & 181.01 & 189.23 & 199.52 & 190.01 & 190.86 & 6.87 \\
\hline Si2516 & 1.06 & 1.24 & 0.86 & 0.91 & 0.88 & 0.99 & 0.16 \\
\hline Sr3464 & 64.50 & 60.88 & 63.63 & 67.92 & 64.83 & 64.35 & 2.53 \\
\hline Zn2062 & 33.80 & 32.03 & 33.42 & 35.70 & 33.92 & 33.77 & 1.31 \\
\hline Zr3391 & 21.41 & 20.20 & 21.61 & 22.98 & 14.92 & 20.22 & 3.12 \\
\hline
\end{tabular}

\begin{tabular}{|c|c|c|c|c|c|c|c|}
\hline & 0325-211B-0.2MOH-0 & 0325-211B-0.2MOH-6 & 0325-211B-0.2MOH-12 & 0325-211B-0.2MOH-24 & 0325-211B-0.2MOH-48 & average & stddev \\
\hline & (ppm) & (ppm) & (ppm) & (ppm) & (ppm) & & \\
\hline Al3082 & 267.46 & 262.57 & 269.33 & 271.38 & & 267.69 & 3.77 \\
\hline B_2497 & 19.38 & 18.43 & 18.82 & 18.72 & 19.85 & 19.04 & 0.57 \\
\hline Ca3179 & \begin{tabular}{|l|l|}
168.30 \\
\end{tabular} & 164.99 & 167.66 & 168.33 & 175.14 & 168.89 & 3.76 \\
\hline Ce4186 & \begin{tabular}{l|l|}
5.12 \\
\end{tabular} & 4.96 & 5.17 & 5.14 & 5.33 & 5.14 & 0.13 \\
\hline Cr3578 & 87.93 & 88.54 & 88.85 & 91.66 & 92.69 & 89.93 & 2.10 \\
\hline Cu3247 & 22.18 & 21.93 & 22.32 & 22.90 & 23.60 & 22.58 & 0.67 \\
\hline Fe2599 & \begin{tabular}{|l|l|}
187.37 \\
\end{tabular} & 183.81 & 186.26 & 184.68 & 194.18 & 187.26 & 4.11 \\
\hline K_7664 & \begin{tabular}{|l|}
1769.75 \\
\end{tabular} & 1771.69 & 1781.42 & 1833.97 & 1851.48 & 1801.66 & 38.25 \\
\hline La3949 & 2.65 & 2.64 & 2.60 & 2.65 & 2.80 & 2.67 & 0.08 \\
\hline Mg2790 & 2.90 & 1.99 & 2.96 & 2.66 & 1.47 & 2.40 & 0.64 \\
\hline Mn2576 & \begin{tabular}{|l|l|}
246.75 \\
\end{tabular} & 241.14 & 245.59 & 248.31 & 256.09 & 247.58 & 5.46 \\
\hline Mo2020 & 29.30 & 29.38 & 29.61 & 30.11 & 30.72 & 29.82 & 0.59 \\
\hline Nd4061 & 8.74 & 8.97 & 9.13 & 8.65 & 8.73 & 8.84 & 0.20 \\
\hline $\mathrm{Ni2316}$ & 424.51 & 426.45 & 428.68 & 434.24 & 442.02 & 431.18 & 7.07 \\
\hline P_1774 & \begin{tabular}{|l|l|}
322.76 \\
\end{tabular} & 318.59 & 326.09 & 327.48 & 338.88 & 326.76 & 7.59 \\
\hline $\mathrm{Pb} 2203$ & \begin{tabular}{|l|l|}
173.03 \\
\end{tabular} & \begin{tabular}{|l|}
171.78 \\
\end{tabular} & 174.03 & 174.50 & 179.20 & 174.51 & 2.82 \\
\hline Si2516 & - & 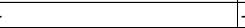 & 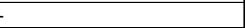 & & 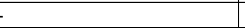 & & \\
\hline Sr3464 & 63.50 & 63.50 & 64.22 & 65.30 & 66.69 & 64.64 & 1.36 \\
\hline Zn2062 & 31.41 & 31.39 & 31.55 & 31.64 & 32.36 & 31.67 & 0.40 \\
\hline Zr3391 & 16.99 & 16.96 & 16.99 & 16.88 & 17.81 & 17.13 & 0.38 \\
\hline
\end{tabular}


WSRC-TR-2003-00232, Rev. 0

SRT-RPP-2003-00105, Rev. 0

Table C.9 ICP-AES Data for AN-107 Primary Effects Samples (Filter@ $90{ }^{\circ} \mathrm{C}$ Samples)

\begin{tabular}{|c|c|c|c|c|c|c|c|}
\hline & $0315-231 \mathrm{~A}-0$ & $0315-231 \mathrm{~A}-6$ & $0315-231 \mathrm{~A}-12$ & $0315-231 \mathrm{~A}-24$ & $0315-231 \mathrm{~A}-48$ & average & stddev \\
\hline & (ppm) & (ppm) & (ppm) & (ppm) & (ppm) & & \\
\hline Al3082 & 248.55 & 255.25 & 261.48 & 267.39 & 258.54 & 258.24 & 7.02 \\
\hline B_2497 & 17.51 & 18.31 & 19.07 & 22.24 & 18.41 & 19.11 & 1.84 \\
\hline Ca3179 & 143.97 & 126.80 & 145.62 & 169.14 & 144.94 & 146.09 & 15.08 \\
\hline Ce4186 & 8.24 & 2.62 & 8.21 & 9.83 & 7.96 & 7.37 & 2.76 \\
\hline Cr3578 & 83.94 & 81.20 & 79.62 & 93.43 & 79.67 & 83.57 & 5.78 \\
\hline Cu3247 & 15.28 & 14.84 & 14.64 & 17.30 & 14.79 & 15.37 & 1.11 \\
\hline Fe2599 & 215.88 & 222.21 & 233.88 & 270.54 & 228.11 & 234.12 & 21.43 \\
\hline K_7664 & 1626.41 & 1622.00 & 1649.93 & 1922.76 & 1639.34 & 1692.09 & 129.42 \\
\hline La3949 & 4.72 & - & 4.86 & 5.62 & 4.79 & 5.00 & 0.42 \\
\hline Mg2790 & 3.34 & 1.96 & 2.11 & 1.80 & 2.86 & 2.41 & 0.66 \\
\hline Mn2576 & 167.23 & 168.81 & 170.43 & 199.10 & 168.81 & 174.88 & 13.59 \\
\hline Mo2020 & 27.12 & 27.29 & 27.50 & 32.28 & 27.64 & 28.37 & 2.20 \\
\hline Nd4061 & 17.04 & 3.06 & 17.71 & 20.48 & 18.16 & 15.29 & 6.96 \\
\hline Ni2316 & 383.96 & 380.14 & 374.56 & 436.30 & 375.44 & 390.08 & 26.11 \\
\hline P_1774 & 330.75 & 344.86 & 357.80 & 420.71 & 360.74 & 362.97 & 34.40 \\
\hline $\mathrm{Pb} 2203$ & 55.48 & 57.18 & 58.45 & 67.91 & 57.92 & 59.39 & 4.90 \\
\hline Si2516 & 9.05 & 8.78 & 9.25 & 10.64 & 10.87 & 9.72 & 0.96 \\
\hline Sr3464 & 113.95 & 112.37 & 114.19 & 132.74 & 113.48 & 117.35 & 8.63 \\
\hline Zn2062 & 24.03 & 24.26 & 24.12 & 27.64 & 24.06 & 24.82 & 1.58 \\
\hline Zr3391 & 16.73 & 16.60 & 16.33 & 19.13 & 16.37 & 17.03 & 1.19 \\
\hline
\end{tabular}

\begin{tabular}{|c|c|c|c|c|c|c|c|}
\hline & $0325-231 \mathrm{~B}-0$ & 0325-231B-6 & 0325-231B-12 & 0325-231B-24 & 0325-231B-48 & average & stddev \\
\hline & $(\mathrm{ppm})$ & $(\mathrm{ppm})$ & (ppm) & (ppm) & (ppm) & & \\
\hline Al3082 & - & - & - & - & - & - & - \\
\hline B_2497 & 19.42 & 18.98 & 21.42 & 19.53 & 19.81 & 19.83 & 0.93 \\
\hline Ca3179 & 135.75 & 133.27 & 147.02 & 134.14 & 136.63 & 137.36 & 5.56 \\
\hline Ce4186 & 14.70 & 15.90 & 17.14 & 15.61 & 15.95 & 15.86 & 0.88 \\
\hline Cr3578 & 96.13 & 91.57 & 102.99 & 94.02 & 94.58 & 95.86 & 4.31 \\
\hline Cu3247 & 16.74 & 16.22 & 18.17 & 16.78 & 17.01 & 16.99 & 0.72 \\
\hline Fe2599 & 374.34 & 365.29 & 403.54 & 369.09 & 366.46 & 375.75 & 15.93 \\
\hline K_7664 & 1900.63 & 1823.25 & 2023.85 & 1832.59 & 1815.36 & 1879.14 & 87.69 \\
\hline La3949 & 7.38 & 7.92 & 8.68 & 7.95 & 7.98 & 7.98 & 0.46 \\
\hline Mg2790 & 3.66 & 2.65 & 2.88 & 2.84 & 2.65 & 2.94 & 0.42 \\
\hline Mn2576 & 224.72 & 219.47 & 242.33 & 219.91 & 222.47 & 225.78 & 9.49 \\
\hline Mo2020 & 30.72 & 29.81 & 32.94 & 29.73 & 29.93 & 30.62 & 1.35 \\
\hline Nd4061 & 26.12 & 32.15 & 34.40 & 31.83 & 31.59 & 31.22 & 3.06 \\
\hline Ni2316 & 433.33 & 420.77 & 466.03 & 422.52 & 429.53 & 434.44 & 18.39 \\
\hline P_1774 & 367.04 & 357.70 & 394.78 & 354.49 & 358.87 & 366.58 & 16.43 \\
\hline Pb2203 & 74.34 & 72.33 & 78.55 & 71.42 & 71.60 & 73.65 & 2.97 \\
\hline Si2516 & 6.57 & 6.38 & 7.52 & 7.55 & 9.01 & 7.41 & 1.05 \\
\hline Sr3464 & 137.56 & 133.91 & 147.26 & 134.29 & 136.22 & 137.85 & 5.46 \\
\hline Zn2062 & 28.05 & 27.05 & 30.11 & 26.98 & 27.53 & 27.94 & 1.28 \\
\hline Zr3391 & 28.06 & 27.06 & 30.08 & 27.56 & 27.84 & 28.12 & 1.16 \\
\hline
\end{tabular}


WSRC-TR-2003-00232, Rev. 0

SRT-RPP-2003-00105, Rev. 0

Table C.10 ICP-AES Data for AN-107 Primary Effects Samples (25 ${ }^{\circ} \mathrm{C}$ Rxn Samples)

\begin{tabular}{|c|c|c|c|c|c|c|c|}
\hline & $0417-211-25 A-0$ & $0417-211-25 A-6$ & 0417-211-25A-12 & 0417-211-25A-24 & $0417-211-25 A-48$ & average & stddev \\
\hline Element & (ppm) & (ppm) & (ppm) & (ppm) & (ppm) & & \\
\hline Al3082 & 242.08 & 230.03 & 244.28 & 240.82 & 234.73 & 238.39 & 5.87 \\
\hline B_2497 & 14.64 & 13.87 & 15.25 & 14.68 & 14.36 & 14.56 & 0.50 \\
\hline Ca3179 & 209.62 & 205.21 & 218.06 & 213.74 & 206.80 & 210.69 & 5.24 \\
\hline Ce4186 & 2.66 & 2.57 & 2.65 & 2.21 & 2.59 & 2.54 & 0.19 \\
\hline Cr3578 & 74.73 & 71.21 & 73.82 & 72.27 & 70.74 & 72.55 & 1.70 \\
\hline Cu3247 & 15.00 & 14.08 & 14.91 & 14.57 & 14.23 & 14.56 & 0.41 \\
\hline Fe2599 & 88.29 & 81.29 & 87.14 & 85.61 & 83.08 & 85.08 & 2.88 \\
\hline K_7664 & 1474.12 & 1375.04 & 1415.02 & 1412.38 & 1402.09 & 1415.73 & 36.27 \\
\hline La3949 & 1.43 & 1.36 & 1.42 & 1.38 & 1.33 & 1.38 & 0.04 \\
\hline Mg2790 & - & - & - & - & - & & \\
\hline Mn2576 & 38.87 & 37.22 & 39.28 & 38.66 & 37.51 & 38.31 & 0.89 \\
\hline Mo2020 & 24.73 & 23.65 & 24.60 & 24.45 & 23.74 & 24.23 & 0.50 \\
\hline \begin{tabular}{|l|}
$\mathrm{Nd} 4061$ \\
\end{tabular} & 4.52 & 4.20 & 4.29 & 4.62 & 4.42 & 4.41 & 0.17 \\
\hline Ni2316 & 345.74 & 330.75 & 347.51 & 340.45 & 332.81 & 339.45 & 7.51 \\
\hline P_1774 & 295.18 & 279.36 & 292.59 & 291.03 & 278.12 & 287.26 & 7.92 \\
\hline Pb2203 & 67.30 & 64.50 & 68.18 & 67.18 & 64.83 & 66.40 & 1.63 \\
\hline Si2516 & - & - & - & - & - & & \\
\hline Sr3464 & 231.70 & 222.47 & 234.52 & 228.82 & 222.73 & 228.05 & 5.37 \\
\hline Zn2062 & 22.47 & 21.54 & 22.76 & 22.36 & 21.77 & 22.18 & 0.50 \\
\hline Zr3391 & 6.44 & 6.09 & 6.44 & 6.32 & 6.13 & 6.29 & 0.17 \\
\hline
\end{tabular}

\begin{tabular}{|c|c|c|c|c|c|c|c|}
\hline & $0417-211-25 B-0$ & $0417-211-25 B-6$ & 0417-211-25B-12 & 0417-211-25B-24 & 0417-211-25B-48 & average & stddev \\
\hline Element & (ppm) & (ppm) & (ppm) & (ppm) & (ppm) & & \\
\hline Al3082 & 245.99 & 252.69 & 277.71 & 258.69 & 256.90 & 258.40 & 11.85 \\
\hline B_2497 & 15.56 & 15.52 & 17.82 & 15.72 & 16.20 & 16.17 & 0.96 \\
\hline Ca3179 & 212.21 & 213.65 & 228.88 & 219.65 & 217.74 & 218.42 & 6.57 \\
\hline Ce4186 & 3.24 & 3.19 & 3.25 & 3.68 & 3.77 & 3.42 & 0.28 \\
\hline Cr3578 & 73.26 & 75.56 & 80.44 & 75.44 & 73.35 & 75.61 & 2.91 \\
\hline Cu3247 & 15.35 & 15.84 & 17.25 & 15.96 & 15.66 & 16.01 & 0.73 \\
\hline Fe2599 & 97.58 & 98.55 & 110.57 & 103.52 & 101.61 & 102.36 & 5.17 \\
\hline K_7664 & 1460.30 & 1533.21 & 1641.40 & 1531.45 & 1480.58 & 1529.39 & 70.22 \\
\hline La3949 & 1.75 & 1.65 & 1.84 & 1.77 & 1.71 & 1.74 & 0.07 \\
\hline Mg2790 & - & - & - & - & - & & \\
\hline Mn2576 & 41.60 & 42.34 & 46.28 & 43.51 & 42.92 & 43.33 & 1.79 \\
\hline Mo2020 & 25.00 & 25.51 & 27.55 & 25.92 & 25.53 & 25.90 & 0.98 \\
\hline \begin{tabular}{|l|}
$\mathrm{Nd} 4061$ \\
\end{tabular} & 5.45 & 5.45 & 5.24 & 5.27 & 4.97 & 5.28 & 0.20 \\
\hline \begin{tabular}{|l|}
$\mathrm{Ni2316}$ \\
\end{tabular} & 354.56 & 359.27 & 385.43 & 362.50 & 358.68 & 364.09 & 12.26 \\
\hline P_1774 & 299.29 & 301.06 & 332.81 & 314.29 & 310.46 & 311.58 & 13.43 \\
\hline Pb2203 & 65.53 & 65.91 & 72.38 & 68.00 & 67.24 & 67.81 & 2.74 \\
\hline Si2516 & 1.84 & - & - & - & [- & 1.84 & \\
\hline Sr3464 & 273.39 & 275.45 & 294.88 & 279.12 & 271.04 & 278.78 & 9.48 \\
\hline Zn2062 & 22.62 & 22.71 & 24.70 & 23.20 & 22.96 & 23.24 & 0.85 \\
\hline Zr3391 & 7.53 & 7.67 & 8.24 & 7.79 & 7.64 & 7.78 & 0.28 \\
\hline
\end{tabular}


WSRC-TR-2003-00232, Rev. 0

SRT-RPP-2003-00105, Rev. 0

Table C.11 ICP-AES Data for AN-107 Primary Effects Samples (15 ${ }^{\circ} \mathrm{C}$ Rxn Samples)

\begin{tabular}{|c|c|c|c|c|c|c|c|}
\hline & $0424-211-15 A-0$ & $0424-211-15 A-6$ & $0424-211-15 A-12$ & $0424-211-15 A-24$ & $0424-211-15 A-48$ & average & stddev \\
\hline Element & (ppm) & (ppm) & (ppm) & (ppm) & (ppm) & & \\
\hline Al3082 & 246.03 & 250.89 & 263.16 & 264.36 & 271.98 & 259.28 & 10.59 \\
\hline B_2497 & 14.92 & 15.66 & 16.43 & 16.41 & 16.88 & 16.06 & 0.77 \\
\hline Ca3179 & 253.69 & 246.86 & 266.71 & 247.97 & 274.82 & 258.01 & 12.27 \\
\hline Ce4186 & 3.43 & 3.51 & 3.83 & 3.25 & 3.83 & 3.57 & 0.26 \\
\hline Cr3578 & 74.35 & 74.53 & 77.24 & 77.06 & 76.76 & 75.99 & 1.43 \\
\hline Cu3247 & 15.99 & 16.73 & 17.45 & 17.69 & 17.81 & 17.13 & 0.76 \\
\hline Fe2599 & 175.67 & 175.22 & 182.53 & 183.66 & 192.93 & 182.00 & 7.22 \\
\hline K_7664 & 1478.08 & 1475.10 & 1554.96 & 1534.10 & 1565.39 & 1521.53 & 42.55 \\
\hline La3949 & 2.44 & 2.15 & 2.44 & 2.10 & 2.49 & 2.32 & 0.18 \\
\hline Mg2790 & 2.61 & - & - & - & - & 2.61 & \\
\hline Mn2576 & 55.61 & 56.71 & 58.97 & 58.94 & 60.35 & 58.12 & 1.91 \\
\hline Mo2020 & 25.09 & 25.17 & 26.21 & 26.14 & 26.64 & 25.85 & 0.69 \\
\hline Nd4061 & 8.05 & 7.65 & 9.44 & 7.22 & 8.45 & 8.16 & 0.85 \\
\hline Ni2316 & 350.45 & 355.81 & 370.41 & 367.43 & 365.05 & 361.83 & 8.38 \\
\hline P_1774 & 299.49 & 302.47 & 314.69 & 315.28 & 328.40 & 312.07 & 11.56 \\
\hline Pb2203 & 83.50 & 84.24 & 87.31 & 86.90 & 89.64 & 86.32 & 2.48 \\
\hline Si2516 & - & - & - & 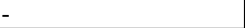 & 2.09 & 2.09 & \\
\hline Sr3464 & 229.16 & 230.32 & 240.61 & 235.33 & 240.66 & 235.22 & 5.46 \\
\hline Zn2062 & 23.48 & 23.85 & 24.85 & 24.59 & 24.65 & 24.28 & 0.59 \\
\hline Zr3391 & 10.53 & 10.76 & 11.17 & 11.11 & 11.04 & 10.92 & 0.27 \\
\hline
\end{tabular}

\begin{tabular}{|c|c|c|c|c|c|c|c|}
\hline & 0424-211-15B-0 & 0424-211-15B-6 & 0424-211-15B-12 & $0424-211-15 B-24$ & $0424-211-15 B-48$ & average & stddev \\
\hline Element & (ppm) & (ppm) & (ppm) & (ppm) & (ppm) & & \\
\hline Al3082 & 322.14 & 354.32 & 354.62 & 270.02 & 265.16 & 313.25 & 43.76 \\
\hline B_2497 & 18.12 & 19.95 & 21.81 & 16.49 & 16.93 & 18.66 & 2.21 \\
\hline Ca3179 & 286.65 & 316.77 & 327.50 & 258.72 & 256.76 & 289.28 & 32.46 \\
\hline Ce4186 & 3.98 & 4.51 & 4.88 & 3.60 & 3.59 & 4.11 & 0.57 \\
\hline Cr3578 & 86.21 & 94.53 & 97.21 & 75.90 & 77.54 & 86.28 & 9.64 \\
\hline Cu3247 & 20.61 & 22.27 & 22.98 & 18.33 & 18.60 & 20.56 & 2.10 \\
\hline \begin{tabular}{|l|} 
Fe2599 \\
\end{tabular} & 201.27 & 221.86 & 231.87 & 183.03 & 178.53 & 203.31 & 23.40 \\
\hline K_7664 & 1750.45 & 1934.62 & 2014.18 & 1572.25 & 1543.34 & 1762.97 & 210.56 \\
\hline La3949 & 2.69 & 2.80 & 3.02 & 2.43 & 2.38 & 2.67 & 0.27 \\
\hline Mg2790 & - & - & - & - & - & & \\
\hline Mn2576 & 69.34 & 76.62 & 78.91 & 62.70 & 61.86 & 69.89 & 7.79 \\
\hline Mo2020 & 29.53 & 32.84 & 33.32 & 26.51 & 26.09 & 29.66 & 3.40 \\
\hline Nd4061 & 9.04 & 8.24 & 10.79 & 9.15 & 7.86 & 9.02 & 1.13 \\
\hline $\mathrm{Ni2316}$ & 408.26 & 452.36 & 459.52 & 365.05 & 368.92 & 410.82 & 44.59 \\
\hline P_1774 & 366.24 & 409.45 & 417.80 & 332.27 & 322.14 & 369.58 & 43.50 \\
\hline Pb2203 & 98.58 & 109.90 & 111.99 & 88.95 & 86.99 & 99.28 & 11.54 \\
\hline Si2516 & - & - & - & - & - & & \\
\hline Sr3464 & 285.90 & 319.46 & 326.31 & 256.64 & 254.55 & 288.57 & 33.77 \\
\hline \begin{tabular}{|l|} 
Zn2062 \\
\end{tabular} & 27.63 & 30.78 & 31.44 & 24.79 & 25.05 & 27.94 & 3.11 \\
\hline Zr3391 & 12.40 & 13.69 & 14.10 & 11.07 & 11.19 & 12.49 & 1.39 \\
\hline
\end{tabular}


WSRC-TR-2003-00232, Rev. 0

SRT-RPP-2003-00105, Rev. 0

Table C.12 ICP-AES Data for AN-107 Primary Effects Samples (0.01 M Added Sr Samples)

\begin{tabular}{|c|c|c|c|c|c|c|c|}
\hline & 0412-211-Sr1A-0 & 0412-211-Sr1A-6 & 0412-211-Sr1A-12 & 0412-211-Sr1A-24 & 0412-211-Sr1A-48 & average & stddev \\
\hline Element & (ppm) & $(\mathrm{ppm})$ & (ppm) & $(\mathrm{ppm})$ & $(\mathrm{ppm})$ & & \\
\hline Al3082 & 261.32 & 255.75 & 256.84 & 247.49 & 252.87 & 254.86 & 5.12 \\
\hline B_2497 & 17.43 & 16.91 & 16.59 & 16.16 & 17.30 & 16.88 & 0.52 \\
\hline Ca3179 & 308.56 & 307.72 & 307.72 & 297.64 & 308.28 & 305.98 & 4.68 \\
\hline Ce4186 & 4.52 & 4.61 & 4.37 & 4.28 & 4.26 & 4.41 & 0.15 \\
\hline Cr3578 & 77.70 & 76.83 & 76.22 & 73.53 & 75.99 & 76.05 & 1.56 \\
\hline Cu3247 & 14.66 & 14.48 & 14.40 & 13.63 & 13.90 & 14.21 & 0.43 \\
\hline Fe2599 & 151.51 & 147.03 & 149.58 & 142.46 & 147.08 & 147.53 & 3.40 \\
\hline K_7664 & 1517.60 & 1527.12 & 1530.48 & 1442.00 & 1494.64 & 1502.37 & 36.53 \\
\hline La3949 & 3.86 & 3.78 & 3.74 & 3.68 & 3.62 & 3.74 & 0.09 \\
\hline Mg2790 & - & - & - & - & - & & \\
\hline Mn2576 & 89.24 & 87.14 & 87.30 & 84.08 & 86.58 & 86.87 & 1.85 \\
\hline Mo2020 & 26.11 & 25.73 & 25.62 & 24.59 & 25.35 & 25.48 & 0.57 \\
\hline $\mathrm{Nd4061}$ & 10.63 & 10.70 & 10.48 & 10.59 & 11.09 & 10.70 & 0.23 \\
\hline Ni2316 & 364.00 & 359.80 & 357.56 & 345.52 & 356.44 & 356.66 & 6.87 \\
\hline P_1774 & 316.96 & 311.92 & 313.04 & 296.80 & 308.00 & 309.34 & 7.70 \\
\hline $\mathrm{Pb} 2203$ & 47.57 & 46.76 & 46.82 & 44.88 & 46.62 & 46.53 & 0.99 \\
\hline Si2516 & 5.20 & 4.62 & 5.10 & 5.55 & 6.30 & 5.35 & 0.63 \\
\hline Sr3464 & 59.67 & 58.60 & 58.60 & 56.56 & 58.77 & 58.44 & 1.14 \\
\hline Zn2062 & 24.53 & 24.05 & 24.08 & 23.18 & 24.06 & 23.98 & 0.49 \\
\hline Zr3391 & 8.20 & 8.15 & 8.11 & 7.75 & 8.05 & 8.05 & 0.18 \\
\hline
\end{tabular}

\begin{tabular}{|c|c|c|c|c|c|c|c|}
\hline & 0412-211-Sr1B-0 & 0412-211-Sr1B-6 & 0412-211-Sr1B-12 & 0412-211-Sr1B-24 & 0412-211-Sr1B-48 & average & stddev \\
\hline Element & (ppm) & (ppm) & (ppm) & (ppm) & (ppm) & & \\
\hline Al3082 & 384.16 & 329.00 & 326.48 & 324.24 & 266.87 & 326.15 & 41.51 \\
\hline B_2497 & 24.70 & 19.90 & 19.73 & 21.02 & 17.76 & 20.62 & 2.56 \\
\hline Ca3179 & 420.28 & 362.60 & 350.84 & 370.16 & 316.68 & 364.11 & 37.48 \\
\hline Ce4186 & 9.27 & 8.28 & 7.43 & 8.00 & 7.04 & 8.00 & 0.86 \\
\hline Cr3578 & 102.93 & 89.24 & 84.25 & 89.18 & 76.75 & 88.47 & 9.56 \\
\hline Cu3247 & 20.45 & 17.72 & 17.70 & 17.62 & 15.82 & 17.86 & 1.66 \\
\hline Fe2599 & 300.16 & 257.10 & 254.44 & 259.98 & 223.47 & 259.03 & 27.30 \\
\hline K_7664 & 2154.60 & 1821.12 & 1738.52 & 1827.84 & 1580.32 & 1824.48 & 209.76 \\
\hline La3949 & 7.44 & 6.36 & 6.15 & 6.52 & 5.63 & 6.42 & 0.66 \\
\hline Mg2790 & 3.19 & 2.28 & 2.15 & 2.30 & 1.15 & 2.22 & 0.72 \\
\hline Mn2576 & 167.64 & 144.68 & 142.69 & 147.06 & 125.83 & 145.58 & 14.90 \\
\hline Mo2020 & 34.86 & 30.38 & 29.43 & 30.38 & 26.44 & 30.30 & 3.02 \\
\hline Nd4061 & 22.07 & 19.32 & 17.53 & 18.86 & 17.84 & 19.13 & 1.80 \\
\hline $\mathrm{Ni2316}$ & 479.92 & 417.48 & 409.92 & 420.28 & 364.00 & 418.32 & 41.29 \\
\hline P_1774 & 431.48 & 377.72 & 365.40 & 376.32 & 329.56 & 376.10 & 36.57 \\
\hline Pb2203 & 66.75 & 58.83 & 56.84 & 58.27 & 50.71 & 58.28 & 5.73 \\
\hline Si2516 & 6.79 & 5.50 & 5.99 & 7.08 & 5.97 & 6.26 & 0.65 \\
\hline Sr3464 & 90.13 & 77.98 & 75.99 & 79.63 & 67.93 & 78.33 & 7.98 \\
\hline Zn2062 & 32.28 & 28.06 & 27.62 & 28.39 & 24.47 & 28.16 & 2.78 \\
\hline Zr3391 & 17.37 & 14.94 & 14.67 & 15.27 & 13.13 & 15.08 & 1.52 \\
\hline
\end{tabular}


WSRC-TR-2003-00232, Rev. 0 SRT-RPP-2003-00105, Rev. 0

Table C.13 ICP-AES Data for AN-107 Primary Effects Samples (0.02 M Added Sr Samples)

\begin{tabular}{|c|c|c|c|c|c|c|c|}
\hline & 0412-211-Sr2A-0 & 0412-211-Sr2A-6 & 0412-211-Sr2A-12 & 0412-211-Sr2A-24 & 0412-211-Sr2A-48 & average & stddev \\
\hline Element & (ppm) & $(\mathrm{ppm})$ & (ppm) & $(\mathrm{ppm})$ & $(\mathrm{ppm})$ & & \\
\hline Al3082 & 325.36 & 271.15 & 279.08 & 269.11 & 276.84 & 284.31 & 23.31 \\
\hline B_2497 & 20.44 & 17.89 & 18.02 & 17.95 & 18.68 & 18.60 & 1.08 \\
\hline Ca3179 & 345.24 & 305.48 & 314.16 & 298.20 & 310.52 & 314.72 & 18.08 \\
\hline Ce4186 & 3.54 & 3.10 & 3.39 & 2.91 & 3.28 & 3.24 & 0.24 \\
\hline Cr3578 & 87.14 & 78.20 & 81.31 & 76.78 & 78.65 & 80.42 & 4.10 \\
\hline Cu3247 & 17.83 & 16.29 & 16.28 & 15.75 & 15.63 & 16.36 & 0.88 \\
\hline Fe2599 & 131.54 & 117.26 & 118.38 & 115.14 & 120.62 & 120.59 & 6.44 \\
\hline K_7664 & 1765.12 & 1585.08 & 1655.36 & 1582.56 & 1603.00 & 1638.22 & 76.75 \\
\hline La3949 & 3.02 & 2.76 & 2.87 & 2.69 & 2.67 & 2.80 & 0.15 \\
\hline Mg2790 & - & - & - & - & - & & \\
\hline Mn2576 & 82.26 & 73.28 & 75.24 & 72.27 & 74.23 & 75.45 & 3.96 \\
\hline Mo2020 & 29.96 & 26.68 & 27.85 & 26.48 & 27.17 & 27.63 & 1.41 \\
\hline $\mathrm{Nd4061}$ & 7.96 & 7.91 & 7.68 & 7.89 & 7.38 & 7.77 & 0.24 \\
\hline Ni2316 & 408.24 & 367.64 & 381.92 & 360.92 & 368.48 & 377.44 & 18.83 \\
\hline P_1774 & 370.16 & 326.48 & 341.60 & 327.04 & 339.64 & 340.98 & 17.74 \\
\hline $\mathrm{Pb} 2203$ & 56.08 & 49.62 & 51.88 & 49.95 & 51.16 & 51.74 & 2.60 \\
\hline Si2516 & 5.34 & 4.62 & 4.82 & 4.85 & 6.33 & 5.19 & 0.69 \\
\hline Sr3464 & 68.60 & 60.87 & 62.72 & 60.09 & 61.71 & 62.80 & 3.39 \\
\hline Zn2062 & 26.76 & 23.93 & 24.74 & 23.62 & 24.14 & 24.64 & 1.25 \\
\hline Zr3391 & 7.15 & 6.49 & 6.62 & 6.29 & 6.42 & 6.60 & 0.33 \\
\hline
\end{tabular}

\begin{tabular}{|c|c|c|c|c|c|c|c|}
\hline & 0412-211-Sr2B-0 & 0412-211-Sr2B-6 & 0412-211-Sr2B-12 & 0412-211-Sr2B-24 & $0412-211-\mathrm{Sr} 2 \mathrm{~B}-48$ & average & stddev \\
\hline Element & (ppm) & (ppm) & (ppm) & (ppm) & (ppm) & & \\
\hline Al3082 & 257.69 & 265.33 & 314.43 & 277.88 & 305.97 & 284.26 & 24.93 \\
\hline B_2497 & 17.70 & 17.13 & 19.12 & 18.63 & 18.98 & 18.31 & 0.86 \\
\hline Ca3179 & 284.54 & 291.02 & 304.28 & 307.94 & 316.97 & 300.95 & 13.08 \\
\hline Ce4186 & 2.94 & 3.74 & 4.16 & 3.70 & 3.91 & 3.69 & 0.46 \\
\hline Cr3578 & 78.93 & 77.13 & 85.14 & 78.28 & 79.78 & 79.85 & 3.11 \\
\hline Cu3247 & 15.69 & 16.52 & 18.05 & 16.39 & 17.49 & 16.83 & 0.94 \\
\hline Fe2599 & 114.89 & 118.52 & 130.96 & 127.10 & 131.41 & 124.58 & 7.49 \\
\hline K_7664 & 1545.92 & 1563.13 & 1736.27 & 1594.71 & 1648.85 & 1617.78 & 76.96 \\
\hline La3949 & 2.77 & 2.80 & 3.13 & 2.94 & 3.04 & 2.94 & 0.15 \\
\hline Mg2790 & - & - & - & - & - & & \\
\hline Mn2576 & 74.84 & 76.53 & 84.26 & 80.12 & 82.57 & 79.67 & 3.96 \\
\hline Mo2020 & 26.35 & 26.04 & 29.07 & 27.25 & 28.14 & 27.37 & 1.26 \\
\hline Nd4061 & 8.12 & 8.96 & 9.10 & 8.87 & 8.27 & 8.66 & 0.44 \\
\hline $\mathrm{Ni2316}$ & 369.70 & 358.70 & 403.54 & 376.19 & 385.78 & 378.78 & 16.99 \\
\hline P_1774 & 321.48 & 321.20 & 354.19 & 336.71 & 349.96 & 336.71 & 15.44 \\
\hline Pb2203 & 47.88 & 47.43 & 52.85 & 50.34 & 52.17 & 50.13 & 2.44 \\
\hline Si2516 & 5.90 & 4.72 & 5.51 & 5.83 & 7.03 & 5.80 & 0.83 \\
\hline Sr3464 & 67.79 & 67.03 & 73.29 & 70.73 & 71.99 & 70.17 & 2.69 \\
\hline Zn2062 & 24.03 & 23.41 & 26.13 & 24.87 & 25.61 & 24.81 & 1.11 \\
\hline Zr3391 & 6.31 & 6.32 & 7.02 & 6.51 & 6.65 & 6.56 & 0.29 \\
\hline
\end{tabular}


WSRC-TR-2003-00232, Rev. 0

SRT-RPP-2003-00105, Rev. 0

Table C.14 ICP-AES Data for AN-107 Primary Effects Samples (0.01 M Added $\mathrm{MnO}_{4}$ Samples)

\begin{tabular}{|c|c|c|c|c|c|c|c|}
\hline & 0412-211-MnO41A-0 & 0412-211-MnO41A-6 & 0412-211-MnO41A-12 & 0412-211-MnO41A-24 & 0412-211-MnO41A-48 & average & stddev \\
\hline Element & (ppm) & (ppm) & (ppm) & (ppm) & (ppm) & & \\
\hline Al3082 & 262.19 & 336.82 & 265.88 & 324.33 & 262.39 & 290.32 & 37.04 \\
\hline B_2497 & 17.57 & 22.40 & 17.57 & 22.21 & 16.95 & 19.34 & 2.72 \\
\hline Ca3179 & 248.95 & 310.70 & 249.30 & 303.88 & 247.96 & 272.16 & 32.16 \\
\hline Ce4186 & 22.42 & 27.91 & 22.65 & 27.24 & 22.77 & 24.60 & 2.73 \\
\hline \begin{tabular}{|l|} 
Cr3578 \\
\end{tabular} & 82.13 & 102.92 & 82.30 & 102.44 & 83.13 & 90.58 & 11.05 \\
\hline Cu3247 & 18.79 & 24.28 & 19.91 & 24.31 & 20.04 & 21.46 & 2.63 \\
\hline Fe2599 & 692.96 & 876.42 & 694.95 & 842.91 & 688.70 & 759.19 & 92.51 \\
\hline K_7664 & 1730.41 & 2019.52 & 1576.48 & 1958.46 & 1581.88 & 1773.35 & 207.44 \\
\hline La3949 & 18.34 & 22.50 & 18.32 & 22.36 & 18.38 & 19.98 & 2.24 \\
\hline Mg2790 & 3.91 & 6.15 & 4.29 & 4.40 & 4.15 & 4.58 & 0.90 \\
\hline Mn2576 & 349.60 & 435.66 & 350.74 & 428.27 & 350.46 & 382.95 & 44.83 \\
\hline Mo2020 & 26.42 & 32.97 & 26.44 & 32.43 & 26.48 & 28.95 & 3.43 \\
\hline Nd4061 & 47.37 & 61.80 & 48.76 & 60.09 & 49.08 & 53.42 & 6.93 \\
\hline Ni2316 & 368.92 & 458.09 & 370.05 & 452.13 & 371.19 & 404.08 & 46.64 \\
\hline P_1774 & 320.35 & 401.01 & 317.80 & 390.50 & 315.24 & 348.98 & 42.90 \\
\hline $\mathrm{Pb} 2203$ & 154.50 & 192.04 & 153.33 & 187.01 & 152.51 & 167.88 & 19.86 \\
\hline Si2516 & 7.76 & 10.42 & 7.69 & 11.76 & 9.01 & 9.33 & 1.76 \\
\hline Sr3464 & 161.23 & 199.45 & 160.06 & 196.33 & 160.26 & 175.47 & 20.51 \\
\hline Zn2062 & 29.14 & 36.52 & 29.08 & 35.67 & 29.17 & 31.92 & 3.83 \\
\hline Zr3391 & 36.07 & 45.18 & 36.55 & 44.73 & 36.58 & 39.82 & 4.69 \\
\hline
\end{tabular}

\begin{tabular}{|c|c|c|c|c|c|c|c|}
\hline & 0412-211-MnO41B-0 & 0412-211-MnO41B-6 & 0412-211-MnO41B-12 & 0412-211-MnO41B-24 & 0412-211-MnO41B-48 & average & stddev \\
\hline Element & $(\mathrm{ppm})$ & (ppm) & (ppm) & (ppm) & (ppm) & & \\
\hline Al3082 & 251.77 & 275.34 & 313.87 & 313.58 & 265.81 & 284.08 & 28.34 \\
\hline B_2497 & 16.37 & 17.60 & 21.71 & 21.98 & 17.34 & 19.00 & 2.64 \\
\hline Ca3179 & 232.14 & 251.09 & 289.90 & 291.02 & 243.00 & 261.43 & 27.34 \\
\hline Ce4186 & 23.73 & 25.35 & 29.47 & 29.61 & 25.03 & 26.64 & 2.72 \\
\hline Cr3578 & 79.16 & 88.38 & 102.03 & 102.54 & 85.31 & 91.48 & 10.41 \\
\hline Cu3247 & 17.97 & 21.14 & 24.13 & 24.03 & 19.91 & 21.44 & 2.67 \\
\hline Fe2599 & 692.31 & 754.07 & 861.51 & 869.97 & 724.46 & 780.46 & 80.91 \\
\hline K_7664 & 1465.27 & 1657.88 & 1944.39 & 1944.67 & 1588.22 & 1720.09 & 216.18 \\
\hline La3949 & 17.77 & 19.51 & 22.42 & 22.37 & 18.96 & 20.21 & 2.10 \\
\hline Mg2790 & 6.98 & 6.68 & 8.30 & 8.07 & 7.09 & 7.42 & 0.72 \\
\hline Mn2576 & 332.76 & 361.24 & 413.13 & 414.54 & 348.55 & 374.04 & 37.70 \\
\hline Mo2020 & 25.40 & 27.43 & 31.89 & 31.92 & 26.67 & 28.66 & 3.05 \\
\hline Nd4061 & 49.43 & 54.62 & 62.10 & 62.94 & 52.37 & 56.29 & 5.98 \\
\hline Ni2316 & 357.86 & 382.96 & 445.56 & 448.66 & 375.06 & 402.02 & 42.17 \\
\hline P_1774 & 309.07 & 333.61 & 386.34 & 387.47 & 324.58 & 348.21 & 36.40 \\
\hline Pb2203 & 151.49 & 161.61 & 187.16 & 188.38 & 158.06 & 169.34 & 17.22 \\
\hline Si2516 & 6.85 & 6.95 & 9.83 & 10.45 & 8.60 & 8.53 & 1.63 \\
\hline Sr3464 & 166.55 & 178.59 & 206.59 & 207.92 & 174.16 & 186.76 & 19.20 \\
\hline Zn2062 & 28.10 & 29.92 & 34.91 & 35.17 & 29.38 & 31.50 & 3.30 \\
\hline Zr3391 & 36.29 & 39.68 & 45.99 & 45.97 & 38.55 & 41.30 & 4.45 \\
\hline
\end{tabular}


WSRC-TR-2003-00232, Rev. 0

SRT-RPP-2003-00105, Rev. 0

Table C.15 ICP-AES Data for AN-107 Primary Effects Samples (0.025 M Added $\mathrm{MnO}_{4}$ Samples)

\begin{tabular}{|c|c|c|c|c|c|c|c|}
\hline & 0412-211-MnO42A-0 & 0412-211-MnO42A-6 & 0412-211-MnO42A-12 & 0412-211-MnO42A-24 & 0412-211-MnO42A-48 & average & stddev \\
\hline Element & (ppm) & (ppm) & (ppm) & (ppm) & (ppm) & & \\
\hline Al3082 & 260.32 & 262.61 & 249.36 & 263.61 & 253.34 & 257.85 & 6.21 \\
\hline B_2497 & 16.67 & 16.86 & 16.40 & 17.66 & 16.84 & 16.89 & 0.47 \\
\hline Ca3179 & 221.88 & 229.29 & 215.13 & 227.28 & 220.25 & 222.77 & 5.67 \\
\hline Ce4186 & 9.26 & 9.44 & 9.41 & 9.14 & 9.23 & 9.29 & 0.13 \\
\hline \begin{tabular}{|l|} 
Cr3578 \\
\end{tabular} & 77.88 & 79.82 & 76.62 & 79.51 & 76.85 & 78.14 & 1.48 \\
\hline Cu3247 & 17.59 & 17.10 & 16.71 & 17.26 & 16.37 & 17.01 & 0.48 \\
\hline Fe2599 & 310.60 & 313.74 & 298.01 & 312.88 & 306.59 & 308.37 & 6.42 \\
\hline K_7664 & 1537.82 & 1582.72 & 1520.09 & 1597.60 & 1523.52 & 1552.35 & 35.54 \\
\hline La3949 & 6.90 & 6.88 & 6.63 & 7.18 & 6.77 & 6.87 & 0.20 \\
\hline Mg2790 & 2.45 & 3.57 & 2.29 & 3.87 & 2.56 & 2.94 & 0.72 \\
\hline Mn2576 & 187.93 & 190.91 & 181.10 & 190.96 & 185.16 & 187.21 & 4.18 \\
\hline Mo2020 & 25.98 & 26.59 & 25.33 & 26.56 & 25.95 & 26.08 & 0.52 \\
\hline Nd4061 & 22.51 & 21.65 & 22.39 & 21.56 & 21.14 & 21.85 & 0.58 \\
\hline Ni2316 & 361.79 & 370.66 & 354.64 & 374.37 & 360.65 & 364.42 & 7.98 \\
\hline P_1774 & 311.74 & 318.03 & 302.87 & 318.32 & 310.60 & 312.31 & 6.35 \\
\hline $\mathrm{Pb} 2203$ & 85.11 & 87.52 & 82.51 & 87.12 & 85.11 & 85.47 & 1.99 \\
\hline Si2516 & 4.80 & 5.17 & 5.63 & 6.86 & 7.22 & 5.94 & 1.06 \\
\hline Sr3464 & 137.19 & 140.31 & 133.36 & 140.60 & 136.62 & 137.62 & 2.98 \\
\hline Zn2062 & 24.58 & 25.22 & 23.91 & 25.47 & 25.24 & 24.89 & 0.64 \\
\hline Zr3391 & 19.65 & 20.03 & 19.19 & 20.23 & 19.35 & 19.69 & 0.44 \\
\hline
\end{tabular}

\begin{tabular}{|c|c|c|c|c|c|c|c|}
\hline & 0412-211-MnO42B-0 & 0412-211-MnO42B-6 & 0412-211-MnO42B-12 & 0412-211-MnO42B-24 & 0412-211-MnO42B-48 & average & stddev \\
\hline Element & $(\mathrm{ppm})$ & (ppm) & (ppm) & (ppm) & (ppm) & & \\
\hline Al3082 & 281.62 & 269.18 & 265.21 & 266.35 & 261.03 & 268.68 & 7.81 \\
\hline B_2497 & 18.82 & 18.09 & 17.62 & 17.91 & 17.35 & 17.96 & 0.56 \\
\hline Ca3179 & 240.41 & 229.46 & 225.94 & 227.31 & 226.05 & 229.84 & 6.08 \\
\hline Ce4186 & 21.55 & 20.72 & 20.09 & 20.14 & 20.48 & 20.60 & 0.59 \\
\hline Cr3578 & 88.89 & 83.51 & 79.39 & 81.51 & 83.28 & 83.32 & 3.53 \\
\hline Cu3247 & 19.70 & 18.35 & 18.47 & 19.08 & 18.26 & 18.77 & 0.61 \\
\hline Fe2599 & 548.26 & 525.38 & 527.10 & 522.24 & 516.23 & 527.84 & 12.14 \\
\hline K_7664 & 1739.45 & 1619.62 & 1592.73 & 1574.72 & 1597.60 & 1624.82 & 66.05 \\
\hline La3949 & 14.34 & 13.50 & 13.16 & 13.24 & 13.42 & 13.53 & 0.47 \\
\hline Mg2790 & 4.82 & 3.74 & 3.73 & 4.14 & 4.63 & 4.21 & 0.50 \\
\hline Mn2576 & 244.47 & 234.06 & 230.89 & 232.00 & 231.37 & 234.56 & 5.67 \\
\hline Mo2020 & 28.46 & 27.19 & 26.23 & 26.66 & 26.75 & 27.06 & 0.86 \\
\hline Nd4061 & 45.82 & 44.39 & 42.81 & 42.99 & 43.30 & 43.86 & 1.25 \\
\hline Ni2316 & 400.40 & 382.10 & 365.51 & 374.66 & 378.38 & 380.21 & 12.86 \\
\hline P_1774 & 341.48 & 330.90 & 323.18 & 323.75 & 324.90 & 328.84 & 7.71 \\
\hline Pb2203 & 109.57 & 105.68 & 102.65 & 103.02 & 104.28 & 105.04 & 2.80 \\
\hline Si2516 & 6.38 & 6.22 & 6.10 & 6.46 & 7.81 & 6.59 & 0.70 \\
\hline Sr3464 & 177.01 & 169.88 & 164.19 & 166.08 & 167.80 & 168.99 & 4.95 \\
\hline Zn2062 & 26.92 & 25.77 & 24.85 & 25.31 & 25.58 & 25.69 & 0.77 \\
\hline Zr3391 & 35.84 & 33.92 & 32.89 & 33.61 & 33.98 & 34.05 & 1.09 \\
\hline
\end{tabular}


WSRC-TR-2003-00232, Rev. 0
SRT-RPP-2003-00105, Rev. 0

Table C.16 ICP-AES Data for AN-107 Primary Effects Samples (Nitrogen Purge Samples)

\begin{tabular}{|c|c|c|c|c|c|c|c|}
\hline & $0516-213 \mathrm{~A}-0$ & 0516-213A-6 & $0516-213 A-12$ & 0516-213A-24 & 0516-213A-48 & AVG & SD \\
\hline & (ppm) & $(\mathrm{ppm})$ & $(\mathrm{ppm})$ & $(\mathrm{ppm})$ & $(\mathrm{ppm})$ & & \\
\hline Al3082 & 267.82 & 268.83 & 255.60 & 256.22 & 260.89 & 261.87 & 6.25 \\
\hline B_2497 & 16.82 & 18.00 & 16.52 & 16.55 & 17.32 & 17.04 & 0.62 \\
\hline Ca3179 & 190.30 & 190.33 & 188.55 & 183.49 & 186.33 & 187.80 & 2.91 \\
\hline Ce4186 & 2.42 & 2.50 & 2.71 & 2.36 & 2.62 & 2.52 & 0.15 \\
\hline Cr3578 & 83.50 & 84.21 & 78.82 & 77.58 & 76.87 & 80.20 & 3.42 \\
\hline Cu3247 & 15.92 & 15.71 & 14.74 & 14.88 & 14.96 & 15.24 & 0.54 \\
\hline Fe2599 & 74.80 & 74.89 & 70.74 & 72.67 & 76.28 & 73.88 & 2.17 \\
\hline K_7664 & 1631.26 & 1633.03 & 1546.90 & 1517.89 & 1535.35 & 1572.88 & 55.08 \\
\hline La3949 & 2.02 & 2.06 & 1.94 & 1.89 & 1.91 & 1.97 & 0.07 \\
\hline Mg2790 & 1.16 & 0.30 & 1.84 & 1.28 & 1.20 & 1.16 & 0.55 \\
\hline Mn2576 & 58.08 & 57.96 & 54.97 & 55.32 & 56.09 & 56.48 & 1.46 \\
\hline Mo2020 & 26.70 & 26.85 & 25.49 & 25.15 & 25.13 & 25.86 & 0.85 \\
\hline $\mathrm{Nd} 4061$ & 5.29 & 6.12 & 6.29 & 4.99 & 5.31 & 5.60 & 0.57 \\
\hline Ni2316 & 372.37 & 374.44 & 354.02 & 353.42 & 350.17 & 360.88 & 11.55 \\
\hline P_1774 & 323.53 & 324.12 & 308.14 & 305.18 & 308.73 & 313.94 & 9.13 \\
\hline $\mathrm{Pb} 2203$ & 56.77 & 56.92 & 54.46 & 53.93 & 54.17 & 55.25 & 1.47 \\
\hline Si2516 & 5.16 & 5.95 & 9.63 & 6.01 & 7.12 & 6.77 & 1.74 \\
\hline Sr3464 & 128.08 & 128.43 & 121.24 & 122.01 & 122.93 & 124.54 & 3.45 \\
\hline Zn2062 & 25.06 & 25.25 & 24.00 & 24.00 & 24.28 & 24.52 & 0.59 \\
\hline Zr3391 & 4.19 & 4.23 & 4.00 & 3.93 & 3.95 & 4.06 & 0.14 \\
\hline
\end{tabular}

\begin{tabular}{|c|c|c|c|c|c|c|c|}
\hline & 0516-213B-0 & 0325-211A-0MOH-6 & 0516-213B-12 & $0516-213 B-24$ & 0516-213B-48 & AVG & SD \\
\hline & (ppm) & (ppm) & (ppm) & (ppm) & (ppm) & & \\
\hline Al3082 & 260.01 & 259.95 & 294.16 & 274.90 & 255.74 & 268.95 & 15.86 \\
\hline B_2497 & 16.50 & 16.69 & 19.43 & 18.13 & 17.21 & 17.59 & 1.21 \\
\hline Ca3179 & 186.30 & 185.06 & 210.01 & 196.81 & 182.78 & 192.19 & 11.33 \\
\hline \begin{tabular}{|l|l} 
Ce4186 \\
\end{tabular} & 2.62 & 2.42 & 2.72 & 2.80 & 2.63 & 2.64 & 0.14 \\
\hline Cr3578 & 82.14 & 81.81 & 91.11 & 84.66 & 79.77 & 83.90 & 4.39 \\
\hline Cu3247 & 15.75 & 15.73 & 17.41 & 16.61 & 15.37 & 16.17 & 0.83 \\
\hline \begin{tabular}{|l}
$F e 2599$ \\
\end{tabular} & 70.86 & 71.48 & 81.43 & 74.65 & 70.89 & 73.86 & 4.51 \\
\hline K_7664 & 1641.91 & 1593.37 & 1796.72 & 1658.49 & 1561.10 & 1650.32 & 90.52 \\
\hline \begin{tabular}{|l|c|} 
La3949 \\
\end{tabular} & 1.87 & 1.87 & 2.19 & 1.89 & 1.86 & 1.94 & 0.14 \\
\hline \begin{tabular}{|l} 
Mg2790 \\
\end{tabular} & 0.84 & 1.18 & 0.66 & 0.78 & 0.96 & 0.88 & 0.20 \\
\hline Mn2576 & 55.65 & 55.35 & 62.54 & 58.40 & 54.61 & 57.31 & 3.26 \\
\hline Mo2020 & 26.10 & 26.06 & 29.15 & 27.19 & 25.59 & 26.82 & 1.43 \\
\hline \begin{tabular}{|l|l}
$\mathrm{Nd} 4061$ \\
\end{tabular} & 6.13 & 6.30 & 6.28 & 5.92 & 5.73 & 6.07 & 0.24 \\
\hline $\mathrm{Ni2316}$ & 366.15 & 364.97 & 406.41 & 380.66 & 358.46 & 375.33 & 19.17 \\
\hline P_1774 & 316.42 & 319.38 & 358.75 & 331.82 & 311.10 & 327.49 & 19.06 \\
\hline$\overline{\mathrm{Pb}} 2203$ & 55.14 & 55.38 & 62.25 & 57.93 & 54.43 & 57.03 & 3.20 \\
\hline Si2516 & 5.29 & 5.61 & 6.59 & 6.83 & 7.47 & 6.36 & 0.90 \\
\hline Sr3464 & 125.95 & 125.27 & 140.87 & 131.99 & 123.70 & 129.55 & 7.06 \\
\hline Zn2062 & 24.60 & 24.62 & 27.45 & 25.86 & 24.16 & 25.34 & 1.34 \\
\hline Zr3391 & 3.94 & 3.97 & 4.34 & 4.03 & 3.83 & 4.02 & 0.19 \\
\hline
\end{tabular}


WSRC-TR-2003-00232, Rev. 0

SRT-RPP-2003-00105, Rev. 0

Table C.17 ICP-AES Data for AN-107 Primary Effects Samples (Oxygen Purge Samples)

\begin{tabular}{|c|c|c|c|c|c|c|c|}
\hline & $0516-212 A-0$ & 0516-212A-6 & 0516-212A-12 & 0516-212A-24 & $0516-212 A-48$ & AVG & SD \\
\hline & (ppm) & (ppm) & (ppm) & (ppm) & (ppm) & & \\
\hline Al3082 & 309.32 & 276.38 & 264.03 & 247.72 & 260.92 & 271.67 & 23.38 \\
\hline B_2497 & 20.39 & 17.60 & 17.22 & 16.38 & 17.26 & 17.77 & 1.53 \\
\hline Ca3179 & 229.22 & 202.85 & 192.99 & 182.25 & 192.10 & 199.88 & 17.95 \\
\hline Ce4186 & 3.37 & 2.97 & 2.83 & 2.54 & 2.52 & 2.85 & 0.35 \\
\hline Cr3578 & 97.09 & 86.96 & 84.42 & 79.56 & 82.11 & 86.03 & 6.76 \\
\hline Cu3247 & 18.04 & 16.37 & 15.42 & 14.31 & 15.44 & 15.91 & 1.39 \\
\hline Fe2599 & 86.99 & 71.99 & 68.67 & 63.79 & 67.49 & 71.79 & 8.99 \\
\hline K_7664 & 1856.81 & 1676.25 & 1608.76 & 1501.90 & 1593.37 & 1647.42 & 132.54 \\
\hline La3949 & 2.39 & 2.12 & 2.00 & 1.87 & 1.89 & 2.05 & 0.21 \\
\hline Mg2790 & 0.93 & 0.69 & 1.23 & 1.89 & 1.58 & 1.27 & 0.48 \\
\hline Mn2576 & 66.07 & 46.44 & 43.33 & 39.81 & 40.26 & 47.18 & 10.89 \\
\hline Mo2020 & 30.81 & 27.68 & 26.68 & 24.98 & 26.18 & 27.27 & 2.21 \\
\hline Nd4061 & 5.64 & 5.97 & 5.20 & 5.51 & 5.97 & 5.66 & 0.33 \\
\hline Ni2316 & 430.09 & 386.87 & 371.78 & 349.87 & 366.45 & 381.01 & 30.45 \\
\hline P_1774 & 375.03 & 332.41 & 319.38 & 297.18 & 313.17 & 327.44 & 29.47 \\
\hline $\mathrm{Pb} 2203$ & 65.12 & 57.78 & 55.71 & 52.13 & 54.70 & 57.09 & 4.93 \\
\hline Si2516 & 6.95 & 5.67 & 5.28 & 6.22 & 6.78 & 6.18 & 0.71 \\
\hline Sr3464 & 144.45 & 129.17 & 124.14 & 116.71 & 121.95 & 127.29 & 10.59 \\
\hline Zn2062 & 28.42 & 25.13 & 24.38 & 24.62 & 23.99 & 25.31 & 1.79 \\
\hline Zr3391 & 4.79 & 4.31 & 4.14 & 3.91 & 4.07 & 4.24 & 0.34 \\
\hline
\end{tabular}

\begin{tabular}{|c|c|c|c|c|c|c|c|}
\hline & 0516-212B-0 & 0516-212B-6 & 0516-212B-12 & 0516-212B-24 & 0516-212B-48 & AVG & SD \\
\hline & (ppm) & (ppm) & (ppm) & (ppm) & (ppm) & & \\
\hline Al3082 & 264.06 & 256.63 & 277.88 & 250.03 & 257.43 & 261.21 & 10.56 \\
\hline B_2497 & 17.10 & 17.17 & 18.13 & 15.78 & 16.99 & 17.03 & 0.84 \\
\hline Ca3179 & 177.07 & 174.37 & 186.75 & 168.93 & 176.77 & 176.78 & 6.46 \\
\hline \begin{tabular}{|l|} 
Ce4186 \\
\end{tabular} & - & - & - & - & - & & \\
\hline Cr3578 & 81.02 & 79.59 & 85.48 & 78.65 & 82.08 & 81.36 & 2.65 \\
\hline Cu3247 & 15.98 & 15.21 & 16.81 & 15.26 & 15.73 & 15.80 & 0.65 \\
\hline Fe2599 & 69.50 & 65.48 & 69.68 & 64.97 & 64.74 & 66.87 & 2.50 \\
\hline K_7664 & 1556.07 & 1538.90 & 1674.18 & 1517.59 & 1569.98 & 1571.35 & 60.73 \\
\hline La3949 & 1.77 & 1.69 & 1.75 & 1.65 & 1.78 & 1.73 & 0.05 \\
\hline Mg2790 & 1.69 & 1.35 & 1.65 & 1.22 & 0.65 & 1.31 & 0.42 \\
\hline Mn2576 & 55.12 & 48.10 & 50.08 & 43.84 & 42.80 & 47.99 & 4.98 \\
\hline Mo2020 & 26.00 & 25.43 & 27.36 & 24.96 & 26.04 & 25.96 & 0.90 \\
\hline Nd4061 & 5.48 & 5.07 & 5.85 & 5.23 & 4.78 & 5.28 & 0.41 \\
\hline Ni2316 & 359.94 & 354.31 & 377.40 & 347.21 & 365.56 & 360.88 & 11.46 \\
\hline P_1774 & 321.46 & 313.17 & 338.33 & 302.22 & 314.35 & 317.90 & 13.33 \\
\hline $\mathrm{Pb} 2203$ & 55.47 & 54.17 & 57.87 & 52.01 & 54.64 & 54.83 & 2.13 \\
\hline Si2516 & 5.08 & 5.54 & 5.82 & 6.10 & 7.42 & 5.99 & 0.88 \\
\hline Sr3464 & 114.46 & 113.37 & 120.95 & 109.61 & 114.14 & 114.50 & 4.09 \\
\hline Zn2062 & 23.67 & 23.49 & 24.85 & 22.85 & 24.23 & 23.82 & 0.76 \\
\hline Zr3391 & 3.87 & 3.77 & 4.04 & 3.69 & 3.86 & 3.85 & 0.13 \\
\hline
\end{tabular}


WSRC-TR-2003-00232, Rev. 0
SRT-RPP-2003-00105, Rev. 0

Table C.18 ICP-AES Data for AN-107 Primary Effects Samples (Shear Samples)

\begin{tabular}{|c|c|c|c|c|c|c|c|}
\hline & 0607-211A-SHEAR-48 & 0607-211A-SHEAR-24 & 0607-211A-SHEAR-18 & 0607-211A-SHEAR-6 & 0607-211A-SHEAR-0 & AVG & SD \\
\hline & (ppm) & (ppm) & (ppm) & (ppm) & (ppm) & & \\
\hline \begin{tabular}{|l|l|}
$\mathrm{A} 3082$ \\
\end{tabular} & 276.96 & 279.47 & 279.10 & 280.94 & 279.01 & 279.10 & 1.42 \\
\hline B_2497 & 15.71 & 15.99 & 16.28 & 15.85 & 15.73 & 15.91 & 0.23 \\
\hline Ca3179 & 184.03 & 183.94 & 188.50 & 185.22 & 181.86 & 184.71 & 2.44 \\
\hline Ce4186 & 2.90 & 3.00 & 2.95 & 3.09 & 2.97 & 2.98 & 0.07 \\
\hline Cr3578 & 78.12 & 77.63 & 75.15 & 75.00 & 77.05 & 76.59 & 1.43 \\
\hline Cu3247 & 17.24 & 15.72 & 15.35 & 15.21 & 15.20 & 15.74 & 0.86 \\
\hline Fe2599 & 60.37 & 61.90 & 64.72 & 63.31 & 61.35 & 62.33 & 1.71 \\
\hline K_7664 & 1405.76 & 1402.70 & 1376.08 & 1384.96 & 1412.80 & 1396.46 & 15.33 \\
\hline La3949 & 2.05 & 2.10 & 2.04 & 2.07 & 2.05 & 2.06 & 0.02 \\
\hline Mg2790 & - & - & - & - & - & & \\
\hline Mn2576 & 50.77 & 51.04 & 51.53 & 51.10 & 50.67 & 51.02 & 0.34 \\
\hline Mo2020 & 26.14 & 25.84 & 25.47 & 25.66 & 25.98 & 25.82 & 0.26 \\
\hline $\mathrm{Nd} 4061$ & 6.94 & 6.56 & 6.16 & 6.58 & 6.42 & 6.53 & 0.28 \\
\hline Ni2316 & 360.77 & 355.27 & 350.06 & 349.15 & 354.65 & 353.98 & 4.66 \\
\hline P_1774 & 347.92 & 346.70 & 346.39 & 351.90 & 355.57 & 349.70 & 3.95 \\
\hline Pb2203 & 55.75 & 54.96 & 54.62 & 55.57 & 55.45 & 55.27 & 0.47 \\
\hline Si2516 & - & $\begin{array}{lll}- & & \end{array}$ & - & $\begin{array}{lll}- & \\
-\end{array}$ & - & & \\
\hline Sr3464 & 128.40 & 127.63 & 129.35 & 127.27 & 126.35 & 127.80 & 1.14 \\
\hline Zn2062 & 22.40 & 22.07 & 22.03 & 21.67 & 22.00 & 22.03 & 0.26 \\
\hline Zr3391 & 4.02 & 4.01 & 3.93 & 3.85 & 3.87 & 3.94 & 0.08 \\
\hline
\end{tabular}

\begin{tabular}{|c|c|c|c|c|c|c|c|}
\hline & 0607-211B-SHEAR-48 & 0607-211B-SHEAR-24 & 0607-211B-SHEAR-18 & 0607-211B-SHEAR-6 & 0607-211B-SHEAR-0 & AVG & SD \\
\hline & $(\mathrm{ppm})$ & (ppm) & $(\mathrm{ppm})$ & $(\mathrm{ppm})$ & (ppm) & & \\
\hline Al3082 & 243.31 & 268.82 & 274.18 & 269.52 & 255.63 & 262.29 & 12.66 \\
\hline B_2497 & 14.40 & 15.59 & 16.15 & 15.17 & 15.32 & 15.33 & 0.64 \\
\hline Ca3179 & 153.39 & 173.96 & 178.95 & 174.88 & 164.17 & 169.07 & 10.31 \\
\hline Ce4186 & 2.57 & 2.71 & 3.06 & 2.72 & 2.63 & 2.74 & 0.19 \\
\hline \begin{tabular}{|l|} 
Cr3578 \\
\end{tabular} & 71.16 & 77.39 & 73.07 & 75.03 & 71.94 & 73.72 & 2.52 \\
\hline Cu3247 & 15.56 & 17.19 & 16.34 & 16.32 & 15.82 & 16.25 & 0.63 \\
\hline Fe2599 & 48.99 & 55.11 & 58.51 & 56.21 & 51.71 & 54.11 & 3.76 \\
\hline K_7664 & 1268.62 & 1380.37 & 1359.25 & 1362.92 & 1291.93 & 1332.62 & 49.14 \\
\hline \begin{tabular}{|l|} 
La3949 \\
\end{tabular} & 1.76 & 1.88 & 1.94 & 1.85 & 1.79 & 1.84 & 0.07 \\
\hline Mg2790 & - & $\begin{array}{l}- \\
-\end{array}$ & 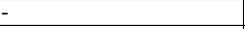 & - & - & & \\
\hline Mn2576 & 44.42 & 49.33 & 50.18 & 49.36 & 46.57 & 47.97 & 2.41 \\
\hline Mo2020 & 23.22 & 25.43 & 25.08 & 25.02 & 24.14 & 24.58 & 0.89 \\
\hline $\mathrm{Nd} 4061$ & 5.63 & 6.49 & 6.42 & \begin{tabular}{|l|l|}
6.11 \\
\end{tabular} & 5.95 & 6.12 & 0.35 \\
\hline Ni2316 & 322.77 & 356.49 & 345.78 & 348.23 & 333.85 & 341.42 & 13.21 \\
\hline P_1774 & 314.00 & 346.09 & 347.62 & 343.33 & 324.97 & 335.20 & 14.94 \\
\hline $\mathrm{Pb} 2203$ & 47.62 & 52.14 & 53.55 & 52.72 & 49.94 & 51.20 & 2.40 \\
\hline Si2516 & - & - & - & - & - & & \\
\hline Sr3464 & 100.56 & 112.76 & 114.93 & 112.61 & 106.70 & 109.51 & 5.87 \\
\hline Zn2062 & 19.55 & 21.89 & 21.51 & 21.38 & 20.55 & 20.98 & 0.93 \\
\hline Zr3391 & 3.37 & 3.74 & 3.67 & 3.72 & 3.52 & 3.60 & 0.16 \\
\hline
\end{tabular}


WSRC-TR-2003-00232, Rev. 0

SRT-RPP-2003-00105, Rev. 0

APPENDIX D

AN-107 Final Filter Photographs

Page 153 of 220 
WSRC-TR-2003-00232, Rev. 0

SRT-RPP-2003-00105, Rev. 0

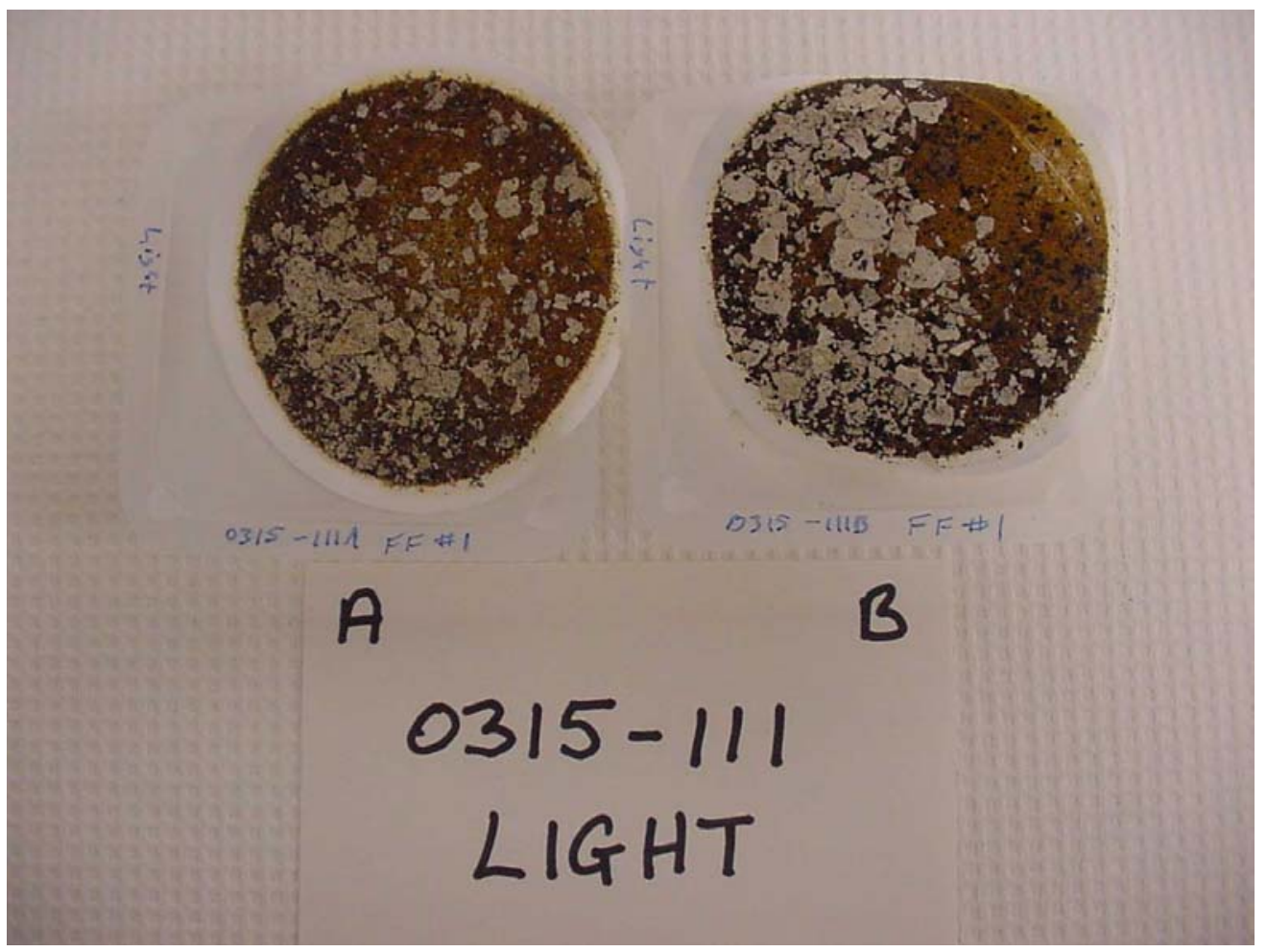

Figure D.1

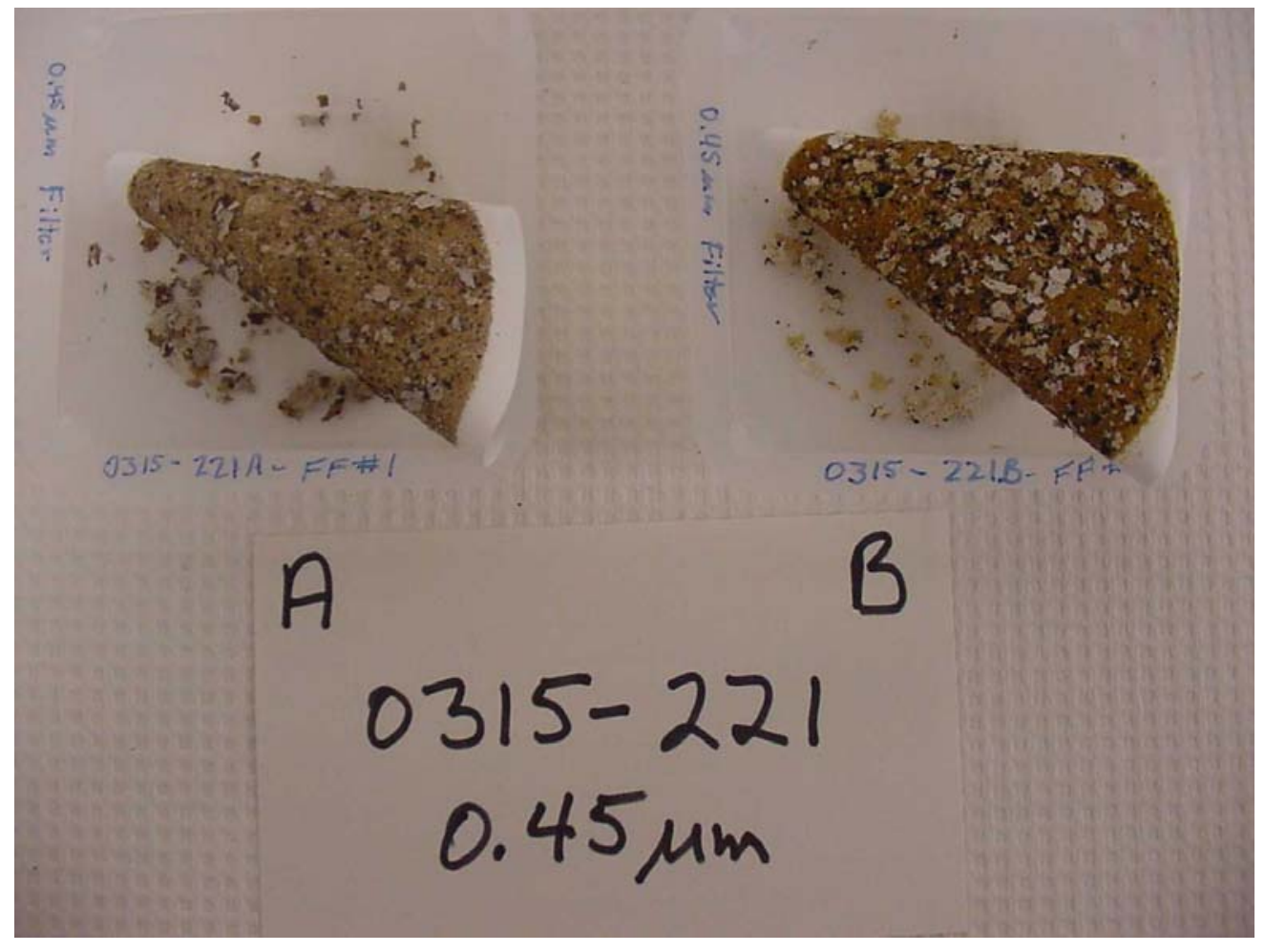

Figure D.2 
WSRC-TR-2003-00232, Rev. 0

SRT-RPP-2003-00105, Rev. 0

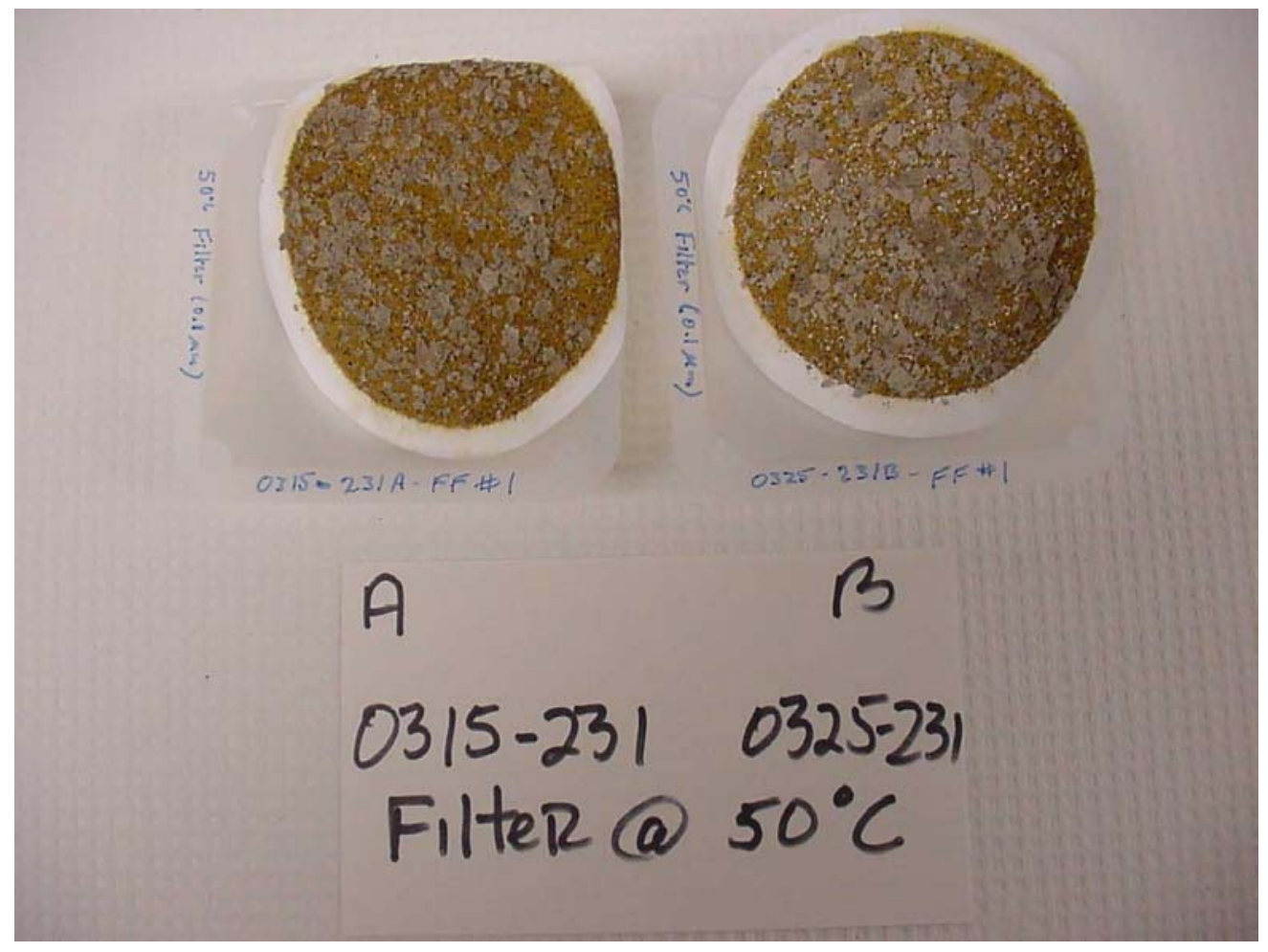

Figure D.3

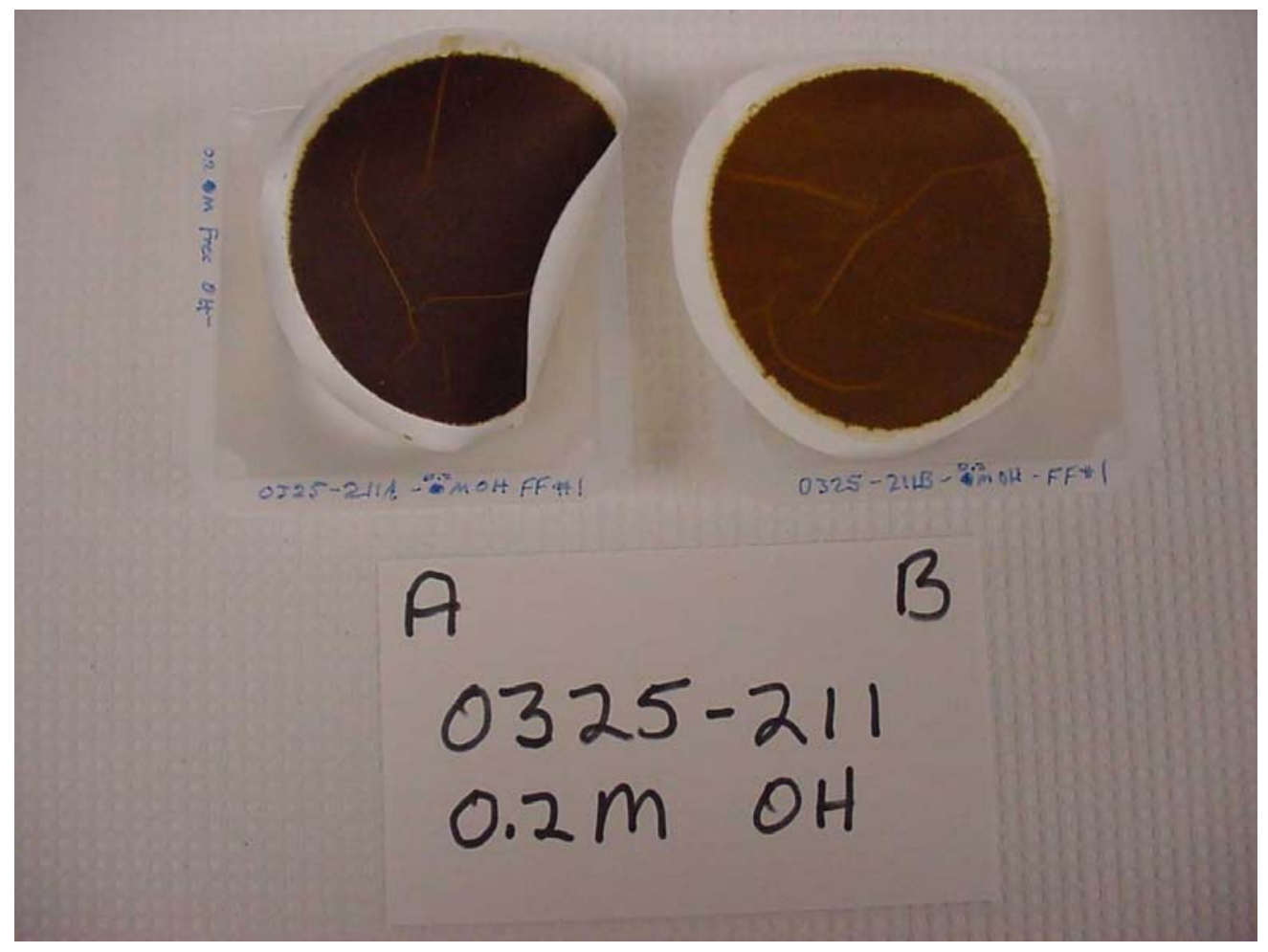

Figure D.4 
WSRC-TR-2003-00232, Rev. 0

SRT-RPP-2003-00105, Rev. 0

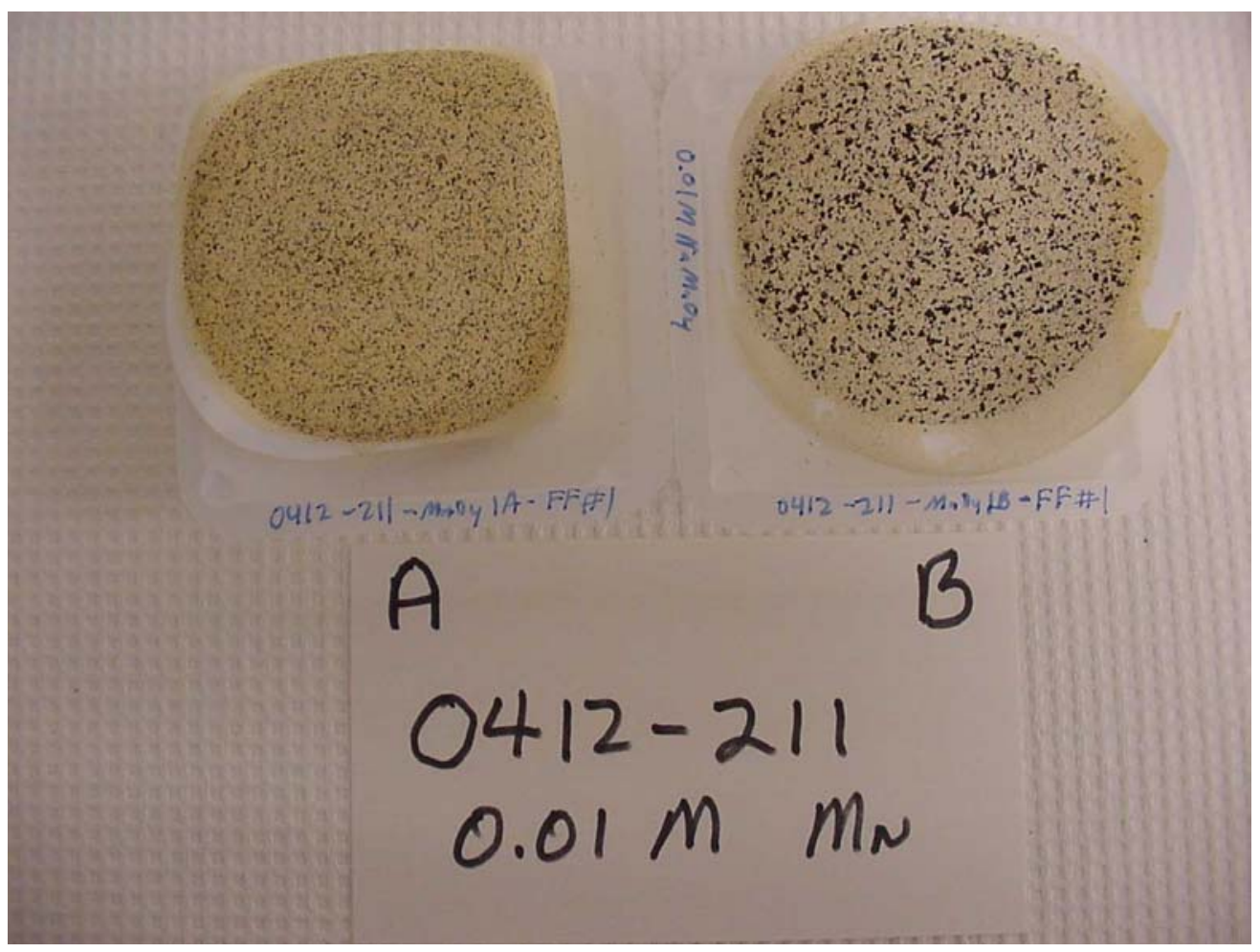

Figure D.5

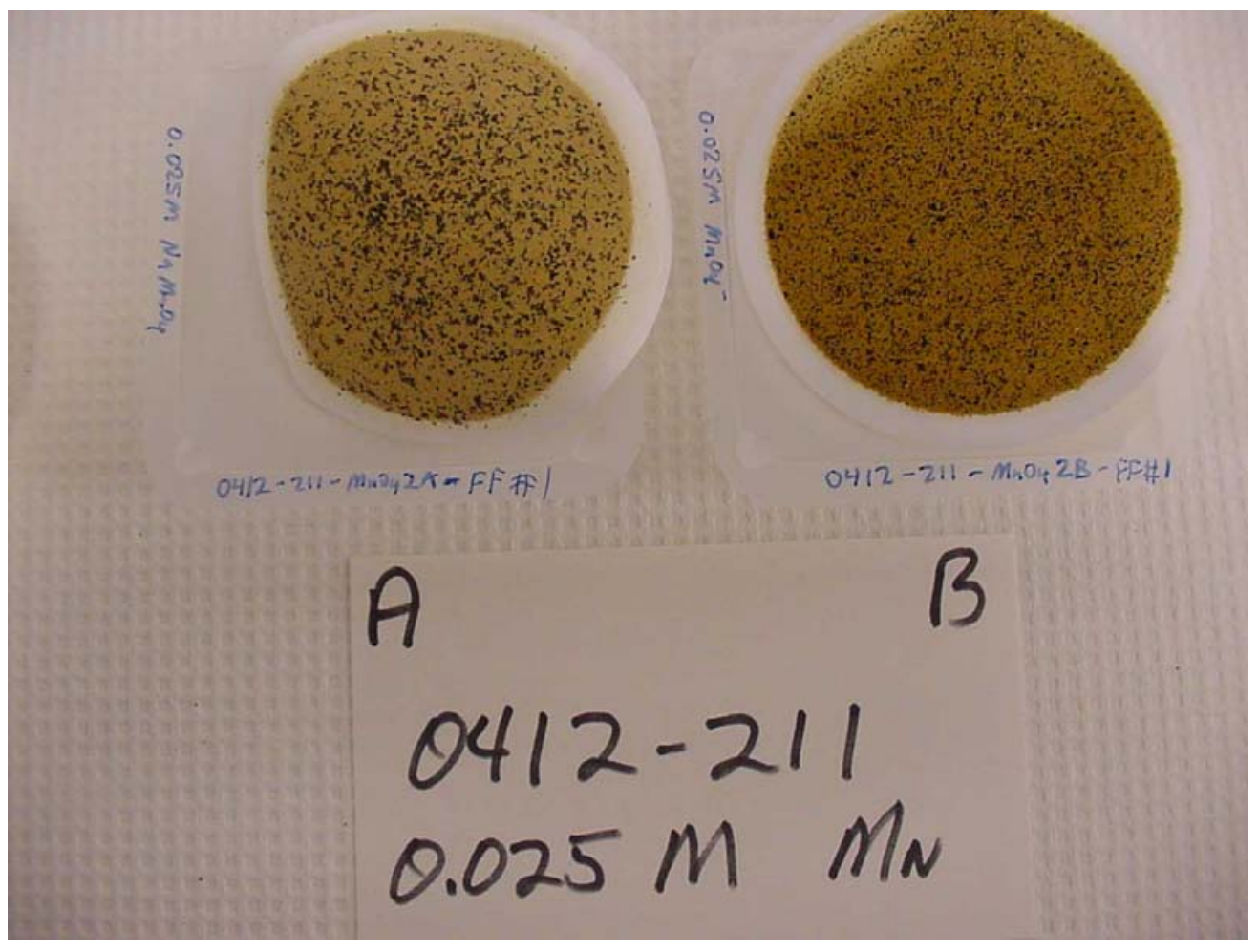

Figure D.6

Page 156 of 220 
WSRC-TR-2003-00232, Rev. 0

SRT-RPP-2003-00105, Rev. 0

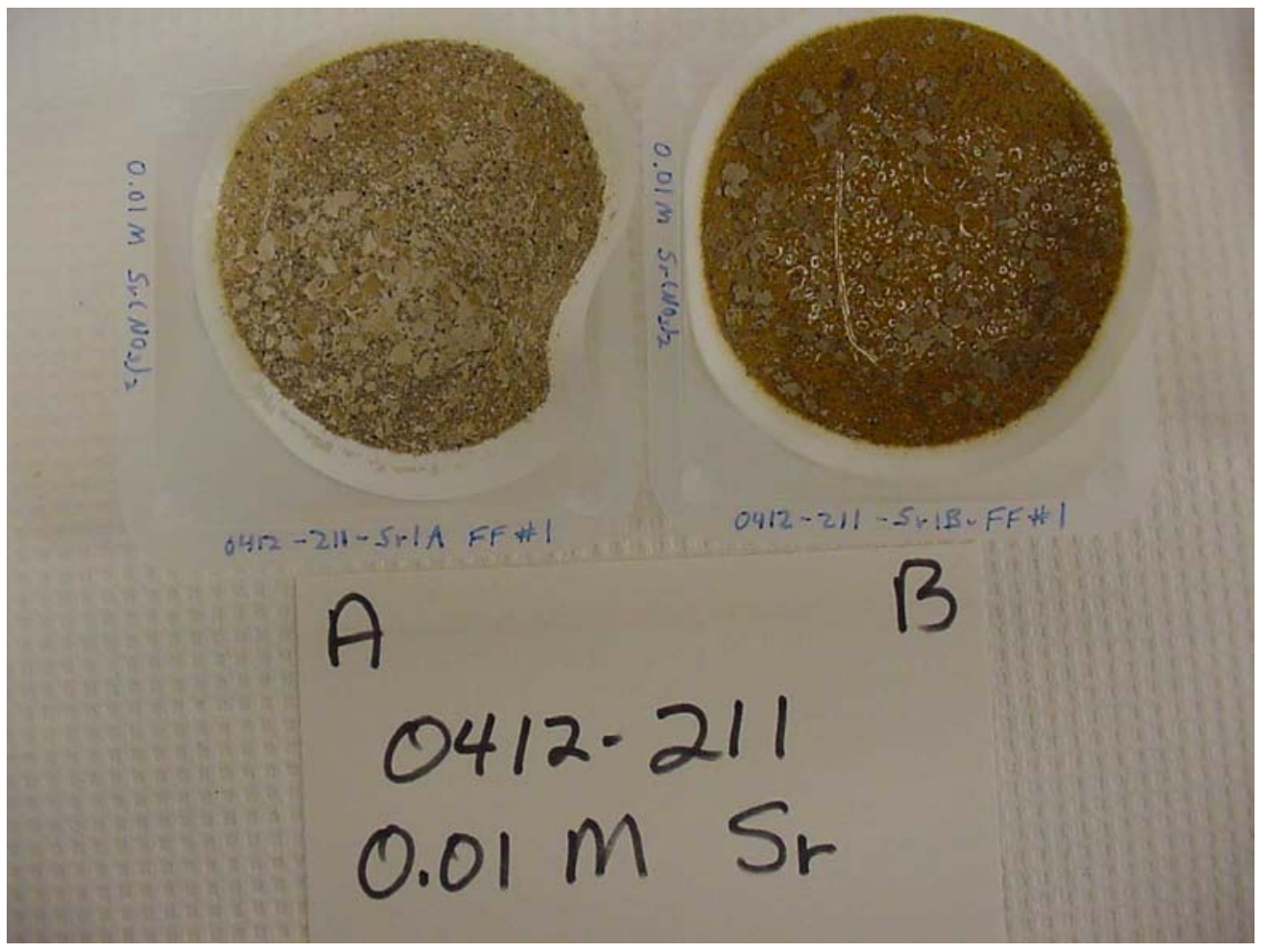

Figure D.7

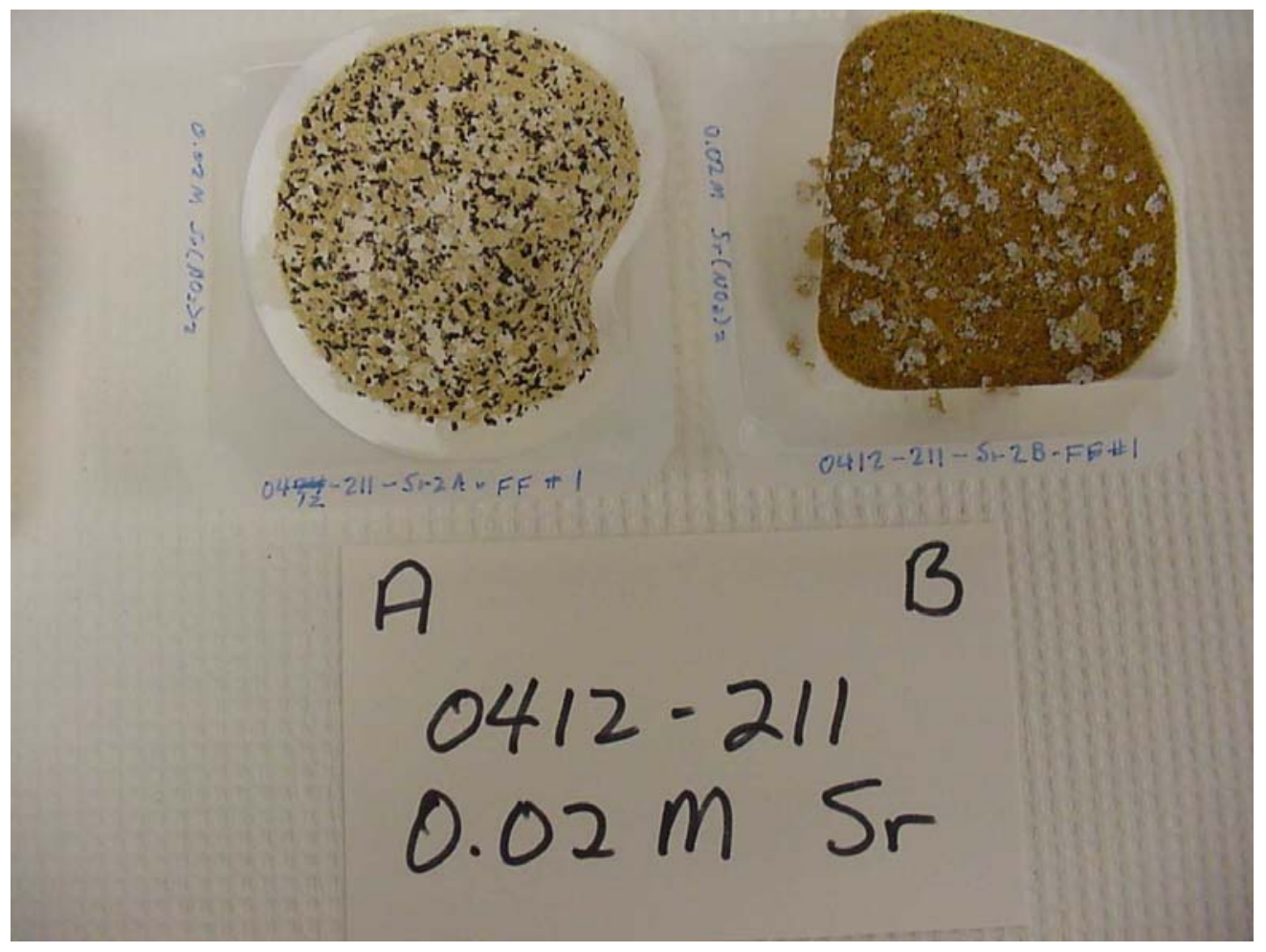

Figure D.8 
WSRC-TR-2003-00232, Rev. 0 SRT-RPP-2003-00105, Rev. 0

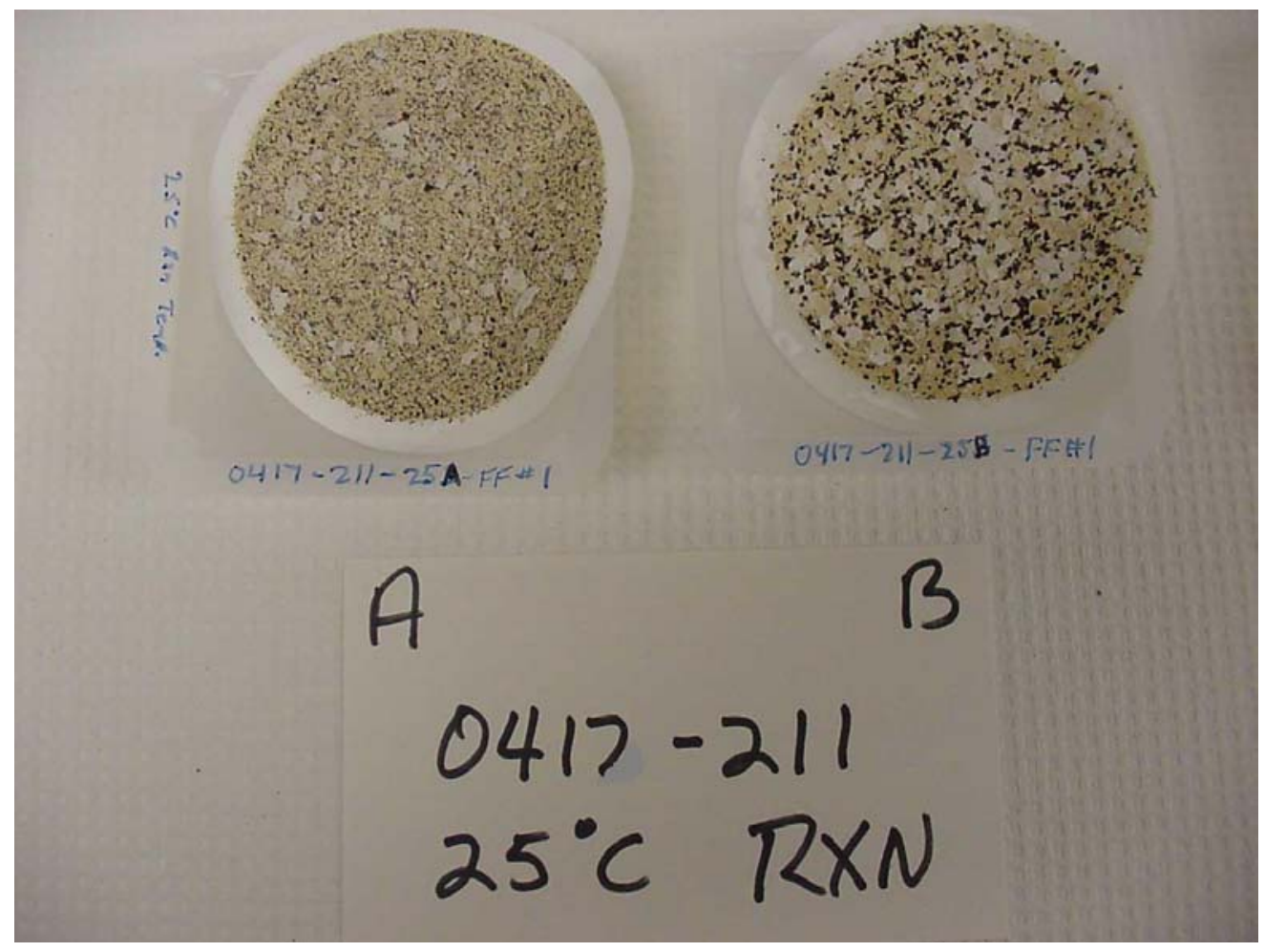

Figure D.9

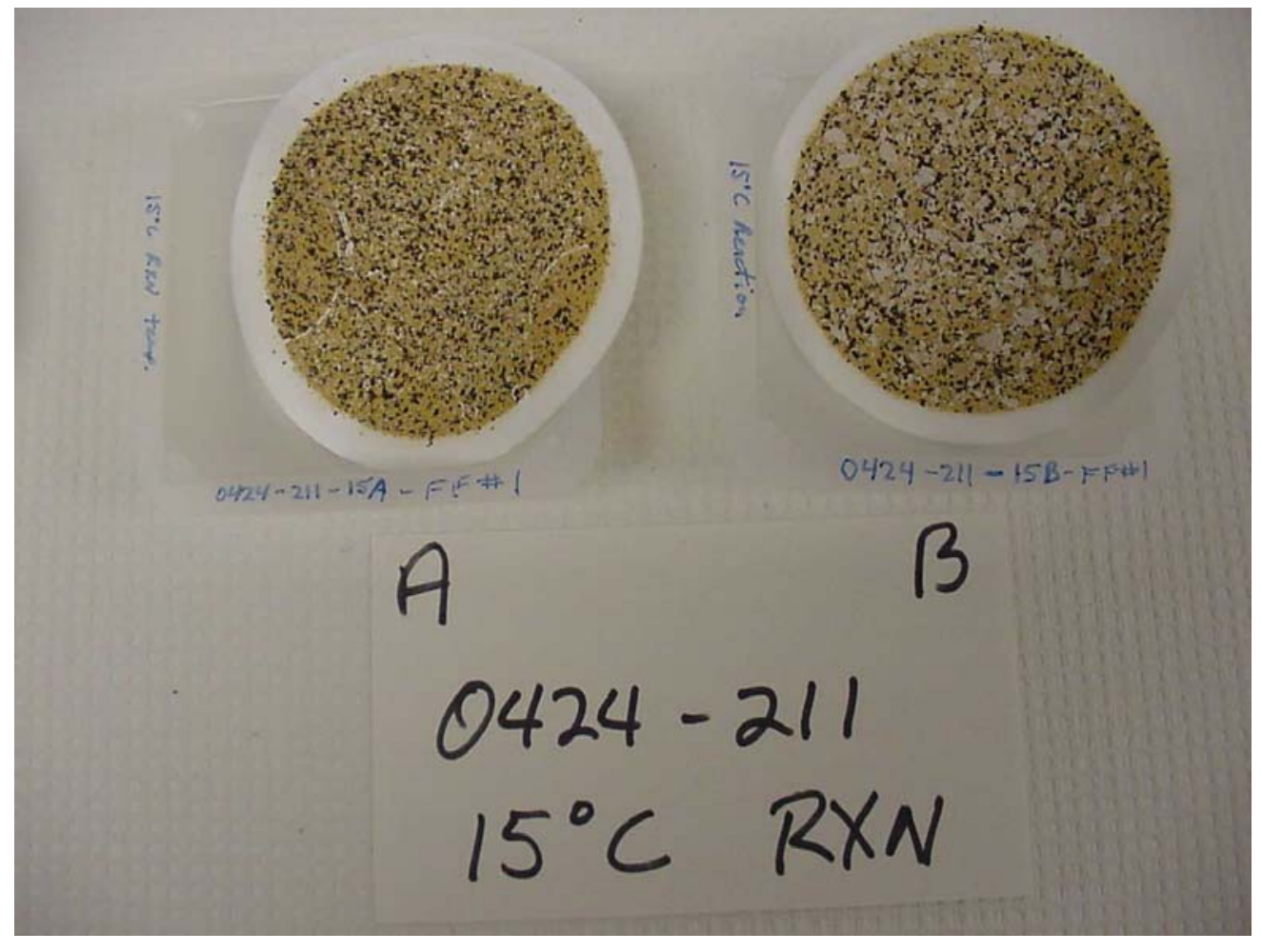

Figure D.10 
WSRC-TR-2003-00232, Rev. 0

SRT-RPP-2003-00105, Rev. 0

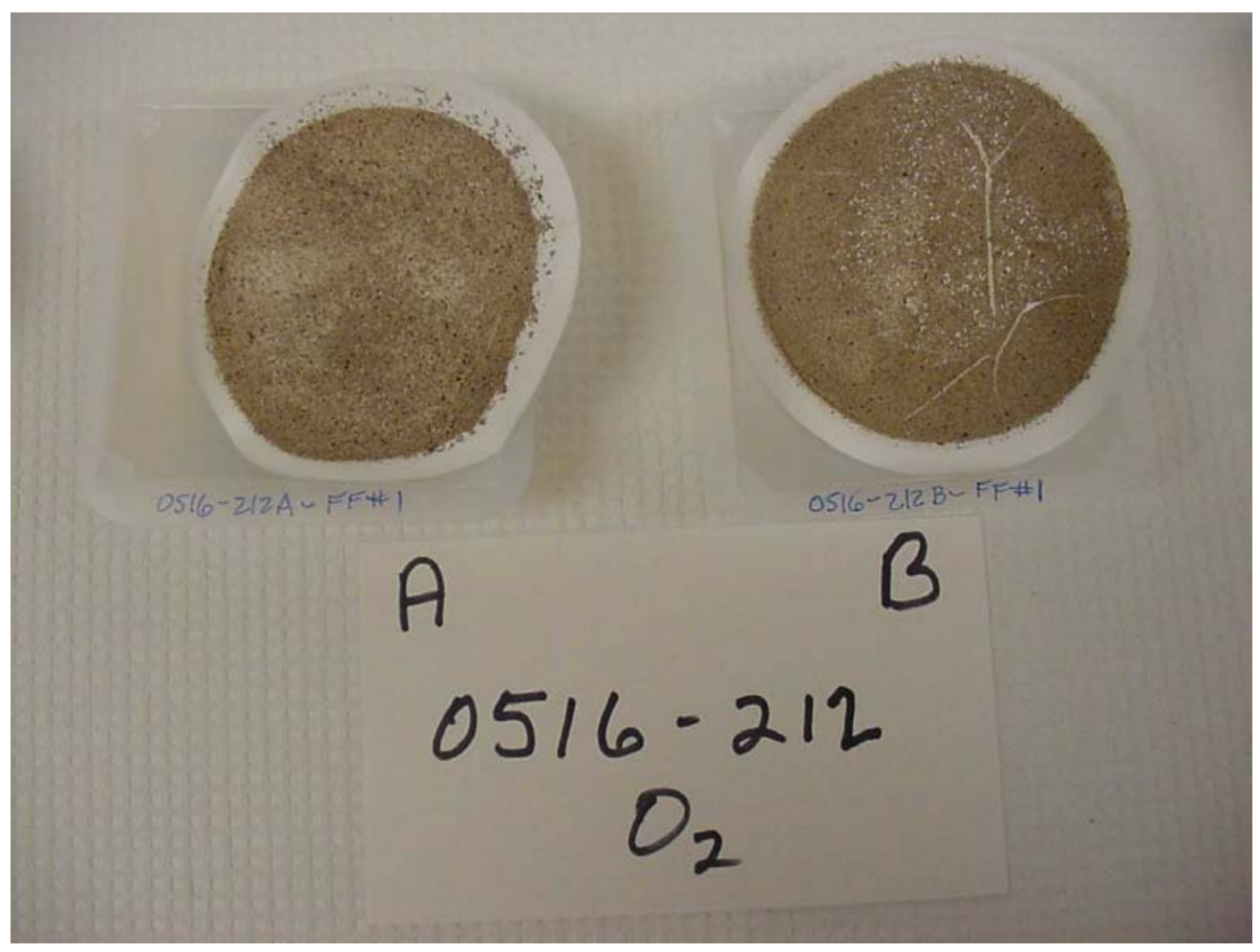

Figure D.11

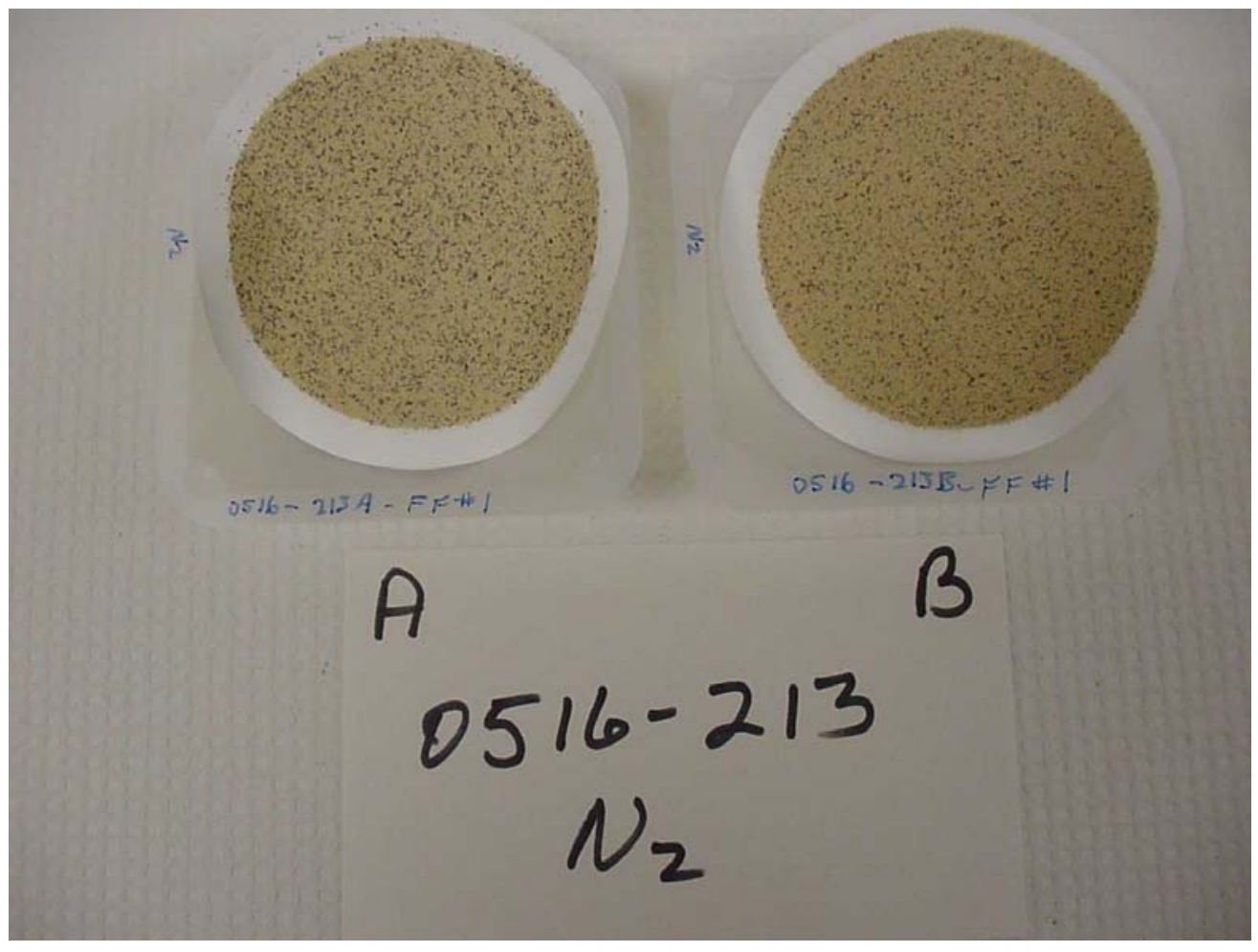

Figure D.12

Page 159 of 220 
WSRC-TR-2003-00232, Rev. 0

SRT-RPP-2003-00105, Rev. 0

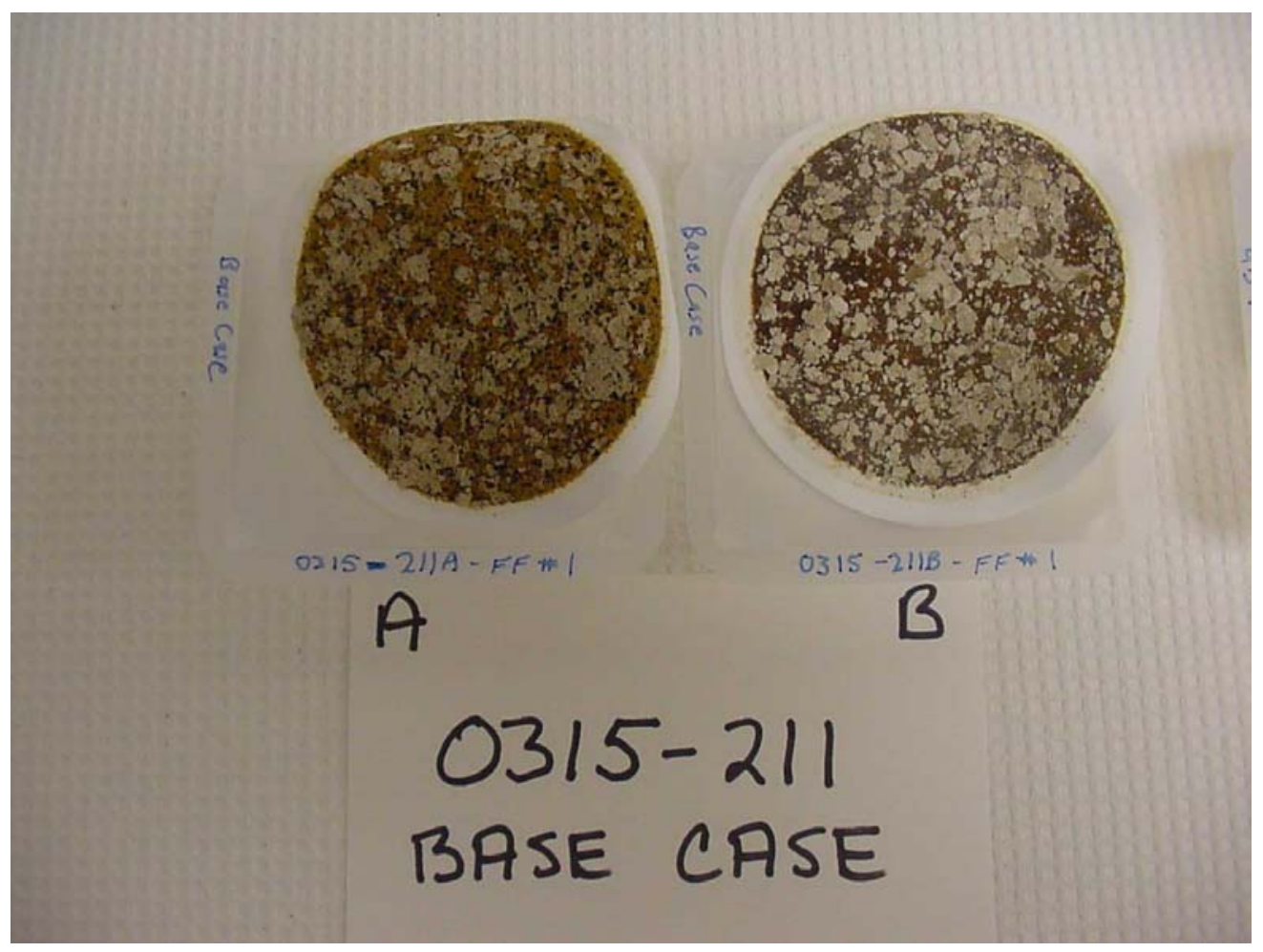

Figure D.13

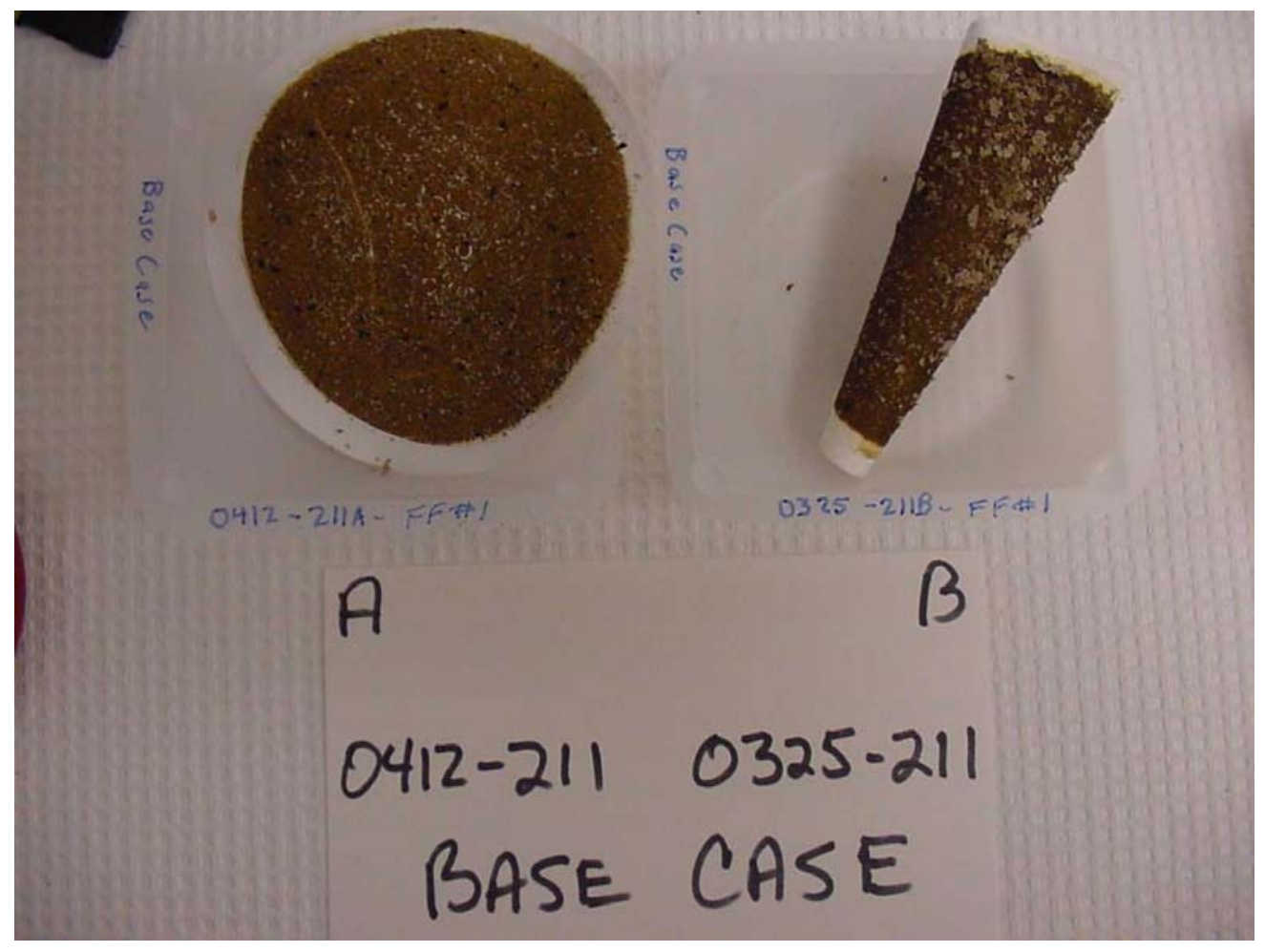

Figure D.14 
WSRC-TR-2003-00232, Rev. 0

SRT-RPP-2003-00105, Rev. 0

APPENDIX E

ICP-AES Analysis of AN-107 Secondary Effects Samples

Page 161 of 220 
WSRC-TR-2003-00232, Rev. 0

SRT-RPP-2003-00105, Rev. 0

Table E.1 ICP-AES Data for AN-107 Secondary Effects Samples (0.03 M $\mathrm{NaMnO}_{4} / \mathrm{Dark} / \mathrm{N}_{2}$ )

\begin{tabular}{|c|c|c|c|c|c|c|}
\hline & 0701-SIM7-DkN2-384 & 0701-SIM7-DkN2-192 & 0701-SIM7-DkN2-120 & 0701-SIM7-DkN2-0 & AVG & SD \\
\hline & (ppm) & (ppm) & (ppm) & (ppm) & & \\
\hline Al3082 & 263.42 & 266.64 & 261.28 & 267.96 & 264.83 & 3.04 \\
\hline B_2497 & 17.84 & 17.46 & 16.73 & 16.85 & 17.22 & 0.52 \\
\hline Ca3179 & 307.03 & 307.30 & 300.70 & 308.35 & 305.84 & 3.48 \\
\hline Ce4186 & 8.21 & 8.57 & 8.39 & 8.35 & 8.38 & 0.15 \\
\hline Cr3578 & 83.71 & 87.30 & 85.03 & 85.98 & 85.51 & 1.52 \\
\hline Cu3247 & 18.50 & 18.91 & 18.64 & 19.04 & 18.77 & 0.25 \\
\hline Fe2599 & 294.36 & 297.00 & 290.40 & 295.42 & 294.29 & 2.81 \\
\hline K_7664 & 1339.01 & 1386.79 & 1354.06 & 1368.58 & 1362.11 & 20.41 \\
\hline La3949 & 6.52 & 6.77 & 6.56 & 6.70 & 6.64 & 0.12 \\
\hline Mg2790 & - & - & - & - & & \\
\hline Mn2576 & 73.58 & 74.37 & 73.02 & 74.16 & 73.78 & 0.61 \\
\hline Mo2020 & 27.14 & 27.22 & 26.45 & 26.64 & 26.86 & 0.37 \\
\hline Nd4061 & 18.23 & 18.77 & 18.60 & 18.69 & 18.57 & 0.24 \\
\hline $\mathrm{Ni2316}$ & 371.98 & 381.74 & 373.03 & 375.67 & 375.61 & 4.38 \\
\hline P_1774 & 314.69 & 315.48 & 308.88 & 313.37 & 313.10 & 2.95 \\
\hline$\overline{\mathrm{Pb}} 2203$ & 110.83 & 112.62 & 109.06 & 110.46 & 110.74 & 1.47 \\
\hline Si2516 & - & - & - & - & & \\
\hline Sr3464 & 104.20 & 110.56 & 109.56 & 112.99 & 109.33 & 3.71 \\
\hline Zn2062 & 21.68 & 22.35 & 21.38 & 21.72 & 21.78 & 0.41 \\
\hline Zr3391 & 21.17 & 21.67 & 21.48 & 21.64 & 21.49 & 0.23 \\
\hline & 0701-SIM8-DkN2-384 & 0701-SIM8-DkN2-192 & 0701-SIM8-DkN2-120 & 0701-SIM8-DkN2-0 & AVG & SD \\
\hline & (ppm) & (ppm) & (ppm) & (ppm) & & \\
\hline Al3082 & 264.53 & 264.26 & 270.86 & 267.43 & 266.77 & 3.08 \\
\hline B_2497 & 16.92 & 16.93 & 17.01 & 16.56 & 16.85 & 0.20 \\
\hline Ca3179 & 290.40 & 294.89 & 301.75 & 292.51 & 294.89 & 4.93 \\
\hline Ce4186 & 8.19 & 8.37 & 8.42 & 8.33 & 8.33 & 0.10 \\
\hline Cr3578 & 87.04 & 86.91 & 85.64 & 85.91 & 86.37 & 0.70 \\
\hline Cu3247 & 19.07 & 19.37 & 19.86 & 19.24 & 19.38 & 0.34 \\
\hline Fe2599 & 293.30 & 293.57 & 305.45 & 298.06 & 297.59 & 5.67 \\
\hline K_7664 & 1377.82 & 1387.85 & 1376.23 & 1384.94 & 1381.71 & 5.58 \\
\hline La3949 & 6.43 & 6.63 & 6.62 & 6.65 & 6.58 & 0.10 \\
\hline Mg2790 & - & - & - & - & & \\
\hline Mn2576 & 81.31 & 81.55 & 83.32 & 81.58 & 81.94 & 0.93 \\
\hline Mo2020 & 26.72 & 26.74 & 26.77 & 26.58 & 26.70 & 0.08 \\
\hline \begin{tabular}{|l|}
$\mathrm{Nd} 4061$ \\
\end{tabular} & 18.62 & 18.56 & 18.37 & 18.89 & 18.61 & 0.21 \\
\hline \begin{tabular}{|l|}
$\mathrm{Ni} 2316$ \\
\end{tabular} & 377.78 & 381.48 & 380.95 & 375.41 & 378.91 & 2.85 \\
\hline P_1774 & 314.42 & 314.16 & 321.29 & 321.29 & 317.79 & 4.04 \\
\hline Pb2203 & 114.55 & 114.81 & 115.68 & 115.21 & 115.06 & 0.49 \\
\hline Si2516 & - & - & - & - & & \\
\hline Sr3464 & 99.95 & 116.32 & 125.72 & 132.11 & 118.52 & 13.98 \\
\hline Zn2062 & 22.26 & 22.50 & 22.82 & 22.18 & 22.44 & 0.29 \\
\hline Zr3391 & 22.27 & 22.47 & 22.50 & 22.13 & 22.34 & 0.17 \\
\hline
\end{tabular}


WSRC-TR-2003-00232, Rev. 0

SRT-RPP-2003-00105, Rev. 0

Table E.2 ICP-AES Data for AN-107 Secondary Effects Samples (0.01 M $\mathrm{NaMnO}_{4} /$ Dark/ $\mathrm{N}_{2}$ )

\begin{tabular}{|c|c|c|c|c|c|c|}
\hline & 0724-SIM7-DkN2-384 & 0724-SIM7-Dk2-192 & 0725-SIM8-LtAtm-120 & 0724-SIM7-Dk2N2-0 & AVG & SD \\
\hline & (ppm) & (ppm) & (ppm) & (ppm) & & \\
\hline Al3082 & 278.12 & 266.51 & 260.84 & 265.74 & 267.80 & 7.32 \\
\hline B_2497 & 16.06 & 15.30 & 15.15 & 15.47 & 15.50 & 0.40 \\
\hline Ca3179 & 306.50 & 295.67 & 274.51 & 288.96 & 291.41 & 13.39 \\
\hline Ce4186 & 27.92 & 25.70 & 26.29 & 26.86 & 26.69 & 0.94 \\
\hline Cr3578 & 85.37 & 79.08 & 83.46 & 85.09 & 83.25 & 2.91 \\
\hline Cu3247 & 20.80 & 19.51 & 20.28 & 20.58 & 20.29 & 0.57 \\
\hline Fe2599 & 869.72 & 841.34 & 799.54 & 818.12 & 832.18 & 30.31 \\
\hline K_7664 & 1370.50 & 1259.56 & 1283.03 & 1308.83 & 1305.48 & 47.79 \\
\hline La3949 & 13.33 & 12.52 & 12.57 & 13.63 & 13.01 & 0.55 \\
\hline $\operatorname{Mg} 2790$ & - & - & - & - & & \\
\hline Mn2576 & 425.18 & 407.12 & 388.03 & 399.38 & 404.93 & 15.61 \\
\hline Mo2020 & 26.34 & 24.55 & 24.93 & 25.31 & 25.28 & 0.77 \\
\hline Nd4061 & 43.11 & 39.84 & 41.05 & 41.43 & 41.36 & 1.35 \\
\hline $\mathrm{Ni2316}$ & 358.62 & 340.56 & 343.66 & 352.17 & 348.75 & 8.21 \\
\hline P_1774 & 343.40 & 325.08 & 335.40 & 336.69 & 335.14 & 7.57 \\
\hline Pb2203 & 198.84 & 189.22 & 184.21 & 185.89 & 189.54 & 6.54 \\
\hline Si2516 & - & - & - & - & & \\
\hline Sr3464 & 128.05 & 152.53 & 157.38 & 221.62 & 164.89 & 39.94 \\
\hline Zn2062 & 26.11 & 25.27 & 24.83 & 25.05 & 25.32 & 0.56 \\
\hline Zr3391 & 39.14 & 25.62 & 37.13 & 37.93 & 34.95 & 6.27 \\
\hline & 0724-SIM8-DkN2-384 & 0724-SIM8-Dk2N2-192 & 0724-SIM8-Dk2N2-120 & 0724-SIM8-Dk2N2-0 & AVG & SD \\
\hline & (ppm) & (ppm) & (ppm) & (ppm) & & \\
\hline Al3082 & 276.06 & 277.61 & 278.90 & 293.35 & 281.48 & 8.00 \\
\hline B_2497 & 16.54 & 16.39 & 16.85 & 16.86 & 16.66 & 0.23 \\
\hline Ca3179 & 307.02 & 284.06 & 294.38 & 300.05 & 296.38 & 9.70 \\
\hline Ce4186 & 28.23 & 27.74 & 27.12 & 29.33 & 28.10 & 0.94 \\
\hline Cr3578 & 89.27 & 91.18 & 82.90 & 89.68 & 88.26 & 3.67 \\
\hline Cu3247 & 21.58 & 22.03 & 20.97 & 22.26 & 21.71 & 0.57 \\
\hline Fe2599 & 867.40 & 832.57 & 869.72 & 891.91 & 865.40 & 24.52 \\
\hline K_7664 & 1379.53 & 1375.40 & 1324.06 & 1413.32 & 1373.08 & 36.83 \\
\hline La3949 & 13.56 & 13.73 & 13.10 & 14.57 & 13.74 & 0.61 \\
\hline Mg2790 & - & - & - & - & & \\
\hline Mn2576 & 441.44 & 421.06 & 423.89 & 433.96 & 430.09 & 9.38 \\
\hline Mo2020 & 26.70 & 26.52 & 25.19 & 26.99 & 26.35 & 0.80 \\
\hline \begin{tabular}{|l|}
$\mathrm{Nd} 4061$ \\
\end{tabular} & 43.42 & 43.76 & 42.83 & 45.64 & 43.91 & 1.21 \\
\hline \begin{tabular}{|l|}
$\mathrm{Ni} 2316$ \\
\end{tabular} & 379.00 & 372.04 & 351.91 & 372.04 & 368.75 & 11.69 \\
\hline P_1774 & 332.05 & 348.30 & 343.91 & 370.49 & 348.69 & 16.07 \\
\hline Pb2203 & 201.34 & 194.17 & 192.44 & 202.25 & 197.55 & 4.96 \\
\hline Si2516 & - & - & - & - & & \\
\hline Sr3464 & 126.32 & 151.11 & 168.24 & 245.49 & 172.79 & 51.43 \\
\hline Zn2062 & 27.81 & 26.39 & 25.74 & 26.63 & 26.64 & 0.86 \\
\hline Zr3391 & 41.05 & 38.06 & 32.25 & 40.48 & 37.96 & 4.02 \\
\hline
\end{tabular}


WSRC-TR-2003-00232, Rev. 0

SRT-RPP-2003-00105, Rev. 0

Table E.3 ICP-AES Data for AN-107 Secondary Effects Samples (0.03 M $\mathrm{NaMnO}_{4} /$ Light $/ \mathrm{N}_{2}$ )

\begin{tabular}{|c|c|c|c|c|c|c|}
\hline & 0701-SIM7-LtN2-384 & 0701-SIM7-LtN2-192 & 0701-SIM7-LtN2-120 & 0701-SIM7-LtN2-0 & AVG & SD \\
\hline & (ppm) & (ppm) & (ppm) & (ppm) & & \\
\hline Al3082 & 265.85 & 269.02 & 267.70 & 261.28 & 265.96 & 3.38 \\
\hline B_2497 & 16.06 & 16.87 & 16.80 & 15.78 & 16.38 & 0.54 \\
\hline Ca3179 & 298.06 & 305.71 & 303.60 & 294.62 & 300.50 & 5.08 \\
\hline Ce4186 & 7.86 & 7.86 & 7.96 & 8.01 & 7.92 & 0.08 \\
\hline Cr3578 & 85.43 & 85.83 & 84.16 & 85.09 & 85.13 & 0.71 \\
\hline Cu3247 & 19.06 & 19.40 & 19.10 & 18.80 & 19.09 & 0.24 \\
\hline Fe2599 & 280.90 & 291.72 & 290.14 & 281.69 & 286.11 & 5.61 \\
\hline K_7664 & 1425.07 & 1442.50 & 1435.10 & 1344.55 & 1411.81 & 45.40 \\
\hline La3949 & 5.65 & 5.90 & 5.90 & 5.99 & 5.86 & 0.15 \\
\hline Mg2790 & - & - & - & - & & \\
\hline Mn2576 & 64.84 & 73.95 & 73.89 & 72.12 & 71.20 & 4.33 \\
\hline Mo2020 & 26.72 & 26.90 & 26.53 & 26.34 & 26.62 & 0.24 \\
\hline Nd4061 & 17.18 & 17.21 & 17.38 & 17.33 & 17.27 & 0.09 \\
\hline $\mathrm{Ni2316}$ & 378.31 & 379.90 & 373.82 & 375.41 & 376.86 & 2.75 \\
\hline P_1774 & 315.48 & 321.02 & 317.33 & 311.26 & 316.27 & 4.06 \\
\hline$\overline{\mathrm{Pb}} 2203$ & 110.80 & 113.23 & 112.75 & 110.25 & 111.76 & 1.46 \\
\hline Si2516 & - & - & - & - & & \\
\hline Sr3464 & 93.17 & 112.09 & 118.59 & 128.57 & 113.10 & 14.92 \\
\hline Zn2062 & 21.91 & 22.27 & 21.78 & 21.55 & 21.88 & 0.30 \\
\hline Zr3391 & 21.09 & 21.39 & 21.05 & 20.92 & 21.11 & 0.20 \\
\hline & 0702-SIM7-DkAtm-384 & 0702-SIM7-DkAtm-192 & 0702-SIM7-DkAtm-120 & 0702-SIM7-DkAtm-0 & AVG & SD \\
\hline & (ppm) & (ppm) & (ppm) & (ppm) & & \\
\hline Al3082 & 272.71 & 273.24 & 268.75 & 285.65 & 275.09 & 7.32 \\
\hline B_2497 & 16.82 & 16.54 & 16.79 & 16.96 & 16.78 & 0.18 \\
\hline Ca3179 & 325.51 & 316.01 & 312.84 & 324.46 & 319.70 & 6.25 \\
\hline Ce4186 & 8.69 & 8.62 & 8.35 & 8.97 & 8.66 & 0.26 \\
\hline Cr3578 & 88.04 & 87.83 & 90.18 & 92.51 & 89.64 & 2.18 \\
\hline Cu3247 & 20.03 & 19.72 & 19.81 & 20.73 & 20.07 & 0.46 \\
\hline Fe2599 & 304.13 & 306.24 & 299.11 & 315.74 & 306.31 & 6.97 \\
\hline K_7664 & 1390.49 & 1406.33 & 1409.50 & 1467.84 & 1418.54 & 33.90 \\
\hline La3949 & 7.01 & 6.98 & 6.98 & 7.31 & 7.07 & 0.16 \\
\hline Mg2790 & - & - & - & - & & \\
\hline Mn2576 & 67.98 & 67.95 & 67.37 & 70.09 & 68.35 & 1.19 \\
\hline Mo2020 & 27.46 & 27.03 & 27.35 & 28.09 & 27.48 & 0.44 \\
\hline \begin{tabular}{|l|}
$\mathrm{Nd} 4061$ \\
\end{tabular} & 19.41 & 19.49 & 19.02 & 19.96 & 19.47 & 0.39 \\
\hline \begin{tabular}{|l|}
$\mathrm{Ni} 2316$ \\
\end{tabular} & 376.99 & 377.26 & 384.65 & 391.78 & 382.67 & 7.03 \\
\hline P_1774 & 319.97 & 322.08 & 322.08 & 335.81 & 324.98 & 7.28 \\
\hline Pb2203 & 110.56 & 111.65 & 111.99 & 116.08 & 112.57 & 2.42 \\
\hline Si2516 & - & - & - & - & & \\
\hline Sr3464 & 95.81 & 100.43 & 101.03 & 104.44 & 100.43 & 3.55 \\
\hline Zn2062 & 28.12 & 21.48 & 21.59 & 22.20 & 23.35 & 3.20 \\
\hline Zr3391 & 22.46 & 22.29 & 22.56 & 23.24 & 22.63 & 0.42 \\
\hline
\end{tabular}


WSRC-TR-2003-00232, Rev. 0

SRT-RPP-2003-00105, Rev. 0

Table E.4 ICP-AES Data for AN-107 Secondary Effects Samples (0.01 M $\mathrm{NaMnO}_{4} /$ Light $/ \mathrm{N}_{2}$ )

\begin{tabular}{|c|c|c|c|c|c|c|}
\hline & 0724-SIM7-LtN2-384 & 0724-SIM7-LtN2-192 & 0724-SIM7-LtN2-120 & 0724-SIM7-LtN2-0 & AVG & SD \\
\hline & (ppm) & (ppm) & (ppm) & (ppm) & & \\
\hline Al3082 & 277.87 & 277.35 & 276.58 & 275.03 & 276.71 & 1.24 \\
\hline B_2497 & 15.64 & 16.74 & 16.23 & 15.50 & 16.03 & 0.57 \\
\hline Ca3179 & 279.93 & 284.06 & 276.83 & 275.54 & 279.09 & 3.79 \\
\hline Ce4186 & 27.66 & 27.40 & 26.94 & 27.63 & 27.41 & 0.33 \\
\hline Cr3578 & 85.04 & 86.56 & 88.86 & 88.06 & 87.13 & 1.69 \\
\hline Cu3247 & 20.46 & 21.27 & 21.42 & 21.08 & 21.06 & 0.42 \\
\hline Fe2599 & 866.36 & 862.24 & 852.17 & 835.15 & 853.98 & 13.90 \\
\hline K_7664 & 1360.18 & 1335.15 & 1356.05 & 1334.63 & 1346.50 & 13.51 \\
\hline La3949 & 11.86 & 12.12 & 12.28 & 12.69 & 12.23 & 0.35 \\
\hline Mg2790 & - & - & - & - & & \\
\hline Mn2576 & 419.77 & 428.28 & 422.35 & 413.06 & 420.86 & 6.31 \\
\hline Mo2020 & 26.34 & 25.63 & 25.88 & 25.66 & 25.88 & 0.33 \\
\hline Nd4061 & 40.89 & 40.74 & 41.25 & 41.31 & 41.05 & 0.28 \\
\hline $\mathrm{Ni2316}$ & 355.78 & 361.72 & 361.20 & 357.85 & 359.14 & 2.82 \\
\hline P_1774 & 347.01 & 323.79 & 324.56 & 328.43 & 330.95 & 10.90 \\
\hline $\mathrm{Pb} 2203$ & 200.62 & 194.71 & 194.97 & 191.64 & 195.49 & 3.74 \\
\hline Si2516 & - & - & - & - & & \\
\hline Sr3464 & 115.02 & 153.38 & 169.35 & 248.04 & 171.45 & 55.92 \\
\hline Zn2062 & 25.95 & 26.88 & 26.37 & 26.08 & 26.32 & 0.41 \\
\hline Zr3391 & 38.39 & 37.98 & 31.81 & 38.52 & 36.67 & 3.25 \\
\hline & 0724-SIM8-LtN2-384 & 0724-SIM8-LtN2-192 & 0724-SIM8-LtN2-120 & 0724-SIM8-LtN2-0 & AVG & SD \\
\hline & (ppm) & (ppm) & (ppm) & (ppm) & & \\
\hline Al3082 & 269.35 & 257.25 & 260.58 & 259.03 & 261.55 & 5.37 \\
\hline B_2497 & 16.09 & 15.09 & 15.16 & 14.90 & 15.31 & 0.53 \\
\hline Ca3179 & 286.90 & 259.81 & 260.32 & 263.42 & 267.61 & 12.96 \\
\hline Ce4186 & 26.94 & 25.49 & 25.77 & 26.34 & 26.13 & 0.64 \\
\hline Cr3578 & 88.65 & 83.54 & 83.51 & 86.84 & 85.64 & 2.54 \\
\hline Cu3247 & 21.07 & 20.34 & 20.34 & 20.68 & 20.61 & 0.35 \\
\hline Fe2599 & 832.82 & 787.67 & 797.99 & 786.90 & 801.35 & 21.58 \\
\hline K_7664 & 1356.05 & 1263.94 & 1266.01 & 1291.81 & 1294.45 & 42.98 \\
\hline La3949 & 12.47 & 11.78 & 11.99 & 12.96 & 12.30 & 0.53 \\
\hline Mg2790 & - & - & - & - & & \\
\hline Mn2576 & 408.16 & 392.16 & 394.22 & 393.71 & 397.06 & 7.45 \\
\hline Mo2020 & 26.21 & 24.41 & 24.60 & 24.97 & 25.05 & 0.81 \\
\hline $\mathrm{Nd} 4061$ & 41.18 & 39.29 & 39.47 & 40.22 & 40.04 & 0.86 \\
\hline $\mathrm{Ni2316}$ & 373.84 & 348.04 & 348.30 & 357.59 & 356.94 & 12.11 \\
\hline P_1774 & 320.95 & 310.63 & 319.15 & 320.18 & 317.73 & 4.79 \\
\hline $\mathrm{Pb} 2203$ & 194.53 & 181.76 & 182.64 & 182.90 & 185.46 & 6.07 \\
\hline Si2516 & - & - & - & - & & \\
\hline Sr3464 & 113.60 & 132.43 & 150.08 & 251.37 & 161.87 & 61.50 \\
\hline Zn2062 & 27.32 & 25.22 & 25.13 & 25.73 & 25.85 & 1.01 \\
\hline Zr3391 & 40.43 & 35.94 & 37.00 & 38.39 & 37.94 & 1.94 \\
\hline
\end{tabular}


WSRC-TR-2003-00232, Rev. 0

SRT-RPP-2003-00105, Rev. 0

Table E.5 ICP-AES Data for AN-107 Secondary Effects Samples (0.03 M $\mathrm{NaMnO}_{4} /$ Dark/Atm)

\begin{tabular}{|c|c|c|c|c|c|c|}
\hline & 0702-SIM7-DkAtm-384 & 0702-SIM7-DkAtm-192 & 0702-SIM7-DkAtm-120 & 0702-SIM7-DkAtm-0 & AVG & SD \\
\hline & (ppm) & (ppm) & (ppm) & (ppm) & & \\
\hline Al3082 & 272.71 & 273.24 & 268.75 & 285.65 & 275.09 & 7.32 \\
\hline B_2497 & 16.82 & 16.54 & 16.79 & 16.96 & 16.78 & 0.18 \\
\hline$\overline{\mathrm{Ca}} 3179$ & 325.51 & 316.01 & 312.84 & 324.46 & 319.70 & 6.25 \\
\hline Ce4186 & 8.69 & 8.62 & 8.35 & 8.97 & 8.66 & 0.26 \\
\hline Cr3578 & 88.04 & 87.83 & 90.18 & 92.51 & 89.64 & 2.18 \\
\hline Cu3247 & 20.03 & 19.72 & 19.81 & 20.73 & 20.07 & 0.46 \\
\hline Fe2599 & 304.13 & 306.24 & 299.11 & 315.74 & 306.31 & 6.97 \\
\hline K_7664 & 1390.49 & 1406.33 & 1409.50 & 1467.84 & 1418.54 & 33.90 \\
\hline La3949 & 7.01 & 6.98 & 6.98 & 7.31 & 7.07 & 0.16 \\
\hline Mg2790 & - & - & - & - & & \\
\hline Mn2576 & 67.98 & 67.95 & 67.37 & 70.09 & 68.35 & 1.19 \\
\hline Mo2020 & 27.46 & 27.03 & 27.35 & 28.09 & 27.48 & 0.44 \\
\hline Nd4061 & 19.41 & 19.49 & 19.02 & 19.96 & 19.47 & 0.39 \\
\hline \begin{tabular}{|l|}
$\mathrm{Ni} 2316$ \\
\end{tabular} & 376.99 & 377.26 & 384.65 & 391.78 & 382.67 & 7.03 \\
\hline P_1774 & 319.97 & 322.08 & 322.08 & 335.81 & 324.98 & 7.28 \\
\hline Pb-2203 & 110.56 & 111.65 & 111.99 & 116.08 & 112.57 & 2.42 \\
\hline Si2516 & - & - & - & - & & \\
\hline Sr3464 & 95.81 & 100.43 & 101.03 & 104.44 & 100.43 & 3.55 \\
\hline Zn2062 & 28.12 & 21.48 & 21.59 & 22.20 & 23.35 & 3.20 \\
\hline Zr3391 & 22.46 & 22.29 & 22.56 & 23.24 & 22.63 & 0.42 \\
\hline
\end{tabular}

\begin{tabular}{|c|c|c|c|c|c|c|}
\hline & 0702-SIM8-DkAtm-384 & 0702-SIM8-DkAtm-192 & 0702-SIM8-DkAtm-120 & 0702-SIM8-DkAtm-0 & AVG & SD \\
\hline & (ppm) & (ppm) & (ppm) & (ppm) & & \\
\hline Al3082 & 274.30 & 275.62 & 270.86 & 277.08 & 274.46 & 2.66 \\
\hline B_2497 & 16.46 & 15.92 & 15.77 & 12.18 & 15.08 & 1.95 \\
\hline Ca3179 & 286.70 & 291.98 & 295.68 & 331.33 & 301.42 & 20.27 \\
\hline Ce4186 & 8.18 & 8.40 & 8.25 & 8.79 & 8.41 & 0.27 \\
\hline Cr3578 & 87.75 & 91.24 & 87.62 & 89.42 & 89.01 & 1.70 \\
\hline Cu3247 & 20.55 & 20.97 & 20.63 & 21.11 & 20.81 & 0.27 \\
\hline Fe2599 & 297.53 & 297.79 & 298.32 & 315.39 & 302.26 & 8.76 \\
\hline K_7664 & 1420.85 & 1450.94 & 1421.64 & 1417.65 & 1427.77 & 15.55 \\
\hline Lä3949 & 5.66 & 6.04 & 6.05 & 6.32 & 6.02 & 0.27 \\
\hline Mg2790 & - & - & - & - & & \\
\hline Mn2576 & 77.85 & 78.72 & 78.09 & 84.82 & 79.87 & 3.32 \\
\hline Mo2020 & 27.24 & 27.59 & 26.98 & 28.27 & 27.52 & 0.56 \\
\hline Nd4061 & 17.62 & 17.98 & 17.54 & 19.80 & 18.23 & 1.06 \\
\hline $\mathrm{Ni2316}$ & 384.65 & 393.89 & 384.12 & 410.76 & 393.36 & 12.44 \\
\hline P_1774 & 324.98 & 318.38 & 317.06 & 319.38 & 319.95 & 3.49 \\
\hline Pb̄2203 & 118.06 & 117.08 & 117.11 & 124.04 & 119.07 & 3.34 \\
\hline Si2516 & - & - & - & - & & \\
\hline Sr3464 & 98.58 & 128.54 & 138.57 & 177.67 & 135.84 & 32.65 \\
\hline Zn2062 & 22.49 & 23.01 & 22.73 & 24.50 & 23.18 & 0.90 \\
\hline Zr3391 & 22.28 & 22.93 & 22.39 & 23.94 & 22.89 & 0.76 \\
\hline
\end{tabular}


WSRC-TR-2003-00232, Rev. 0

SRT-RPP-2003-00105, Rev. 0

Table E.6 ICP-AES Data for AN-107 Secondary Effects Samples (0.01 M $\mathrm{NaMnO}_{4} /$ Dark/Atm)

\begin{tabular}{|c|c|c|c|c|c|c|}
\hline & 0725-SIM7-DkAtm-384 & 0725-SIM7-DkAtm-192 & 0725-SIM7-DkAtm-120 & 0725-SIM7-DkAtm-0 & AVG & SD \\
\hline & (ppm) & (ppm) & (ppm) & (ppm) & & \\
\hline Al3082 & 273.22 & 258.00 & 271.67 & 261.61 & 266.13 & 7.47 \\
\hline B_2497 & 16.11 & 15.60 & 16.43 & 15.43 & 15.89 & 0.46 \\
\hline Ca3179 & 290.77 & 263.68 & 276.83 & 271.93 & 275.80 & 11.36 \\
\hline Ce4186 & 27.06 & 25.44 & 26.60 & 26.21 & 26.33 & 0.69 \\
\hline Cr3578 & 91.49 & 85.97 & 91.05 & 89.76 & 89.56 & 2.51 \\
\hline Cu3247 & 21.64 & 20.43 & 21.74 & 21.40 & 21.30 & 0.60 \\
\hline Fe2599 & 827.66 & 775.81 & 812.96 & 787.93 & 801.09 & 23.52 \\
\hline K_7664 & 1383.14 & 1276.33 & 1360.18 & 1318.38 & 1334.51 & 47.15 \\
\hline La3949 & 12.32 & 11.83 & 12.60 & 12.96 & 12.43 & 0.48 \\
\hline Mg2790 & - & - & - & - & & \\
\hline Mn2576 & 424.41 & 391.90 & 407.64 & 397.32 & 405.32 & 14.30 \\
\hline Mo2020 & 26.45 & 24.67 & 26.21 & 25.69 & 25.75 & 0.79 \\
\hline Nd4061 & 39.99 & 38.85 & 40.74 & 40.53 & 40.03 & 0.84 \\
\hline Ni2316 & 378.74 & 351.40 & 371.26 & 366.62 & 367.01 & 11.54 \\
\hline P_1774 & 328.18 & 310.12 & 335.92 & 326.89 & 325.27 & 10.86 \\
\hline Pb2203 & 197.11 & 179.93 & 190.77 & 185.61 & 188.35 & 7.33 \\
\hline Si2516 & - & - & - & - & & \\
\hline Sr3464 & 139.50 & 159.42 & 184.52 & 227.69 & 177.78 & 38.03 \\
\hline Zn2062 & 27.35 & 24.78 & 26.24 & 25.83 & 26.05 & 1.06 \\
\hline Zr3391 & 40.51 & 35.76 & 39.60 & 39.04 & 38.73 & 2.07 \\
\hline & 0725-SIM8-DkAtm-384 & 0725-SIM8-DkAtm-192 & 0725-SIM8-DkAtm-120 & 0725-SIM8-DkAtm-0 & AVG & SD \\
\hline & (ppm) & (ppm) & (ppm) & (ppm) & & \\
\hline Al3082 & 272.45 & 271.93 & 259.03 & 265.48 & 267.22 & 6.31 \\
\hline B_2497 & 15.99 & 16.06 & 14.91 & 15.84 & 15.70 & 0.53 \\
\hline Ca3179 & 293.60 & 264.19 & 259.55 & 267.80 & 271.29 & 15.26 \\
\hline Ce4186 & 27.24 & 26.60 & 25.53 & 26.26 & 26.41 & 0.71 \\
\hline Cr3578 & 87.23 & 92.00 & 86.28 & 90.12 & 88.91 & 2.63 \\
\hline Cu3247 & 20.91 & 22.10 & 20.95 & 21.68 & 21.41 & 0.58 \\
\hline Fe2599 & 852.95 & 801.61 & 778.13 & 793.09 & 806.44 & 32.49 \\
\hline K_7664 & 1375.66 & 1361.98 & 1286.90 & 1329.22 & 1338.44 & 39.50 \\
\hline La3949 & 11.62 & 11.99 & 11.65 & 12.35 & 11.90 & 0.34 \\
\hline Mg2790 & - & - & - & - & & \\
\hline Mn2576 & 432.41 & 404.80 & 392.93 & 397.06 & 406.80 & 17.77 \\
\hline Mo2020 & 26.14 & 25.83 & 24.71 & 25.60 & 25.57 & 0.61 \\
\hline \begin{tabular}{|l|}
$\mathrm{Nd} 4061$ \\
\end{tabular} & 39.11 & 40.51 & 39.50 & 40.17 & 39.82 & 0.63 \\
\hline \begin{tabular}{|l|}
$\mathrm{Ni} 2316$ \\
\end{tabular} & 373.58 & 367.91 & 353.20 & 366.62 & 365.33 & 8.63 \\
\hline P_1774 & 329.72 & 332.30 & 319.15 & 330.50 & 327.92 & 5.95 \\
\hline Pb2203 & 201.81 & 187.39 & 181.12 & 185.48 & 188.95 & 8.97 \\
\hline Si2516 & - & - & - & - & & \\
\hline Sr3464 & 142.49 & 165.92 & 179.36 & 237.77 & 181.39 & 40.56 \\
\hline Zn2062 & 28.04 & 25.93 & 25.38 & 25.98 & 26.33 & 1.17 \\
\hline Zr3391 & 40.40 & 39.89 & 38.31 & 39.45 & 39.51 & 0.89 \\
\hline
\end{tabular}


WSRC-TR-2003-00232, Rev. 0

SRT-RPP-2003-00105, Rev. 0

Table E.7 ICP-AES Data for AN-107 Secondary Effects Samples (0.03 M $\mathrm{NaMnO}_{4} /$ Light/Atm)

\begin{tabular}{|c|c|c|c|c|c|c|}
\hline & 0702-SIM-DkAtm-384 & 0702-SIM8-LtAtm-192 & 0702-SIM8-LtAtm-120 & 0702-SIM8-LtAtm-0 & AVG & SD \\
\hline & (ppm) & (ppm) & (ppm) & (ppm) & & \\
\hline Al3082 & 267.96 & 264.79 & 277.20 & 294.10 & 276.01 & 13.16 \\
\hline B_2497 & 16.32 & 15.91 & 16.24 & 17.33 & 16.45 & 0.61 \\
\hline Ca3179 & 254.76 & 252.38 & 272.18 & 285.91 & 266.31 & 15.77 \\
\hline Ce4186 & 7.64 & 7.86 & 8.00 & 8.82 & 8.08 & 0.52 \\
\hline Cr3578 & 83.69 & 87.86 & 90.79 & 91.00 & 88.33 & 3.41 \\
\hline Cu3247 & 19.82 & 20.24 & 21.55 & 21.73 & 20.84 & 0.95 \\
\hline Fe2599 & 275.88 & 273.50 & 287.76 & 312.31 & 287.36 & 17.76 \\
\hline K_7664 & 1373.06 & 1390.22 & 1445.66 & 1465.99 & 1418.74 & 44.19 \\
\hline La3949 & 4.62 & 4.90 & 5.20 & 6.01 & 5.18 & 0.60 \\
\hline Mg2790 & - & - & - & - & & \\
\hline Mn2576 & 62.41 & 73.84 & 80.15 & 85.17 & 75.39 & 9.82 \\
\hline Mo2020 & 26.38 & 26.66 & 27.54 & 28.43 & 27.25 & 0.93 \\
\hline Nd4061 & 15.96 & 16.50 & 17.00 & 18.30 & 16.94 & 1.00 \\
\hline $\mathrm{Ni2316}$ & 370.39 & 378.05 & 388.87 & 397.85 & 383.79 & 12.05 \\
\hline P_1774 & 316.54 & 313.10 & 327.62 & 346.90 & 326.04 & 15.22 \\
\hline$\overline{\mathrm{Pb}} 2203$ & 113.49 & 113.28 & 116.13 & 123.34 & 116.56 & 4.70 \\
\hline Si2516 & - & - & - & - & & \\
\hline Sr3464 & 83.08 & 105.68 & 122.05 & 220.36 & 132.79 & 60.53 \\
\hline Zn2062 & 21.92 & 22.27 & 22.90 & 23.59 & 22.67 & 0.73 \\
\hline Zr3391 & 20.65 & 21.23 & 21.92 & 22.54 & 21.58 & 0.82 \\
\hline & 0702-SIM7-LtAtm-384 & 0702-SIM7-LtAtm-192 & 0702-SIM7-LtAtm-120 & 0708-SIM7-LtAtm-0 & AVG & SD \\
\hline & (ppm) & (ppm) & (ppm) & (ppm) & & \\
\hline Al3082 & 275.09 & 268.49 & 266.11 & 263.52 & 268.30 & 4.96 \\
\hline B_2497 & 16.23 & 15.03 & 15.49 & 20.35 & 16.78 & 2.44 \\
\hline Ca3179 & 285.38 & 279.84 & 282.48 & 271.13 & 279.71 & 6.15 \\
\hline Ce4186 & 8.16 & 8.36 & 8.24 & 8.51 & 8.32 & 0.16 \\
\hline Cr3578 & 85.91 & 83.48 & 84.24 & 78.91 & 83.13 & 2.99 \\
\hline Cu3247 & 20.10 & 19.46 & 19.29 & 18.46 & 19.33 & 0.68 \\
\hline Fe2599 & 300.43 & 297.79 & 297.00 & 296.47 & 297.92 & 1.76 \\
\hline K_7664 & 1390.49 & 1347.46 & 1372.01 & 1316.30 & 1356.56 & 32.11 \\
\hline La3949 & 5.15 & 5.39 & 5.30 & 5.52 & 5.34 & 0.16 \\
\hline Mg2790 & - & - & - & - & & \\
\hline Mn2576 & 65.68 & 74.95 & 73.84 & 74.18 & 72.16 & 4.35 \\
\hline Mo2020 & 26.98 & 26.10 & 26.51 & 25.37 & 26.24 & 0.68 \\
\hline \begin{tabular}{|l|}
$\mathrm{Nd} 4061$ \\
\end{tabular} & 17.17 & 17.01 & 17.09 & 16.65 & 16.98 & 0.23 \\
\hline \begin{tabular}{|l|}
$\mathrm{Ni} 2316$ \\
\end{tabular} & 378.05 & 363.26 & 372.50 & 359.04 & 368.21 & 8.64 \\
\hline P_1774 & 319.70 & 312.58 & 312.58 & 313.90 & 314.69 & 3.40 \\
\hline Pb2203 & 114.07 & 112.91 & 114.15 & 112.33 & 113.37 & 0.89 \\
\hline Si2516 & - & - & - & - & & \\
\hline Sr3464 & 85.14 & 115.71 & 107.37 & 151.17 & 114.85 & 27.44 \\
\hline Zn2062 & 21.84 & 21.27 & 21.94 & 21.06 & 21.53 & 0.43 \\
\hline Zr3391 & 21.84 & 21.06 & 21.39 & 20.35 & 21.16 & 0.63 \\
\hline
\end{tabular}


WSRC-TR-2003-00232, Rev. 0

SRT-RPP-2003-00105, Rev. 0

Table E.8 ICP-AES Data for AN-107 Secondary Effects Samples (0.01 M $\mathrm{NaMnO}_{4} /$ Light/Atm)

\begin{tabular}{|c|c|c|c|c|c|c|}
\hline & 0725-SIM7-LtAtm-384 & 0725-SIM7-LtAtm-192 & 0725-SIM7-LtAtm-120 & 0725-SIM7-LtAtm-0 & AVG & SD \\
\hline & (ppm) & (ppm) & (ppm) & (ppm) & & \\
\hline Al3082 & 586.63 & 261.87 & 263.16 & 256.14 & 341.95 & 163.15 \\
\hline B_2497 & 34.35 & 15.66 & 15.49 & 14.93 & 20.11 & 9.50 \\
\hline Ca3179 & 665.58 & 274.77 & 276.06 & 277.09 & 373.37 & 194.80 \\
\hline Ce4186 & 56.74 & 25.98 & 26.16 & 25.88 & 33.69 & 15.37 \\
\hline Cr3578 & 179.94 & 88.70 & 88.55 & 86.53 & 110.93 & 46.02 \\
\hline Cu3247 & 43.76 & 21.41 & 21.24 & 20.78 & 26.80 & 11.31 \\
\hline Fe2599 & 1859.12 & 795.41 & 800.57 & 784.32 & 1059.86 & 532.88 \\
\hline K_7664 & 2922.17 & 1327.67 & 1329.22 & 1296.19 & 1718.81 & 802.38 \\
\hline La3949 & 23.67 & 11.44 & 11.48 & 11.85 & 14.61 & 6.04 \\
\hline $\operatorname{Mg} 2790$ & - & - & - & - & & \\
\hline Mn2576 & 936.96 & 406.61 & 406.87 & 398.09 & 537.13 & 266.58 \\
\hline Mo2020 & 55.15 & 25.38 & 25.38 & 24.82 & 32.69 & 14.98 \\
\hline Nd4061 & 80.37 & 38.96 & 38.75 & 38.16 & 49.06 & 20.88 \\
\hline $\mathrm{Ni2316}$ & 783.45 & 362.23 & 361.72 & 356.56 & 465.99 & 211.66 \\
\hline P_1774 & 693.54 & 321.21 & 326.63 & 316.05 & 414.36 & 186.17 \\
\hline Pb2203 & 425.11 & 184.93 & 186.51 & 181.25 & 244.45 & 120.46 \\
\hline Si2516 & - & - & - & - & & \\
\hline Sr3464 & 276.70 & 153.90 & 168.86 & 227.32 & 206.70 & 56.41 \\
\hline Zn2062 & 58.94 & 25.59 & 25.65 & 25.39 & 33.89 & 16.70 \\
\hline Zr3391 & 84.32 & 37.07 & 39.29 & 38.47 & 49.79 & 23.04 \\
\hline & 0725-SIM8-LtAtm-384 & 0725-SIM8-LtAtm-192 & 0725-SIM8-LtAtm-120 & 0725-SIM8-LtAtm-0 & AVG & SD \\
\hline & (ppm) & (ppm) & (ppm) & (ppm) & & \\
\hline Al3082 & 285.09 & 263.93 & 266.77 & 268.58 & 271.09 & 9.52 \\
\hline B_2497 & 16.08 & 15.13 & 15.00 & 15.43 & 15.41 & 0.48 \\
\hline Ca3179 & 294.64 & 274.51 & 280.19 & 290.77 & 285.03 & 9.30 \\
\hline Ce4186 & 27.89 & 25.76 & 26.29 & 26.42 & 26.59 & 0.91 \\
\hline Cr3578 & 95.87 & 80.13 & 81.58 & 79.44 & 84.26 & 7.80 \\
\hline Cu3247 & 24.40 & 19.91 & 20.37 & 20.20 & 21.22 & 2.13 \\
\hline Fe2599 & 843.92 & 821.99 & 826.37 & 847.01 & 834.82 & 12.48 \\
\hline K_7664 & 1464.92 & 1290.52 & 1299.03 & 1274.52 & 1332.25 & 89.03 \\
\hline La3949 & 12.90 & 12.07 & 12.18 & 12.72 & 12.47 & 0.41 \\
\hline Mg2790 & - & - & - & - & & \\
\hline Mn2576 & 430.60 & 406.35 & 409.70 & 415.90 & 415.64 & 10.73 \\
\hline Mo2020 & 27.32 & 24.45 & 24.44 & 24.33 & 25.14 & 1.46 \\
\hline \begin{tabular}{|l|}
$\mathrm{Nd} 4061$ \\
\end{tabular} & 42.36 & 40.20 & 40.20 & 40.07 & 40.71 & 1.11 \\
\hline \begin{tabular}{|l|}
$\mathrm{Ni} 2316$ \\
\end{tabular} & 390.61 & 341.59 & 344.43 & 343.91 & 355.14 & 23.68 \\
\hline P_1774 & 341.33 & 329.98 & 331.79 & 333.34 & 334.11 & 5.01 \\
\hline Pb2203 & 201.11 & 186.59 & 185.81 & 188.34 & 190.46 & 7.18 \\
\hline Si2516 & - & - & - & - & & \\
\hline Sr3464 & 120.87 & 146.60 & 164.32 & 238.03 & 167.45 & 50.32 \\
\hline Zn2062 & 28.61 & 24.96 & 25.17 & 25.54 & 26.07 & 1.71 \\
\hline Zr3391 & 41.98 & 35.86 & 37.93 & 37.59 & 38.34 & 2.59 \\
\hline
\end{tabular}


WSRC-TR-2003-00232, Rev. 0

SRT-RPP-2003-00105, Rev. 0

Table E.9 Percent of Cation Mass Present in the Solids Relative to Time Zero Cation Mass in the AN-107 Secondary Effects Study

\begin{tabular}{|c|c|c|c|c|c|c|c|c|}
\hline Element & $\begin{array}{c}0.03 \mathrm{M} \mathrm{Mn} \\
\text { SIM7-DkN2 }\end{array}$ & $\begin{array}{l}0.03 \mathrm{M} M n \\
\text { SIM7-LtN2 }\end{array}$ & $\begin{array}{c}0.03 \mathrm{M} \mathrm{Mn} \\
\text { SIM7-DkAtm }\end{array}$ & $\begin{array}{c}0.03 \mathrm{M} \mathrm{Mn} \\
\text { SIM7-LtAtm }\end{array}$ & $\begin{array}{l}0.01 M M n \\
\text { SIM7-LtN2 }\end{array}$ & $\begin{array}{c}0.01 \mathrm{M} \mathrm{Mn} \\
\text { SIM7-DkAtm }\end{array}$ & $\begin{array}{l}0.01 \mathrm{M} \mathrm{Mn} \\
\text { SIM7-LtAtm }\end{array}$ & $\begin{array}{c}0.01 \mathrm{M} \mathrm{Mn} \\
\text { SIM7-Dk2N2 }\end{array}$ \\
\hline Al & 0.05 & 0.05 & 0.03 & 0.07 & 0.03 & 0.09 & 0.11 & 0.55 \\
\hline B & 0.17 & 0.13 & 0.00 & 0.04 & ND & ND & ND & ND \\
\hline $\mathrm{Ca}$ & 0.15 & 0.60 & 0.11 & 1.06 & 2.22 & 1.57 & 2.14 & 0.91 \\
\hline $\mathrm{Ce}$ & 0.06 & 2.50 & ND & 3.78 & 2.53 & 1.81 & 4.52 & 0.65 \\
\hline $\mathrm{Cr}$ & 0.08 & 0.14 & 0.05 & 0.15 & 0.10 & 0.26 & 0.71 & 0.06 \\
\hline $\mathrm{Cu}$ & ND & 0.09 & 0.02 & 0.04 & 0.26 & 0.31 & 0.46 & ND \\
\hline $\mathrm{Fe}$ & 0.02 & 0.52 & 0.02 & 0.75 & 0.22 & 0.79 & 2.67 & 0.04 \\
\hline $\mathrm{K}$ & 0.10 & 0.11 & 0.08 & 0.10 & 0.10 & 0.13 & 0.15 & 0.10 \\
\hline La & 0.36 & 3.86 & ND & 7.12 & 6.34 & 5.43 & 8.49 & 2.79 \\
\hline $\mathrm{Mg}$ & ND & ND & ND & ND & ND & ND & ND & ND \\
\hline Mn & 0.04 & 7.58 & 0.01 & 10.01 & 1.61 & 1.84 & 5.57 & 0.13 \\
\hline Mo & 0.06 & 0.06 & 0.04 & 0.06 & ND & ND & ND & 0.06 \\
\hline Nd & 0.03 & 0.94 & ND & 1.71 & 1.06 & 1.61 & 2.85 & 0.50 \\
\hline $\mathrm{Ni}$ & 0.11 & 0.11 & 0.09 & 0.10 & 0.11 & 0.13 & 0.15 & 0.10 \\
\hline $\mathbf{P}$ & 0.05 & 0.08 & 0.06 & 0.07 & 0.10 & 0.10 & 0.11 & 0.06 \\
\hline $\mathbf{P b}$ & 0.09 & 0.36 & 0.06 & 0.45 & 0.30 & 0.68 & 1.83 & 0.09 \\
\hline Si & ND & ND & ND & ND & ND & ND & ND & ND \\
\hline $\mathrm{Sr}$ & 2.46 & 19.28 & 0.67 & 32.51 & 50.87 & 33.71 & 43.63 & 22.89 \\
\hline $\mathrm{Zn}$ & 0.01 & 0.29 & 0.03 & 0.16 & 0.11 & 0.30 & 0.99 & 0.04 \\
\hline $\mathrm{Zr}$ & 0.11 & 0.19 & 0.08 & 0.21 & 0.15 & 0.46 & 1.12 & 0.11 \\
\hline
\end{tabular}


WSRC-TR-2003-00232, Rev. 0

SRT-RPP-2003-00105, Rev. 0

APPENDIX F

AN-102 Filtrate and Filter Photographs

Page 171 of 220 

WSRC-TR-2003-00232, Rev. 0

SRT-RPP-2003-00105, Rev. 0

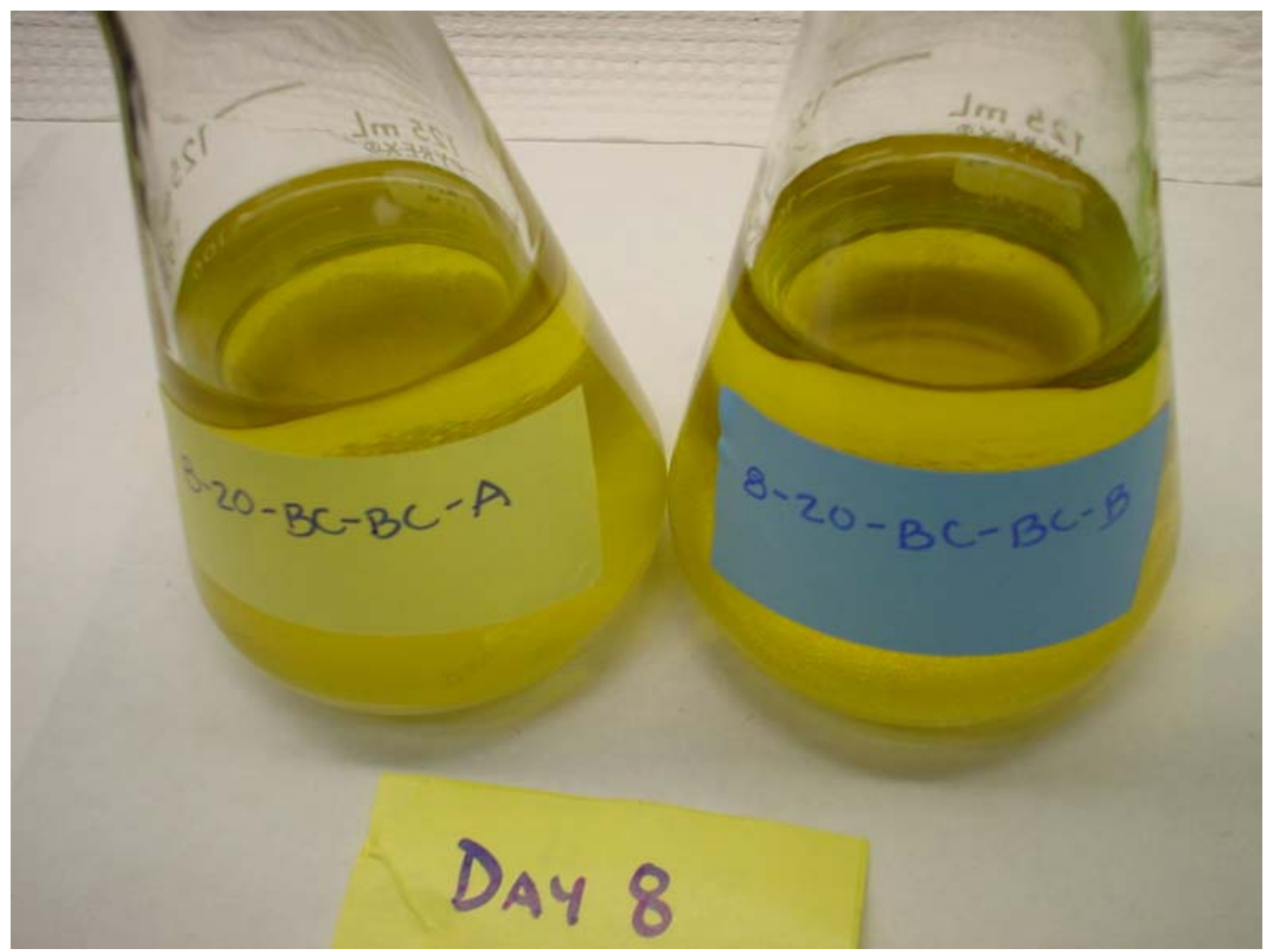

Figure F.1 Simulant AN-102 Sample 8-20-BC-BC Filtrates

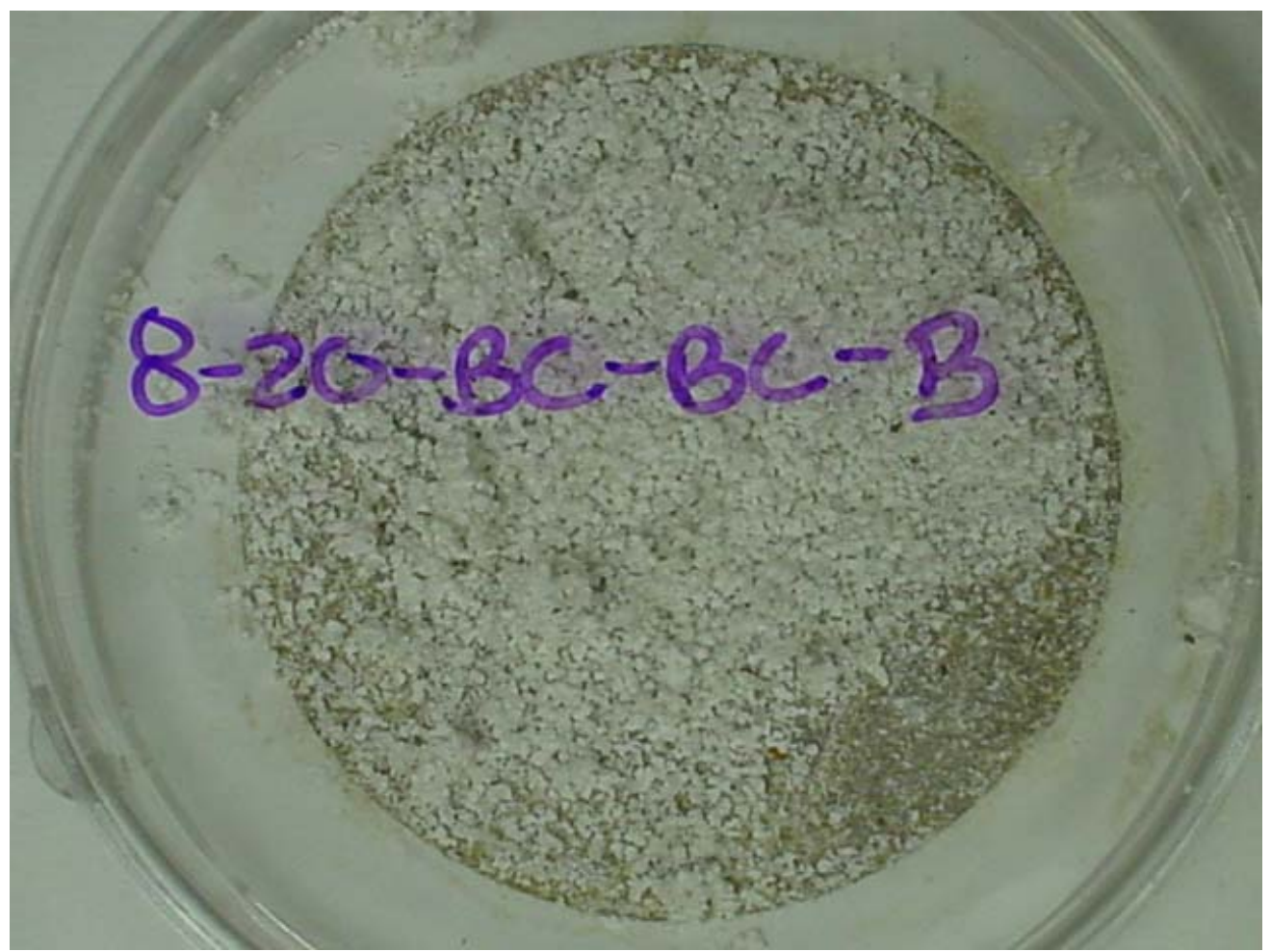

Figure F.2 Simulant AN-102 Sample 8-20-BC-BC Filter 
WSRC-TR-2003-00232, Rev. 0

SRT-RPP-2003-00105, Rev. 0

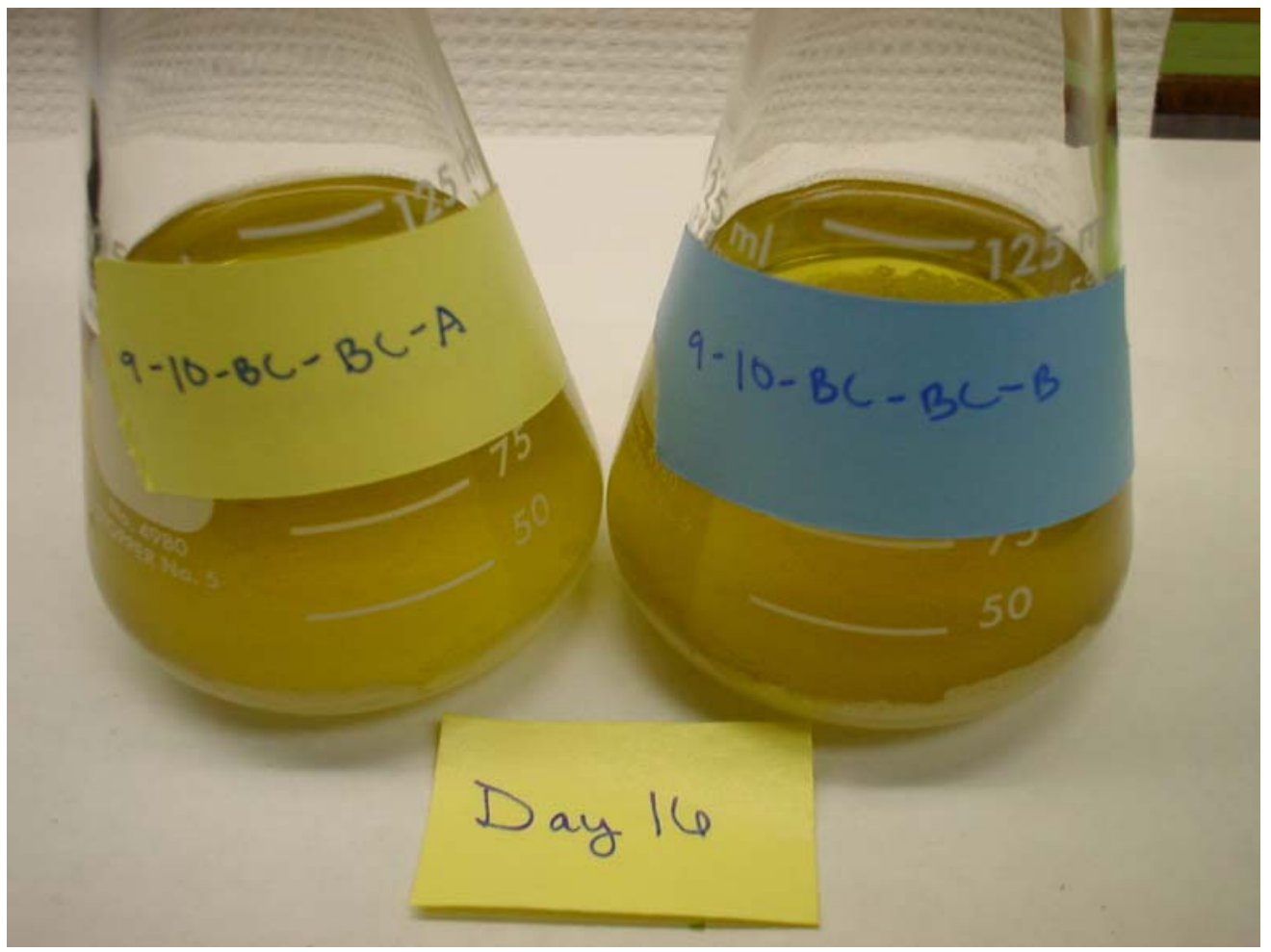

Figure F.3 Simulant AN-102 Sample 9-10-BC-BC Filtrates

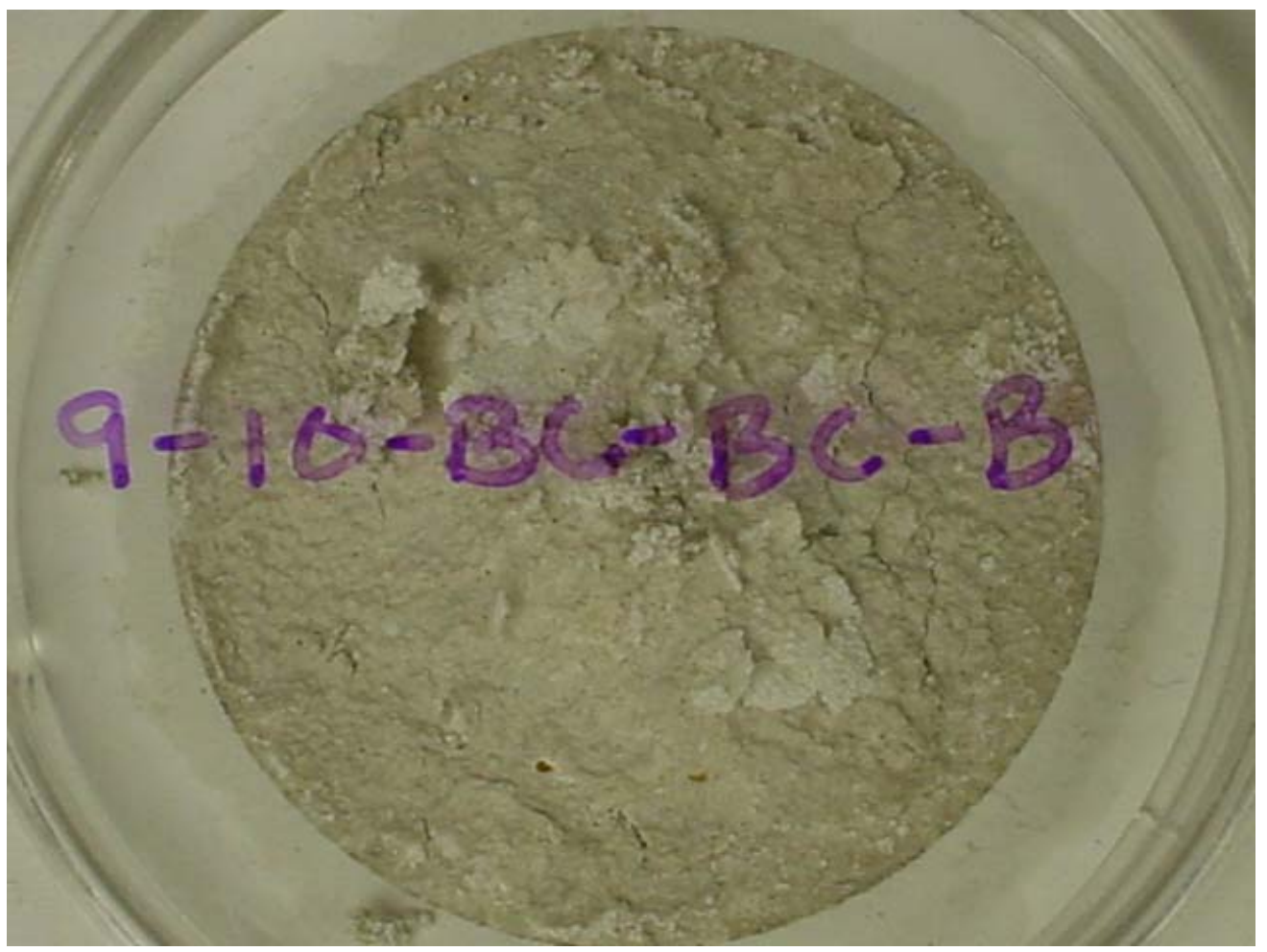

Figure F.4 Simulant AN-102 Sample 9-10-BC-BC Filter 
WSRC-TR-2003-00232, Rev. 0

SRT-RPP-2003-00105, Rev. 0

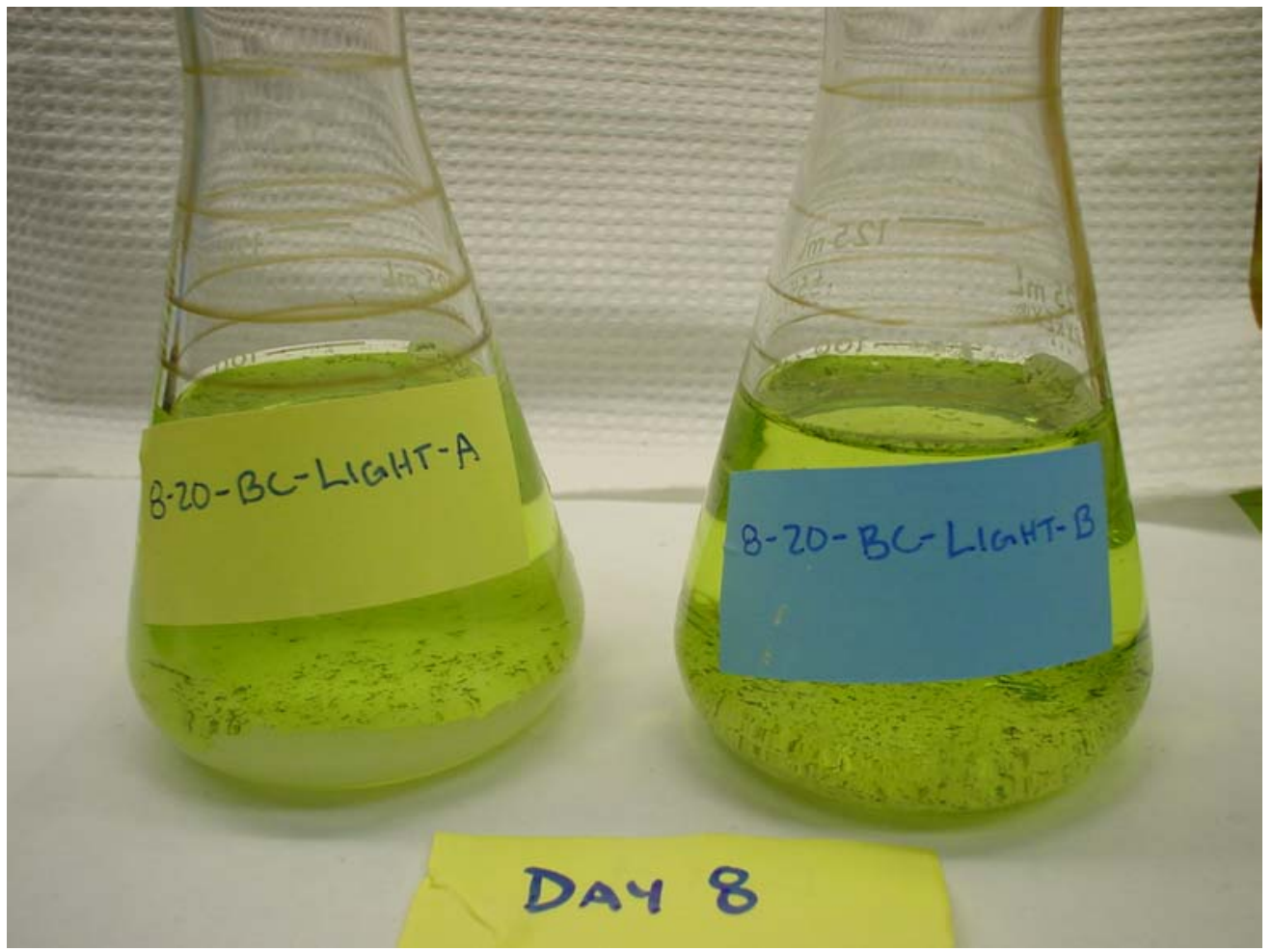

Figure F.5 Simulant AN-102 Sample 8-20-BC-Light Filtrates

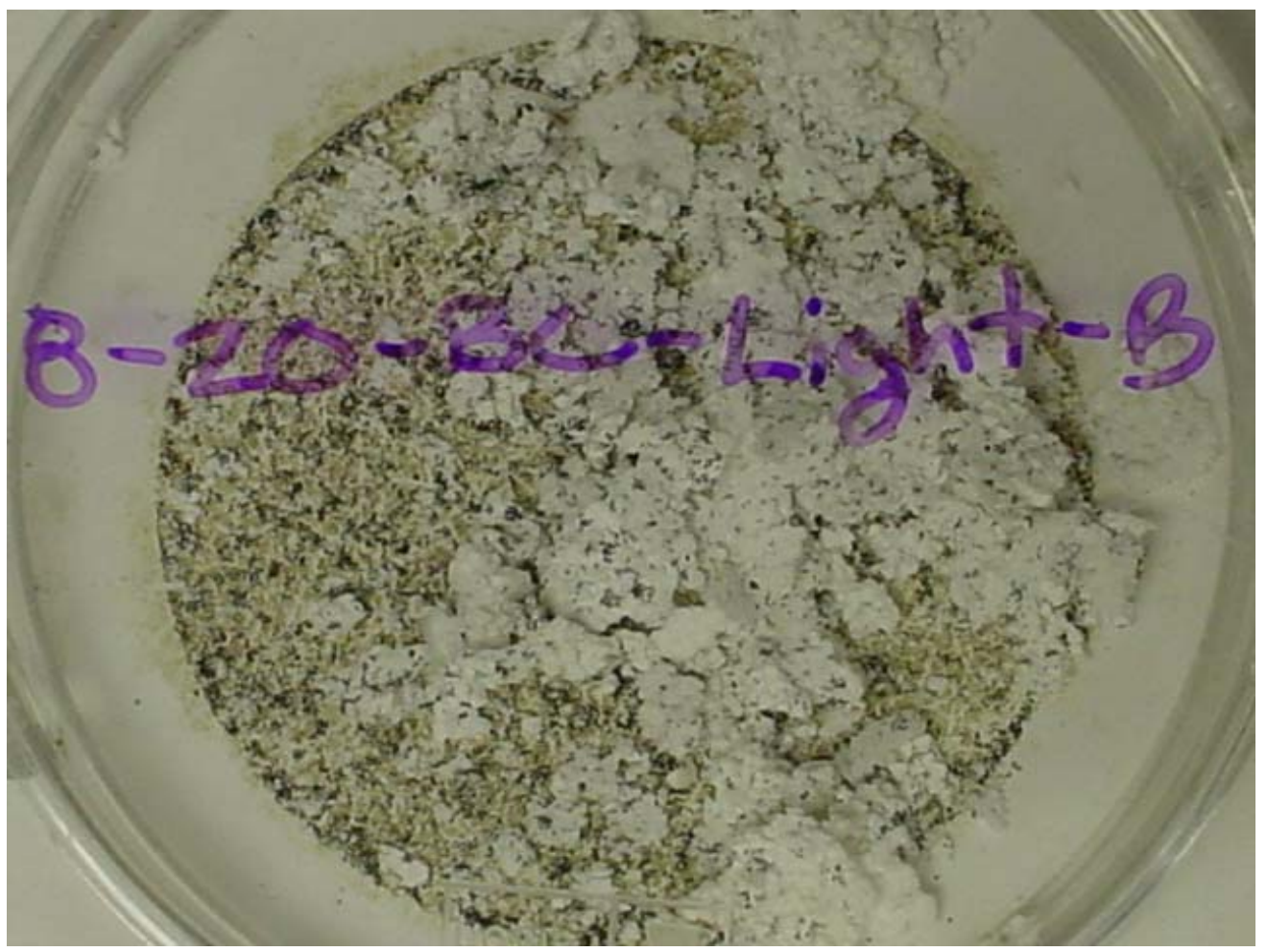

Figure F.6 Simulant AN-102 Sample 8-20-BC-Light Filter 
WSRC-TR-2003-00232, Rev. 0

SRT-RPP-2003-00105, Rev. 0

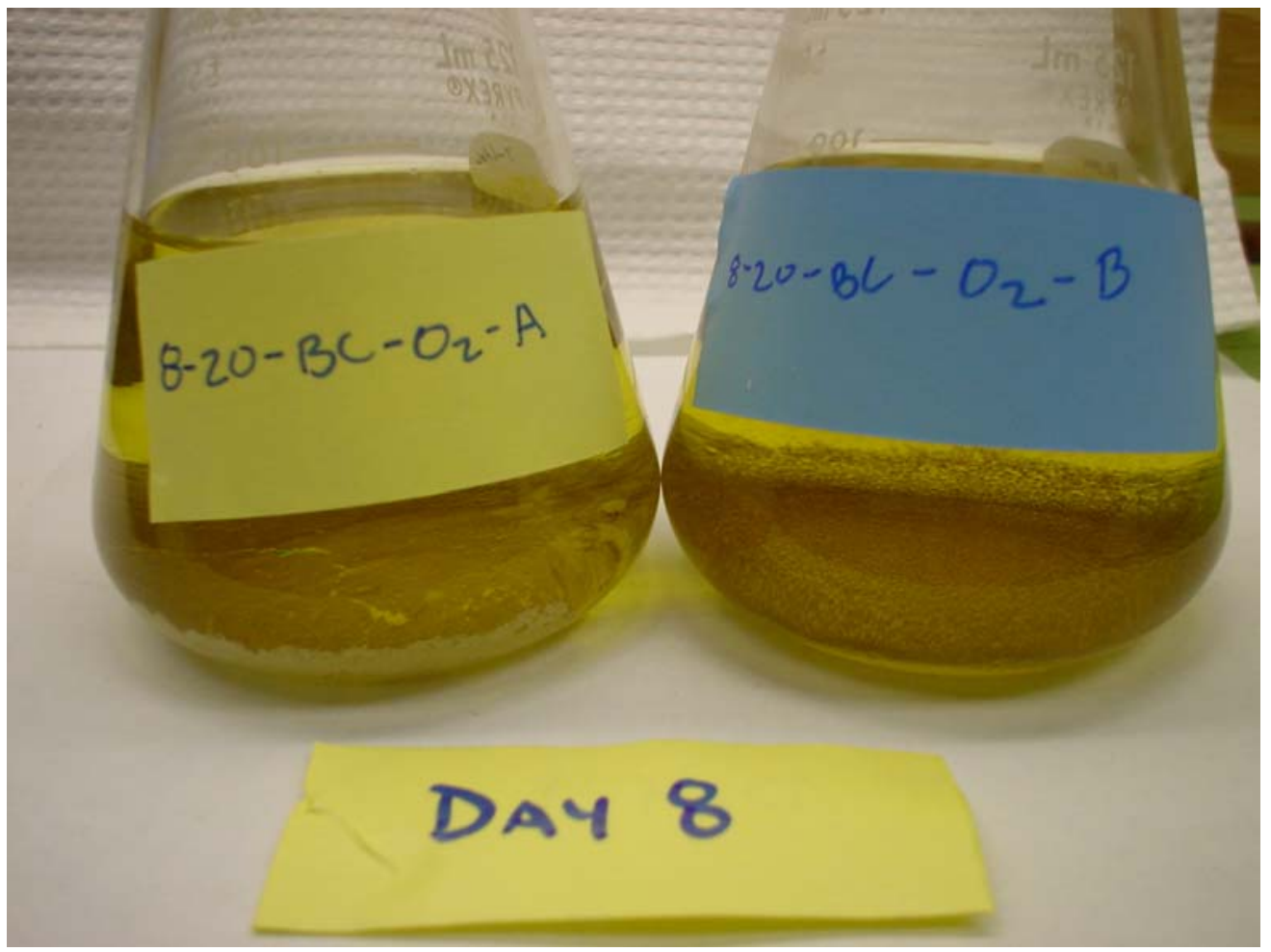

Figure F.7 Simulant AN-102 Sample 8-20-BC-O $\mathrm{O}_{2}$ Filtrates

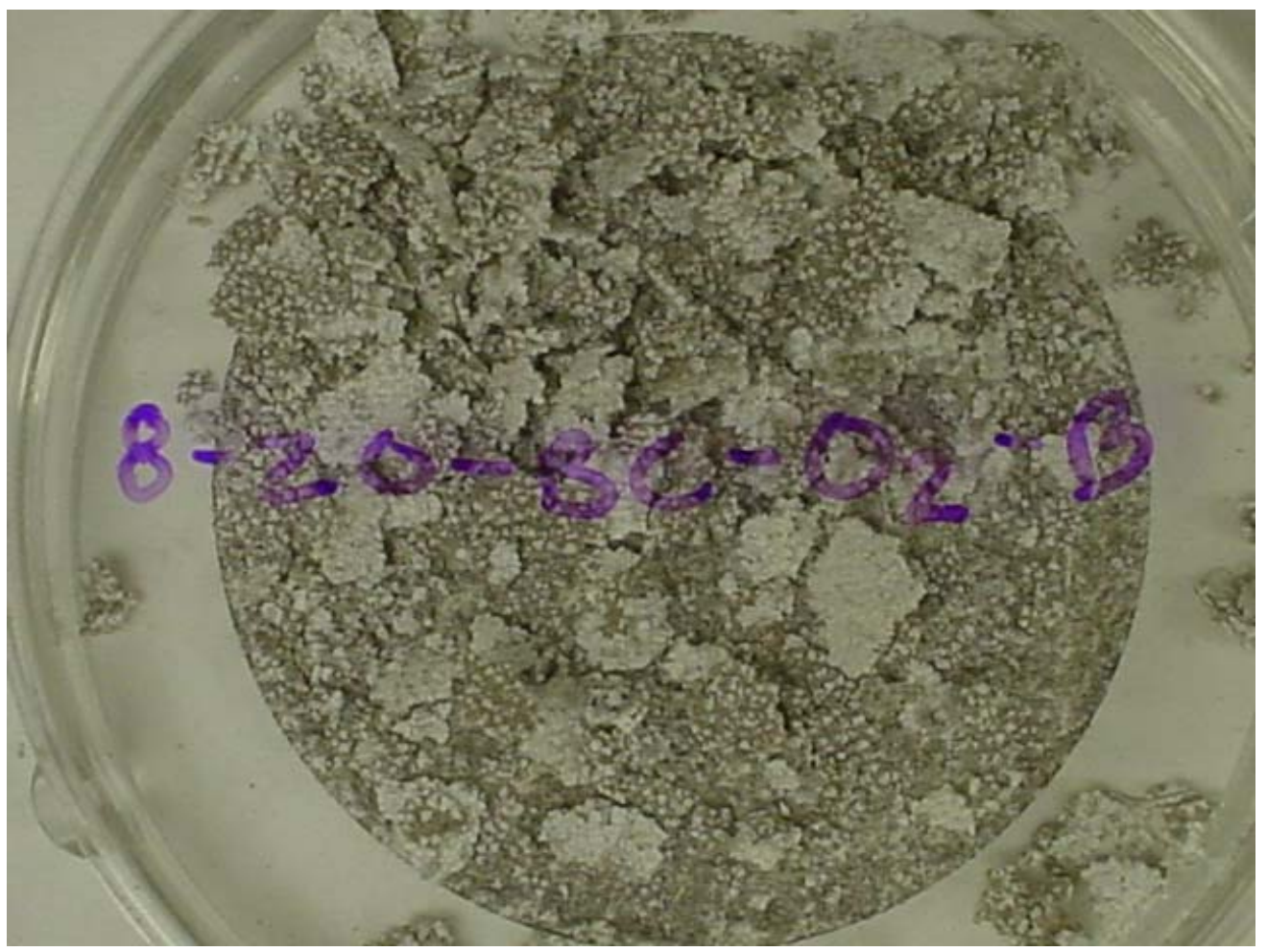

Figure F.8 Simulant AN-102 Sample 8-20-BC-O ${ }_{2}$ Filter 
WSRC-TR-2003-00232, Rev. 0

SRT-RPP-2003-00105, Rev. 0

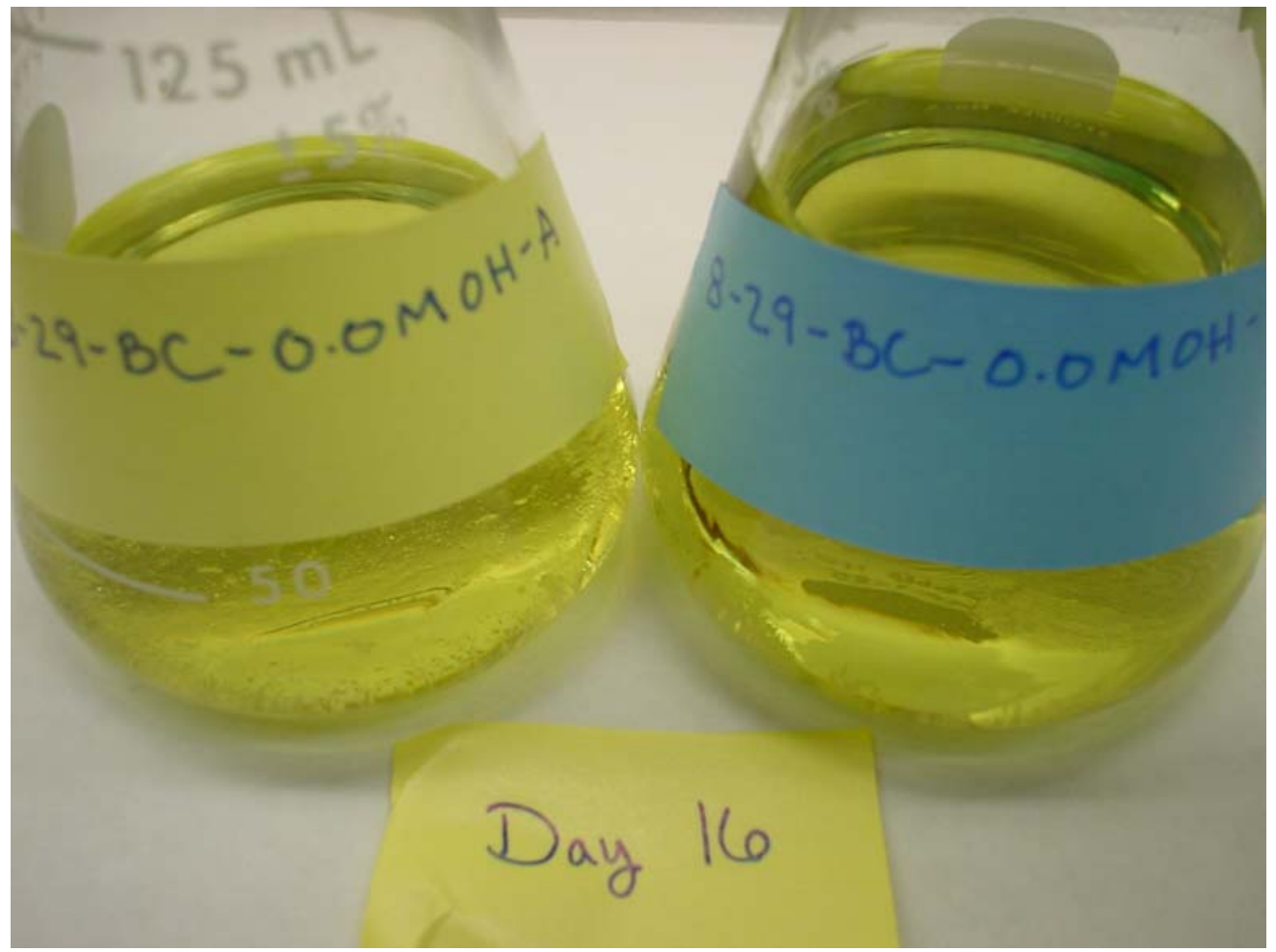

Figure F.9 Simulant AN-102 Sample 8-29-BC-0.0M OH Filtrates

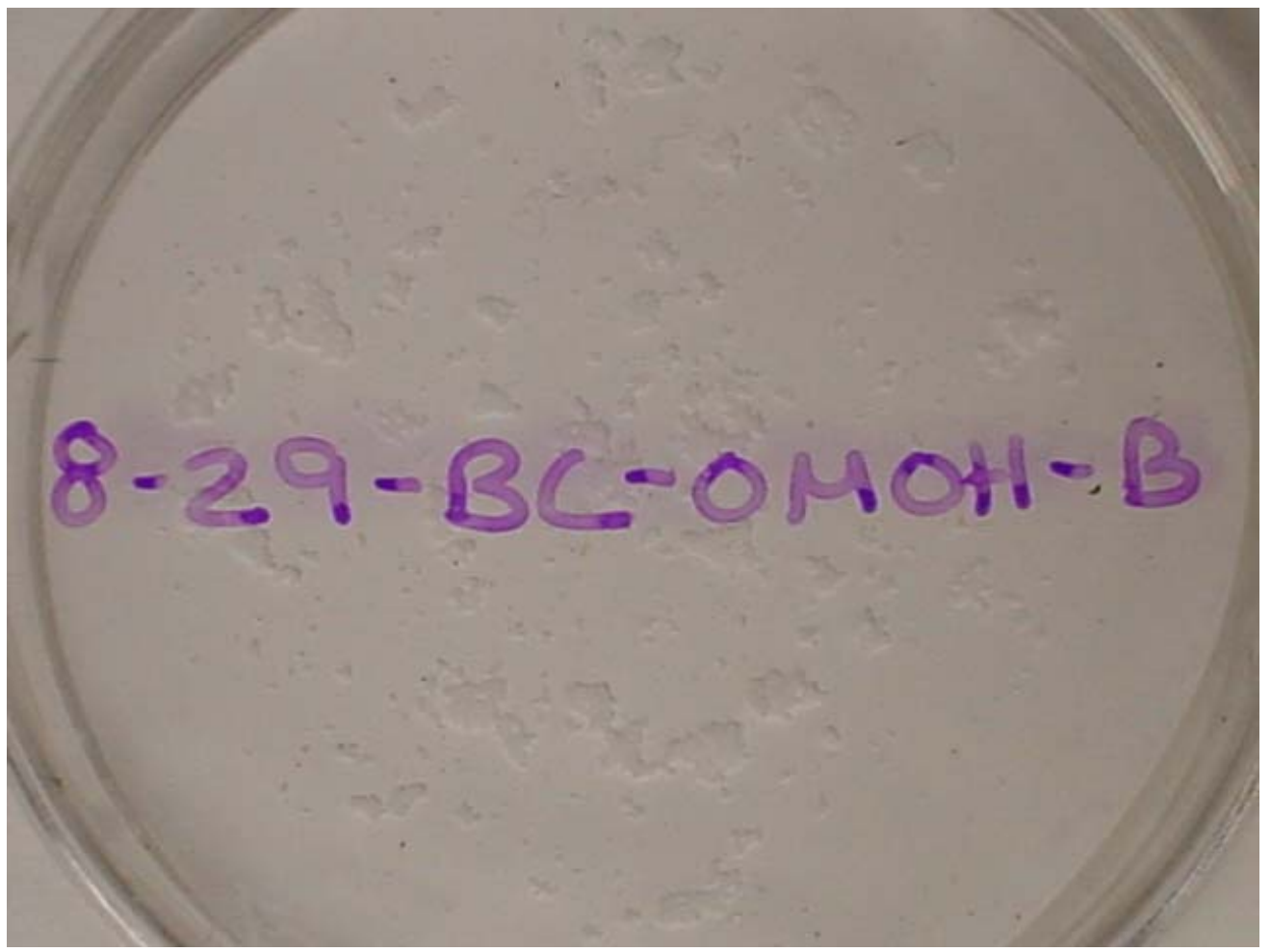

Figure F.10 Simulant AN-102 Sample 8-29-BC-0.0M OH Filter 
WSRC-TR-2003-00232, Rev. 0

SRT-RPP-2003-00105, Rev. 0

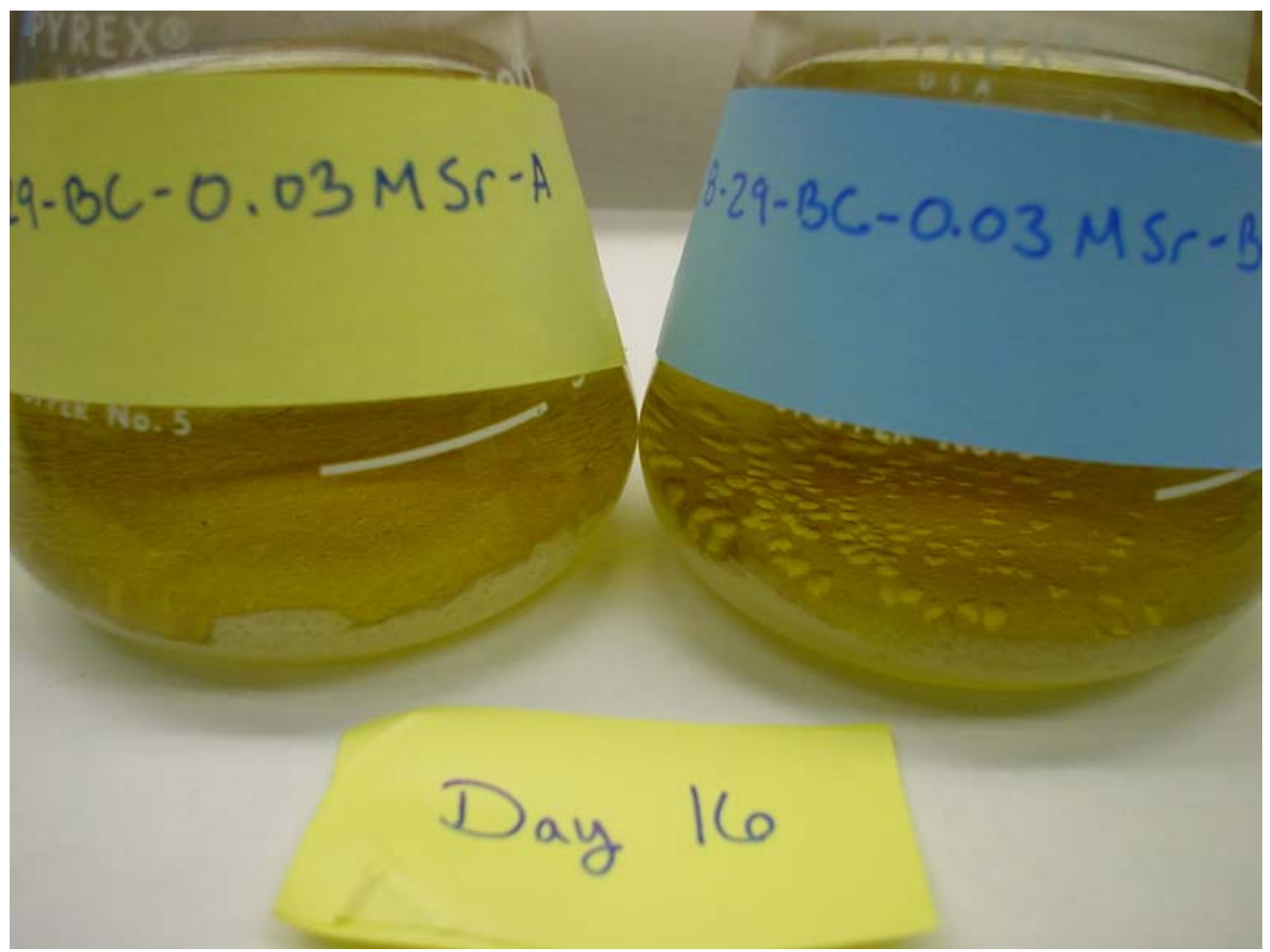

Figure F.11 Simulant AN-102 Sample 8-29-BC-0.03M Sr Filtrates

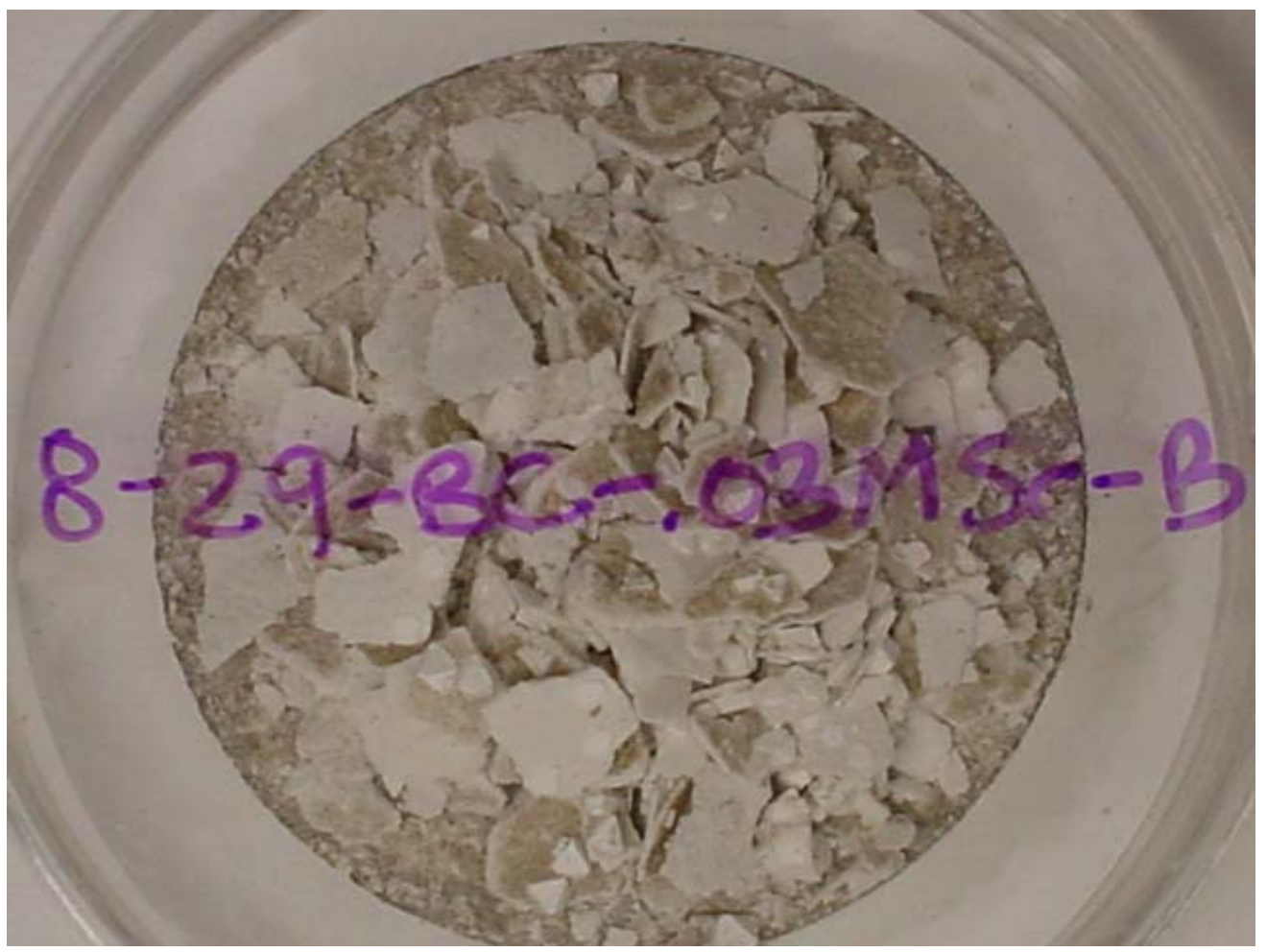

Figure F.12 Simulant AN-102 Sample 8-29-BC-0.03M Sr Filter 
WSRC-TR-2003-00232, Rev. 0

SRT-RPP-2003-00105, Rev. 0

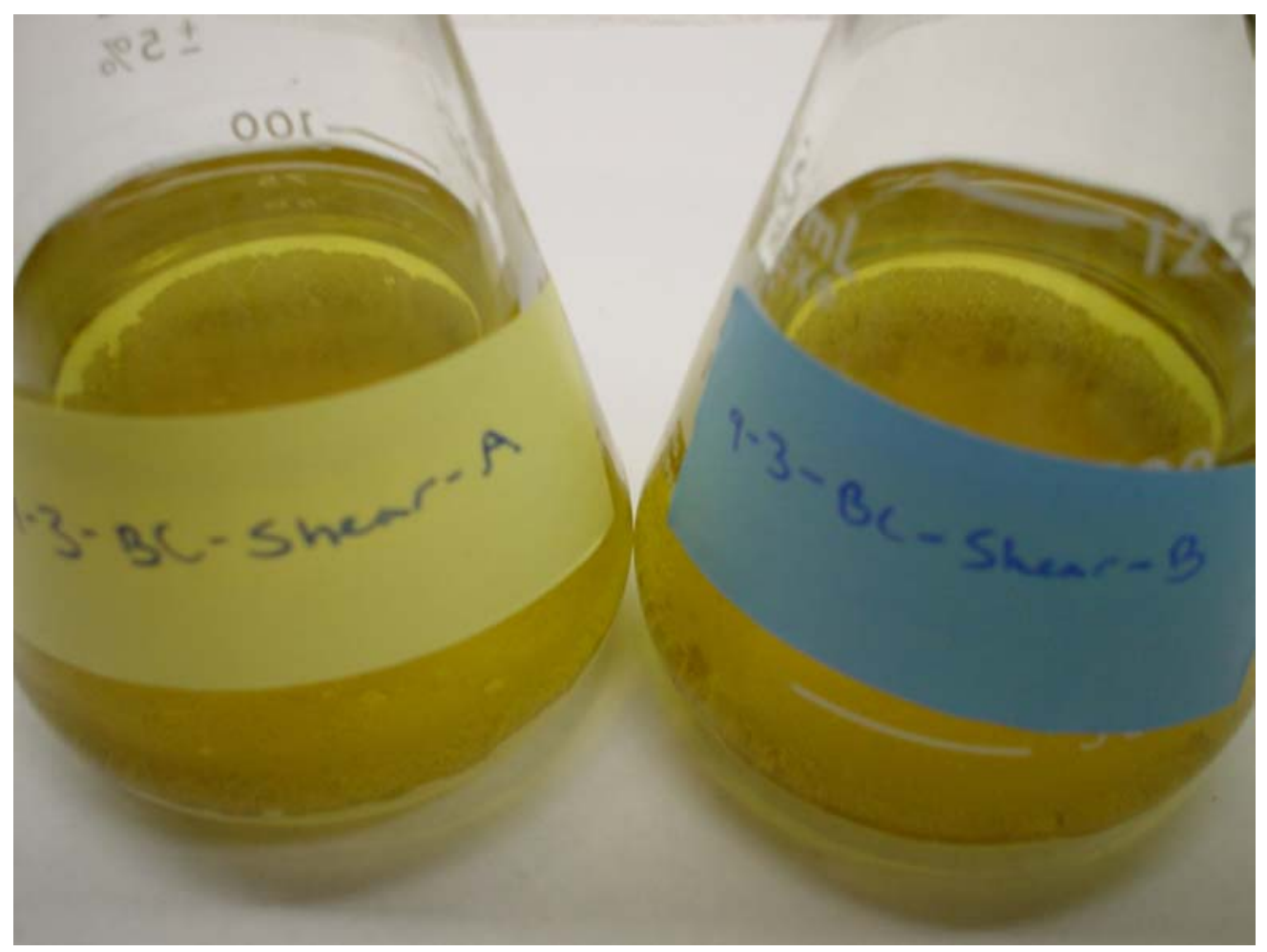

Figure F.13 Simulant AN-102 Sample 9-3-BC-Shear Filtrates

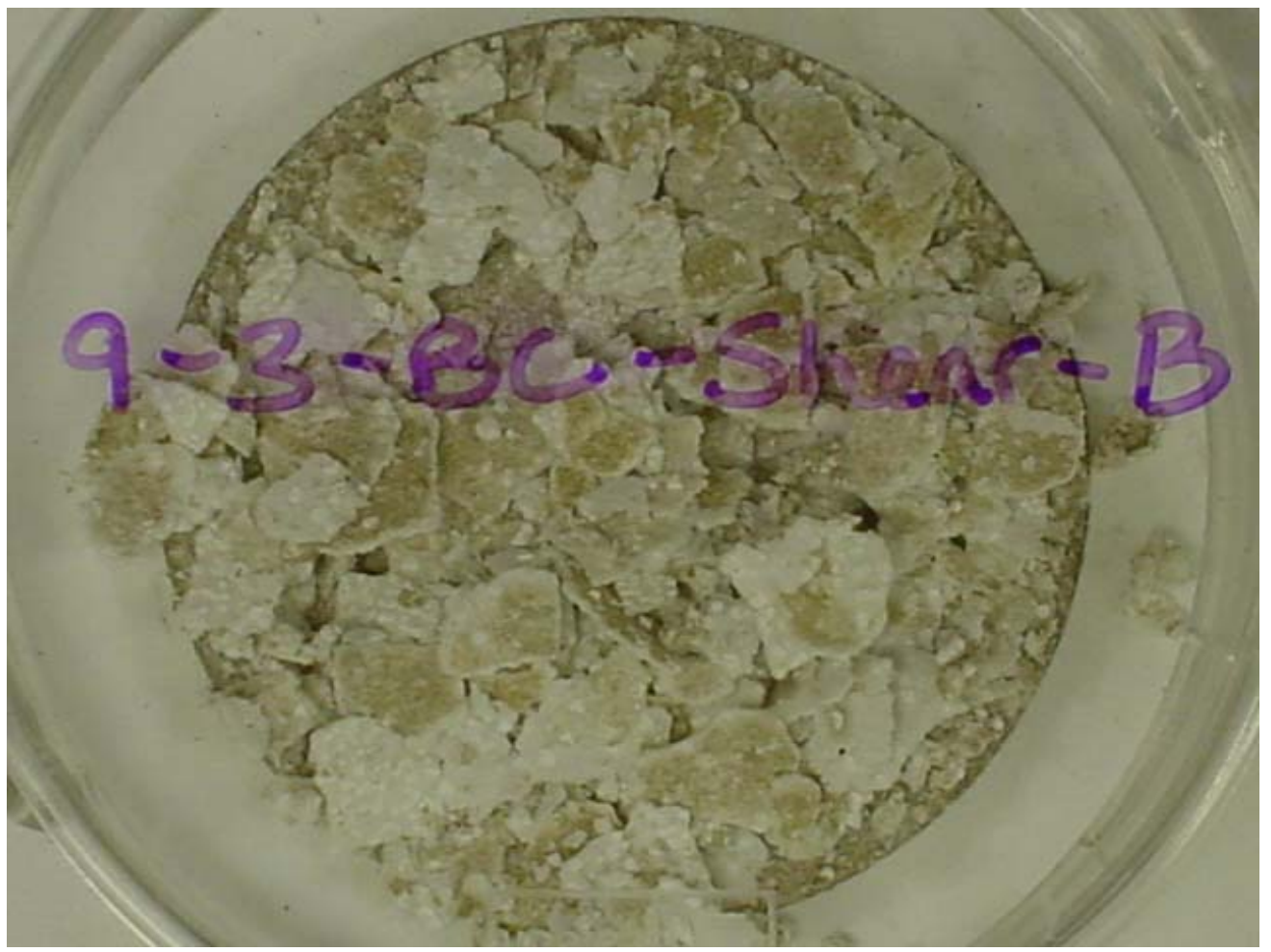

Figure F.14 Simulant AN-102 Sample 9-3-BC-Shear Filter 
WSRC-TR-2003-00232, Rev. 0

SRT-RPP-2003-00105, Rev. 0

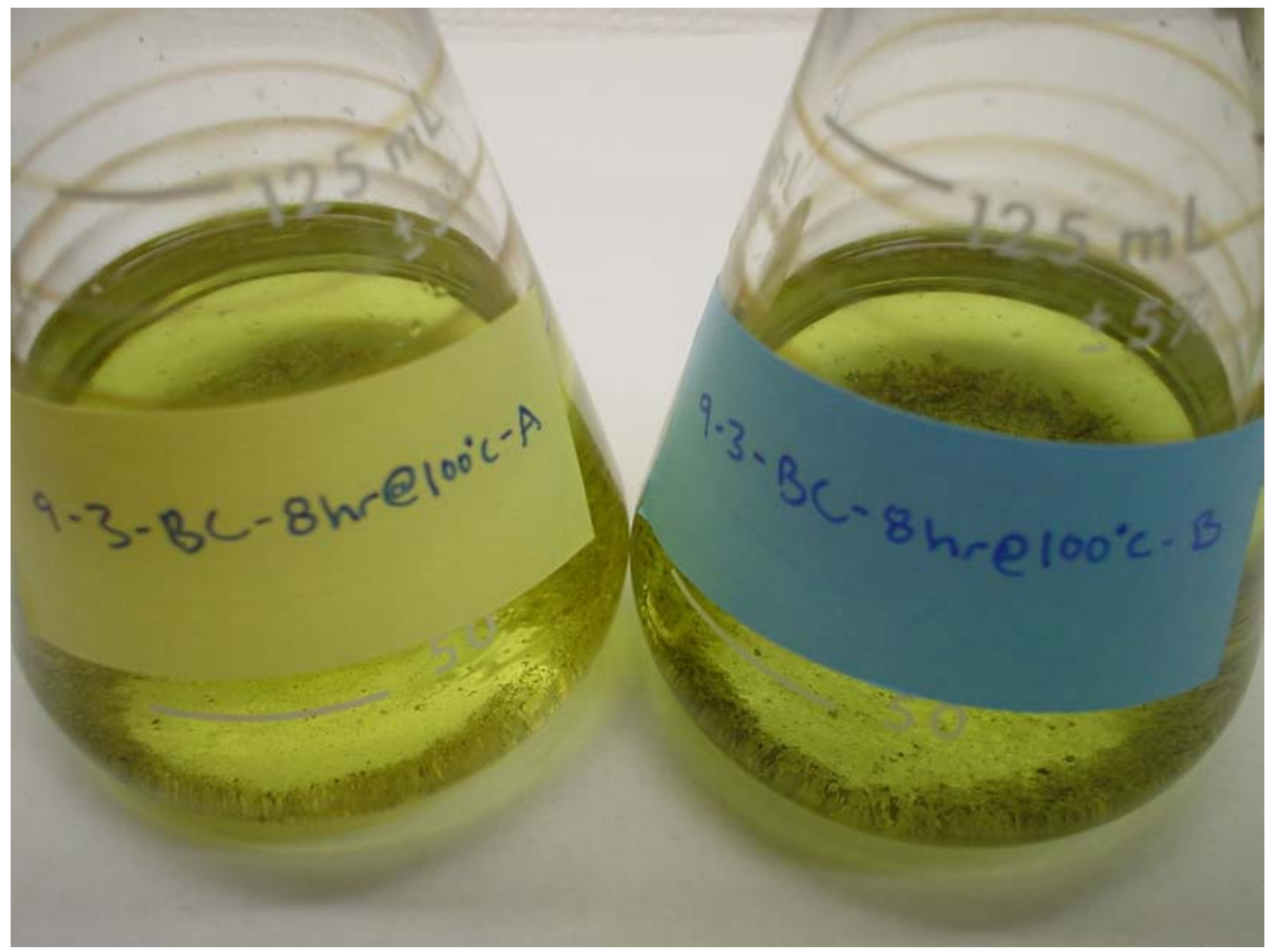

Figure F.15 Simulant AN-102 Sample 9-3-BC-8hr@100 $10{ }^{\circ}$ Filtrates

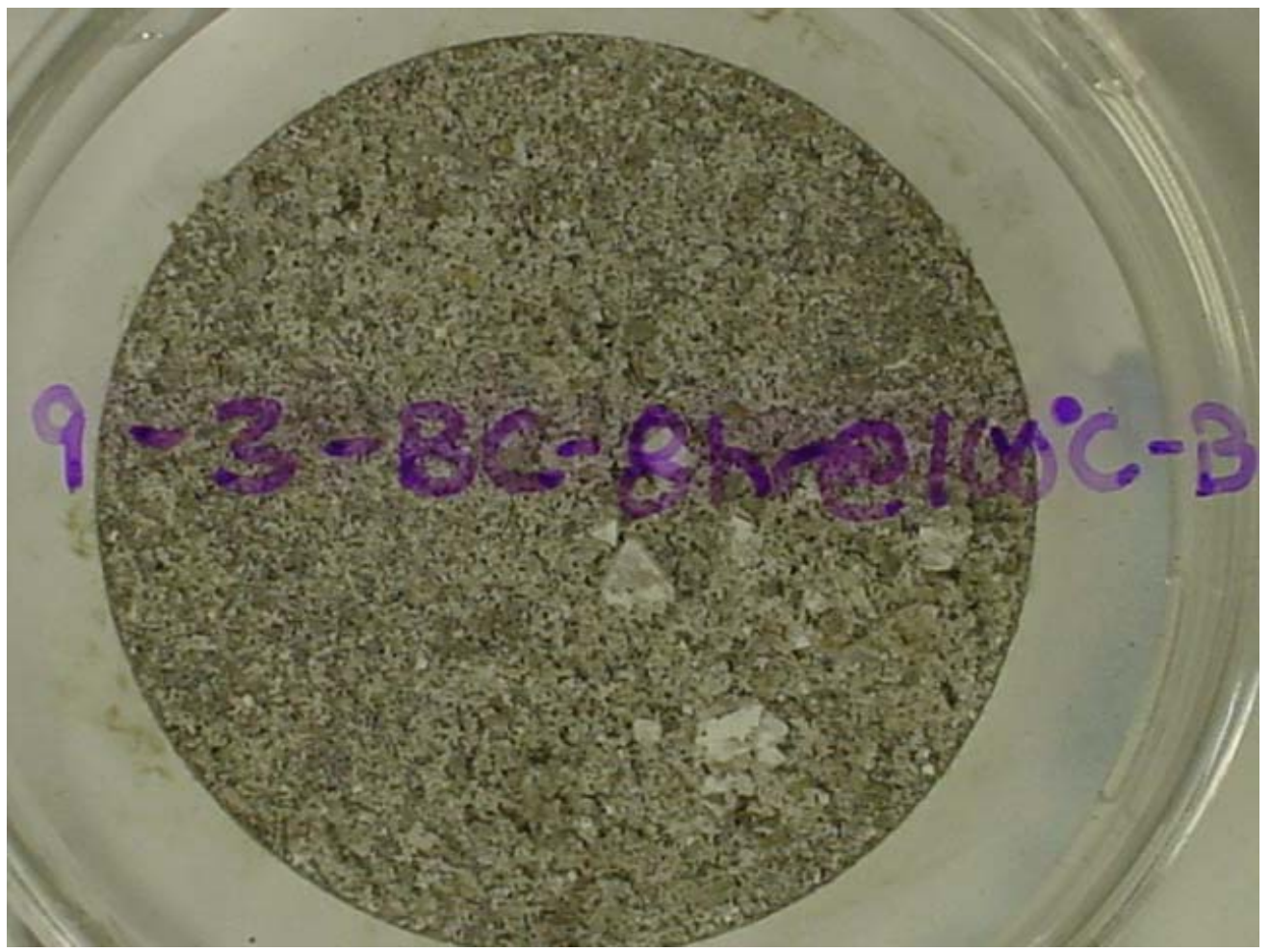

Figure F.16 Simulant AN-102 Sample 9-3-BC-8hr@100C Filter 
WSRC-TR-2003-00232, Rev. 0

SRT-RPP-2003-00105, Rev. 0

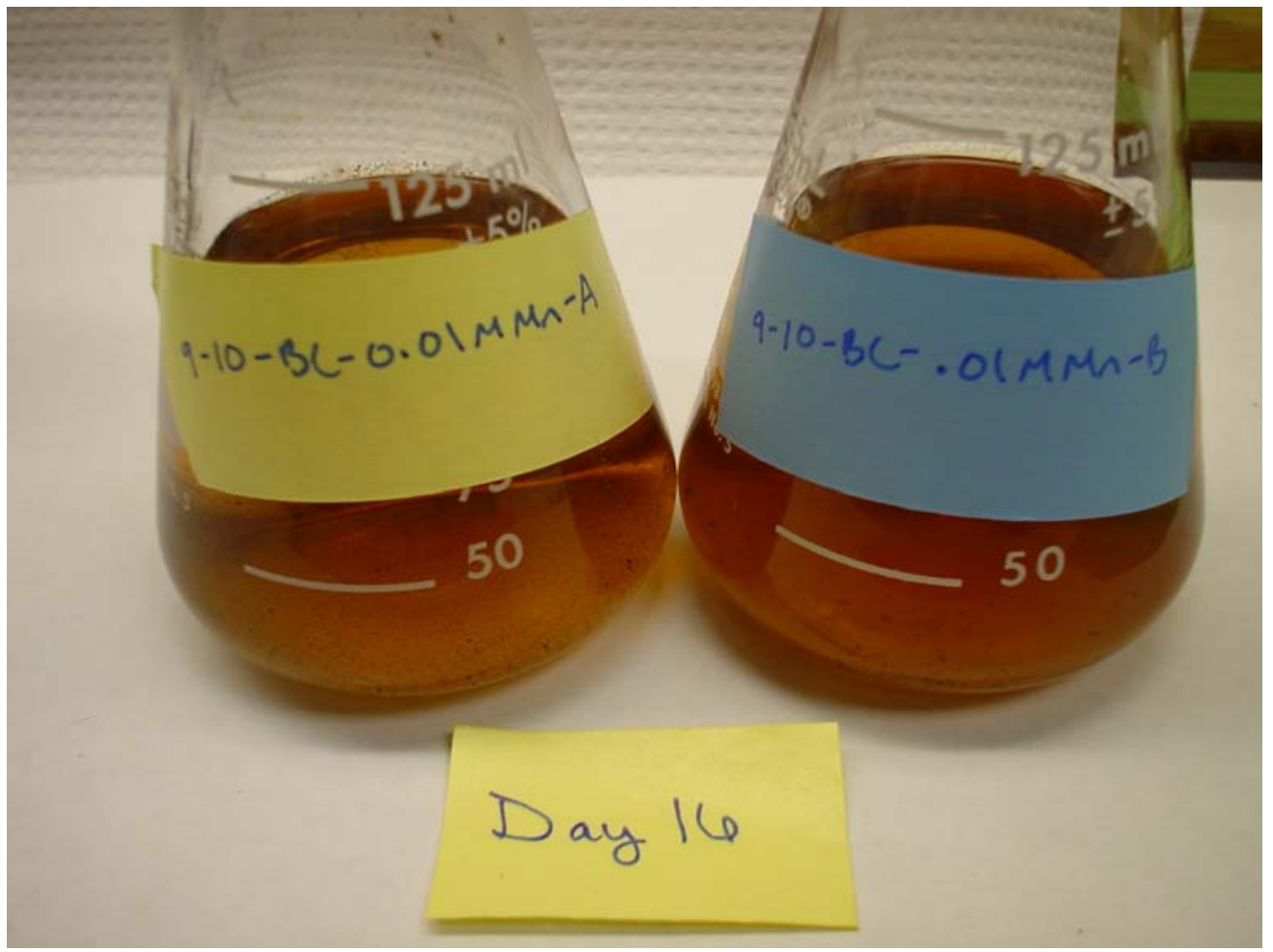

Figure F.17 Simulant AN-102 Sample 9-10-BC-0.01M Mn Filtrates

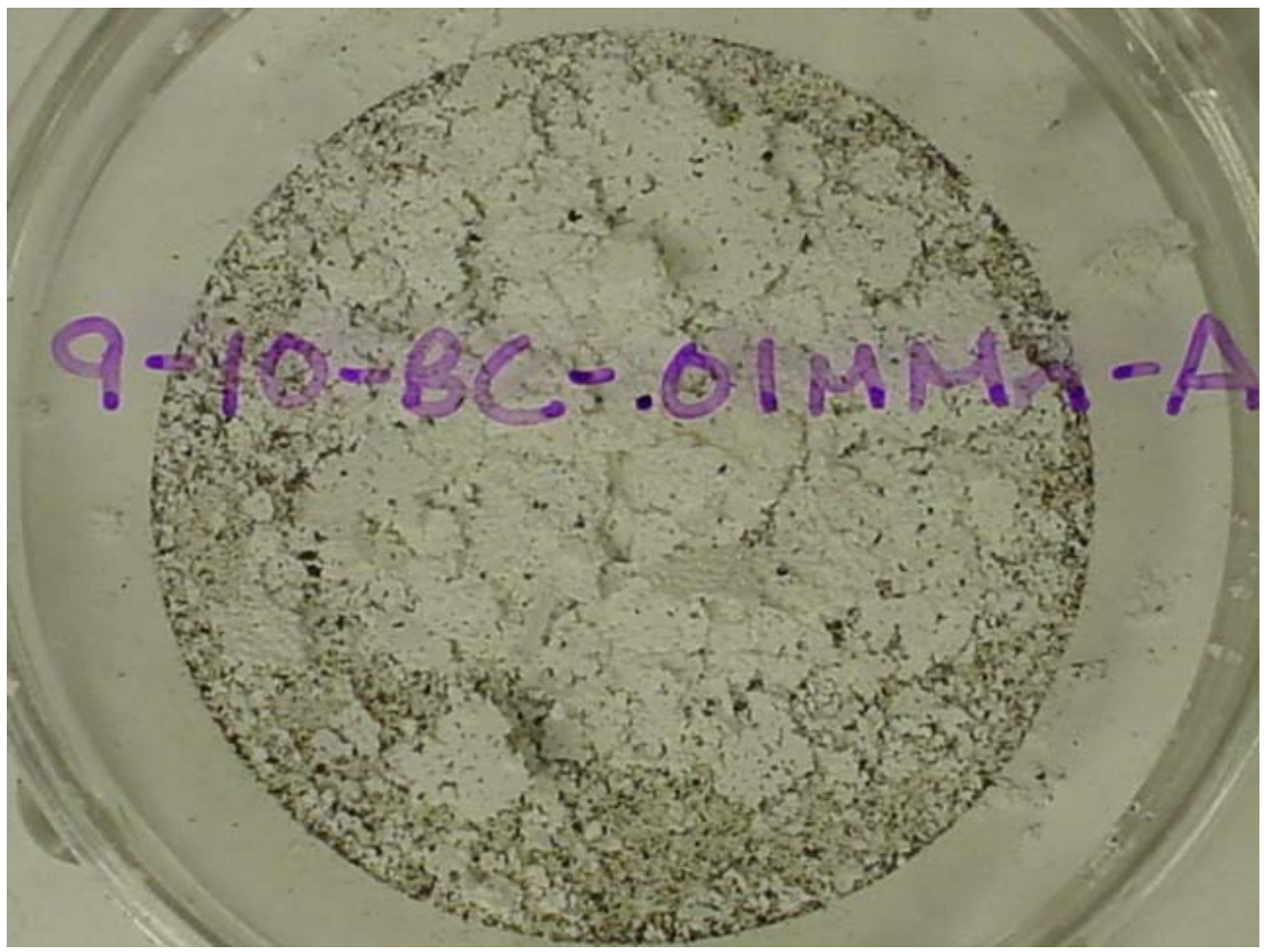

Figure F.18 Simulant AN-102 Sample 9-10-BC-0.01M Mn Filter 
WSRC-TR-2003-00232, Rev. 0

SRT-RPP-2003-00105, Rev. 0

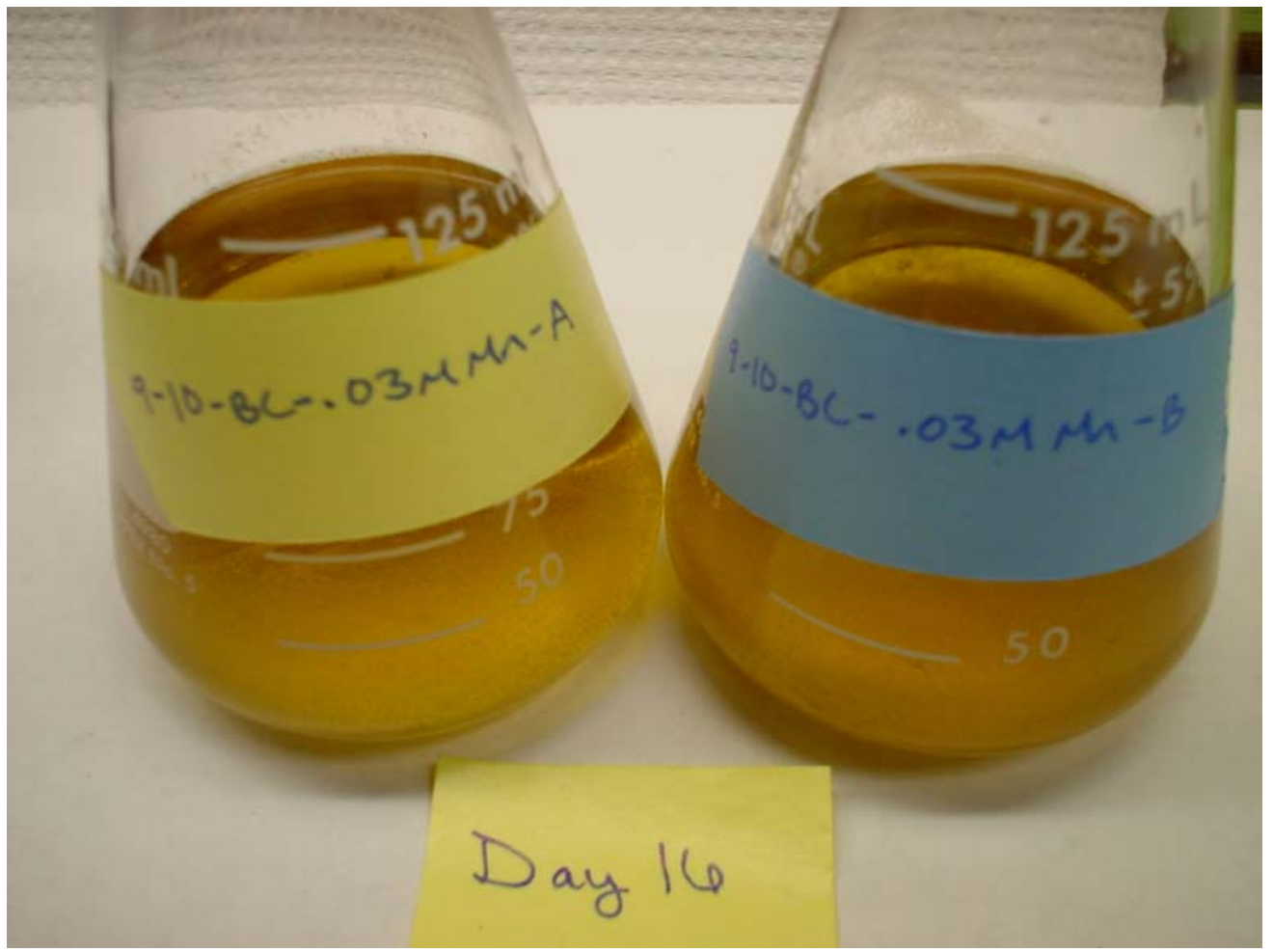

Figure F.19 Simulant AN-102 Sample 9-10-BC-0.03M Mn Filtrates

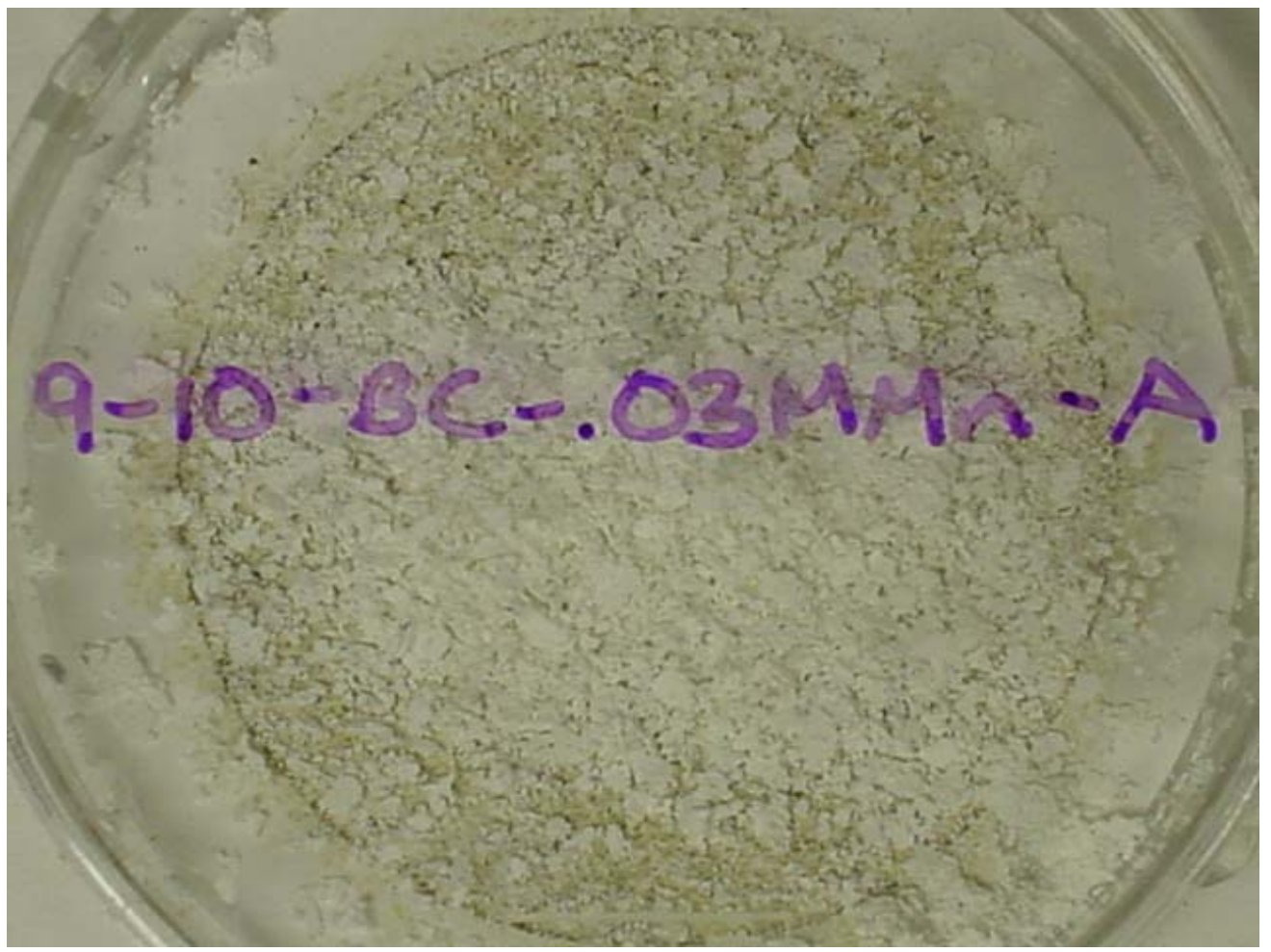

Figure F.20 Simulant AN-102 Sample 9-10-BC-0.03M Mn Filter 
WSRC-TR-2003-00232, Rev. 0

SRT-RPP-2003-00105, Rev. 0

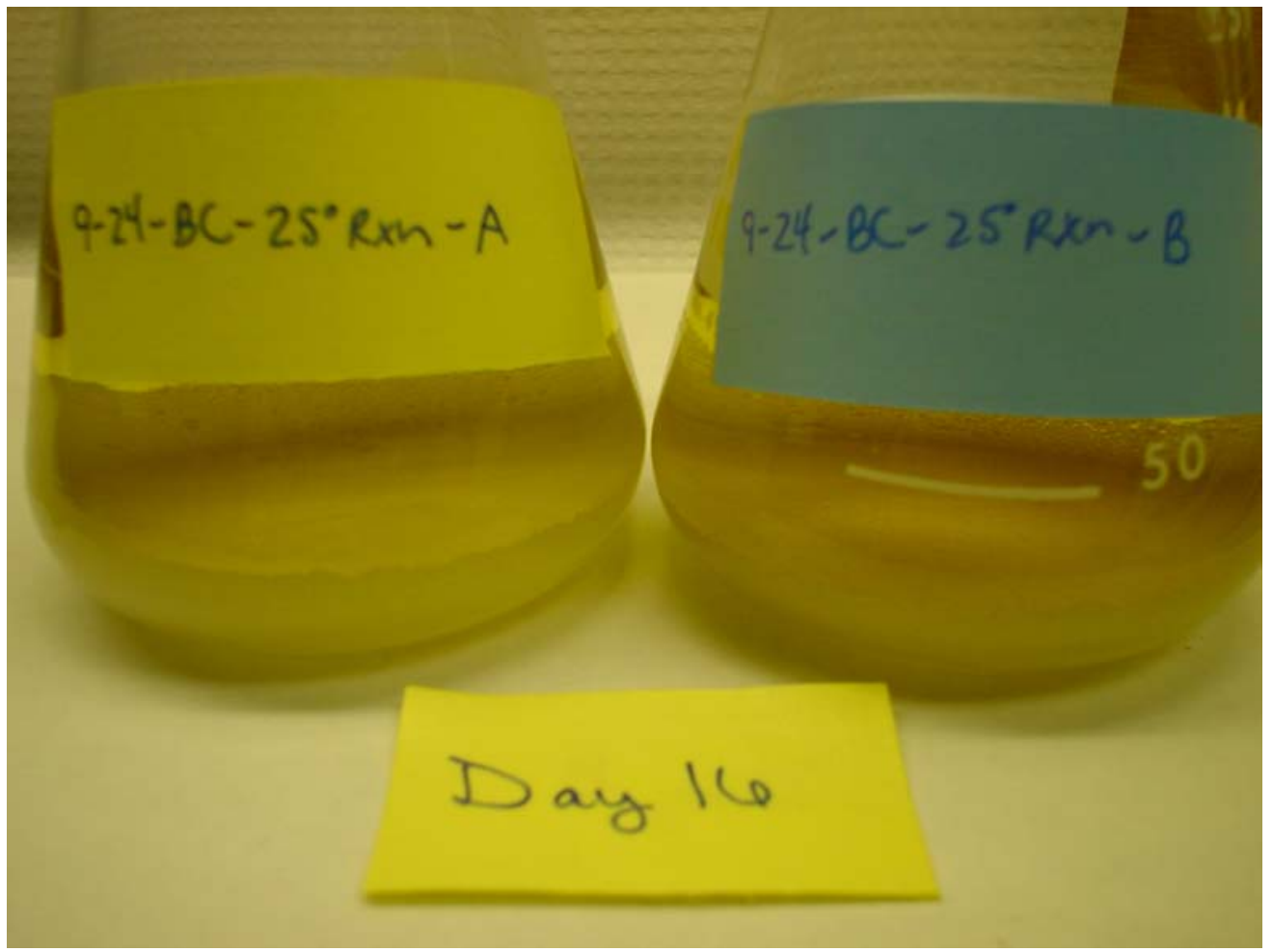

Figure F.21 Simulant AN-102 Sample 9-24-BC-25C Rxn Filtrates

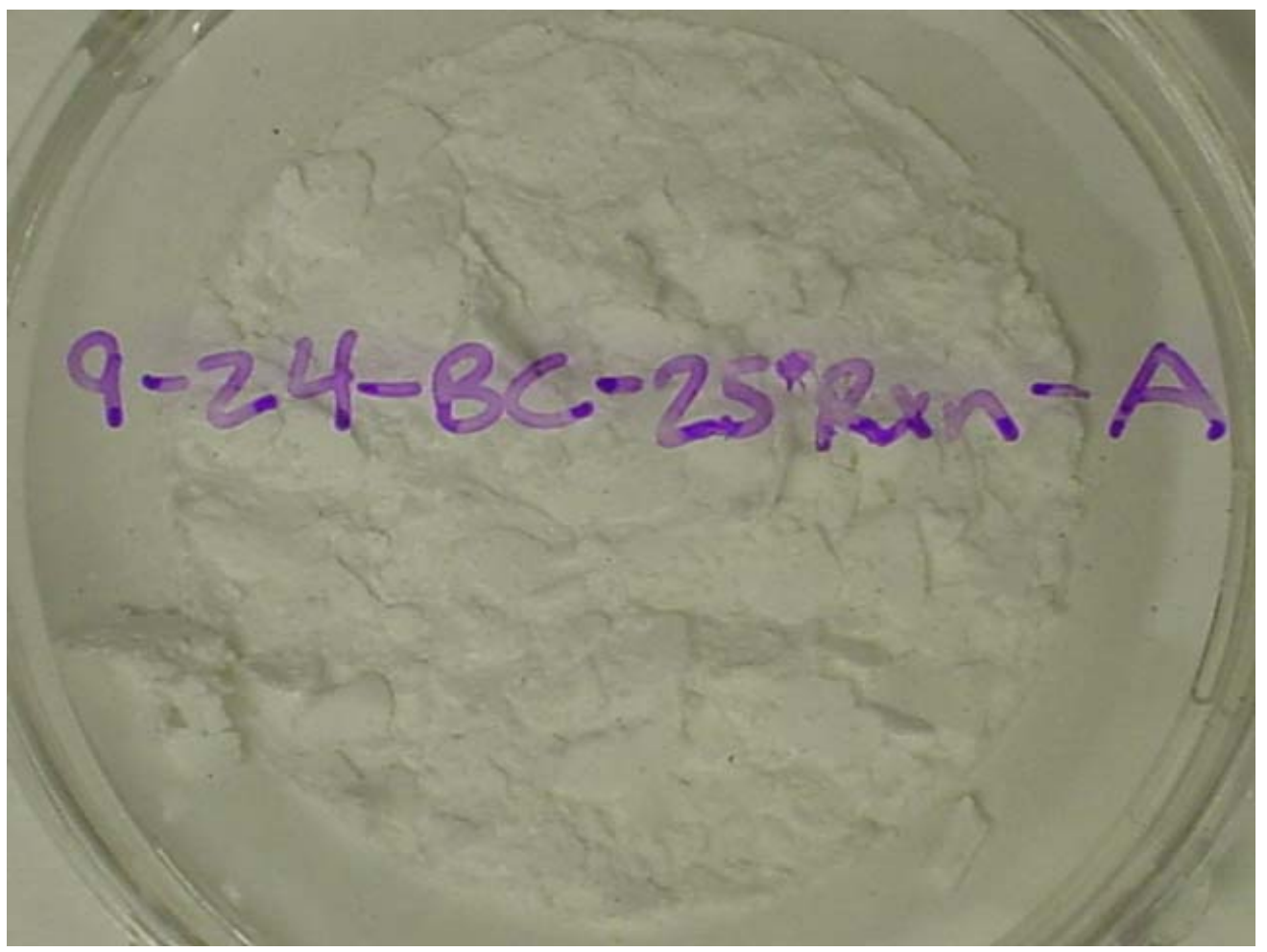

Figure F.22 Simulant AN-102 Sample 9-24-BC-25 ${ }^{\circ}$ C Rxn Filters 
WSRC-TR-2003-00232, Rev. 0

SRT-RPP-2003-00105, Rev. 0

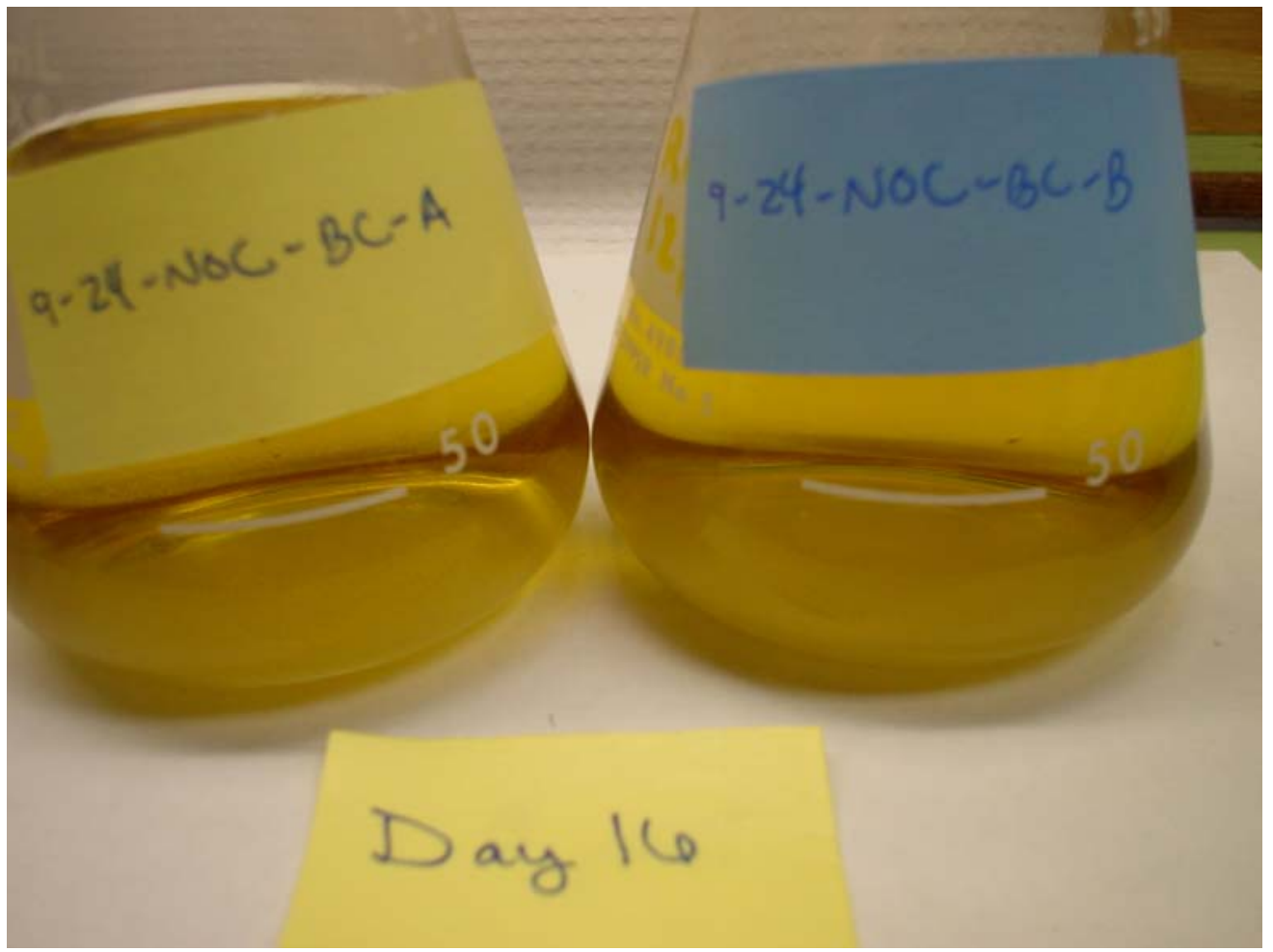

Figure F.23 Simulant AN-102 Sample 9-24-NOC-BC Filtrates

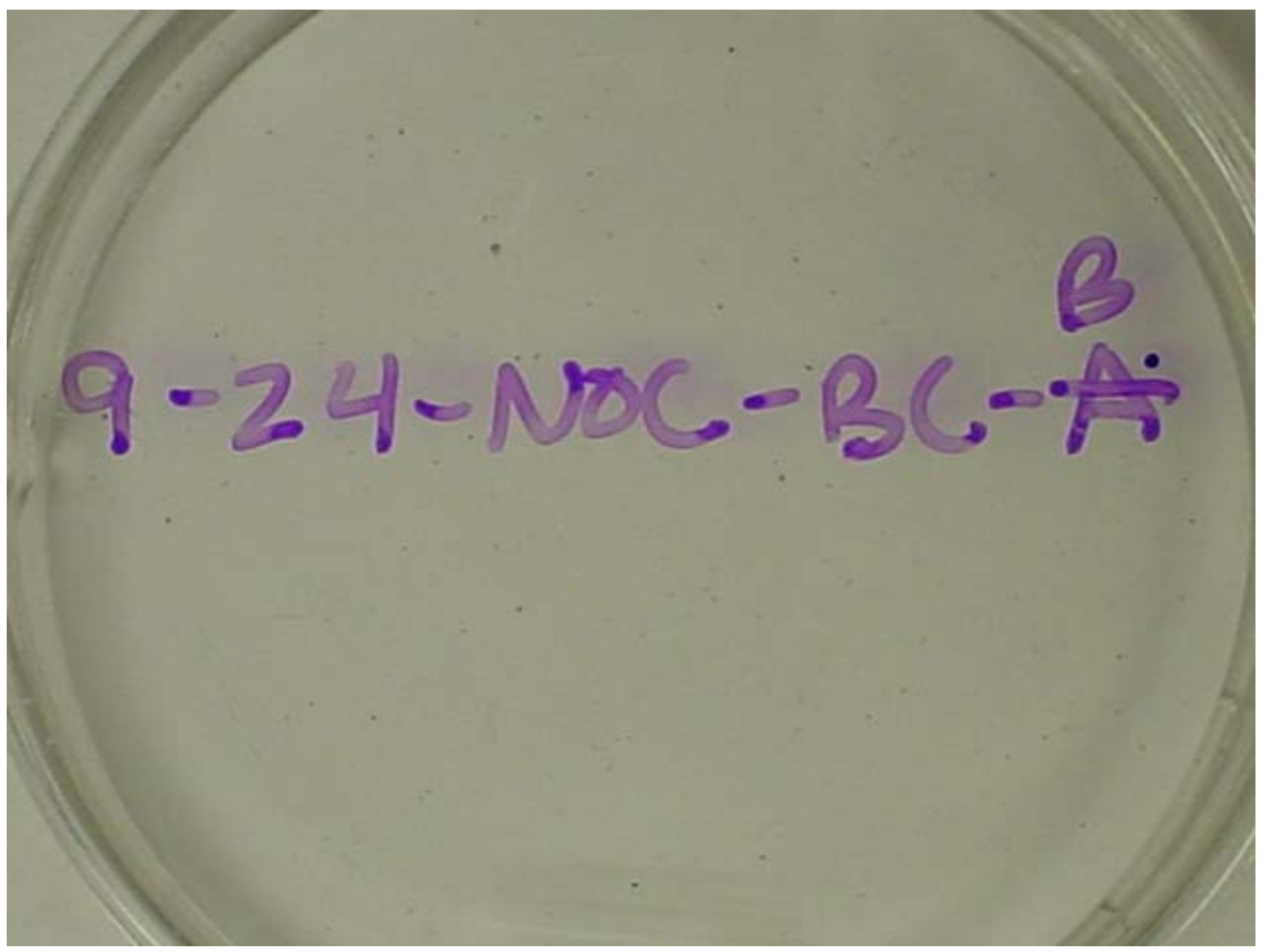

Figure F.24 Simulant AN-102 Sample 9-24-NOC-BC Filter 
WSRC-TR-2003-00232, Rev. 0

SRT-RPP-2003-00105, Rev. 0

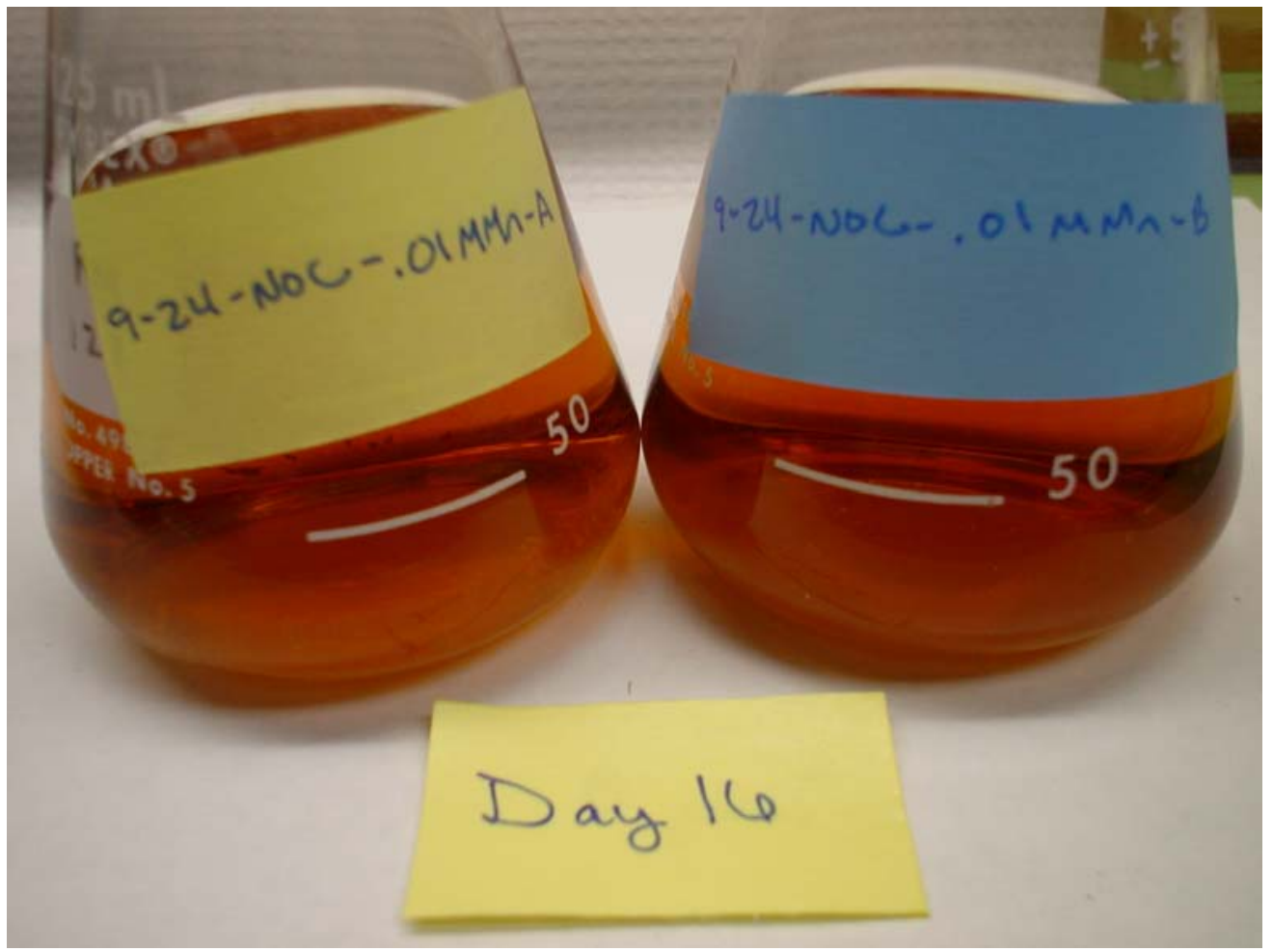

Figure F.25 Simulant AN-102 Sample 9-24-NOC-0.01M Mn Filtrates

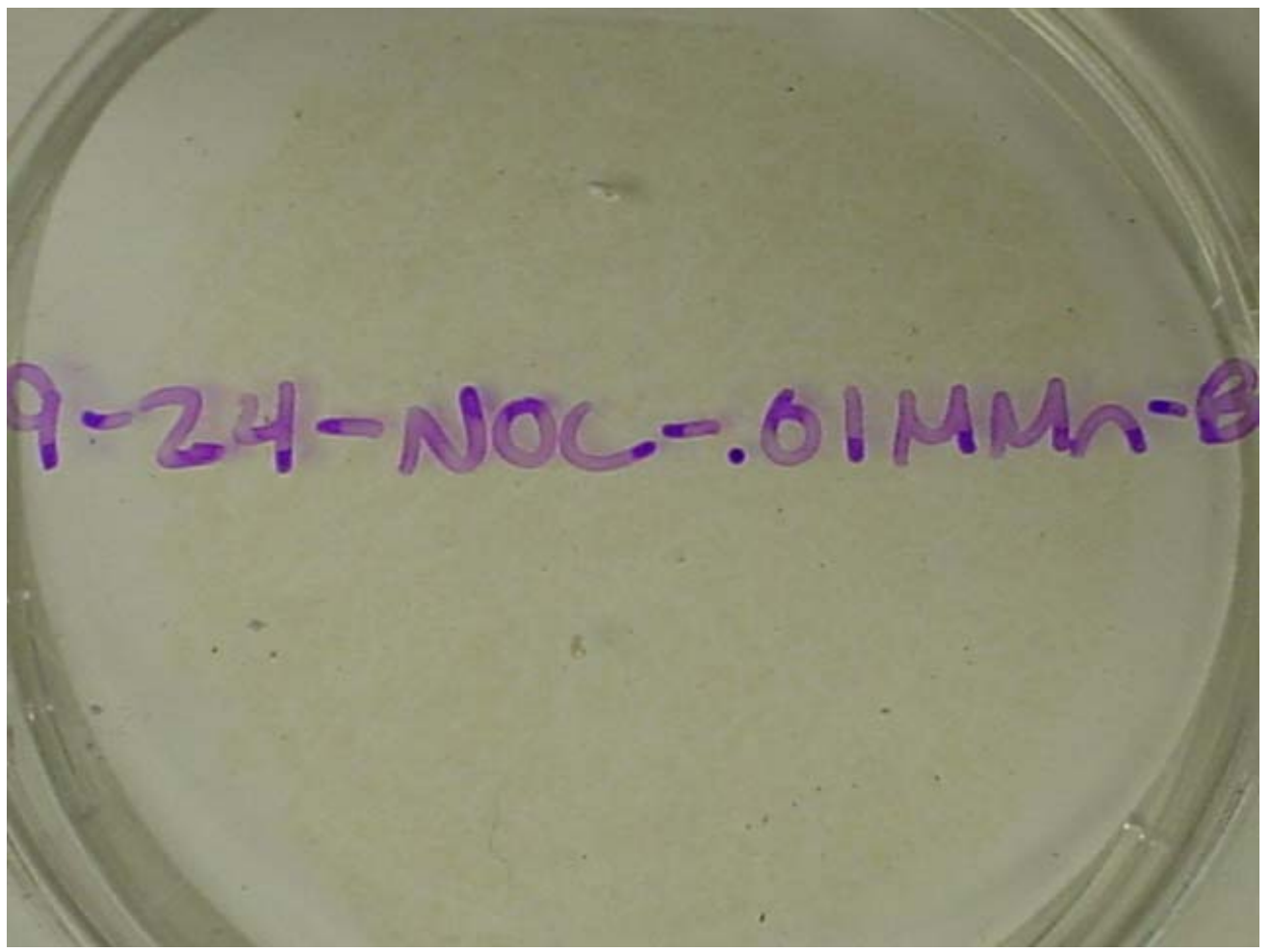

Figure F.26 Simulant AN-102 Sample 9-24-NOC-0.01M Mn Filter 
WSRC-TR-2003-00232, Rev. 0

SRT-RPP-2003-00105, Rev. 0

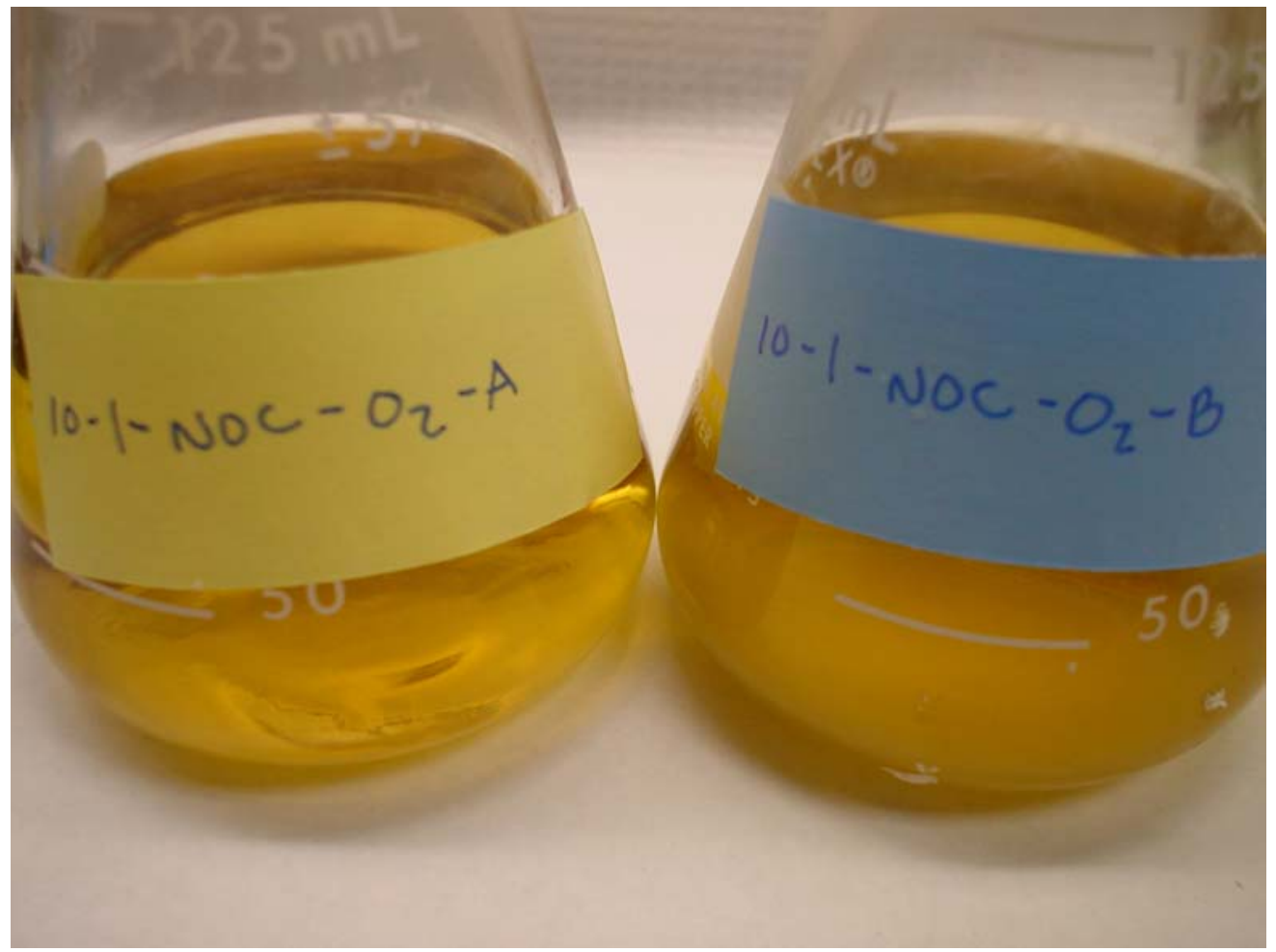

Figure F.27 Simulant AN-102 Sample 10-1-NOC-O 2 Filtrates

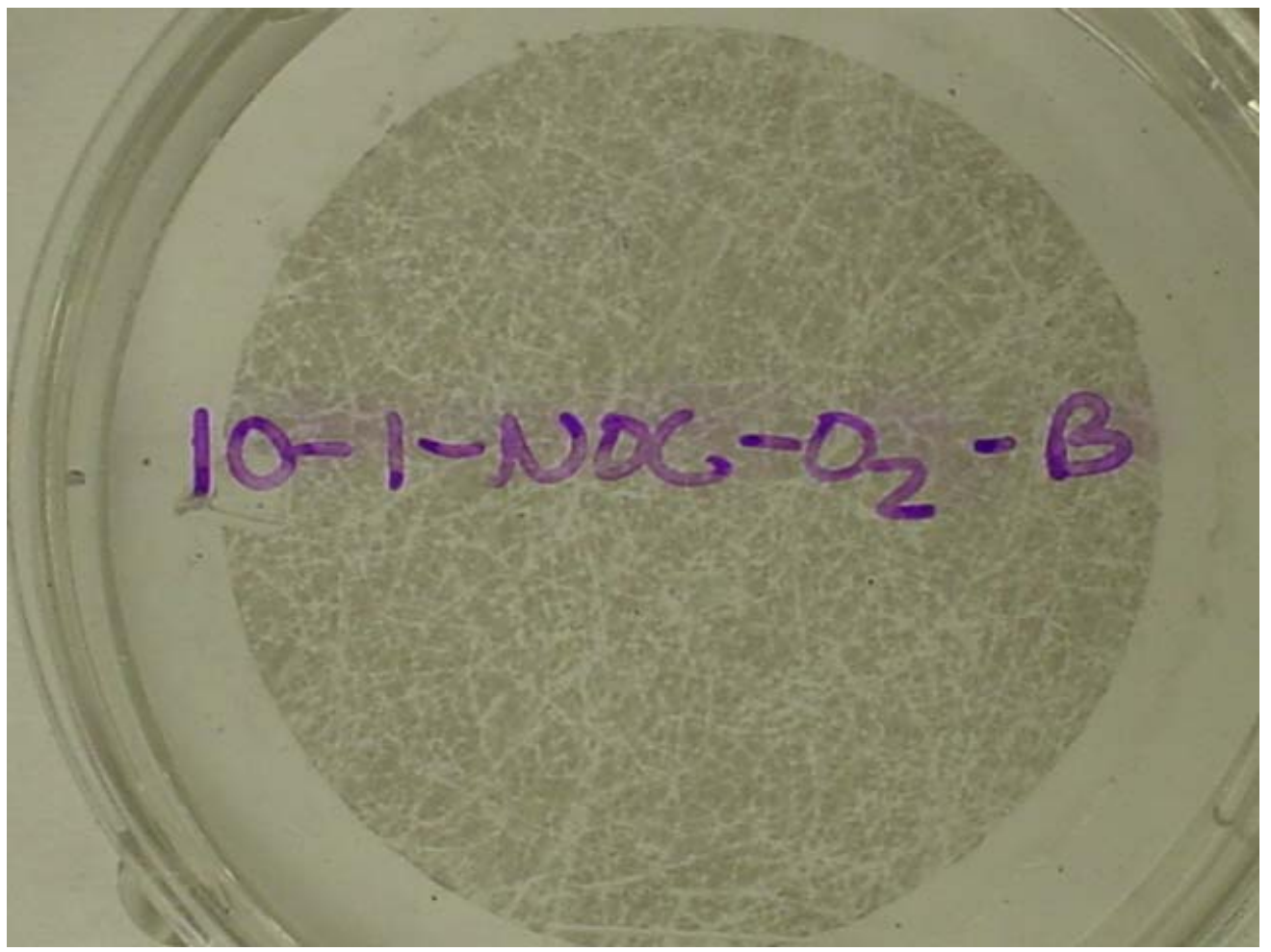

Figure F.28 Simulant AN-102 Sample 10-1-NOC-O 2 Filter 
WSRC-TR-2003-00232, Rev. 0

SRT-RPP-2003-00105, Rev. 0

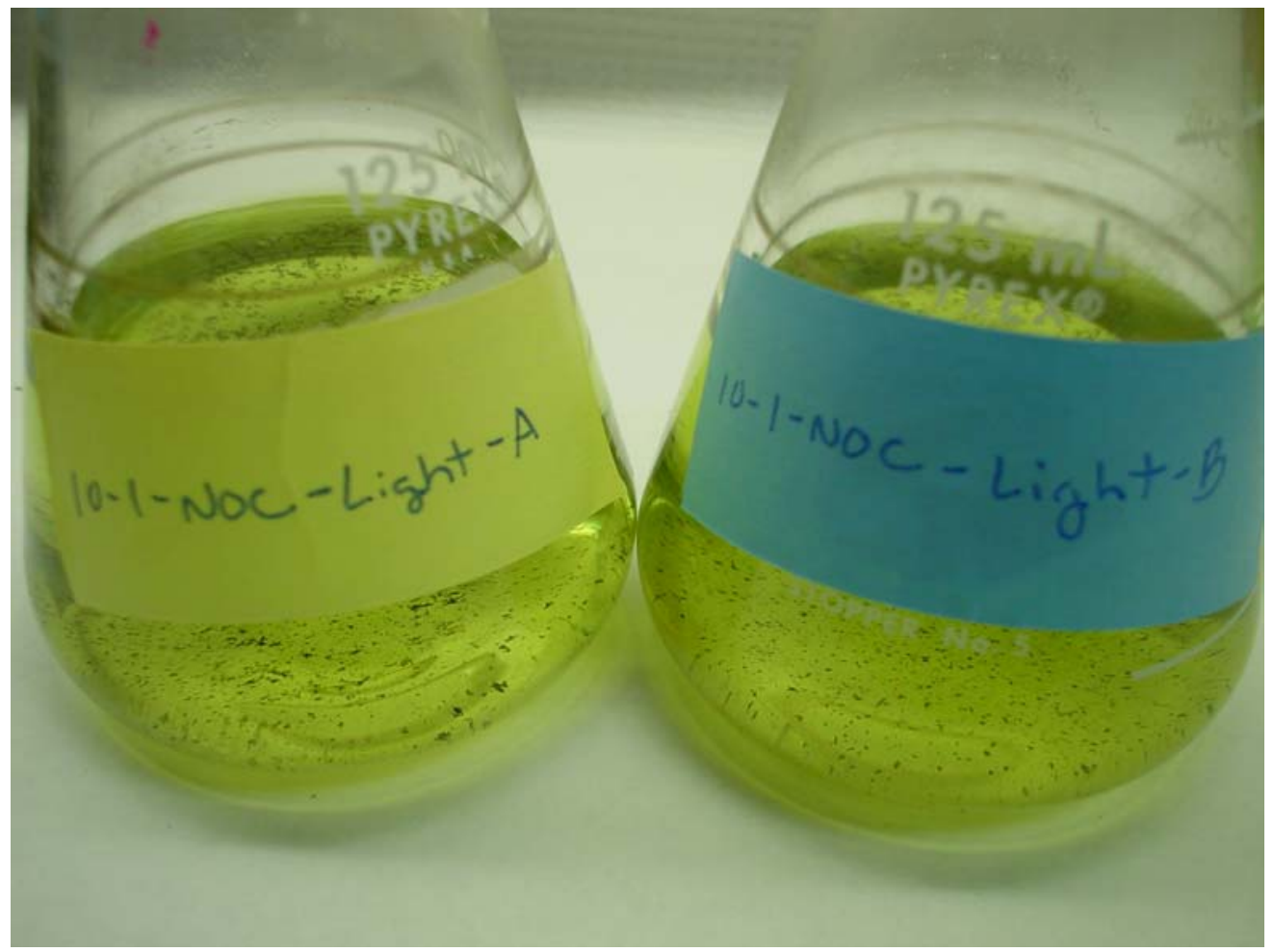

Figure F.29 Simulant AN-102 Sample 10-1-NOC-Light Filtrates

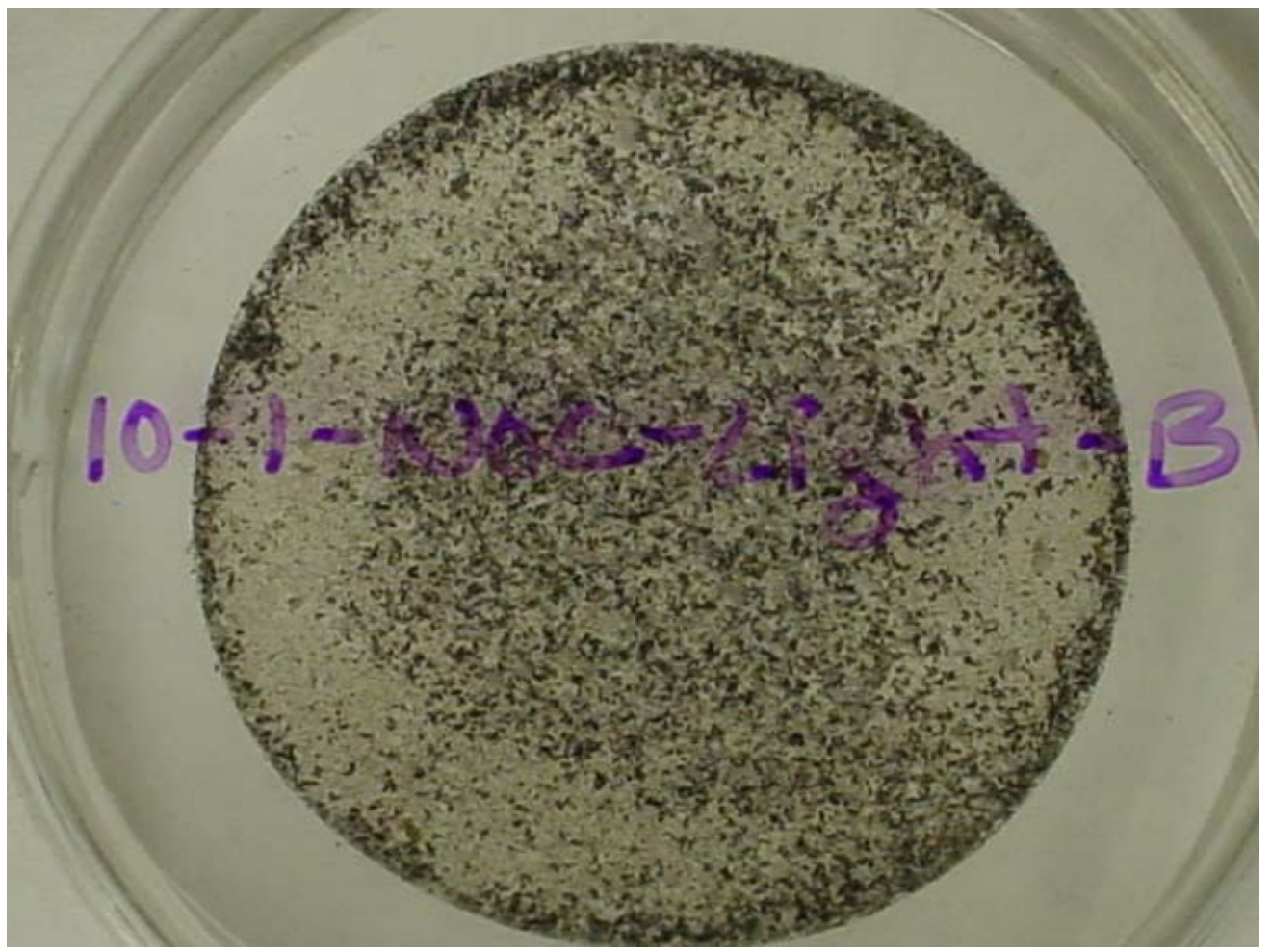

Figure F.30 Simulant AN-102 Sample 10-1-NOC-Light Filter 
WSRC-TR-2003-00232, Rev. 0

SRT-RPP-2003-00105, Rev. 0

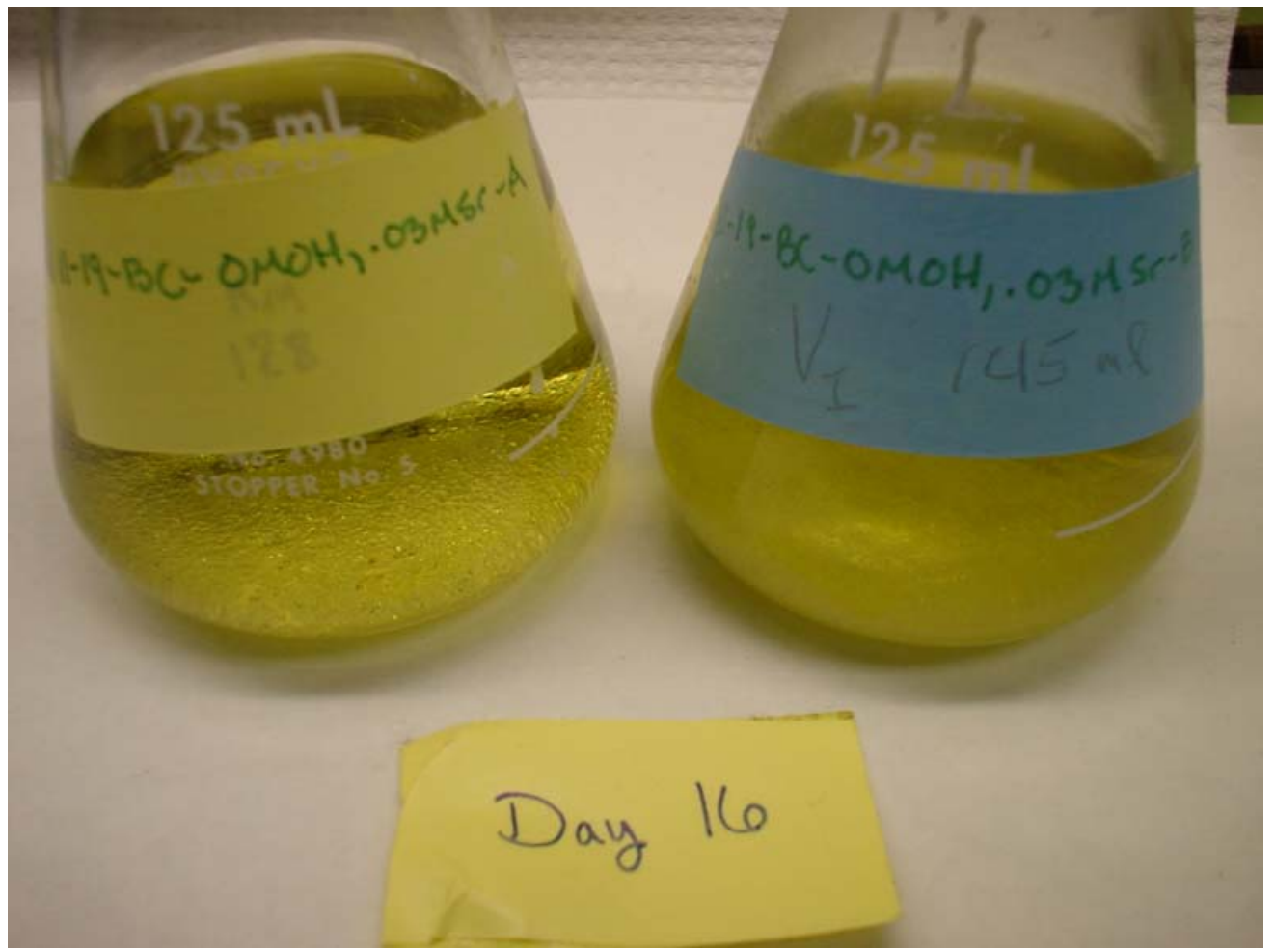

Figure F.31 Simulant AN-102 Sample 11-19-BC-0.0M OH, 0.03M Sr Filtrates

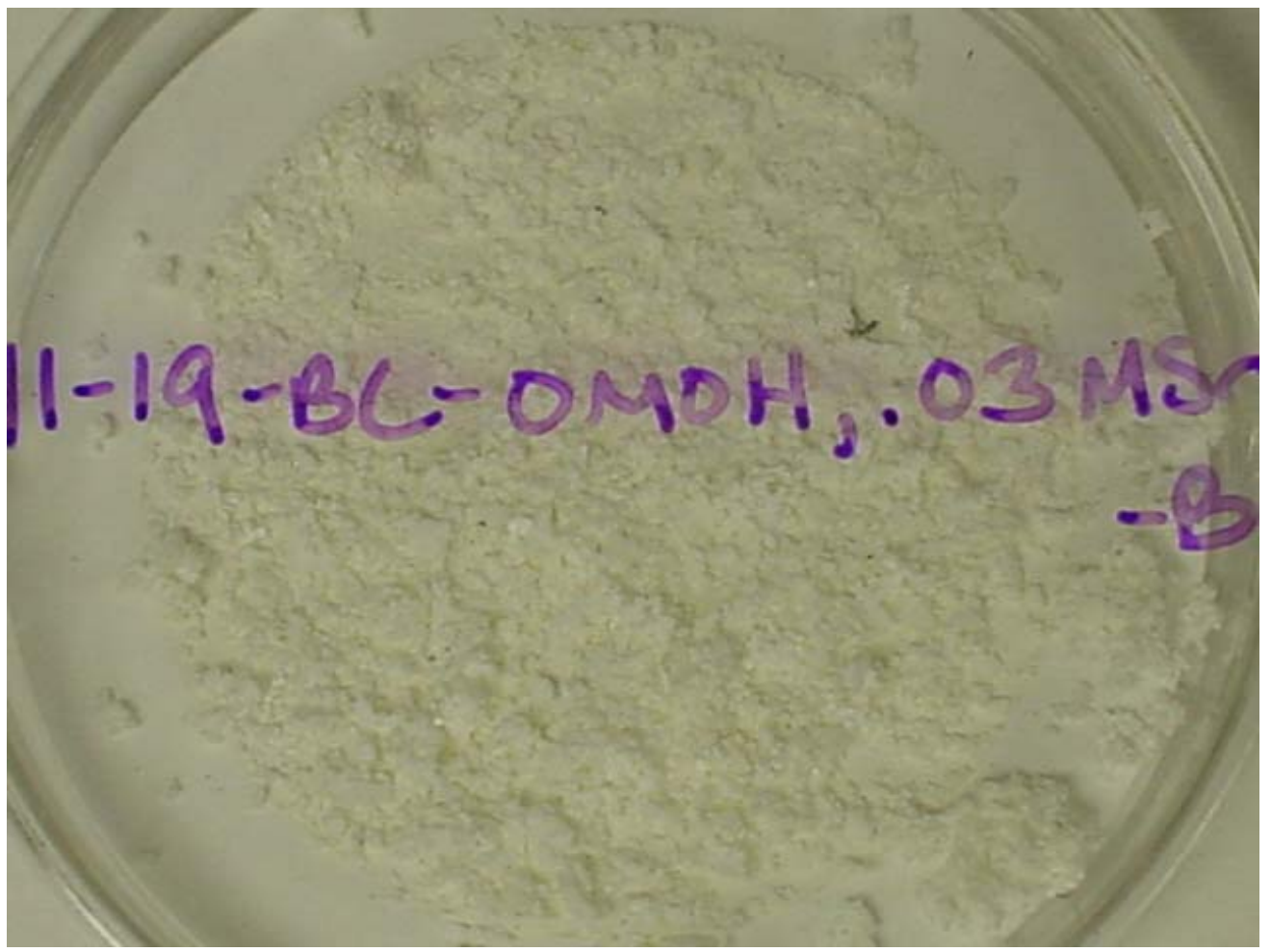

Figure F.32 Simulant AN-102 Sample 11-19-BC-0.0M OH, 0.03M Sr Filter 
WSRC-TR-2003-00232, Rev. 0

SRT-RPP-2003-00105, Rev. 0

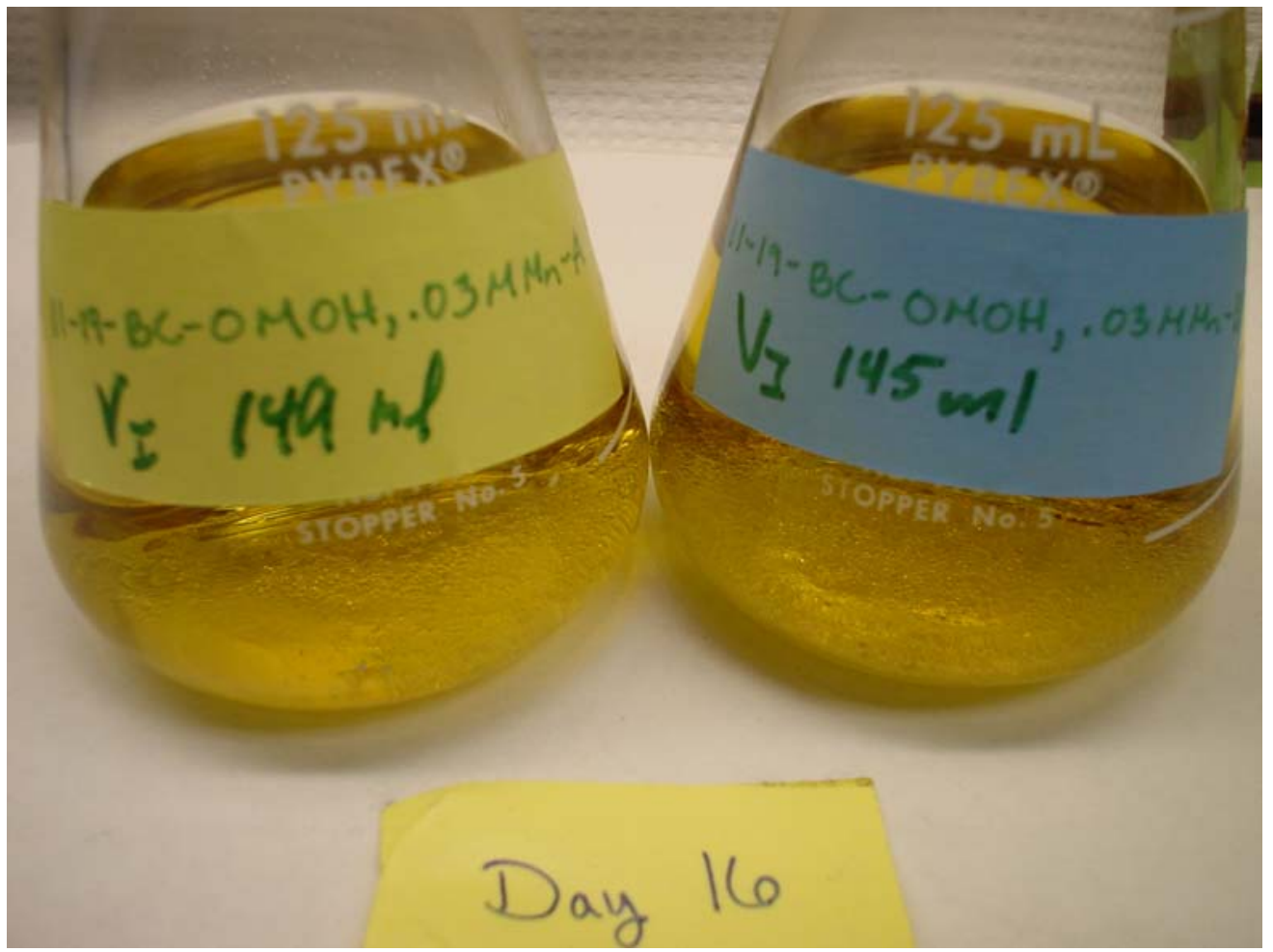

Figure F.33 Simulant AN-102 Sample 11-19-BC-0.0M OH, 0.03M Mn Filtrates

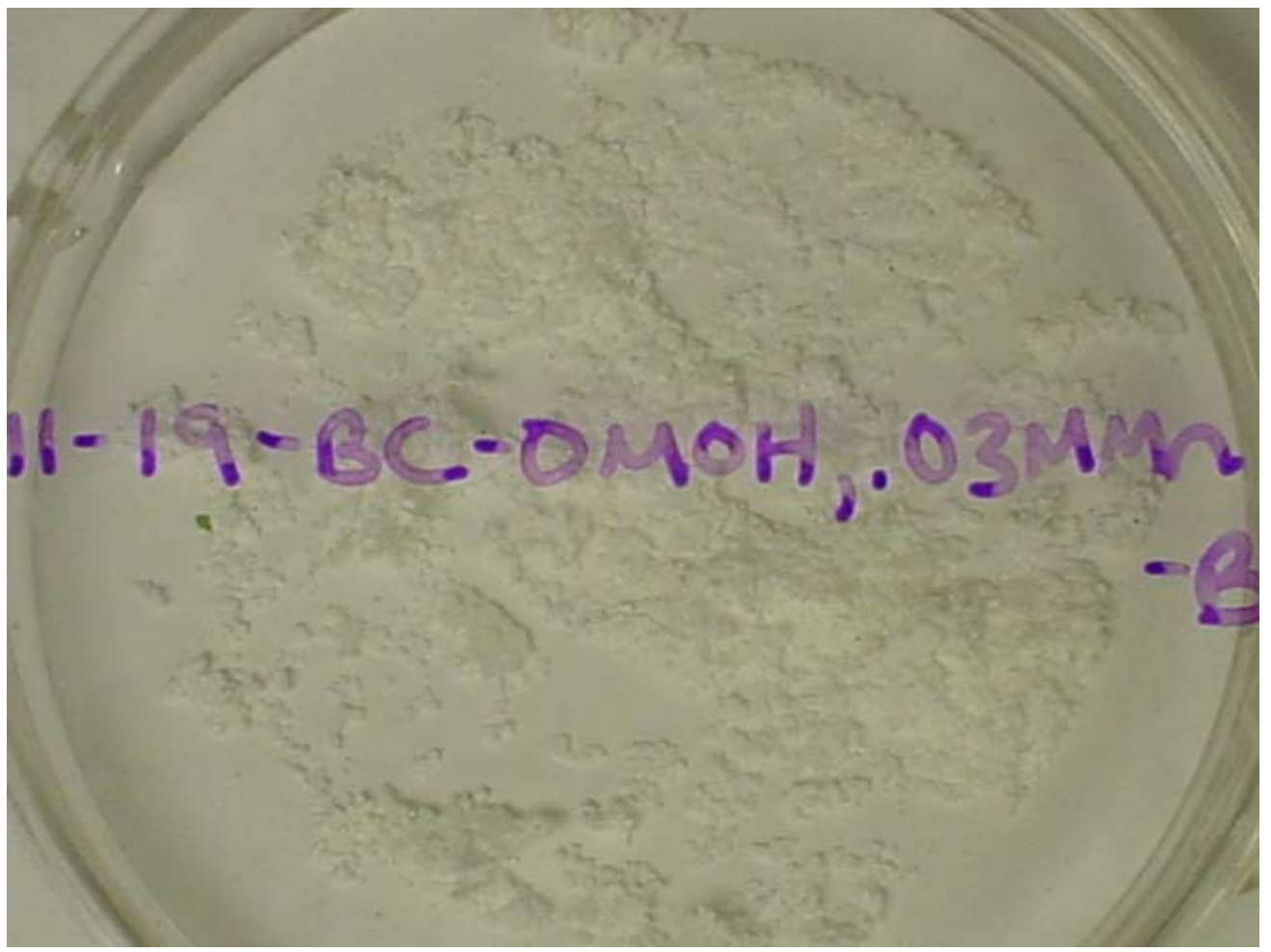

Figure F.34 Simulant AN-102 Sample 11-19-BC-0.0M OH, 0.03M Mn Filter 
WSRC-TR-2003-00232, Rev. 0

SRT-RPP-2003-00105, Rev. 0

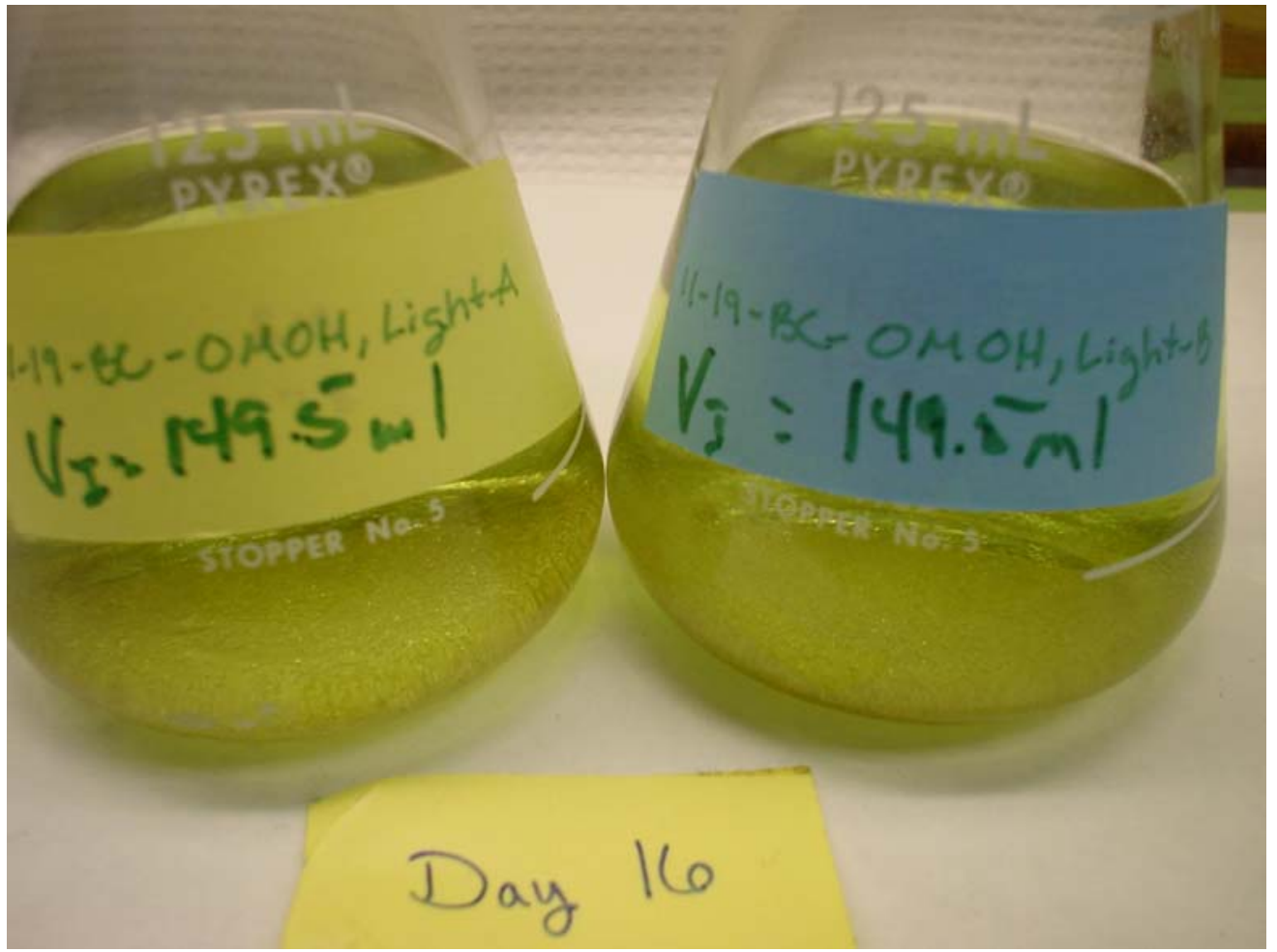

Figure F.35 Simulant AN-102 Sample 11-19-BC-0.0M OH, Light Filtrates

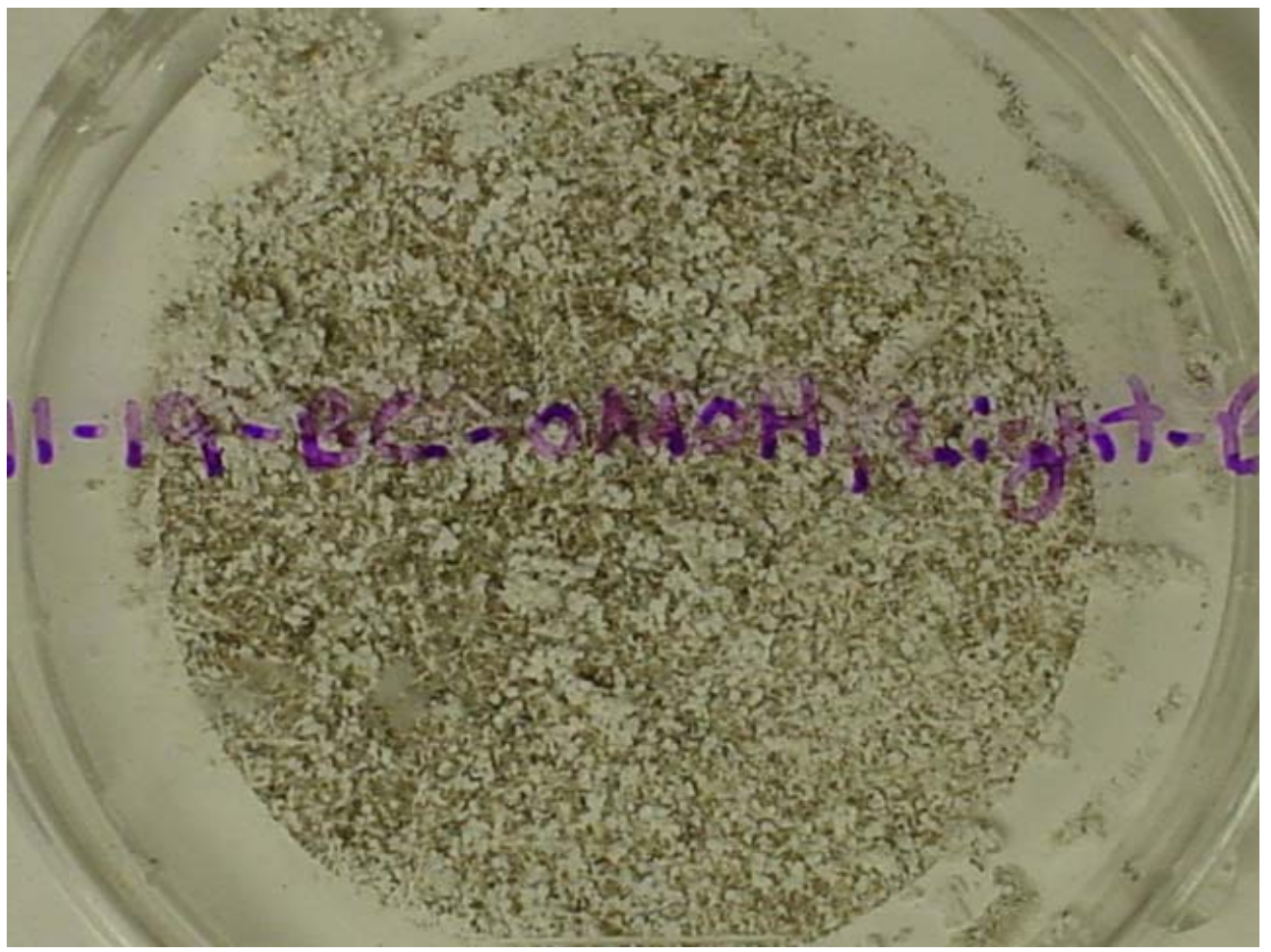

Figure F.36 Simulant AN-102 Sample 11-19-BC-0.0M OH, Light Filter 
WSRC-TR-2003-00232, Rev. 0

SRT-RPP-2003-00105, Rev. 0

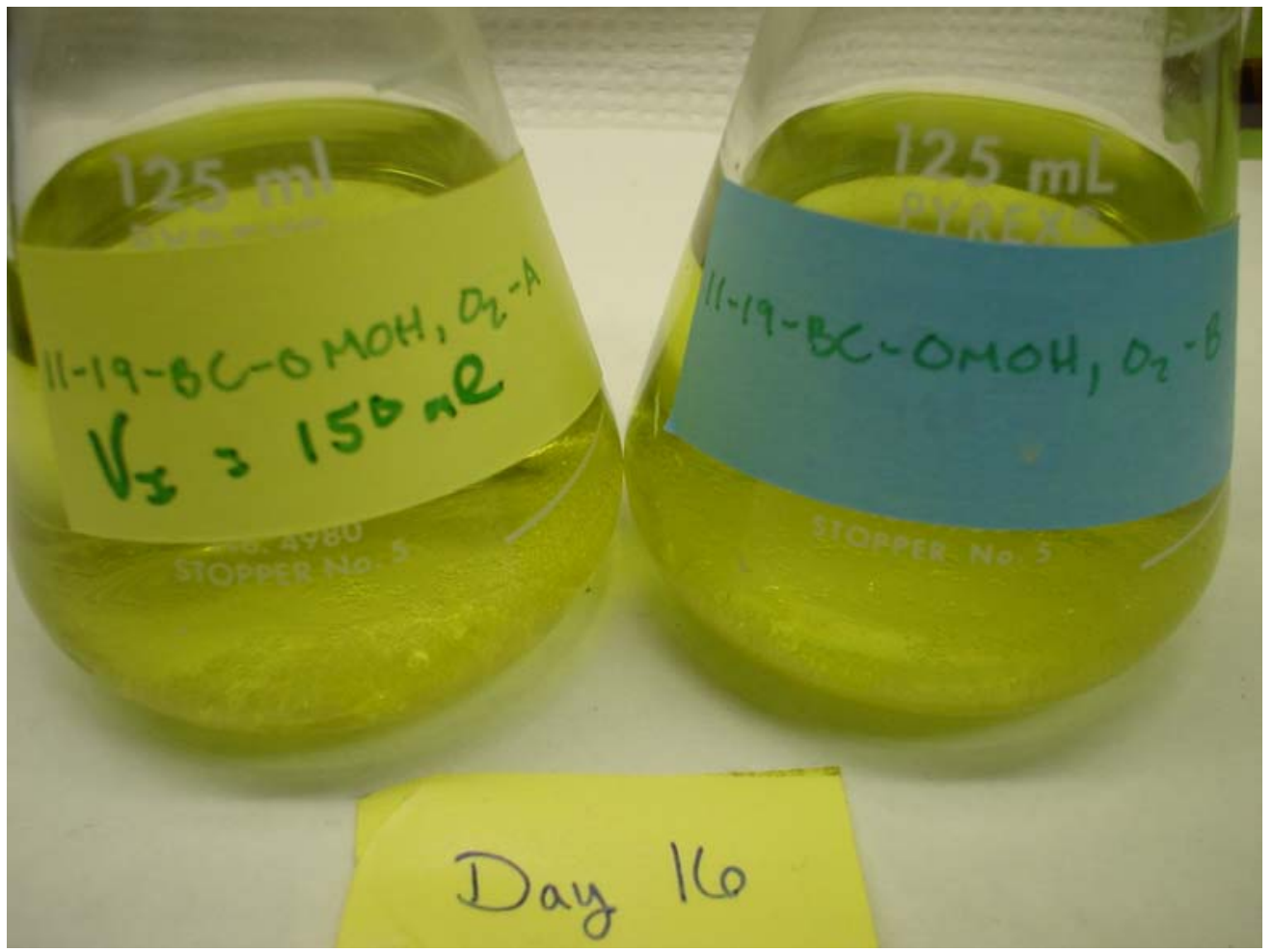

Figure F.37 Simulant AN-102 Sample 11-19-BC-0.0M OH, $\mathrm{O}_{2}$ Filtrates

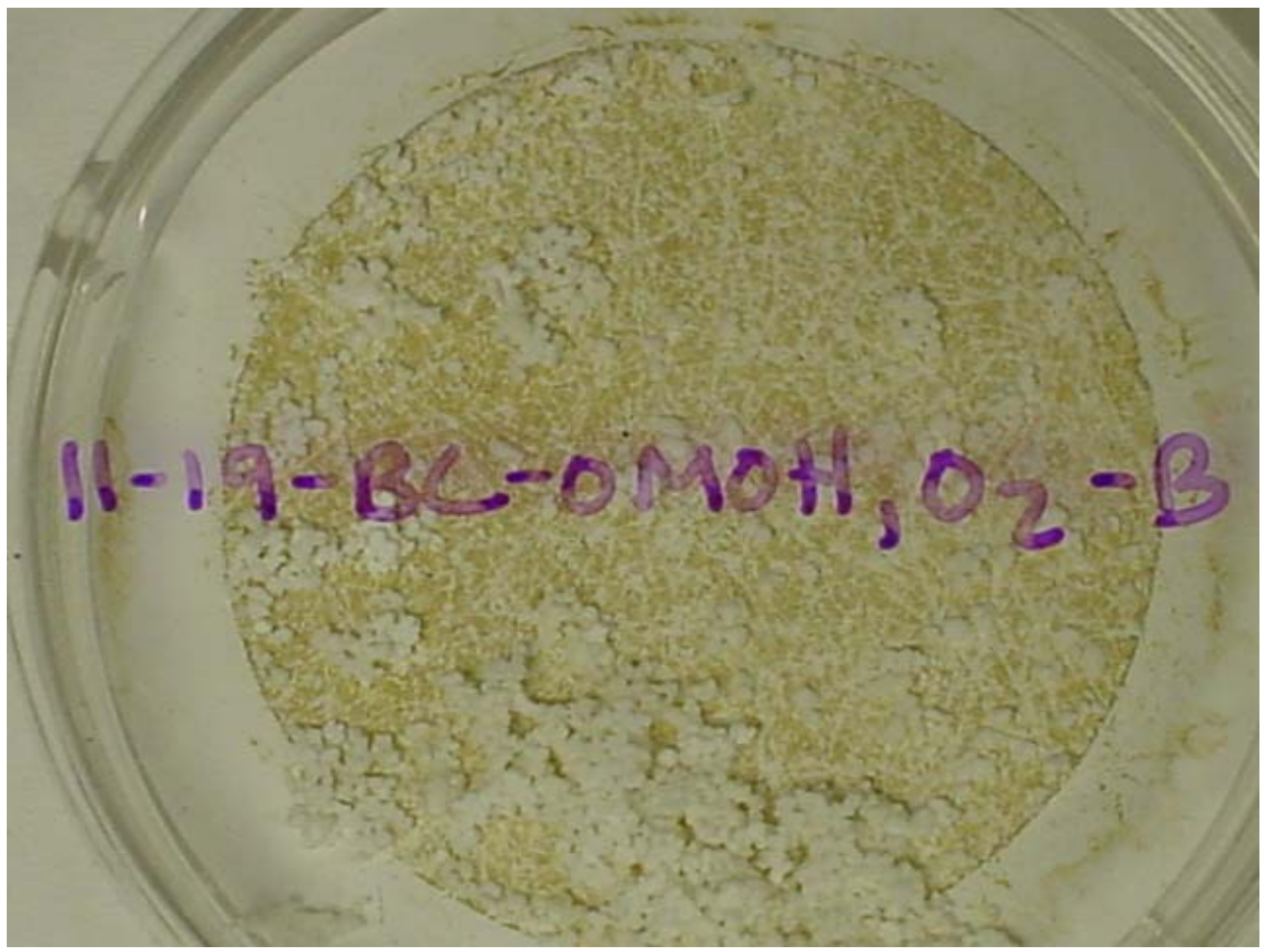

Figure F.38 Simulant AN-102 Sample 11-19-BC-0.0M OH, $\mathrm{O}_{2}$ Filter 
WSRC-TR-2003-00232, Rev. 0

SRT-RPP-2003-00105, Rev. 0

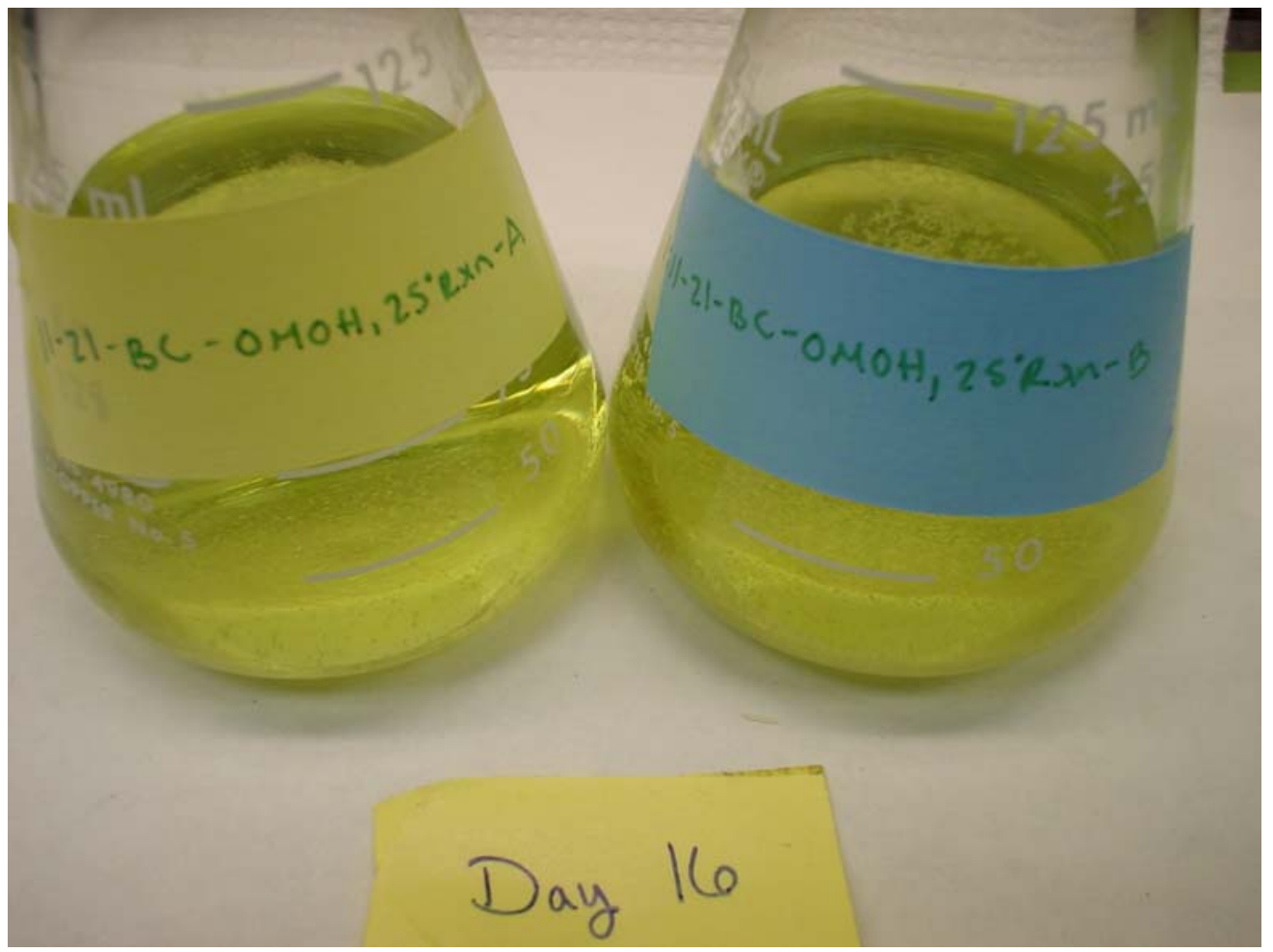

Figure F.39 Simulant AN-102 Sample 11-19-BC-0.0M OH, $25^{\circ} \mathrm{C}$ Rxn Filtrates

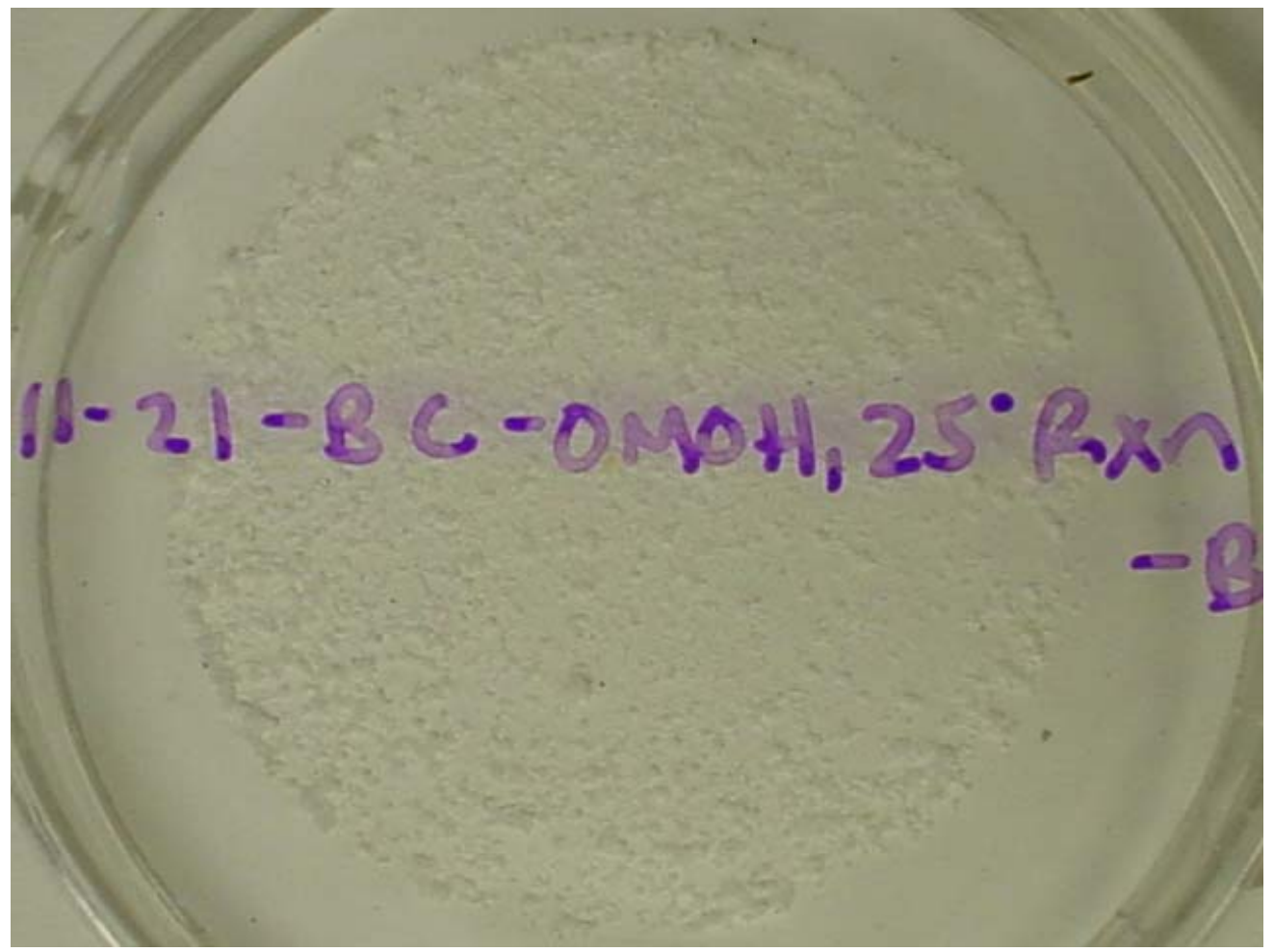

Figure F.40 Simulant AN-102 Sample 11-19-BC-0.0M OH, $25^{\circ}$ C Rxn Filter 
WSRC-TR-2003-00232, Rev. 0

SRT-RPP-2003-00105, Rev. 0

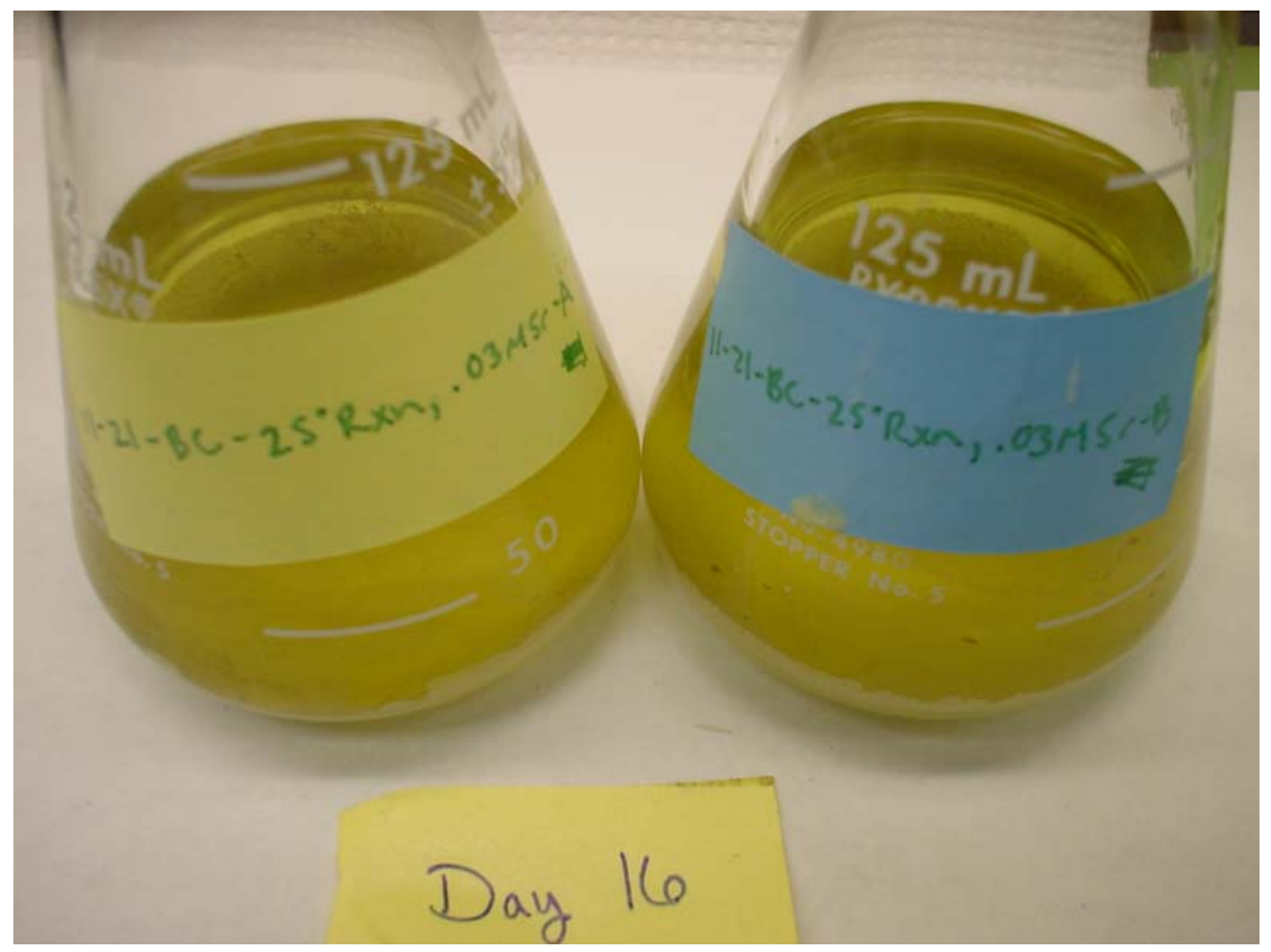

Figure F.41 Simulant AN-102 Sample 11-19-BC-25 ${ }^{\circ}$ C Rxn, 0.03M Sr Filtrates

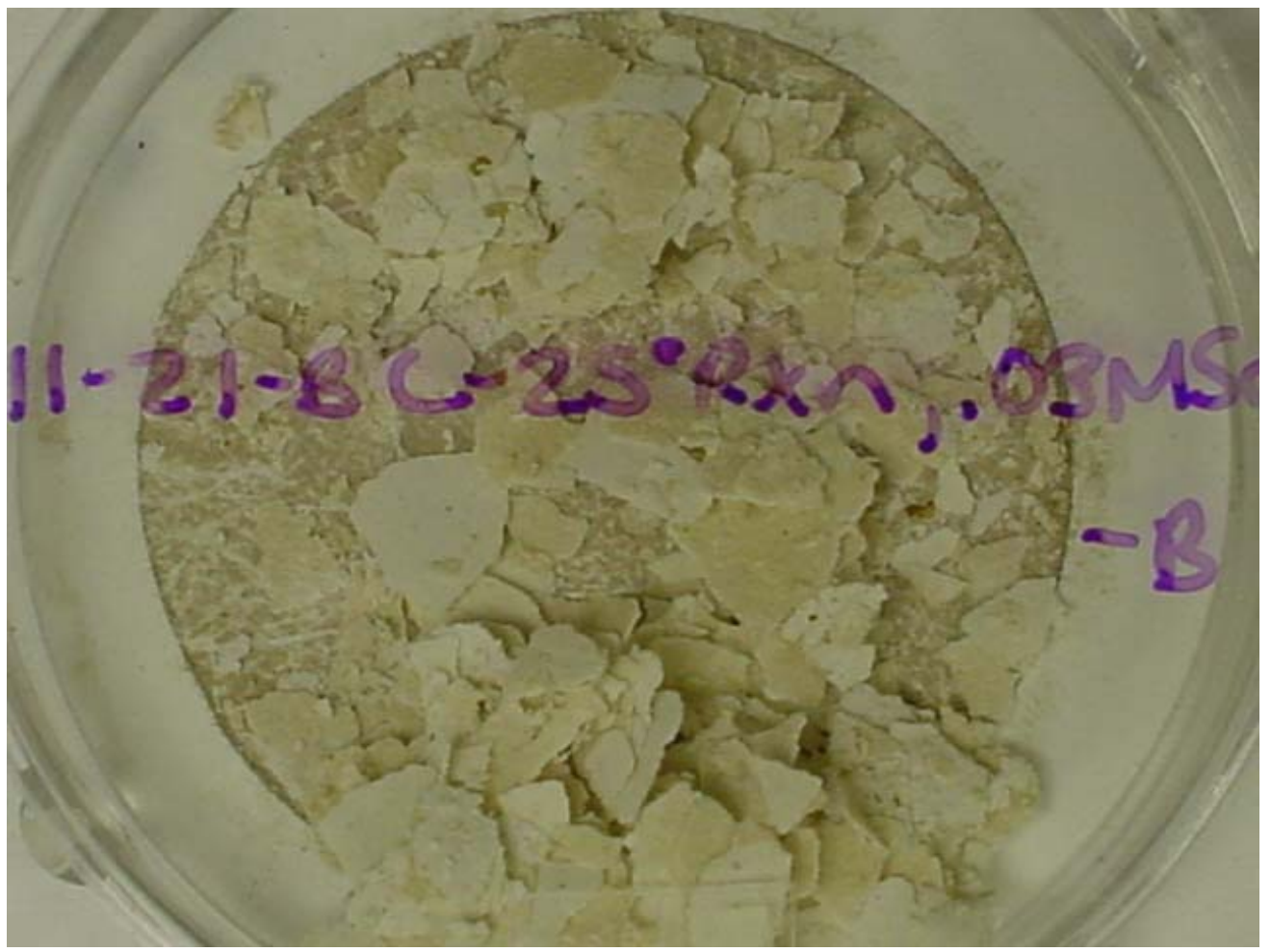

Figure F.42 Simulant AN-102 Sample 11-19-BC-25 C Rxn, 0.03M Sr Filter 
WSRC-TR-2003-00232, Rev. 0

SRT-RPP-2003-00105, Rev. 0

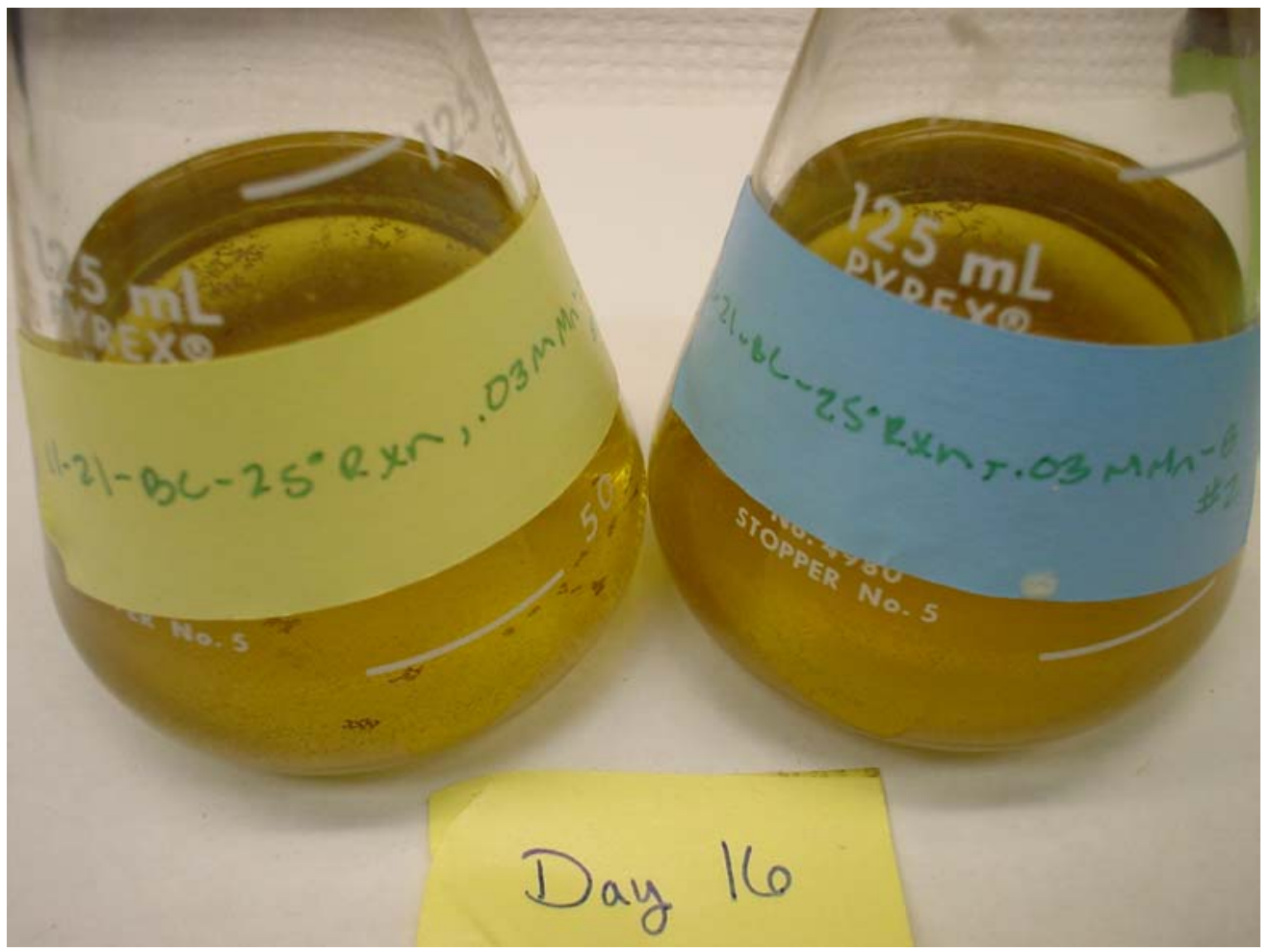

Figure F.43 Simulant AN-102 Sample 11-19-BC-25 ${ }^{\circ} \mathrm{C}$ Rxn, 0.03M Mn Filtrates

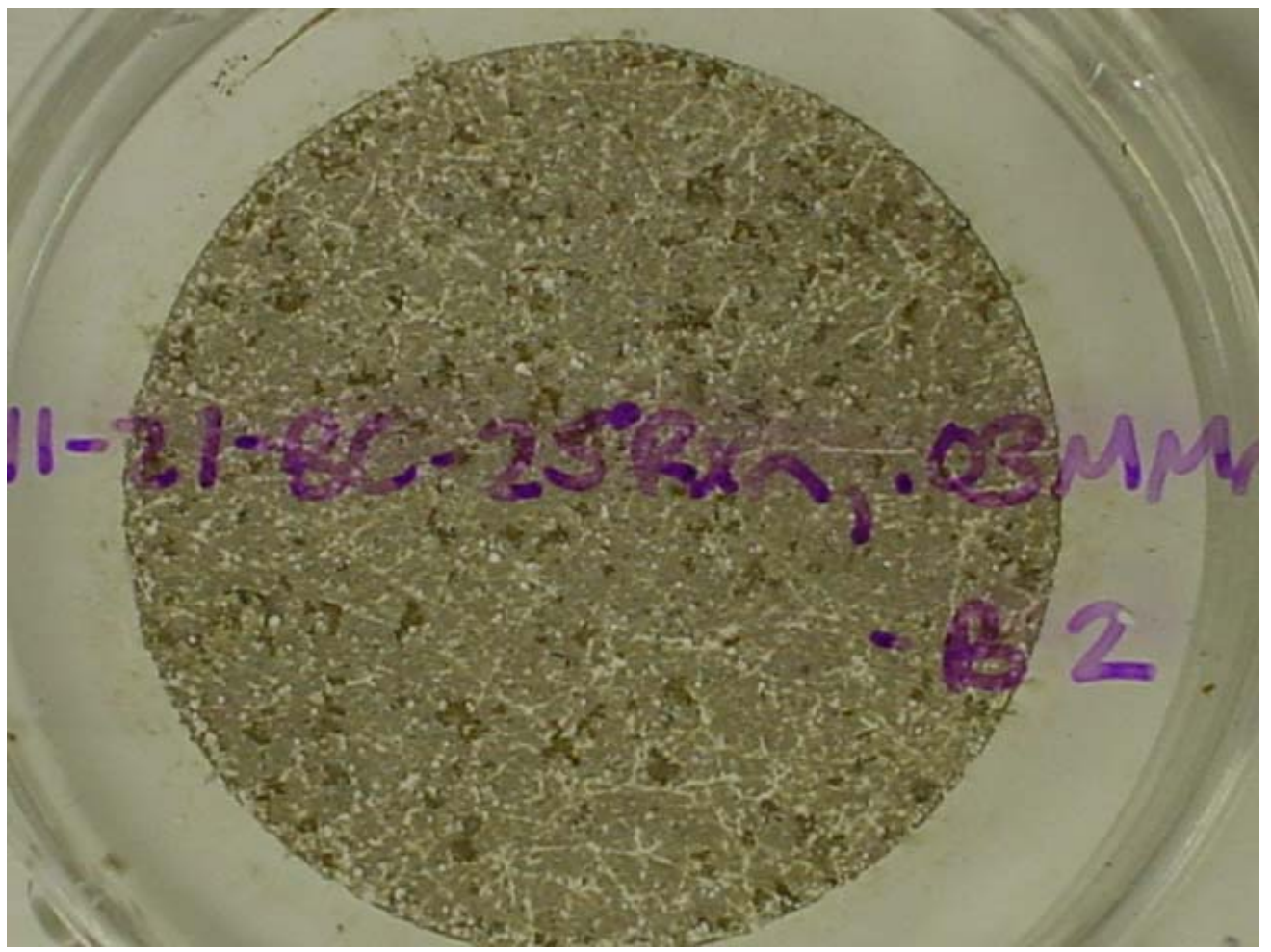

Figure F.44 Simulant AN-102 Sample 11-19-BC-25 ${ }^{\circ}$ C Rxn, 0.03M Mn Filter 
WSRC-TR-2003-00232, Rev. 0

SRT-RPP-2003-00105, Rev. 0

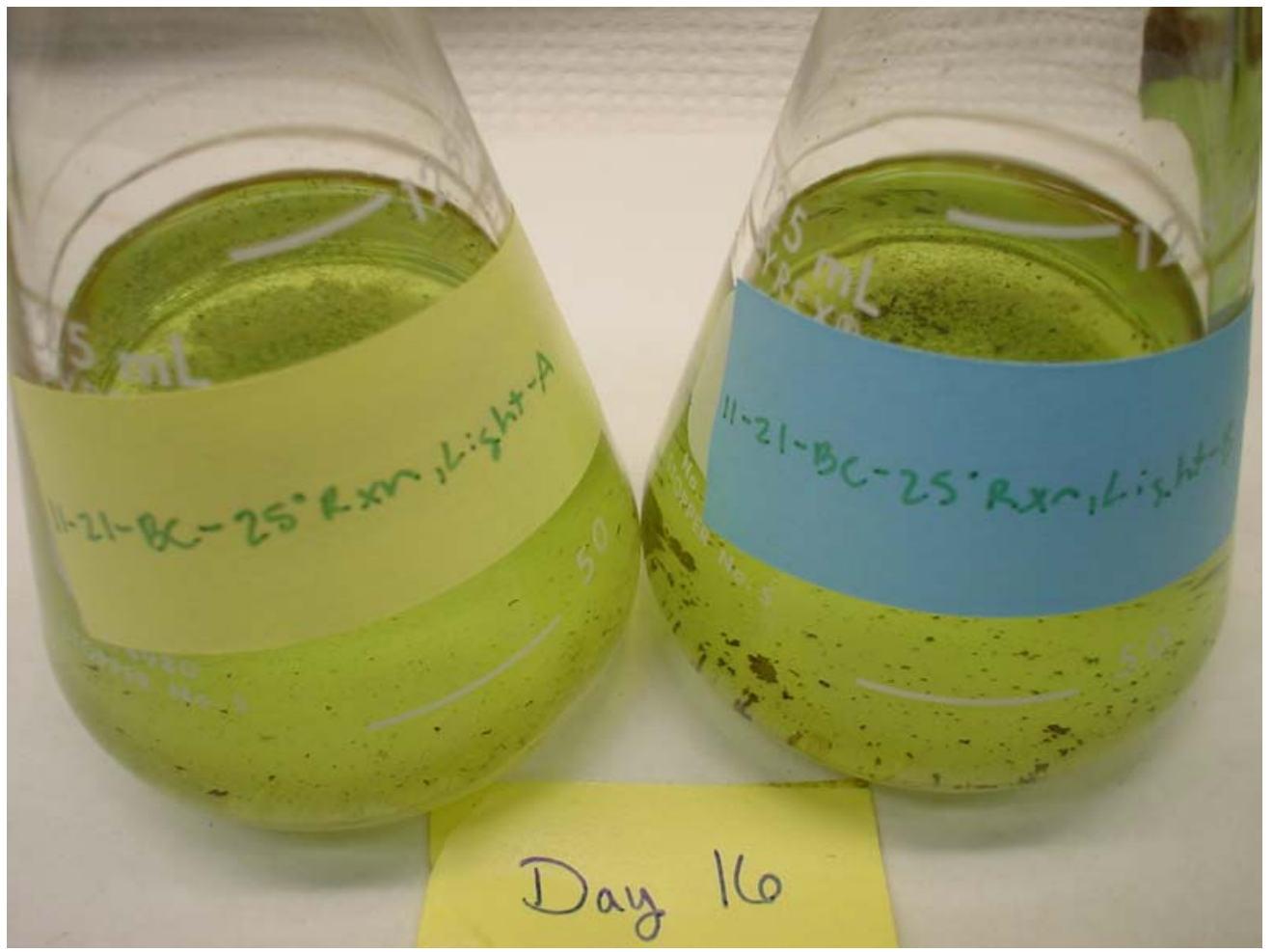

Figure F.45 Simulant AN-102 Sample 11-19-BC-25C Rxn, Light Filtrates

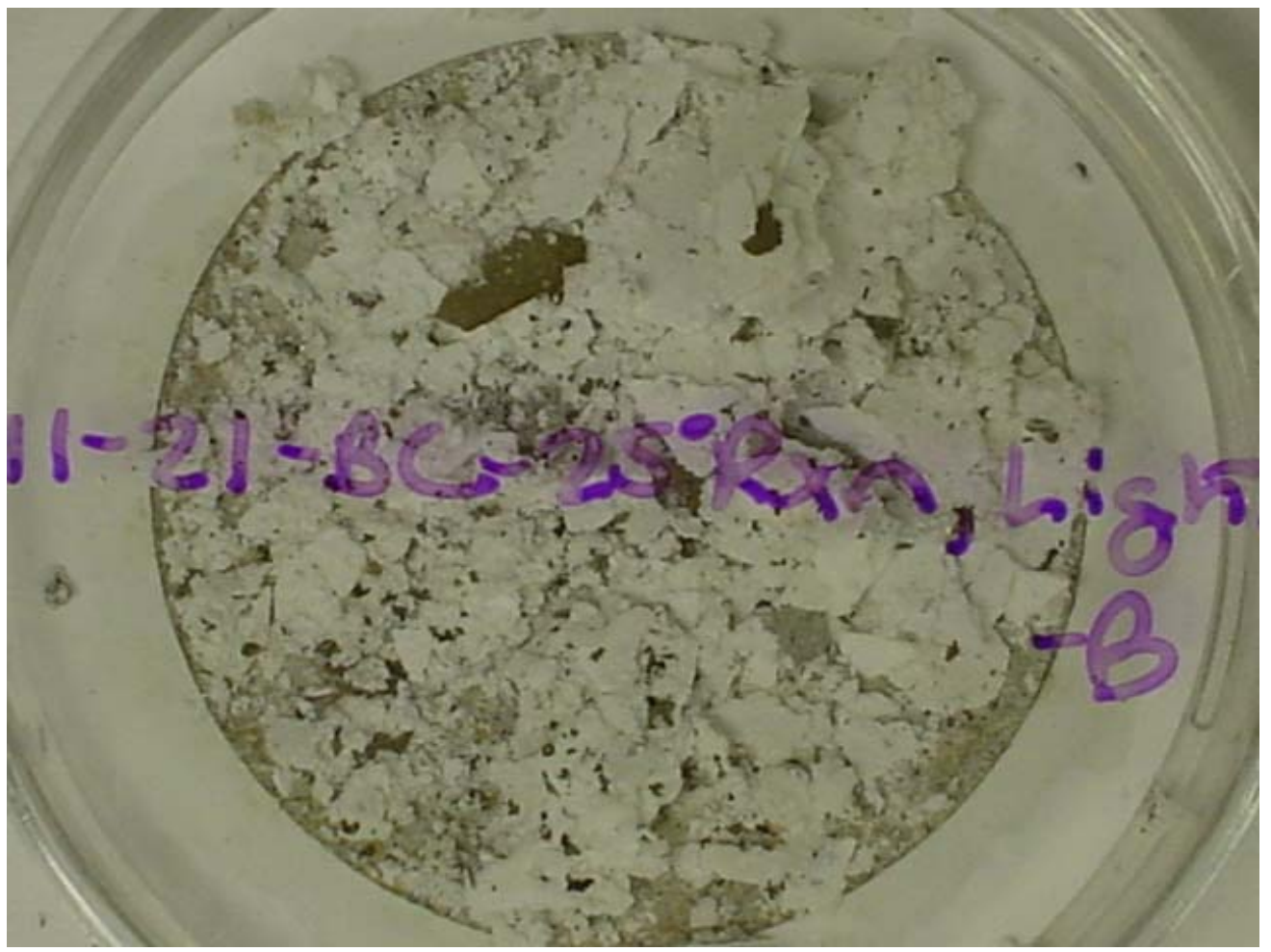

Figure F.46 Simulant AN-102 Sample 11-19-BC-25 $5^{\circ}$ Rxn, Light Filter 
WSRC-TR-2003-00232, Rev. 0

SRT-RPP-2003-00105, Rev. 0

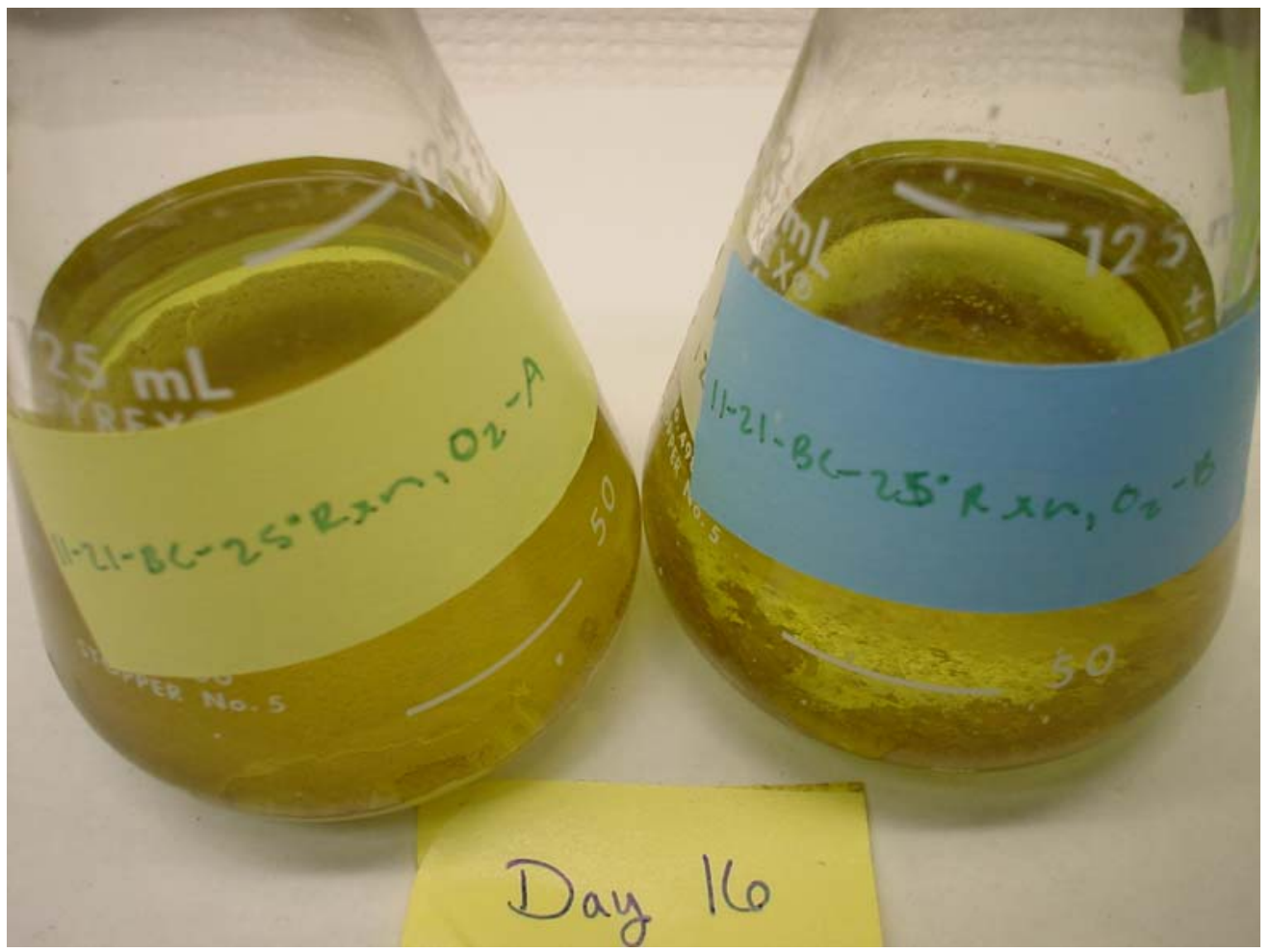

Figure F.47 Simulant AN-102 Sample 11-19-BC-25 ${ }^{\circ} \mathrm{C}$ Rxn, $\mathrm{O}_{2}$ Filtrates

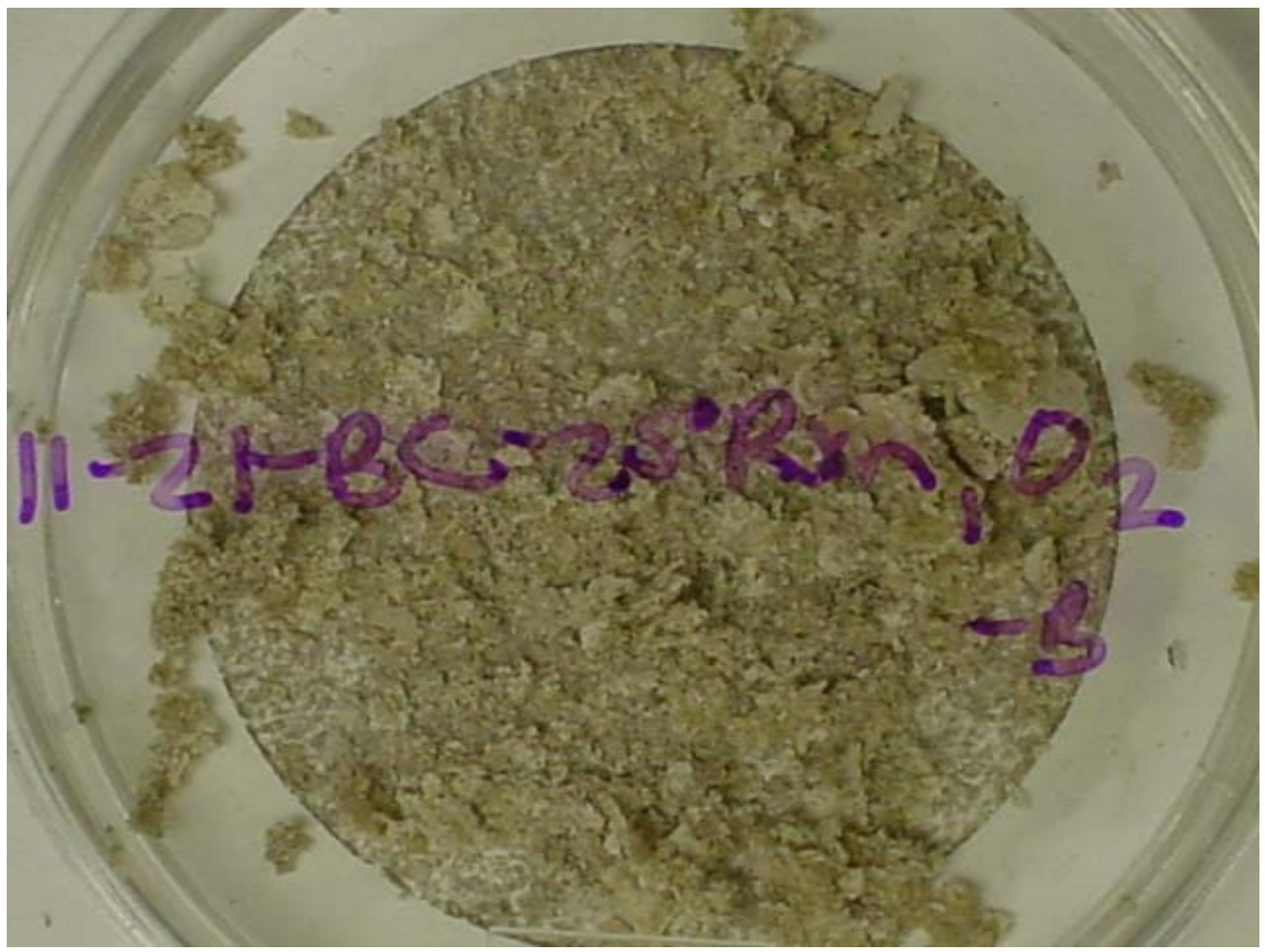

Figure F.48 Simulant AN-102 Sample 11-19-BC-25 ${ }^{\circ} \mathrm{C}$ Rxn, $\mathrm{O}_{2}$ Filter 
WSRC-TR-2003-00232, Rev. 0

SRT-RPP-2003-00105, Rev. 0

APPENDIX G

ICP-AES Analysis of AN-102 Primary and Secondary Effects Samples 
WSRC-TR-2003-00232, Rev. 0

SRT-RPP-2003-00105, Rev. 0

Table G.1 ICP-AES Data for AN-102 Primary Effects Samples

\begin{tabular}{|c|c|c|c|c|c|c|c|c|c|c|c|c|c|c|c|c|c|}
\hline & \multicolumn{3}{|c|}{ 8-20-BC-BC-A- } & \multicolumn{3}{|c|}{ 8-20-BC-BC-B- } & \multicolumn{3}{|c|}{ 8-20-BC-Light-A- } & \multicolumn{3}{|c|}{ 8-20-BC-Light-B- } & \multicolumn{3}{|c|}{ 8-20-BC-O2-A- } & \multicolumn{2}{|c|}{ 8-20-BC-O2-I } \\
\hline & 0 & 8 & 16 & 0 & 8 & 16 & 0 & 8 & 16 & 0 & 8 & 16 & 0 & 8 & 16 & 0 & \\
\hline Al & 9939.046 & 9711.868 & 9535.174 & 10500.68 & 10216.71 & 10494.37 & 9800.215 & 9390.032 & 9749.731 & 10103.12 & 10506.99 & 10513.3 & 9743.421 & 9440.516 & 9686.626 & 10260.88 & 1022 \\
\hline B & 11.92054 & 12.84188 & 12.05307 & 13.79477 & 13.29624 & 14.35009 & 13.18265 & 11.4157 & 13.13216 & 13.29624 & 14.40688 & 14.46368 & 12.4317 & 11.56085 & 12.50742 & 13.29624 & 13.84525 \\
\hline $\mathrm{Ca}$ & 58.23335 & 57.65278 & 57.79161 & 57.45084 & 55.34944 & 57.45715 & 85.38114 & 57.91151 & 102.7981 & 55.94263 & 59.77311 & 64.99821 & 61.89975 & 60.30319 & 68.5952 & 77.80853 & 56.8829 \\
\hline $\mathrm{Ce}$ & 113589 & 0.100968 & -0.25873 & -0.11359 & -0.04417 & -0.25873 & 0.075726 & -0.25873 & -0.24611 & -0.00631 & -0.05048 & 0.056795 & -0.27135 & -0.13883 & -0.39125 & 0.227178 & 79 \\
\hline $\mathrm{Cr}$ & 4.6497 & 200.9896 & 199.7906 & 214.4941 & 210.6447 & 215.7562 & 201.9362 & 187.8638 & 193.6694 & 205.5963 & 212.7902 & 214.431 & 203.1352 & 197.7712 & 200.2954 & 215.9455 & \\
\hline $\mathrm{Cu}$ & 2.978559 & 2.61886 & 2.404303 & 3.142632 & 3.079527 & 3.174184 & 3.010111 & 2.49896 & 2.587307 & 3.098458 & 2.890212 & 2.776622 & 2.549444 & 2.467408 & 2.555755 & 2.74507 & 2.574686 \\
\hline $\mathrm{Fe}$ & 294514 & 5.793044 & 6.026533 & 6.272643 & 5.654213 & 6.152743 & 6.998351 & 5.925565 & 6.24109 & 6.159053 & 5.837218 & 6.272643 & 638 & 464 & 6.228469 & 6.039154 & \\
\hline $\mathrm{K}$ & 1664.711 & 1635.683 & 1637.576 & 1764.417 & 173 & 1776.407 & 164 & & 1619.907 & 1724.661 & 1760 & 1765.679 & 16 & .82 & 848 & 621 & 43 \\
\hline La & 0.063105 & -0.01262 & -0.00631 & 0.201936 & 0.10 & 0.189315 & -0.01 & 0.0 & -0.04417 & 0.189315 & 0.347078 & 0.25242 & 0.0 & & 0.100968 & 0.157763 & 0. \\
\hline $\mathrm{Mg}$ & 120294 & 4.202797 & 2.795554 & 4.903263 & 4.95 & 3.634851 & 3.571746 & 545 & 5.250341 & 3.773682 & 4.549875 & 2.290714 & 335 & 8594 & 3.344568 & 4.562496 & 4604 \\
\hline $\mathrm{Mn}$ & 02868 & 15.76995 & 11.06863 & 19.7014 & 18.60337 & 15.97189 & 16.23062 & 9.680316 & 2.953317 & 19.87809 & 1086 & 4.032413 & 15.7 & 585 & 7.048835 & 18.88103 & 12.70305 \\
\hline Mo & 51 & 37.1 & 36.6 & & 38.9 & & 37.4 & & & 38. & & 40.2 & & & & & $3 \varepsilon$ \\
\hline $\mathrm{Nd}$ & 51 & 1.92 & 2.53 & 38 & & 3.0 & & 43 & 394 & 2.240229 & 507 & 3.294084 & 563 & 426 & 2.233919 & 3.186805 & 2. \\
\hline $\mathrm{Ni}$ & 289.2736 & 286.8125 & 283.7203 & 308.0158 & 299.6228 & 309.0255 & 288.7056 & 271.7935 & 281.0068 & 300.5694 & 308.7099 & 311.4866 & 289.6522 & 281.133 & 287.6328 & 311.2972 & 295.7103 \\
\hline $\mathrm{P}$ & & $114 \mathrm{~s}$ & & 1632.528 & 912. & 912.4991 & 1260.208 & & & 140 & & 977.4973 & & & 1070.262 & 1647.673 & .470 \\
\hline $\mathrm{Pb}$ & 35 & 40.79742 & 39.74987 & 45.82058 & 45.1 & 44.97497 & 88 & & 131 & 45.7 & 63 & 45.20846 & & 48 & 40.545 & 337 & 43. \\
\hline $\mathrm{Si}$ & 912513 & 6.058085 & 6.821657 & 7.74299 & 8.329867 & 11.23901 & 14.26174 & 6.821657 & 21.73338 & 5.830907 & 8.632772 & 10.93611 & 5.401793 & 6.651273 & 10.32399 & 16.09179 & 8.449767 \\
\hline $\mathrm{Sr}$ & & 26.78179 & 26.07501 & 28.78222 & 27.1 & 28.66863 & & & 25.45658 & & & 29.95597 & & & 25.80366 & 27.82933 & \\
\hline $\mathrm{Zn}$ & 368 & 1.93 & 1.58 & 1.893152 & 1.88 & & & & & & & 2.46 & & 1316 & 2.240229 & 2.050914 & \\
\hline $\mathrm{Zr}$ & 0.694156 & 0.713087 & 0.713087 & 0.927644 & 0.908713 & 0.908713 & 0.75095 & 0.694156 & 0.675224 & 0.927644 & 0.952886 & 0.959197 & 0.719398 & 0.681535 & 0.719398 & 0.915023 & 0.86453 \\
\hline
\end{tabular}

\section{8-29-BC-ОМОH-A- 8-29-BC-OMOH-B- 8-29-BC-.03MSr-A-}

\begin{tabular}{rrrrrr}
\multicolumn{2}{c}{ 8-29-BC-OMOH-A- } & \multicolumn{3}{c}{ 8-29-BC-OMOH-B- } \\
0 & 8 & 16 & 0 & 8 & 16 \\
9667.179 & 9812.55 & 9447.057 & 9751.979 & 9739.865 & 9194.677
\end{tabular} $\begin{array}{rrrrrr}9667.179 & 9812.55 & 9447.057 & 9751.979 & 9739.865 & 9194.677 \\ 13.15609 & 13.18031 & 17.43719 & 12.88957 & 12.22329 & 17.55765\end{array}$ $\begin{array}{llllll}13.15609 & 13.18031 & 17.43719 & 12.88957 & 12.22329 & 17.55765 \\ 48.82652 & 77.10726 & 46.89113 & 52.72126 & 53.33908 & 46.03074\end{array}$ $\begin{array}{rrrrrr}48.82652 & 77.10726 & 46.89113 & 52.72126 & 53.33908 & 46.03074 \\ -0.03029 & 0.0424 & \text { \#VALUE! } & -0.19383 & -0.01817 & \text { \#VALUE! }\end{array}$ $\begin{array}{rrrrrr}-0.03029 & 0.0424 & \text { \#VALUE! } & -0.19383 & -0.01817 & \text { \#VALUE! } \\ 200.6121 & 204.7916 & 209.0169 & 204.0041 & 199.7036 & 201.0153\end{array}$ $\begin{array}{llrlrr}4.336905 & 4.439876 & 4.34209 & 4.427762 & 4.45199 & 4.433865\end{array}$ $\begin{array}{lllllll}5.675531 & 5.984444 & 3.103132 & 6.093473 & 5.778502 & 2.753241\end{array}$ $\begin{array}{llllll}1637.848 & 1670.556 & 1631.869 & 1660.865 & 1636.636 & 1581.393\end{array}$ -0.11509 - 0.01817 \#VALUE! $0.030286-0.02423$ \#VALUE! $3.010393 \quad 3.585821$ \#VALUE! $3.216336 \quad 3.785706$ \#VALUE! $\begin{array}{rrrrrr}3.010393 & 3.585821 & \text { \#VALUE! } & 3.216336 & 3.785706 & \text { \#VALUE! } \\ 4.83359 & 5.009246 & 4.712057 & 4.518619 & 4.53679 & 4.445337\end{array}$ $\begin{array}{rrrrrr}4.83359 & 5.009246 & 4.712057 & 4.518619 & 4.53679 & 4.445337 \\ 37.43306 & 37.96609 & 35.99289 & 37.82072 & 37.24529 & 35.01778\end{array}$ $\begin{array}{llllll}37.43306 & 37.96609 & 35.99289 & 37.82072 & 37.24529 & 35.01778 \\ 1.193255 & 0.860112 & \text { \#VALUE! } & 1.502168 & 1.798968 & \text { \#VALUE! }\end{array}$ $\begin{array}{lllllll}1.193255 & 0.860112 & \text { \#VALUE! } & 1.502168 & 1.798968 & \text { \#VALUE! } \\ 311.9422 & 316.3033 & 304.8641 & 316.3033 & 311.6999 & 299.9885\end{array}$ $\begin{array}{rrrrrrr}311.9422 & 316.3033 & 304.8641 & 316.3033 & 311.6999 & 299.9885 \\ 1513.071 & 1528.82 & 1393.828 & 1420.397 & 1397.986 & 1348.228\end{array}$ $\begin{array}{lllllll}1513.071 & 1528.82 & 1393.828 & 1420.397 & 1397.986 & 1348.228 \\ 41.04311 & 40.94014 & 36.45176 & 38.35375 & 37.53603 & 32.89549\end{array}$ $\begin{array}{lllllll}41.04311 & 40.94014 & 36.45176 & 38.35375 & 37.53603 & 32.89549\end{array}$ $\begin{array}{lllllll}3.918963 & 10.50306 & 8.061833 & 3.985591 & 4.869932 & 7.797981\end{array}$ $\begin{array}{lllllll}31.1397 & 31.81205 & 28.56201 & 30.68542 & 30.91559 & 27.91958\end{array}$ $0.296799 \quad 1.586968$ \#VALUE! 0.4663990 .284685 \#VALUE! 0.569370 .617827 \#VALUE! 0.5814840 .629941 \#VALUE!

$\begin{array}{rrrr}\text { 8-29-BC-.03MSr-A- } & & 8-29-B C- \\ 0 & 8 & 16 & 0 \\ 9708 & 8976 & 9539.773 & 9768 \\ 13.326 & 12.3 & 18.19886 & 12.72 \\ 82.98 & 69.54 & 69.0625 & 80.46 \\ 0.198 & -0.108 & \text { \#VALUE! } & -0.342 \\ 201.66 & 189.78 & 208.2102 & 198.84 \\ 3.66 & 3.192 & 3.383523 & 3.906 \\ 5.82 & 5.73 & 2.59375 & 6.012 \\ 1627.2 & 1586.4 & 1630.114 & 1624.2 \\ 0.192 & 0.072 & \text { \#VALUE! } & 0.252 \\ 1.002 & 4.11 & \text { \#VALUE! } & 4.698 \\ 18.33 & 17.178 & 12.1108 & 18.324 \\ 36.948 & 35.4 & 35.96591 & 36.678 \\ 3.456 & 2.862 & 1.911932 & 3.63 \\ 286.38 & 277.62 & 284.9432 & 286.14 \\ 1556.4 & 885 & 872.1591 & 1530.6 \\ 36.936 & 34.752 & 32.92614 & 38.64 \\ 9.93 & 8.04 & 19.11932 & 11.628 \\ 40.578 & 38.628 & 38.89205 & 44.472 \\ 1.596 & 1.266 & \text { \#VALUE! } & 1.878 \\ 0.822 & 0.726 & \text { \#VALUE! } & 0.87\end{array}$
9-3-BC-Shear-A-

9-3-BC-Shear MSr-B16 16 0 8 $\begin{array}{lllllll}9852 & 9542.614 & 9888.55 & 9326.915 & 9552.396 & 9781.271 & 9774.961\end{array}$ $\begin{array}{llllllll}13.02 & 18.21023 & 11.51035 & 11.9647 & 17.70943 & 12.67779 & 12.75352\end{array}$ $\begin{array}{lllllll}102.84 & 63.94886 & 60.41039 & 56.30226 & 59.87802 & 60.24632 & 58.51093\end{array}$ 0.252 \#VALUE! -0.227180 .283972 \#VALUE! \#VALUE! -0.0631 $\begin{array}{llllllll}198.3 & 203.2386 & 207.6785 & 189.0625 & 208.0791 & 203.4504 & 209.7609\end{array}$ $\begin{array}{llllllll}3.75 & 3.204545 & 2.858655 & 2.833413 & 3.155249 & 2.555752 & 2.883897\end{array}$ $\begin{array}{llllllll}5.292 & 2.991477 & 6.260014 & 5.673137 & 3.301657 & 5.988662 & 5.45227\end{array}$ $\begin{array}{lllllll}1630.2 & 1618.182 & 1680.486 & 1537.868 & 1626.925 & 1635.681 & 1672.282\end{array}$

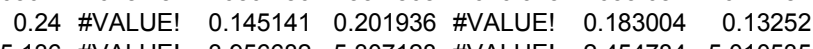
5.136 \#VALUE! 3.9566825 .307128 \#VALUE! 2.4547845 .010535 $\begin{array}{rrrrrrrr}17.802 & 11.5 & 15.70683 & 14.51414 & 10.72067 & 16.25584 & 15.82042\end{array}$ $\begin{array}{rrrrrrr}17.802 & 11.5 & 15.70683 & 14.51414 & 10.72067 & 16.25584 & 15.82042 \\ 36.696 & 35.22727 & 37.56639 & 34.9286 & 35.49655 & 37.22563 & 37.62319\end{array}$ $\begin{array}{rrrrrrrr}36.696 & 35.22727 & 37.56639 & 34.9286 & 35.49655 & 37.22563 & 37.62319 \\ 2.484 & 1.815341 & 3.641157 & 3.275148 & 1.691166 & 4.007166 & 4.347933\end{array}$ $\begin{array}{rrrrrrrr}2.484 & 1.815341 & 3.641157 & 3.275148 & 1.691166 & 4.007166 & 4.347933 \\ 284.52 & 282.3011 & 291.2926 & 271.3514 & 281.3729 & 293.5643 & 297.6662\end{array}$ $\begin{array}{llllllll}1089.6 & 916.4773 & 1520.83 & 1352.971 & 1193.975 & 1515.15 & 1157.976\end{array}$ $\begin{array}{llllllll}38.046 & 34.17614 & 38.33627 & 35.73635 & 33.88307 & 39.6173 & 39.61099\end{array}$ $\begin{array}{lllllll}25.812 & 19.21591 & 7.894432 & 8.683245 & 19.02113 & 8.708487 & 10.43125\end{array}$ $\begin{array}{llllllll}44.436 & 42.64205 & 27.16038 & 25.47548 & 25.40035 & 27.91133 & 26.49778\end{array}$ $\begin{array}{llllllll}4.314 & 0.295455 & 1.211616 & 1.198995 & \text { \#VALUE! } & 1.217926 & 1.173753\end{array}$ $\begin{array}{lllllll}0.882 & 0.198864 & 0.706776 & 0.662602 & \text { \#VALUE! } & 0.807744 & 0.795123\end{array}$

Page 198 of 220 
WSRC-TR-2003-00232, Rev. 0

SRT-RPP-2003-00105, Rev. 0

Table G.2 ICP-AES Data for AN-102 Primary Effects Samples

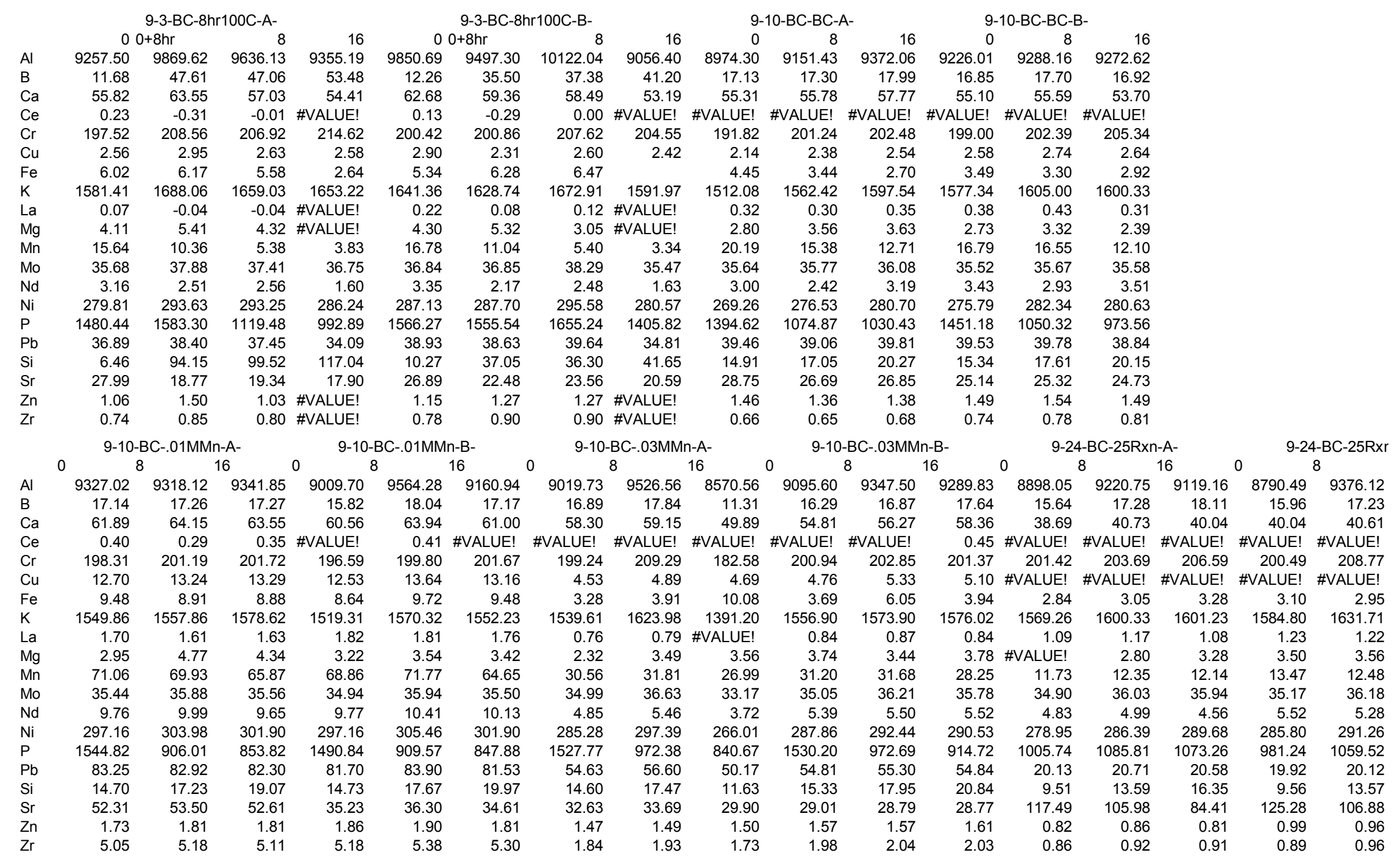


WSRC-TR-2003-00232, Rev. 0

SRT-RPP-2003-00105, Rev. 0

Table G.3 ICP-AES Data for AN-102 NOC Samples

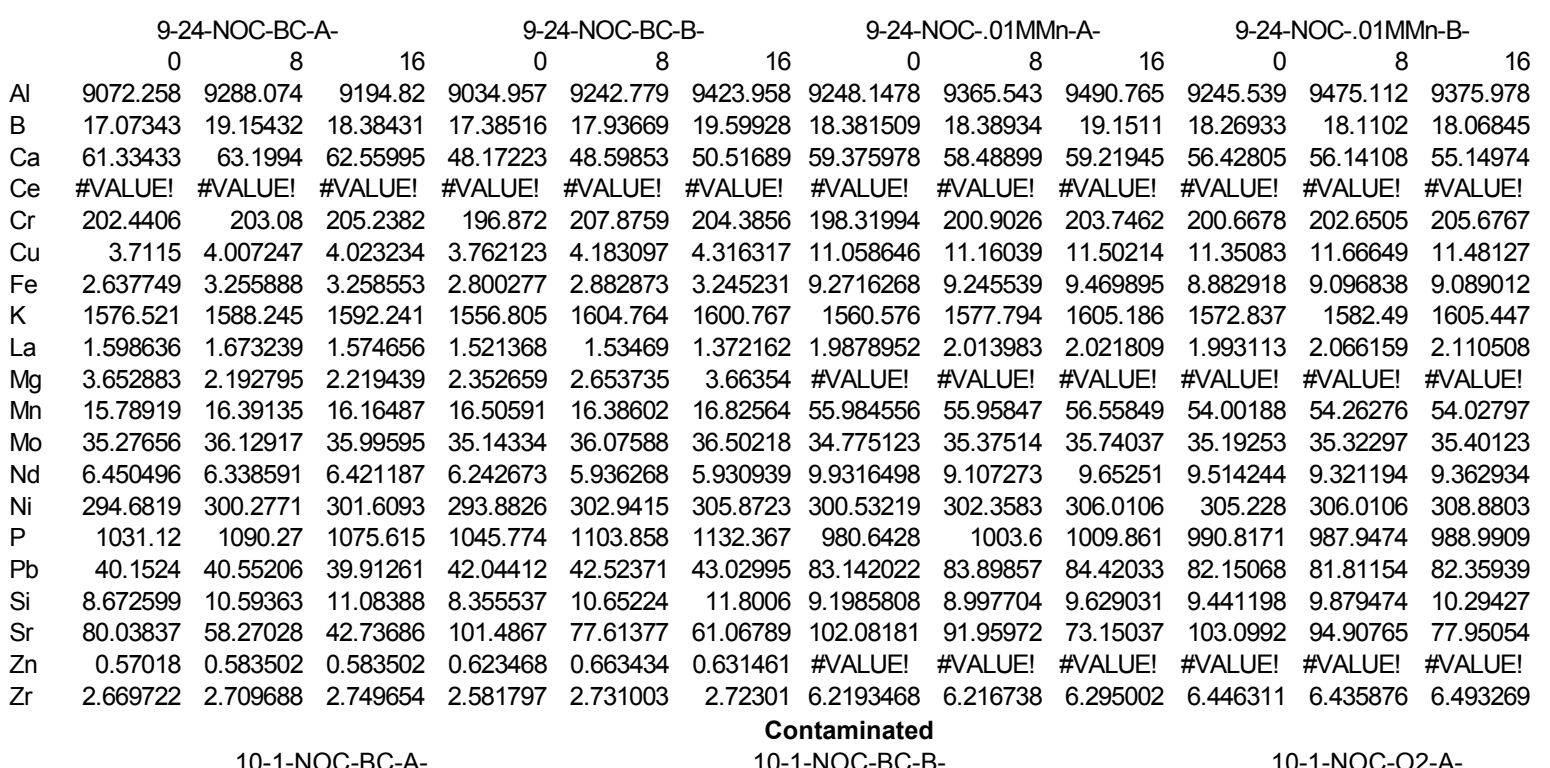

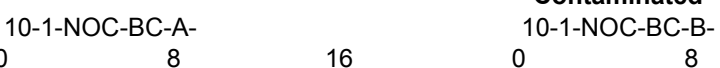

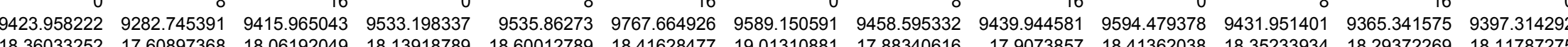
$\begin{array}{lllllllllllll}18.36033252 & 17.60897368 & 18.06192049 & 18.13918789 & 18.60012789 & 18.41628477 & 19.01310881 & 17.88340616 & 17.9073857 & 18.41362038 & 18.35233934 & 18.29372269 & 18.11787275\end{array}$

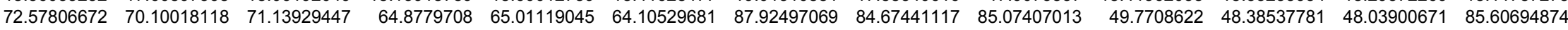

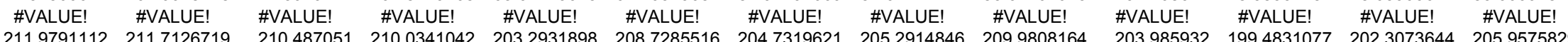

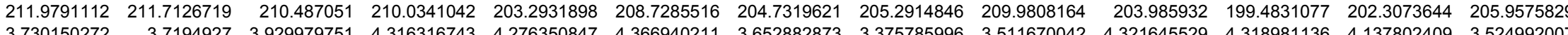

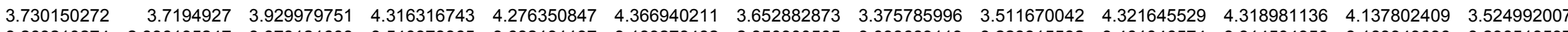

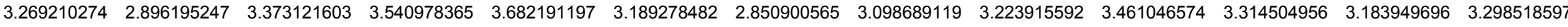

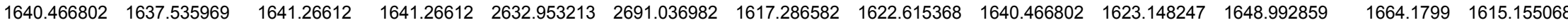

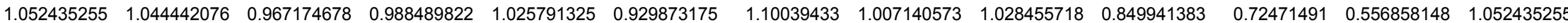
\#VALUE! \#VALUE! \#VALUE! \#VALUE! \#VALUE! \#VALUE! \#VALUE! \#VALUE! \#VALUE! \#VALUE! \#VALUE! \#VALUE! \#VALUE!

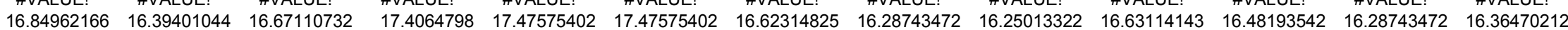

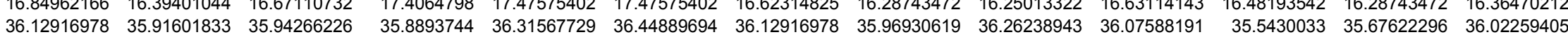

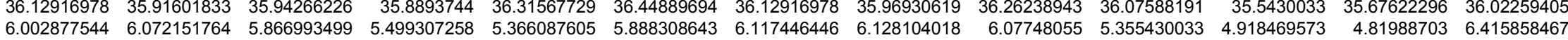

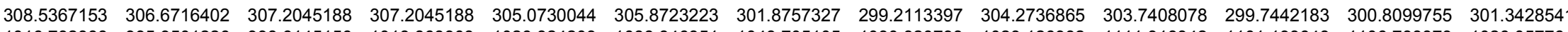

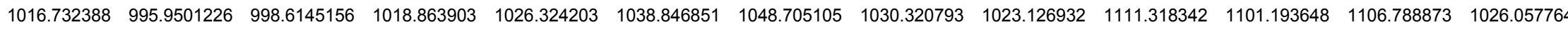

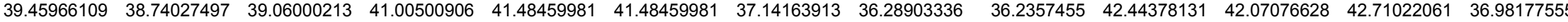

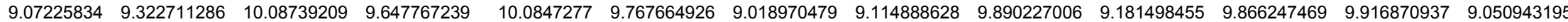
$\begin{array}{lllllllllllll}66.66311414 & 47.98571885 & 36.74198018 & 7359053608 & 54.64670148 & 39.35308537 & 41.48459981 & 37.64787381 & 29.8678461 & 99.56836833 & 54.24704252 & 40.76521368 & 37.96760098\end{array}$ \#VALUE! \#VAUE! \#VALUE! \#VALE! \#VALE! \#VALE! \#ALUE! \#VALUE! \#VALUE! \#VALUE!

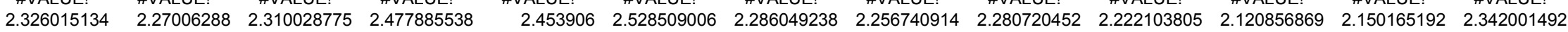


WSRC-TR-2003-00232, Rev. 0

SRT-RPP-2003-00105, Rev. 0

Table G.4 ICP-AES Data for AN-102 Secondary Effect Samples

\begin{tabular}{|c|c|c|c|c|c|c|c|c|c|c|c|c|c|c|c|c|c|}
\hline & \multicolumn{3}{|c|}{ 11-19-BC-OMOH,.03MSr-A- } & \multicolumn{3}{|c|}{ 11-19-BC-0MOH,.03MSr-B- } & \multicolumn{3}{|c|}{ 11-19-BC-OMOH,.03MMn-A- } & \multicolumn{3}{|c|}{ 11-19-BC-OMOH,.03MMn-B- } & \multicolumn{3}{|c|}{ 11-19-BC-OMOH,Light-A- } & \multicolumn{2}{|c|}{ 11-19-BC-OMOH,L } \\
\hline & 0 & 8 & 16 & 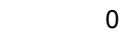 & 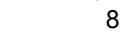 & 16 & 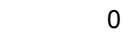 & . & 16 & & 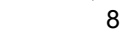 & 16 & 0 & 8 & 16 & 0 & \\
\hline & 9694.544 & 931.395 & 344.277 & 808.886 & 724.491 & 25.025 & 604.795 & 9895.85 & 47.524 & 21.587 & 342.676 & 9694.35 & 39.211 & 9.665 & 042 & 17 & 9817.0 \\
\hline & 20.57606 & 0.69857 & 0.77752 & 0.14592 & 21.18861 & 3.43189 & 9.09765 & & & .41949 & & & & & 19.74016 & & \\
\hline $\mathrm{Ca}$ & 52.02548 & 52.76054 & 52.48829 & 50.3648 & 50.88206 & 9.22139 & 9.25536 & 47.32433 & 0.31883 & .63217 & .90653 & 47.46426 & .86624 & & 48.78399 & 3.67902 & 5.80131 \\
\hline $\mathrm{Ce}$ & \#VALUE! & \#VALUE! & \#VAL & VALI & AVAL & TreU & AL & VAL & $V A$ & E! & & $\mathrm{E} !$ & $\mathrm{E} !$ & $\mathrm{E} !$ & & $E !$ & \\
\hline $\mathrm{Cr}$ & 216.4053 & 223.0752 & 222.9664 & 216.8954 & 15.1258 & 211.505 & 218.0109 & 23.2443 & 607 & 218.7106 & 225.791 & 219.858 & & & & 215.9 & \\
\hline $\mathrm{Cu}$ & 4.554612 & 4.704345 & & & 4.685288 & 4.546445 & 6.198899 & 6.543127 & & & & & & & 375 & & 983 \\
\hline $\mathrm{Fe}$ & 2.46 & 2.45 & 31 & $2.5 \varepsilon$ & 2.5 & 2.5 & $<0.15$ & & 0 & & & & 2. & & & & \\
\hline & 171 & 951 & 79 & 171 & 109 & & 169 & & 75 & & & & & & 067 & 812 & \\
\hline La & $\mathrm{E} !$ & \#VALUE! & $\mathrm{E} !$ & \#VAL & JE! & & & 0.4 & & & & & & & & & \\
\hline $\mathrm{Mg}$ & $\# \mathrm{VA}$ & $E !$ & $!$ & & & & v & & & & & & & & 329 & $\# \mathrm{~V}$ & \\
\hline $\mathrm{Mn}$ & 6.258848 & 6.365022 & 6.060111 & 6.40 & 6.3 & 6.33 & 14. & 12 & & & & & 4.4 & & 0 & 4.49 & 393 \\
\hline Mo & 37.3 & 37.6 & & & & & & & & & & & & & 046 & & \\
\hline Id & & & & & & & & & & & & & & & & & \\
\hline $\mathrm{Ni}$ & .55 & 308. & 311 & 306. & 668 & 302.1888 & 308 & 26 & & & & 342 & 91 & 18 & 171 & 302 & 351 \\
\hline & 1691.441 & 123 & 112 & 1683 & & 1061.2 & & & & & & & 171 & & 62 & 162 & \\
\hline $\mathrm{Pb}$ & & & & & & & & & & & & & & & & & \\
\hline SI & 8.88 & 10. & 35 & 65 & & & & 19 & & & & & & & 194 & 99 & 443 \\
\hline $\mathrm{Sr}$ & 27.04454 & 27.16977 & 27.1126 & 26.14886 & 26.28226 & 25.39475 & 28.71364 & 29.60919 & 29.27336 & 29.69315 & 29.80509 & 29.5812 & 30.68716 & 132 & 30.88792 & 29.25318 & 30.31433 \\
\hline $\mathrm{Zn}$ & & \#VAL & & & & & & & & & & & & & & & \\
\hline 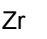 & 0.579876 & 0.588043 & 0.577153 & 0.585321 & 545 & 799 & 071 & & & $\$ 12$ & & & & & 365 & 176 & 932 \\
\hline
\end{tabular}

Page 201 of 220 
WSRC-TR-2003-00232, Rev. 0

Table G.5 ICP-AES Data for AN-102 Secondary Effect Samples

\begin{tabular}{|c|c|c|c|c|c|c|c|c|c|c|c|c|c|c|c|c|c|}
\hline & \multicolumn{3}{|c|}{ 11-19-BC-OMOH,O2-A- } & \multicolumn{3}{|c|}{ 11-19-BC-OMOH,O2-B- } & \multicolumn{3}{|c|}{ 11-21-BC-OMOH,25Rxn-A- } & \multicolumn{3}{|c|}{ 11-21-BC-OMOH,25Rxn-B- } & \multicolumn{3}{|c|}{ 11-21-25Rxn,.03MSr-A- } & \multicolumn{2}{|c|}{$11-21-25 R \times n, .03 n$} \\
\hline & & 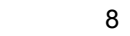 & 16 & 0 & 8 & 16 & & 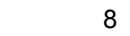 & 10 & & 8 & 10 & & & 10 & & \\
\hline & 681 & .572 & 912 & & 25 & 362 & & & 306 & & 42 & .266 & & 56 & 46 & 75 & 9381.487 \\
\hline & & 38 & & & & 8.70196 & & & & & & 121 & & & & & \\
\hline & & 24 & & & & & & & & & & & & & & & \\
\hline & & & & & & & & & & & & & & & & & \\
\hline & & & & & & & 145 & & & & & & & & & & \\
\hline & & & & & & & & & & & & & & & & & \\
\hline & & & & & & & & & & & & & & & & & \\
\hline & & & & & & & & & & & & & & & & & \\
\hline & & & & & & & & & & & & & & & & & \\
\hline & & & & & & & & & & & & & & & & & \\
\hline & & & & & & & & & & & & & & & & & \\
\hline & & & & & & & & & & & & & & & & & \\
\hline & & & & & & & & & & & & & & & & & \\
\hline & & & & & & & & & & & & & & & & & \\
\hline & & & & & & & & & & & & & & & & & \\
\hline & & 5 & 64 & 3 & & 37.0 & & & & & & & & & & & \\
\hline & & & & & & & & & & & & & & & & & \\
\hline & & & & & & & & & & & & & & & & & \\
\hline & & & & & & & & & & & & & & & & & \\
\hline $\mathrm{Zr}$ & 539176 & 54778 & 567856 & 542044 & 579328 & 613743 & .459544 & 0.479904 & 0.474087 & 0.465361 & 0.450819 & 0.439185 & 0.749015 & 0.806854 & .882045 & 0.760583 & .89 \\
\hline
\end{tabular}

$$
\begin{aligned}
& \text { 11-21-25Rxn,.03MMn-A2- 11-21-25Rxn,.03MMn-B2- 11-21-25Rxn,Light-A- } \\
& 0 \quad 8
\end{aligned}
$$

1-21-25Rxn,Light-B-

16

11-21-25Rxn, O2-A-

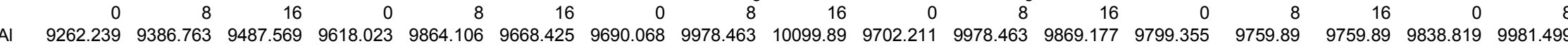

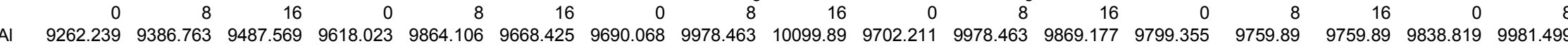

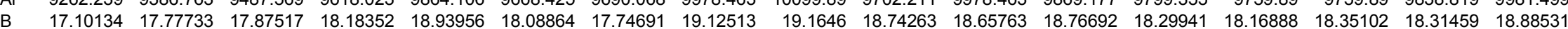

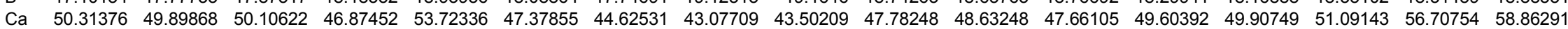

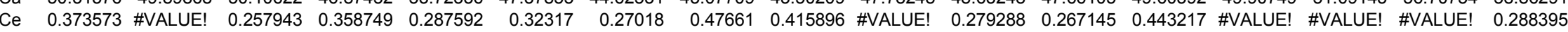

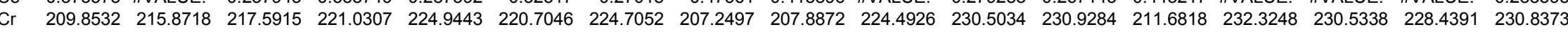

Cu 2 2.155457 2.235508 2.202895 2.75436 2.819587 2.730641 \#VALUE! \#VALUE! \#VALUE! \#VALUE! \#VALUE! \#VALUE! \#VALUE! \#VALUE! \#VALUE! \#VALUE! \#VALUE!

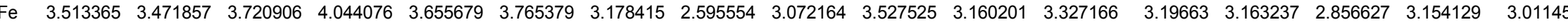

$\begin{array}{lllllllllllllllllll}1639.867 & 1670.702 & 1687.008 & 1713.692 & 1746.009 & 1715.471 & 1726.423 & 1659.94 & 1673.297 & 1734.923 & 1781.37 & 1780.155 & 1655.083 & 1769.227 & 1766.798 & 1767.102 & 1793.513\end{array}$

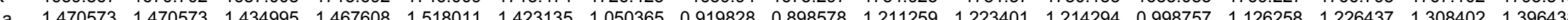
$\begin{array}{lllllllllllllllllllllll}K & 1.470573 & 1.470573 & 1.434995 & 1.467608 & 1.518011 & 1.423135 & 1.050365 & 0.919828 & 0.898578 & 1.211259 & 1.223401 & 1.214294 & 0.998757 & 1.126258 & 1.226437 & 1.308402 & 1.396438\end{array}$ $\begin{array}{llllllllllllllllll}M g & 3.196125 & 3.329544 & 3.222808 & 3.252457 & 4.304984 & 2.917427 & 3.396988 & 2.495375 & 2.376981 & \text { \#VALUE! } & 3.642883 & 3.65199 & 3.230023 & 2.86877 & 2.971985 & 3.299845 & 2.61984\end{array}$

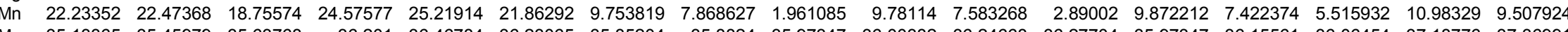

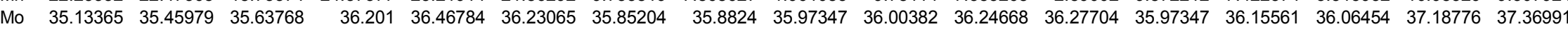

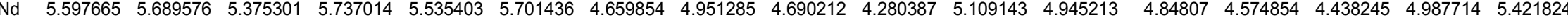

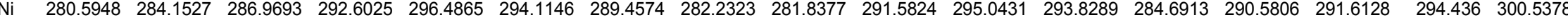

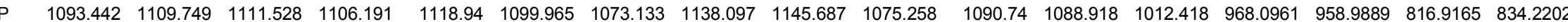
$\begin{array}{llllllllllllllllll}\mathrm{Pb} & 37.97992 & 38.18746 & 37.71309 & 42.10109 & 42.04179 & 41.98249 & 17.37351 & 18.65763 & 18.48459 & 16.76333 & 17.13976 & 16.83315 & 18.21441 & 17.59816 & 17.54655 & 17.57084 & 17.88959\end{array}$ $\begin{array}{lllllllllllllllll}9.67139 & 16.1259 & 19.15006 & 10.45115 & 16.624 & 14.76503 & 11.1199 & 12.7167 & 15.7069 & 11.38704 & 13.78528 & 15.23332 & 10.77383 & 12.74705 & 15.10582 & 10.16971 & 14.28314\end{array}$ $\begin{array}{lllllllllllllllll}104.2447 & 103.2663 & 93.68974 & 114.088 & 114.8292 & 96.06163 & 112.1097 & 105.674 & 92.8328 & 105.4007 & 99.96677 & 81.96486 & 97.53819 & 83.69523 & 65.48082 & 87.55062 & 88.37026\end{array}$

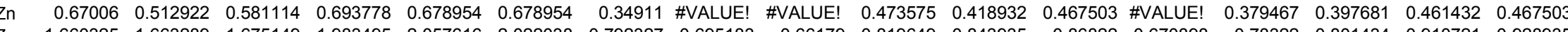

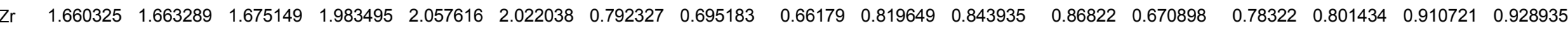

Page 202 of 220 
WSRC-TR-2003-00232, Rev. 0

SRT-RPP-2003-00105, Rev. 0

APPENDIX H

XRD Analysis of AN-107 Post-filtration Solids 
WSRC-TR-2003-00232, Rev. 0

SRT-RPP-2003-00105, Rev. 0

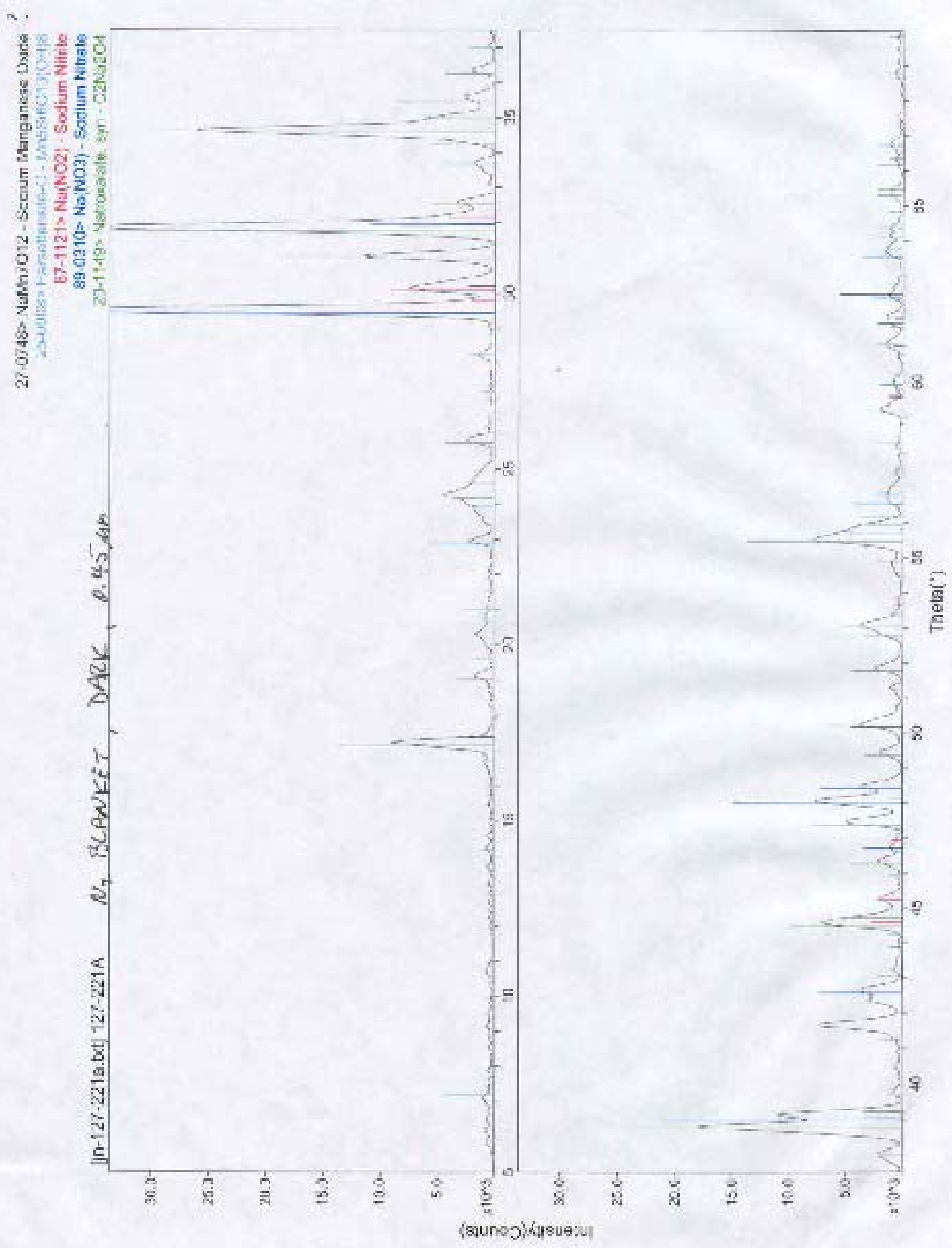

Page 204 of 220 
WSRC-TR-2003-00232, Rev. 0

SRT-RPP-2003-00105, Rev. 0

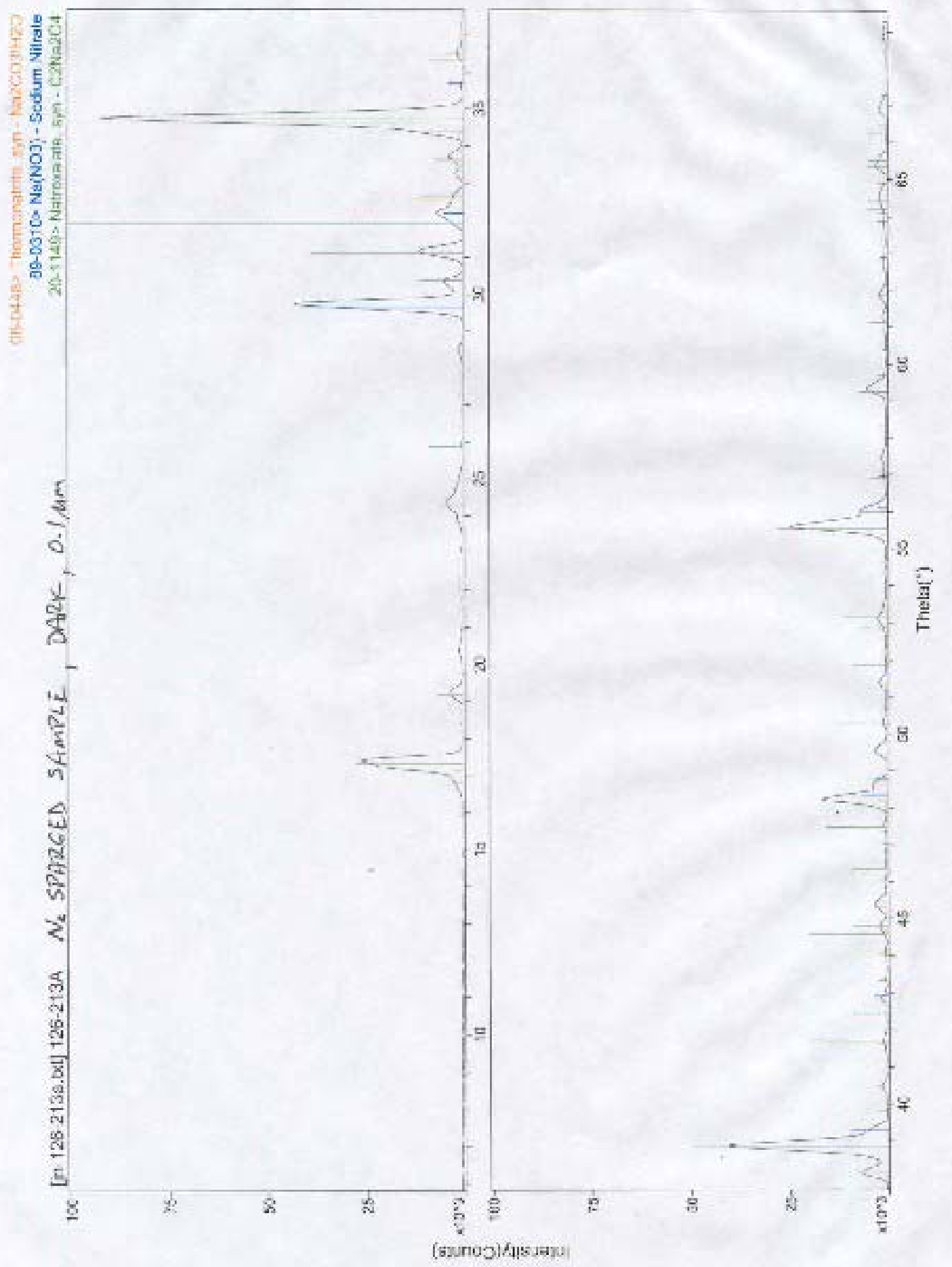

Page 205 of 220 
WSRC-TR-2003-00232, Rev. 0

SRT-RPP-2003-00105, Rev. 0

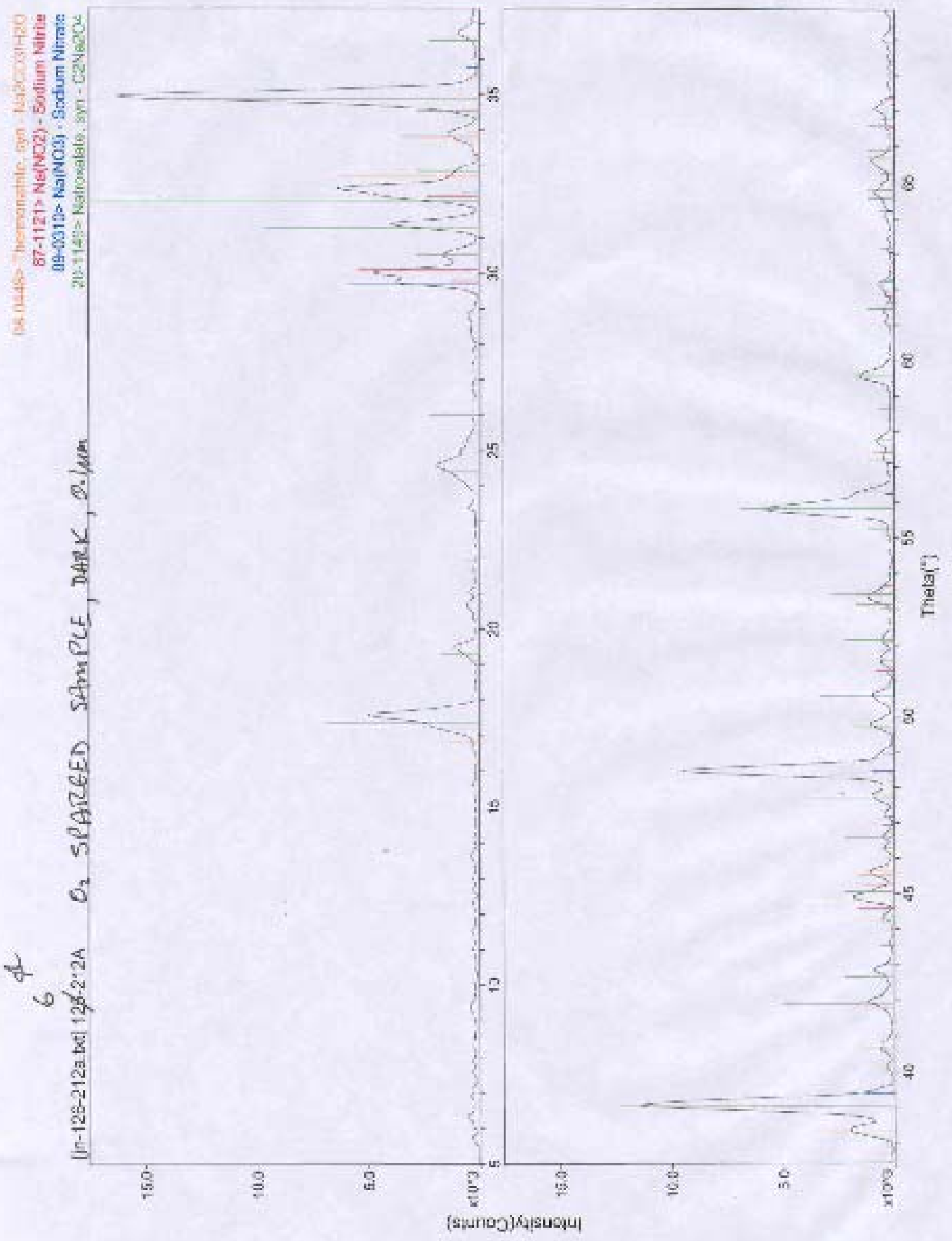

Page 206 of 220 
WSRC-TR-2003-00232, Rev. 0

SRT-RPP-2003-00105, Rev. 0

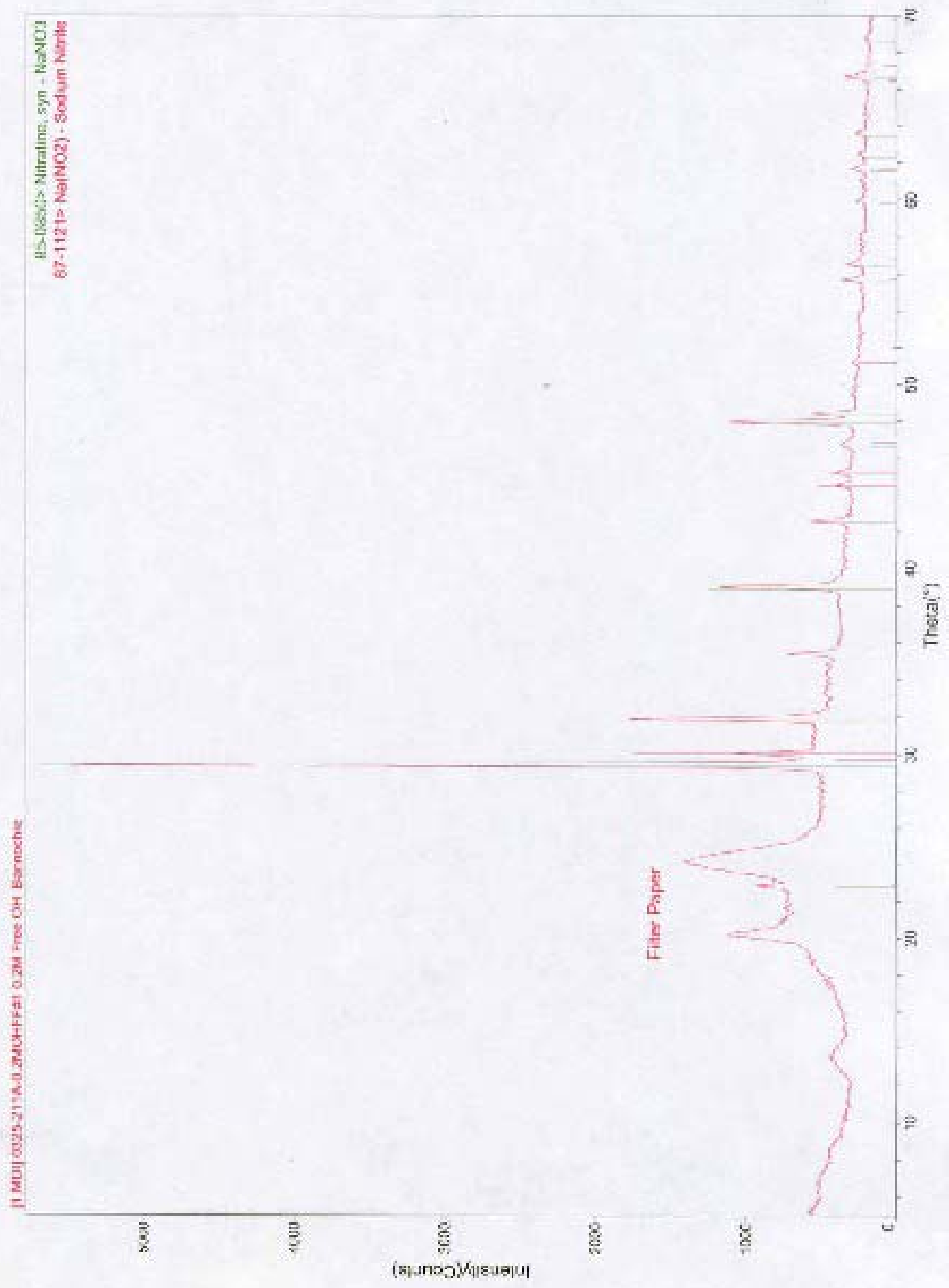


WSRC-TR-2003-00232, Rev. 0

SRT-RPP-2003-00105, Rev. 0

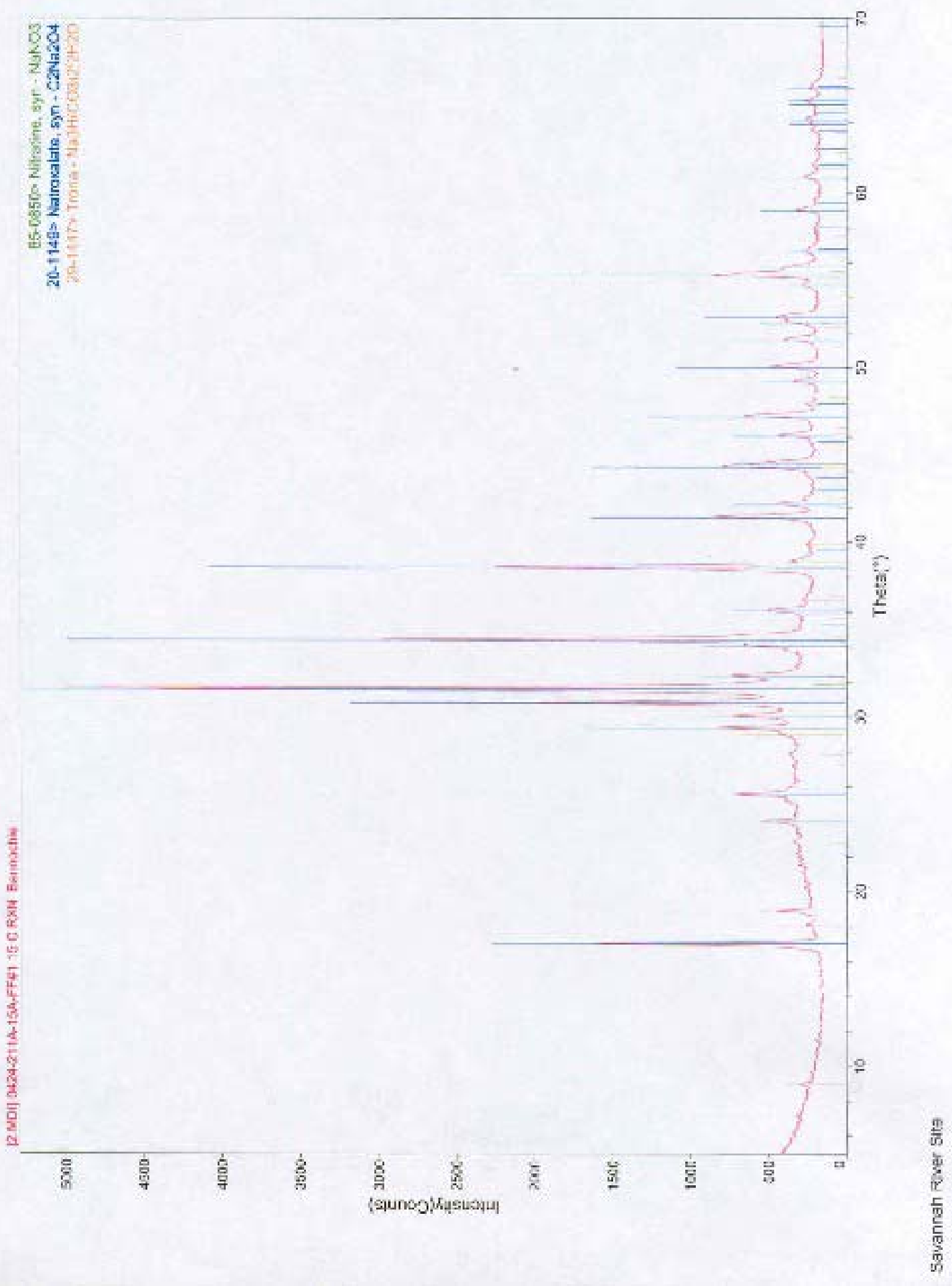

Page 208 of 220 
WSRC-TR-2003-00232, Rev. 0

SRT-RPP-2003-00105, Rev. 0

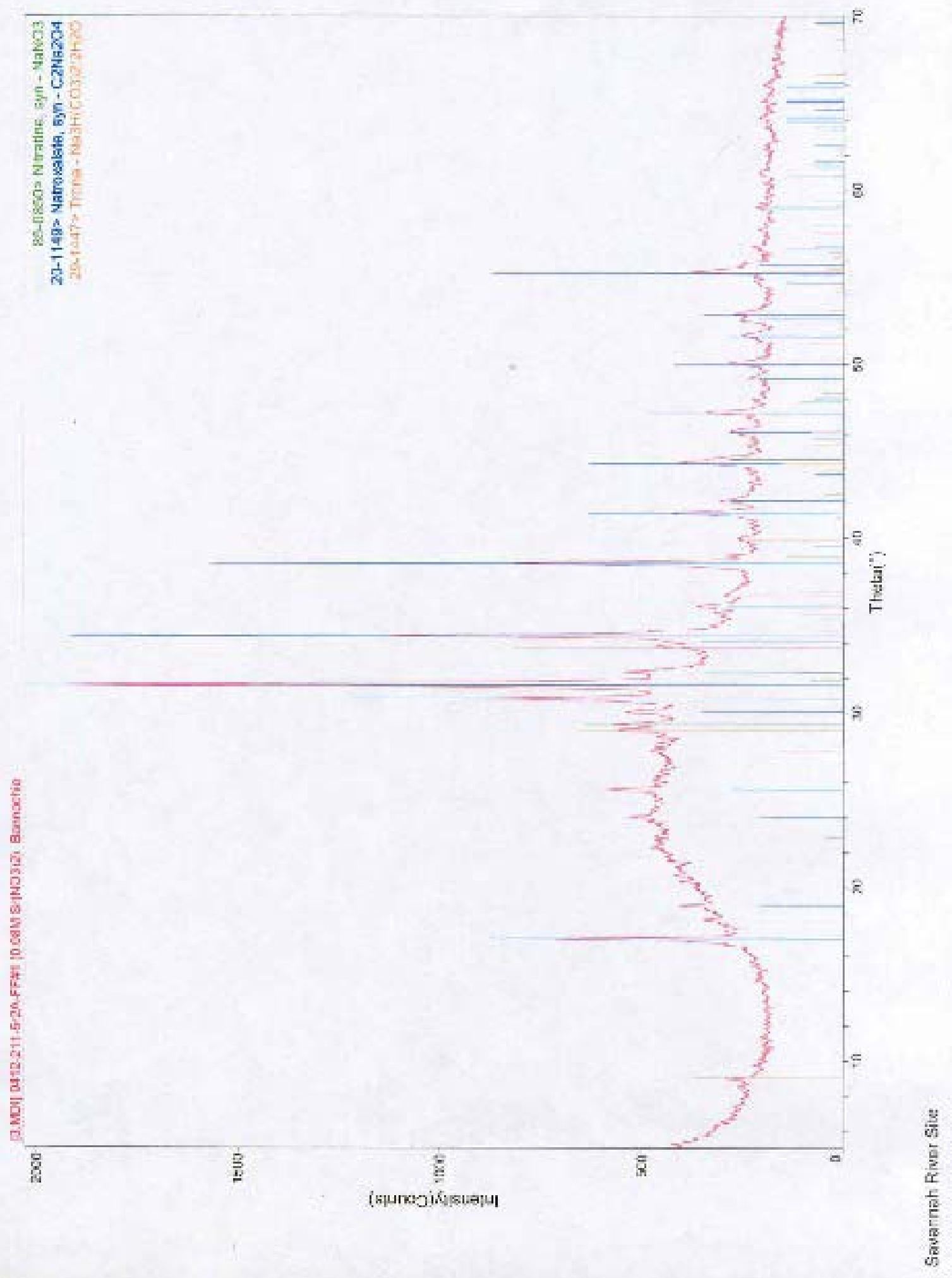

Page 209 of 220 
WSRC-TR-2003-00232, Rev. 0

SRT-RPP-2003-00105, Rev. 0

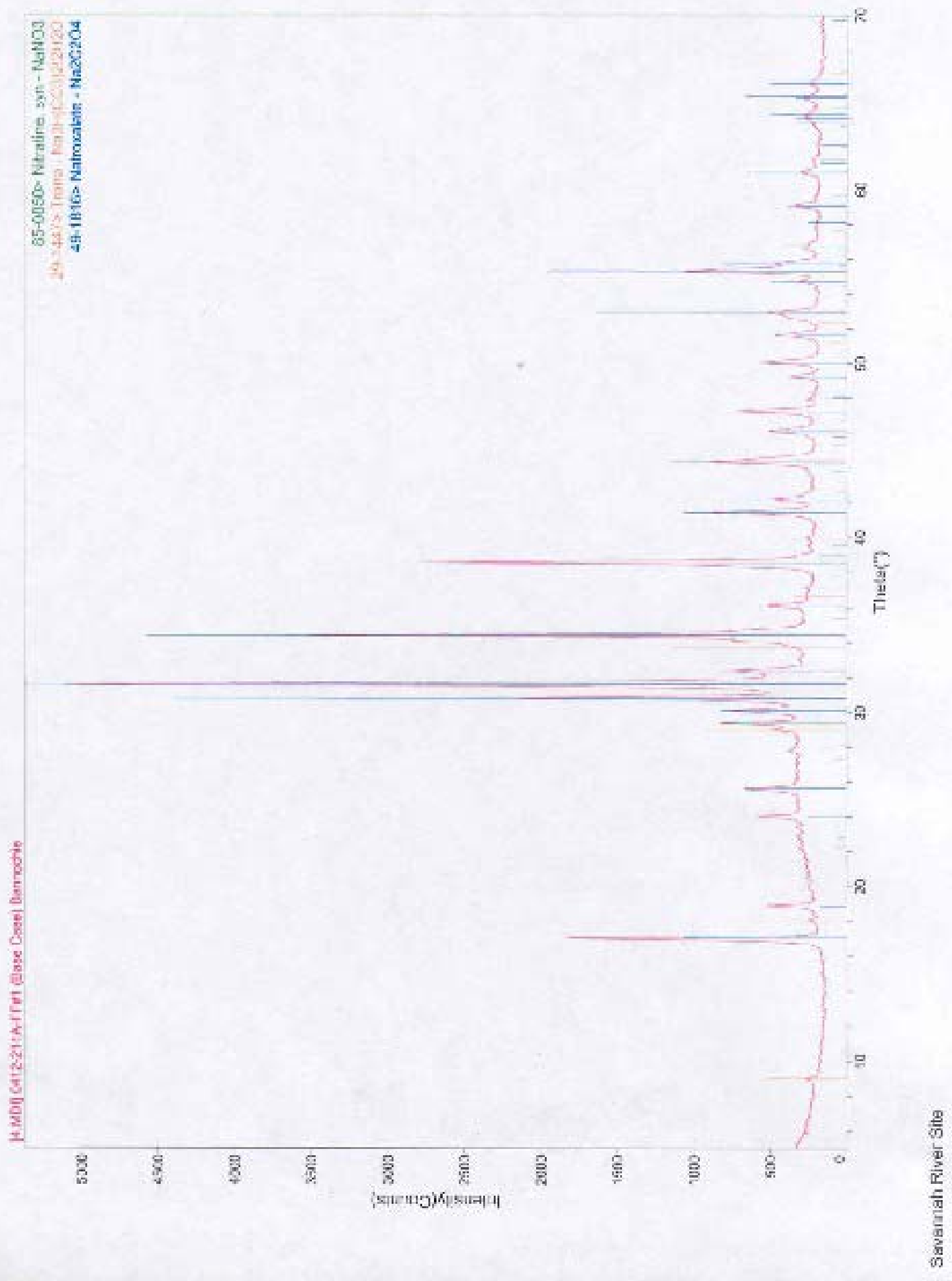

Page 210 of 220 
WSRC-TR-2003-00232, Rev. 0

SRT-RPP-2003-00105, Rev. 0

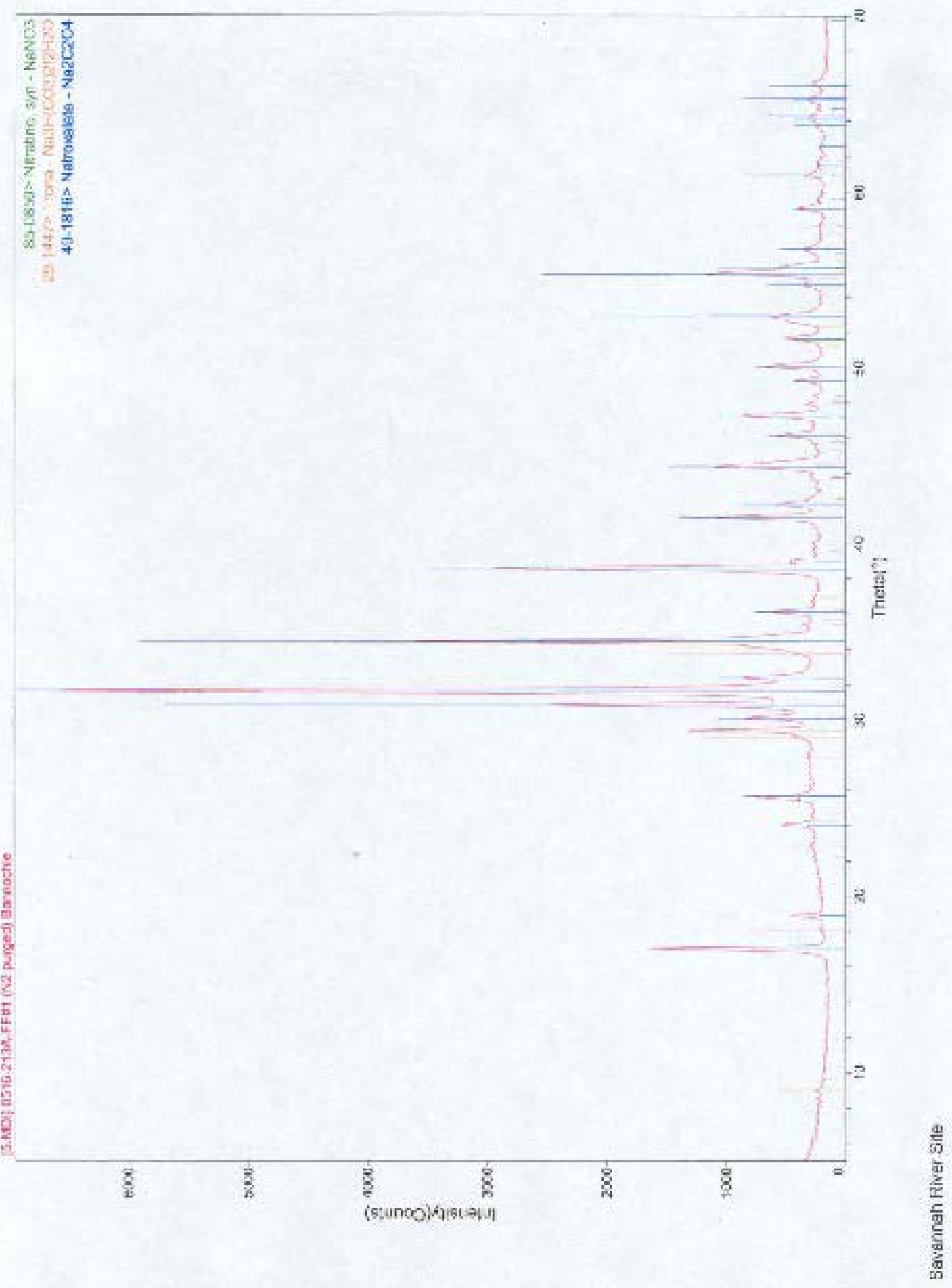

Page 211 of 220 
WSRC-TR-2003-00232, Rev. 0

SRT-RPP-2003-00105, Rev. 0

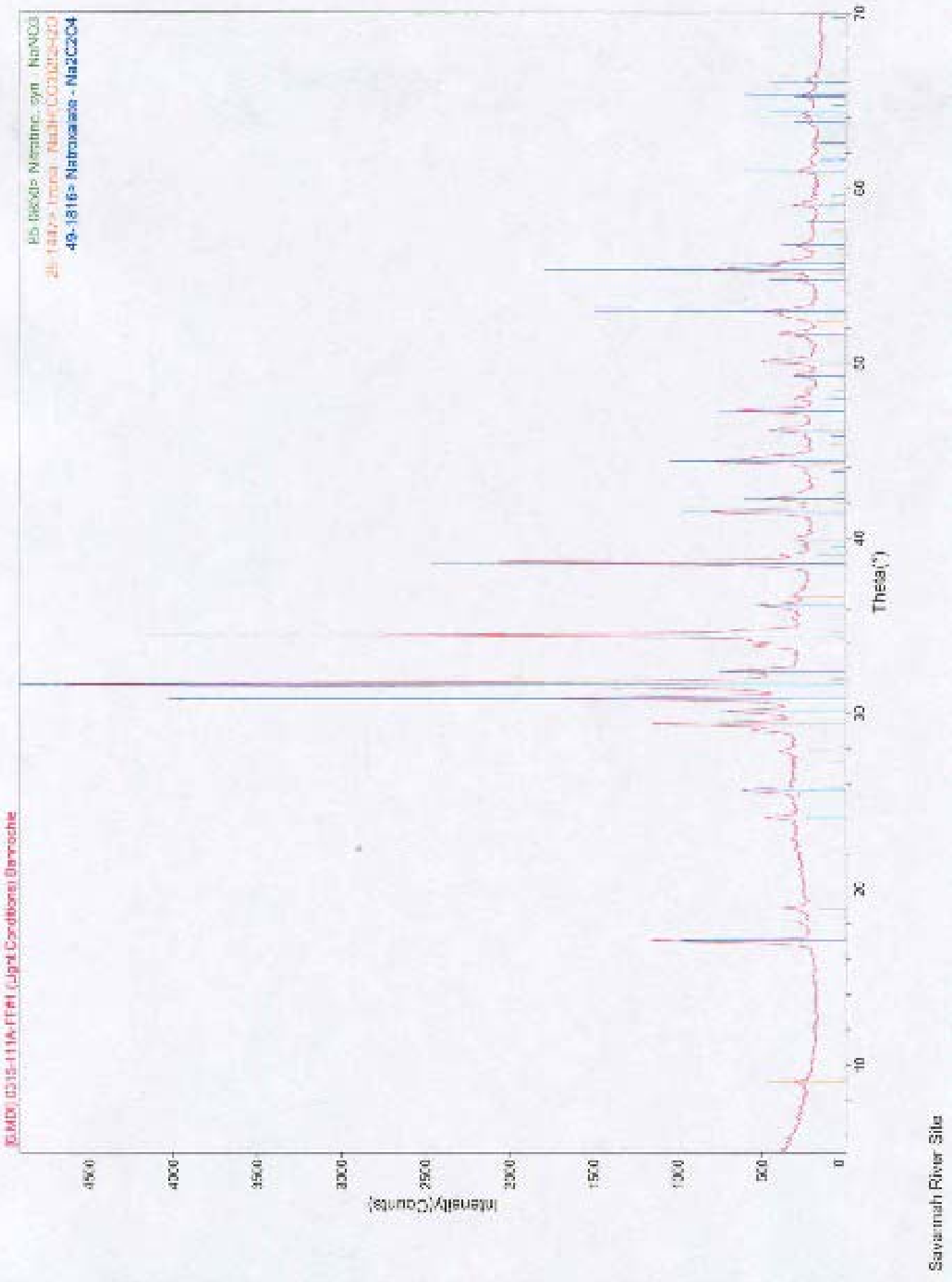

Page 212 of 220 
WSRC-TR-2003-00232, Rev. 0

SRT-RPP-2003-00105, Rev. 0

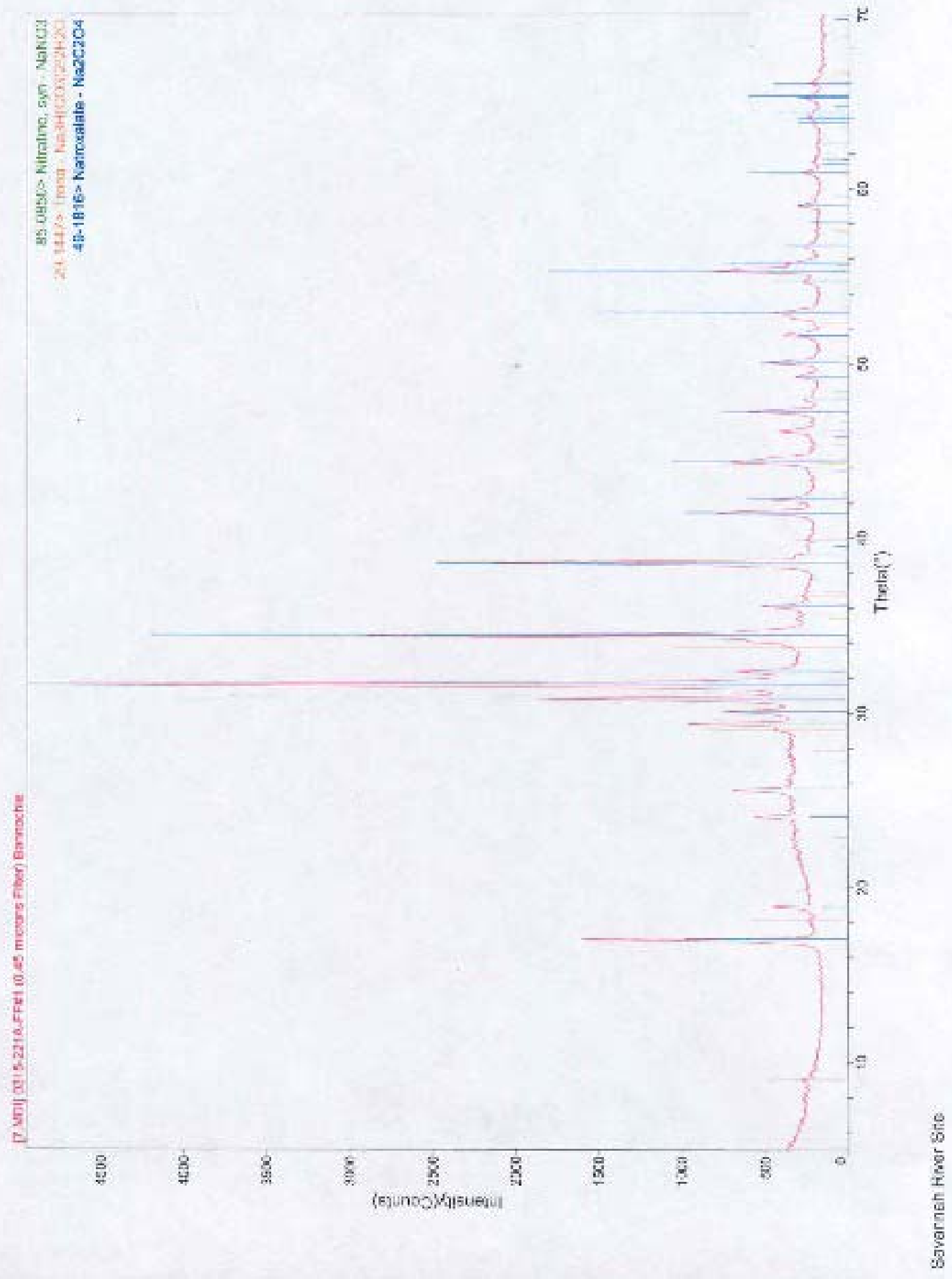

Page 213 of 220 
WSRC-TR-2003-00232, Rev. 0

SRT-RPP-2003-00105, Rev. 0

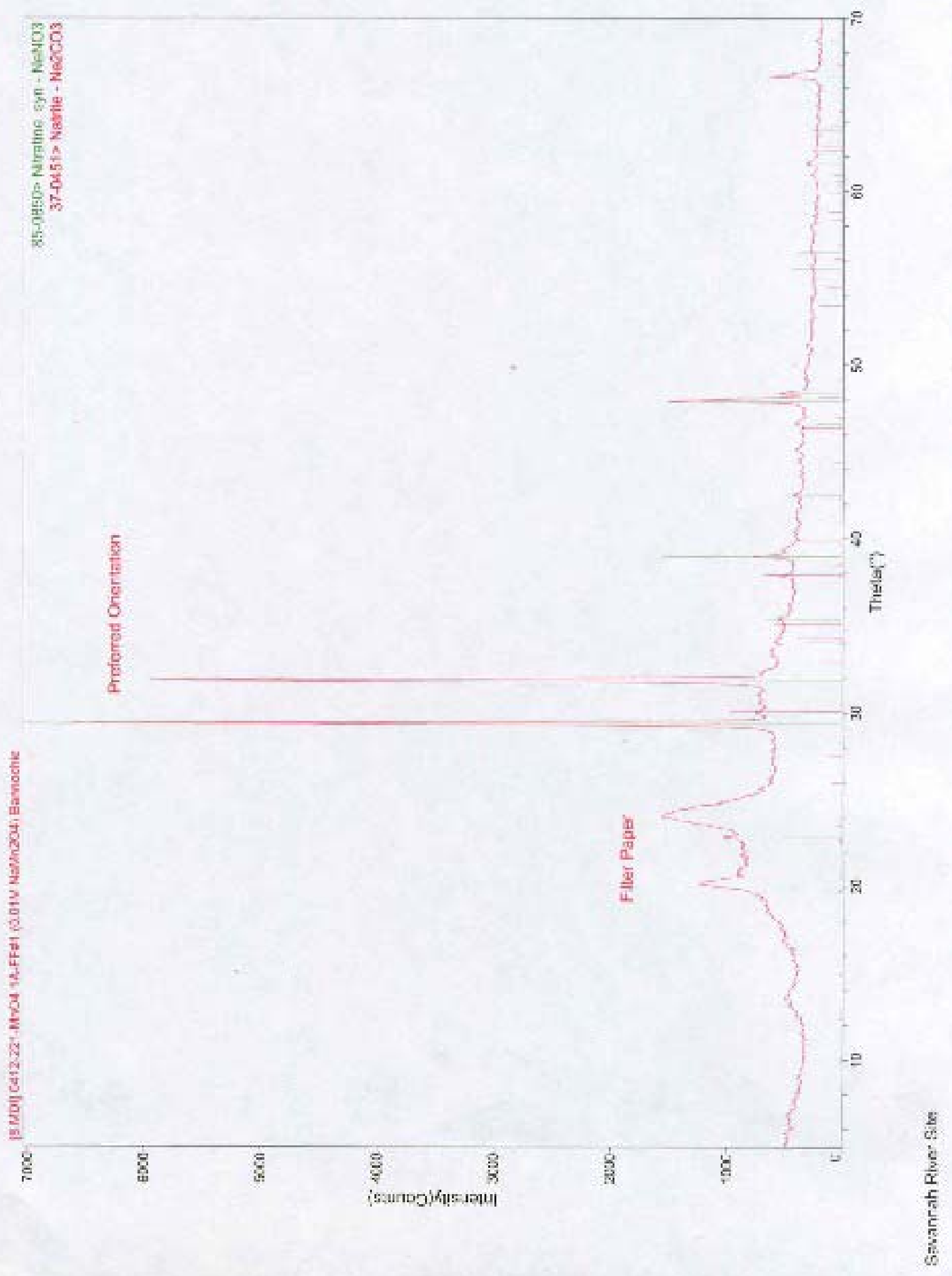

Page 214 of 220 
WSRC-TR-2003-00232, Rev. 0

SRT-RPP-2003-00105, Rev. 0

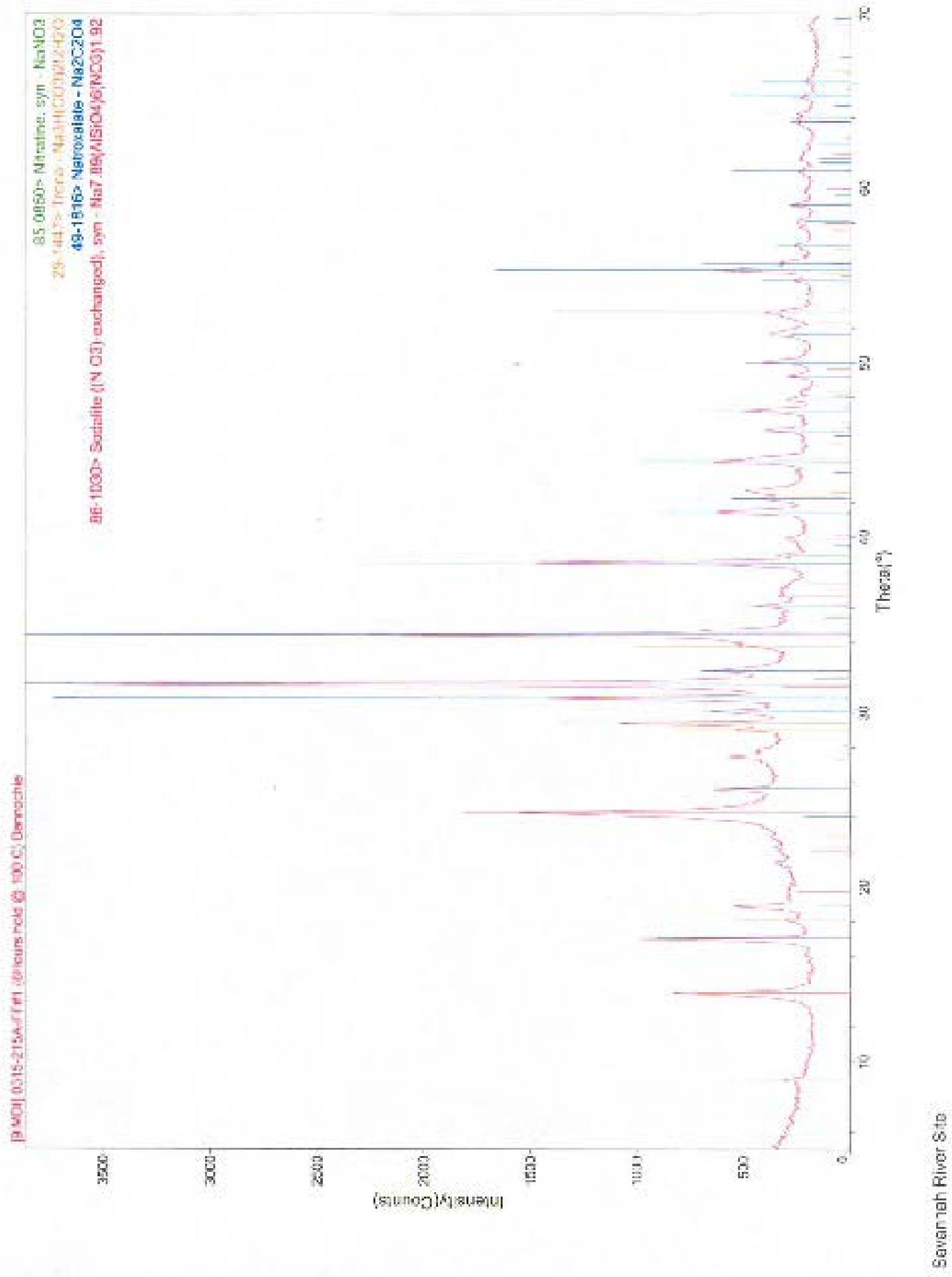

Page 215 of 220 
WSRC-TR-2003-00232, Rev. 0

SRT-RPP-2003-00105, Rev. 0

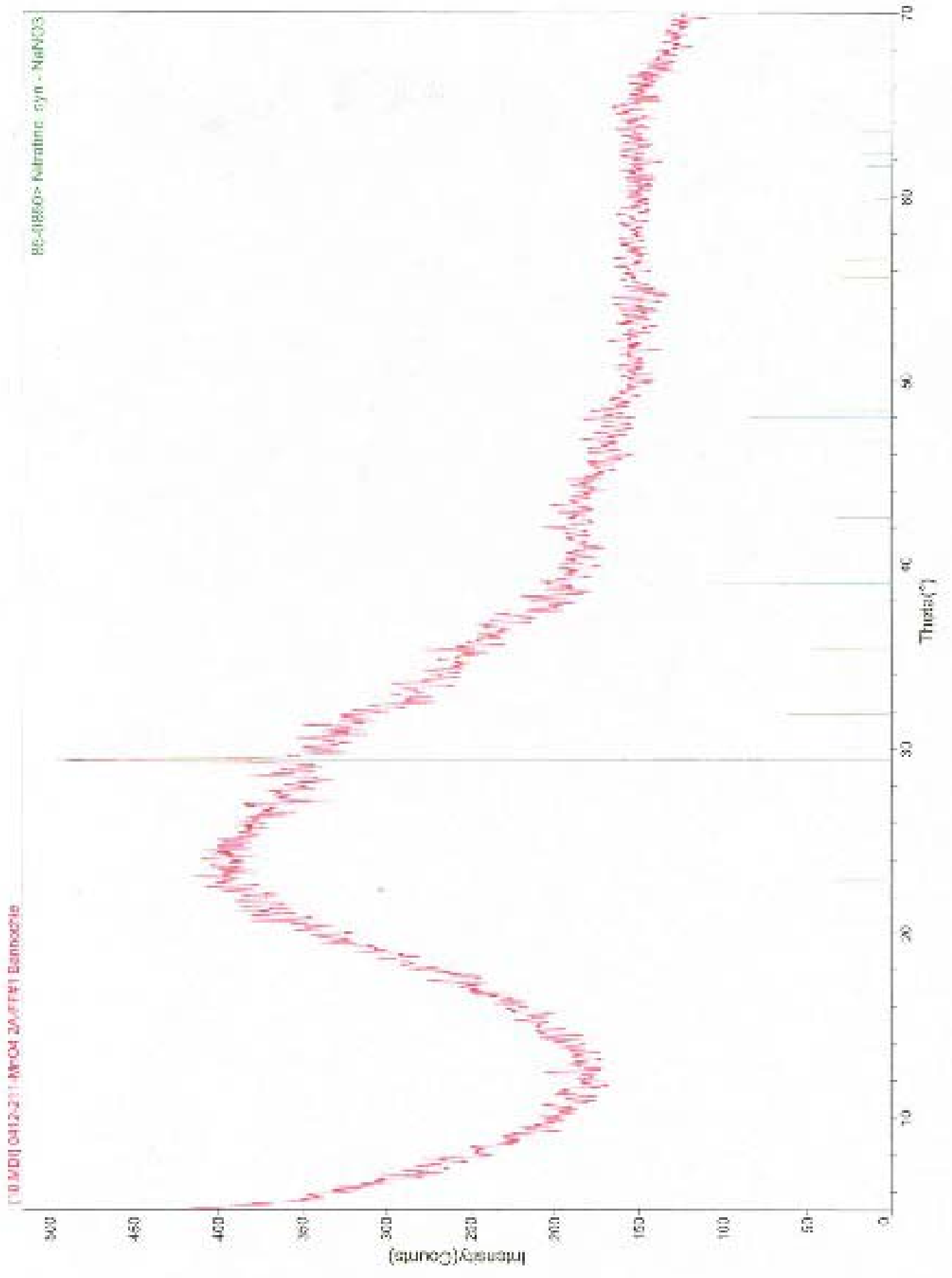

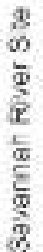

Page 216 of 220 
WSRC-TR-2003-00232, Rev. 0

SRT-RPP-2003-00105, Rev. 0
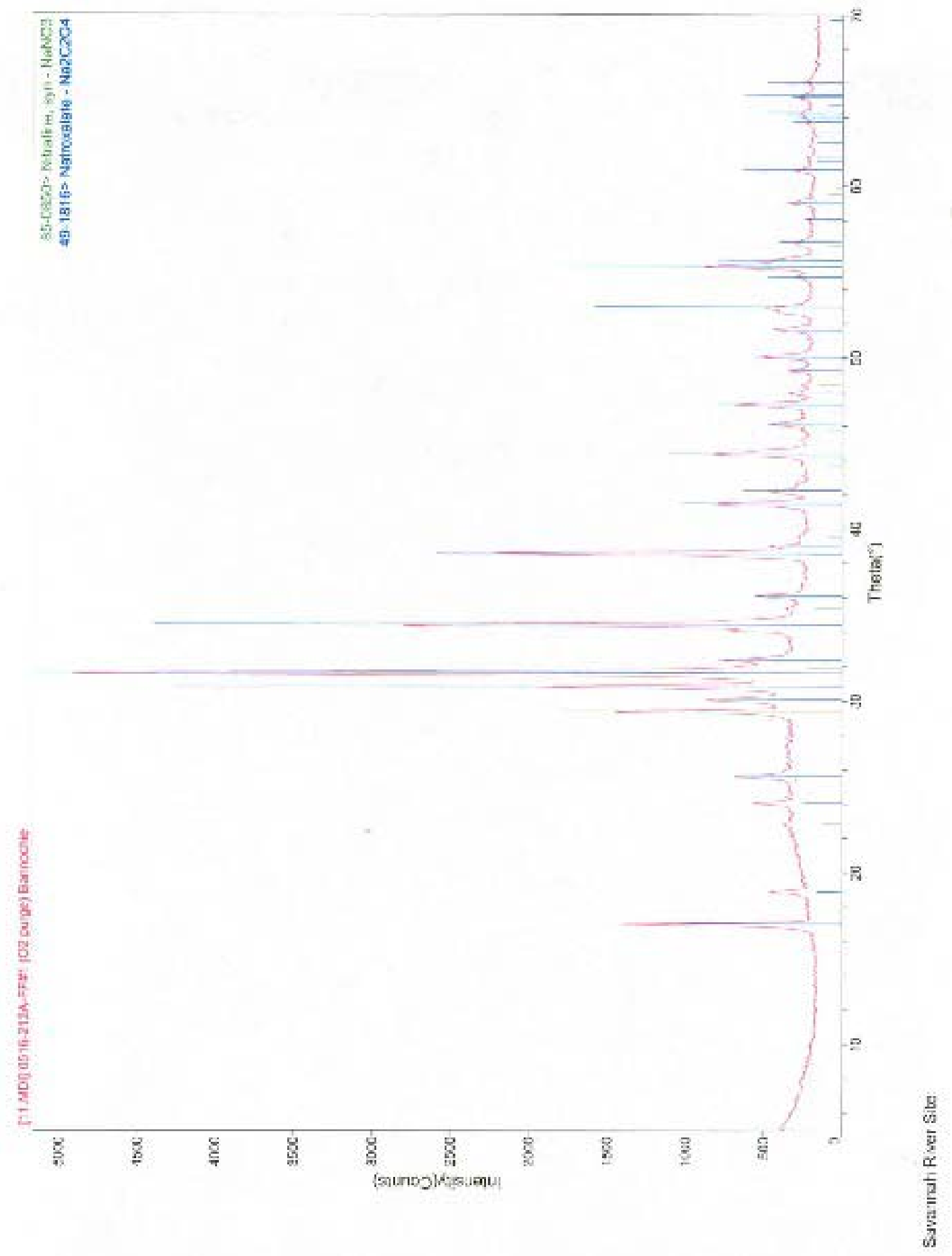

Page 217 of 220 
WSRC-TR-2003-00232, Rev. 0

SRT-RPP-2003-00105, Rev. 0

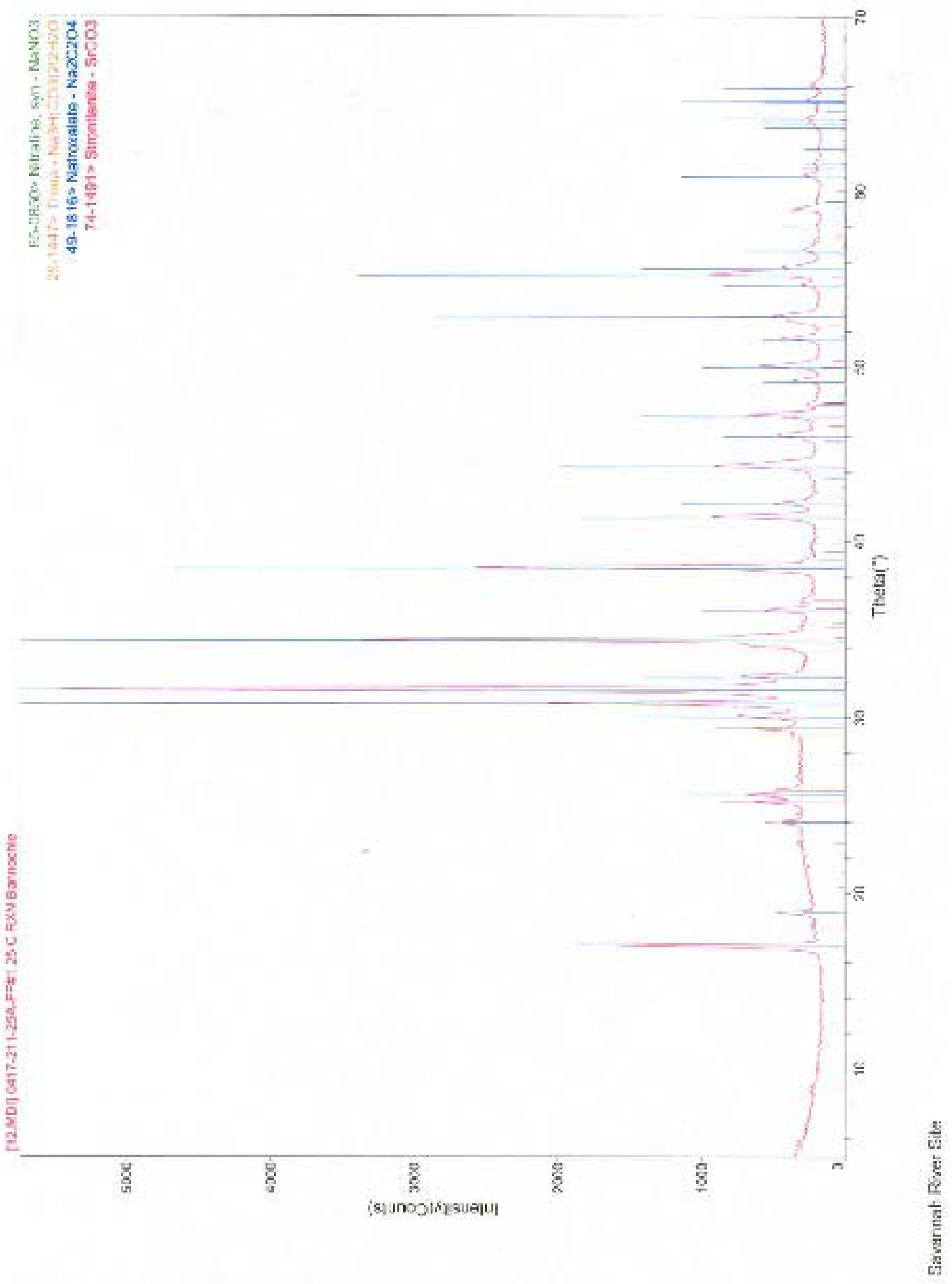

Page 218 of 220 
WSRC-TR-2003-00232, Rev. 0

SRT-RPP-2003-00105, Rev. 0

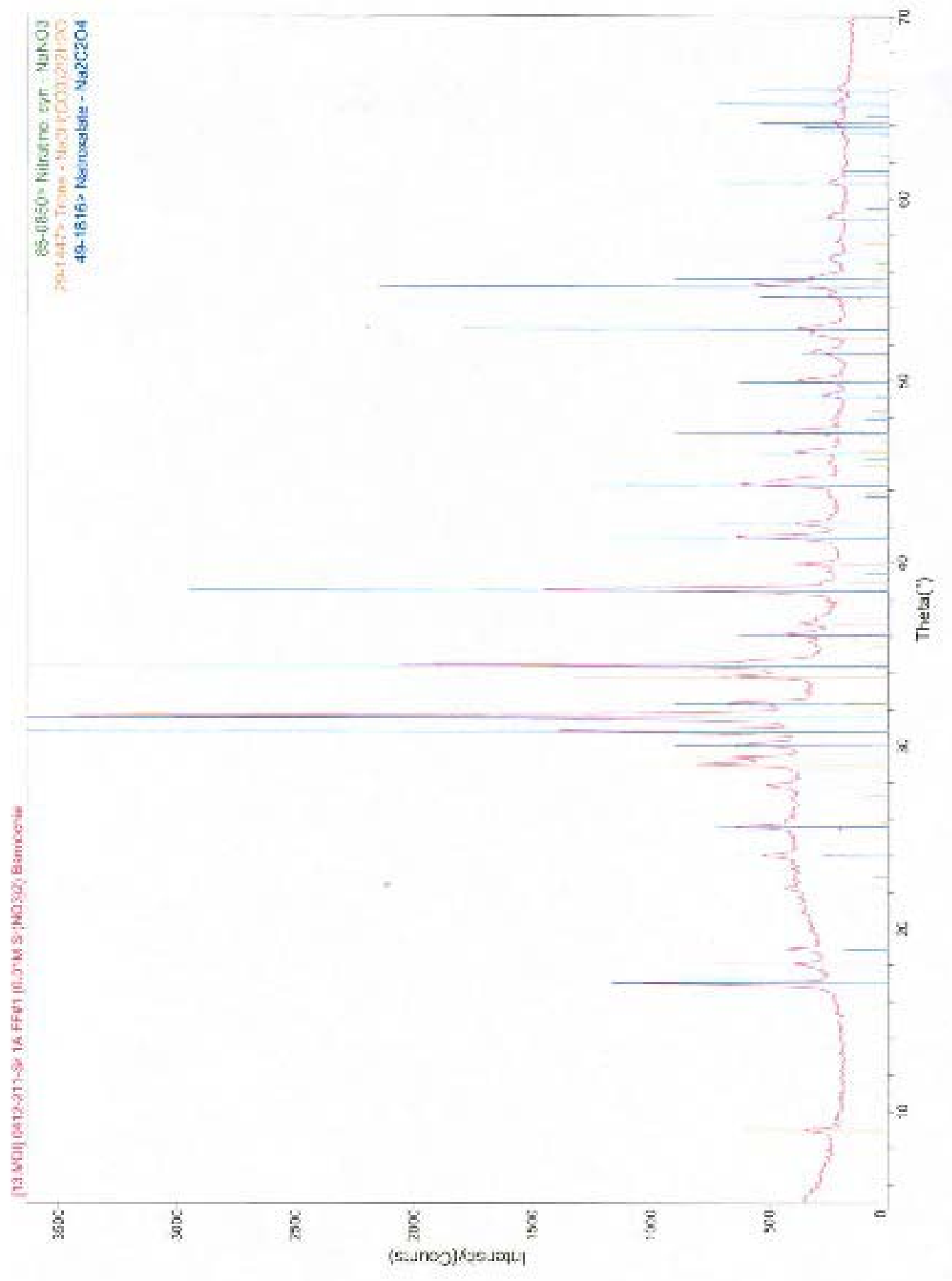


WSRC-TR-2003-00232, Rev. 0

SRT-RPP-2003-00105, Rev. 0

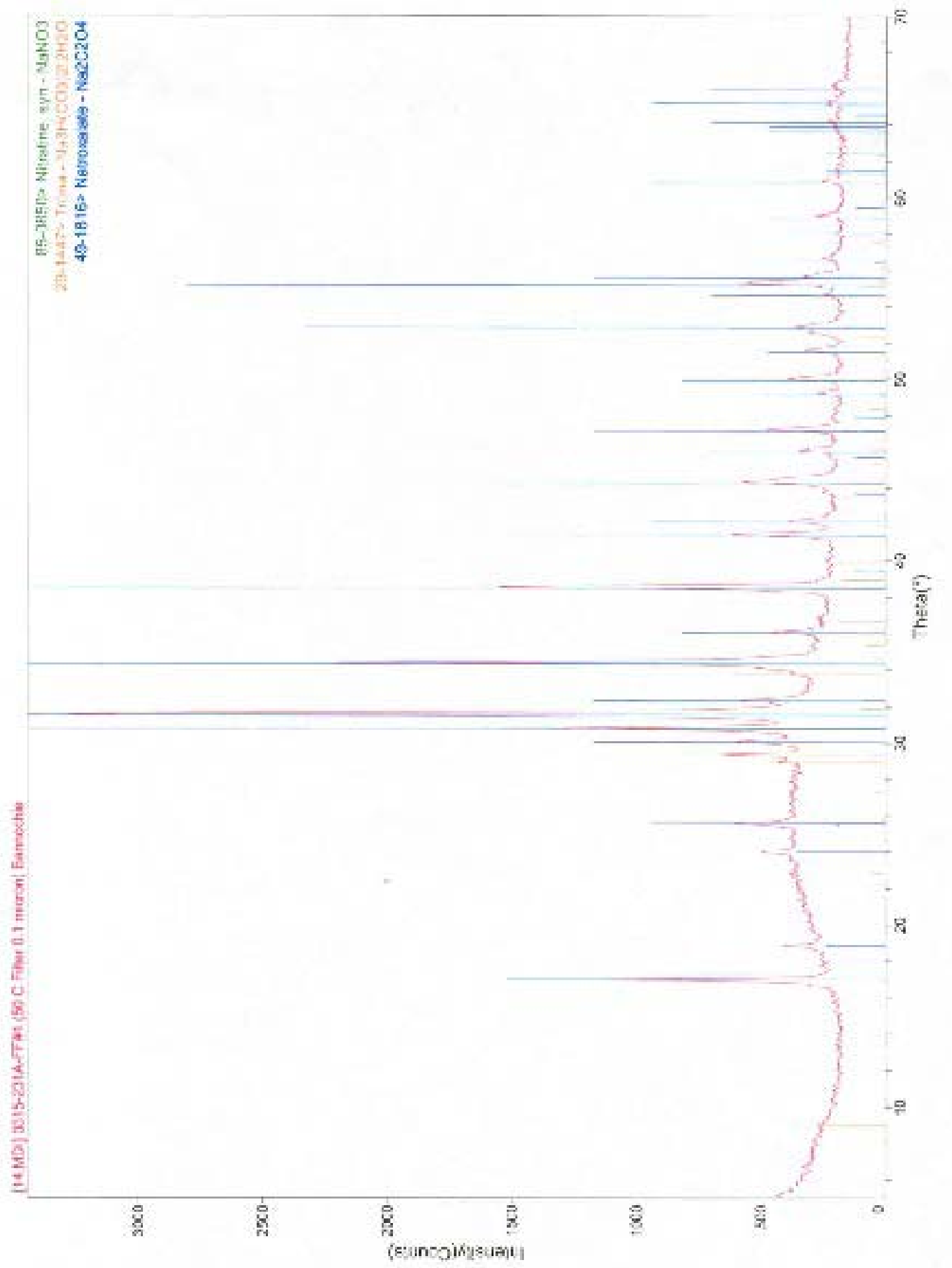

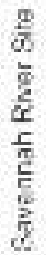

Page 220 of 220 